QA: QA

MDL-NBS-GS-000005 REV 01

September 2004

\title{
Thermal Conductivity of the Potential Repository Horizon
}

Prepared for:

U.S. Department of Energy

Office of Civilian Radioactive Waste Management

Office of Repository Development

1551 Hillshire Drive

Las Vegas, Nevada 89134-6321

Prepared by:

Bechtel SAIC Company, LLC

1180 Town Center Drive

Las Vegas, Nevada 89144

Under Contract Number

DE-AC28-01RW12101 


\section{DISCLAIMER}

This report was prepared as an account of work sponsored by an agency of the United States Government. Neither the United States Government nor any agency thereof, nor any of their employees, nor any of their contractors, subcontractors or their employees, makes any warranty, express or implied, or assumes any legal liability or responsibility for the accuracy, completeness, or any third party's use or the results of such use of any information, apparatus, product, or process disclosed, or represents that its use would not infringe privately owned rights. Reference herein to any specific commercial product, process, or service by trade name, trademark, manufacturer, or otherwise, does not necessarily constitute or imply its endorsement, recommendation, or favoring by the United States Government or any agency thereof or its contractors or subcontractors. The views and opinions of authors expressed herein do not necessarily state or reflect those of the United States Government or any agency thereof. 
QA: QA

Thermal Conductivity of the Potential Repository Horizon

MDL-NBS-GS-000005 REV 01

September 2004 


\section{OCRWm Model Signature Page/Change History}

Page iii

1. Total Pages: 226

\section{Type of Mathematical Model}

$\bigotimes$ Process Model

Describe Intended Use of Model

The Thermal Conductivity of the Potential Repository Horizon model report provides distribution and mean values for matrix, lithophysal porosity, dry bulk density, wet and dry matrix thermal conductivity, and wet and dry bulk thermal conductivity for the following stratigraphic units: the Tptpul, Tptpmn, Tptpll, and Tptpln.

\section{Title}

Thermal Conductivity of the Potential Repository Horizon

4. DI (including Rev. No., if applicable):

MDL-NBS-GS-000005 REV 01

\begin{tabular}{|l|l|}
\hline $\begin{array}{l}\text { 5. Total Appendices } \\
\text { Four (4) }\end{array}$ & $\begin{array}{l}\text { 6. No. of Pages in Each Appendix } \\
\text { A-6, B-46, C-6, D-4 }\end{array}$ \\
\hline
\end{tabular}

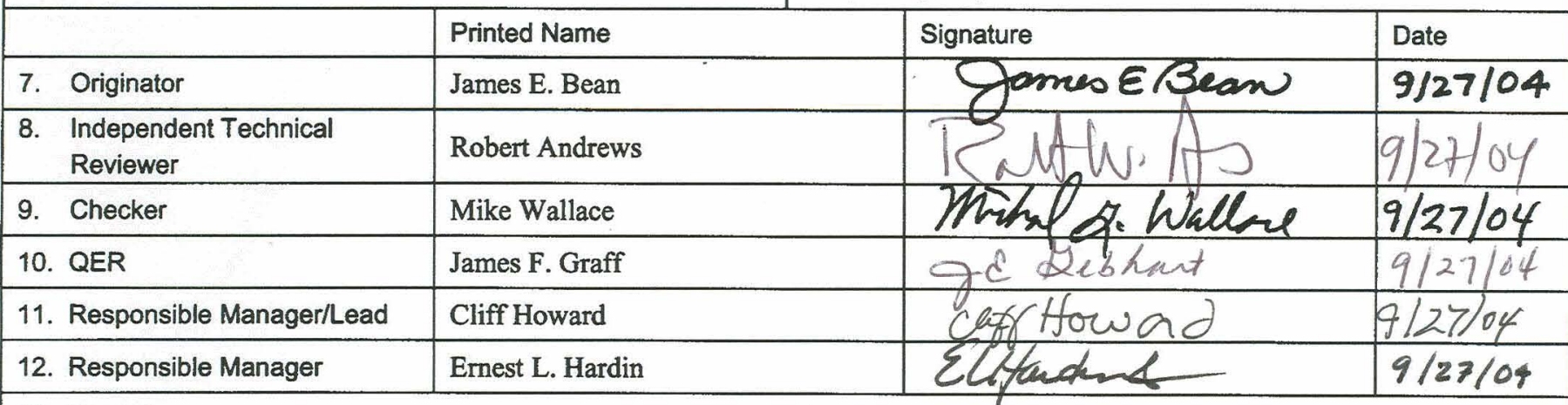

13. Remarks

Yue Hao assisted in checking the Post AP-2.14Q final check copy (Draft D)

\begin{tabular}{|l|l|}
\hline \multicolumn{2}{|l|}{ Change History } \\
\hline 14. Revision No. & \multicolumn{1}{|c|}{ 15. Description of Change } \\
\hline REV 00 & Initial Issue. \\
\hline REV 01 & $\begin{array}{l}\text { This revision incorporates new discussion of higher order models of thermal conductivity and the potential } \\
\text { impact of radiation on bulk thermal conductivity (Section 6.1.8). The lithophysal porosity model is validated } \\
\text { using both ECRB lithophysal mapping data in the Tptpll, and video mapping of the boreholes in the field } \\
\text { thermal conductivity tests. The six-hole thermal conductivity test is introduced as an additional bulk thermal } \\
\text { conductivity validation case. Supporting documentation used in developing the report modifications is } \\
\text { included in the new output DTN: SN0406T0503102.012. The original output DTN (SN0208T05030102.007) } \\
\text { from REV 00 of this report has also been superseded by SN0404T0503102.011 in order to include computer } \\
\text { files that were missing in the original submittal. Document reorganization included moving Section 7.5 in } \\
\text { REV 00 to Section 6.2 in this revision. Changes to this version are too extensive to be indicated by change } \\
\text { bars. }\end{array}$ \\
\hline
\end{tabular}




\section{INTENTIONALLY LEFT BLANK}




\section{CONTENTS}

Page

ACRONYMS AND ABBREVIATIONS .. $\mathrm{XV}$

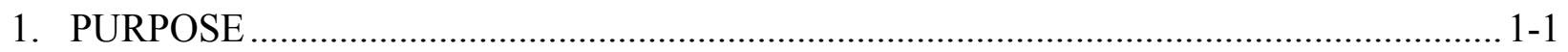

2. QUALITY ASSURANCE ................................................................................ 2-1

3. USE OF SOFTWARE ........................................................................................ 3-1

3.1 SOFTWARE TRACKED BY CONFIGURATION MANAGEMENT ...................... 3-1

3.2 EXEMPT SOFTWARE ............................................................................... $3-1$

4. INPUTS

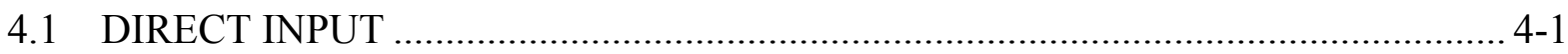

4.1.1 Laboratory Core Physical Property Data .................................................. 4-2

4.1.2 Petrophysical Data ................................................................................ 4-2

4.1.3 Matrix Thermal Conductivity Data...................................................... 4-3

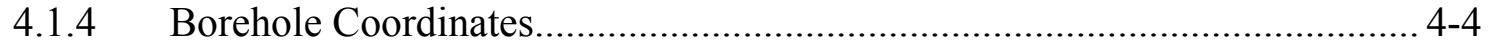

4.1.5 Observed Lithostratigraphic Contacts..................................................... 4-4

4.1.6 Lithostratigraphic Contacts .............................................................. 4-4

4.1.7 Thermal Conductivity of Air and Water ................................................ 4-5

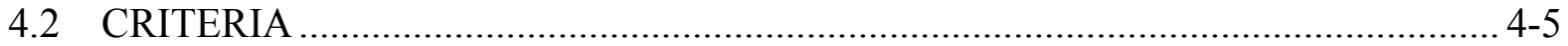

4.2.1 Acceptance Criterion 1 - System Description and Model Integration are Adequate ............................................................................ 4-6

4.2.2 Acceptance Criterion 2 - Data are Sufficient for Model Justification........... 4-6

4.2.3 Acceptance Criterion 3 - Data Uncertainty Is Characterized and Propagated Through the Model Abstraction............................................... 4-6

4.2.4 Acceptance Criterion 4 - Model Uncertainty is Characterized and Propagated Through the Model Abstraction.............................................. 4-7

4.3 CODES, STANDARDS, AND REGULATIONS ............................................ 4-7

5. ASSUMPTIONS .................................................................................................... $5-1$

5.1 THE PROPERTIES OF GEOLOGIC STRATA MAY BE REPRESENTED BY STATIONARY RANDOM FUNCTIONS .......................................................... 5-1

5.2 THE ROCK MATRIX IS ASSUMED TO BE FULLY SATURATED .................... 5-1

5.3 THE PARTICLE DENSITY IS CONSTANT IN THE

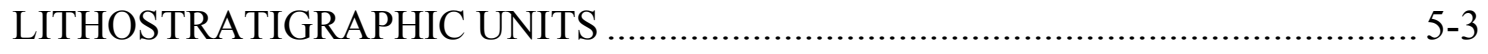

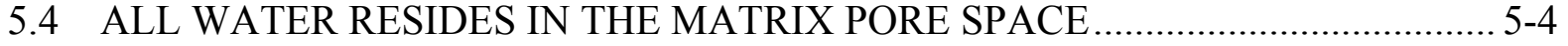

5.5 SPATIAL CORRELATION MODELS DEVELOPED FOR MATRIX POROSITY ARE APPLICABLE TO OTHER PARAMETERS ............................... 5-4

5.6 PARALLEL MODEL IS USED TO REPRESENT BULK THERMAL

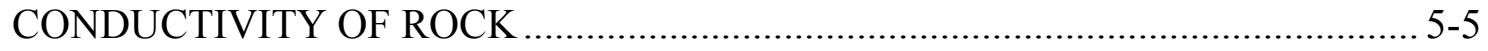

5.7 THERMAL CONDUCTIVITY MODEL IS VALID ACROSS ALL FOUR LITHOSTRATIGRAPHIC UNITS OF THE REPOSITORY 


\section{CONTENTS (Continued)}

Page

5.8 PETROPHYSICAL AND LABORATORY DATA USED IN THE MODEL DEVELOPMENT ADEQUATELY REPRESENT THE TRUE SPATIAL VARIABILITY OF THE ROCK UNITS ….............................................................. 5-6

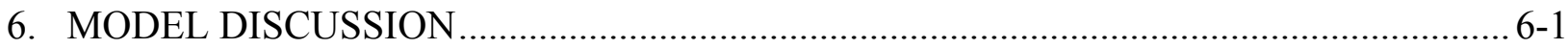

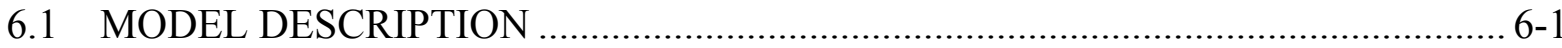

6.1.1 Overview of Model Development ………….......................................... 6-4

6.1.2 Model Domain and Discretization........................................................... 6-5

6.1.3 Sequential Gaussian Simulation ............................................................ 6-9

6.1.4 Lithophysal Porosity ....................................................................... 6-12

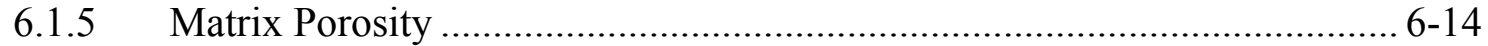

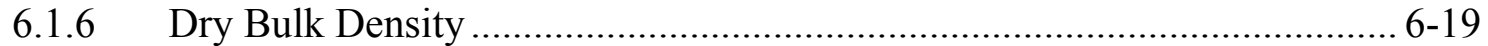

6.1.7 Matrix Thermal Conductivity ............................................................. 6-20

6.1.8 Bulk Thermal Conductivity ............................................................... 6-32

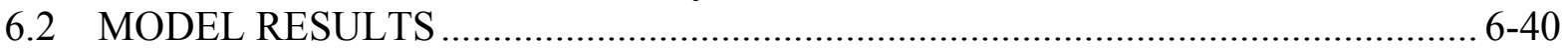

6.2.1 Expected Value and Uncertainty .................................................... 6-40

6.2.2 Sample Realization ......................................................................... 6-46

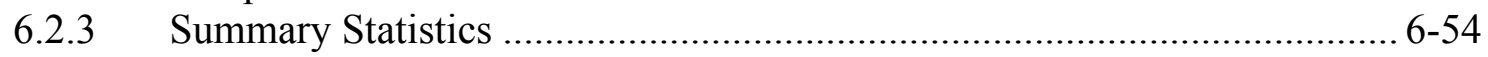

6.2.4 Summary Histograms........................................................................ 6-55

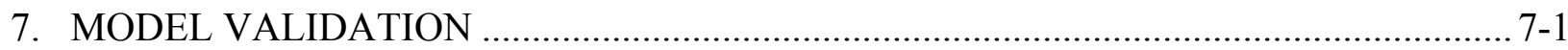

7.1 CONFIDENCE BUILDING DURING MODEL DEVELOPMENT ............................ 7-1

7.2 MATRIX POROSITY MODEL VALIDATION ……………….......................... 7-2

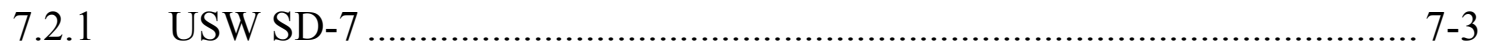

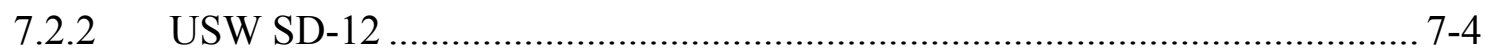

7.2.3 Matrix Porosity Model Validation: Summary and Conclusions.................... 7-4

7.3 LITHOPHYSAL POROSITY MODEL VALIDATION .......................................... 7-9

7.3.1 Comparison of Model Predictions with Feature Mapping in the Tptpll............................................................................................. 7-10

7.3.2 Lithophysal Porosity in Thermal Conductivity Test Areas ......................... 7-12

7.3.3 Lithophysal Porosity Model Validation: Summary and Conclusions .......... 7-18

7.4 MATRIX THERMAL CONDUCTIVITY MODEL VALIDATION ……………..... 7-18

7.4.1 Comparison of Matrix Thermal Conductivity Model to Laboratory

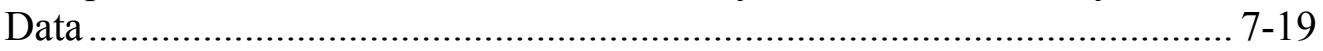

7.4.2 Matrix Thermal Conductivity Model Validation: Summary and

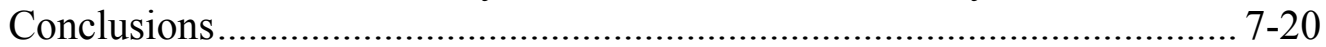

7.5 BULK THERMAL CONDUCTIVITY MODEL VALIDATION …………............. 7-21

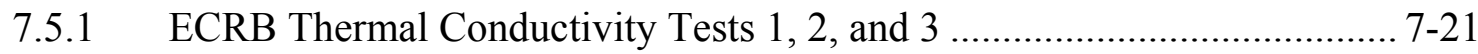

7.5.2 Bulk Thermal Conductivity Model Validation: Summary and

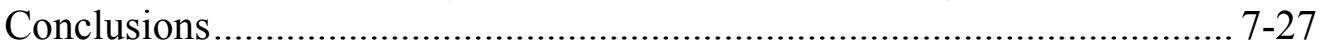

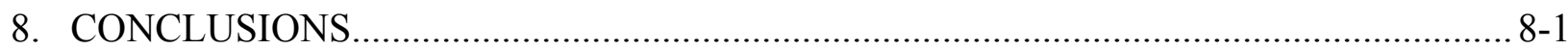

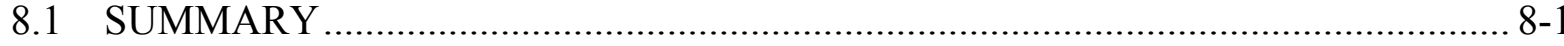

8.2 YUCCA MOUNTAIN REVIEW PLAN CRITERIA ASSESSMENT ....................... 8-2 


\section{CONTENTS (Continued)}

Page

8.2.1 Acceptance Criterion 1 - System Description and Model Integration Are Adequate

8.2.2 Acceptance Criterion 2 - Data Are Sufficient for Model Justification

8.2.3 Acceptance Criterion 3 - Data Uncertainty Is Characterized and Propagated Through the Model Abstraction.

8.2.4 Acceptance Criterion 4 - Model Uncertainty is Characterized and Propagated Through the Model Abstraction

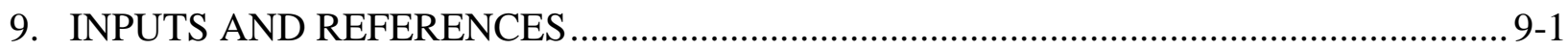

9.1 DOCUMENTS CITED .................................................................................... 9-1

9.2 CODES, STANDARDS, REGULATIONS, AND PROCEDURES ............................ 9-5

9.3 SOURCE DATA, LISTED BY DATA TRACKING NUMBER ……………............. 9-5

9.4 OUTPUT DATA, LISTED BY DATA TRACKING NUMBER .................................. 9-7

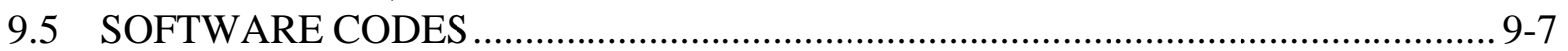

APPENDIX A-CALCULATIONS OF MATRIX AND LITHOPHYSAL POROSITY ..... A-1 APPENDIX B-INPUT DATA ANALYSIS ................................................................... APPENDIX C-MATRIX THERMAL CONDUCTIVITY DATA …….............................. 1 APPENDIX D-STRATIGRAPHIC CONTACTS .......................................................... D-1 


\section{INTENTIONALLY LEFT BLANK}




\section{FIGURES}

Page

4-1. Yucca Mountain Boreholes that Penetrate the Topopah Spring Tuff Crystal-Poor Upper Lithophysal Zone (Tptpul) ................................................................................... 4-3

6-1. Yucca Mountain Stratigraphy....

6-2. Map Showing the Model Domain Relative to Geologic Features and Constructed Tunnels 6-6

6-3. The Process of Converting to Stratigraphic Coordinates

6-4. Graphical Representation of the Quantile-Preserving Normal-Score Transformation

6-5. Histogram of Lithophysal Porosity Conditioning Data ............................................... 6-16

6-6. Lithophysal Porosity Semivariograms .................................................................. 6-17

6-7. Histogram of Matrix Porosity Conditioning Data ....................................................... 6-21

6-8. Matrix Porosity Semivariograms ……………….................................................... 6-22

6-9. Histogram Plots of Particle Density Obtained from Core Measurement........................ 6-23

6-10. Three-Dimensional Cubic Model ..........................................................................6-25

6-11. Parameter Distributions for the Three-dimensional Cubic Model............................... 6-28

6-12. Matrix Thermal Conductivity as a Function of Solid Connectivity .............................. 6-29

6-13. Relative Difference in Wet Thermal Conductivity Between Model Predictions and Experimental Measurement ................................................................................

6-14. Ranges of Thermal Conductivities for Various Materials ............................................ 6-31

6-15. Systems Described by the Series and the Parallel Model ............................................ 6-34

6-16. First-, Second-, and Third-Order Upper and Lower Bounds of the Bulk Thermal Conductivity and the Torquato Model ..................................................................... 6-37

6-17. Effect of the Length Scale of the Air Gaps $(\alpha)$ on the Bulk Thermal

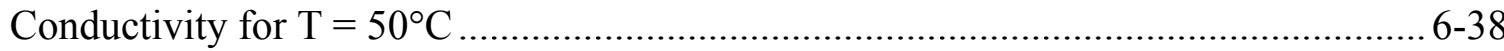

6-18. Effect of Temperature on the Bulk Thermal Conductivity for $\alpha=0.05 \mathrm{~m}$.................. 6-39

6-19. Comparison of the Parallel Model with the Torquato Model Accounting for

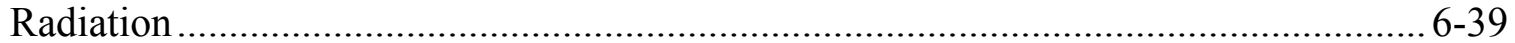

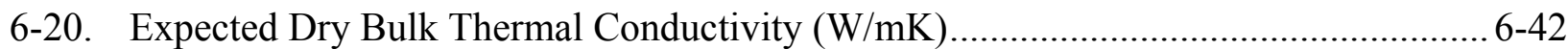

6-21. Expected Wet Bulk Thermal Conductivity (W/mK) ............................................. 6-43

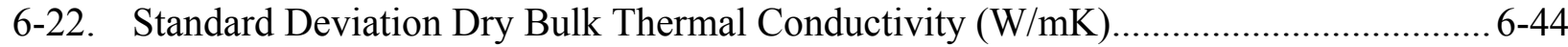

6-23. Standard Deviation Wet Bulk Thermal Conductivity (W/mK) ................................... 6-45

6-24. Matrix Porosity Realization 15 (Dimensionless) .......................................................6-47

6-25. Lithophysal Porosity Realization 15 (Dimensionless)............................................... 6-48

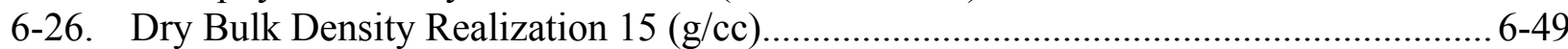

6-27. Matrix Dry Thermal Conductivity Realization $15(\mathrm{~W} / \mathrm{mK})$.....................................6-50

6-28. Matrix Wet Thermal Conductivity Realization $15(\mathrm{~W} / \mathrm{mK}) \ldots \ldots \ldots \ldots \ldots \ldots \ldots \ldots \ldots \ldots \ldots \ldots \ldots \ldots \ldots . . . .6-51$

6-29. Bulk Dry Thermal Conductivity Realization $15(\mathrm{~W} / \mathrm{mK})$......................................... 6-52

6-30. Bulk Wet Thermal Conductivity Realization $15(\mathrm{~W} / \mathrm{mK})$......................................... 6-53

6-31. Dry Bulk Thermal Conductivity $(\mathrm{W} / \mathrm{mK})$ in the Tptpul.............................................. 6-56

6-32. Wet Bulk Thermal Conductivity $(\mathrm{W} / \mathrm{mK})$ in the Tptpul .......................................... 6-57

6-33. Dry Bulk Density $(\mathrm{g} / \mathrm{cc})$ in the Tptpul ..................................................................6-58

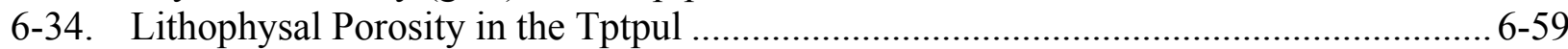




\section{FIGURES (Continued)}

6-35. Matrix Porosity in the Tptpul

6-60

6-36. Solid Connectivity in the Tptpul, $\gamma_{c}$ 6-61

6-37. Solid Conductivity in the Tptpul, $\mathrm{k}_{\mathrm{s}}$ $6-62$

6-38. Dry Matrix Thermal Conductivity $(\mathrm{W} / \mathrm{mK})$ in the Tptpul 6-63

6-39. Wet Matrix Thermal Conductivity $(\mathrm{W} / \mathrm{mK})$ in the Tptpul 6-64

6-40. Dry Bulk Thermal Conductivity $(\mathrm{W} / \mathrm{mK})$ in the Tptpmn ..... 6-65

6-41. Wet Bulk Thermal Conductivity $(\mathrm{W} / \mathrm{mK})$ in the Tptpmn 6-66

6-42. Dry Bulk Density (g/cc) in the Tptpmn 6-67

6-43. Lithophysal Porosity in the Tptpmn 6-68

6-44. Matrix Porosity in the Tptpmn. 6-69

6-45. Dry Bulk Thermal Conductivity $(\mathrm{W} / \mathrm{mK})$ in the Tptpll ........................................ 6-70

6-46. Wet Bulk Thermal Conductivity $(\mathrm{W} / \mathrm{mK})$ in the Tptpll ........................................ 6-71

6-47. Dry Bulk Density (g/cc) in the Tptpll .............................................................. 6-72

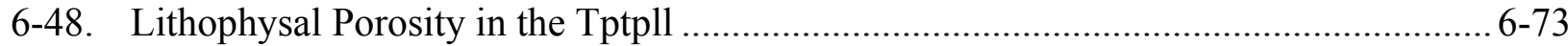

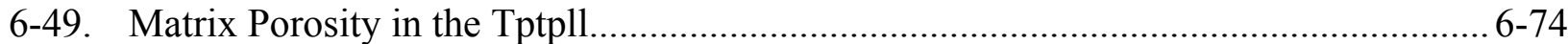

6-50. Dry Bulk Thermal Conductivity $(\mathrm{W} / \mathrm{mK})$ in the Tptpln ......................................... 6-75

6-51. Wet Bulk Thermal Conductivity $(\mathrm{W} / \mathrm{mK})$ in the Tptpln ....................................... 6-76

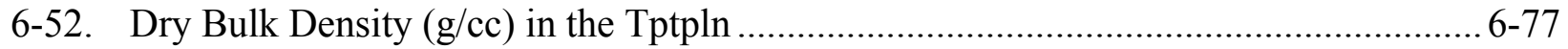

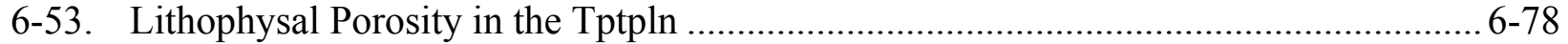

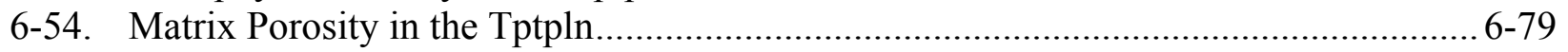

7-1. USW SD-7 (a) (b) Core and Petrophysical Data; (c) Method B Porosity ..................... 7-5

7-2. USW SD-7 Comparison of Core and Method B Matrix Porosity ................................. 7-6

7-3. USW SD-12 (a) (b) Core and Petrophysical Data; (c) Method B Porosity ................... 7-7

7-4. USW SD-12 Comparison of Core and Method B Matrix Porosity .............................. 7-8

7-5a. Comparison of Model Results and ECRB Mapping (Without Large Lithophysae

Data) .............................................................................................................. $7-11$

7-5b. Comparison of Model Results and ECRB Mapping (Including Large Lithophysae

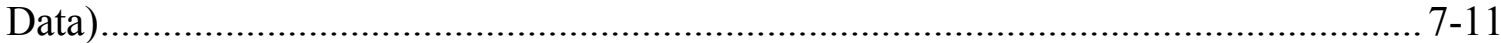

7-6. ECRB Thermal Conductivity Test 1 and Test 3 Layout............................................ 7-13

7-7. ECRB Thermal Conductivity Test 2 Layout ............................................................. 7-14

7-8. Model Prediction of Lithophysal Porosity at Site of ECRB Thermal Conductivity

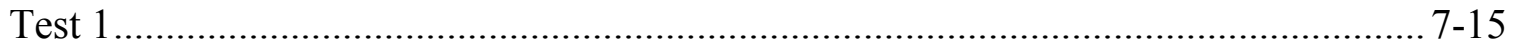

7-9. Model Prediction of Lithophysal Porosity at Site of ECRB Thermal Conductivity

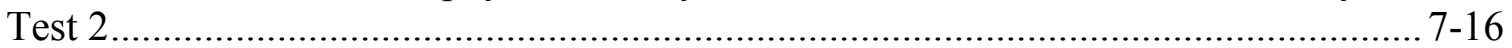

7-10. Model Prediction of Lithophysal Porosity at Site of ECRB Thermal Conductivity

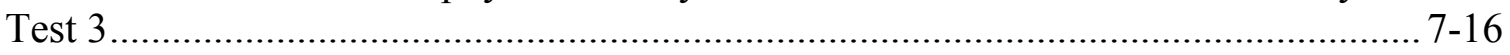

7-11. Model Predictions of Matrix Thermal Conductivity (W/mK) at (a) Alcove 5 and (b) Alcove 7

7-12. Model Predictions of Bulk Thermal Conductivity (W/mK) ECRB Thermal

Conductivity Test 1 


\section{FIGURES (Continued)}

7-13. Model Predictions of Bulk Thermal Conductivity (W/mK) ECRB Thermal Conductivity Test 2 .

7-14. Model Predictions of Bulk Thermal Conductivity (W/mK) ECRB Thermal Conductivity Test 3

7-15. Histogram Plot of Matrix Water Saturation in the Tptpll ....................................... 7-26

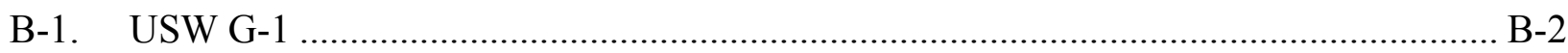

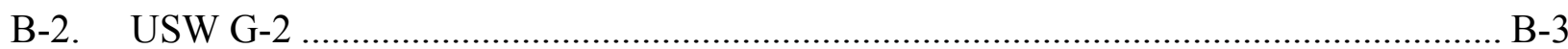

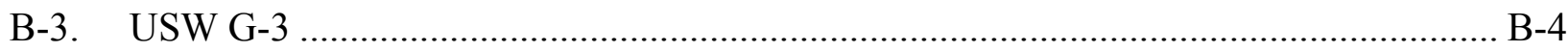

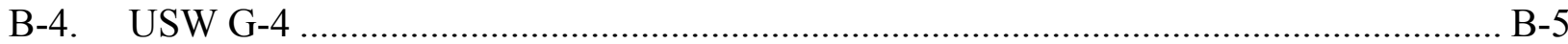

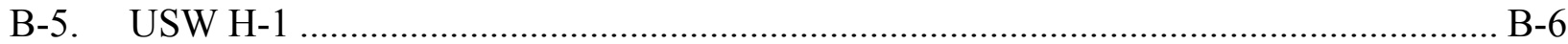

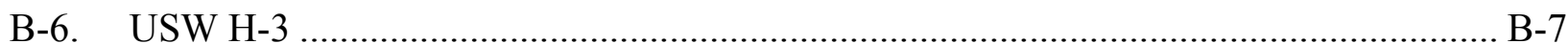

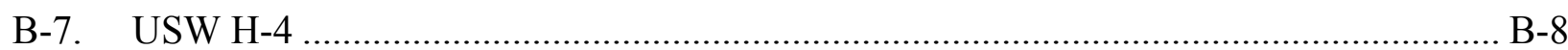

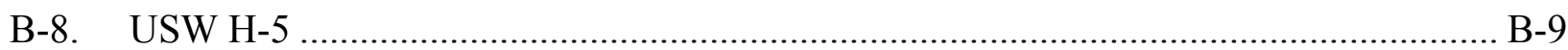

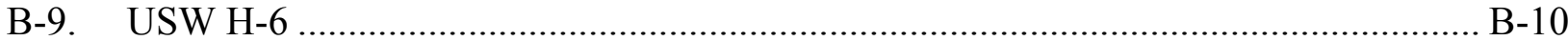

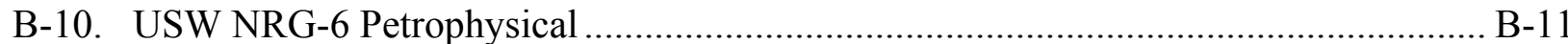

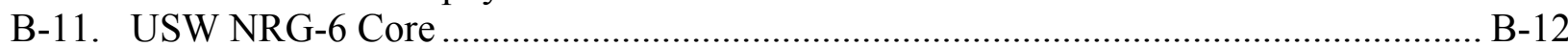

B-12. USW NRG-7/7a Petrophysical ………………................................................. B-13

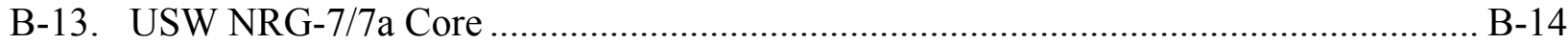

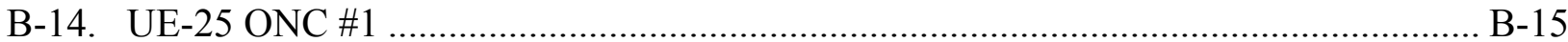

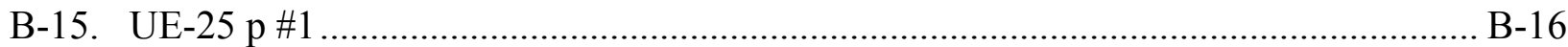

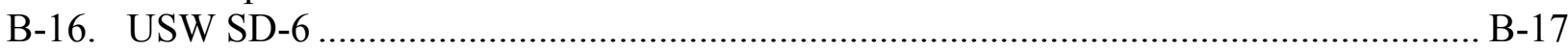

B-17. USW SD-7 Petrophysical ……………………........................................... B-18

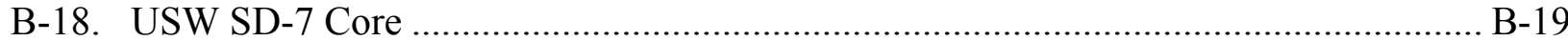

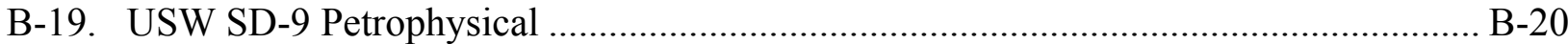

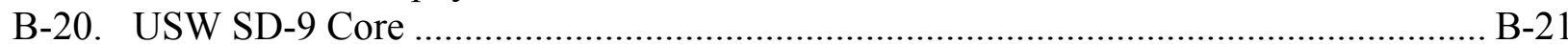

B-21. USW SD-12 Petrophysical ……………………....................................... B-22

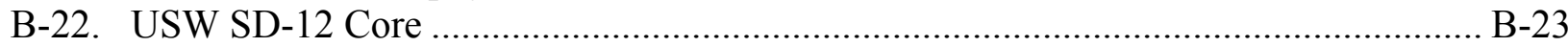

B-23. USW UZ-1/UZ-14 Petrophysical ………………....................................... B-24

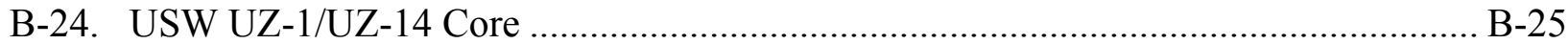

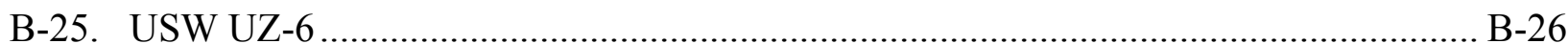

B-26. USW UZ-16 Petrophysical …………………….......................................... B-27

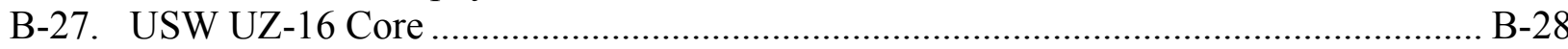

B-28. USW UZ-7a ………………………………

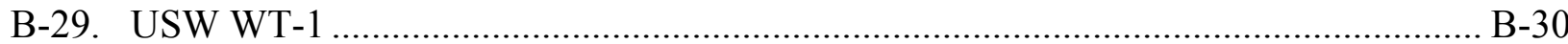

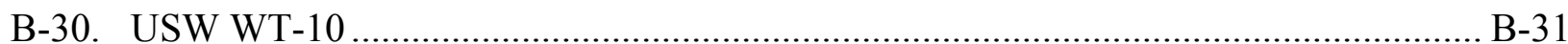

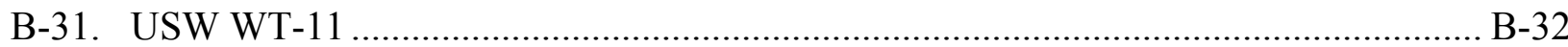

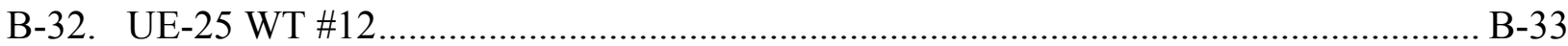

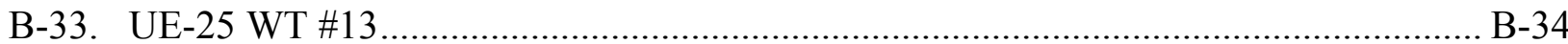

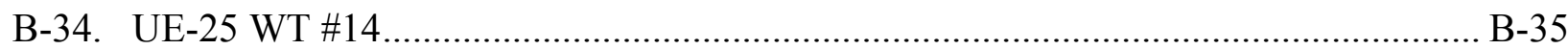

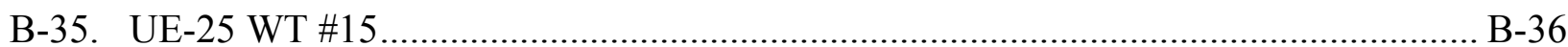

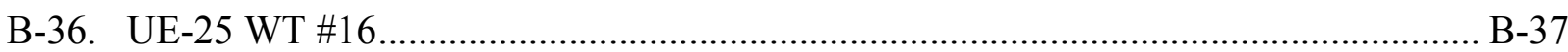

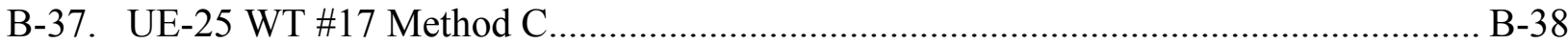

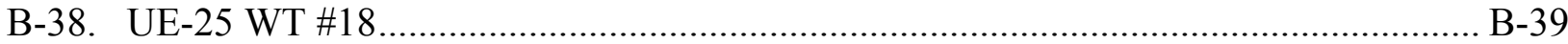




\section{FIGURES (Continued)}

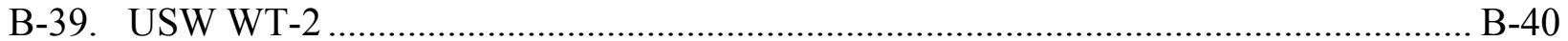

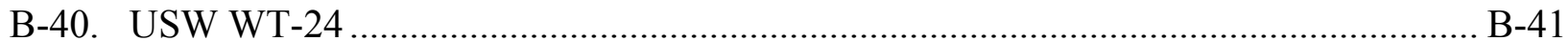

B-41. UE-25 WT \#3 ................................................................................................ B-42

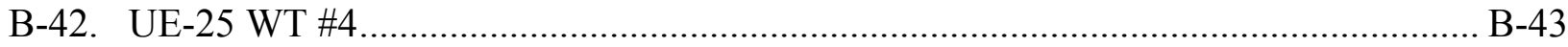

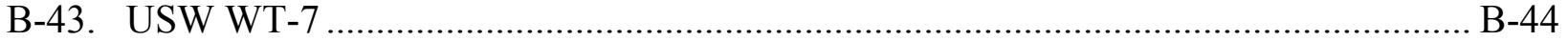




\section{TABLES}

Page

3-1. Software Tracked by Configuration Management.................................................... 3-2

4-1. Source of Laboratory Core Physical Properties Data .............................................. 4-1

4-2. Source of Input Petrophysical Data .................................................................... 4-2

4-3. Source of Matrix Thermal Conductivity Data ..................................................... 4-4

4-4. Source of Borehole Coordinate Data ............................................................................ 4-4

4-5. Source of Input for Observed Lithostratigraphic Contacts ........................................... 4-4

4-6. Source of Input for Lithostratigraphic Contacts ................................................. 4-5

4-7. Source of Input for Air and Water Thermal Conductivity ......................................... 4-5

5-1. Change in Calculated Porosity Caused by Changing Matrix Saturation from 100 to 80 Percent ..................................................................................................... 5-2

5-2. Change in Calculated Matrix Thermal Conductivity Caused by Changing Matrix Saturation from 100 to 80 Percent ........................................................................... 5-2

5-3. Change in Calculated Bulk Thermal Conductivity Caused by Changing Matrix Saturation from 100 to 80 Percent ................................................................................. 5-3

5-4. Mean Particle Density in the Four Lithostratigraphic Layers...................................... 5-4

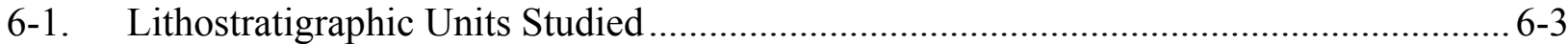

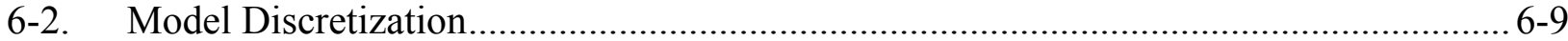

6-3. Lithophysal Porosity Model Variogram Parameters............................................. 6-18

6-4. Matrix Porosity Variogram Parameters ................................................................... 6-18

6-5. Model Parameters for the Three-Dimensional Cubic Model.................................... 6-27

6-6. Summary of Primary Property Statistics................................................................... 6-46

6-7. Summary of Intermediate Property Statistics ...................................................... 6-55

7-1. ECRB Cross-Drift Tunnel: Lithostratigraphic Units and Stations ........................... 7-10

7-2. Borehole Locations and Mean Lithophysal Porosity for ECRB Thermal

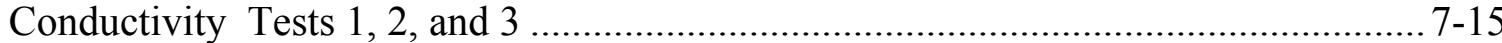

7-3. Stratigraphic Coordinates of Alcove 5 and Alcove 7 Core Samples ........................... 7-19

7-4. Statistical Measures of Alcove 5 and Alcove 7 Thermal Conductivity

7-5. Summary of Results of ECRB Thermal Conductivity Tests 1, 2, and 3 ................... 7-22

C-1. Borehole Thermal Conductivity Measurements ..................................................... C-2

C-2. Alcove 5 Thermal Conductivity Data ..................................................................... C-4

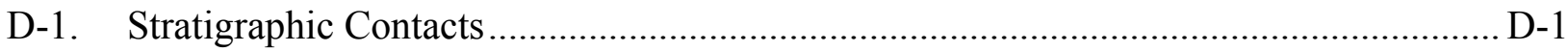


INTENTIONALLY LEFT BLANK 


\section{ACRONYMS AND ABBREVIATIONS}

DTN data tracking number

ECRB Enhanced Characterization of the Repository Block

LDTH Line-averaged-heat-source, Drift-scale, Thermal-Hydrologic submodel

OD oven-dried

$\mathrm{RH} \quad$ relative humidity

SMT Smeared-heat-source, Mountain-scale, Thermal-conduction submodel

TSPA total system performance assessment

TWP technical work plan

Tpt Topopah Spring Tuff

Tptpll Tonopah Spring Tuff crystal-poor lower lithophysal zone

Tptpln Topopah Spring Tuff crystal-poor lower nonlithophysal zone

Tptpmn Topopah Spring Tuff crystal-poor middle nonlithophysal zone

Tptpul Topopah Spring Tuff crystal-poor upper lithophysal zone

W/mK Watts per meter per degree Kelvin 


\section{INTENTIONALLY LEFT BLANK}




\section{PURPOSE}

The primary purpose of this report is to assess the spatial variability and uncertainty of bulk thermal conductivity in the host horizon for the repository at Yucca Mountain. More specifically, the lithostratigraphic units studied are located within the Topopah Spring Tuff (Tpt) and consist of the upper lithophysal zone (Tptpul), the middle nonlithophysal zone (Tptpmn), the lower lithophysal zone (Tptpll), and the lower nonlithophysal zone (Tptpln). Design plans indicate that approximately 81 percent of the repository will be excavated in the Tptpll, approximately 12 percent in the Tptpmn, and the remainder in the Tptul and Tptpln (BSC 2004 [DIRS 168370]).

This report provides three-dimensional geostatistical estimates of the bulk thermal conductivity for the four stratigraphic layers of the repository horizon. The three-dimensional geostatistical estimates of matrix and lithophysal porosity, dry bulk density, and matrix thermal conductivity are also provided. This report provides input to various models and calculations that simulate heat transport through the rock mass. These models include the Drift Degradation Analysis, Multiscale Thermohydrologic Model, Ventilation Model and Analysis Report, Igneous Intrusion Impacts on Waste Packages and Waste Forms, Drift-Scale Coupled Processes (DST and TH Seepage) Models, and Drift Scale THM Model. These models directly or indirectly provide input to the total system performance assessment (TSPA).

The main distinguishing characteristic among the lithophysal and nonlithophysal units is the percentage of large-scale (centimeters-meters) voids within the rock. The Tptpul and Tptpll, as their names suggest, have a higher percentage of lithophysae than the Tptpmn and the Tptpln. Understanding the influence of the lithophysae is of great importance to understanding bulk thermal conductivity.

To assess the spatial variability and uncertainty of thermal conductivity, a model is proposed that is functionally dependent on the volume fraction of lithophysae and the thermal conductivity of the matrix portion of the rock. In this model, void space characterized as lithophysae is assumed to be air-saturated under all conditions, while void space characterized as matrix may be either water or air-saturated. Lithophysae are assumed to be air-saturated under all conditions since the units being studied are all located above the water table in the region of interest, and the relatively strong capillary forces of the matrix and fractures will, under virtually all conditions, preferentially retain any moisture present in the rock.

Furthermore, three published models of thermal conductivity developed for porous media applications are investigated in this report. Based on the criteria and evaluation described in Section 6.1 .7 of this report, the Hsu et al. (1995 [DIRS 158073]) three-dimensional cubic model was ultimately selected and subsequently used to model the spatial variability of matrix thermal conductivity. In this model, matrix thermal conductivity is a function of matrix porosity, the thermal conductivity of the saturating fluid, the thermal conductivity of the solid minerals, and the geometry and connectivity of the solid. The thermal conductivity of the saturating fluid is treated as constant, but the remaining model parameters are treated as spatially uncertain random functions. The geostatistical method known as sequential Gaussian simulation is used to develop 50 independent, equally likely realizations of these uncertain properties. Available measurements from core samples and borehole petrophysical logs are used to derive models of 
spatial continuity and to condition the geostatistical simulations. These three-dimensional property sets then serve as inputs to the matrix thermal conductivity model yielding three-dimensional geostatically-based realizations of matrix thermal conductivity.

The spatial heterogeneity and uncertainty of lithophysal porosity are addressed in a similar manner. A method of characterizing lithophysal porosity from borehole petrophysical data is developed and applied in this endeavor. The results are used to derive models of spatial continuity and to condition geostatistical simulations of this property.

The geostatistical modeling conducted in this work follows closely the methodologies and thought processes developed in the Rock Properties Model. In an effort to create a self-contained document, much of the introductory text concerning geostatistics (Sections 6.1.2 and 6.1.3) has been paraphrased and in some places copied directly from the Rock Properties Model. Readers interested in acquiring a greater understanding of the application and limitations of the geostatistical methods applied in this work are encouraged to read that report. The models developed for bulk thermal conductivity in this report supersedes the corresponding output from the Rock Properties Model. The Thermal Conductivity of the Non-Repository Layers report provides these properties for the layers not covered in this report.

This revision of the model report addresses activities described in Technical Work Plan for: Near Field Environment and Transport Thermal Properties Model and Analysis Reports Integration (BSC 2004 [DIRS 171708]) with regard to thermal conductivity. The spatial distribution of bulk thermal conductivity shown by the model is based on the spatial distribution of the matrix and lithophysal porosity input parameters. This is a conduction-only bulk thermal conductivity model and conductivity values are provided for both saturated and dry conditions. The evaluation of bulk thermal conductivity at intermediate saturation conditions can be determined by appropriate interpolations (e.g., linear) using the saturated and dry values.

Two deviations from the technical work plan (TWP) (BSC 2004 [DIRS 171708], Section 3.2) are noted. The first concerns the Yucca Mountain Review Plan, Final Report (NRC 2003 [DIRS 163274]) acceptance criteria. The TWP states that the acceptance criteria are not relevant to this report because the outputs are not specifically covered by any category but instead provide inputs to downstream numerical models. Contrary to this, the report identifies and discusses the relevant acceptance criteria in Sections 4.2 and 8.2, respectively. The second deviation from the TWP (BSC 2004 [DIRS 171708], Section 9) concerns the use of the software in this report. The TWP provides a list of software that was expected to be used for additional model validation activities for this report revision. It did not list all the software used to produce the results in this revision or the previous version of report; that list can be found in Section 3 and Table 3-1. EARTHVISION V. 5.1 (STN: 10174-5.1-00 [DIRS 167994]) was not identified in the TWP; however, the software was used in the evaluation of the stratigraphic coordinates for the lithophysal porosity validation described in Sections 7.3.1 and 7.3.2. 


\section{QUALITY ASSURANCE}

Development of this model report and the supporting analyses have been determined to be subject to the Office of Civilian Radioactive Waste Management quality assurance program (BSC 2004 [DIRS 171708], Section 8.1). Approved quality assurance procedures identified in the technical work plan (BSC 2004 [DIRS 171708], Section 4) have been used to conduct and document the activities described in this analysis report. The technical work plan also identifies the methods used to control the electronic management of data (BSC 2004 [DIRS 171708], Section 8.4) during the analysis and documentation activities. This report has been prepared in accordance with AP-SIII.10Q, Models.

This model report contributes to the analysis and modeling of the unsaturated zone, which is a natural barrier and is classified on the Q-List (BSC 2004 [DIRS 168361] as safety category because it is important to waste isolation, as defined in AP-2.22Q, Classification Analyses and Maintenance of the Q-List. 


\section{INTENTIONALLY LEFT BLANK}




\section{USE OF SOFTWARE}

\subsection{SOFTWARE TRACKED BY CONFIGURATION MANAGEMENT}

The parameters documented in this report were constructed using geostatistical algorithms that comprise the public-domain geostatistical software library (Deutsch and Journel 1992 [DIRS 100567], 1998 [DIRS 102895], and other internally developed codes). The codes, subject to Software Configuration Management, are listed in Table 3-1, together with a brief description of their functionality. These software packages were obtained from Software Configuration Management and were judged appropriate for use in this type of modeling activity. The software was used within the range of validation. Most of the codes listed in Table 3-1 were run on a personal computer under the Microsoft Windows 2000 or the Microsoft Windows 2000 Server operating system. The exceptions are GSLIB V. 1.4MNSCOREV1.201 (STN: 10109-1.4MNSCOREV1.201-02 [DIRS 158222]), which was run on a HP 9000 workstation operating under the HP UX 10.20 operating system, and EARTHVISION V. 5.1 (EARTHVISION V. 5.1, STN: 10174-5.1-00 [DIRS 167994]), which was run on a Silicon Graphics Octane workstation operating under the IRIX Version 6.5 operating system. Input and output files for the software are contained in Output DTNs: SN0404T0503102.011 [DIRS 169129] and SN0406T0503102.012 [DIRS 170045]. The qualification status of the software is shown in the electronic Document Input Reference System.

\subsection{EXEMPT SOFTWARE}

Software products such as operating systems, utilities, compilers and their associated libraries, spreadsheets, desktop database managers, graphical representations of data, computer aided design systems, and acquired software that is embedded in the test and measurement equipment and the standard functions of commercial off-the-shelf software products are exempt software products in accordance with LP-SI.11Q-BSC, Software Management.

AFPL Ghostscript Version 7.04 is a set of software programs that provide an interpreter for the PostScript language with the ability to convert PostScript language files to many raster formats, view them on displays, print them on non-postscript printers, and act as an interpreter for Adobe Portable Document Format. Ghostscript also has the ability to convert back and forth between PostScript language to portable document format files and provides a set of $\mathrm{C}$ procedures that implement the graphics capabilities appearing as primitive operations in the PostScript language.

Compaq Visual FORTRAN Version 6.1A is a FORTRAN 95 compiler for Windows. Compaq Visual FORTRAN is a complete development system that includes Compaq's FORTRAN 95 compiler, the latest visual development environment from Microsoft, and support for numerous industry standard FORTRAN language extensions.

Cygwin Version 1.3.9 tools are ports of the GNU development tools and utilities for Windows NT 9x, and Windows 2000. They function through the use of the Cygwin library, which provides the UNIX system calls and the environment that these programs require. 
Table 3-1. Software Tracked by Configuration Management

\begin{tabular}{|c|c|c|c|c|c|}
\hline Code Name & Version & STN & $\begin{array}{l}\text { Operating } \\
\text { Platform }\end{array}$ & $\begin{array}{l}\text { Operating } \\
\text { System }\end{array}$ & Brief Description \\
\hline $\begin{array}{l}\text { EARTHVISION } \\
\text { [DIRS 167994] }\end{array}$ & V. 5.1 & $10174-5.1-00$ & SGI & IRIX 6.5 & $\begin{array}{l}\text { Three-dimensional earth science modeling package used } \\
\text { to produce visualizations of this report and to project } \\
\text { stratigraphic contacts. }\end{array}$ \\
\hline $\begin{array}{l}\text { GSLIB V. 1.4MBACKTR } \\
\text { [DIRS 113642] }\end{array}$ & V1.20 & 10108-1.4MBACKTRV1.20-01 & PC & $\begin{array}{l}\text { Windows } \\
2000 \text { Server }\end{array}$ & $\begin{array}{l}\text { Transforms a standard-normal distribution (GSLIB } \\
\text { format) to match a reference histogram (from the } \\
\text { software library, GSLIB; inverse of program NSCORE). }\end{array}$ \\
\hline $\begin{array}{l}\text { GSLIB V. 1.0MGAMV2 } \\
\text { [DIRS 158221] }\end{array}$ & V1.201 & 10087-1.0MGAMV2V1.201-02 & PC & $\begin{array}{l}\text { Windows } \\
2000 \text { Server } \\
\text { and Windows } \\
2000\end{array}$ & $\begin{array}{l}\text { A geostatistical software utility that is used to calculate } \\
\text { variograms and related statistical measures for (up to) } \\
\text { three-dimensional data sets. Designed for use with non- } \\
\text { gridded data. }\end{array}$ \\
\hline $\begin{array}{l}\text { GSLIB V. 1.4MNSCORE } \\
\text { [DIRS 158222] }\end{array}$ & V1.201 & 10109-1.4MNSCOREV1.201-02 & $\begin{array}{l}\mathrm{PC} \text { and } \\
\mathrm{HP}\end{array}$ & $\begin{array}{l}\text { Windows } \\
2000 \text { Server } \\
\text { and HP-UX } \\
10.20\end{array}$ & $\begin{array}{l}\text { Transforms a distribution of values to standard-normal } \\
\text { form while preserving quantile relationships (from the } \\
\text { software library, GSLIB). }\end{array}$ \\
\hline $\begin{array}{l}\text { GSLIB HISTPLT } \\
\text { [DIRS 158223] }\end{array}$ & V. 2.01 & $10802-2.01-00$ & PC & $\begin{array}{l}\text { Windows } \\
2000 \text { Server }\end{array}$ & $\begin{array}{l}\text { Generates univariate statistical summaries and } \\
\text { histograms that are compatible with a PostScript display } \\
\text { device (from the software library, GSLIB). }\end{array}$ \\
\hline $\begin{array}{l}\text { GSLIB V. 1.4SGSIM } \\
\text { [DIRS 158224] }\end{array}$ & V1.41 & 10110-1.4SGSIMV1.41-00 & PC & $\begin{array}{l}\text { Windows } \\
2000 \text { Server }\end{array}$ & $\begin{array}{l}\text { Generates conditional or unconditional Gaussian } \\
\text { simulations of a continuous variable; optional normal- } \\
\text { score forward and back transformation (from the software } \\
\text { library, GSLIB). }\end{array}$ \\
\hline $\begin{array}{l}\text { Etype } \\
\text { [DIRS 159417] }\end{array}$ & V. 2.01 & $10731-2.01-00$ & PC & $\begin{array}{l}\text { Windows } \\
2000 \text { Server }\end{array}$ & $\begin{array}{l}\text { Reads a set of simulation output (GSLIB format) files and } \\
\text { computes mean and standard deviation of simulations. }\end{array}$ \\
\hline $\begin{array}{l}\text { HSUINV } \\
\text { [DIRS 158228] }\end{array}$ & V. 1.0 & $10804-1.0-00$ & PC & $\begin{array}{l}\text { Windows } \\
2000 \text { Server }\end{array}$ & $\begin{array}{l}\text { The code solves the inverse problem for Hsu et al. (1995 } \\
\text { [DIRS 158073]) three-dimensional cube model of matrix } \\
\text { thermal conductivity. The inverse problem consists of } \\
\text { simultaneously solving two non-linear equations. }\end{array}$ \\
\hline $\begin{array}{l}\text { LITHO } \\
\text { [DIRS 158256] }\end{array}$ & V. 1.0 & $10800-1.0-00$ & PC & $\begin{array}{l}\text { Windows } \\
2000 \text { Server }\end{array}$ & $\begin{array}{l}\text { Designed to process data from geophysical logs and } \\
\text { core data to generate "GEO-EAS" formatted files that } \\
\text { can be input into GSLIB programs. The formatted output } \\
\text { consists of the measured data as a function of } \\
\text { stratigraphic elevation. }\end{array}$ \\
\hline
\end{tabular}


Table 3-1. Software Tracked by Configuration Management (Continued)

\begin{tabular}{|l|l|l|l|l|l|}
\hline \multicolumn{1}{|c|}{ Code Name } & Version & \multicolumn{1}{|c|}{ STN } & $\begin{array}{l}\text { Operating } \\
\text { Platform }\end{array}$ & $\begin{array}{c}\text { Operating } \\
\text { System }\end{array}$ & \multicolumn{1}{c|}{ Brief Description } \\
\hline $\begin{array}{l}\text { MODGEOM } \\
\text { [DIRS 158257] }\end{array}$ & V. 1.02 & $10597-1.02-01$ & PC & $\begin{array}{l}\text { Windows } \\
\text { 2000 Server }\end{array}$ & $\begin{array}{l}\text { A software utility program that modifies the random seed } \\
\text { for a SGSIM parameter file. }\end{array}$ \\
\hline $\begin{array}{l}\text { SMOOTH } \\
\text { [DIRS 158258] }\end{array}$ & V. 1.0 & $10734-1.0-01$ & PC & $\begin{array}{l}\text { Windows } \\
\text { 2000 Server }\end{array}$ & $\begin{array}{l}\text { A software utility that reads in external data that varies } \\
\text { as a function of depth (such as borehole data), } \\
\text { computes the mean of a moving window. }\end{array}$ \\
\hline $\begin{array}{l}\text { POINT } \\
\text { [DIRS 158336] }\end{array}$ & V. 1.0 & $10826-1.0-00$ & PC & $\begin{array}{l}\text { Windows } \\
\text { 2000 Server }\end{array}$ & $\begin{array}{l}\text { A utility program that extracts point data from multiple } \\
\text { GSLIB-formatted realizations. }\end{array}$ \\
\hline $\begin{array}{l}\text { TCOND } \\
\text { [DIRS 158260] }\end{array}$ & V. 1.0 & $10801-1.0-00$ & PC & $\begin{array}{l}\text { Windows } \\
\text { 2000 Server }\end{array}$ & $\begin{array}{l}\text { Computes an effective wet and dry bulk thermal } \\
\text { conductivity for porous rock that includes both } \\
\text { small-scale (< 1mm) intergranular porosity and much } \\
\text { larger scale (centimeters to meters) void spaces. }\end{array}$ \\
\hline
\end{tabular}

NOTES: EARTHVISION was run on an Octane model CPU (barcode 700800) manufactured by Silicon Graphics (SGI). All other software was run on a 530 Work Station model CPU (barcode 436032) manufactured by Dell.

$\mathrm{PC}=$ personal computer 
GSView Version 4.2 is a graphical interface for Ghostscript. Ghostscript is an interpreter for the PostScript page description language used by laser printers. For documents following the Adobe PostScript document structuring conventions, GSView allows selected pages to be viewed or printed. GSview requires AFPL Ghostscript.

Microsoft Excel 2000 was used to calculate matrix and lithophysal porosity. Standard functions were used in these calculations.

Microsoft Visual $\mathrm{C}++$ Version 6.0 provides the development environment for compiling $\mathrm{C}$ and $\mathrm{C}++$ computer software.

Microsoft Word 2000 is an office automation system word processor used to author, format, edit, and review project documents.

Sigma Plot Version 8.0 was used to plot the figures presented in this report. 


\section{INPUTS}

The model of bulk thermal conductivity developed in this report is highly dependent on the existing data collected at Yucca Mountain from well-log and laboratory core analyses. These data appear to be high-quality measurements and are used directly as inputs to the model. There are data, however, which, if not removed from the input data set, could lead to inappropriate model predictions. Examples for which this might be the case include data obtained over an insufficient range of conditions or outside the calibrated range of the measuring device. For this reason, a significant effort was devoted to examining input data and removing unsuitable data from the input set.

Appendices B and C document data usage decisions and summarize model inputs. Appendix B consists of plots of processed well-log data and, where available, comparisons with laboratory core measurements. Data use restrictions, if any, are discussed on the same page on which the data are presented in Appendix B. Appendix C discusses thermal conductivity measurements acquired from laboratory core samples. Several of these data are excluded from the analysis. The reasons for excluding certain thermal conductivity measurements are discussed in Appendix C. Often these decisions are subjective and based on limited information. Therefore, all decisions regarding data quality usage are subject to interpretation and may change as new information becomes available.

\subsection{DIRECT INPUT}

Laboratory core measurements of porosity, particle density, water saturation, and thermal conductivity are used in this report to develop geostatistically-based models of thermal conductivity (Table 4-1) and various other important rock properties. Petrophysical well-log measurements, from a total of 37 different boreholes that, at a minimum, penetrated the top of the Tptpul (Table 4-2), are used to characterize the spatial variability of both lithophysae and matrix porosity. The locations of the boreholes used in this work are depicted graphically in Figure 4-1.

Table 4-1. Source of Laboratory Core Physical Properties Data

\begin{tabular}{|c|c|}
\hline Data Source Description & Reference \\
\hline Particle Density, Water Saturation, and Porosity data & $\begin{array}{l}\text { DTN: MO0109HYMXPROP.001 [DIRS } \\
\text { 155989] }\end{array}$ \\
\hline Particle Density, Water Saturation, and Porosity data & DTN: GS980808312242.014 [DIRS 106748] \\
\hline \multicolumn{2}{|c|}{$\begin{array}{ll}\text { a'Boreholes: } & \text { USW SD-7, USW SD-9, USW SD-12, USW NRG-7/7a, USW UZ-7a, USW NRG-6, and } \\
& \text { USW UZ-1/USW UZ-14. }\end{array}$} \\
\hline 'Borehole: $\quad$ USW SD-6. & \\
\hline
\end{tabular}


Table 4-2. Source of Input Petrophysical Data

\begin{tabular}{|l|c|}
\hline \multicolumn{1}{|c|}{ Data Source Description } & Reference \\
\hline Neutron porosity and bulk density data & DTN: MO0010CPORGLOG.002 [DIRS 155229] \\
\hline Neutron porosity and bulk density data & DTN: MO0010CPORGLOG.003 [DIRS 155959] \\
\hline
\end{tabular}

A second type of data required in this work consists of borehole locations and borehole stratigraphic contacts. The sources of these data are given in Sections 4.1.4 through 4.1.6. Data tracking numbers (DTNs) associated with each type of data are provided in Tables 4-4, 4-5, and 4-6.

\subsubsection{Laboratory Core Physical Property Data}

Laboratory core measurements of particle density, water saturation, and porosity from eight different boreholes are used in this work. The DTNs associated with these measurements are presented in Table 4-1. These DTNs are appropriate because the core data contained within them are specific to the lithostratigraphic units and spatial region for which this model is being developed.

\subsubsection{Petrophysical Data}

Borehole petrophysical measurements of bulk density and neutron porosity are used to make quantitative estimates of matrix and lithophysal porosity. These data provide substantial information regarding the spatial heterogeneity of porosity across the entire site (Figure 4-1). This is particularly true for regions distant from the proposed repository block where no core samples have been acquired. Data from regions outside the model boundaries are useful for identifying patterns of long-range spatial correlation. The DTNs associated with borehole petrophysical data are presented in Table 4-2. These DTNs are appropriate because the petrophysical data contained within them are specific to the lithostratigraphic units and spatial region for which this model is being developed.

Data acquired from the Technical Data Management System must first be partitioned into model units and then reformatted to accommodate the input configuration used by the GSLIB software suite. Furthermore, to obtain a consistent scale of measurement between core and petrophysical data, the petrophysical data are smoothed and re-sampled on an interval equal to the nominal length of core, which happens to be $3 \mathrm{ft}$. Two software utility codes are used in this pre-processing step: SMOOTH (SMOOTH V. 1.0, STN: 10734-1.0-01 [DIRS 158258]) and LITHO V. 1.0 (LITHO V. 1.0, STN: 10800-1.0-00 [DIRS 158256]). The code SMOOTH is applied only to borehole petrophysical data, and the code LITHO V. 1.0 is a pre-processor applied to both core and smoothed petrophysical data. 


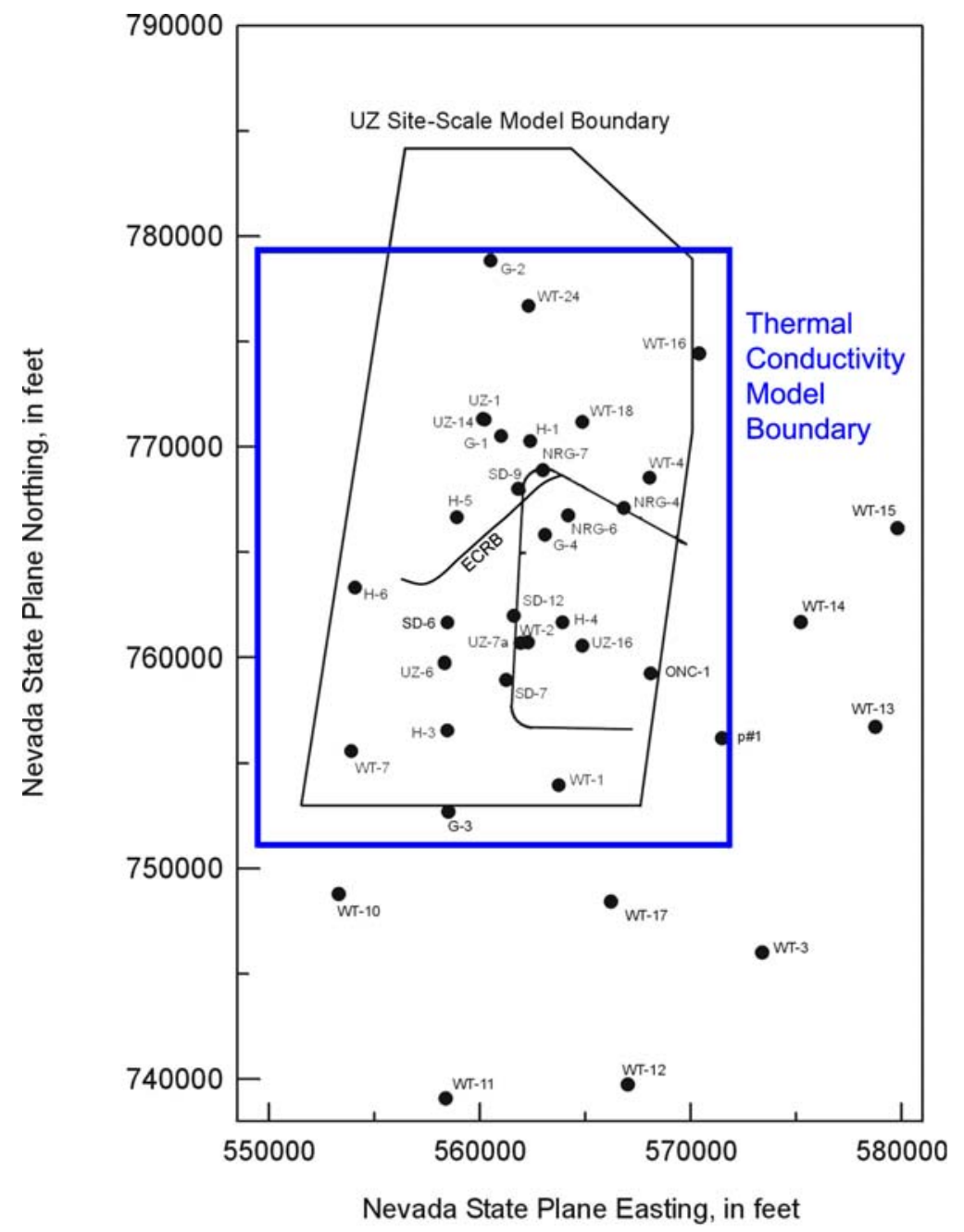

Input DTN: MO0012MWDGFM02.002 [DIRS 153777].

Figure 4-1. Yucca Mountain Boreholes that Penetrate the Topopah Spring Tuff Crystal-Poor Upper Lithophysal Zone (Tptpul)

\subsubsection{Matrix Thermal Conductivity Data}

Two sources of laboratory matrix thermal conductivity measurements were used in this study. These two sources plus the matrix porosity data associated with the borehole core samples are listed in Table 4-3. The three DTNs include data that were used to calibrate the matrix thermal conductivity model. A detailed discussion of these data including the rationale for excluding certain data is provided in Appendix C. These DTNs are appropriate because the thermal conductivity data contained within them are specific to the lithostratigraphic units. In addition, the DTNs provide wet and dry thermal conductivity (as explained in Appendix C) and porosity values on the same samples or sample splits. 
Table 4-3. Source of Matrix Thermal Conductivity Data

\begin{tabular}{|l|l|}
\hline \multicolumn{1}{|c|}{ Data Source Description } & \multicolumn{1}{c|}{ Reference } \\
\hline Borehole Core Samples & DTN: SNL01A05059301.005 [DIRS 109002] \\
\hline Borehole Sample Porosity & DTN: SNL01A05059301.007 [DIRS 108980] \\
\hline Alcove 5 Core Samples & DTN: SNL22100196001.006 [DIRS 158213] \\
\hline
\end{tabular}

\subsubsection{Borehole Coordinates}

The Nevada State plane coordinates of borehole wellheads are obtained from the DTN listed in Table 4-4. The locations of the boreholes used in this study are shown in Figure 4-1.

Table 4-4. Source of Borehole Coordinate Data

\begin{tabular}{|c|c|}
\hline Data Source Description & Reference \\
\hline Borehole Wellhead Coordinates & DTN: MO9906GPS98410.000 [DIRS 109059] \\
\hline
\end{tabular}

\subsubsection{Observed Lithostratigraphic Contacts}

The geostatistic models produced in this report are developed using a stratigraphic coordinate system, which represents the relative vertical position of each measured property value within a model unit. The conversion from natural $(\mathrm{x}, \mathrm{y}, \mathrm{z})$ coordinates to stratigraphic coordinates requires the upper and lower contact of each aggregate model unit in each borehole. This process is described in Section 6.1.2. Typically, the required depth values are observed, either in core specimens, petrophysical logs, or downhole video records. The DTNs associated with observed lithostratigraphic contact data are presented in Table 4-5, and the contacts themselves are reproduced in Appendix D. These DTNs are appropriate because the lithostratigraphic contacts contained within them are specific to the units and spatial region being modeled. They represent the compilation of borehole data that are used as input to the Geologic Framework Model (GFM2000) (DTN: MO0012MWDGFM02.002 [DIRS 153777]).

Table 4-5. Source of Input for Observed Lithostratigraphic Contacts

\begin{tabular}{|l|l|}
\hline \multicolumn{1}{|c|}{ Data Source Description } & \multicolumn{1}{c|}{ Reference } \\
\hline Lithostratigraphic Contacts & DTN: MO0004QGFMPICK.000 [DIRS 152554] \\
\hline Contacts for SD-6 & DTN: SNF40060298001.001 [DIRS 107372] \\
\hline
\end{tabular}

\subsubsection{Lithostratigraphic Contacts}

Most of the lithostratigraphic contacts were obtained from the observed contacts defined in Table 4-5. A small number of the contacts were obtained by using the Geologic Framework Model 2000 (DTN: MO0012MWDGFM02.002 [DIRS 153777]) in conjunction with the software EARTHVISION V. 5.1 (EARTHVISION V. 5.1, STN: 10174-5.1-00 [DIRS 167994]). Projected contacts are sometimes required when a borehole only partially penetrates the region of interest or crosses a fault. The DTN for the data obtained from the Geologic Framework 
Model is given in Table 4-6. The projected lithostratigraphic contacts are presented in Appendix D. The DTN is appropriate because the model results provide a three-dimensional geologic representation of the units and spatial region being modeled.

Table 4-6. Source of Input for Lithostratigraphic Contacts

\begin{tabular}{|c|c|}
\hline Data Source Description & Reference \\
\hline Geologic Framework Model 2000 & DTN: MO0012MWDGFM02.002 [DIRS 153777] \\
\hline
\end{tabular}

\subsubsection{Thermal Conductivity of Air and Water}

The constant values shown in Table 4-7 were used to represent the thermal conductivities of air and water. These thermal conductivities are used in the development of the matrix and bulk thermal conductivity models described in Sections 6.1.7 and 6.1.8.

Table 4-7. Source of Input for Air and Water Thermal Conductivity

\begin{tabular}{|l|c|l|}
\hline \multicolumn{1}{|c|}{ Data Source Description } & Value (W/mK) & \multicolumn{1}{|c|}{ Reference } \\
\hline Thermal Conductivity of Air & 0.028 & $\begin{array}{l}\text { Holman 1997 [DIRS 101978], } \\
\text { p. 646 }\end{array}$ \\
\hline Thermal Conductivity of Water & 0.64 & $\begin{array}{l}\text { Holman 1997 [DIRS 101978], } \\
\text { p. 650 }\end{array}$ \\
\hline
\end{tabular}

These values are demonstrated to be suitable for their intended use in this report by corroboration (AP-SIII.10Q, Section 5.2.1 k) with data in the Chapter 2 of the Handbook of Heat Transfer (Irvine 1998 [DIRS 170361], Tables 2.10 and 2.19), and are considered qualified inputs. The thermal conductivity of water varies from 0.60 to $0.68 \mathrm{~W} / \mathrm{mK}$ over the temperature range of 20 to $100^{\circ} \mathrm{C}$, and $0.64 \mathrm{~W} / \mathrm{mK}$ is representative of this range. At $70^{\circ} \mathrm{C}$, which corresponds to the nominal temperature at which the laboratory tests on wet samples were performed, the thermal conductivity of water is $0.66 \mathrm{~W} / \mathrm{mK}$. The thermal conductivity of air at $110^{\circ} \mathrm{C}$, the nominal temperature at which the laboratory tests on dry samples were performed, is approximately 0.032 $\mathrm{W} / \mathrm{mK}$ which is approximately 15 percent greater than the value used in model development. Both of these values demonstrate the properties of interest, per AP-SIII.10Q, Section 5.2.1 k). Using constant values for these conductivities will have a negligible impact on the thermal conductivity model development because relative to the thermal conductivity of the solid material, their contribution is small.

\subsection{CRITERIA}

The Project Requirements Document (Canori and Leitner 2003 [DIRS 166275]) contains the following criterion that is relevant to the work documented in this report:

- PRD-002/T-015 Requirements for Performance Assessment; see 10 CFR 63.114 [DIRS 156605] for complete requirement text. 
Work described in this model report supports these requirements, but more specific criteria exists in the Yucca Mountain Review Plan, Final Report (NRC 2003 [DIRS 163274]). The criteria established for the quantity and chemistry of water contacting engineered barriers and waste forms as presented in Section 2.2.1.3.3.3 of NRC (2003 [DIRS 163274]) and 10 CFR 63.114(a)-(c) and (e)-(g) [DIRS 156605] are applicable to this model report. The criteria and subcriteria relevant to this model report are presented in the following subsections, and an assessment of how these criteria are addressed is provided in Section 8.2 of this report.

\subsubsection{Acceptance Criterion 1 - System Description and Model Integration are Adequate}

(2) The abstraction of the quantity and chemistry of water contacting engineered barriers and waste forms uses assumptions, technical bases, data, and models, that are appropriate and consistent with other related U.S. Department of Energy abstractions. For example, the assumptions used for the quantity and chemistry of water contacting engineered barriers and waste forms are consistent with the abstractions of "Degradation of Engineered Barriers" (Section 2.2.1.3.1); "Mechanical Disruption of Engineered Barriers" (Section 2.2.1.3.2); "Radionuclide Release Rates and Solubility Limits" (Section 2.2.1.3.4); "Climate and Infiltration" (Section 2.2.1.3.5); and "Flow Paths in the Unsaturated Zone" (Section 2.2.1.3.6). The descriptions and technical bases provide transparent and traceable support for the abstraction of quantity and chemistry of water contacting engineered barriers and waste forms.

\subsubsection{Acceptance Criterion 2 - Data are Sufficient for Model Justification}

(1) Geological, hydrological, and geochemical values used in the license application are adequately justified. Adequate description of how the data were used, interpreted, and appropriately synthesized into the parameters is provided.

(2) Sufficient data were collected on the characteristics of the natural system and engineered materials to establish initial and boundary conditions for conceptual models of thermal-hydrologic-mechanical-chemical coupled processes, that affect seepage and flow and the engineered barrier chemical environment.

\subsubsection{Acceptance Criterion 3 - Data Uncertainty Is Characterized and Propagated Through the Model Abstraction}

(1) Models use parameter values, assumed ranges, probability distributions, and bounding assumptions that are technically defensible, reasonably account for uncertainties and variabilities, and do not result in an under-representation of the risk estimate.

(2) Parameter values, assumed ranges, probability distributions, and bounding assumptions used in the total system performance assessment calculations of quantity and chemistry of water contacting engineered barriers and waste forms are technically defensible and reasonable, based on data from the Yucca Mountain region (e.g., results from large block and drift-scale heater and niche tests), and a combination of techniques that may include laboratory experiments, field measurements, natural analog research, and process-level modeling studies. 
(3) Input values used in the total system performance assessment calculations of quantity and chemistry of water contacting engineered barriers (e.g., drip shield and waste package) are consistent with the initial and boundary conditions and the assumptions of the conceptual models and design concepts for the Yucca Mountain site. Correlations between input values are appropriately established in the U.S. Department of Energy total system performance assessment. Parameters used to define initial conditions, boundary conditions, and computational domain in sensitivity analyses involving coupled thermal-hydrologic-mechanical-chemical effects on seepage and flow, the waste package chemical environment, and the chemical environment for radionuclide release, are consistent with available data. Reasonable or conservative ranges of parameters or functional relations are established.

(4) Adequate representation of uncertainties in the characteristics of the natural system and engineered materials is provided in parameter development for conceptual models, process-level models, and alternative conceptual models. The U.S. Department of Energy may constrain these uncertainties using sensitivity analyses or conservative limits. For example, the U.S. Department of Energy demonstrates how parameters used to describe flow through the engineered barrier system bound the effects of excavation-induced changes.

\subsubsection{Acceptance Criterion 4 - Model Uncertainty is Characterized and Propagated Through the Model Abstraction}

(2) Alternative modeling approaches are considered and the selected modeling approach is consistent with available data and current scientific understanding. A description that includes a discussion of alternative modeling approaches not considered in the final analysis and the limitations and uncertainties of the chosen model is provided;

\subsection{CODES, STANDARDS, AND REGULATIONS}

This report was prepared to comply with 10 CFR Part 63 [DIRS 156605], the U.S. Nuclear Regulatory Commission rule on high-level radioactive waste. Subparts of this rule that are applicable to data and models include Subpart E, Section 114 (Requirements for Performance Assessment). 


\section{INTENTIONALLY LEFT BLANK}




\section{ASSUMPTIONS}

\subsection{THE PROPERTIES OF GEOLOGIC STRATA MAY BE REPRESENTED BY STATIONARY RANDOM FUNCTIONS}

Assumption: The principal assumption applied in this work is that the properties of geologic strata may be represented by stationary random functions.

Basis: A random function is a set of spatially distributed random variables whose dependence on one another is specified by some probabilistic mechanism. The term "stationary" implies that the probabilistic mechanism is independent of spatial location. Stationary random functions are widely used and commonly found in most geostatistical estimation procedures. Isaaks and Srivastava (1989 [DIRS 109018], pp. 198 to 236) introduce the concept of random function models and discuss the use of those models in the field of geostatistics.

Confirmation Status: This is a commonly accepted assumption applied in geostatistical modeling and does not require further justification.

Use in the Model: This assumption is used throughout Section 6.

\subsection{THE ROCK MATRIX IS ASSUMED TO BE FULLY SATURATED}

Assumption: For the purposes of computing matrix and lithophysal porosity from petrophysical measurements, the rock matrix is assumed to be saturated in each of the four lithostratigraphic units studied.

Basis: Justification of this assumption can be provided by evaluating the impact of the assumption over the range of observed matrix saturation values for the Tpt units (Tptpul, Tptmn, Tptpll, and Tptpln) that have been modeled as part of the analysis of thermal conductivity presented in this report. As indicated by the data for boreholes SD-7 and SD-9 plotted in Figures 3 and 4 of Flint (1998 [DIRS 100033]), matrix saturation within these units ranges from 80 to 100 percent with an average saturation of about 90 percent.

To evaluate the assumption, data from three sample depths from borehole USW H-6 were selected. This borehole was selected for this evaluation because petrophysical well-log measurements of bulk density and neutron porosity were available which allow evaluation of matrix porosity and lithophysal porosity using Method B described in Sections 6.1.4, 6.1.5, and Appendix A. These borehole data were used in this analysis to generate the matrix and bulk thermal conductivity values discussed in Sections 6.1.7 and 6.1.8 of this report. Calculations that show the impact of changing the matrix saturation from 100 to 80 percent are presented in Table 5-1. These borehole samples were selected to bracket the range of matrix and lithophysal porosities observed in the borehole. 
Table 5-1. Change in Calculated Porosity Caused by Changing Matrix Saturation from 100 to 80 Percent

\begin{tabular}{|c|c|c|c|c|c|c|c|c|}
\hline \multirow{2}{*}{$\begin{array}{c}\text { Sample } \\
\text { USW H-6 }\end{array}$} & \multicolumn{2}{|c|}{ Saturation 100\% } & \multicolumn{2}{c|}{ Saturation 80\% } & \multicolumn{2}{c|}{ Relative Change } & \multicolumn{2}{c|}{ Magnitude Change } \\
\cline { 2 - 8 } & $\begin{array}{c}\text { Patrix } \\
\text { Porosity }\end{array}$ & $\begin{array}{c}\text { Lithophysal } \\
\text { Porosity }\end{array}$ & $\begin{array}{c}\text { Matrix } \\
\text { Porosity }\end{array}$ & $\begin{array}{c}\text { Lithophysal } \\
\text { Porosity }\end{array}$ & $\begin{array}{c}\text { Matrix } \\
\text { Porosity }\end{array}$ & $\begin{array}{c}\text { Lithophysal } \\
\text { Porosity }\end{array}$ & $\begin{array}{c}\text { Matrix } \\
\text { Porosity }\end{array}$ & $\begin{array}{c}\text { Lithophysal } \\
\text { Porosity }\end{array}$ \\
\hline $586 \mathrm{ft}$ & 0.128 & 0.291 & 0.155 & 0.268 & $+21 \%$ & $-8 \%$ & +0.027 & -0.023 \\
\hline $625 \mathrm{ft}$ & 0.083 & 0.137 & 0.102 & 0.119 & $+23 \%$ & $-13 \%$ & +0.019 & -0.018 \\
\hline
\end{tabular}

Output DTN: SN0404T0503102.011 [DIRS 169129].

The results of the calculation indicate that changing the saturation from 100 to 80 percent results in a relative change in matrix porosity of about 19 to 23 percent (which is consistent with the definition of matrix porosity presented in Appendix A). The relative change in lithophysal porosity is -8 to -32 percent. The change in matrix porosity ranges from 0.019 to 0.036 and in lithophysal porosity from 0.018 to 0.041 . Applying the methodology described in Section 6.1.7, specifically Equations 6-9 and 6-10, the impact of the results presented in Table 5-1 on dry and wet matrix thermal conductivity was calculated. The results of these calculations are presented in Table 5-2. To calculate the matrix thermal conductivity values, the following inputs for the HSUINV V. 1.0 (SNL 2002 [DIRS 158228]) model for the Tptpul layer were used: a solid thermal conductivity of 2.6011 watts per meter per degree Kelvin $(\mathrm{W} / \mathrm{mK})$ and a geometry factor (gamma c) of 0.8517, which are the same values that were used in the modeling described in Section 6.1 .7 for the Tptpul unit.

Table 5-2. Change in Calculated Matrix Thermal Conductivity Caused by Changing Matrix Saturation from 100 to 80 Percent

\begin{tabular}{|c|c|c|c|c|c|c|c|c|}
\hline & \multicolumn{2}{|c|}{ Saturation 100\% } & \multicolumn{2}{c|}{ Saturation 80\% } & \multicolumn{2}{c|}{ Percent Change } & \multicolumn{2}{c|}{ Magnitude Change } \\
\cline { 2 - 9 } $\begin{array}{c}\text { Sample } \\
\text { USW H-6 }\end{array}$ & $\begin{array}{c}\text { Dry Matrix } \\
\text { Thermal K } \\
\text { (W/mK) }\end{array}$ & $\begin{array}{c}\text { Wet } \\
\text { Matrix } \\
\text { Thermal K K } \\
\text { (W/mK) }\end{array}$ & $\begin{array}{c}\text { Dry Matrix } \\
\text { Thermal K } \\
\text { (W/mK) }\end{array}$ & $\begin{array}{c}\text { Wet } \\
\text { Matrix } \\
\text { Thermal K K } \\
\text { (W/mK) }\end{array}$ & $\begin{array}{c}\text { Dry Matrix } \\
\text { Thermal K } \\
\text { (Percent) }\end{array}$ & $\begin{array}{c}\text { Wet } \\
\text { Matrix } \\
\text { Thermal K K } \\
\text { (Percent) }\end{array}$ & $\begin{array}{c}\text { Dry Matrix } \\
\text { Thermal K } \\
\text { (W/mK) }\end{array}$ & $\begin{array}{c}\text { Wet } \\
\text { Matrix } \\
\text { Thermal K } \\
\text { (W/mK) }\end{array}$ \\
\hline $541 \mathrm{ft}$ & 1.490 & 2.125 & 1.406 & 2.047 & $-5.64 \%$ & $-3.67 \%$ & -0.084 & -0.078 \\
\hline $586 \mathrm{ft}$ & 1.649 & 2.266 & 1.578 & 2.204 & $-4.31 \%$ & $-2.74 \%$ & -0.071 & -0.062 \\
\hline $625 \mathrm{ft}$ & 1.316 & 1.962 & 1.223 & 1.873 & $-7.07 \%$ & $-4.54 \%$ & -0.093 & -0.089 \\
\hline
\end{tabular}

Output DTN: SN0404T0503102.011 [DIRS 169129].

$\mathrm{W} / \mathrm{mK}=$ watts per meter per degree Kelvin

These results indicate that the change in dry matrix thermal conductivity ranges from -4.31 to -7.07 percent, while the change in wet thermal conductivity values ranges from -2.74 to -4.54 percent (watts per meter per degree Kelvin). The bias resulting from the use of 100 percent saturation leads to a higher prediction of matrix thermal conductivity. These percentage differences are of the same magnitude as the experimental error of \pm 5 percent associated with thermal conductivity values determined from core samples (SNL 1998 [DIRS 118788], p. 10) and represent an acceptable range of uncertainty. 
In order to completely evaluate the effect of this assumption, the impact on the calculation of bulk thermal conductivity was examined using the parallel model of thermal conductivity described in Section 6.1.8. The results of this impact evaluation are shown in Table 5-3.

Table 5-3. Change in Calculated Bulk Thermal Conductivity Caused by Changing Matrix Saturation from 100 to 80 Percent

\begin{tabular}{|c|c|c|c|c|}
\hline $\begin{array}{c}\text { Sample } \\
\text { USW H-6 }\end{array}$ & $\begin{array}{c}\text { Saturation 100\% } \\
\text { Culk Thermal } \\
\text { Conductivity } \\
\text { (W/mK) }\end{array}$ & $\begin{array}{c}\text { Saturation 80\% } \\
\text { Bulk Thermal } \\
\text { Conductivity } \\
\text { (W/mK) }\end{array}$ & $\begin{array}{c}\text { Percent Change } \\
\text { Bulk Thermal } \\
\text { Conductivity (Percent) }\end{array}$ & $\begin{array}{c}\text { Magnitude Change } \\
\text { Bulk Thermal } \\
\text { Conductivity (W/mK) }\end{array}$ \\
\hline $541 \mathrm{ft}$ & 1.329 & 1.252 & $-5.79 \%$ & -0.077 \\
\hline $586 \mathrm{ft}$ & 1.838 & 1.735 & $-5.60 \%$ & -0.103 \\
\hline $625 \mathrm{ft}$ & 1.615 & 1.530 & $-5.26 \%$ & -0.085 \\
\hline
\end{tabular}

Output DTN: SN0404T0503102.011 [DIRS 169129].

These results indicate that the change in bulk thermal conductivity due to the difference in assumed matrix saturation values range from -5.26 to -5.79 percent. The bias resulting from the use of 100 percent saturation leads to a higher prediction of bulk thermal conductivity than would be calculated using a lower saturation value. This percentage change in bulk thermal conductivity is also of the same magnitude as the experimental error of \pm 5 percent associated with determining thermal conductivity on core samples (SNL 1998 [DIRS 118788], p. 10) and is within the acceptable limit of uncertainty.

Confirmation Status: On the basis of this evaluation of impact, it is concluded that assuming a matrix saturation of 100 percent, when it is at least 80 percent, leads to calculated thermal conductivity values that are within acceptable ranges of uncertainty. No further confirmation is required.

Use in the Model: This assumption is used in Section 6.1.4.

\subsection{THE PARTICLE DENSITY IS CONSTANT IN THE LITHOSTRATIGRAPHIC UNITS}

Assumption: For computing matrix and lithophysal porosity from petrophysical measurements, the particle density is assumed to be constant in each of the four lithostratigraphic units studied. It is also assumed that the particle density and the grain density are equivalent in these units.

Basis: This assumption is supported by evaluating Figures 3 and 4 from Flint (1998 [DIRS 100033]). The figures indicate that the particle density for the Tptpul, Tptpmn, Tptpll, and Tptpln lithostratigraphic units is quite constant and varies from 2.5 to $2.6 \mathrm{~g} / \mathrm{cc}$. This homogeneity can be compared to the variable density for the formations underlying the repository zones. In general, particle density is lower than grain density because of occluded pores but approaches it for rocks having small occluded pore space. Comparison of mean particle and grain density data in Table 5-4 verifies that this assumption is valid.

Confirmation Status: No further justification of this assumption is required.

Use in the Model: This assumption is used in Sections 6.1.4, 6.1.5, 6.1.6, and Appendix A. 
Table 5-4. Mean Particle Density in the Four Lithostratigraphic Layers

\begin{tabular}{|c|c|c|}
\hline $\begin{array}{c}\text { Lithostratigraphic } \\
\text { Unit }\end{array}$ & $\begin{array}{c}\text { Particle Density }^{\mathbf{1}} \\
\text { (g/cc) }\end{array}$ & $\begin{array}{c}\text { Grain Density }^{\mathbf{2}} \\
\text { (g/cc) }\end{array}$ \\
\hline Tptpul & 2.51 & 2.53 \\
\hline Tptpmn & 2.53 & 2.53 \\
\hline Tptpll & 2.55 & 2.56 \\
\hline Tptpln & 2.55 & 2.56 \\
\hline
\end{tabular}

${ }^{1}$ See Section 6.1.6.

${ }^{2}$ CRWMS M\&O 1996 [DIRS 111105], pp. 5-30 to 5-31.

\subsection{ALL WATER RESIDES IN THE MATRIX PORE SPACE}

Assumption: It is assumed that any water present in the rock is contained within the small-scale pore space of the matrix.

Basis: This assumption is an application of basic capillary response of the host rock, that for partially saturated conditions, large-scale voids (e.g., centimeter-scale lithophysae) and fractures will contain very small amounts of water (Hillel 1980 [DIRS 101134], pp. 196 to 197). Evidence specific to the proposed site is provided by the texture of calcite and opal coating in the interior of the lithophysae that indicates that the lithophysae within the welded tuffs exposed in the Exploratory Studies Facility have been open and air-filled throughout the geologic period of record (Paces et al. 2001 [DIRS 156507], p. 66).

Confirmation Status: No further confirmation is required.

Use in the Model: This assumption is used in Sections 6.1.4 and 6.1.5.

\subsection{SPATIAL CORRELATION MODELS DEVELOPED FOR MATRIX POROSITY ARE APPLICABLE TO OTHER PARAMETERS}

Assumption: It is assumed that the spatial correlation models developed for matrix porosity are applied to other uncertain model parameters (solid thermal conductivity, $\mathrm{k}_{\mathrm{s}}$, and solid connectivity, $\gamma_{c}$ ) in the development of the matrix thermal conductivity model.

Basis: The spatial variability of the solid thermal conductivity, $\mathrm{k}_{\mathrm{s}}$, and solid connectivity, $\gamma_{\mathrm{c}}$ cannot be confidently described because they were developed from a small number of matrix thermal conductivity measurements. Matrix porosity has also been used as a surrogate for modeling the spatial variability of other variables as described in the Rock Properties Model (BSC 2004 [DIRS 170032], Section 5).

Confirmation Status: The appropriateness of this assumption is confirmed by the validation of the matrix thermal conductivity model in Section 7.4. No further justification of this assumption is required.

Use in the Model: This assumption is used in Sections 6.1.3 and 6.1.7. 


\subsection{PARALLEL MODEL IS USED TO REPRESENT BULK THERMAL CONDUCTIVITY OF ROCK}

Assumption: A parallel model of thermal conductivity is assumed to represent the bulk thermal conductivity of the rock.

Basis: The basis for the selection of this model is provided in Section 6.1.8. After examining several different conceptual models, this model was selected. It was determined that the parallel model may overestimate the bulk thermal conductivity for geologic materials when conduction is the only heat transfer mode. However, the presence of lithophysae may also result in radiative heat transfer effects. The parallel model may provide an acceptable approximation to the effective thermal conductivity when both conduction and radiation are present.

Confirmation Status: The appropriateness of this assumption is confirmed by the validation of the bulk thermal conductivity model in Section 7.5. No further justification of this assumption is required.

Use in the Model: This assumption is used in Section 6.1.8.

\subsection{THERMAL CONDUCTIVITY MODEL IS VALID ACROSS ALL FOUR LITHOSTRATIGRAPHIC UNITS OF THE REPOSITORY}

Assumption: The model and associated method for predicting matrix and bulk thermal conductivity is appropriate and adequate for all layers considered in this report, even though the matrix thermal conductivity model is only validated in the Tptpmn and the bulk thermal conductivity model is only validated in the Tptpll lithostratigraphic unit.

Basis: This assumption is based on the observation that the repository horizon layers are very similar in mineralogical composition (BSC 2004 [DIRS 170003], Table 6-2) and differ primarily in terms of matrix ground mass and lithophysal porosity percentages (BSC 2003 [DIRS 166660, Section 5.3.3.3]) as shown in Table 6-1 of this report. Because the mineralogical abundance and chemical composition for these units are very similar, the thermal conductivity of the solids making up the matrix will be similar. The matrix thermal conductivity model of Hsu et al. (1995 [DIRS 158073]) used in this work (Section 6.1.7) is dependent on four parameters: matrix porosity, solid and pore fluid conductivity, and a connectivity parameter. Figure 6-11 illustrates that the solid thermal conductivity values for all repository horizon samples can be represented by a normal distribution. This indicates there are no significant differences observed in solid thermal conductivity between samples from different layers. This same argument also holds for the connectivity parameter shown in Figure 6-11. The pore fluid conductivities are well characterized by the values listed in Table 4-7. Therefore, by accounting for the spatially variable and layer specific matrix porosities, the matrix thermal conductivity model will be appropriate for all repository host horizon layers. 
The bulk thermal conductivity model used in this report (Section 6.1.8) is based on the application of a parallel or volume average for the matrix/lithophysae composite (Hadley 1986 [DIRS 153165], Equation 18). Using the argument that the matrix thermal conductivity is applicable to all repository horizon layers, along with the use of spatially variable and layer specific estimates of lithophysal porosity provides the basis that the bulk thermal conductivity is applicable to all repository horizon layers.

Confirmation Status: The appropriateness of this assumption is confirmed by the discussion of the temperature measurements for USW-G4 as presented in Thermal Conductivity Properties for the Tptpll and Tptpul (BSC 2001 [DIRS 155008], Section 5.4.8). This discussion cites the work of Sass et al., (1988 [DIRS 100644], p.34) who stated that heat transfer in the vadose zone is dominated by heat conduction, and that for the constant geothermal heat flux through the various strata, the product of the bulk rock thermal conductivity times the temperature gradient is a constant. This analysis examined the relationship of bulk rock thermal conductivities and temperature gradients between the welded and nonwelded units and showed that for the higher porosity nonwelded units above and below the repository, the temperature gradients were higher to compensate for the lower thermal conductivity of these units.

Further analysis of the welded units in Thermal Conductivity Properties for the Tptpll and Tptpul (BSC 2001 [DIRS 155008], Section 5.4.8), based upon the original analysis by Sass et al., (1988 [DIRS 100644]), showed that the same relationships apply to the lithophysal and nonlithophysal units at the repository horizon. Further, the analysis showed that volumetric averaging, as applied to scaling the matrix thermal conductivity to the bulk rock mass thermal conductivity, was in close agreement with the observed variations in thermal gradient (BSC 2001 [DIRS 155008], Section 5.4.8).

On the basis of the original analysis by Sass et al. (1988 [DIRS 100644]), and the analysis extended to the lithophysal and nonlithophysal units of the repository horizon in Thermal Conductivity Properties for the Tptpll and Tptpul (BSC 2001 [155008], Section 5.4.8), it is concluded that models for matrix thermal conductivity and bulk thermal conductivity are appropriate for the intended use of modeling the thermal conductivity in the repository horizon stratigraphic layers. No further justification of this assumption is required.

Use in the Model: This assumption is used in Sections 6.1.7, 6.1.8, and 6.2.

\subsection{PETROPHYSICAL AND LABORATORY DATA USED IN THE MODEL DEVELOPMENT ADEQUATELY REPRESENT THE TRUE SPATIAL VARIABILITY OF THE ROCK UNITS}

Assumption: Petrophysical data used in the model development adequately represent the true spatial variability of the rock units.

Basis: The laboratory and petrophysical borehole data used in the development of the matrix and lithophysal porosity models were obtained from Project qualified data sources (Tables 4-1 and 4-2). These data are used as conditioning data and in the development of the variograms in Sections 6.1.4 and 6.1.5. These data incorporate uncertainty due to experimental measurement 
errors and any bias introduced due to interpretation of the data. The measurement errors and biases are believed to be small in comparison to the spatial heterogeneity of the data.

Confirmation Status: The appropriateness of this assumption is confirmed by the validation performed in Sections 7.

Use in the Model: This assumption is used in Sections 6.1.4 and 6.1.5. 


\section{INTENTIONALLY LEFT BLANK}




\section{MODEL DISCUSSION}

\subsection{MODEL DESCRIPTION}

Energy transport within the nuclear waste repository at Yucca Mountain is a complex phenomenon dependent on many physical processes. These processes include heat conduction through the surrounding rock, fluid migration and phase changes, radiative heat transport and natural convection cells. Heat conduction is considered to be one of the more dominant energy transport mechanisms and is controlled principally by the thermal conductivity of the rock surrounding the repository. Furthermore, recent studies show that thermal conductivity has a strong influence on rock dryout/rewetting and boiling duration (BSC 2004 [DIRS 169565], Section 6.3.2.2). Thermal conductivity also has been shown to be an important parameter in the prediction of ventilation efficiency (BSC 2004 [DIRS 169862], Section 6.11). The purpose of this report is to investigate the spatial distribution of thermal conductivity and assess its uncertainty in the repository host horizon.

The geologic stratigraphy of Yucca Mountain is shown in Figure 6-1 (DTN: MO9510RIB00002.004 [DIRS 103801]). In the current design plans, the repository host rock is located within the Tpt in the Paintbrush Group. This report develops three-dimensional, geostatistically-based representations of thermal conductivity for certain lithostratigraphic layers of the Tpt. These layers are the Tptpul, Tptpmn, Tptpll, and Tptpln. The complete names and a brief description of these units are provided in Table 6-1.

Numerous scientists have studied heat transfer through porous media over many years. Indeed, books have been written on this topic. Kaviany (1991 [DIRS 148383], pp. 1 to 5, 123 to 127) summarizes the historical development of this field and reviews many predictive models of thermal conductivity. Yucca Mountain, however, presents a unique and interesting challenge due to the presence of large-scale (centimeters-meters) void spaces not typically encountered in porous media applications. These voids are called lithophysae and can be found to varying degrees in all four of the lithostratigraphic layers studied.

In this work, the rock is conceptualized as a thermally isotropic composition of matrix and lithophysae. The rock properties developed in this report are applicable for use in numerical models where the concept of a continuum is employed. The properties are developed on a grid scale, as described in Section 6.1.2, suitable for use in mountain and drift-scale modeling. The properties are not intended to be applicable to heat transfer at the scale of the matrix pore or the individual lithophysal cavity.

The term lithophysae is used in this work to refer only to air-filled large-scale voids. Vapor-phase alteration or other mineral deposits commonly associated with lithophysae are conceptualized as matrix. The matrix component consists of solid minerals and their associated intergranular pore space. Matrix materials possess strong capillary forces that preferentially retain water in comparison to the same forces in lithophysae. This important matrix property is used to differentiate matrix from lithophysal porosity using well-log measurements of bulk density and neutron porosity. 


\begin{tabular}{|c|c|c|}
\hline \multicolumn{2}{|r|}{ Stratigraphic Unit } & \multirow[t]{2}{*}{ Abbreviation } \\
\hline 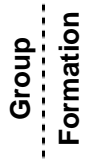 & 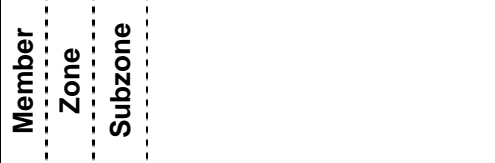 & \\
\hline \multicolumn{2}{|c|}{ Alluvium and Colluvium } & Qal, Qc \\
\hline \multicolumn{2}{|c|}{ Timber Mountain Group } & $\mathrm{Tm}$ \\
\hline \multicolumn{2}{|c|}{ Paintbrush Group } & $\mathrm{Tp}$ \\
\hline \multicolumn{2}{|c|}{ Tiva Canyon Tuff } & $\mathrm{Tpc}$ \\
\hline \multicolumn{2}{|r|}{ Crystal-Rich Member } & Tpcr \\
\hline \multicolumn{2}{|r|}{ Crystal-Poor Member } & Tpcp \\
\hline \multicolumn{2}{|r|}{ Vitric zone } & Tpcpv \\
\hline \multicolumn{2}{|r|}{ Densely welded subzone } & Tpcpv3 \\
\hline \multicolumn{2}{|r|}{ Moderately welded subzone } & Tpcpv2 \\
\hline \multicolumn{2}{|r|}{ Nonwelded subzone } & Tpcpv1 \\
\hline \multicolumn{2}{|r|}{ Pre-Tiva Canyon bedded tuff } & Tpbt4 \\
\hline \multicolumn{2}{|c|}{ Yucca Mountain tuff } & Tpy \\
\hline \multicolumn{2}{|c|}{ Pre-Yucca Mountain bedded tuff } & Tpbt3 \\
\hline \multicolumn{2}{|c|}{ Pah Canyon Tuff } & Tpp \\
\hline \multicolumn{2}{|c|}{ Pre-Pah Canyon bedded tuff } & Tpbt2 \\
\hline \multicolumn{2}{|c|}{ Topopah Spring Tuff } & Tpt \\
\hline \multicolumn{2}{|c|}{ Crystal-Rich Member } & Tptr \\
\hline \multicolumn{2}{|r|}{ Vitric zone } & Tptrv \\
\hline \multicolumn{2}{|r|}{ Nonwelded subzone } & Tptrv3 \\
\hline \multicolumn{2}{|r|}{ Moderately welded subzone } & Tptrv2 \\
\hline \multicolumn{2}{|r|}{ Densely welded subzone } & Tptrv1 \\
\hline \multicolumn{2}{|r|}{ Nonlithophysal zone } & Tptrn \\
\hline \multicolumn{2}{|r|}{ Lithophysal zone } & Tptrl \\
\hline \multicolumn{2}{|r|}{ Crystal-Poor Member } & Tptp \\
\hline & Upper lithophysal zone & Tptpul \\
\hline & Middle nonlithophysal zone & Tptpmn \\
\hline & Lower lithophysal zone & Tptpll \\
\hline & Lower nonlithophysal zone & Tptpln \\
\hline & Vitric zone & Tptpv \\
\hline & Densely welded subzone & Tptpv3 \\
\hline & Moderately welded subzone & Tptpv2 \\
\hline & Nonwelded subzone & Tptpv1 \\
\hline & Pre-Topopah Spring bedded tuff & Tpbt1 \\
\hline $\mathrm{Ca}$ & ico Hills Formation & $\mathrm{Ta}$ \\
\hline & Bedded tuff & (Tacbt) \\
\hline Crater & Flat Group & Tc \\
\hline :Pro & w Pass Tuff & Tcp \\
\hline 3 & Pre-Prow Pass bedded tuff & (Tcbbt) \\
\hline Bul & Ifrog Tuff & Tcb \\
\hline & Pre-Bullfrog Tuff bedded tuff & (Tcbbt) \\
\hline Tra & m Tuff & Tct \\
\hline 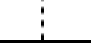 & Bedded tuff & (Tctbt) \\
\hline
\end{tabular}

DTN: MO9510RIB00002.004 [DIRS 103801].

Figure 6-1. Yucca Mountain Stratigraphy 
Table 6-1. Lithostratigraphic Units Studied

\begin{tabular}{|c|c|c|c|}
\hline $\begin{array}{l}\text { Litho- } \\
\text { stratigraphic } \\
\text { Unit } \\
\end{array}$ & Name & ECRB Station & Description \\
\hline Tptpul & $\begin{array}{l}\text { Topopah Spring Tuff } \\
\text { Crystal-poor upper } \\
\text { lithophysal zone }\end{array}$ & $\begin{array}{l}0+00 \text { to } 10+15 \\
25+90 \text { to } \\
26+57.5\end{array}$ & $\begin{array}{l}\text { The crystal-poor upper lithophysal zone is moderately } \\
\text { to densely welded, devitrified and vapor phase altered. } \\
\text { In general, the rock contains } 10 \text { to } 40 \text { percent vapor } \\
\text { phase spots, stringers, and partings. The central and } \\
\text { lower parts of the layer are exposed between Stations } \\
0+00 \text { and } 10+15 \text { of the ECRB, the rock is composed of } \\
0 \text { to } 15 \text { percent pumice, } 1 \text { to } 3 \text { percent phenocrysts, } 0 \text { to } \\
5 \text { percent lithic fragments, } 10 \text { to } 60 \text { percent lithophysae } \\
\text { and } 40 \text { to } 90 \text { percent matrix ground mass. The upper } \\
\text { part of the layers is exposed between Station } 25+90 \\
\text { and } 26+57.5 \text {. The rock is composed of } 5 \text { to } 15 \text { percent } \\
\text { pumice, } 2 \text { to } 5 \text { percent phenocrysts, less than } 1 \text { percent } \\
\text { lithic fragments, } 3 \text { to } 20 \text { percent lithophysae, and } 60 \text { to } \\
90 \text { percent matrix ground mass. }\end{array}$ \\
\hline Tptpmn & $\begin{array}{l}\text { Topopah Spring Tuff } \\
\text { Crystal-poor middle } \\
\text { nonlithophysal zone }\end{array}$ & $\begin{array}{l}10+15 \text { to } \\
14+44\end{array}$ & $\begin{array}{l}\text { The middle nonlithophysal zone is moderately to } \\
\text { densely welded, devitrified, and composed of less than } \\
5 \text { to } 10 \text { percent pumice (locally } 25 \text { to } 35 \text { percent), } 1 \text { to } 2 \\
\text { percent phenocrysts, } 0 \text { to } 1 \text { percent lithophysae, } 1 \text { to } 2 \\
\text { percent lithic fragments, and } 85 \text { to } 93 \text { percent matrix } \\
\text { groundmass. Vapor phase spots, stringers, and } \\
\text { partings compose } 1 \text { to } 15 \text { percent of the rock. }\end{array}$ \\
\hline Tptpll & $\begin{array}{l}\text { Topopah Spring Tuff } \\
\text { Crystal-poor lower } \\
\text { lithophysal zone }\end{array}$ & $\begin{array}{l}14+44 \text { to } \\
23+26\end{array}$ & $\begin{array}{l}\text { The lower lithophysal unit is moderately to densely } \\
\text { welded, devitrified, and composed of } 3 \text { to } 7 \text { percent } \\
\text { pumice (locally } 10 \text { to } 35 \text { percent), } 56 \text { to } 90 \text { percent } \\
\text { groundmass, } 5 \text { to } 30 \text { percent lithophysae (locally } 1 \text { to } 5 \\
\text { percent), and } 1 \text { to } 2 \text { percent phenocrysts. Vapor phase } \\
\text { spots, stringers, and wisps comprise between } 3 \text { and } 12 \\
\text { percent of the rock. In several intervals, the vapor } \\
\text { phase alteration products form } 15 \text { to } 40 \text { percent of the } \\
\text { rock. }\end{array}$ \\
\hline Tptpln & $\begin{array}{l}\text { Topopah Spring Tuff } \\
\text { Crystal-poor lower } \\
\text { nonlithophysal zone }\end{array}$ & $\begin{array}{l}23+26 \text { to } \\
25+85\end{array}$ & $\begin{array}{l}\text { The lower nonlithophysal zone is moderate to densely } \\
\text { welded, devitrified pyroclastic-flow material, and } \\
\text { composed of } 3 \text { to } 20 \text { percent pumice, } 66 \text { to } 93 \text { percent } \\
\text { groundmass, } 1 \text { to } 2 \text { percent phenocrysts, } 1 \text { to } 15 \\
\text { percent pumice clasts, and } 3 \text { to } 7 \text { percent lithic } \\
\text { fragments. Lithophysae abundance ranges from } 0 \text { to } 5 \\
\text { percent. }\end{array}$ \\
\hline
\end{tabular}

Source: BSC 2003 [DIRS 166660], Section 5.3.3.3.

NOTE: Description is based on geologic mapping of units exposed in the main drift /ramps of the Exploratory Studies Facility and the Enhanced Characterization of the Repository Block (ECRB) Cross-Drift.

Bulk thermal conductivity is defined as the effective value of thermal conductivity, which satisfies Fourier's law of heat conduction (Rohsenow and Choi 1961 [DIRS 158324], p. 5) for a system composed of two or more materials with different heat transfer characteristics. Bulk thermal conductivity for the Tpt is calculated by considering that the matrix and lithophysae act in parallel with respect to energy transport, as described in Section 6.1.8. Applying Fourier's equation of heat conduction to a parallel system yields the following expression (Hadley 1986 [DIRS 153165], p. 914, Equation 18):

$$
\mathrm{k}_{\mathrm{b}}=\phi_{\mathrm{L}} \mathrm{k}_{\mathrm{a}}+\left(1-\phi_{\mathrm{L}}\right) \mathrm{k}_{\mathrm{m}}
$$


The derivation of Equation 6-1 is provided in Section 6.1.8. In Equation 6-1, $\phi_{\mathrm{L}}$ is the volume fraction of the lithophysae, $\mathrm{k}_{\mathrm{b}}$ and $\mathrm{k}_{\mathrm{m}}$ are the bulk and matrix thermal conductivities, respectively, and $\mathrm{k}_{\mathrm{a}}$ is the thermal conductivity of air.

Matrix thermal conductivity is a function of matrix porosity, water saturation, the geometry and packing of the solid, and the thermal conductivity of the solid minerals. The Three-Dimensional Cubic Model, developed by Hsu et al. (1995 [DIRS 158073]) and described in Section 6.1.7, is used to predict matrix thermal conductivity from these fundamental rock properties. With the exception of matrix water saturation, these fundamental properties are treated as spatially uncertain random functions. The geostatistical method known as sequential Gaussian simulation is used to generate 50 equally likely independent realizations of these properties in order to provide a sufficient statistical sample for each property. Available measurements from core samples and petrophysical logs are used to derive models of spatial continuity and to condition the geostatistical simulations. The spatial heterogeneity and uncertainty in lithophysal porosity is addressed in the same manner.

Matrix water saturation, $S_{\mathrm{w}}$, is expected to vary both spatially and temporally due to thermal loading. Therefore, thermal conductivity is presented only at the two end states, $S_{w}=1$ (wet) and $\mathrm{S}_{\mathrm{w}}=0$ (dry), as explained in Appendix C. The user of these data should apply some method of interpolation for the saturation state of their particular application. The report, Laboratory Measurements of Thermal Conductivity as a Function of Saturation State for Welded and Nonwelded Tuff Specimens (SNL 1998 [DIRS 118788]), investigates two commonly used interpolation methods for estimating matrix thermal conductivity at intermediate saturation states: linear interpolation and square root interpolation. It is shown that these same interpolation methods may also be applied to bulk thermal conductivity (Section 7.5.1).

\subsubsection{Overview of Model Development}

The purpose of this analysis is to assess the spatial heterogeneity and uncertainty of bulk thermal conductivity for selected units of the Tpt. Bulk thermal conductivity cannot be easily measured in a laboratory setting due to the sample size that would be required to incorporate the effects of large lithophysae. For this reason, the project has conducted a series of in situ thermal conductivity tests that contributed to the understanding of the energy transport processes and the evaluation of bulk thermal conductivity in the Tpt. The quantity of these bulk thermal conductivity measurements will necessarily be limited because of limited access to the units of concern. For these reasons, a theoretical model of bulk thermal conductivity, dependent on lithophysal porosity estimates from petrophysical log data and matrix thermal conductivity from core testing, was developed (Equation 6-1).

Lithophysal porosity is calculated from the relatively abundant well-log petrophysical measurements of bulk density and neutron porosity. In this calculation, it is necessary to make certain assumptions regarding the state of matrix water saturation. These calculations are discussed in detail in Sections 5.2, 6.1.4, and Appendix A. The resulting values of lithophysal porosity are used to develop spatial correlation models and condition geostatistical simulations of this rock property. 
Matrix thermal conductivity has been measured on a limited number of laboratory core samples from a few select locations. Consequently, the spatial heterogeneity and uncertainty in matrix thermal conductivity is determined solely from the available laboratory core measurements. Alternatively, there is a large volume of literature addressing the thermal conduction properties of porous media. Many researchers have developed theoretical models of thermal conductivity that may be applied at Yucca Mountain (Sections 6.1.7 and 6.1.8). After examining several of these models, the Three-Dimensional Cubic Model developed by Hsu et al. (1995 [DIRS 158073]) was selected to calculate matrix thermal conductivity based on the criteria set forth in Section 6.1.7.

Having chosen an appropriate theoretical model for matrix thermal conductivity, parameter distributions specific to the chosen model were developed based on core thermal conductivity measurements extracted from the Tpt. Geostatistical representations of these model parameters, namely, matrix porosity, mineral thermal conductivity, and solid connectivity, were then developed using the sequential Gaussian simulation procedure described in Section 6.1.3.

Lastly, dry bulk density is another important rock property in energy transport calculations due to its contribution to the rock mass heat capacity. This property is calculated directly from simulated values of matrix and lithophysal porosity and unit-specific estimates of grain density as described in Section 6.1.6.

\subsubsection{Model Domain and Discretization}

The model domain chosen for this study is shown in Figure 6-2. The modeled region was chosen to be consistent with the unsaturated zone Site-Scale Model boundary shown in Figure 6-1 and encompasses the repository drift layout incorporated in Multiscale Thermohydrologic Model (BSC 2004 [DIRS 169565], Figure 4-1). The region extends from the vicinity of Fatigue Wash in the west to the middle of Midway Valley in the east and from central Yucca Wash in the north to the middle of Dune Wash in the south. In Nevada State plane coordinates, the model domain extends from $167,500 \mathrm{~m}$ to $174,300 \mathrm{~m}(549,541 \mathrm{ft}$ to $571,850 \mathrm{ft})$ in the east and from $228,900 \mathrm{~m}$ to $237,500 \mathrm{~m}(750,984 \mathrm{ft}$ to $779,199 \mathrm{ft})$ in the north (DTN: SN9910T0501399.001 ([DIRS 129717]). This same model domain has been used previously in the Rock Properties Model (BSC 2004 [DIRS 170032], Figure 1-1).

Each of the four lithostratigraphic intervals is modeled in a stratigraphic coordinate system that reflects the original, pre-faulted depositional continuity of these ash-flow tuffaceous deposits (Figure 6-3). This coordinate system uses Nevada State plane coordinates in the east-west and north-south direction; however, the vertical coordinate represents the fractional elevation relative to the thickness of the lithologic unit. The use of a stratigraphic coordinate system effectively repositions the rock back to its original point of deposition, removing the effect of depositional thinning and post-depositional features such as faulting and deformation. The process of constructing such a coordinate system is illustrated graphically in Figure 6-3. 


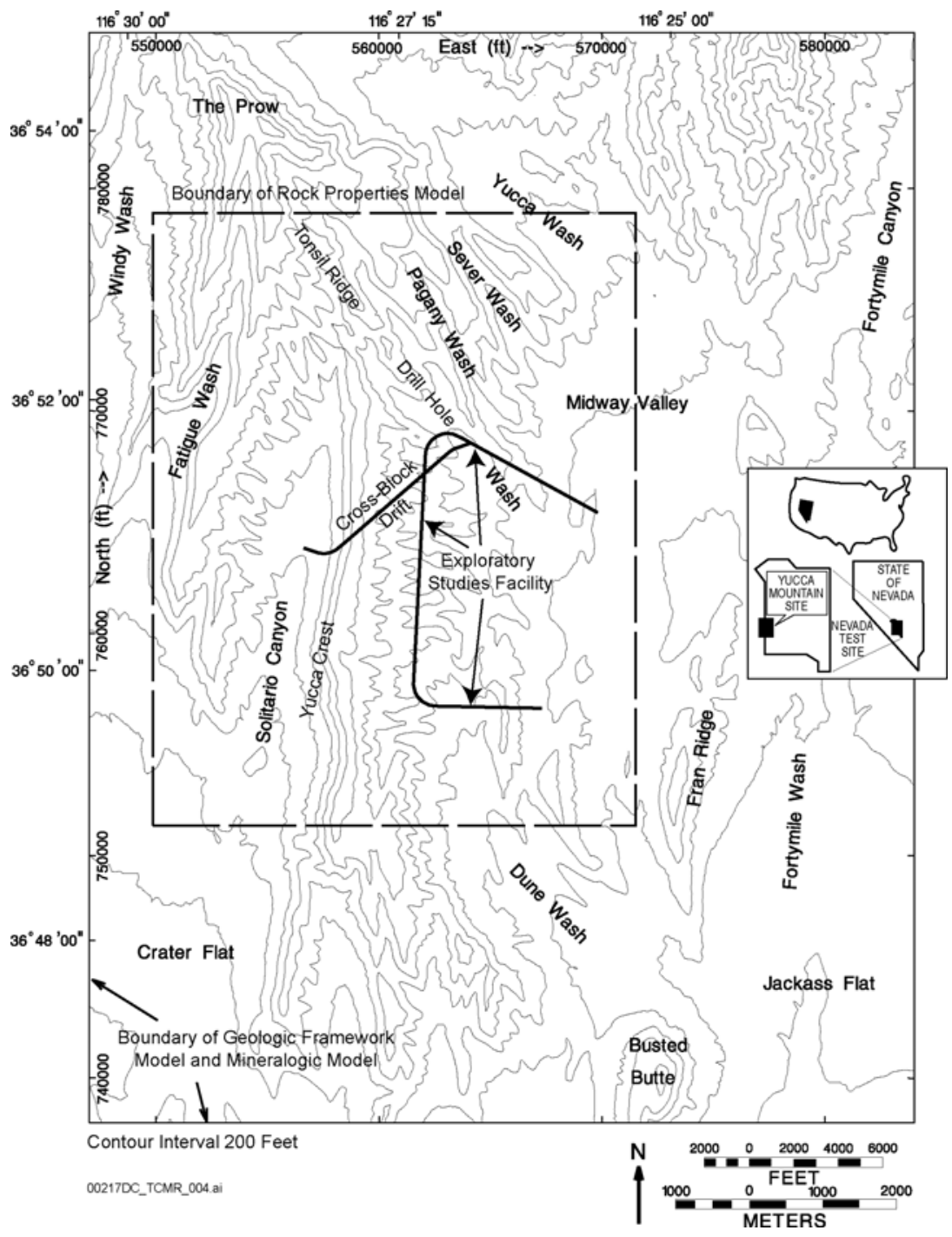

Source: BSC 2004 [DIRS 170032], Figure 1-1.

Figure 6-2. Map Showing the Model Domain Relative to Geologic Features and Constructed Tunnels

At Yucca Mountain, regions of varying material properties have been emplaced or otherwise formed in an essentially stratiform manner. The volumetrically dominant rocks were formed by pyroclastic flows deposited in thick ash-flow sheets that thin laterally away from their source. Since rocks formed under similar depositional, pressure, and temperature conditions tend to have similar material properties, there is a tendency for rock of the same unit and relative vertical elevation to have similar material properties. This behavior is illustrated in part (a) of Figure 6-3.

Later, faulting as part of Basin and Range tectonism disrupted the originally continuous volcanic rocks and tilted the rock units as indicated in part (b). To exploit the observed and measurable spatial continuity of material properties with respect to depositional environment, the measured data must first be translated to a relative deposition position. This is accomplished through the conversion to stratigraphic coordinates, which is illustrated in part (c). In this translation, the 
vertical location of data is specified as the fractional elevation from the base of the unit, which is assigned a distance of zero, to the top of the unit, which is assigned a distance of one. This value is then multiplied by the nominal thickness of the unit in order to ensure meaningful parameters in the vertical variography.

(a)

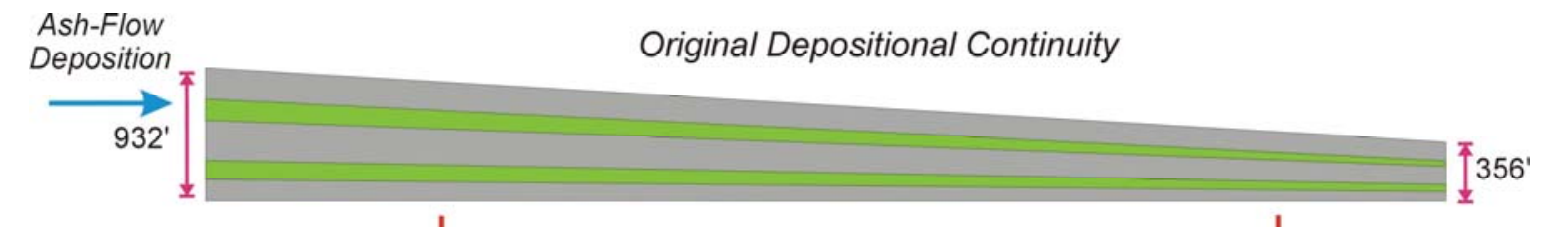

(b)

(c)

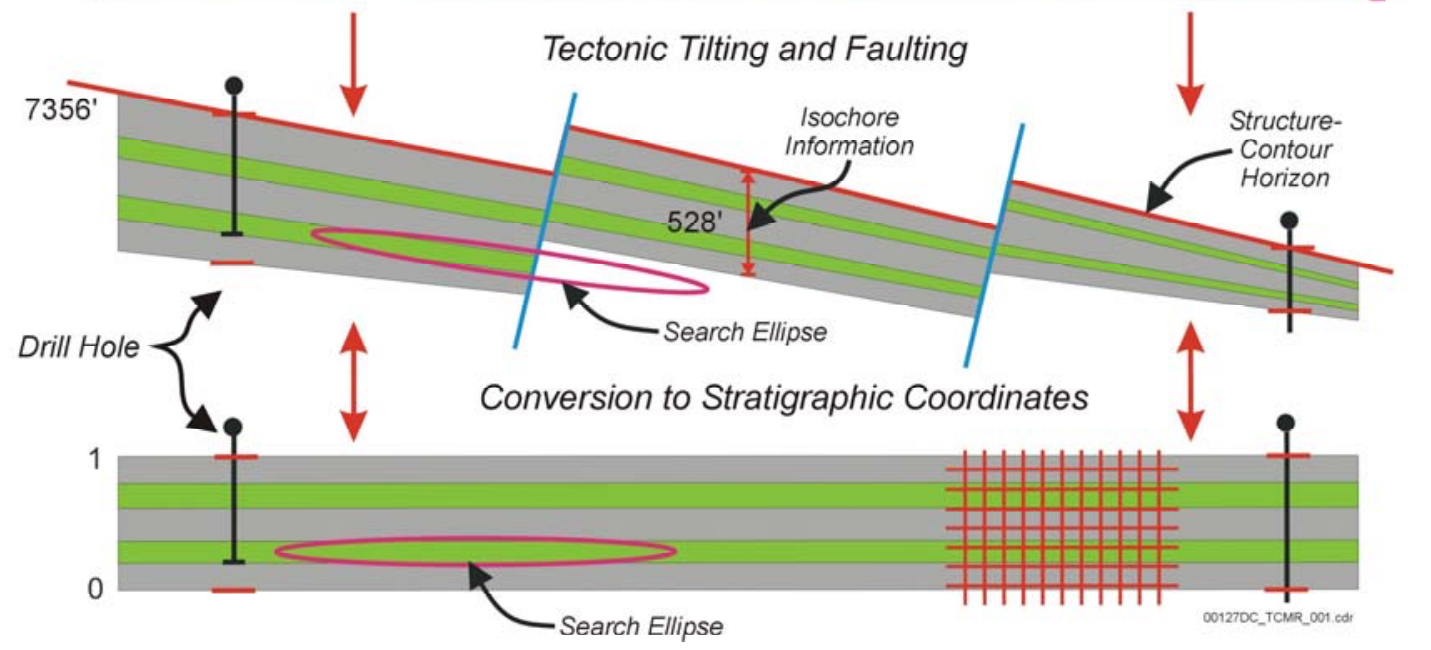

Source: BSC 2004 [DIRS 170032], Figure 6.4-5.

NOTES: Steps in the construction of stratigraphic coordinates. (a) Rock unit is formed by really extensive volcanic (or sedimentary) processes. Zones of differing rock properties (shaded colors) are formed in a stratiform manner. (b) Tectonic deformation tilts and disrupts original stratiform continuity by faulting. (c) Modeling unit is returned to an approximation of original continuity in a rectangular coordinate system in which all vertical distances are measured as a fractional position measured from the top or bottom of the rock unit.

Figure 6-3. The Process of Converting to Stratigraphic Coordinates

As suggested by the mesh of intersecting dotted lines in the right-hand portion of Figure 6-3(c), a regular rectangular modeling grid is defined within each stratigraphic coordinate system. Note that the various material property zones have been stretched or compressed vertically so that the overall stratigraphic thickness of the unit is constant. Defining the modeling grid within this framework positions rock with similar material properties in a stratigraphically horizontal plane. This repositioning greatly simplifies the search methods required for data in the geostatistical modeling, as shown conceptually by the search ellipse in part (c). Although it is possible to rotate the principal direction of the search ellipse to match the overall tectonic dip of the unit as shown in part (b), it is virtually impossible to modify the search strategy used by the Sequential Gaussian Simulation algorithm (Section 6.1.3) to account for the vertical displacement of material property zones through faulting. 
After completing the modeling exercise, the transformation from the stratigraphic coordinate system to standard Nevada State plane coordinates is achieved by computing the vertical elevation of each node in the grid. This reverse transformation requires knowledge of the spatially varying structure contour and thickness for each unit. This information and the transformation itself are obtained from the independently developed Geologic Framework Model (GFM2000) (DTN: MO0012MWDGFM02.002 [DIRS 153777]).

Implementation of the stratigraphic coordinate system is more complicated than the example discussed in Figure 6-3. This is primarily because sample locations are typically specified in terms of depth and are specific to a particular drill hole. These depths must be converted to stratigraphic elevations using lithologic contact data (observed or predicted) obtained from the Geologic Framework Model (GFM2000) (DTN: MO0012MWDGFM02.002 [DIRS 153777]). The software routine LITHO V. 1.0 [DIRS 158256] was written to extract pertinent well-log or core data from the original data source, compute stratigraphic elevations, and then assemble the data extracted from multiple sources into a single file formatted according to GSLIB specifications.

The equation for calculating the stratigraphic elevation, $\mathrm{E}_{\mathrm{s}}$, from depth is:

$$
E_{s}=\left[1-\left(\frac{D-T}{B-T}\right)\right] \cdot H
$$

where $\mathrm{D}$ is the measured depth, $\mathrm{H}$ is the nominal thickness of the lithologic unit, and $\mathrm{B}$ and $\mathrm{T}$ are the measured or projected depths to the bottom and top lithologic contacts of the unit, respectively. Equation 6-2 simply converts the elevations $D, B$, and $T$ into stratigraphic elevations used in the model. Note for $D=B$, then $E_{s}=0$ and for $D=T, E_{s}=H$. The values of $H$ for each layer are given in Table 6-2 below.

Due to differences in nominal thickness, each of the four lithostratigraphic units utilizes a different model domain vertically. Horizontally, the model domains are identical and are therefore all discretized using a uniform, $50 \times 50 \mathrm{~m}(164.042 \times 164.042 \mathrm{ft})$ grid. Vertically, the domain is discretized using $3.048 \mathrm{~m}(10 \mathrm{ft})$ elements in all units except the Tptpll, which is discretized using $4.572 \mathrm{~m}$ (15 ft) elements. Larger elements are used in Tptpll to moderate the computational burden of this relatively thick unit. This information is summarized in Table 6-2.

The horizontal and vertical grid resolution used in the model domain provide the spatial resolution needed by the Smeared-heat-source, Mountain-scale, Thermal-conduction (SMT) and Line-averaged-heat-source, Drift-scale, Thermal-Hydrologic (LDTH) submodels and meshes used in Multiscale Thermohydrologic Model (BSC 2004 [DIRS 169565], Sections 6.2.5.1 and 6.2.6.2). The three-dimensional SMT submodel, which solves for thermal conduction of a heat source smeared over the repository area, represents the heated footprint of the repository and allows for consideration of edge-cooling effects and the influence of the varying overburden thickness above the repository. The SMT submodel represents each emplacement drift using cells with dimensions that are $20 \mathrm{~m}$ along the drift axis, $81 \mathrm{~m}$ perpendicular to the drift axis, and $6 \mathrm{~m}$ thick in the vertical direction. The LDTH submodel is a two-dimensional model, which extends down from the ground surface to the water table and laterally $40.5 \mathrm{~m}$ (one-half the drift spacing) (BSC 2004 [DIRS 169565], Figure 6.2-6). 
Table 6-2. Model Discretization

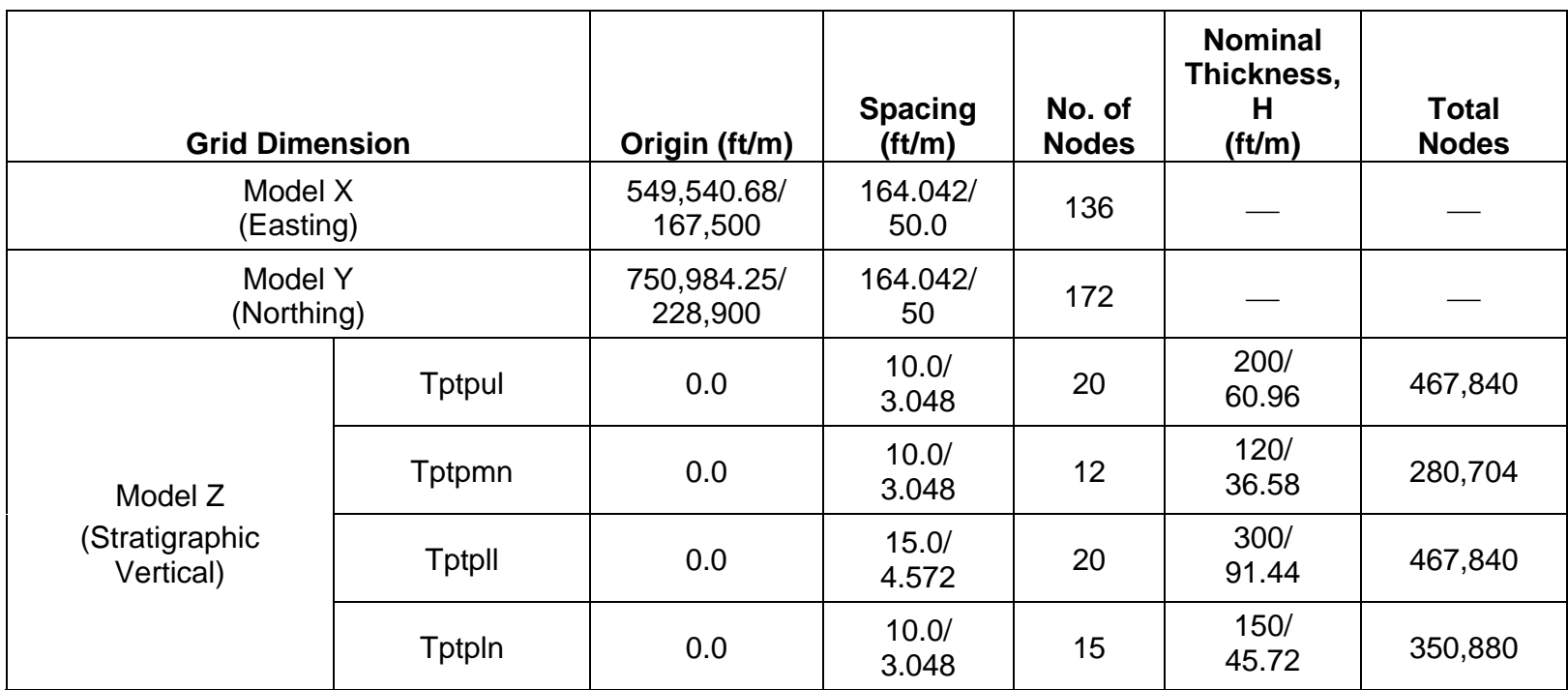

Output DTN: SN0404T0503102.011 [DIRS 169129].

\subsubsection{Sequential Gaussian Simulation}

Geostatistics offers a method of distributing isolated measurements in space and quantifying their uncertainty. A fundamental characteristic underlying all geostatistical techniques is the idea of spatial correlation. Spatial correlation may informally be defined as the degree to which samples that are close to one another resemble each other in a certain attribute or material property.

Within the field of geostatistics, there are two broad classes of algorithms used to predict material properties at unsampled locations: estimation and simulation. Geostatistical estimation is focused on the prediction of property values most likely to be encountered at a given spatial location, and it may be thought of as modeling the expected value of a variable of interest. Estimation in the field of geostatistics is known as "kriging," and it is simply a weighted-average interpolation method invoking neighboring nearby data. A common feature among all estimation techniques (including non-geostatistical ones) is that estimated values generally grade smoothly away from the locations of known values.

The other broad class of geostatistical methods consists of simulation algorithms. Simulation may be thought of as expanding the information available in a stochastic manner that is consistent with the data ensemble and spatial context of those data. The process builds on the fact that unsampled locations near a known value tend to resemble that value, whereas unsampled locations at increasing distances progressively resemble that value less and less. In contrast to estimation, geostatistical simulation attempts to reproduce not only the known data but also the overall statistical character of those data, including the specified spatial correlation. Property sets produced by geostatistical simulation do not typically grade smoothly between measured data. Where spatial correlations are weak or in the vicinity of conflicting measurements, predicted property values may fluctuate greatly over short distances. 
Deutsch and Journel (1998 [DIRS 102895], p. 119) state that Gaussian-related simulation algorithms "are the algorithms of choice for most continuous variables." Sequential Gaussian simulation is perhaps the most popular and widely used member of this family. These simulations may be conditional or unconditional. Conditional simulations are anchored numerically to a specific set of measured data and exhibit three important attributes that are useful in evaluating geologic heterogeneity. Specifically, conditional simulations:

1. Reproduce known data values at the location they were measured

2. Reproduce the full range of measurement variability, as represented by histogram and univariate descriptive statistics of the known data

3. Reproduce the bivariate statistics (or two-point spatial correlation structure) of the known data

Unconditional simulations are similar, except that they are not spatially anchored to any particular data, and thus Item 1 does not apply. Simulations produced using sequential Gaussian simulation cannot be distinguished statistically from the data ensemble they were derived from or from each other. Consequently, they serve as alternative, equally likely stochastic realizations of an incompletely sampled reality.

The sequential Gaussian simulation program, GSLIB V. 1.4SGSIMV1.41 (STN: 101101.4SGSIMV1.41-00 [DIRS 158224], Table 3-1; Deutsch and Journel 1992 [DIRS 100567], pp. 123 to 125 and 164 to 167), is used to generate a sufficient statistical sample based on 50 realizations of each of the four uncertain model parameters (lithophysal porosity, matrix porosity, solid thermal conductivity, and solid connectivity). Realizations of lithophysal and matrix porosity are conditioned to available well-log and core measurements. Realizations of solid thermal conductivity and solid connectivity are unconditioned and identical in all four layers. The parameters were treated as unconditioned because they were developed from a small number of matrix thermal conductivity measurements. These parameters are discussed in Section 6.1.7.

The sequential modeling process is relatively straightforward and is implemented as follows:

1. Conditioning data are first transformed into a univariate standard-normal distribution $\left(\mu=0, \sigma^{2}=1\right)$ using a normal-score transformation (Figure 6-4). The normal-score transform is implemented using the program GSLIB V. 1.4MNSCOREV1.201 (STN: 10109-1.4MNSCOREV1.201-02 [DIRS 158222], Table 3-1; Deutsch and Journel 1992 [DIRS 100567], pp. 138 and 209 to 211). This transformation does not alter the structure of spatial correlation since the transformation is quantile-preserving.

2. The spatial correlation structure is identified using the normal-score transformed values and modeled using standard variography.

3. A sequential random path is defined that stops at each node in the grid once. 
(a)

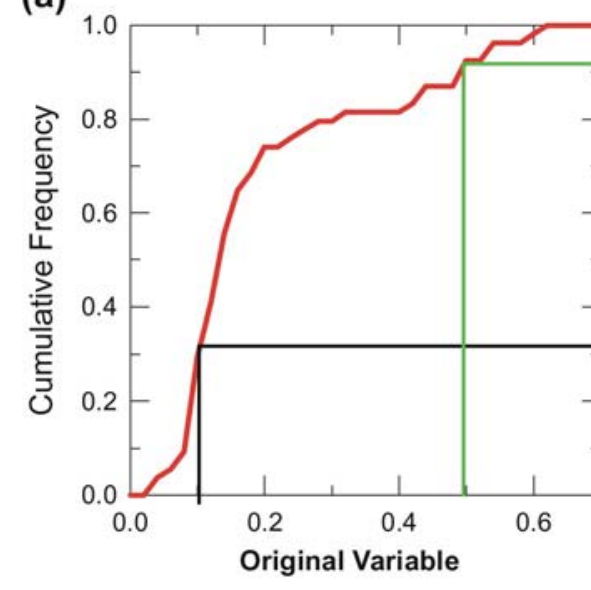

(b)

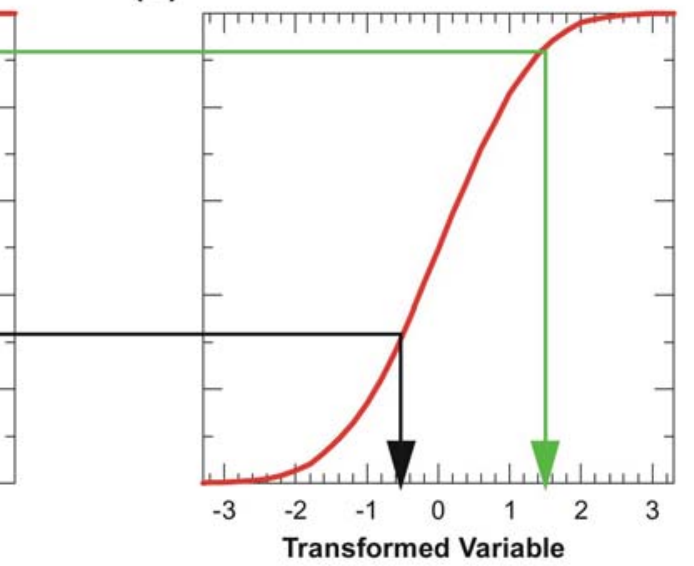

00217DC_TCMR_002.cdr

Figure 6-4. Graphical Representation of the Quantile-Preserving Normal-Score Transformation

4. At each node along this path, a search is conducted for nearby data including any previously simulated nodes. The search parameters specified in this study require that the full range of the spatial continuity model (variogram) be searched for data.

5. The user-specified $\mathrm{N}$ closest data within the search radius are identified and subsequently used to compute a conditional expected value and variance through simple kriging.

6. A random value is drawn (in standard-normal space) from a conditional Gaussian probability distribution defined by the mean and variance obtained in Step 5. This value is assigned to the current node and the simulation proceeds to the next location on the random path. Steps 4 through 6 are repeated until all nodes have been simulated.

7. Once the random path has been completed, the simulated values must be back-transformed from standard-normal space to their original space. This inverse transform is conducted using the program GSLIB V. 1.4MBACKTR (STN: 10108-1.4MBACKTRV1.20-01 [DIRS 113642], Table 3-1).

Because there is a certain degree of randomness in the simulation algorithm, simulated values depend on the random path followed. Independent realizations utilize different random seeds to determine the path. Simple logic dictates that independent realizations will have different simulated values. However, at locations that are well constrained by consistent measured data, the variability in simulated values tends to be small. On the other hand, at locations far from measured data, or at grid nodes that are in the vicinity of conflicting measurements, the spread of simulated values can be quite broad. Such variability may approach the univariate variance of the property being simulated, indicating that the spatial attributes of the conditioning data provide no additional knowledge of the property being simulated at that particular location. This information is quite valuable in assessing spatial uncertainty. 


\subsubsection{Lithophysal Porosity}

In Subsurface Geotechnical Parameters Report (BSC 2003 [DIRS 166660], Section 8.2.3.1), three distinct phases of the bulk rock are identified: matrix ground mass, lithophysal, and a vapor phase altered material consisting of rims and spots. Lithophysal porosity is defined as the fractional volume of large-scale (centimeters-meters) void space per unit volume of rock. Recent mappings of this property in the Enhanced Characterization of the Repository Block (ECRB) Cross-Drift show that lithophysae vary in size, shape, and abundance throughout all four lithostratigraphic layers (Mongano et al. 1999 [DIRS 149850], pp. 16 to 35; BSC 2003 [DIRS 166660], Section 5.3.3.3; and BSC 2004 [DIRS 166107], Appendix O). The abundance of lithophysae, as suggested by their given names, is greater in the upper and lower lithophysal zones than in the middle and lower nonlithophysal zones.

The measurement of lithophysal porosity is somewhat challenging since what constitutes large-scale versus small-scale void space must first be established. Mongano et al. (1999 [DIRS 149850], pp. 16 to 35) report that lithophysal spaces vary in size from as small as $1 \mathrm{~cm}$ to as large as $100 \mathrm{~cm}$. Conversely, capillary pressure measurements from the core indicate that the intergranular size of matrix voids is substantially less than $1 \mathrm{~cm}$ by at least an order of magnitude. This considerable difference in scale is useful in interpreting well-log petrophysical measurements and ultimately serves as the basis for distinguishing lithophysae from matrix porosity.

Since capillary forces in porous media are directly related to pore size, it is assumed that under unsaturated, equilibrium, or near equilibrium conditions, the water present in units of the Tpt will preferentially reside within the small-scale pore space of the matrix. This fact is used to develop equations to calculate matrix and lithophysal porosity from petrophysical and, where available, core measurements.

Bulk density, defined in Appendix A, is the principal petrophysical measurement used to calculate lithophysal porosity. In theory, petrophysical measurements of bulk density account for all contributions of mass to the system (liquid, solid, gas). Lithophysal porosity can be calculated directly from bulk density (Appendix A) when certain properties of the matrix (porosity and saturation) have been established either through direct measurement (i.e., core samples) or assumption. Depending on the availability of direct measurements, one of three methods is used. These can be summarized as follows:

- Method A-In boreholes where core samples were collected and measurements of matrix porosity obtained, depth-matched bulk density values are linearly interpolated from the smoothed bulk density data set (Section 4.1.2). Lithophysal porosity is calculated using Equation A-14 from the core matrix porosity, interpolated bulk density, unit-specific particle density (Table 5-4), and an assumed matrix water saturation of unity.

- Method B-In boreholes where core samples were not collected, but neutron porosity petrophysical data exist and are within the range of expected values, Equation A-23 is used to calculate lithophysal porosity. In this case the smoothed neutron porosity data (Section 4.1.2) are used to calculate the volumetric water content of the composite rock. 
As in Method A, the unit-specific particle density (Table 5-4) and an assumed matrix water saturation of unity are applied, as discussed in Section 5.2.

- Method C-In boreholes where core samples were not collected and neutron porosity data either do not exist or do not appear reasonable, Equation A-14 is used to calculate lithophysal porosity. In such circumstances, matrix porosity, particle density, and water saturation are all assumed in the calculation of lithophysal porosity. Matrix porosity is assumed equal to 0.10 , particle density is obtained from Table 5-4, and water saturation is once again assumed equal to unity. The value of 0.10 for matrix porosity, which lies at the near the lower end of the matrix porosity conditioning data (Figure 6-7), was chosen because it leads to somewhat larger calculated lithophysal porosity. The effect of this assumption results in smaller calculated values of bulk thermal conductivity, which in turn would result in higher temperatures in the repository.

The equations used in Method A and Method B are developed in Appendix A. The equations used in Method $\mathrm{C}$ are identical to those of Method A when the assumptions noted above are invoked.

Of the three calculations, Method A is considered to be the most reliable, as it is uses direct measurements for all parameters affecting lithophysal porosity. It is followed by Method B, which uses the same measurements except for the matrix density. The matrix density is estimated from the neutron density data, as opposed to the more reliable estimate from core data used in Method A. Finally, Method C provides the least reliable estimates. Instead of using a value of the matrix porosity based on data, Method $\mathrm{C}$ introduces the assumption that it is 0.10 . Method B was applied most often since most older boreholes were not cored, and Method C was applied the least since neutron porosity data are nearly as abundant as bulk density. Appendix B provides comments pertaining to the specific choice of calculation method including plots of the smoothed petrophysical data and computed porosities for each borehole.

In all three methods, the matrix continuum is assumed to be water saturated (Section 5.2). Setting $\mathrm{S}_{\mathrm{w}}$ to unity may lead to smaller calculated matrix porosities; however, the calculated values of lithophysal porosity are not highly dependent on the values of matrix saturation (Appendix A, Equations A-14 and A-23).

All three methods also use the values of particle density given in Table 5-4. These are the unit-specific mean values from corresponding histograms, presented later in Section 6.1.6. The narrowness of these histograms justifies the use of constant values. For comparison, the mean grain density for each unit is also given in Table 5-4.

Histogram plots of calculated lithophysal porosity are depicted in Figure 6-5 for each of the four lithostratigraphic units. The data from as many as 37 boreholes are used in the construction of these plots. Consequently, these distributions reflect the spatial variability of lithophysal porosity across the entire repository region. For a number of boreholes (e.g., Figure B-3), negative values of lithophysal porosity are calculated over some intervals. This is the result of the possible measurement errors associated with the petrophysical measurements and the analytical methods applied to calculate lithophysal porosity. These nonphysical negative values are plotted in the figures in Appendix B; however, the negative values are treated as zeros in the 
construction of the lithophysal porosity distributions. This can be verified by examining the minimum values of lithophysal porosity tabulated in Figure 6-5.

Variogram models of spatial continuity were then developed from the normal-score transformed lithophysal porosity data. The computer program GSLIB V. 1.0MGAMV2 (STN: 10087-1.0MGAMV2V1.201-02 [DIRS 158221], Table 3-1) is used to generate experimental semivariogram data that are then fit to traditional spherical models (Deutsch and Journel 1998 [DIRS 102895], p. 25). The experimental data and resulting models are presented graphically in Figure 6-6. The variogram analysis files for lithophysal porosity are located in directory Thermal_Cond/gamv of output DTN SN0404T0503102.011 filename: Therm_CondData1.zip. The lithophysal porosity model semivariograms shown in Figure 6-6 are a linear combination of an isotropic nugget effect and two spherical semivariogram models. The specific parameters that implement these models in the GSLIB V. 1.4SGSIMV1.41 software are provided in Table 6-3. All analysis files for the sequential gaussian simulation software are contained in SN0404T0503102.011 in directories Tptpul, Tptpmn, Tptpll, and Tptpln. For example, the input and output files for realization 1 in the Tptpll are named sgsim_Tptpll_LithPor_1.par and sgsim_Tptpll_LithPor_1.out respectively.

The horizontal and vertical search radii specify that only data falling within the search ellipsoid are to be considered in the Gaussian simulations. The sill, the horizontal and vertical range parameters, and the three rotation angles defining the geometric anisotropy are required to define each spherical model component (Deutsch and Journel 1998 [DIRS 102895], pp. 25 to 28). These parameters are estimated to provide an accurate approximation to the experimental semivariogram data. In this work, the three rotation angles were set equal to zero, indicating the principal directions of the semivariogram model are aligned with the stratigraphic coordinate directions.

The anisotropy ratios given in the last two columns of Table 6-4 correspond to the horizontal and vertical planes, respectively. A value of one in the horizontal plane implies the maximum and minimum horizontal ranges are identical and is equivalent to isotropy in this plane. The anisotropy ratio in the vertical plane is computed as the ratio of the vertical to horizontal values.

The reliability of the experimental semivariogram data decreases as the lag distance increases. The distance at which the semivariogram approaches a value equal to one defines the scale at which two measurements of a variable are essentially uncorrelated. The deviations between the model and the experimental semivariogram at large lag distances are acceptable because the search radii are chosen to control the extent of data inclusion. The emphasis on determining model parameters is aimed at lag distances for which sufficient data and meaningful correlations exist.

\subsubsection{Matrix Porosity}

Geostatistical representations of matrix porosity are developed based on laboratory core and well-log petrophysical measurements. Matrix porosity can be calculated either by comparing saturated and dry bulk densities or by comparing dry bulk and grain densities. Reports of laboratory core measurements produced for the Yucca Mountain Project generally include two values of dry bulk density. The first dry density is obtained by drying the sample in a relative 
humidity oven at elevated temperature and humidity levels $\left(60^{\circ} \mathrm{C}\right.$ and 65 percent $\left.\mathrm{RH}\right)$, and the second is obtained by drying the sample in a $105^{\circ} \mathrm{C}$ oven at ambient but very low $\mathrm{RH}$. Oven-dried calculations of porosity are almost always greater than $\mathrm{RH}$ calculations since water that is bound to minerals or otherwise trapped in unconnected pores is displaced in the OD measurements but remains behind in RH measurements. Consequently, the OD value is a better measure of the total potential water content and, therefore, more appropriate for the purpose of calculating matrix thermal conductivity.

Applying many of the same concepts discussed in the previous section, a method of calculating matrix porosity from bulk density and neutron porosity is presented in Appendix A, Equation A-22. This equation is applied at locations where petrophysical data are available, but core data are not (Method B). Where core data are available (Method A), matrix porosity is measured directly from the core; therefore, it is unnecessary to calculate. Finally, where bulk density measurements are the only reliable data available (Method C), matrix porosity is set equal to 0.10 , but solely for the purpose of estimating lithophysal porosity. Bulk density measurement alone provides inadequate information to estimate matrix porosity. Therefore, data sets classified as Method $\mathrm{C}$ are simply ignored with respect to matrix porosity.

One important distinction between matrix and lithophysal porosity is that the two properties are defined with respect to different reference volumes. Consequently, these properties cannot be added directly, and care must be exercised when applying the geostatistical results. This difference in definition is required because core measurements do not account for the volume of lithophysae and, hence, are not based on the total volume. Instead, matrix porosity is measured and, therefore, defined as the volume fraction of small-scale void space with respect to the matrix volume, $\mathrm{V}_{\mathrm{m}}$, where the matrix volume is simply the total volume, $\mathrm{V}_{\mathrm{t}}$, less the lithophysae volume, $\mathrm{V}_{\mathrm{L}}$ :

$$
\mathrm{V}_{\mathrm{m}}=\mathrm{V}_{\mathrm{t}}-\mathrm{V}_{\mathrm{L}}
$$

This same definition of matrix porosity is used in the derivation of Equation A-22, so it is appropriate to combine the petrophysically derived values of matrix porosity with the laboratory measured values into a composite data set.

Using the matrix porosity $\left(\phi_{\mathrm{m}}\right)$ and lithophysal porosity $\left(\phi_{\mathrm{L}}\right)$ definitions employed in this report the total porosity $\left(\phi_{\mathrm{T}}\right)$ is given by the following equation.

$$
\phi_{T}=\phi_{L}+\phi_{m}\left(1-\phi_{L}\right)
$$

Histogram plots of this composite matrix porosity data set are depicted in Figure 6-7 for each of the four lithostratigraphic units. As was the case for lithophysal porosity, these distributions reflect the spatial variability of matrix porosity across the entire repository region. It should be noted that both the mean and the variance are greater in the lithophysal zones than in the nonlithophysal zones. 

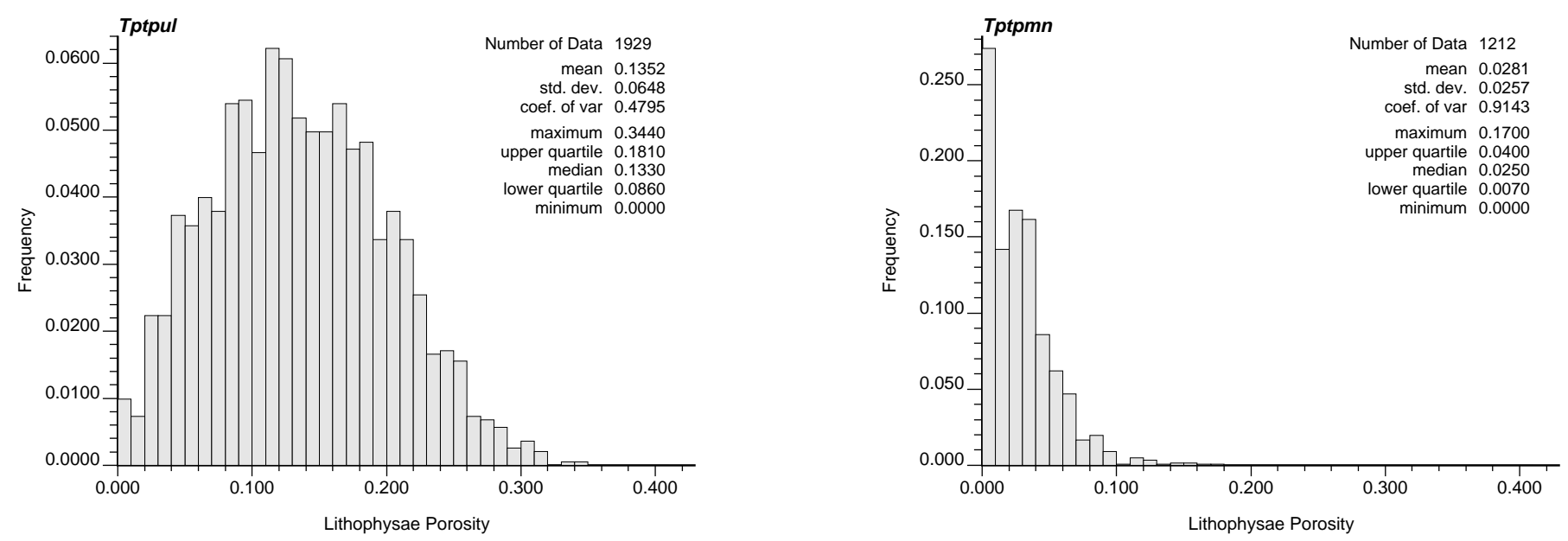

$\stackrel{i}{a}$
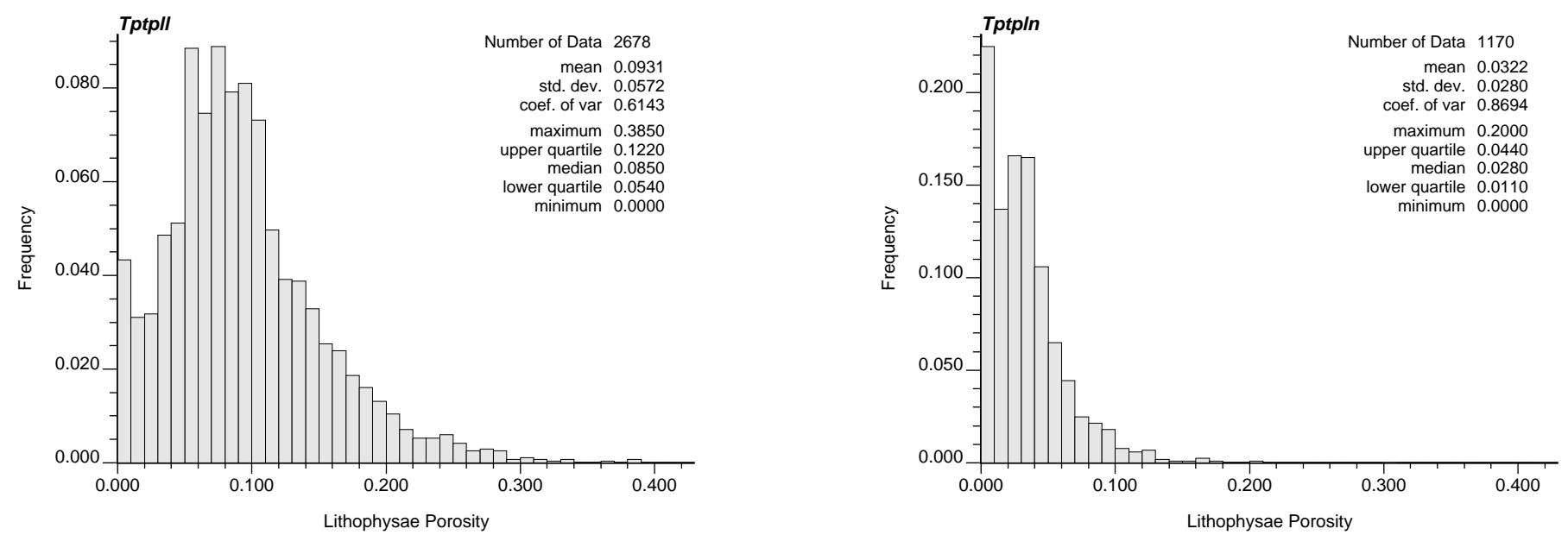

Output DTN: SN0404T0503102.011 [DIRS 169129].

Figure 6-5. Histogram of Lithophysal Porosity Conditioning Data 

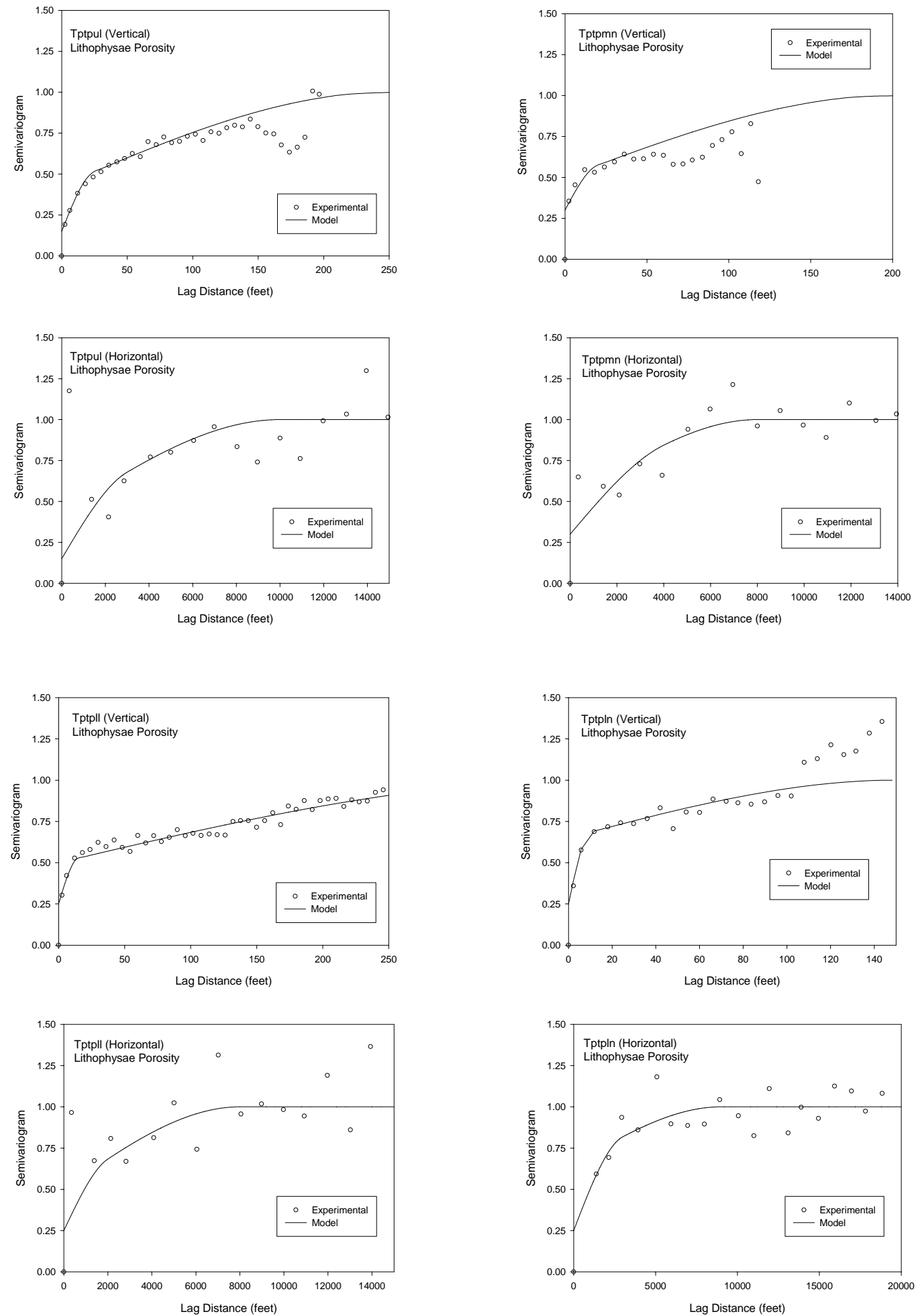

Output DTN: SN0404T0503102.011 [DIRS 169129].

Figure 6-6. Lithophysal Porosity Semivariograms 
Table 6-3. Lithophysal Porosity Model Variogram Parameters

\begin{tabular}{|c|c|c|c|c|c|c|c|c|c|}
\hline \multirow[b]{2}{*}{$\begin{array}{l}\text { Nest } \\
\text { No. }\end{array}$} & \multirow[b]{2}{*}{$\begin{array}{l}\text { Model } \\
\text { Type }\end{array}$} & \multicolumn{2}{|c|}{$\begin{array}{c}\text { Range/Search Radius } \\
\text { (feet) }\end{array}$} & \multirow[b]{2}{*}{ Sill } & \multicolumn{3}{|c|}{$\begin{array}{l}\text { Rotation Angles } \\
\text { (degrees) }\end{array}$} & \multicolumn{2}{|c|}{ Anisotropy Ratio } \\
\hline & & $\begin{array}{l}\text { Horizontal } \\
\text { (Maximum) }\end{array}$ & $\begin{array}{l}\text { Vertical } \\
\text { (Minimum) }\end{array}$ & & 1 & 2 & 3 & 1 & 2 \\
\hline \multicolumn{10}{|c|}{ Tptpul Unit } \\
\hline 0 & Nugget & 10,000 & 200 & 0.15 & - & - & - & 1.0 & 0.0200 \\
\hline 1 & Spherical & 3,000 & 25 & 0.28 & 0 & 0 & 0 & 1.0 & 0.0083 \\
\hline 2 & Spherical & 10,000 & 250 & 0.57 & 0 & 0 & 0 & 1.0 & 0.0250 \\
\hline \multicolumn{10}{|c|}{ Tptpmn Unit } \\
\hline 0 & Nugget & 8,000 & 120 & 0.30 & - & - & - & 1.0 & 0.0150 \\
\hline 1 & Spherical & 4,000 & 20 & 0.20 & 0 & 0 & 0 & 1.0 & 0.0050 \\
\hline 2 & Spherical & 8,000 & 200 & 0.50 & 0 & 0 & 0 & 1.0 & 0.0250 \\
\hline \multicolumn{10}{|c|}{ Tptpll Unit } \\
\hline 0 & Nugget & 8,000 & 300 & 0.25 & - & - & - & 1.0 & 0.0300 \\
\hline 1 & Spherical & 2,000 & 15 & 0.25 & 0 & 0 & 0 & 1.0 & 0.0050 \\
\hline 2 & Spherical & 8,000 & 400 & 0.50 & 0 & 0 & 0 & 1.0 & 0.0400 \\
\hline \multicolumn{10}{|c|}{ Tptpln Unit } \\
\hline 0 & Nugget & 9,000 & 100 & 0.25 & - & - & - & 1.0 & 0.0111 \\
\hline 1 & Spherical & 3,000 & 10 & 0.40 & 0 & 0 & 0 & 1.0 & 0.0033 \\
\hline 2 & Spherical & 9,000 & 150 & 0.35 & 0 & 0 & 0 & 1.0 & 0.0167 \\
\hline
\end{tabular}

Output DTN: SN0404T0503102.011 [DIRS 169129].

Table 6-4. Matrix Porosity Variogram Parameters

\begin{tabular}{|c|c|c|c|c|c|c|c|c|c|}
\hline \multirow[b]{2}{*}{$\begin{array}{c}\text { Nest } \\
\text { No. }\end{array}$} & \multirow[b]{2}{*}{$\begin{array}{c}\text { Model } \\
\text { Type }\end{array}$} & \multicolumn{2}{|c|}{$\begin{array}{c}\text { Range/Search Radius } \\
\text { (feet) }\end{array}$} & \multirow[b]{2}{*}{ Sill } & \multicolumn{3}{|c|}{$\begin{array}{c}\text { Rotation Angles } \\
\text { (degrees) }\end{array}$} & \multicolumn{2}{|c|}{$\begin{array}{c}\text { Anisotropy } \\
\text { Ratio }\end{array}$} \\
\hline & & $\begin{array}{l}\text { Horizontal } \\
\text { (Maximum) }\end{array}$ & $\begin{array}{c}\text { Vertical } \\
\text { (Minimum) }\end{array}$ & & 1 & 2 & 3 & 1 & 2 \\
\hline \multicolumn{10}{|c|}{ Tptpul Unit } \\
\hline 0 & Nugget & 5,000 & 150 & 0.05 & 一 & - & - & 1.0 & 0.0300 \\
\hline 1 & Spherical & 500 & 25 & 0.20 & 0 & 0 & 0 & 1.0 & 0.0500 \\
\hline 2 & Spherical & 5,000 & 600 & 0.75 & 0 & 0 & 0 & 1.0 & 0.1200 \\
\hline \multicolumn{10}{|c|}{ Tptpmn Unit } \\
\hline 0 & Nugget & 8,000 & 120 & 0.08 & - & - & - & 1.0 & 0.0150 \\
\hline 1 & Spherical & 4,000 & 25 & 0.20 & 0 & 0 & 0 & 1.0 & 0.0063 \\
\hline 2 & Spherical & 8,000 & 240 & 0.72 & 0 & 0 & 0 & 1.0 & 0.0300 \\
\hline \multicolumn{10}{|c|}{ Tptpll Unit } \\
\hline 0 & Nugget & 4,000 & 200 & 0.10 & - & - & - & 1.0 & 0.0500 \\
\hline 1 & Spherical & 600 & 17 & 0.28 & 0 & 0 & 0 & 1.0 & 0.0283 \\
\hline 2 & Spherical & 4,000 & 800 & 0.62 & 0 & 0 & 0 & 1.0 & 0.2000 \\
\hline \multicolumn{10}{|c|}{ Tptpln Unit } \\
\hline 0 & Nugget & 6,000 & 90 & 0.20 & - & - & - & 1.0 & 0.0150 \\
\hline 1 & Spherical & 2,500 & 25 & 0.13 & 0 & 0 & 0 & 1.0 & 0.0100 \\
\hline 2 & Spherical & 6,000 & 90 & 0.67 & 0 & 0 & 0 & 1.0 & 0.0150 \\
\hline
\end{tabular}

Output DTN: SN0404T0503102.011 [DIRS 169129]. 
In this report, the matrix groundmass and vapor phase altered material are treated as matrix material. Based on samples from the Tptpul and Tptpll, the porosities of vapor phase altered material (rim and spots) range from 23 to 36 percent with a mean of 30 percent while matrix ground mass is reported to range between 8 to 13 percent with a mean of 10 percent (BSC 2003 [DIRS 166660], Section 8.2.3.1). Therefore, the higher matrix porosity mean and variance is likely caused by the formation lithophysae and the associated vapor phase alteration.

Variogram models of spatial continuity were then developed from the normal-score transformed matrix porosity data. The computer program GSLIB V. 1.0MGAMV2V1.201 (STN: 10087-1.0MGAMV2V1.201-02 [DIRS 158221], Table 3-1) is used to generate experimental semivariogram data that are then fit to traditional spherical models (Deutsch and Journel 1998 [DIRS 102895], p. 25). The variogram analysis files for matrix porosity are located in directory Thermal_Cond/gamv of the output DTN SN0404T0503102.011 filename: Therm_CondData1.zip. The experimental data and resulting models are presented graphically in Figure 6-8. Finally, the specific parameters that implement these models in the GSLIB V. 1.4SGSIMV1.41 software are provided in Table 6-4. All analysis files for the sequential gaussian simulation software are contained in SN0404T0503102.011 in directories Tptpul, Tptpmn, Tptpll, and Tptpln. For example, the input and output files for realization 1 in the Tptpll are named sgsim_Tptpll_MatPor_1.par and sgsim_Tptpll_MatPor_1.out respectively.

\subsubsection{Dry Bulk Density}

Dry bulk density, $\rho_{\text {bd }}$, is defined as the mass per unit volume of an air-saturated porous rock. In lithophysae bearing units, $\rho_{\text {bd }}$ can be expressed as a function of matrix porosity, $\phi_{m}$; lithophysal porosity, $\phi_{\mathrm{L}}$; and the particle density, $\rho_{\mathrm{g}}$ :

$$
\rho_{\mathrm{bd}}=\left(1-\phi_{\mathrm{L}}\right)\left(1-\phi_{\mathrm{m}}\right) \rho_{\mathrm{g}}
$$

In Equation 6-4 the density of air has been neglected, and the term 1- $\phi_{\mathrm{L}}$ represents the volume of matrix, $V_{m}$, per unit total volume, $V_{t}$. The term 1- $\phi_{m}$ represents the volume of solid portion of the rock, $V_{r}$, per unit volume of matrix, and $\rho_{g}$ is the mass, $M$, per unit volume of rock. In terms of these more fundamental properties, Equation 6-4 can be written as:

$$
\rho_{\mathrm{bd}}=\frac{\mathrm{V}_{\mathrm{m}}}{\mathrm{V}_{\mathrm{t}}} \frac{\mathrm{V}_{\mathrm{r}}}{\mathrm{V}_{\mathrm{m}}} \frac{\mathrm{M}}{\mathrm{V}_{\mathrm{r}}}=\frac{\mathrm{M}}{\mathrm{V}_{\mathrm{t}}}
$$

which demonstrates that $\rho_{\text {bd }}$ is correctly defined.

Histogram plots of particle density derived from core measurements are presented in Figure 6-9. These plots illustrate the observation that particle density gradually increases with depth over these four units. The coefficient of variation of these data within a given unit is, however, reasonably small (0.01), indicating that for the purpose of computing dry bulk density, it is appropriate to ignore sub-unit spatial variability and simply use a constant value of particle density. The unit-specific mean particle density values shown in Figure 6-9 are used for this purpose and are tabulated in Table 5-4. 
Unlike matrix and lithophysal porosity, dry bulk density is not simulated explicitly but rather computed at each node in the model grid from simulated values of $\phi_{\mathrm{L}}(\mathrm{x}, \mathrm{y}, \mathrm{z})$ and $\phi_{\mathrm{m}}(\mathrm{x}, \mathrm{y}, \mathrm{z})$ by applying Equation 6-4. This calculation is performed using the program TCOND V. 1.0 (STN: 10801-1.0-00 [DIRS 158260], Table 3-1) and yields 50 equally likely realizations of dry bulk density that are spatially consistent with the corresponding realizations of matrix and lithophysal porosity.

\subsubsection{Matrix Thermal Conductivity}

The spatial variability and uncertainty in matrix thermal conductivity is addressed by first selecting one of several thermal conductivity models from the literature. The decision to apply a theoretical model rather than conditionally simulate matrix thermal conductivity is based on the quantity, quality, and type of available data. At the present time there are relatively abundant data regarding fundamental rock properties such as matrix porosity but only a limited number of the more difficult measurements of thermal conductivity. Consequently, it was decided to implement a model that uses the more abundant fundamental property data sets. This is not to say that the information from laboratory thermal conductivity measurement was neglected. Indeed, these measurements are used to constrain and calibrate the selected model through the development of model parameter values and uncertainty distributions.

The thermal conductivity of porous materials has been the subject of considerable study over several decades. Consequently, many analytical and empirical models have been developed for this property. This research is beneficial from the perspective of finding a predictive model that may be applied at Yucca Mountain. However, the task of selecting the "best" model from all those proposed is a substantial and difficult one. Much of the early work in this field (prior to 1960) pertains mostly to unconsolidated substances and is, therefore, not particularly suited to the welded tuff of the Tpt. More recent models tend to address consolidated porous media but may also include additional model parameters and varying degrees of complexity. In general, those parameters associated with pore structure or geometry must be evaluated experimentally.

In this work, three candidate models are examined for application at Yucca Mountain. The proposed models are Kunii and Smith (1960 [DIRS 153166]), Hadley (1986 [DIRS 153165]), and Hsu et al. (1995 [DIRS 158073]). All three models address consolidated porous media and in theory are good candidates for this work. One of the three was ultimately selected based on the following screening criteria:

1. The theoretical development must be well documented, relatively easy to comprehend, and appropriate for consolidated porous media.

2. The model must be capable of reproducing experimental results within the estimated range of experimental error.

3. The model parameters and their uncertainty must be easily derived through existing qualified data. 

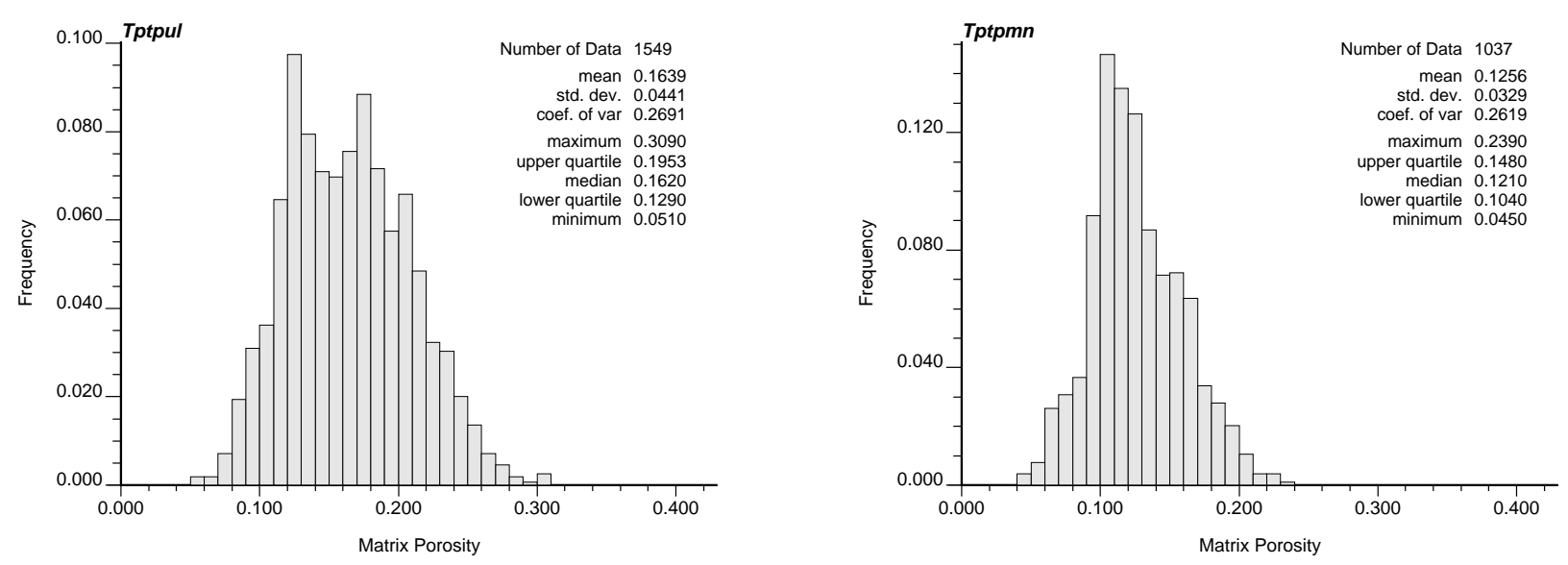

ì
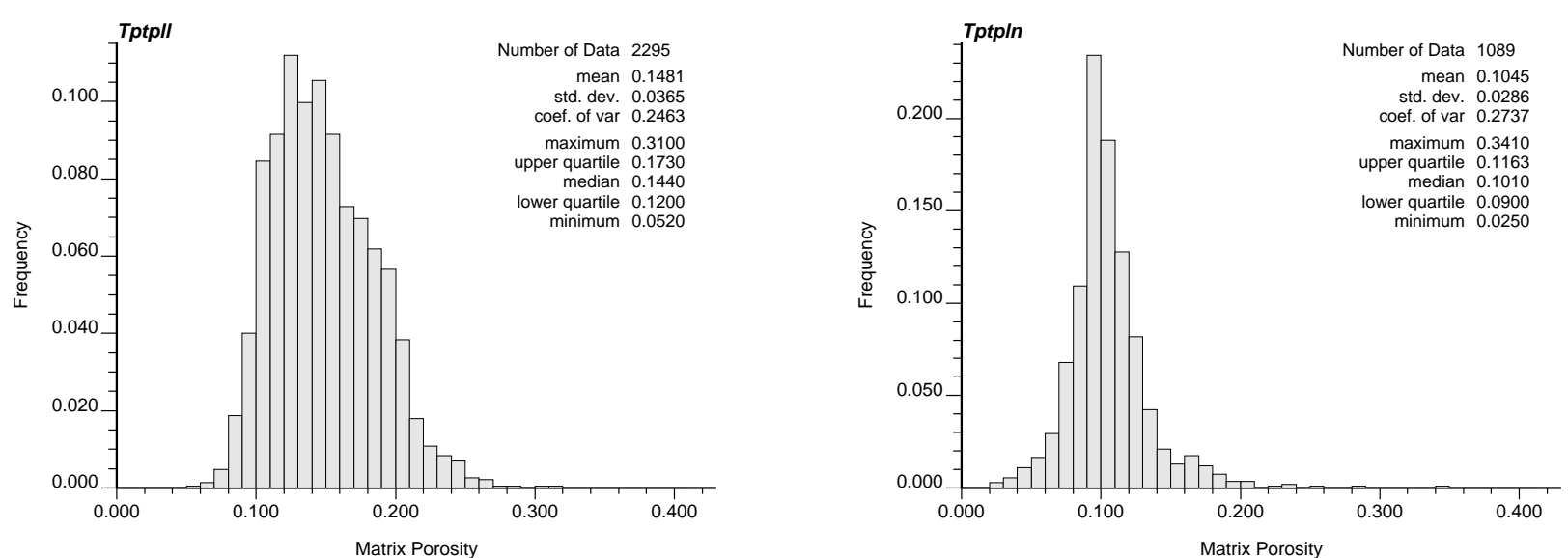

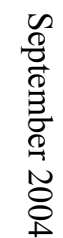

Output DTN: SN0404T0503102.011 [DIRS 169129].

NOTE: The histograms in this figure combine matrix porosity data from core measurements and estimates based on petrophysical logging (Method B using 

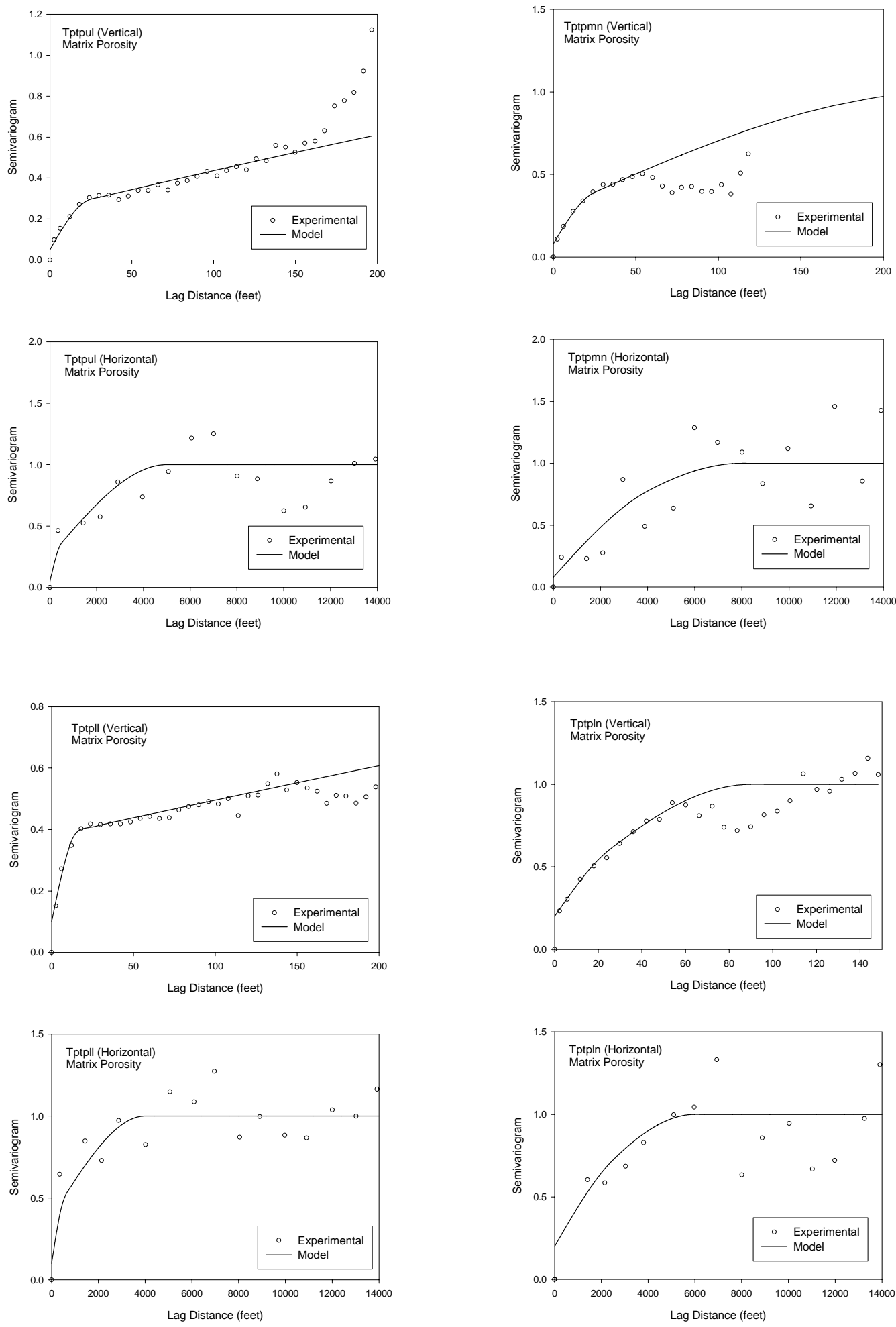

Output DTN: SN0404T0503102.011 [DIRS 169129].

Figure 6-8. Matrix Porosity Semivariograms 

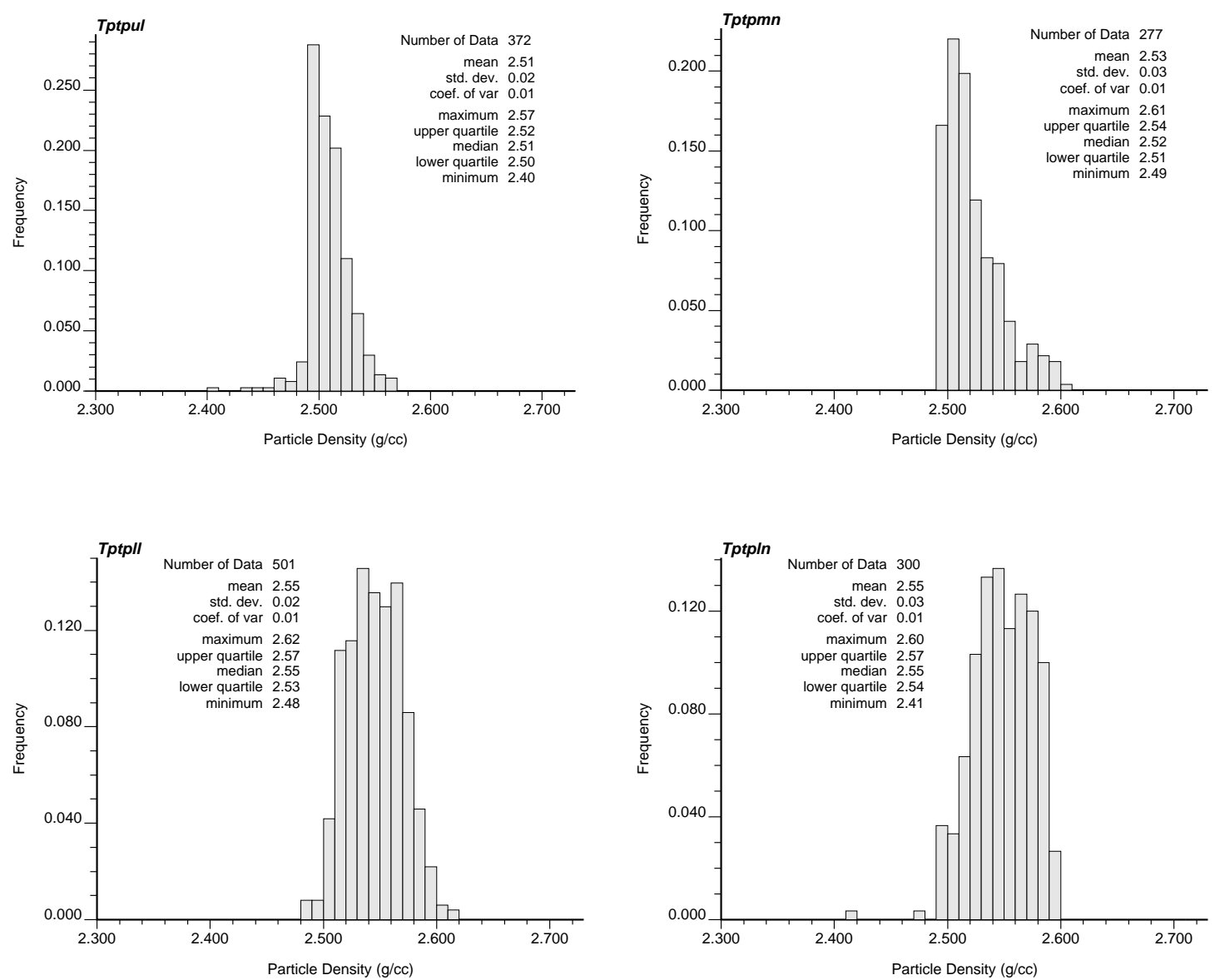

Output DTN: SN0404T0503102.011 [DIRS 169129].

Figure 6-9. Histogram Plots of Particle Density Obtained from Core Measurement

Kunii and Smith (1960 [DIRS 153166]) assume that the thermal conductivity of a porous medium can be represented by a layer of fluid acting in parallel with a composite layer consisting of both fluid and solid phases. Parameters that dictate the geometry of the composite layer are derived based on an analytical solution of heat flow between two spheres. The authors extrapolate this solution to approximate multiple spheres by considering additional contact points and the orientation of these contacts for various packing arrangements. The theory can be extended to consolidated porous media by adjusting the shape and relative size of void and solid space.

The fundamental premise behind the Kunii and Smith model is that the analytical solution of heat flux between two spheres can be stretched and approximated to the point that it is applicable to consolidated porous substances. This argument is convincing for unconsolidated granular substances but not as convincing for consolidated media, because the geometric configuration of the pore space in the latter is quite different for loosely packed spheres for which the basic formulation of the Kunii and Smith model was developed. This model was, therefore, not selected based on Criterion 1. 
The Hadley (1986 [DIRS 153165]) model is derived from volume-averaging theory and makes use of the pioneering work of Maxwell (1954 [DIRS 158165], pp. 440 and 441). This is a versatile model that is applicable over the complete range of potential pore structures. In addition, the model is unique in that it is not explicitly tied to a specific geometry or packing arrangement. The model was not selected, however, due to the difficulty of quantifying model parameter uncertainty from existing data.

In the Hadley model there are three parameters that must be calibrated to experimental data or otherwise estimated. These parameters consist of a geometry factor $\mathrm{f}_{0}$, a consolidation parameter $\alpha$, and the thermal conductivity of the mineral solids $k_{\mathrm{s}}$. Hadley (1986 [DIRS 153165], p. 917 ) derives equations for $\alpha$ and $f_{0}$ from experimental data; however, it is not clear the specimens used in these experiments are representative of welded tuff. Therefore, it was decided that Hadley's representation of $\alpha$ and $f_{0}$ should not be used unless they could be proven valid for welded tuff.

The Yucca Mountain experimental data set generally consists of one to two measurements of thermal conductivity for a given sample at a specific temperature. Often, thermal conductivity is measured after saturating the sample with water (wet) and then again with the sample saturated with air (dry) or by measuring saturated and dry thermal conductivities on a matched pair of specimens where the two specimens are taken from adjacent locations on a single piece of core. In some cases the mineralogy has also been determined using x-ray diffraction. There are a total of eleven samples, all from USW NRG-6, where all three measurements exist. For many samples, however, there are only one or two constraints and three unknowns in the Hadley model. It may be possible to calibrate the Hadley model from existing data, but it would be difficult, and the resulting parameter distributions would be uncertain. For this reason, the Hadley model was not selected.

The final model examined and ultimately selected is the Three-Dimensional Cubic Model developed by Hsu et al. (1995 [DIRS 158073]). This model is conceptually similar to that proposed by Kunii and Smith (1960 [DIRS 153166]) in that a simplified geometrical representation of the porous medium is proposed and then the effective thermal conductivity of the simplified problem is derived through resistance analogues. In the case of the Three-Dimensional Cubic Model, the porous medium is represented by a periodic array of in-line cubes with connecting nodules. The unit cell of the three-dimensional periodic array is shown in Figure 6-10. 


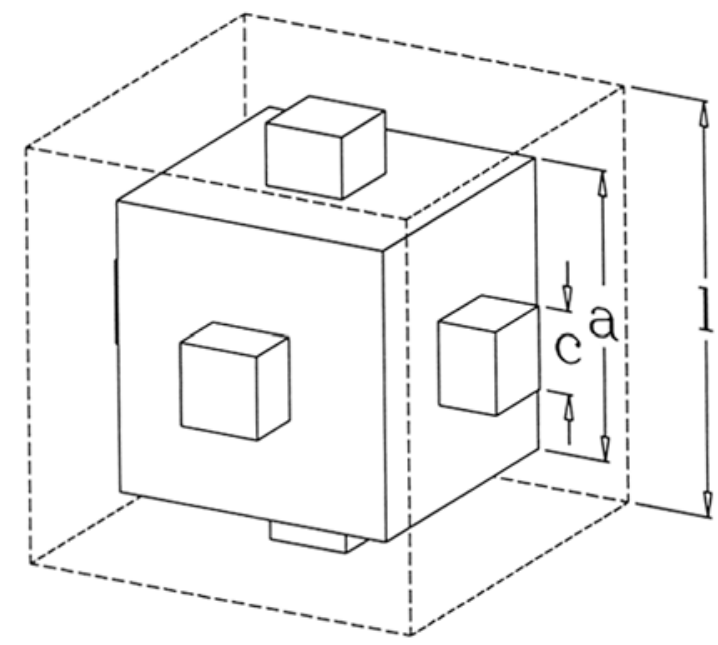

Source: Hsu et al. 1995 [DIRS 158073], Figure 8.

Figure 6-10. Three-Dimensional Cubic Model

Hsu et al. (1995 [DIRS 158073], Equation 14) derive the following equation for this geometry:

$$
\frac{\mathrm{k}_{\mathrm{m}}}{\mathrm{k}_{\mathrm{f}}}=1-\gamma_{\mathrm{a}}^{2}-2 \gamma_{\mathrm{c}} \gamma_{\mathrm{a}}+2 \gamma_{\mathrm{c}} \gamma_{\mathrm{a}}^{2}+\frac{\gamma_{\mathrm{c}}^{2} \gamma_{\mathrm{a}}^{2}}{\lambda}+\frac{\gamma_{\mathrm{a}}^{2}-\gamma_{\mathrm{c}}^{2} \gamma_{\mathrm{a}}^{2}}{1-\gamma_{\mathrm{a}}+\gamma_{\mathrm{a}} \lambda}+\frac{2\left(\gamma_{\mathrm{c}} \gamma_{\mathrm{a}}-\gamma_{\mathrm{c}} \gamma_{\mathrm{a}}^{2}\right)}{1-\gamma_{\mathrm{c}} \gamma_{\mathrm{a}}+\gamma_{\mathrm{c}} \gamma_{\mathrm{a}} \lambda}
$$

where $\gamma_{\mathrm{a}}=\mathrm{a} / \mathrm{l} ; \gamma_{\mathrm{c}}=\mathrm{c} / \mathrm{a} ; \lambda=\mathrm{k}_{\mathrm{f}} / \mathrm{k}_{\mathrm{s}}$; and $\mathrm{k}_{\mathrm{s}}, \mathrm{k}_{\mathrm{f}}$, and $\mathrm{k}_{\mathrm{m}}$ are the thermal conductivities of the solid, fluid, and composite matrix, respectively, and where the scales $a, c$, and $l$ are as shown in Figure 6-10. As illustrated in Figure 6-10, $l$ is the length of the unit cell cube shown, $a$ is the length of one side of the solid square, and $c$ is the width of the connecting nodule. It should be noted that the connecting nodules are square but are not cubes. The connecting nodule protrudes from the face of the solid cube a distance defined by $(l-a) / 2$.

For the three-dimensional Cubic Model unit cell illustrated in Figure 6-10, the pore-volume may be computed by subtracting the volume of the solid cube, $a^{3}$, and the 6 connecting nodules, each having a volume of $c^{2}(l-a) / 2$, from the unit cell volume, $l^{3}$. Furthermore, from geometrical considerations it can be shown that $\gamma_{a}$ and $\gamma_{c}$ are functionally dependent. This dependency may be written as Hsu et al. (1995 [DIRS 158073], Equation 13):

$$
1-\phi_{\mathrm{m}}-\gamma_{\mathrm{a}}^{3}-3 \gamma_{\mathrm{c}}^{2}\left(\gamma_{\mathrm{a}}^{2}-\gamma_{\mathrm{a}}^{3}\right)=0 .
$$

It is apparent from Equations 6-6 and 6-7 that the effective matrix thermal conductivity may be expressed as a function of four independent variables:

$$
\mathrm{k}_{\mathrm{m}}=\mathrm{f}\left(\mathrm{k}_{\mathrm{f}}, \mathrm{k}_{\mathrm{s}}, \phi_{\mathrm{m}}, \gamma_{\mathrm{c}}\right) .
$$

The wet and dry laboratory thermal conductivity measurements extracted from the Tpt were used to calibrate this model. The change in sample mass from the air-saturated state to the water-saturated state is used to calculate $\phi_{\mathrm{m}}$, and the thermal conductivities of the saturating 
fluids are known sufficiently that they are assumed constant. The thermal conductivity of water, $\mathrm{k}_{\mathrm{w}}$, was selected to be $0.64(\mathrm{~W} / \mathrm{mK})$ (Holman 1997 [DIRS 101978], p. 650) and air, $\mathrm{k}_{\mathrm{a}}$, to be $0.028(\mathrm{~W} / \mathrm{mK})$ (Holman 1997 [DIRS 101978], p. 646). This leaves two equations and two unknowns $\left(\mathrm{k}_{\mathrm{s}}\right.$ and $\left.\gamma_{\mathrm{c}}\right)$ for each sample:

$$
\begin{aligned}
& \mathrm{k}_{\mathrm{m}}(\text { wet })=\mathrm{f}\left(\mathrm{k}_{\mathrm{w}}, \mathrm{k}_{\mathrm{s}}, \phi_{\mathrm{m}}, \gamma_{\mathrm{c}}\right), \\
& \mathrm{k}_{\mathrm{m}}(\text { dry })=\mathrm{f}\left(\mathrm{k}_{\mathrm{a}}, \mathrm{k}_{\mathrm{s}}, \phi_{\mathrm{m}}, \gamma_{\mathrm{c}}\right) .
\end{aligned}
$$

The program HSUINV V. 1.0 (SNL 2002 [DIRS 158228]) was used to solve the resulting system of nonlinear equations for each sample for which porosity and wet and dry values were available. Given the wet and dry matrix thermal conductivity, thermal conductivity of air and water, and matrix porosity, HSUINV V. 1.0 (SNL 2002 [DIRS 158228]) iteratively solves these two nonlinear equation for the parameters $k_{s}$ and $\gamma_{c}$. The resulting values obtained for $k_{s}$ and $\gamma_{c}$ are tabulated in Table 6-5 and plotted in the form of histograms in Figure 6-11.

The histograms plotted in Figure 6-11 were created by selecting a suitable uniform bin size, $\Delta \mathrm{x}$, for the data set and assigning each parameter value of the set to the appropriate bin. The number of data values in any bin, $\Delta \mathrm{x}_{\mathrm{i}}$, is the frequency, $\mathrm{f}_{\mathrm{i}}$, for that particular bin. The bin size used for the solid connectivity parameter, $\gamma_{c}$, was chosen to be 0.05 , while the bin size for the solid thermal conductivity parameter, $\mathrm{k}_{\mathrm{s}}$, was chosen to be $0.2 \mathrm{~W} / \mathrm{mK}$. The probability that the data lie within bin $\Delta \mathrm{x}_{\mathrm{i}}$ is simply $\mathrm{f}_{\mathrm{i}} / \mathrm{N}$ where $\mathrm{N}$ is the total number of data points in the entire set. The probability density functions for the solid connectivity and solid thermal conductivity are also plotted in Figure 6-11.

At the bottom of Table 6-5 are six measurements for samples obtained from Alcove 5. The first three Alcove 5 samples were cored horizontally and the last three cored vertically at three different locations. In order to avoid over-weighting the results from Alcove 5, only the first three horizontal samples were used in the development of the histogram plots in Figure 6-11.

Also presented in Figure 6-11 are plots of the parameter distributions chosen to represent the spatial uncertainty for $\gamma_{\mathrm{c}}$ and $\mathrm{k}_{\mathrm{s}}$. The solid connectivity parameter, $\gamma_{\mathrm{c}}$, is represented by a folded normal distribution with a mode of 1.0 and a standard deviation of 0.2 , and the solid thermal conductivity parameter, $\mathrm{k}_{\mathrm{s}}$, is represented by log-normal distribution with a mean of 0.95 and a standard deviation of 0.14 in natural log space.

It should be noted that in the histogram for $\gamma_{c}$ in Figure 6-11, there is a large population of values equal to unity. This spike is somewhat artificial since it results from the treatment of $\gamma_{c}$ when the Three-Dimensional Cubic Model could not reproduce a specific pair of experimental results precisely. 
Table 6-5. Model Parameters for the Three-Dimensional Cubic Model

\begin{tabular}{|c|c|c|c|c|c|}
\hline $\begin{array}{c}\text { Specimen ID } \\
\text { Dry/Wet }\end{array}$ & Porosity & $\begin{array}{c}\text { Dry Thermal } \\
\text { Conductivity at } \\
\text { Nominal } \\
\text { Temperature of } \\
110^{\circ} \mathrm{W} /(\mathrm{mK}) \\
\end{array}$ & \begin{tabular}{|c|} 
Wet Thermal \\
Conductivity at \\
Nominal \\
Temperature of \\
$70^{\circ} \mathrm{C} \mathrm{W} /(\mathrm{mK})$ \\
\end{tabular} & $\begin{array}{c}\mathbf{k}_{\mathrm{s}} \text { Solids } \\
\text { Thermal } \\
\text { Conductivity } \\
\mathrm{W} /(\mathrm{mK})^{\mathrm{a}}\end{array}$ & $\begin{array}{c}\gamma_{c} \text { Solid } \\
\text { Connectivity } \\
\text { Parameter }^{a} \\
\end{array}$ \\
\hline NRG4-529.0B/529.0A & 0.165 & 1.16 & 1.67 & 2.05 & 0.94 \\
\hline NRG4-586.2B/586.2A & 0.194 & 0.95 & 1.64 & 2.10 & 0.75 \\
\hline NRG4-654.0B/654.0A & 0.137 & 1.16 & 1.80 & 2.17 & 0.80 \\
\hline NRG5-781.8A/781.8A & 0.157 & 1.00 & 1.92 & 2.42 & 0.66 \\
\hline NRG5-791.6A/791.3A & 0.246 & 0.82 & 1.78 & 2.57 & 0.62 \\
\hline NRG5-834.8B/834.8A & 0.089 & 1.66 & 1.92 & 2.42 & 1.00 \\
\hline NRG5-843.5A/843.5A & 0.088 & 1.65 & 2.20 & 2.53 & 0.89 \\
\hline NRG5-853.8A/852.5B & 0.087 & 1.71 & 2.26 & 2.61 & 0.89 \\
\hline NRG5-874.9B/874.3B & 0.086 & 1.68 & 2.32 & 2.69 & 0.85 \\
\hline NRG5-886.5B/886.5B & 0.124 & 1.37 & 2.53 & 3.19 & 0.66 \\
\hline NRG6-277.5E/277.5D & 0.100 & 1.26 & 1.68 & 1.89 & 0.95 \\
\hline NRG6-321.1E/321.1D & 0.150 & 1.17 & 1.71 & 2.07 & 0.87 \\
\hline NRG6-354.9C/354.9B & 0.150 & 1.14 & 1.49 & 1.91 & 1.00 \\
\hline NRG6-392.1D/392.1C & 0.040 & 1.19 & 1.55 & 1.62 & 0.84 \\
\hline NRG6-416.0K/416.0J & 0.090 & 1.29 & 1.55 & 1.87 & 1.00 \\
\hline NRG6-421.8D/421.8C & 0.127 & 1.19 & 1.70 & 1.99 & 0.88 \\
\hline NRG6-425.3B/425.3A & 0.138 & 1.26 & 1.82 & 2.19 & 0.87 \\
\hline NRG6-451.2B/451.2A & 0.185 & 1.29 & 1.70 & 2.38 & 1.00 \\
\hline NRG6-693.1C/693.1C & 0.136 & 1.39 & 1.93 & 2.35 & 0.89 \\
\hline NRG6-757.0B/757.0A & 0.096 & 1.61 & 2.02 & 2.40 & 1.00 \\
\hline NRG6-778.1B/778.1A & 0.084 & 1.71 & 1.85 & 2.47 & 1.00 \\
\hline NRG6-787.5B/787.5A & 0.112 & 1.60 & 1.72 & 2.48 & 1.00 \\
\hline NRG6-802.7D/802.7C & 0.094 & 1.67 & 1.78 & 2.48 & 1.00 \\
\hline NRG6-900.4D/900.4C & 0.144 & 1.50 & 2.23 & 2.84 & 0.81 \\
\hline NRG6-926.3E/926.3-D & 0.129 & 1.54 & 2.15 & 2.64 & 0.87 \\
\hline NRG6-987.0B/987.0A & 0.118 & 1.55 & 2.04 & 2.44 & 1.00 \\
\hline NRG7-312.8D/312.8C & 0.106 & 1.33 & 1.63 & 2.02 & 1.00 \\
\hline Alcove5/SPC00515193-G-H & 0.097 & 1.81 & 2.30 & 2.71 & 1.00 \\
\hline Alcove5/SPC00515196-G-H & 0.099 & 1.72 & 2.25 & 2.64 & 0.92 \\
\hline Alcove5/SPC00515199-G-H & 0.096 & 1.87 & 2.33 & 2.79 & 1.00 \\
\hline Alcove5/SPC00515193-C-V & 0.092 & 1.82 & 2.28 & 2.69 & 1.00 \\
\hline
\end{tabular}


Table 6-5. Model Parameters for the Three-Dimensional Cubic Model (Continued)

\begin{tabular}{|c|c|c|c|c|c|}
\hline $\begin{array}{c}\text { Specimen ID } \\
\text { Dry/Wet }\end{array}$ & Porosity & $\begin{array}{c}\text { Dry Thermal } \\
\text { Conductivity at } \\
\text { Nominal } \\
\text { Temperature of } \\
110^{\circ} \mathrm{W} /(\mathrm{mK}) \\
\end{array}$ & $\begin{array}{l}\text { Wet Thermal } \\
\text { Conductivity at } \\
\text { Nominal } \\
\text { Temperature of } \\
70^{\circ} \mathrm{C} \mathrm{W/(mK)} \\
\end{array}$ & $\begin{array}{c}\mathbf{k}_{\mathbf{s}} \text { Solids } \\
\text { Thermal } \\
\text { Conductivity } \\
\mathrm{W}(\mathrm{mK})^{\mathbf{a}}\end{array}$ & $\begin{array}{c}\gamma_{c} \text { Solid } \\
\text { Connectivity } \\
\text { Parameter }^{\mathrm{a}}\end{array}$ \\
\hline Alcove5/SPC00515196-C-V & 0.099 & 1.81 & 2.27 & 2.73 & 1.00 \\
\hline Alcove5/SPC00515199-C-V & 0.101 & 1.80 & 2.27 & 2.73 & 1.00 \\
\hline
\end{tabular}

Input DTN: $\quad$ SNL01A05059301.005 [DIRS 109002], SNL01A05059301.007 [DIRS 108980]; SNL22100196001.006 [DIRS 158213].

Output DTN: ${ }^{\text {a }}$ SN0404T0503102.011 [DIRS 169129].

NOTES: Highlighted fields indicate the same sample was used in both the wet and dry experiments.

For the dry measurements, the values reported at the nominal temperature of $110^{\circ} \mathrm{C}$ (actual range was $108.3-111.3^{\circ} \mathrm{C}$ ) were used. For the wet measurements, the values reported at $70^{\circ} \mathrm{C}$ (actual range 68.9$70.8^{\circ} \mathrm{C}$ ) were used. For samples where more than one measurement of thermal conductivity was reported at the specified temperature, the average of the reported values is given in the table.
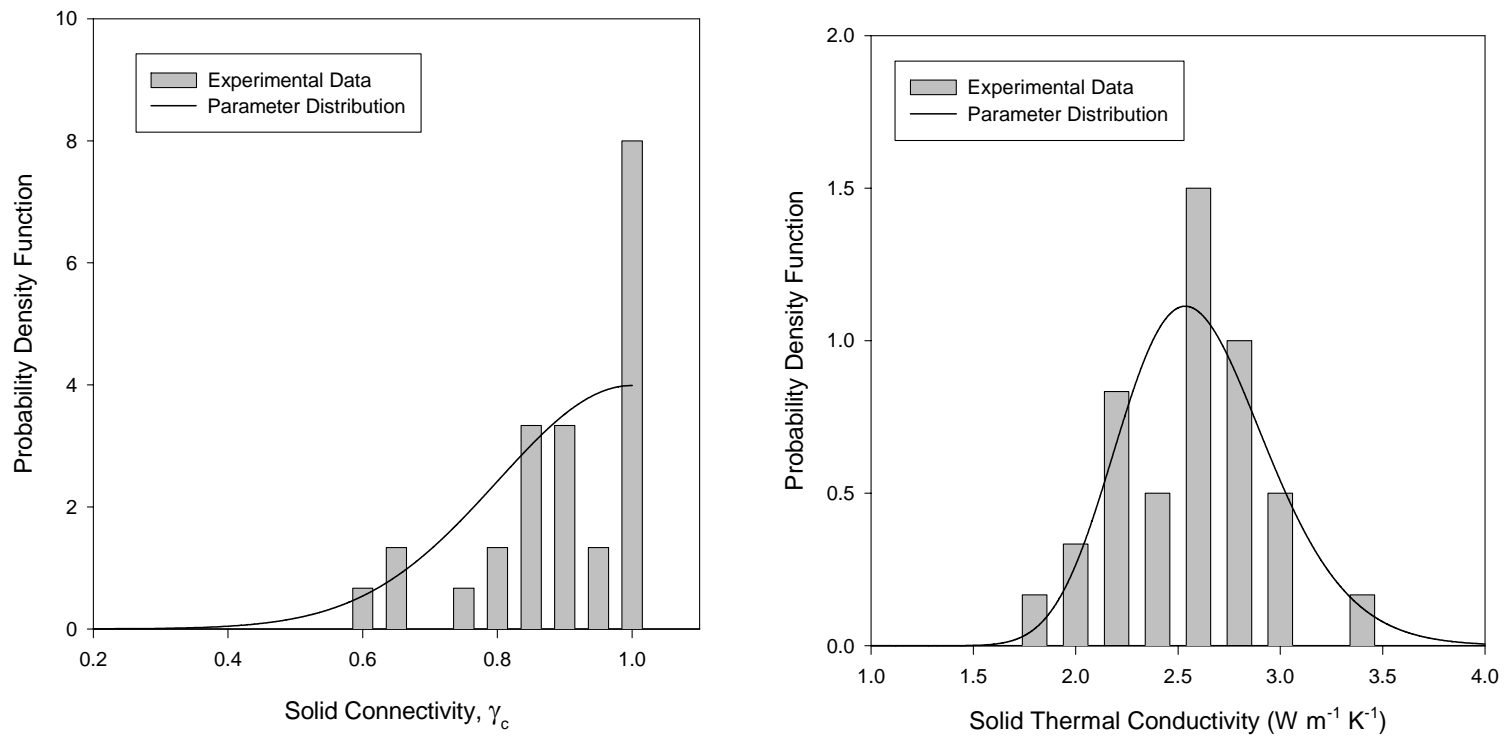

Output DTN: SN0404T0503102.011 [DIRS 169129].

Figure 6-11. Parameter Distributions for the Three-dimensional Cubic Model

To explain the limitations of the Three-Dimensional Cubic Model and the procedures implemented to address these limitations, a plot of predicted wet and dry thermal conductivity as a function of $\gamma_{c}$ is shown in Figure 6-12. In this plot, the matrix porosity and solid thermal conductivity are held constant at values representative of welded tuff. It should be noted that the wet thermal conductivity is relatively insensitive to $\gamma_{c}$ and, therefore, to the geometry of the model. This is because the Three-Dimensional Cubic Model prediction is insensitive to the 
relative difference between the thermal conductivity of the solid and the thermal conductivity of the water filling the matrix pore-space (0.64 W/mK) (Holman 1997 [DIRS 101978], p. 650).

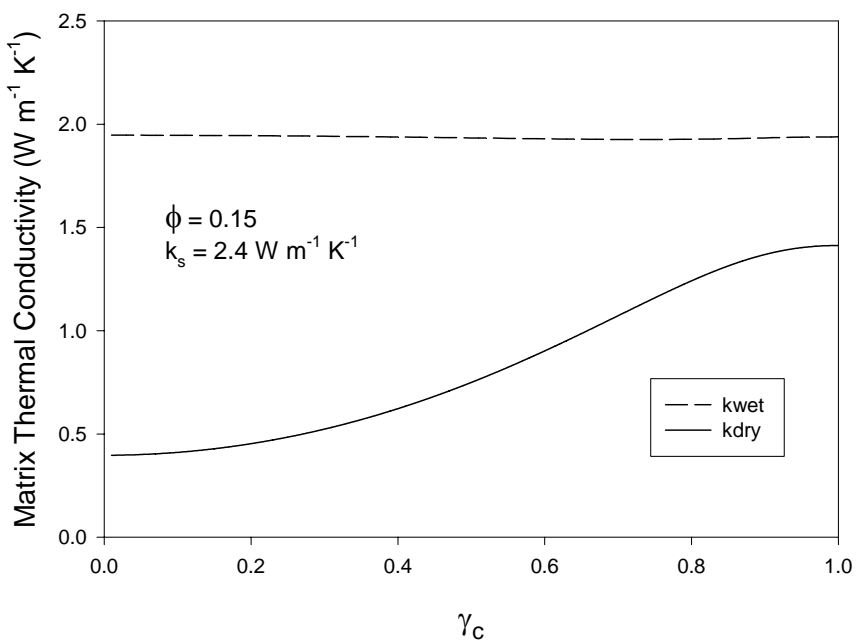

Figure 6-12. Matrix Thermal Conductivity as a Function of Solid Connectivity

The Three-Dimensional Cubic Model prediction of dry thermal conductivity shows a greater sensitivity to $\gamma_{c}$, due to the somewhat greater relative difference between the solid thermal conductivity and the thermal conductivity of air $(0.028 \mathrm{~W} / \mathrm{mK})$ (Holman 1997 [DIRS 101978], p. 646) filling the matrix pore-space. Figure 6-12 illustrates that the differences between the Three-Dimensional Cubic Model predictions of wet and dry matrix thermal conductivity depend on $\gamma_{c}$ and have definite upper and lower bounds. The maximum difference is located at or near $\gamma_{\mathrm{c}}=0$, and the minimum difference is located at or near $\gamma_{\mathrm{c}}=1$.

There are several pairs of experimental wet and dry thermal conductivity measurements in the current data set that the Three-Dimensional Cubic Model is not able to replicate. For these data, the wet and dry thermal conductivity measurements are simply too close to one another to be reproduced by the model. In such circumstances, $\gamma_{\mathrm{c}}$ is set equal to one, and $\mathrm{k}_{\mathrm{s}}$ is calculated such that the dry thermal conductivity measurement is satisfied exactly. The dry measurement is satisfied rather than the wet because dry measurements are easier to control experimentally and, therefore, are presumed to be more reliable. Setting $\gamma_{c}$ to one minimizes the difference between the experimentally measured and the model-predicted wet thermal conductivity. These differences, relative to their measured data, are presented graphically in Figure 6-13. Laboratory Measurements of Thermal Conductivity as a Function of Saturation State for Welded and Nonwelded Tuff Specimens (SNL 1998 [DIRS 118788], p. 21) cites that the calibration procedures used in testing fully saturated specimens very likely lead to an overestimation of the wet thermal conductivity; therefore, the differences between wet and dry thermal conductivity may, in fact, be smaller than experimentally measured. 


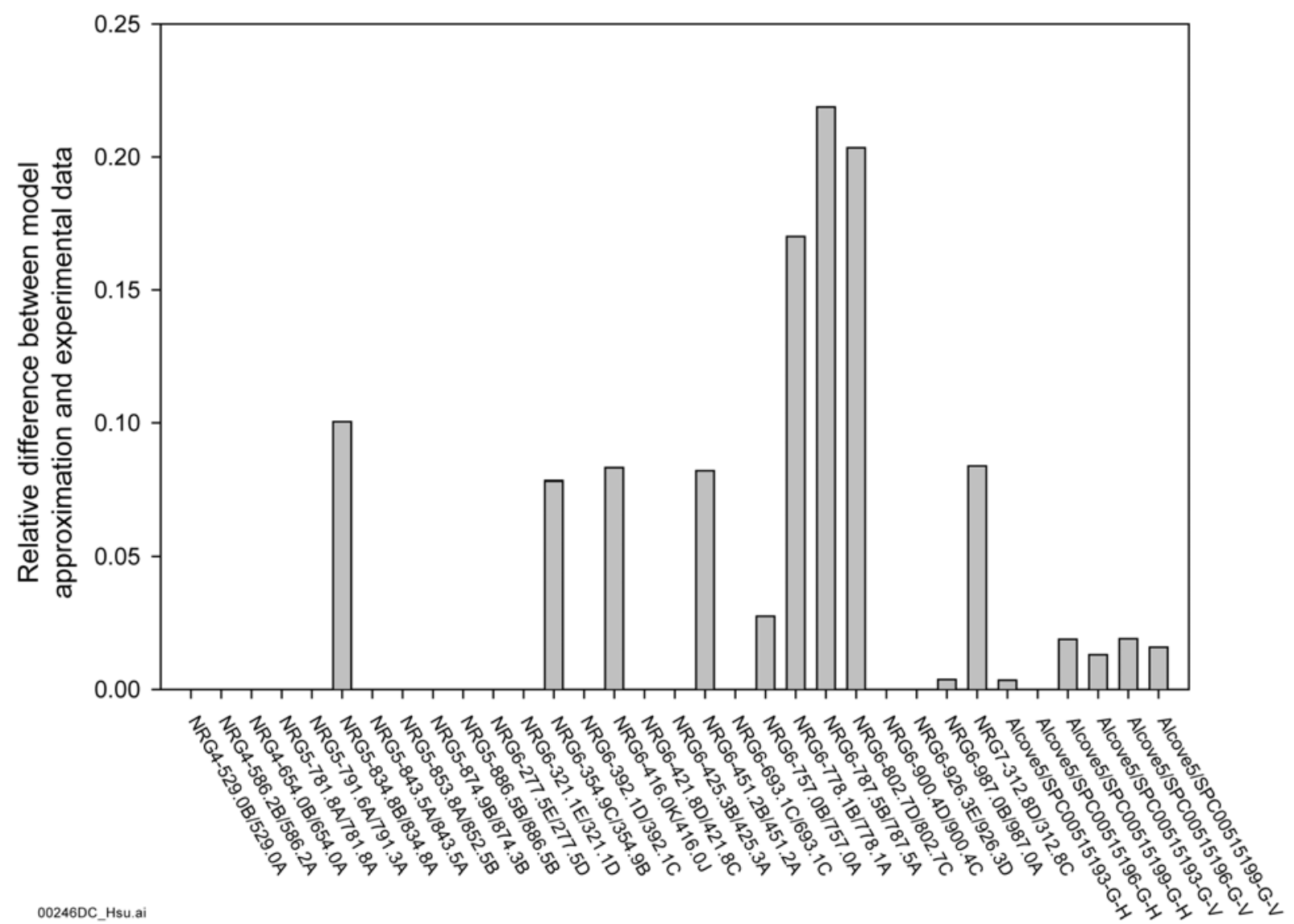

Output DTN: SN0404T0503102.011 [DIRS 169129].

Figure 6-13. Relative Difference in Wet Thermal Conductivity Between Model Predictions and Experimental Measurement

The relative differences reported in Figure 6-13 raise questions regarding the fit of the model to the experimental data. With values up to 20 percent, and the model unable to replicate 15 of 33 experimental data, it seems reasonable to question the applicability of the model (Criteria 2). However, close examination of the experimental data reveals that most of the wet and dry pairs were collected from different samples extracted from the same physical core. One would expect similar results from these samples; however, one cannot be certain of this or estimate the error introduced because of it.

For those cases where the wet and dry thermal conductivity measurements were acquired from the same sample, the Three-Dimensional Cubic Model (Hsu et al. 1995 [DIRS 158073]) is capable of replicating the experimental results quite well. In these cases, model parameters were identified that reproduced both the wet and the dry experimental results exactly, except for five of the six samples collected from Alcove 5 (Table 6-5). In the case of the Alcove 5 data, the dry measurements are reproduced precisely, and the difference between the measured wet thermal conductivity and the model prediction is roughly 2 percent. Such differences are well within the reported experimental error of \pm 5 percent (SNL 1998 [DIRS 118788], p. 10). Therefore, after 
considering all possible sources of experimental error, it was decided that the Three-Dimensional Cubic Model (Hsu et al. 1995 [DIRS 158073]) was the most appropriate.

Having selected the theoretical model for matrix thermal conductivity and developed corresponding model uncertainty parameter distributions, the next task was to create spatial realizations of all uncertain model parameters. In the Three-Dimensional Cubic Model (Hsu et al. 1995 [DIRS 158073]), the uncertain parameters are matrix porosity, solid connectivity, and solid thermal conductivity. Matrix porosity was discussed previously in Section 6.1 .5 , leaving $\gamma_{c}$ and $\mathrm{k}_{\mathrm{s}}$ to be addressed here.

The thermal conductivity of the solid material is dependent on mineralogical composition of the solid phase. In Version 3.0 of the Mineralogic Model (BSC 2004 [DIRS 170031], Sections E2.6-E2.9), the four units of the Tpt studied are described as devitrified rhyolitic tuff with relatively constant feldspar content but highly variable ratios of tridymite, cristobalite, and quartz. The feldspar content (weight percent) ranges between 45 and 75 percent in borehole samples taken from the zones considered in this report, (BSC 2004 [DIRS 170031], Tables A-14, A-15, A-17, and A-18). Tridymite, cristobalite, and quartz are all silica polymorphs in which quartz is the stable species (BSC 2004 [DIRS 170031], Section 6.3.5). Though it is uncertain what, if any, change in thermal conductivity takes place when tridymite and cristobalite convert to quartz, it is clear that even small variations in the combined silica content may influence thermal conductivity. This is true because the thermal conductivity of rock high in quartz content (quartzite) is greater than that of rock having high feldspar content such as tuff and granite, as shown in Figure 6-14 (Stephens and Sinnock 1979 [DIRS 158151]).

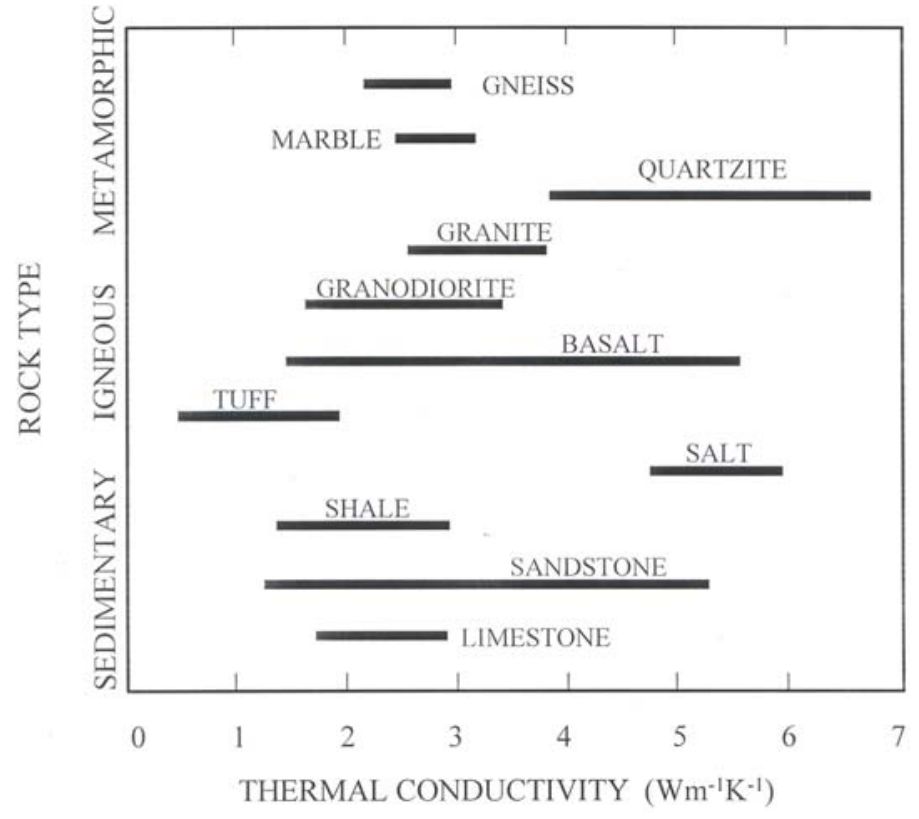

Source: Stephens and Sinnock 1979 [DIRS 158151], Figure 4.

Figure 6-14. Ranges of Thermal Conductivities for Various Materials 
The solid thermal conductivity, $\mathrm{k}_{\mathrm{s}}$, is simulated unconditionally. The spatial correlations (variograms) developed for matrix porosity are applied to $\mathrm{k}_{\mathrm{s}}$ as well.

Lastly, $\gamma_{c}$ is also simulated unconditionally. Once again, the variography developed for matrix porosity is applied to $\gamma_{\mathrm{c}}$.

\subsubsection{Bulk Thermal Conductivity}

For the bulk thermal conductivity, a parallel model is selected to incorporate the effects of lithophysal porosity on the composite conductivity. The selection is based on several criteria:

1. General description of lithophysae as spheroidal.

2. Minimizing the number of model parameters to describe the composite medium.

3. Maxwell's model (Maxwell 1954 [DIRS 158165], pp. 440 and 441) for the effects of spherical cavities on conductivity. The parallel model used produces higher values of the bulk thermal conductivity than Maxwell's model. If conduction were the only heat transfer mechanism, this model would have led to over prediction of the bulk thermal conductivity. However, by over predicting the conductivity due to conduction, the model indirectly compensates for the contribution of radiative heat transfer, which is not explicitly accounted for.

4. Comparison of predictions to direct measurement of bulk thermal conductivity in the field.

A general description of lithophysae in the Tptpll unit is given by Mongano et al. (1999 [DIRS 149850], p. 29, Table 3) and in the Drift Degradation Analysis (BSC 2004 [DIRS 166107], Section 6.1.2). Based on visual inspection of exposed surfaces in the ECRB Cross-Drift excavation, cavity shapes range from spherical to lenticular, often irregular. As stated in the Mongano report, for the interval from Station $22+82$ to $23+26$, "smaller cavities tend to be lenticular or gash-like features, whereas larger cavities generally have ellipsoidal to spherical or irregular shapes" (p. 29). The lithophysae are generally not planar or tabular features and, in general, where lithophysal porosity is greater, the cavities are likely to be larger with more open shapes (e.g., ellipsoidal or spheroidal, irregular cavities) (BSC 2004 [DIRS 166107], Appendix O). Thus, where the effect of lithophysal porosity on conduction is greatest (i.e., greatest lithophysal porosity), open shapes are likely to be present and may predominate.

As stated in the controlling technical work plan report (BSC 2002 [DIRS 158075]) for Revision 00 of this model report, the criteria for conceptual model selection shall include limiting the number of model input parameters. For models of the type under discussion here, additional parameters are used to express the effects of non-ideal geometry (e.g., Hadley 1986 [DIRS 153165], pp. 914 to 915; Kunii and Smith 1960 [DIRS 153166]). For spherical voids (an idealization of spheroidal), no geometrical parameters are required, as shown by Maxwell (1954 [DIRS 158165], pp. 440 and 441). The Maxwell model is, therefore, the simplest representation available for lithophysal porosity with highly uncertain geometry. The Maxwell 
model is described in this section, where it is shown that for media such as lithophysal tuff ( solid conductivity $>>$ void conductivity), the Maxwell model yields bulk conductivities lower than the parallel model. As shown in Figure 6-16, discussed later in this section, for lithophysal porosities of the order of 10 percent, the bulk conductivity given by the Maxwell model is about 5 percent lower than those given by the parallel model. Figure 6-16 also shows that for lithophysal porosities of the order of 25 percent, the bulk conductivity given by the Maxwell model is about 16 percent lower than those given by the parallel model. As explained below, the effect of radiation may increase the effective bulk conductivity by 10 to 25 percent. Therefore, using a parallel model, which accounts for conduction only, to estimate the rock bulk thermal conductivity may counter the effect of ignoring radiation. Thus, the parallel model is selected to represent the effects of lithophysae. This selection incorporates the generalization of sphericity and non-interference between the effects of adjacent voids (a condition of the Maxwell model). To validate the parallel model, comparison of model predictions with field-testing is used in this report (Section 7.5).

Maxwell (1954 [DIRS 158165], p. 440, Equation 17) formulated an expression for the resistance (inverse of thermal conductivity) of a solid body containing dilute inclusions of fluid. Hadley (1986 [DIRS 153165], Equation 26) referred to this formula as the Maxwell upper bound and presented the following general expression, which yields the Maxwell upper bound as a special case:

$$
\frac{k_{b}}{k_{a}}=\frac{\phi f+\kappa(1-\phi f)}{1-\phi(1-f)+\kappa \phi(1-f)} .
$$

In Equation 6-11, $\mathrm{k}_{\mathrm{b}}$ is the bulk thermal conductivity, $\mathrm{k}_{\mathrm{a}}$ is the thermal conductivity of the fluid, $\phi$ is the volume fraction of fluid inclusions, and $\kappa \equiv \mathrm{k}_{\mathrm{m}} / \mathrm{k}_{\mathrm{a}}$, where $\mathrm{k}_{\mathrm{m}}$ is the thermal conductivity of the solid body matrix. Hadley (1986 [DIRS 153165]) also shows that $\mathrm{f}$ is theoretically bounded on the interval $[0,1]$.

Torquato (1987 [DIRS 165105]) reviewed different-order bounds of the bulk thermal conductivity for three-dimensional, isotropic two-phase media, obtained with the aid of variational principles. The first order bounds correspond to heat conduction in a medium where all the solid mass is in a series of parallel plates separated by air gaps as shown in Figure 6-15. In the idealization presented in Figure 6-15, the solid represents the rock matrix and the air gaps represent the lithophysae. The first order bounds of the bulk thermal conductivity are given by the following expressions, which are also often referred to as the series and parallel formulas (Torquato 1987 [DIRS 165105], Equations 2.13 and 2.14; Hadley 1986 [DIRS 153165], Equations 16 and 18):

$$
\begin{array}{ll}
\frac{k_{L}^{(1)}}{k_{a}}=\frac{\kappa}{\kappa \phi+(1-\phi)} & \text { (series formula) } \\
\frac{k_{U}^{(1)}}{k_{a}}=\phi+\kappa(1-\phi) & \text { (parallel formula) }
\end{array}
$$


where $k_{L}^{(1)}, k_{U}^{(1)}$ are the first-order lower and upper bound, respectively, of the bulk thermal conductivity. The lower bound, given by the series formula, corresponds to the condition that the thermal gradient and the heat flux are in the direction normal to the solid plates. The upper bound, given by the parallel formula, corresponds to the condition where the thermal gradient is parallel to the plates (Figure 6-15).

The first-order lower and upper bounds can be obtained from Equation 6-11 by setting $\mathrm{f}=0$ and $\mathrm{f}=1$, respectively.

The second-order bounds of the bulk thermal conductivity can be written as (Hadley 1986 [DIRS 153165], Equations 21 and 20):

$$
\begin{gathered}
\frac{k_{L}^{(2)}}{k_{a}}=\frac{2 \phi+\kappa(3-2 \phi)}{3-\phi+\kappa \phi} \\
\frac{k_{U}^{(2)}}{k_{a}}=\frac{\kappa(1+2 \phi)+2 \kappa^{2}(1-\phi)}{1-\phi+\kappa(2+\phi)}
\end{gathered}
$$

where $k_{L}^{(2)}$ and $k_{U}^{(2)}$ are the second-order lower and upper bound, respectively, of the bulk thermal conductivity.

Volume fraction occupied by the solid: $1-\phi$

Volume fraction occupied by the air: $\phi$

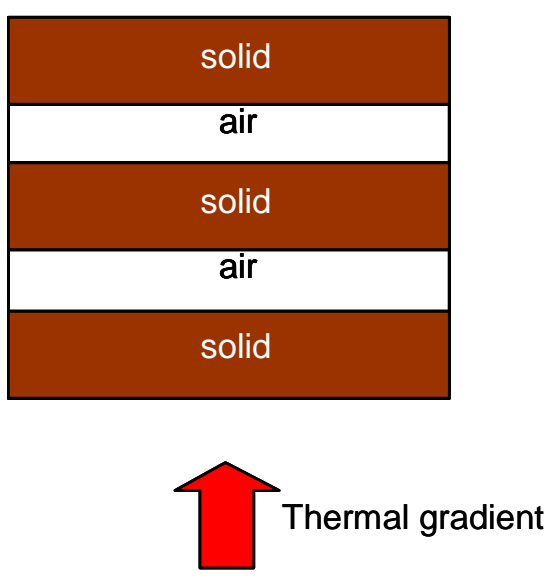

Series model

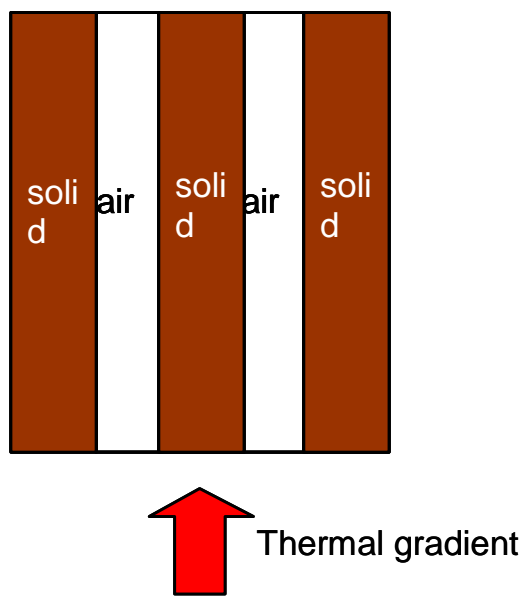

Parallel model

Figure 6-15. Systems Described by the Series and the Parallel Model 
Equation 6-15 is the Maxwell upper bound formula, which can be also obtained from Equation 6-11 by setting the function f equal to (Hadley 1986 [DIRS 153165], Equation 22):

$$
f=\frac{2 \kappa}{2 \kappa+1}
$$

The second-order lower bound given by Equation 6-14 can be obtained from Equation 6-11 by setting $\mathrm{f}=2 / 3$. Hadley (1986 [DIRS 153165]) refers to the bound given by Equation 6-14 as Maxwell's lower bound. The latter gives the bulk conductivity of a dilute suspension of solid spherical particles in an infinite uniform fluid, while Maxwell's upper bound formula gives the bulk conductivity of a solid body containing a dilute "suspension" of fluid-filled voids. Higher order bounds correspond to more complex geometries and configurations of the void space inside the solid matrix.

Applying the general expression given by Torquato (1987 [DIRS 165105], Equations 2.16 and 2.17), the third-order lower and upper bounds for three-dimensional media can be expressed as:

$$
\begin{gathered}
\frac{k_{L}^{(3)}}{k_{a}}=\frac{1+(2+\phi) \beta_{a m}+2 \phi \beta_{a m}^{2}}{1+2(1-\phi) \beta_{a m}+(3 \phi-4) \phi \beta_{a m}^{2}} \kappa \\
\frac{k_{u}^{(3)}}{k_{a}}=\frac{1+(3-4 \phi) \beta_{m a}+(1-3 \phi)(1-\phi) \beta_{m a}^{2}}{1-\phi \beta_{m a}-(1-\phi) \beta_{m a}^{2}}
\end{gathered}
$$

where $k_{L}^{(3)}$ and $k_{U}^{(3)}$ are the third order lower and upper bound, respectively, of the bulk thermal conductivity and (Torquato 1987 [DIRS 165105], Equation 2.10).

$$
\beta_{a m}=\frac{1-\kappa}{1+2 \kappa} \quad \beta_{m a}=\frac{\kappa-1}{\kappa+2}
$$

Torquato (1987 [DIRS 165105], Equation 2.32) has proposed the following expression for the bulk thermal conductivity:

$$
\frac{k_{b}}{k_{a}}=\frac{1+2 \phi \beta_{a m}-2(1-\phi) \phi \beta_{a m}^{2}}{1-2 \phi \beta_{a m}-2(1-\phi) \phi \beta_{a m}^{2}} \kappa=\frac{(1+2 \kappa)^{2}+2 \phi(1+2 \kappa)(1-\kappa)-2(1-\phi) \phi(1-\kappa)^{2}}{(1+2 \kappa)^{2}-2 \phi(1+2 \kappa)(1-\kappa)-2(1-\phi) \phi(1-\kappa)^{2}} \kappa \text {.(Eq. 6-20) }
$$

According to Torquato (1987 [DIRS 165105]), Equation 6-20 yields a highly accurate expression for the bulk conductivity of three-dimensional dispersions, provided that the mean cluster size of the dispersed phase is much smaller than the characteristic length of the macroscopic sample.

Figure 6-16 shows the bulk thermal conductivity estimated as a function of the porosity $\phi$ from the first-, second-, and third-order lower and upper bounds expressions, as well as from Equation 6-20 proposed by Torquato (1987 [DIRS 165105], Equation 2.32). The curves shown in Figure 6-16 were developed using $\mathrm{k}_{\mathrm{m}}=2.15 \mathrm{~W} / \mathrm{m} \mathrm{K}$ and $\mathrm{k}_{\mathrm{a}}=0.026 \mathrm{~W} / \mathrm{m} \mathrm{K}$, i.e. $\kappa=82.7$. 
As can be seen in Figure 6-16, the difference between the first-order upper bound (parallel model) and the second-order upper bound of the bulk conductivity (Maxwell's upper bound) increases with the value of the porosity. It ranges from about 5 percent for lithophysal porosities of the order of 10 percent, to 16 percent for lithophysal porosities of the order of 25 percent.

As pointed out by Torquato (1987 [DIRS 165105], p. 159), as more information on the microstructure is included, the bounds of the bulk thermal conductivity become tighter. One cannot say conclusively which approximation is more appropriate for the bulk thermal conductivity of the repository horizon. However, it is possible to say with quite high degree of confidence that if conduction were the only heat transfer mechanism, a higher-order upper bound model of the thermal conductivity should be used. This is because the first order bound is applicable only for the idealized medium shown on the right half of Figure 6-15.

All the models presented so far are conduction only models. However, at high temperatures and for sizable voids, radiation across the walls of the voids can also make a significant contribution to heat transfer. This point can be illustrated by considering an ideal composite medium, consisting of a parallel solid plates separated by air gaps shown in Figure 6-15.

If the thermal gradient is in the direction normal to the solid plates, radiation across the gap contributes to heat transfer. If the thermal gradient is in the direction parallel to the plates, radiation does not contribute to heat transfer, as the solid surfaces across the air gaps have the same temperature.

The radiative heat flux across two surfaces at temperatures $T_{1}$ and $T_{2}$ can be approximated by taking $\mathrm{T}_{1} \cong \mathrm{T}_{2}=\mathrm{T}$ (Lienhard and Lienhard 2003 [DIRS 169239], Equation 10.24, p. 551)

$$
\frac{\varepsilon}{2-\varepsilon} \sigma\left(T_{1}^{4}-T_{2}^{4}\right) \sim \frac{4 \varepsilon \sigma}{2-\varepsilon} T^{3}\left(T_{1}-T_{2}\right) .
$$

where $\varepsilon$ and $\sigma$ are the rock emissivity and Stefan-Boltzmann constant respectively. This expression can be recast in the following form, where the radiative heat transfer is expressed in terms of an equivalent thermal conductivity, i.e.,

$$
\frac{4 \varepsilon \sigma}{2-\varepsilon} T^{3}\left(T_{1}-T_{2}\right)=\alpha \frac{4 \varepsilon \sigma}{2-\varepsilon} T^{3} \frac{\left(T_{1}-T_{2}\right)}{\alpha}
$$

where $\alpha$ is the distance between the two surfaces.

Under this assumption, it can be shown that the bulk thermal conductivity can be expressed as:

$$
k_{b}=\frac{1}{\frac{\phi}{k_{a}^{\prime}}+\frac{1-\phi}{k_{m}}}
$$




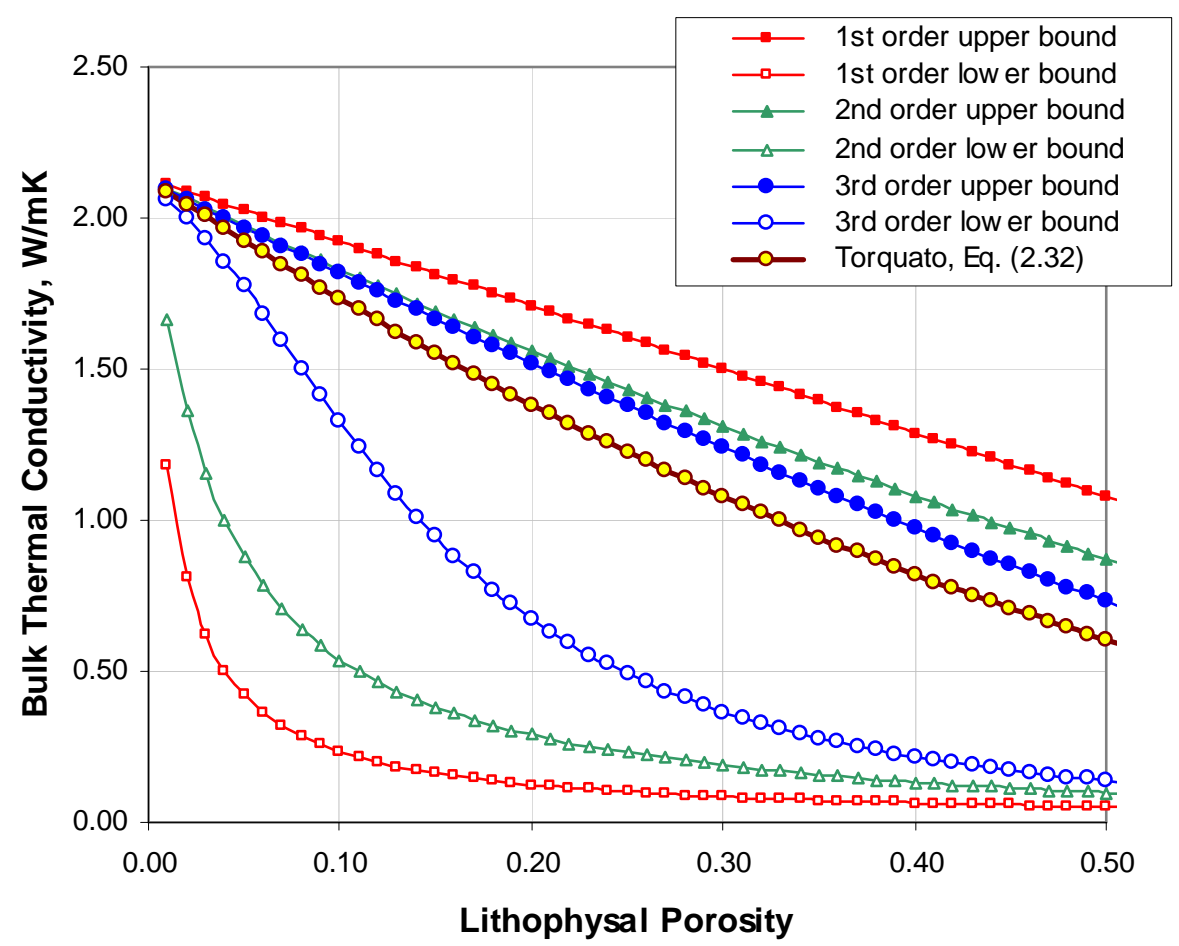

Output DTN: SN0406T0503102.012 [DIRS 170045].

Figure 6-16. First-, Second-, and Third-Order Upper and Lower Bounds of the Bulk Thermal Conductivity and the Torquato Model

where $k_{a}^{\prime}$ is an effective thermal conductivity through the air gaps, which accounts for the combined effect of conduction through the air and radiation, and is given by:

$$
k_{a}^{\prime}=\left(k_{a}+\alpha \frac{4 \varepsilon \sigma}{2-\varepsilon} T^{3}\right) .
$$

It should be noted that $k_{a}^{\prime}$ is a function of both the distance between solid surfaces, $\alpha$, and the temperature $\mathrm{T}$.

Figure 6-17 illustrates the effect of the value of $\alpha$ on the bulk thermal conductivity by showing the latter estimated from Equation 6-23. In Figure 6-17 $k_{a}^{\prime}$ was estimated from Equation 6-24 for $\mathrm{T}=50^{\circ} \mathrm{C}$, and $\alpha=0.002,0.01,0.02,0.05,0.10$ and $0.20 \mathrm{~m}$. As can be seen in Figure 6-17, for voids of the order of $0.20 \mathrm{~m}$, the effect of radiation on the bulk thermal conductivity estimated by the series model (first order lower bound of the pure conduction model) is substantial. The estimated bulk thermal conductivities are of about the same magnitude as the parallel model (first order upper bound of the pure conduction model).

Figure 6-18 illustrates the effect of temperature on the bulk thermal conductivity estimated from Equation 6-23 with $k_{a}^{\prime}$ from Equation 6-24 for $\alpha=0.05 \mathrm{~m}$ and $\mathrm{T}=25,50,90$, and $150^{\circ} \mathrm{C}$. As 
can be seen from Figure 6-18, the temperature effect on the estimated bulk conductivity due to radiation is significant.

It is also interesting to notice that if in the Torquato model, given by Equation 6-20, the thermal conductivity of the air is replaced by the effective conductivity that accounts for radiation, the resulting bulk thermal conductivity comes close to the first-order upper bound estimate. This effect is illustrated in Figure 6-19, which shows the thermal conductivity obtained with the Torquato model replacing $k_{a}$ with $k_{a}^{\prime}$ from Equation 6-24 with $\alpha=0.10 \mathrm{~m}$ and $\mathrm{T}=50^{\circ} \mathrm{C}$. As can be seen in Figure 6-19, the two curves are fairly close.

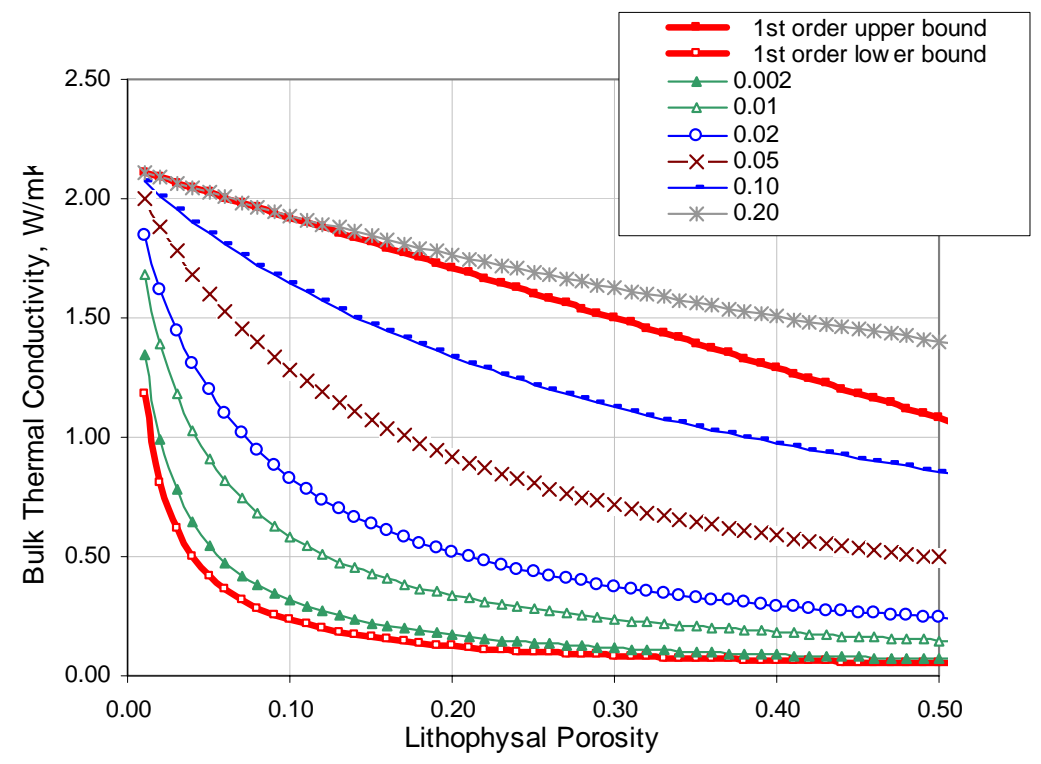

Output DTN: SN0406T0503102.012 [DIRS 170045].

Figure 6-17. Effect of the Length Scale of the Air Gaps $(\alpha)$ on the Bulk Thermal Conductivity for $\mathrm{T}=50^{\circ} \mathrm{C}$

Therefore, it can be argued that even though the parallel model overestimates the bulk thermal conductivity for geologic media when conduction is the only heat transfer mechanism, it may, subject to validation in Section 7.5, provide an acceptable approximation of the bulk thermal conductivity when the effect of radiation is taken into account. The application of the parallel model to the matrix/lithophysae conceptualization (replacing $\phi$ with $\phi_{L}$ in Equation 6-13) can be expressed as (Hadley 1986 [DIRS 153165], Equation 18):

$$
k_{b}=\phi_{L} k_{a}+\left(1-\phi_{L}\right) k_{m} .
$$

Equation 6-25 is invoked by the program TCOND V.1.0 (STN: 10801-1.0-00 [DIRS 158260], Table 3-1) to produce 50 realizations of $\mathrm{k}_{\mathrm{b}}(\mathrm{x}, \mathrm{y}, \mathrm{z})$. TCOND operates on the realization of $\phi_{\mathrm{L}}(\mathrm{x}, \mathrm{y}, \mathrm{z})$ developed in Section 6.1.4 and $\mathrm{k}_{\mathrm{m}}(\mathrm{x}, \mathrm{y}, \mathrm{z})$ developed in Section 6.1.7. 


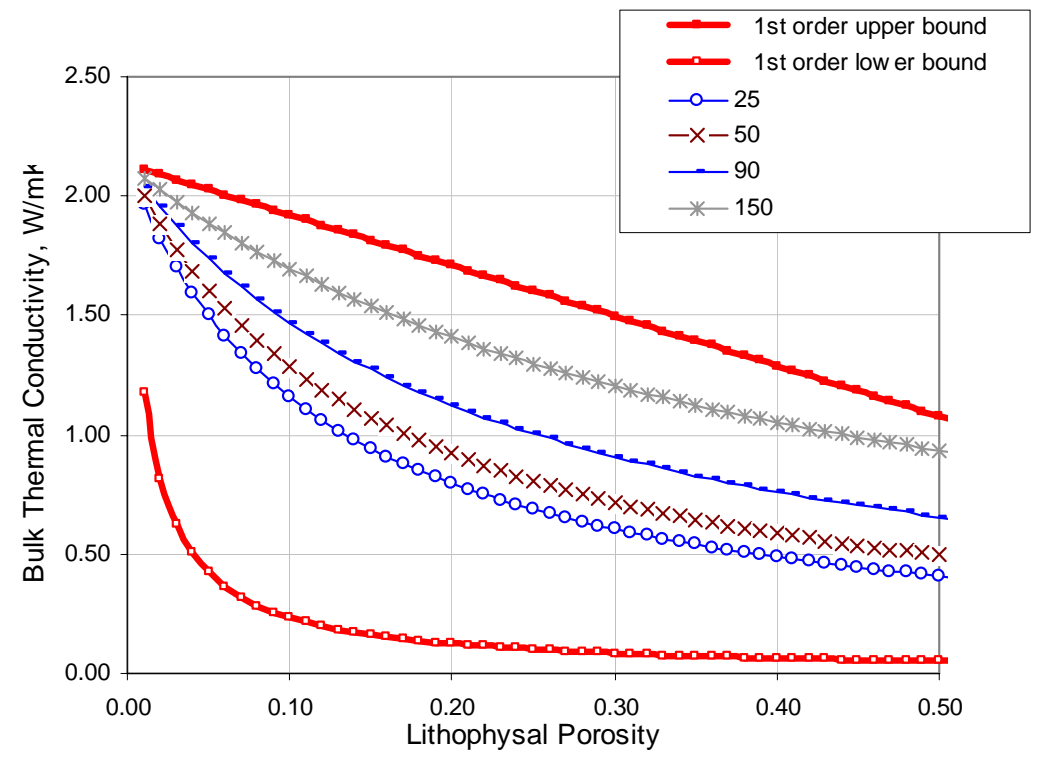

Output DTN: SN0406T0503102.012 [DIRS 170045].

Figure 6-18. Effect of Temperature on the Bulk Thermal Conductivity for $\alpha=0.05 \mathrm{~m}$

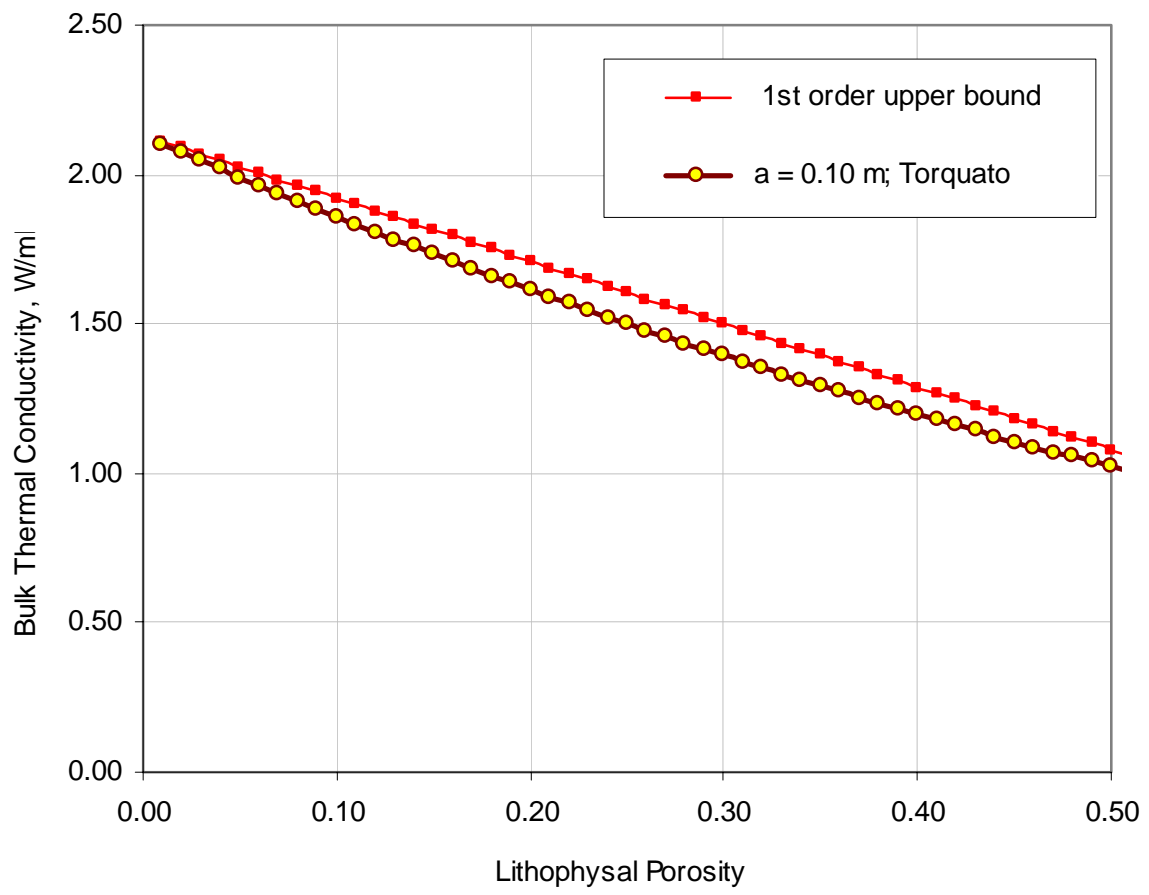

Output DTN: SN0406T0503102.012 [DIRS 170045].

Figure 6-19. Comparison of the Parallel Model with the Torquato Model Accounting for Radiation 


\subsection{MODEL RESULTS}

The principal results of this study are the three-dimensional bulk thermal conductivity fields developed for four lithostratigraphic units of the Tpt. The spatial variability and uncertainty of this property is characterized using a total of 50 equally likely stochastic realizations. Each realization consists of a three-dimensional, discrete set of five rock properties (matrix porosity, lithophysal porosity, dry bulk density, wet bulk thermal conductivity, and dry bulk thermal conductivity) and four intermediate model parameters (matrix solid thermal conductivity, matrix solid connectivity, wet matrix thermal conductivity, and dry matrix thermal conductivity). At each node within the computational grid, these nine different model parameters and rock properties are developed such that they are both mathematically and physically consistent. The geologic uncertainty represented by these geostatistical model results should be used in Monte Carlo-style simulations to fully evaluate their impact on repository performance measures.

Statistical summaries of model results are also provided, which may be used in analyses that treat a layer as a homogeneous material. For these cases, it may also be desirable to conduct a sensitivity study to assess the impact of these parameters on model performance measures. The sensitivity analysis conducted in the Ventilation Model and Analysis Report (BSC 2004 [DIRS 169862], Section 6.11) determined that bulk thermal conductivity is an important parameter in the prediction of ventilation efficiency. In the Multiscale Thermohydrologic Model (BSC 2004 [DIRS 169565], Section 6.3.2.2), it was determined that bulk thermal conductivity impacts drift-wall and waste package temperatures and waste package relative humidity during the first one-to-two thousand years. In Igneous Intrusion Impacts on Waste Packages and Waste Forms, (BSC 2004 [DIRS 168960], Section I.2), the effect of solids thermal conductivity, solid grain density, solid specific heat, matrix porosity and saturation, lithophysal porosity and initial temperature on peak temperature at a distance of $10 \mathrm{~m}$ in the rock mass (representing a distance of $10 \mathrm{~m}$ from a drift filled with magma) was evaluated and the principal source of uncertainty in the rock temperature was determined to be the initial temperature. These analyses used the mean thermal conductivity as the base case and mean \pm 1 standard deviation to evaluate sensitivities of the models. The Drift Degradation Analysis (BSC 2004 [DIRS 166107], Section 6.2) report discusses the effect on drift crown temperature for drift scale thermal calculations by comparing mean parameter results with those obtained by reducing the thermal conductivity and heat capacity by 1 standard deviation. The peak drift crown temperature was found to increase approximately $23^{\circ} \mathrm{C}$ using the lower parameter values.

An alternative procedure has been used to estimate the lithophysal porosity three-dimensional spatial distribution in the Subsurface Geotechnical Parameters Report (BSC 2003 [DIRS 166660], Section 9.4). The procedure "projects" the ECRB Cross-Drift mapping data (which is essentially that identified as "Panel Maps and Tape Traverses without Large Lithophysae" in Figure 7-5a) to a vertically simulated cross section to define the vertical variability of the lithophysal porosity data. The vertical cross section is projected horizontally away from the ECRB to define the data in the third direction.

\subsubsection{Expected Value and Uncertainty}

The spatially dependent expected values and uncertainties of modeled rock properties are estimated by computing the mean and the standard deviation of all 50 realizations at each node in 
the computational mesh. The resulting field of mean values represents the conditional expectation of central tendency and is referred to as the Etype estimate (Deutsch and Journel 1992 [DIRS 100567], pp. 76 and 225). The standard deviation is a familiar statistical property, used here to measure model uncertainty. Expected value and uncertainty models were generated for each of the nine properties modeled using the software Etype V. 2.01 (STN: 10731-2.01-00 [DIRS 159417], Table 3-1).

Surface diagrams of the expected value of dry and wet bulk thermal conductivity are presented in Figures 6-20 and 6-21, respectively, at the end of this section. The definition of the data used to provide these "dry" and "wet" thermal conductivity representations is presented in Appendix C. Each figure presents the results of all four lithostratigraphic units studied in the stratigraphic coordinate system. From the diagrams, it is clear that bulk thermal conductivity is substantially less in the lithophysal zones (Tptpul, Tptpll) than in the nonlithophysal zones (Tptpmn, Tptpln), confirming the anticipated influence of lithophysae on thermal conductivity. Noting the change in scale between Figures 6-20 and 6-21, it is clear that bulk thermal conductivity depends on water saturation. There is some evidence of slightly lower values in the southern portions of the nonlithophysal zones, but the differences are not great.

Etype models inherently reproduce values at the location of measured data. However, these models generally do not reproduce the univariate statistical characteristics or spatial correlation of the same measured data. Averaging across replicate simulations creates a univariate distribution that is, for the most part, void of the tails in the underlying distributions and compressed towards the mean. Etype models also typically grade smoothly and continuously from one measured value to the next (in three dimensions). Thus, the spatial continuity of the Etype model is naturally much greater than that observed in the data themselves. This is the so-called smoothing effect that is typical of virtually all interpolation (in contrast to simulation) algorithms, including kriging, nearest-neighbor estimation, and inverse-distance-to-a-power weighting methods.

The spatial uncertainty of dry and wet bulk thermal conductivity is presented in Figures 6-22 and $6-23$, respectively. Interestingly, the uncertainty in the Etype model is slightly greater in the nonlithophysae zones than in the lithophysae zones. This indicates that the uncertainties in matrix thermal conductivity are, for the most part, controlling the uncertainty of bulk thermal conductivity. This conclusion is based on the observation that the standard deviation of bulk thermal conductivity is approximately the same $(0.25 \mathrm{~W} / \mathrm{mK})$ in both the lithophysae and the nonlithophysae zones (Table 6-6). Because the uncertainty in lithophysal porosity is lower in the nonlithophysae zones, one would expect the uncertainty in bulk thermal conductivity to be lower in the nonlithophysae zones as well. Since this is not the case, it may be concluded that uncertainty in lithophysal porosity does not play a significant role in the uncertainty estimate of bulk thermal conductivity. Furthermore, since the particular model of bulk thermal conductivity used in this report is only dependent on two uncertain inputs, lithophysal porosity and matrix thermal conductivity, the latter must be dominating to some extent. This conclusion may not be valid for other conceptual models of bulk thermal conductivity. 


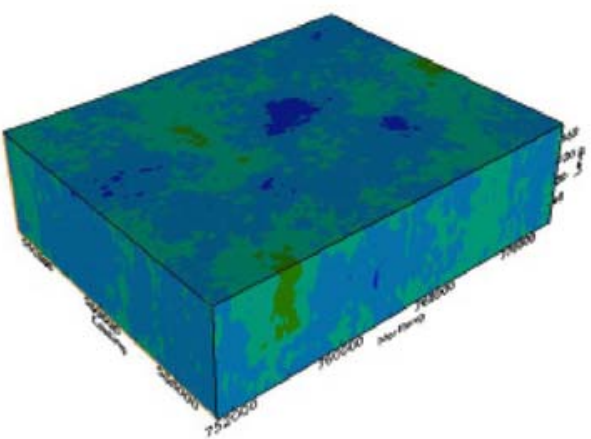

(a) Tptpul
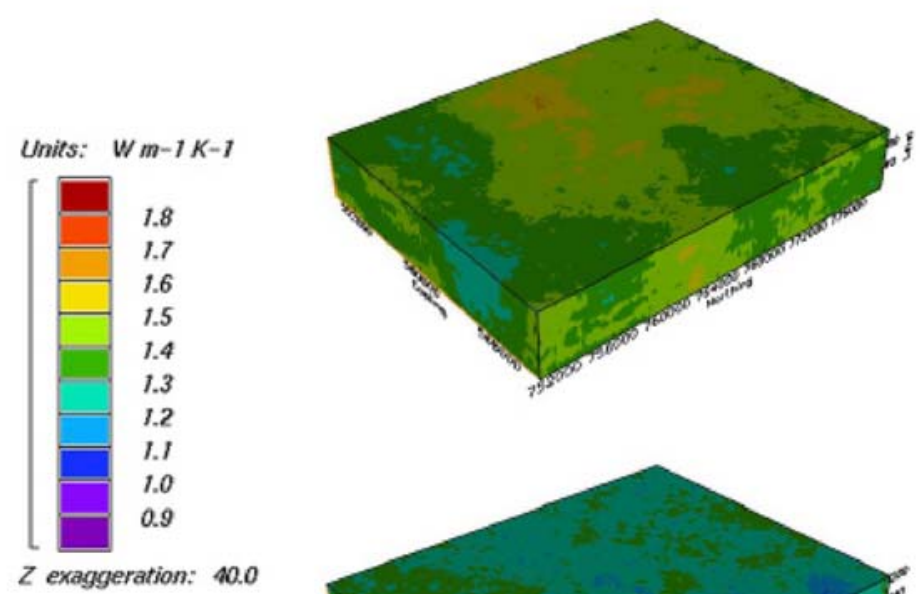

(b) Tptpmn

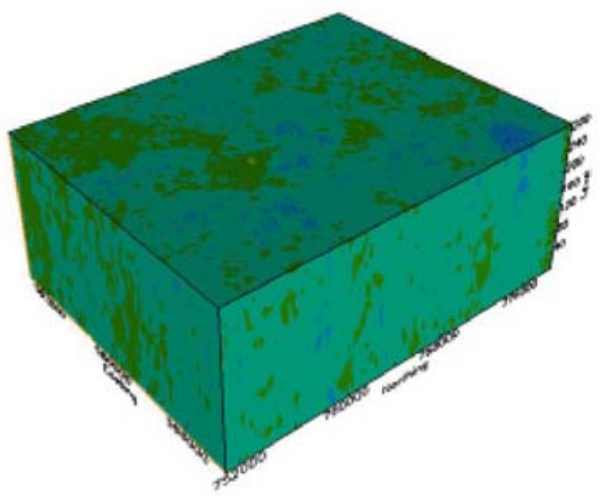

(c) Tptpll

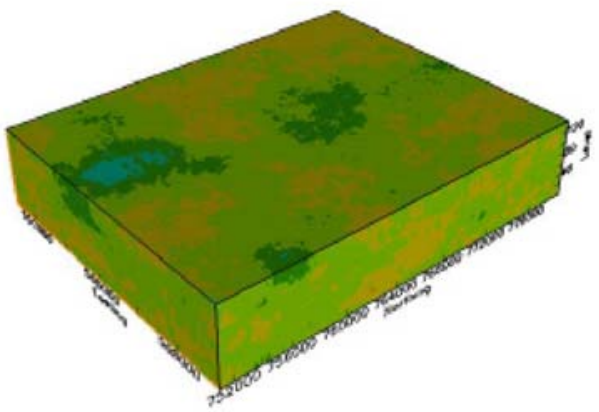

(d) Tptpln

Output DTN: SN0404T0503102.011 [DIRS 169129].

Figure 6-20. Expected Dry Bulk Thermal Conductivity (W/mK) 

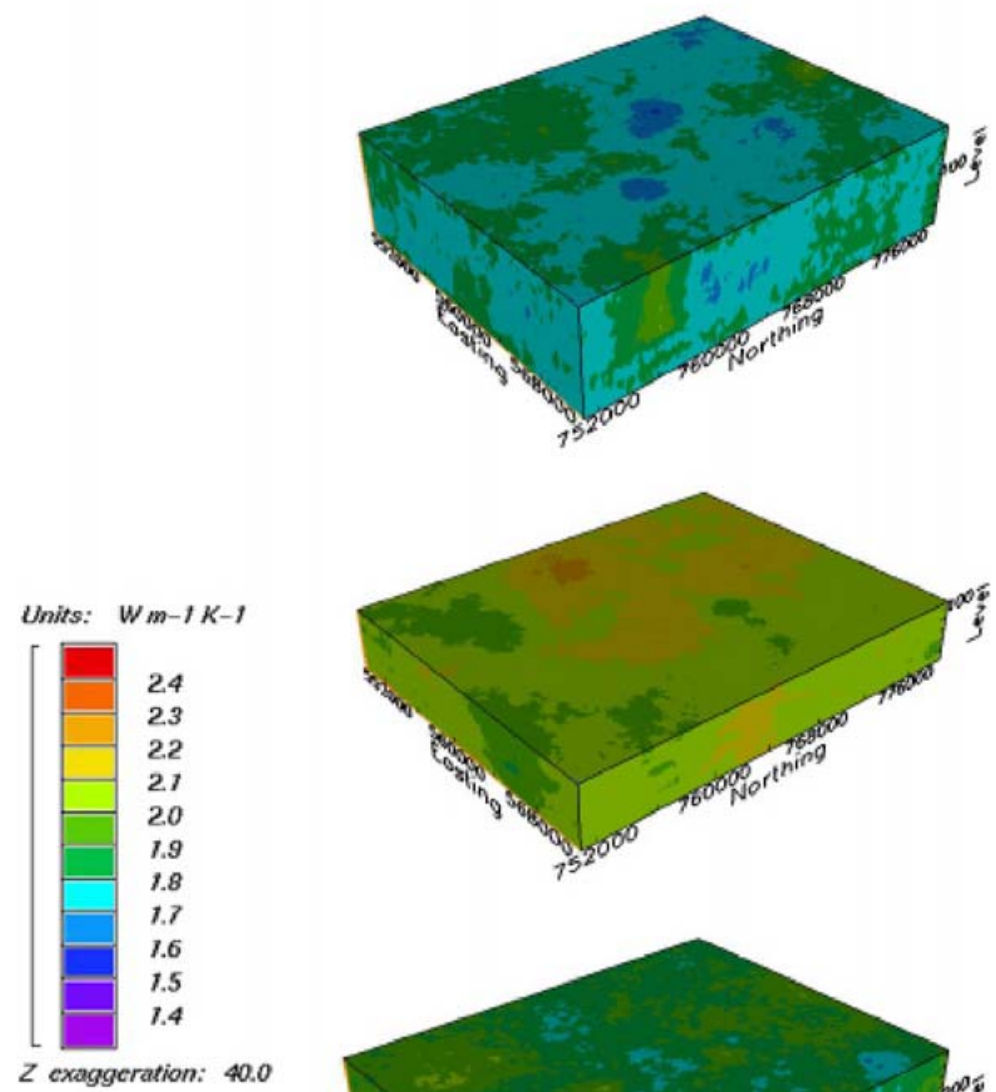

(a) Tptpul

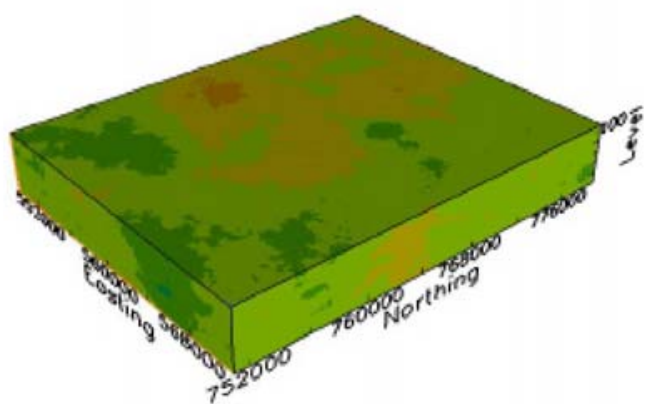

(b) Tptpmn

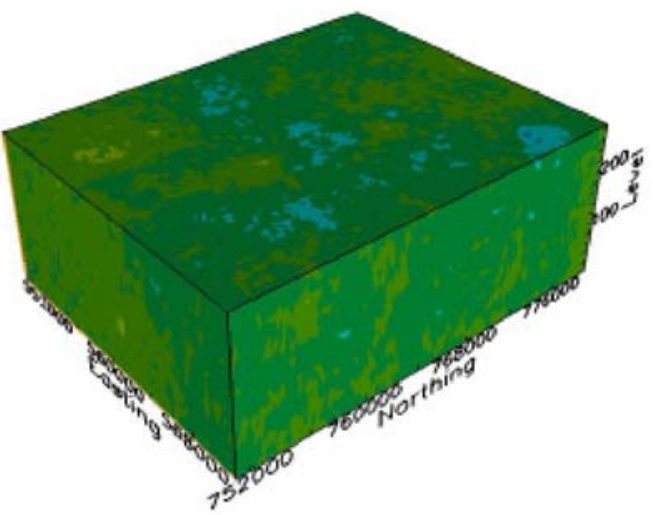

(c) Tptpll

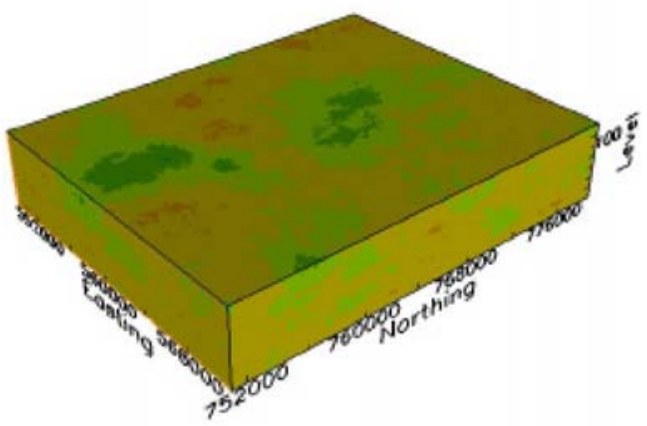

(d) Tptpln

Output DTN: SN0404T0503102.011 [DIRS 169129].

Figure 6-21. Expected Wet Bulk Thermal Conductivity (W/mK) 

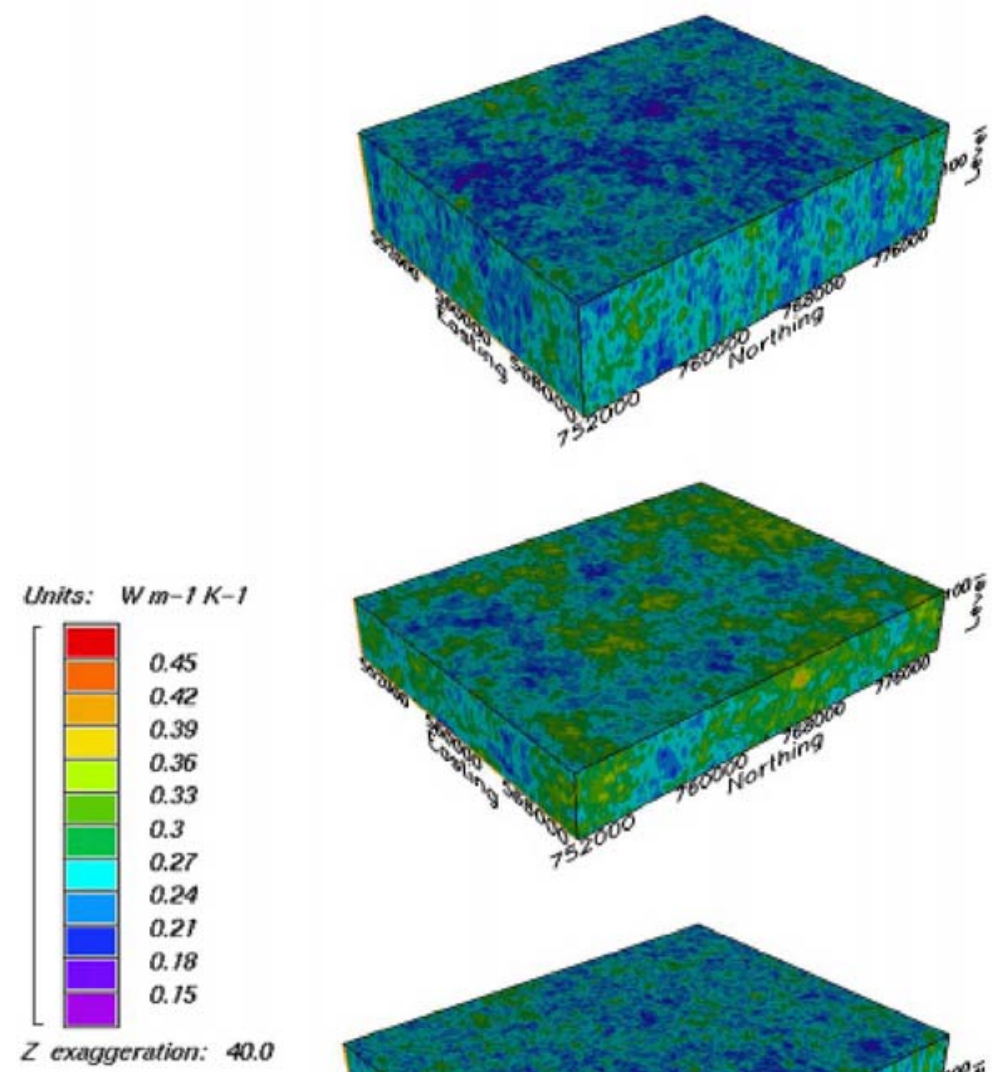

(a) Tptpul

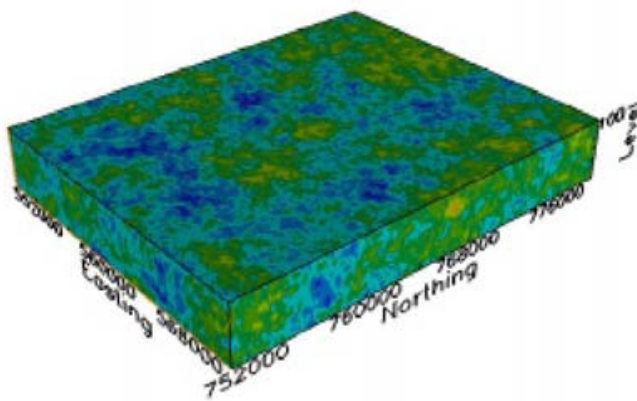

(b) Tptpmn

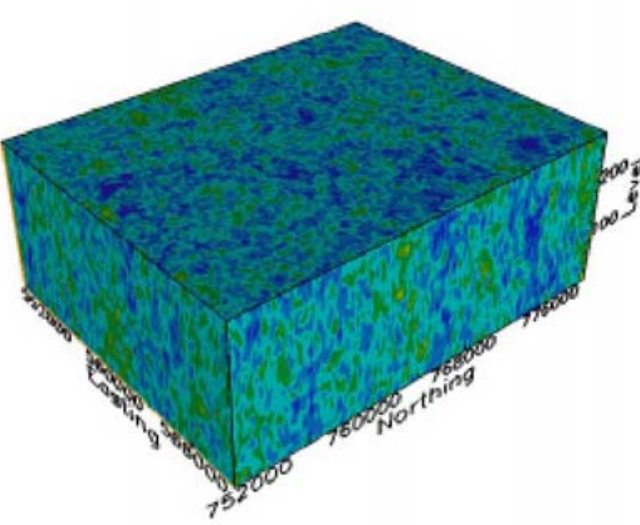

(c) Tptpll

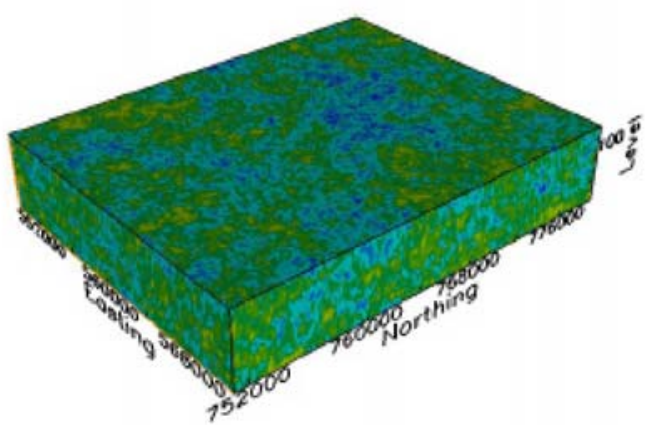

(d) Tptpln

Output DTN: SN0404T0503102.011 [DIRS 169129].

Figure 6-22. Standard Deviation Dry Bulk Thermal Conductivity (W/mK) 

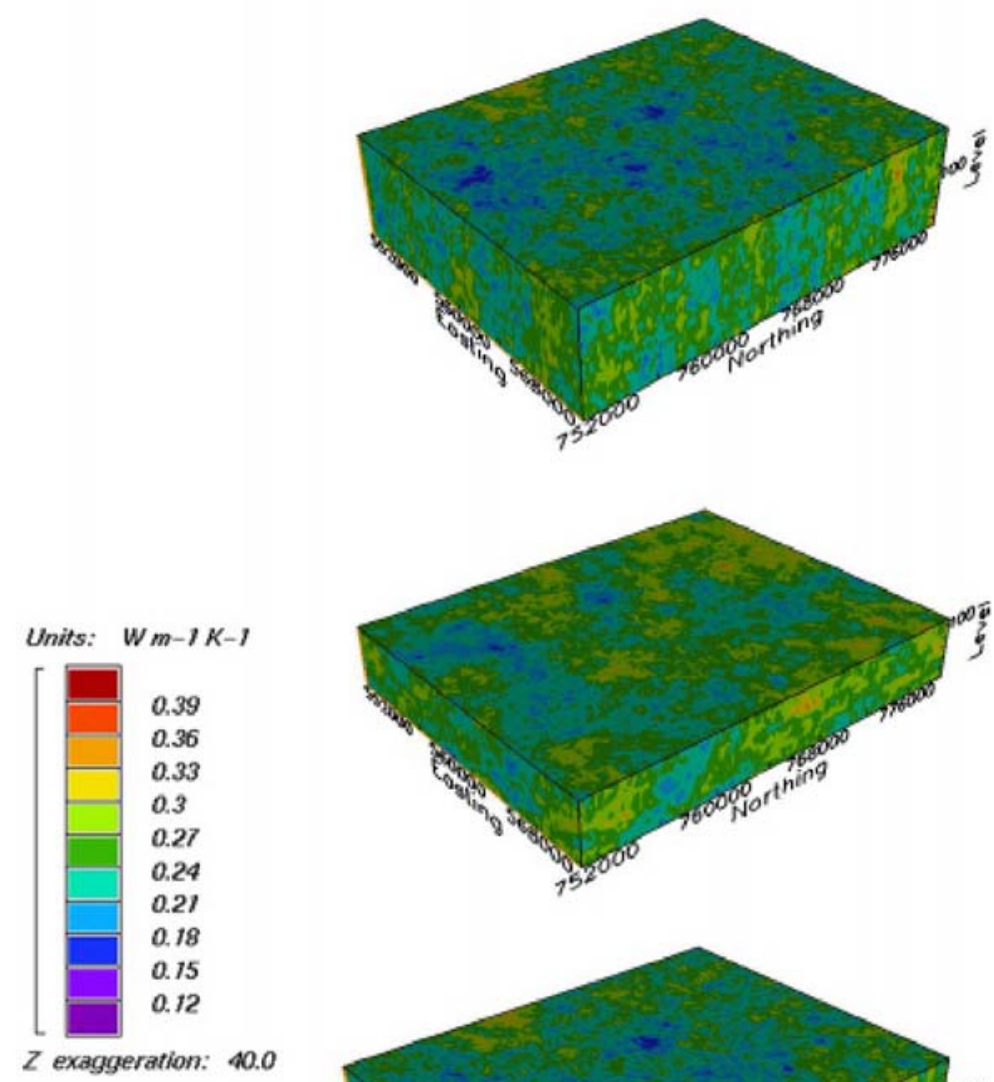

(a) Tptpul

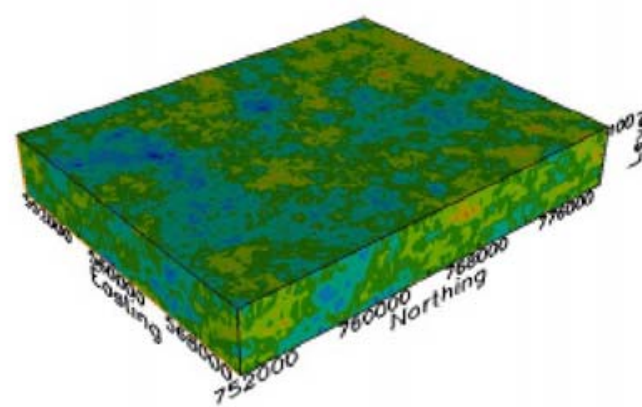

(b) Tptpmn

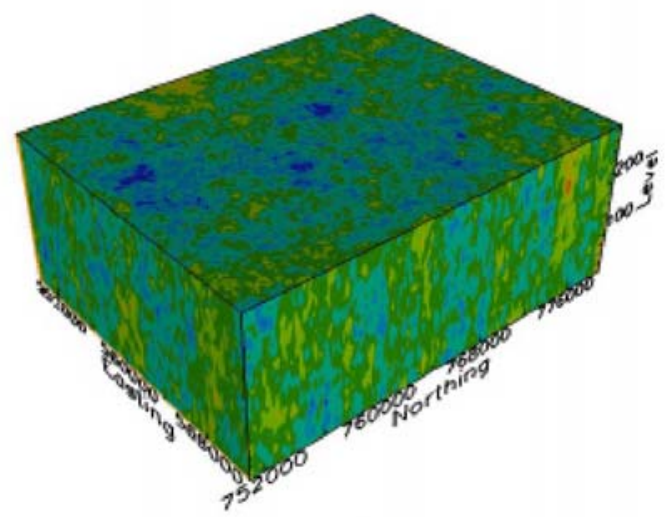

(c) Tptpll

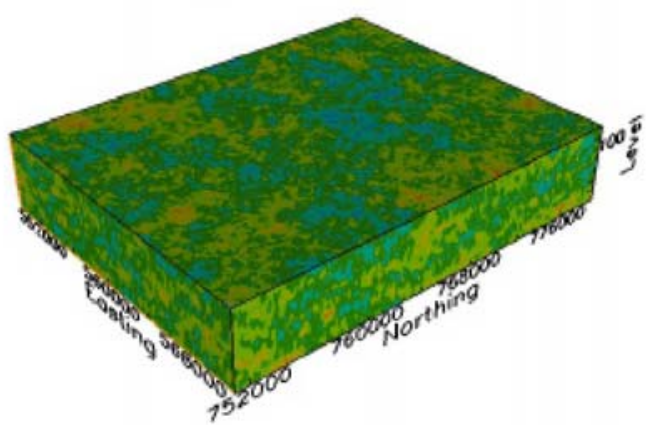

(d) Tptpln

Output DTN: SN0404T0503102.011 [DIRS 169129].

Figure 6-23. Standard Deviation Wet Bulk Thermal Conductivity (W/mK) 
Table 6-6. Summary of Primary Property Statistics

\begin{tabular}{|c|c|c|c|c|c|c|c|c|c|c|}
\hline \multirow[b]{2}{*}{$\begin{array}{c}\text { Stratigraphic } \\
\text { Unit }\end{array}$} & \multicolumn{2}{|c|}{$\begin{array}{c}\text { Dry Bulk Thermal } \\
\text { Conductivity } \\
{[\mathrm{W} /(\mathrm{m} \mathrm{K})]}\end{array}$} & \multicolumn{2}{|c|}{$\begin{array}{c}\text { Wet Bulk Thermal } \\
\text { Conductivity } \\
{[\mathrm{W} /(\mathrm{m} \mathrm{K})]}\end{array}$} & \multicolumn{2}{|c|}{$\begin{array}{c}\text { Dry Bulk Density } \\
\text { [g/cc] }\end{array}$} & \multicolumn{2}{|c|}{ Matrix Porosity } & \multicolumn{2}{|c|}{$\begin{array}{l}\text { Lithophysal } \\
\text { Porosity }\end{array}$} \\
\hline & mean & $\begin{array}{l}\text { std. } \\
\text { dev. }\end{array}$ & mean & $\begin{array}{l}\text { std. } \\
\text { Dev. }\end{array}$ & mean & $\begin{array}{l}\text { std. } \\
\text { dev. }\end{array}$ & mean & $\begin{array}{l}\text { std. } \\
\text { dev. }\end{array}$ & mean & $\begin{array}{l}\text { std. } \\
\text { dev. }\end{array}$ \\
\hline Tptpul & 1.1829 & 0.2440 & 1.7749 & 0.2474 & 1.8344 & 0.1496 & 0.1667 & 0.0412 & 0.1228 & 0.0613 \\
\hline Tptpmn & 1.4189 & 0.2654 & 2.0741 & 0.2517 & 2.1483 & 0.0932 & 0.1287 & 0.0323 & 0.0254 & 0.0225 \\
\hline Tptpll & 1.2784 & 0.2511 & 1.8895 & 0.2484 & 1.9793 & 0.1381 & 0.1486 & 0.0340 & 0.0883 & 0.0540 \\
\hline Tptpln & 1.4900 & 0.2844 & 2.1303 & 0.2676 & 2.2114 & 0.0857 & 0.1058 & 0.0264 & 0.0302 & 0.0253 \\
\hline
\end{tabular}

Output DTN: SN0404T0503102.011 [DIRS 169129].

NOTE: Standard deviations are calculated by averaging the standard deviations from realizations 15,30 , and 45. The standard deviation is a measure of the spatial variability of the data over the entire model region and should not be confused with the uncertainty in the mean values given in the table.

In the lithophysal zones there is some evidence of reduced uncertainty near the location of boreholes. However, there is little evidence of this in the nonlithophysal zones. A likely explanation is that the realizations of matrix thermal conductivity are largely unconditioned. Of the three spatially dependent inputs to the matrix thermal conductivity model, only matrix porosity is conditioned to field measurements. The other two matrix thermal conductivity parameters (solid thermal conductivity, $\mathrm{k}_{\mathrm{s}}$, and solid connectivity, $\gamma_{\mathrm{c}}$ ) are simulated unconditionally. In addition, the parameter distributions that characterize the latter two parameters are rather broad, demonstrating a high degree of model uncertainty (Section 6.1.7, Figure 6-11).

\subsubsection{Sample Realization}

Surface plots of parameters of interest are presented in Figures 6-24 through 6-30. Once again, the stratigraphic coordinate system is used. These plots are for realization number 15, which was selected only because it is one of three realizations that are analyzed further in the following section. It is important to recognize that the vertical axis has been exaggerated by a factor of 40 . This was done to illustrate heterogeneities oriented in the vertical plane. This distortion, however, gives the appearance of large vertical correlation lengths, which is simply not the case. This factor should be considered when viewing these diagrams.

Matrix porosity for realization 15 is presented in Figure 6-24. Matrix porosity tends to be higher in the lithophysal zones than in the nonlithophysal zones. This is presumably due to greater vapor phase alteration products in the lithophysal zones. Elevated matrix porosities are particularly apparent in the upper lithophysal zone, where lithophysal porosity also tends to be greatest.

Lithophysal porosity for realization 15 is presented in Figure 6-25. Both the middle and lower nonlithophysal zones have very low lithophysal porosity, with pockets of slightly elevated values. Lithophysal porosity is greatest in the upper portions of the upper lithophysal zone and 

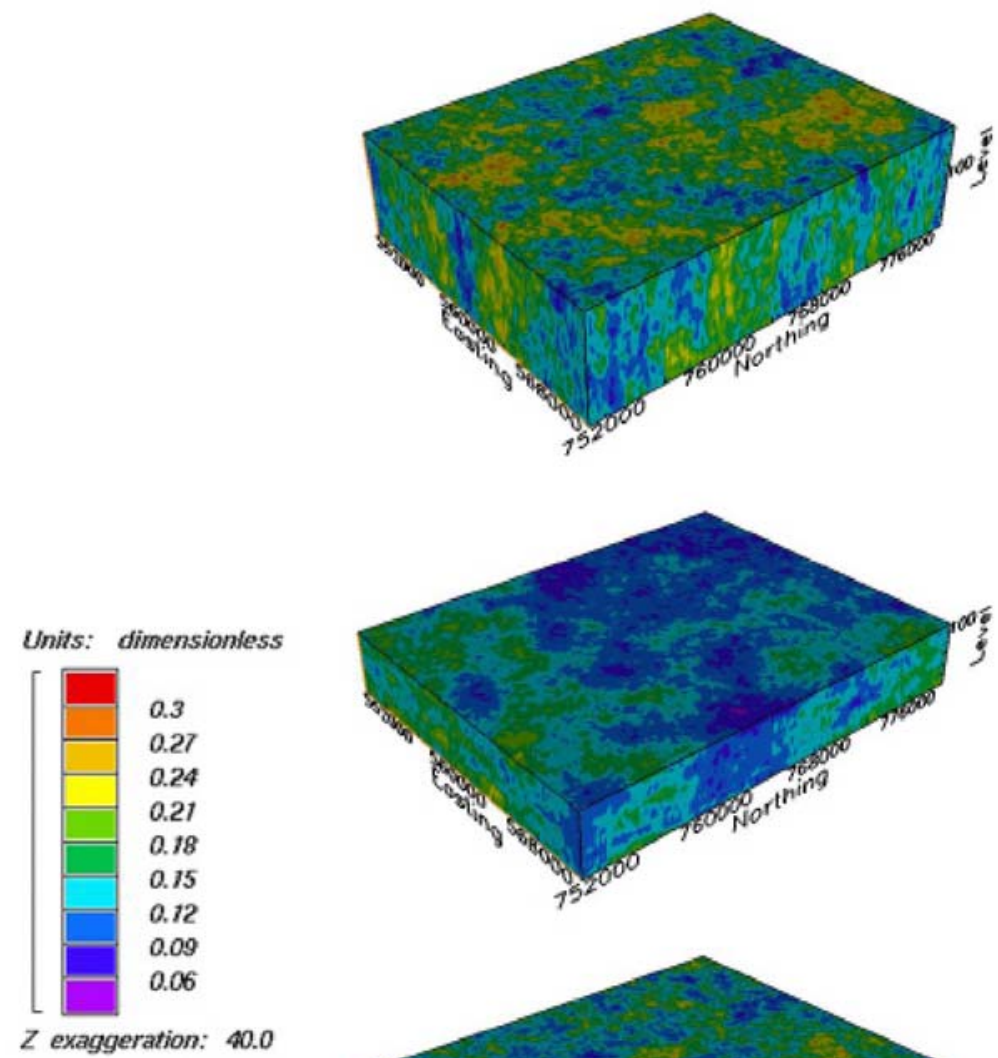

(a) Tptpul

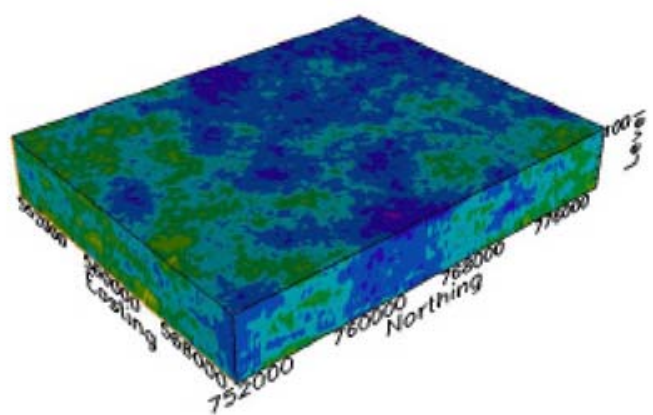

(b) Tptpmn

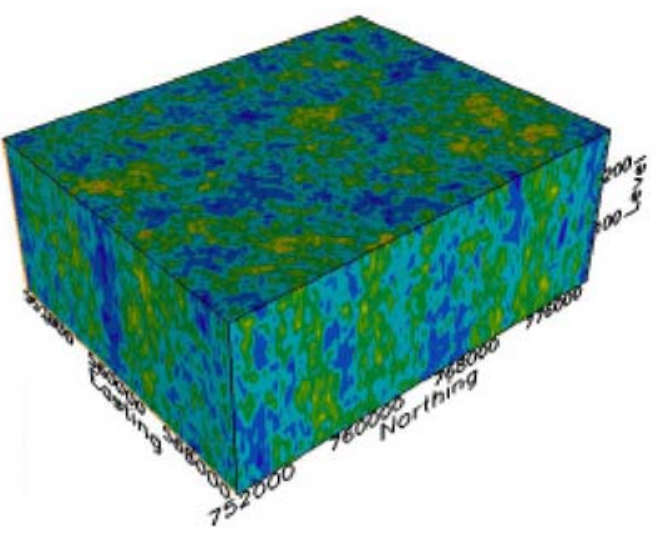

(c) Tptpll

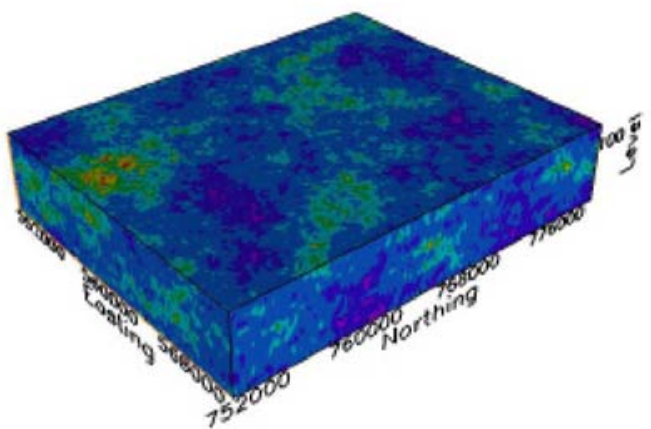

(d) Tptpln

Output DTN: SN0404T0503102.011 [DIRS 169129].

Figure 6-24. Matrix Porosity Realization 15 (Dimensionless) 


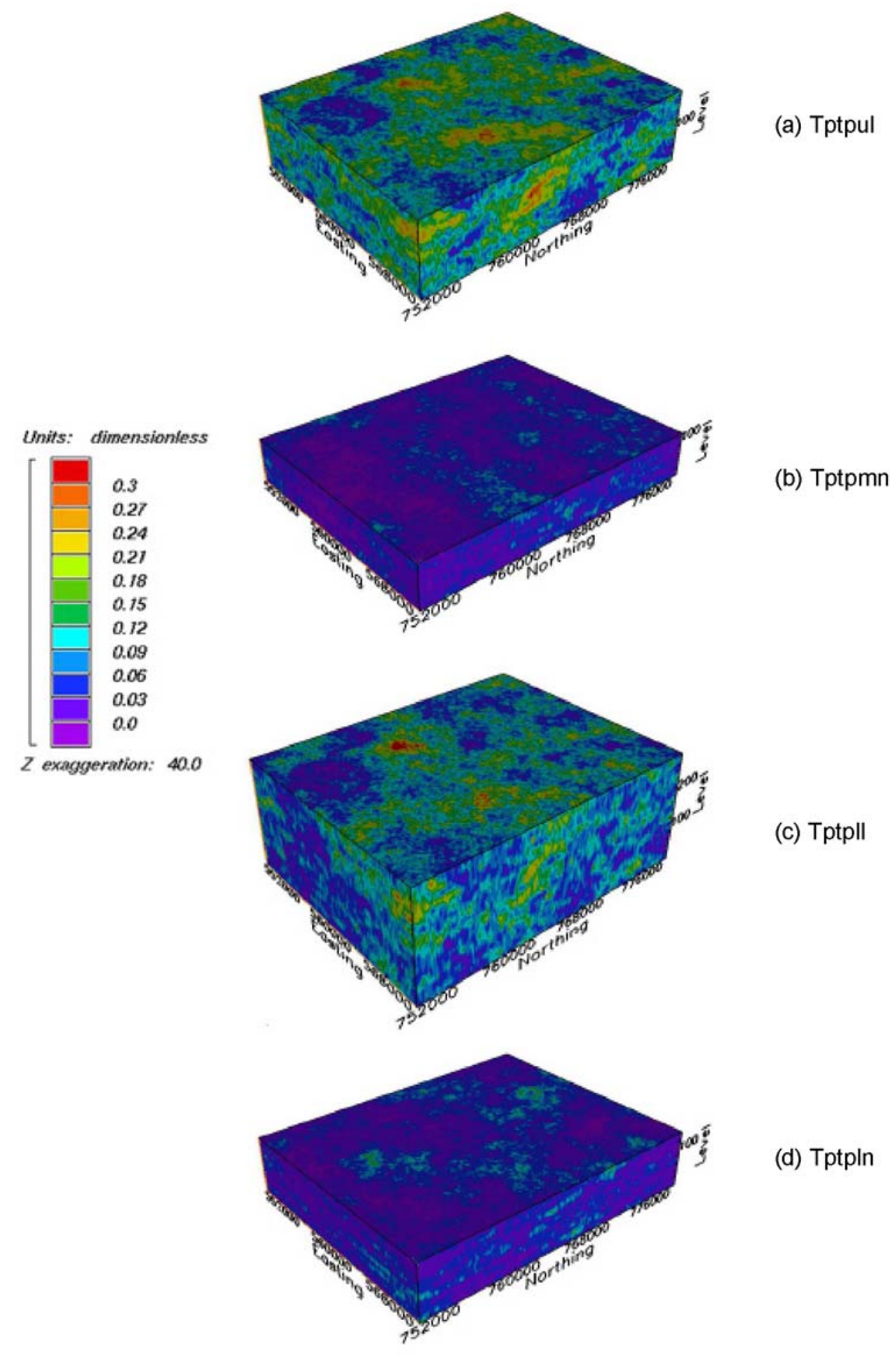

Output DTN: SN0404T0503102.011 [DIRS 169129].

Figure 6-25. Lithophysal Porosity Realization 15 (Dimensionless) 

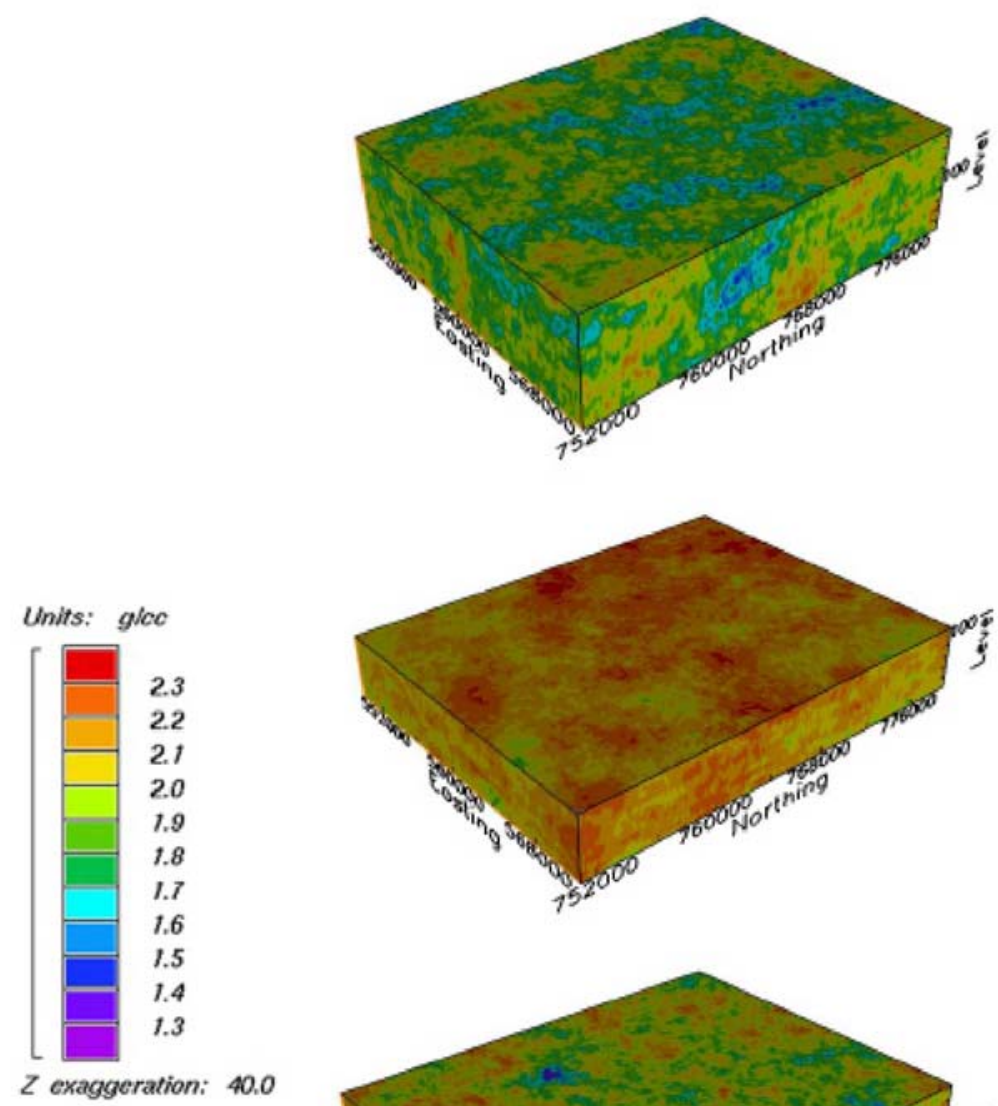

(a) Tptpul

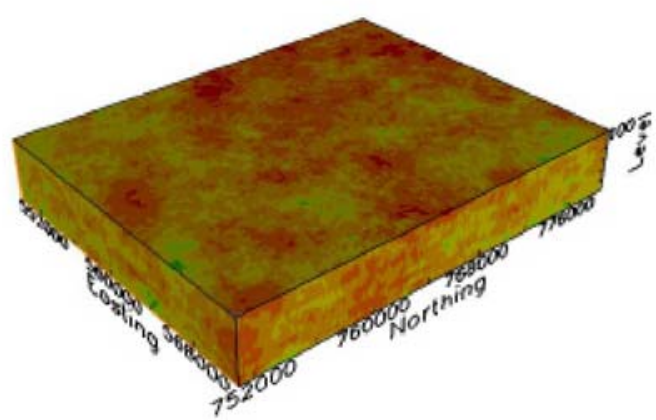

(b) Tptpmn

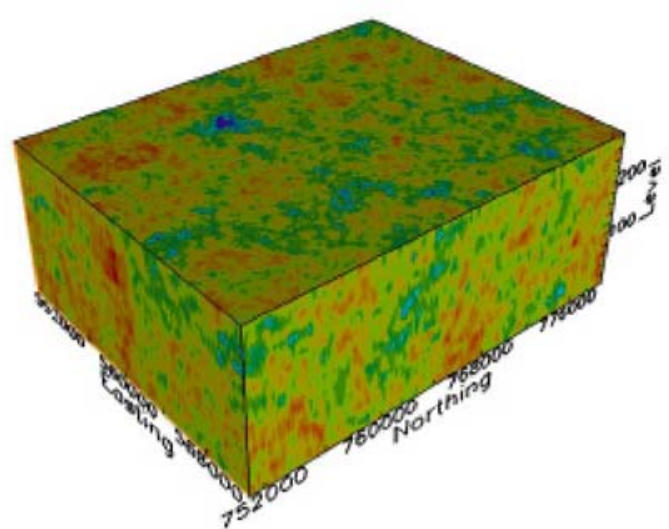

(c) Tptpll

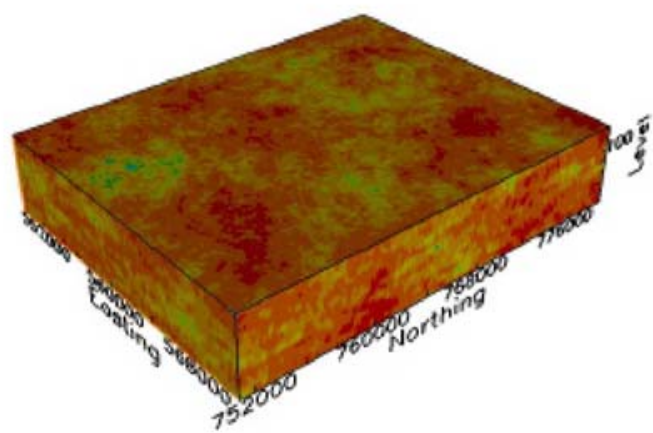

(d) Tptpln

Output DTN: SN0404T0503102.011 [DIRS 169129].

Figure 6-26. Dry Bulk Density Realization 15 (g/cc) 

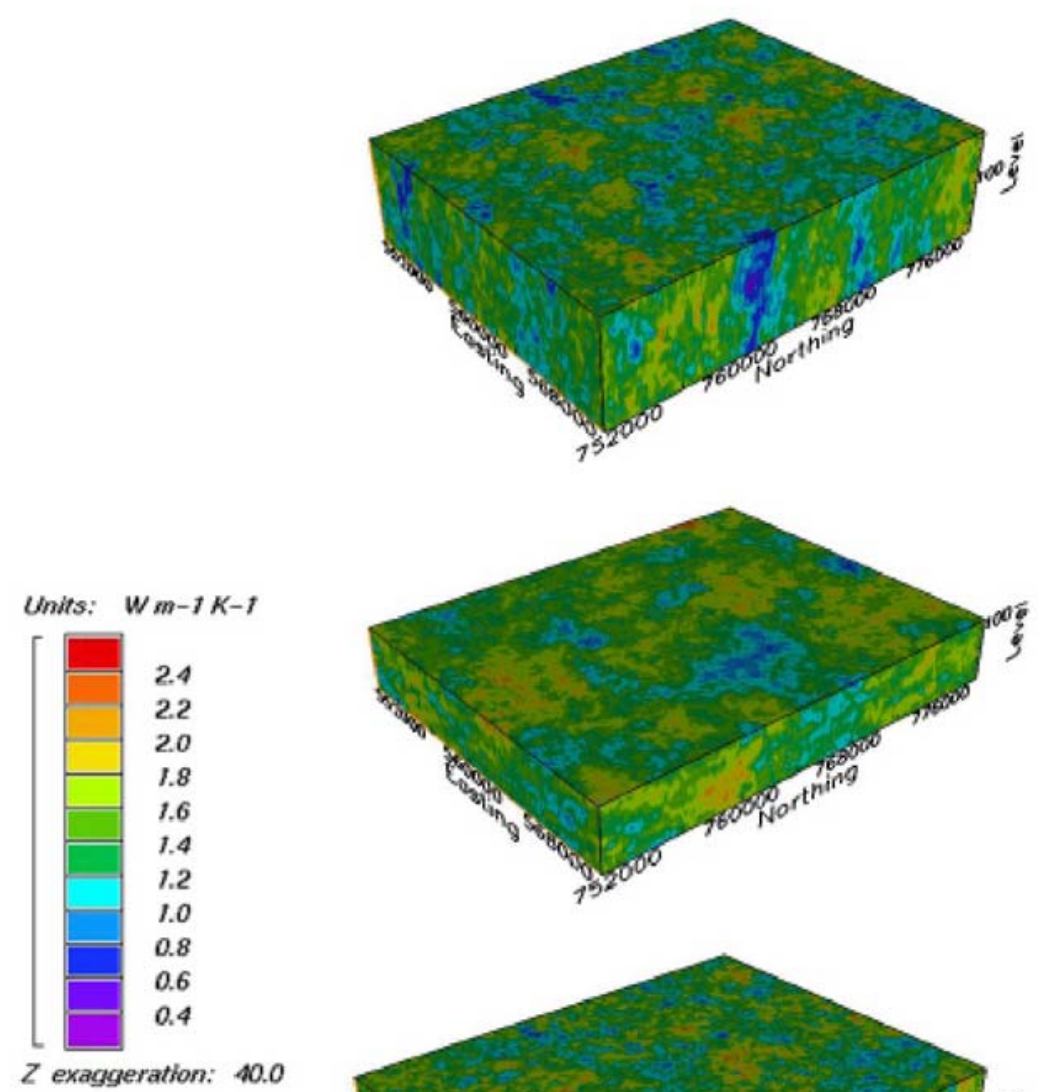

(a) Tptpul

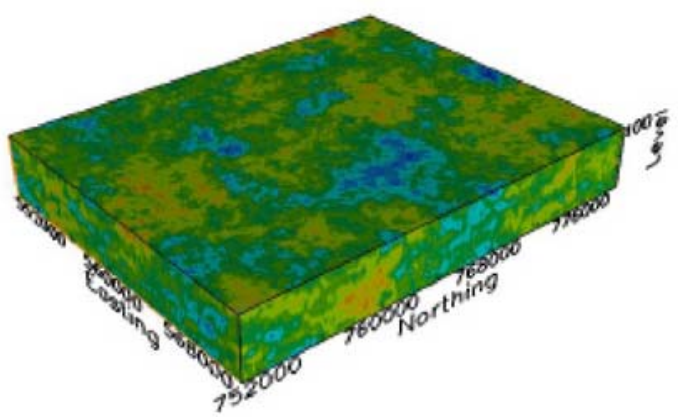

(b) Tptpmn

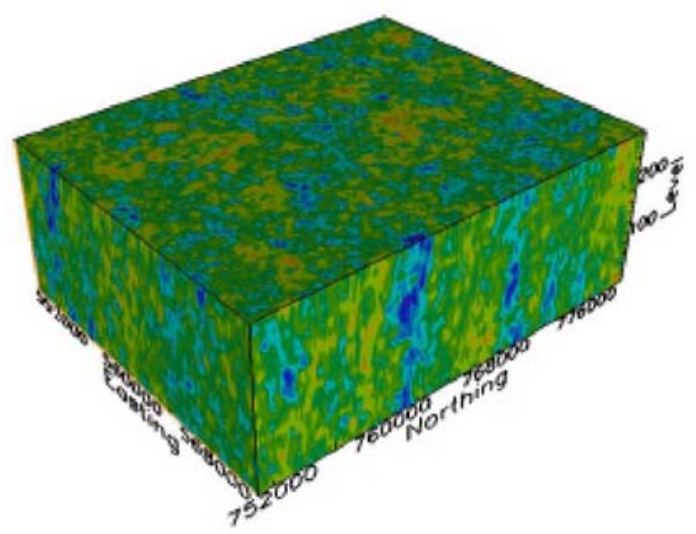

(c) Tptpll

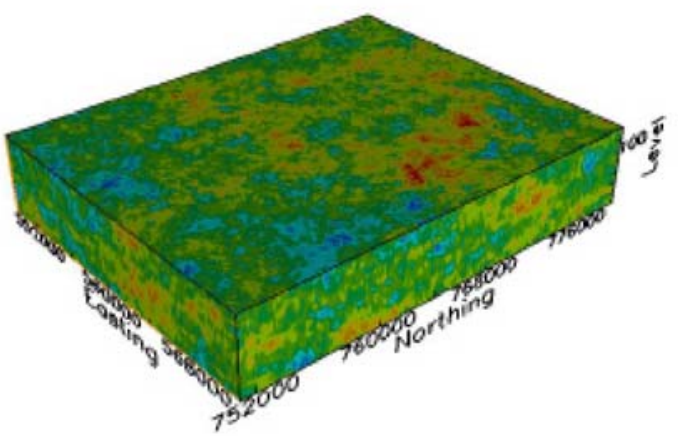

(d) Tptpln

Output DTN: SN0404T0503102.011 [DIRS 169129].

Figure 6-27. Dry Matrix Thermal Conductivity Realization 15 (W/mK) 

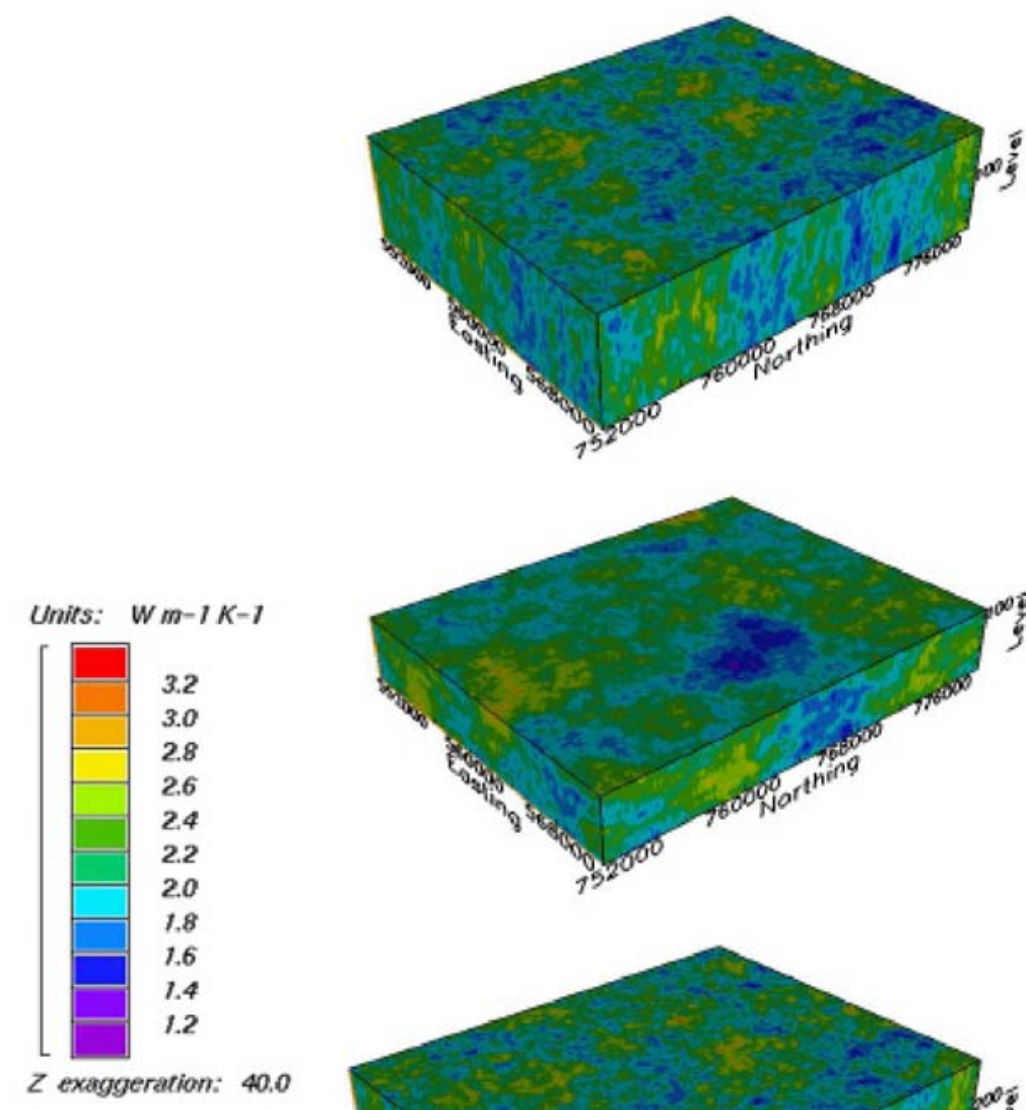

(a) Tptpul

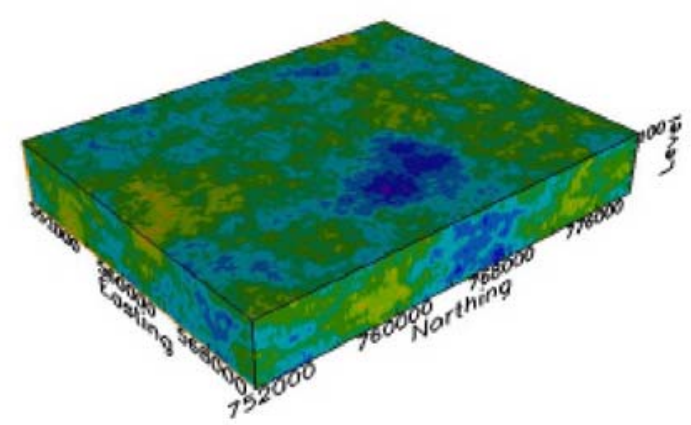

(b) Tptpmn

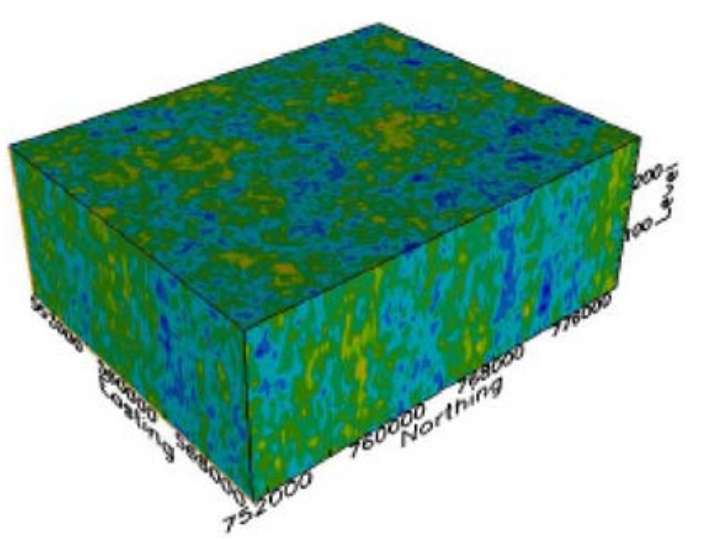

(c) Tptpll

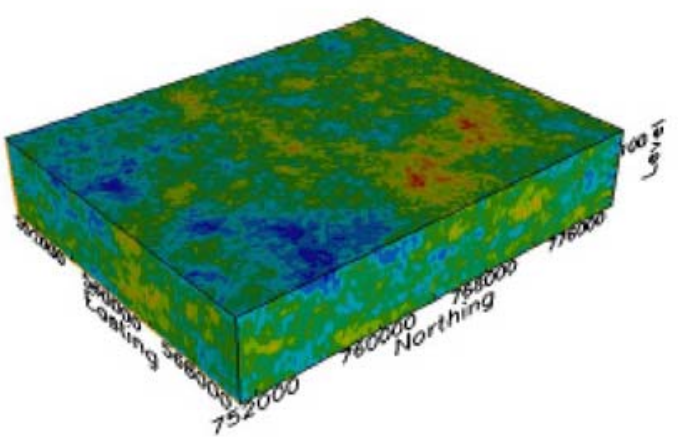

(d) Tptpln

Output DTN: SN0404T0503102.011 [DIRS 169129].

Figure 6-28. Wet Matrix Thermal Conductivity Realization 15 (W/mK) 

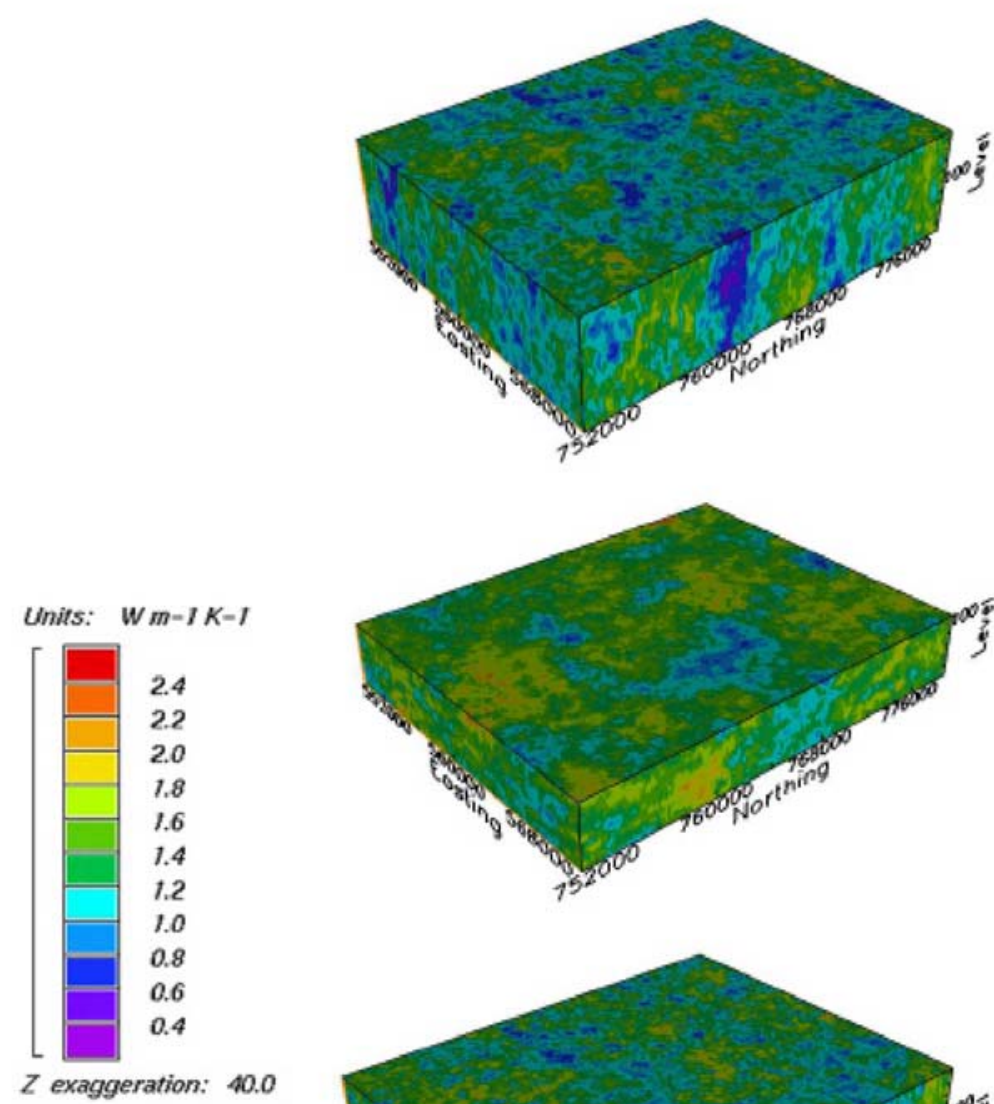

(a) Tptpul

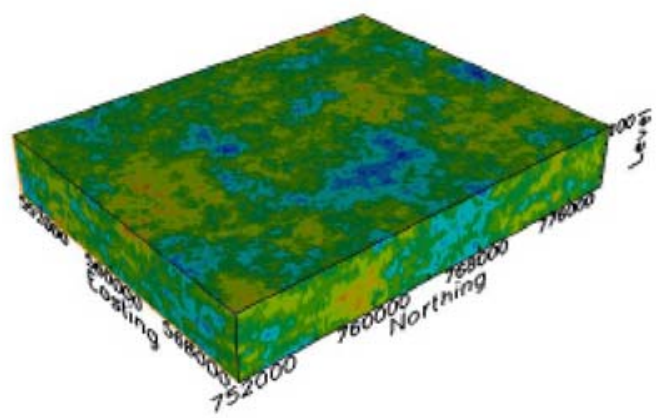

(b) Tptpmn

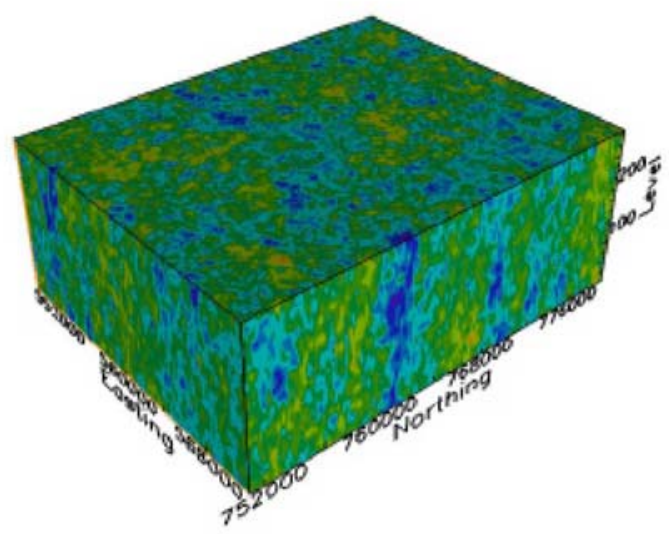

(c) Tptpll

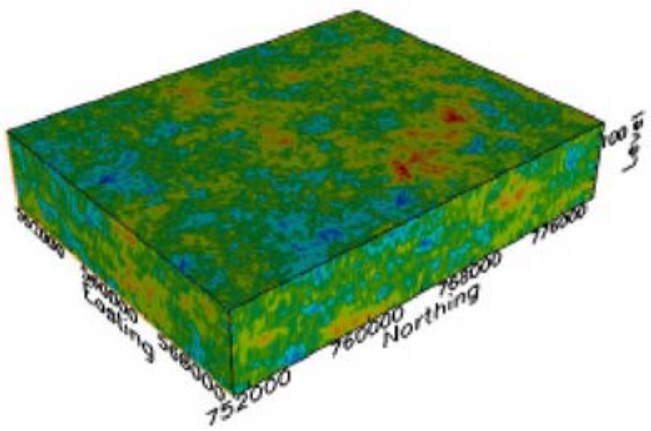

(d) Tptpln

Output DTN: SN0404T0503102.011 [DIRS 169129].

Figure 6-29. Dry Bulk Thermal Conductivity Realization 15 (W/mK) 

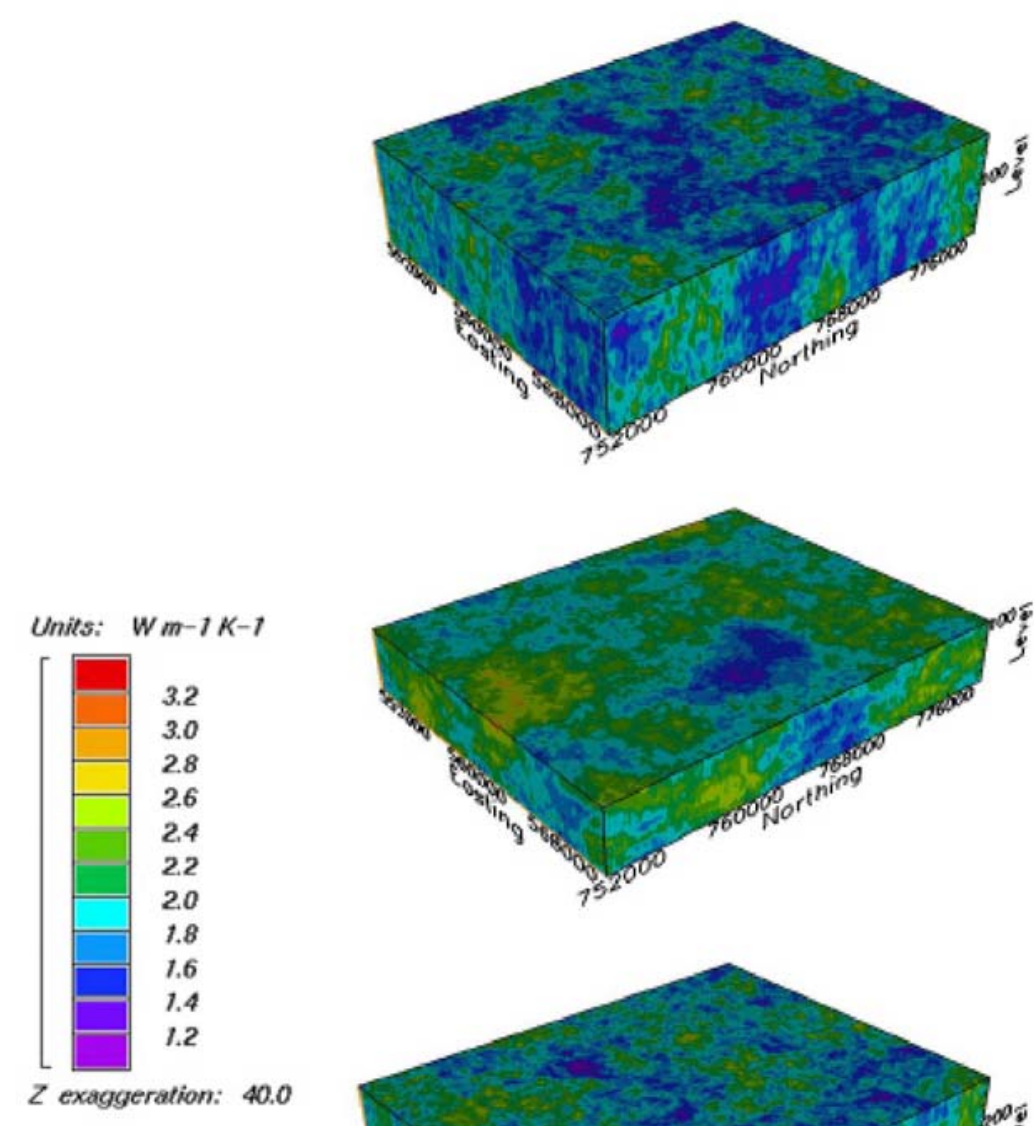

(a) Tptpul

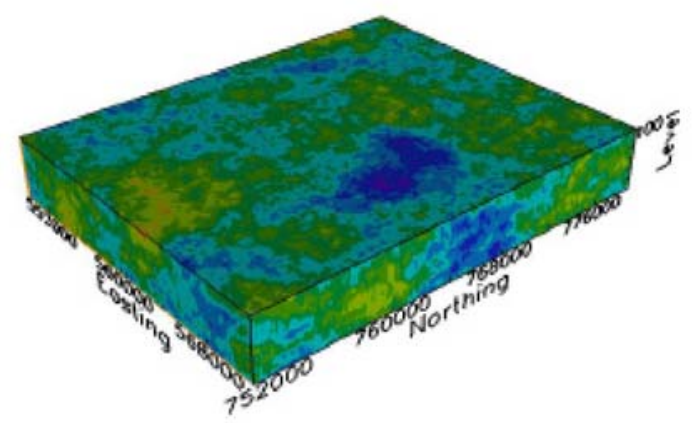

(b) Tptpmn

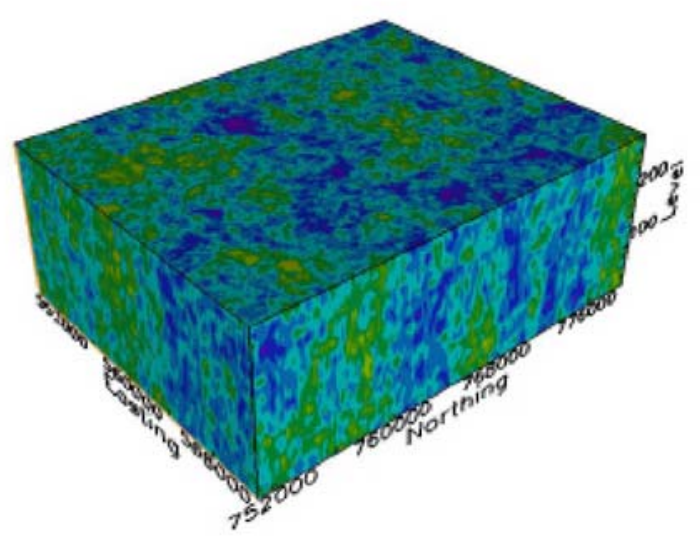

(c) Tptpll

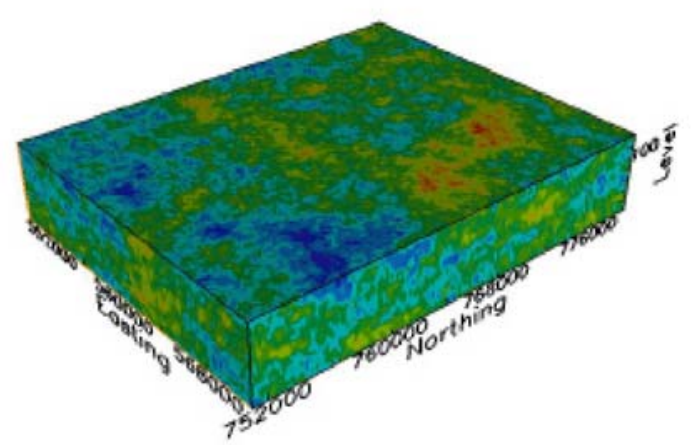

(d) Tptpln

Output DTN: SN0404T0503102.011 [DIRS 169129].

Figure 6-30. Wet Bulk Thermal Conductivity Realization 15 (W/mK) 
tends to decrease with depth. Smaller pockets of high lithophysal porosity are observed in the lower lithophysal zone and also tend to occur in the upper portions of the unit.

Dry bulk density for realization 15 is presented in Figure 6-26. Dry bulk density is inversely proportional to matrix and lithophysal porosity. Consequently, the lithophysal zones, which have the highest porosities, also have the lowest bulk densities. The lowest values are located in the upper lithophysal zone, and there is a strong inverse resemblance with the plot of lithophysal porosity discussed previously.

Dry and wet values of matrix thermal conductivity are presented in Figures 6-27 and 6-28, respectively. In the case of the dry model predictions, values of matrix thermal conductivity are slightly lower in the two lithophysal zones due to higher matrix porosity in these zones. This difference is not quite as apparent in the wet predictions, though, due to the similarity between the thermal conductivity of water and the minerals that compose the matrix solid (Section 6.1.7).

Finally, the realization 15 values of dry and wet bulk thermal conductivity are presented in Figures 6-29 and 6-30, respectively. These results are consistent with the discussion of the expected value results. It is important to notice the significant differences between the results of this individual realization and the expected value model depicted in Figures 6-20 and 6-21. In contrast to the relatively smooth and consistent values of the Etype model, the actual realizations depict much greater variability, often over relatively short distances. The Etype models are useful for identifying trends and regions of abnormal behavior. They are poor models, however, of the spatial heterogeneity and of the parameters' range and distribution.

\subsubsection{Summary Statistics}

Table 6-6 summarizes the mean and the standard deviation of the parameters most critical to thermal hydrologic modeling in each of the four units analyzed. Here the mean is taken as the mean value of the expected value model. This value represents the mean value of all 50 realizations. The standard deviation reported in Table 6-6 is the average standard deviation from realizations 15,30 , and 45 . The standard deviation represents a statistical measure of the spatial variability over the entire model domain (e.g. Tptpul). As seen in the histogram plots that follow (Section 6.2.4), the univariate statistical characteristics from one realization to the next are quite similar. Consequently, the average standard deviation of the three realizations is representative of the spatial variability for all realizations. The standard deviations given in Table 6-6 do not represent the uncertainty in the mean value for the parameter.

Similarly, Table 6-7 summarizes the mean and the standard deviation of intermediate model results. These values were obtained in the same manner as those of Table 6-6. As before, the standard deviation represents a statistical measure of the spatial variability over the entire model domain and does not represent the uncertainty in the mean value for the parameter. It should be noted that the statistical measures for the matrix thermal conductivity model parameters of $\gamma \mathrm{c}$ and ks are nearly identical in all four units. This was expected and is a consequence of assuming the same univariate parameter distribution (Figure 6-11) for all four units. Slight differences in matrix thermal conductivity between the units are a consequence of higher matrix porosity in the lithophysal units (Table 6-6). 
Table 6-7. Summary of Intermediate Property Statistics

\begin{tabular}{|l|c|c|c|c|c|c|c|c|}
\hline \multirow{2}{*}{$\begin{array}{c}\text { Stratigraphic } \\
\text { Unit }\end{array}$} & \multicolumn{2}{|c|}{ Solid Connectivity, $\gamma_{c}$} & \multicolumn{2}{c|}{$\begin{array}{c}\text { Solid Thermal } \\
\text { Conductivity W/mK }\end{array}$} & \multicolumn{2}{c|}{$\begin{array}{c}\text { Dry Matrix Thermal } \\
\text { Conductivity W/mK }\end{array}$} & \multicolumn{2}{c|}{$\begin{array}{c}\text { Wet Matrix Thermal } \\
\text { Conductivity W/mK }\end{array}$} \\
\cline { 2 - 10 } mean & std. dev. & mean & std. dev. & mean & std. dev. & mean & std. dev. \\
\hline Tptpul & 0.8517 & 0.1158 & 2.6011 & 0.3493 & 1.3453 & 0.2639 & 2.0201 & 0.2484 \\
\hline Tptpmn & 0.8476 & 0.1094 & 2.6033 & 0.3518 & 1.4553 & 0.2690 & 2.1276 & 0.2519 \\
\hline Tptpll & 0.8531 & 0.1130 & 2.6030 & 0.3413 & 1.3998 & 0.2640 & 2.0707 & 0.2455 \\
\hline Tptpln & 0.8492 & 0.1151 & 2.6017 & 0.3505 & 1.5356 & 0.2908 & 2.1958 & 0.2764 \\
\hline
\end{tabular}

Output DTN: SN0404T0503102.011 [DIRS 169129].

NOTE: Standard deviations are calculated by averaging the standard deviations from realizations 15,30 , and 45 . The standard deviation is a measure of the spatial variability of the data over the entire model region and should not be confused with the uncertainty in the mean values given in the table.

\subsubsection{Summary Histograms}

Histogram plots for three of the 50 realizations and histogram plots of the expected value model for each of the four lithostratigraphic units are shown in Figures 6-31 through 6-54. Each figure shows the histograms for three realizations plus the Etype result. Realizations 15, 30, and 45 were chosen for this analysis simply because they are each a multiple of the number 15 . They are statistically indistinguishable from the other realizations. The first nine of these plots (Figures 6-31 through 6-39) present the complete set of spatially dependent properties studied for the Tptpul. These are followed by the five more important properties, summarized in Table 6-6, for each of the three remaining lithostratigraphic units. Note the difference between the realization and Etype histograms; the parameter histogram represents the spatial variability of the parameter over the model domain, while the Etype histogram represents the spatial variability of the expected value of the parameter over the model domain The range of expected values from the Etype model is much smaller than the range from the realization histogram. 
3
$\vdots$
2
0
01
1
0
1
8
8
0
0
0
2
1
2
0
0

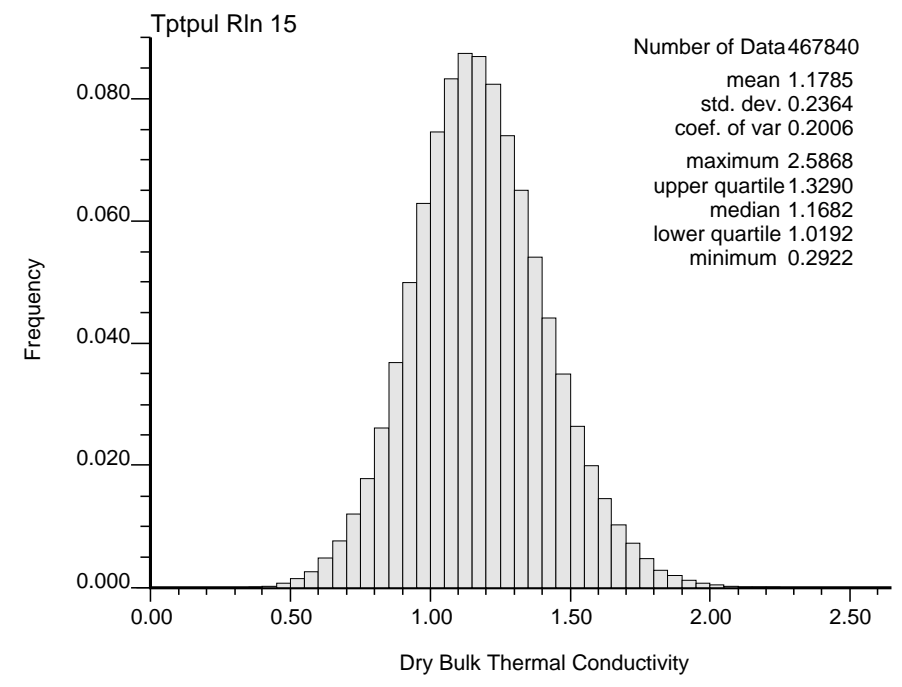

ڤั

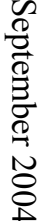

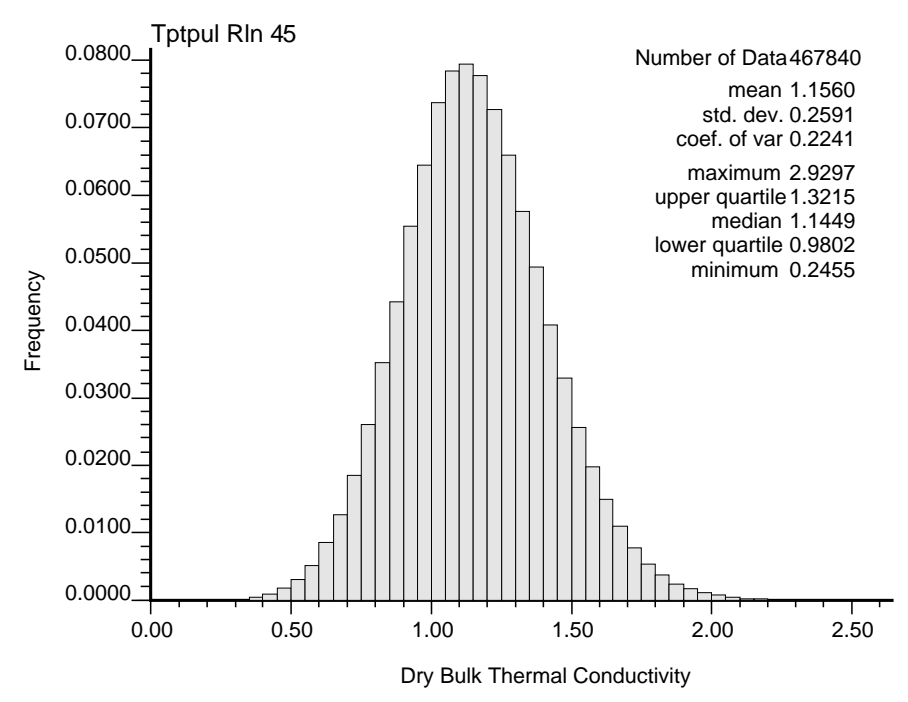

Output DTN: SN0404T0503102.011 [DIRS 169129].
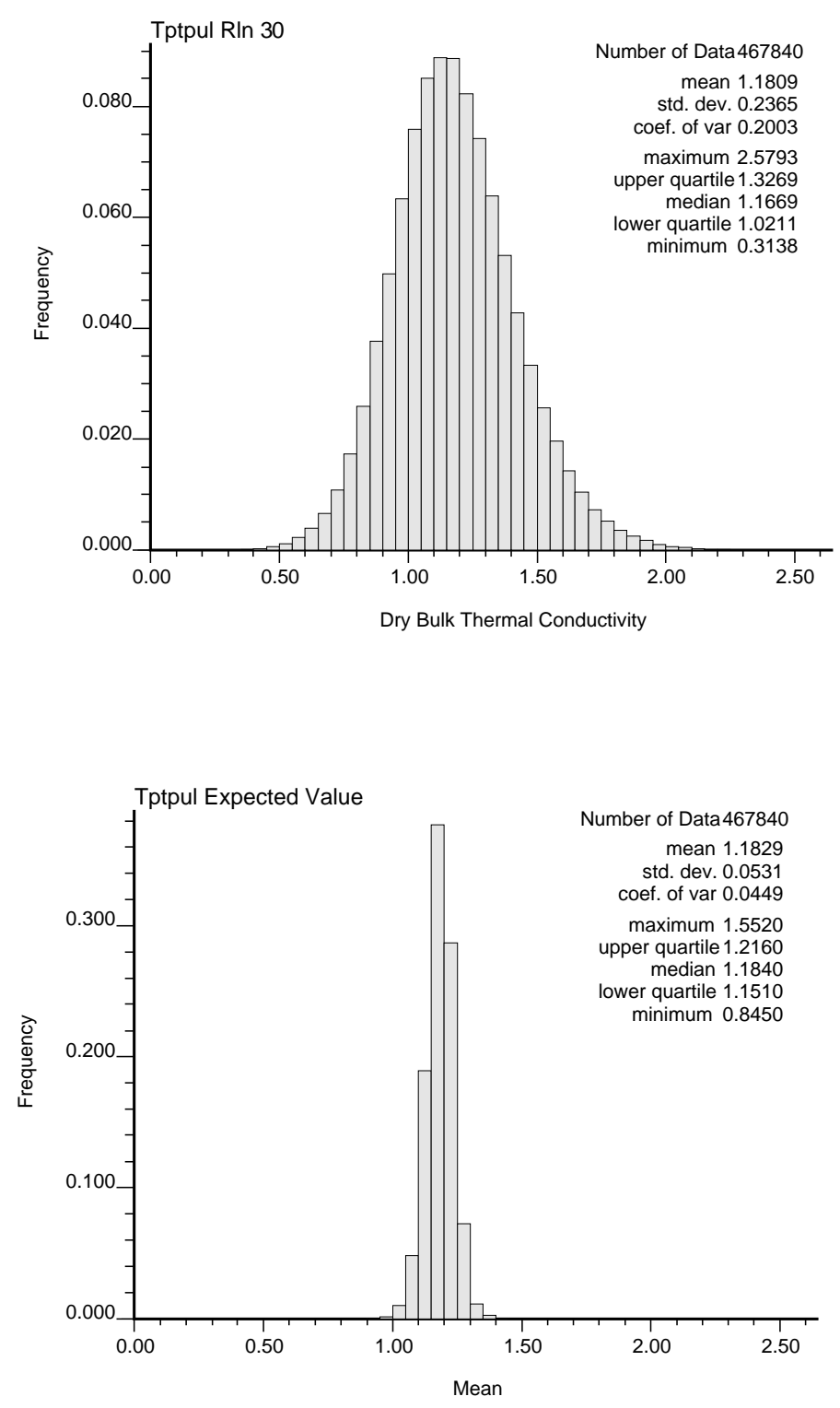

Figure 6-31. Dry Bulk Thermal Conductivity $(\mathrm{W} / \mathrm{mK})$ in the Tptpul 

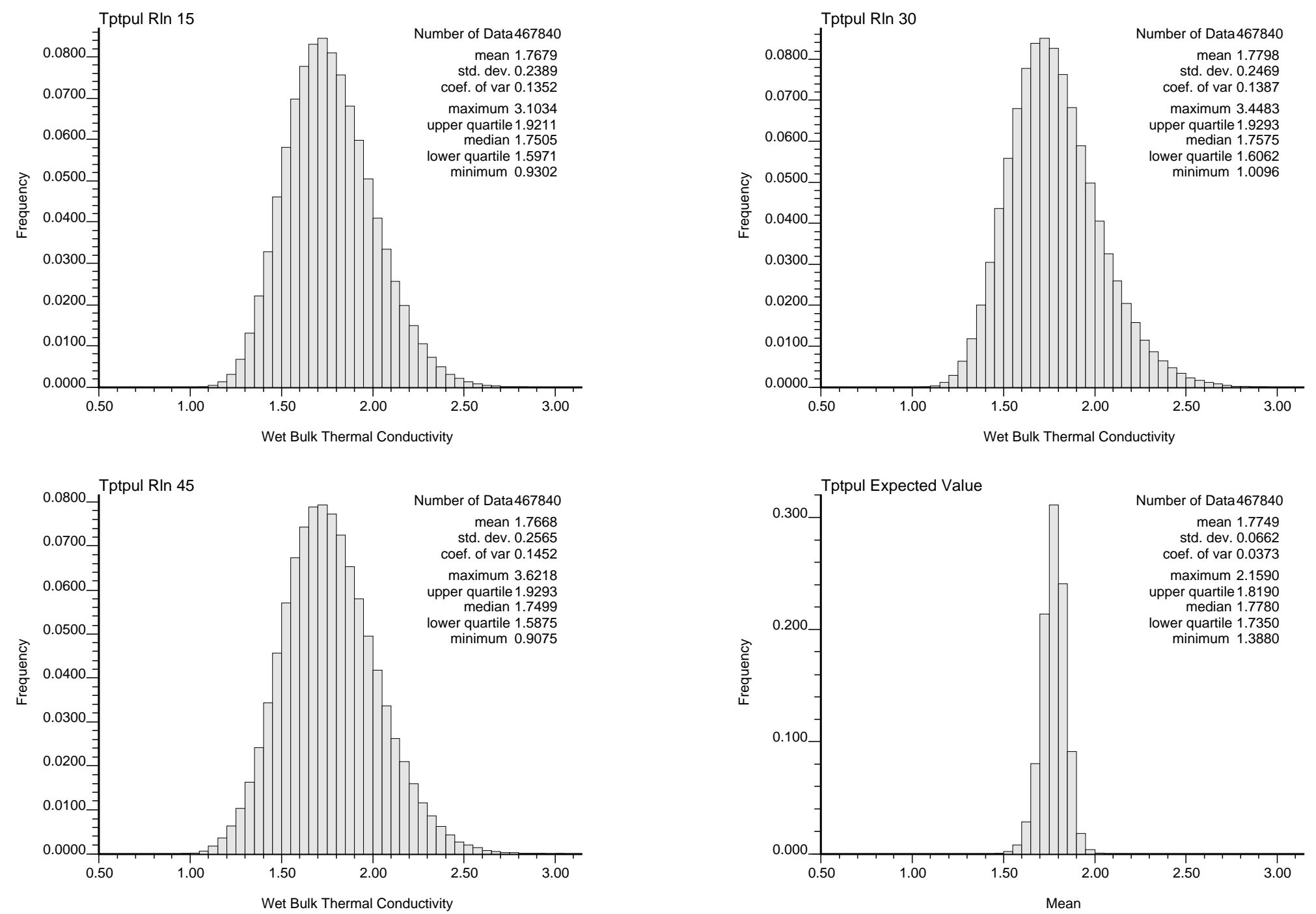

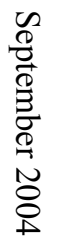

\section{Output DTN: SN0404T0503102.011 [DIRS 169129].}

Figure 6-32. Wet Bulk Thermal Conductivity (W/mK) in the Tptpul 

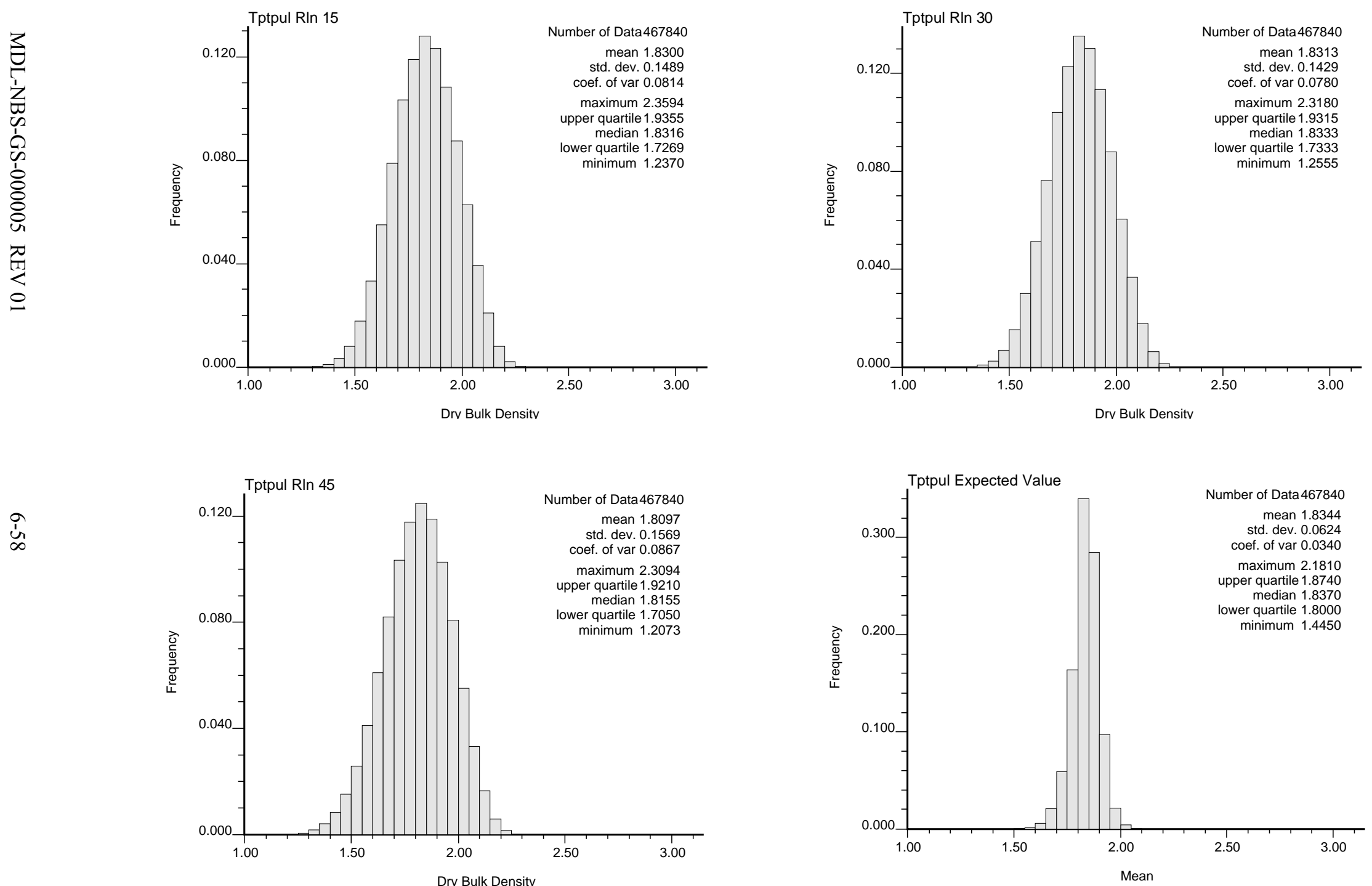

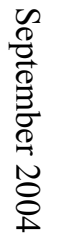

Output DTN: SN0404T0503102.011 [DIRS 169129].

Figure 6-33. Dry Bulk Density ( $/ / c c)$ in the Tptpul 

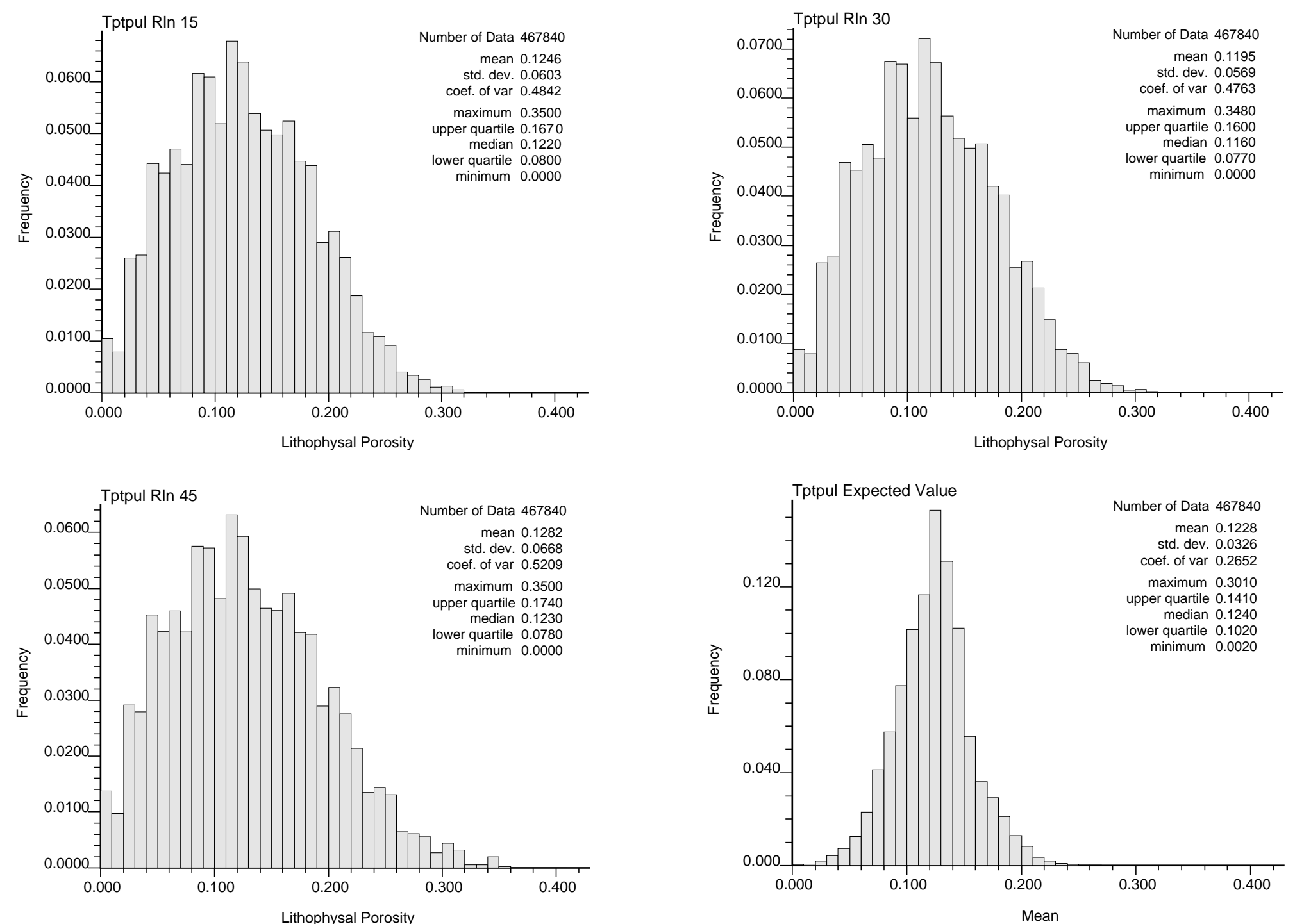

0
0
$\frac{8}{0}$
0
0
0
0
0
0
1

Figure 6-34. Lithophysal Porosity in the Tptpul 

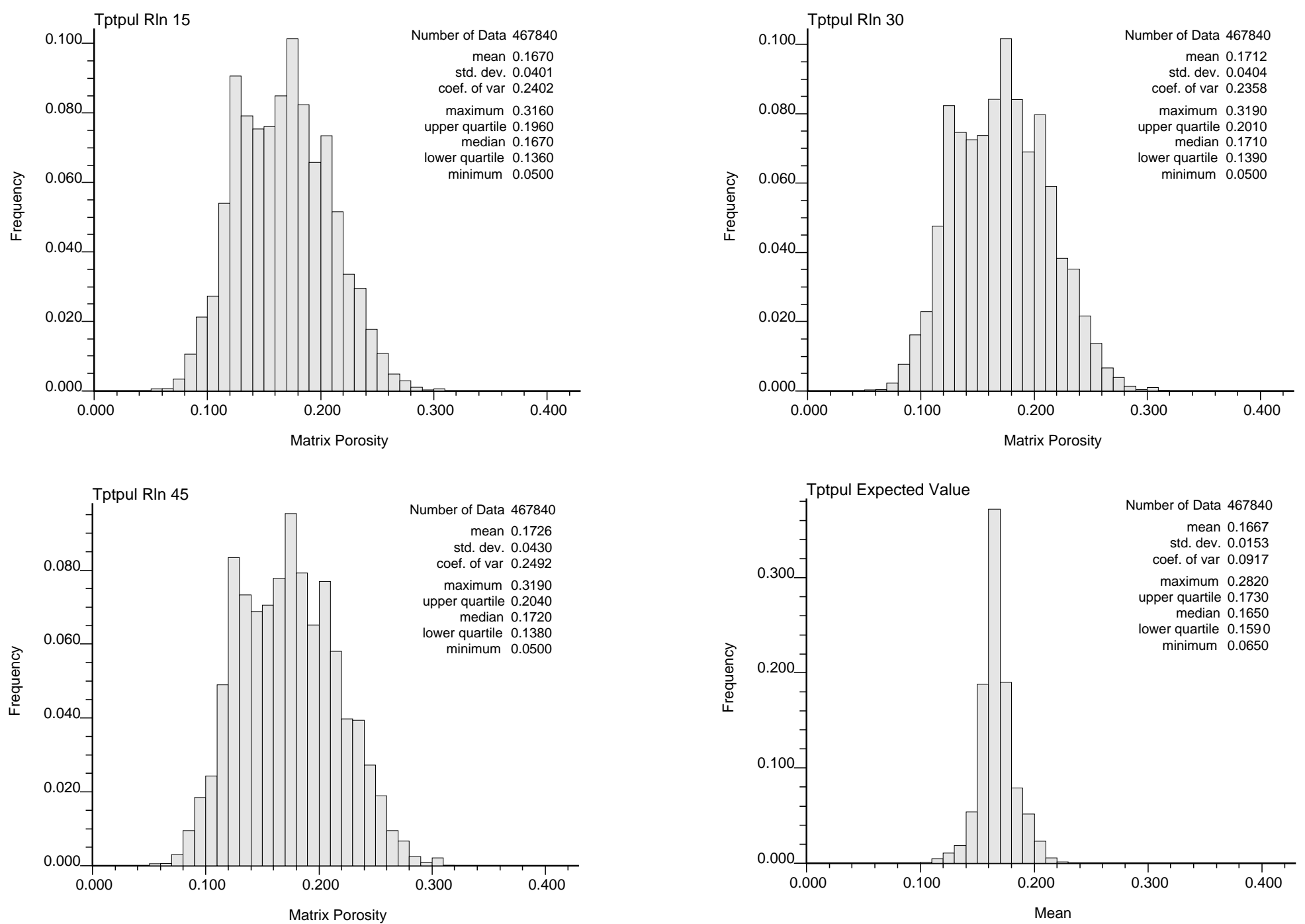

Figure 6-35. Matrix Porosity in the Tptpul 

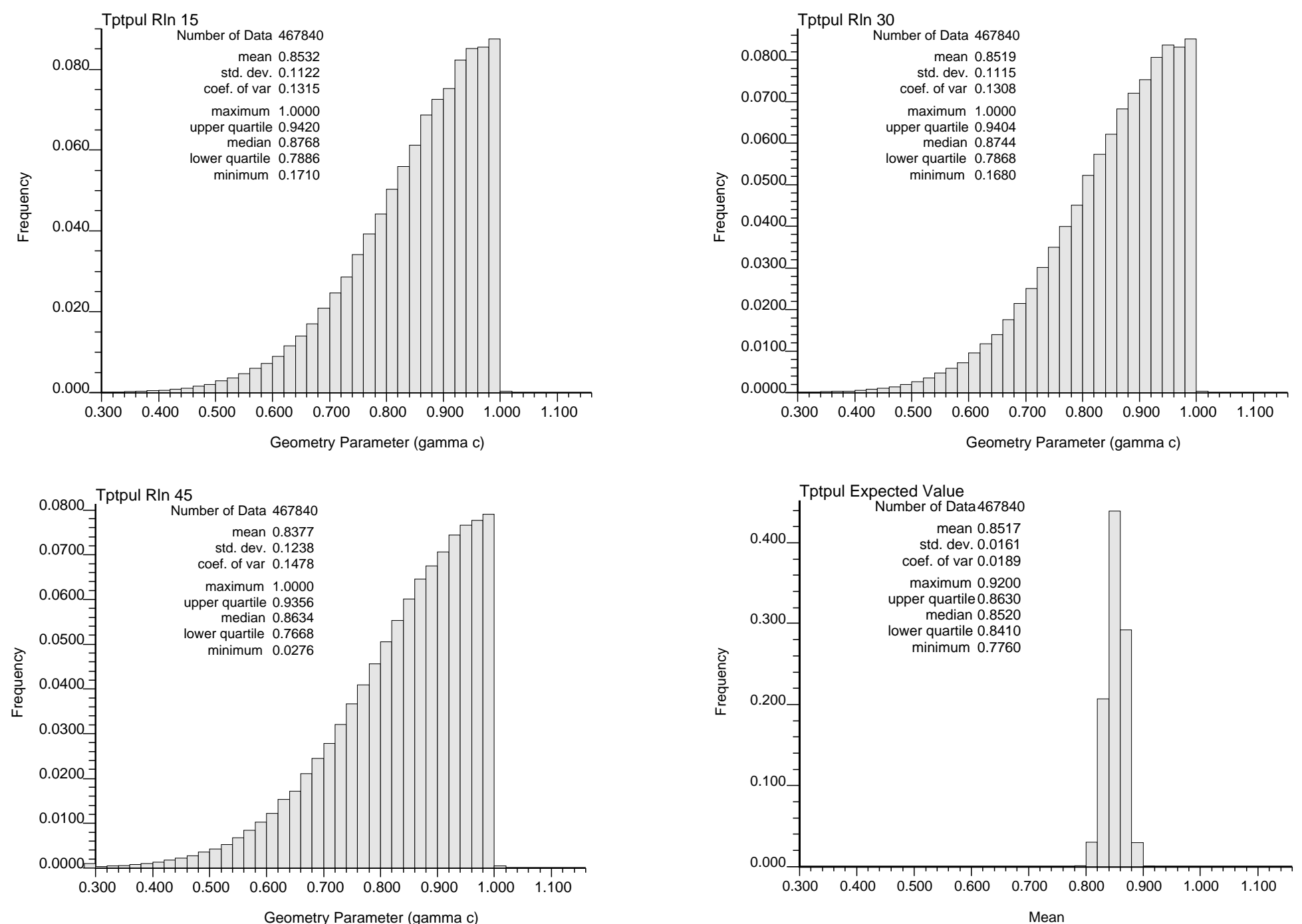

Output DTN: SN0404T0503102.011 [DIRS 169129].

Figure 6-36. Solid Connectivity in the Tptpul, $\gamma_{c}$ 

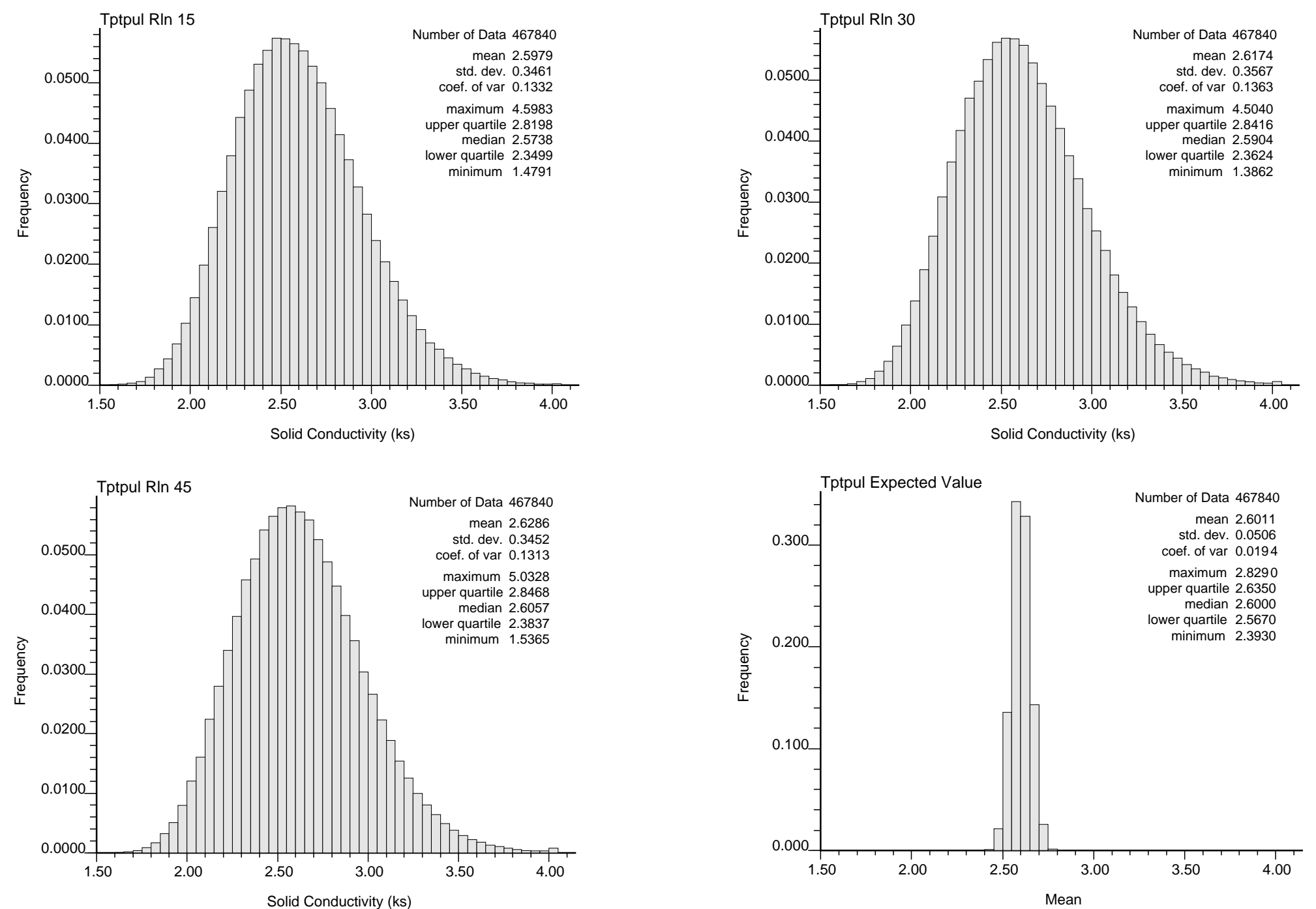

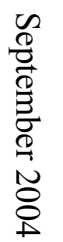

Figure 6-37. Solid Conductivity in the Tptpul, $\mathrm{k}_{\mathrm{s}}$ 

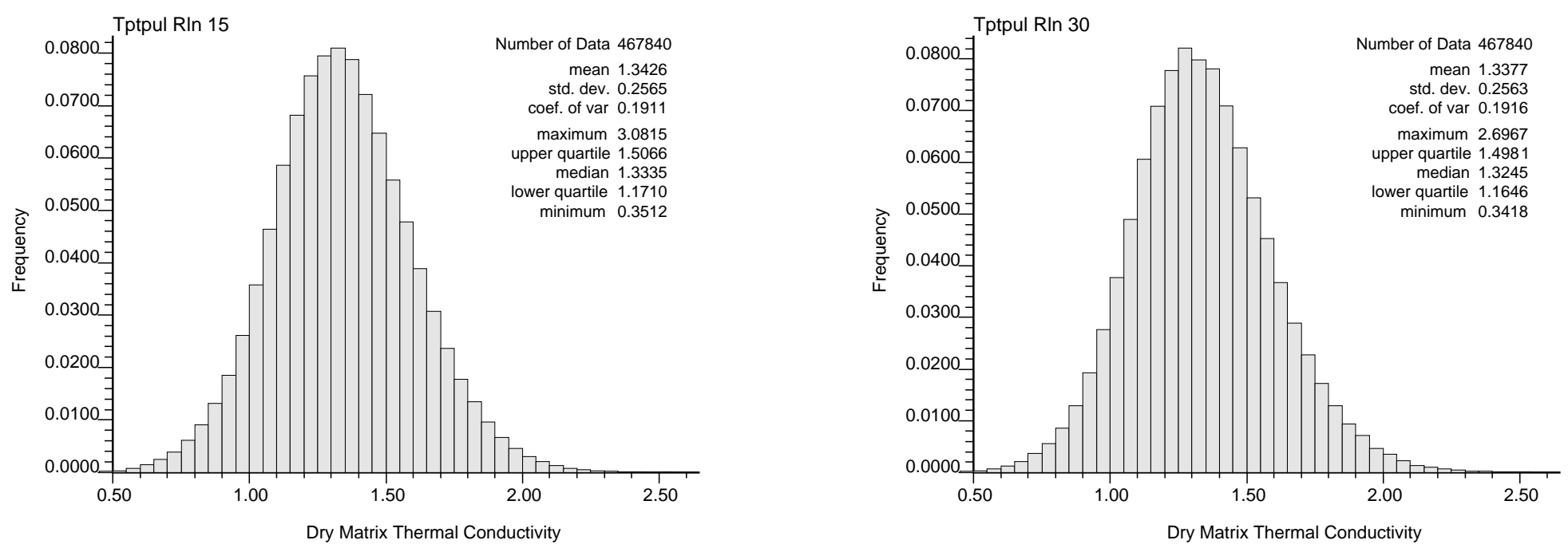

ì
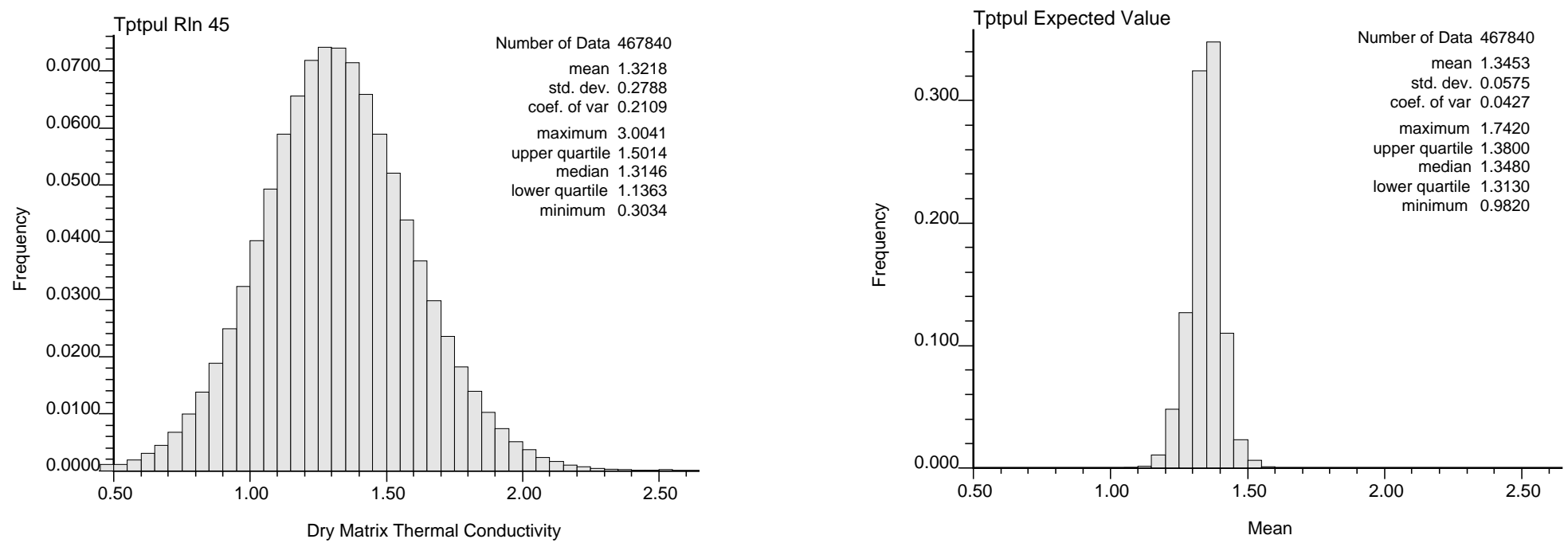

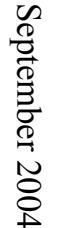

Output DTN: SN0404T0503102.011 [DIRS 169129].

Figure 6-38. Dry Matrix Thermal Conductivity $(\mathrm{W} / \mathrm{mK})$ in the Tptpul 

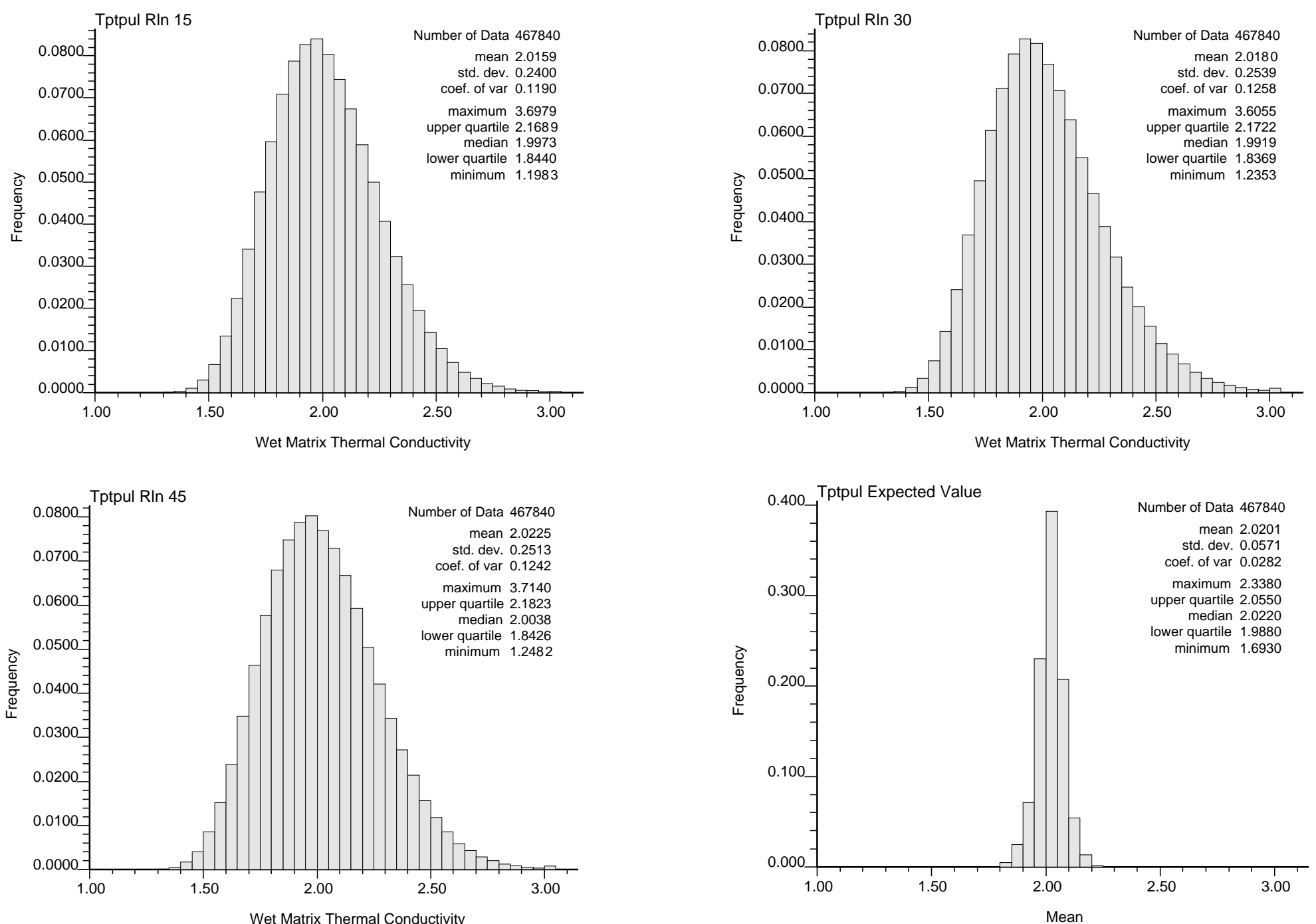

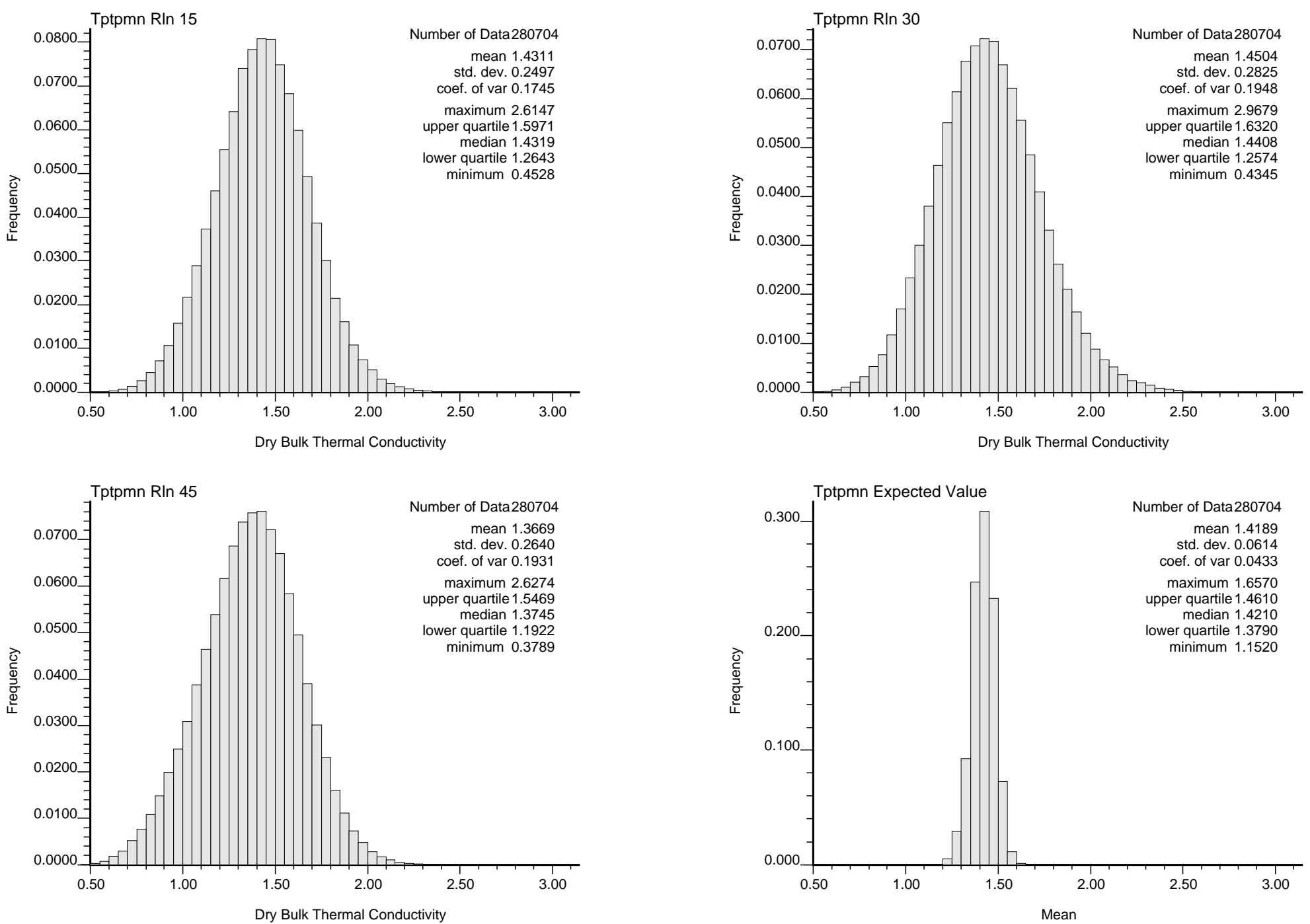

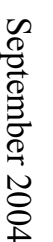

Output DTN: SN0404T0503102.011 [DIRS 169129].

Figure 6-40. Dry Bulk Thermal Conductivity (W/mK) in the Tptpmn 

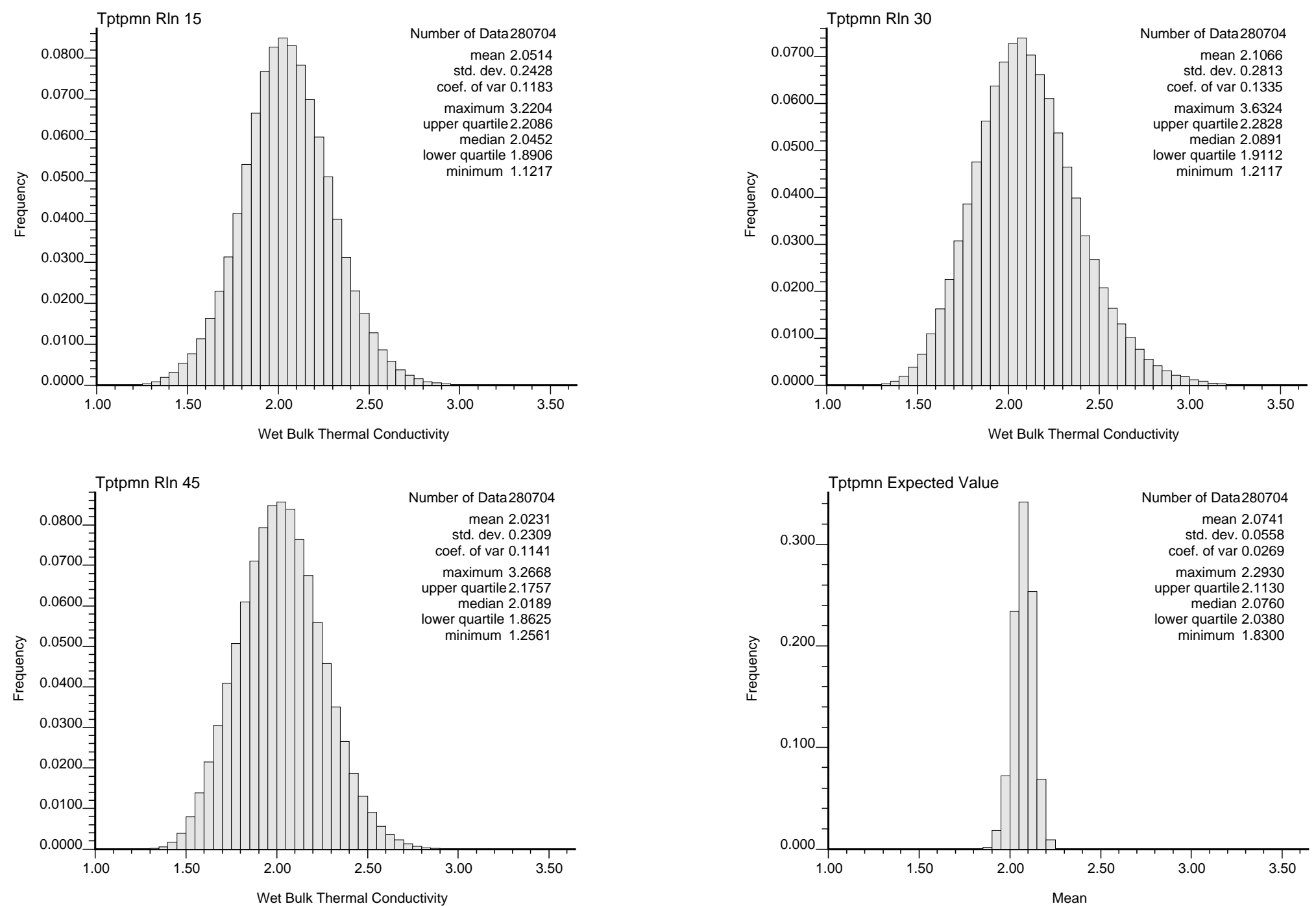

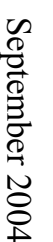

Output DTN: SN0404T0503102.011 [DIRS 169129].

Figure 6-41. Wet Bulk Thermal Conductivity (W/mK) in the Tptpmn 

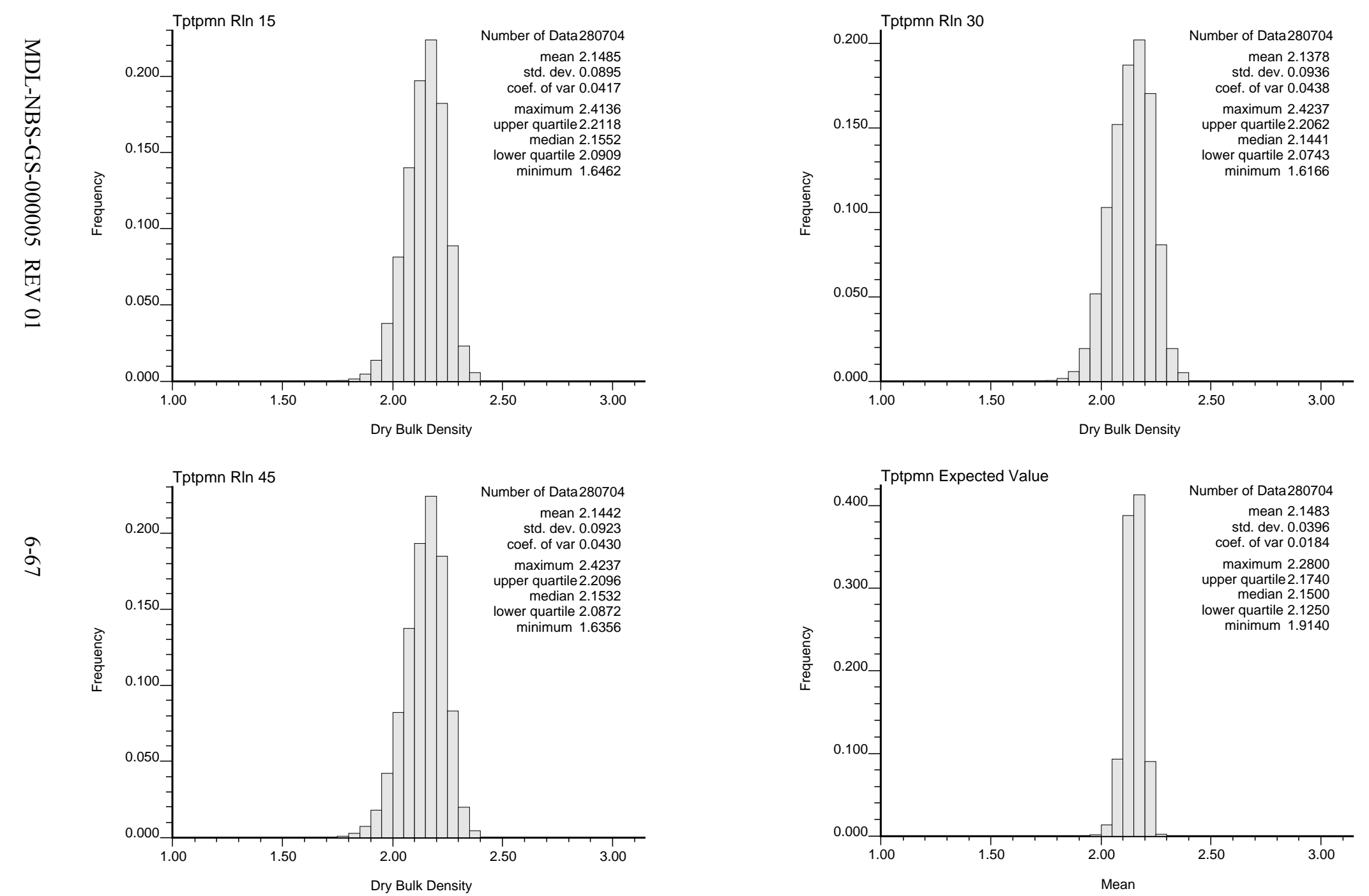

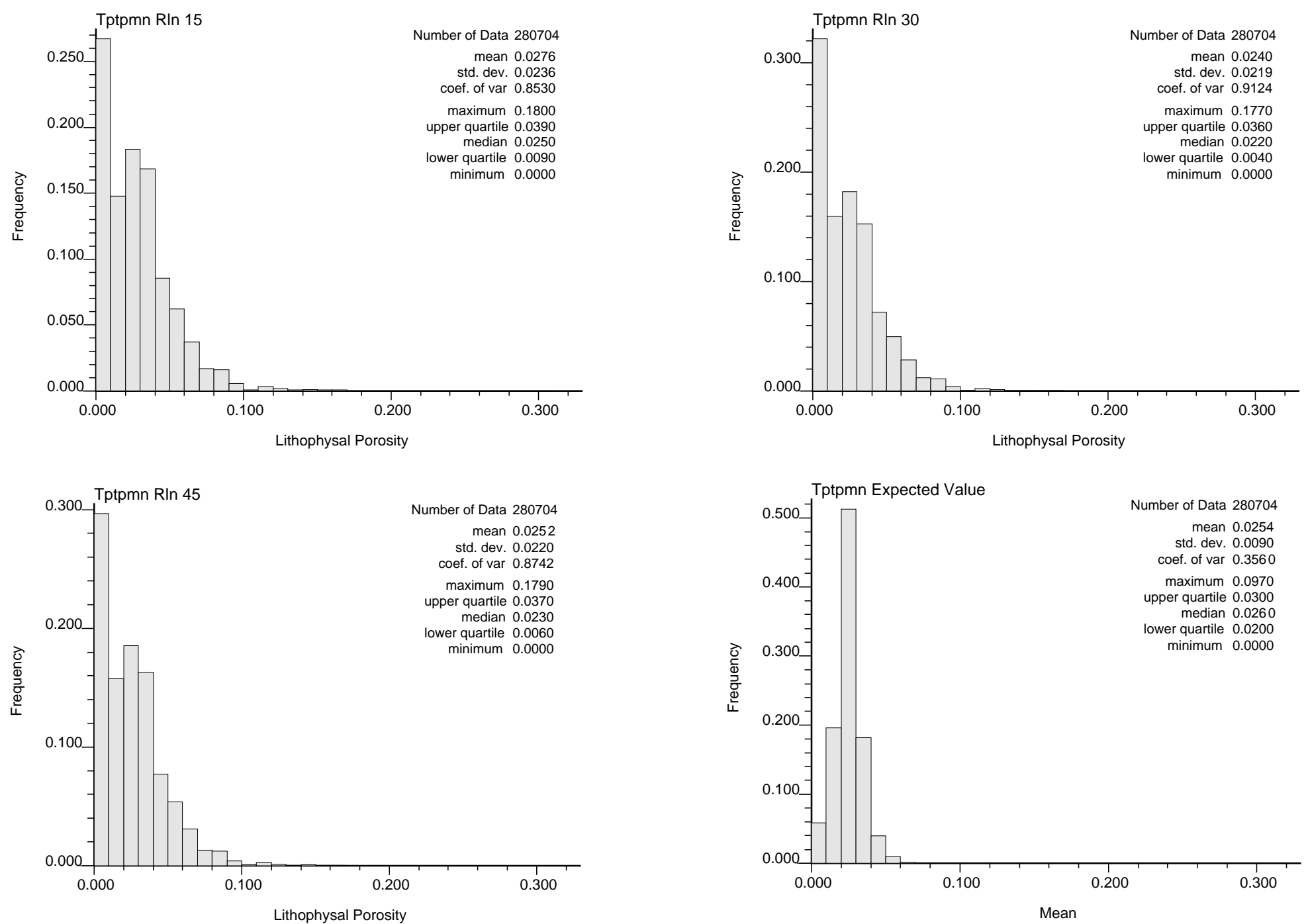

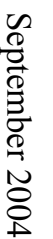

Figure 6-43. Lithophysal Porosity in the Tptpmn 

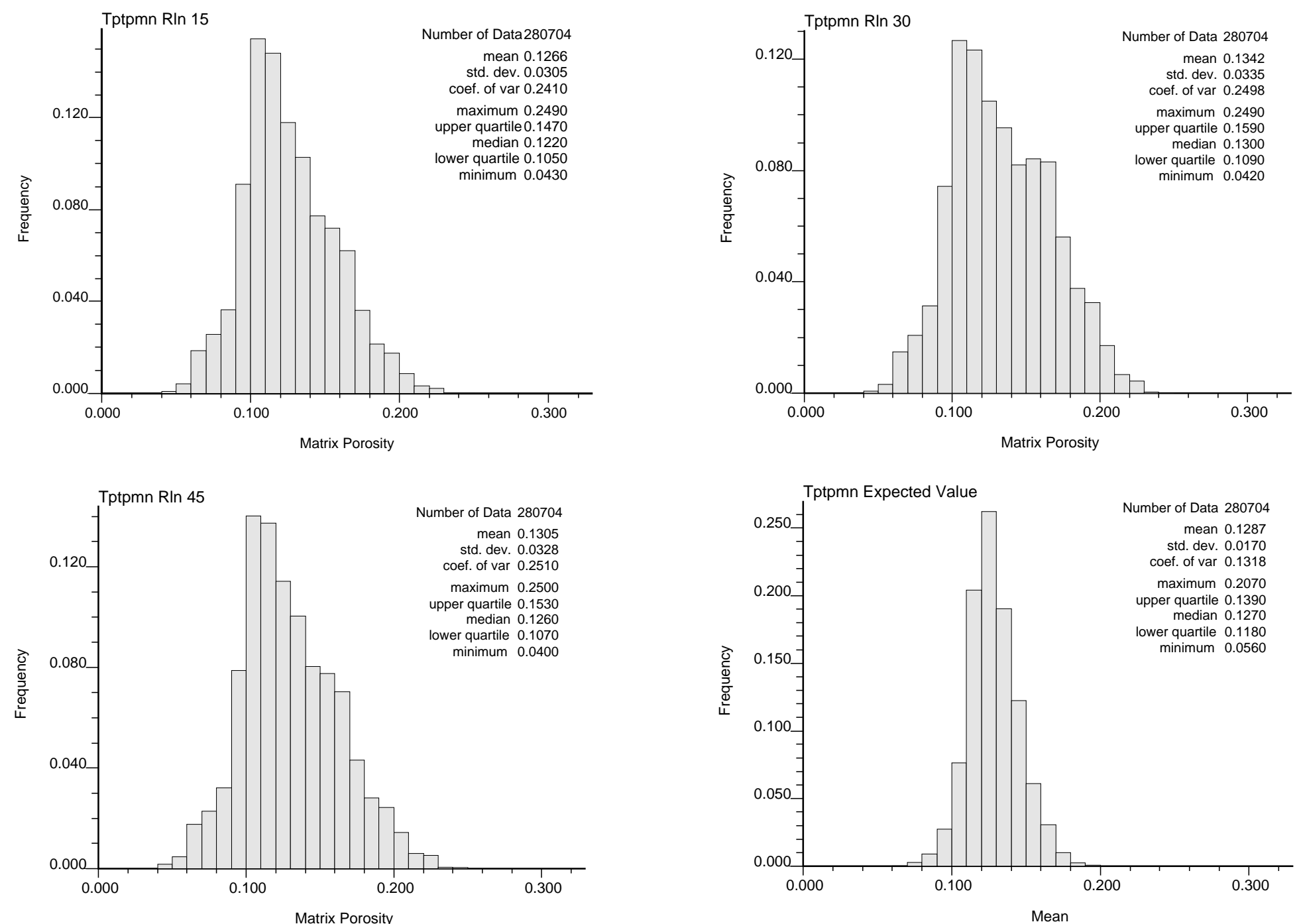

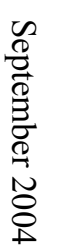

Figure 6-44. Matrix Porosity in the Tptpmn 

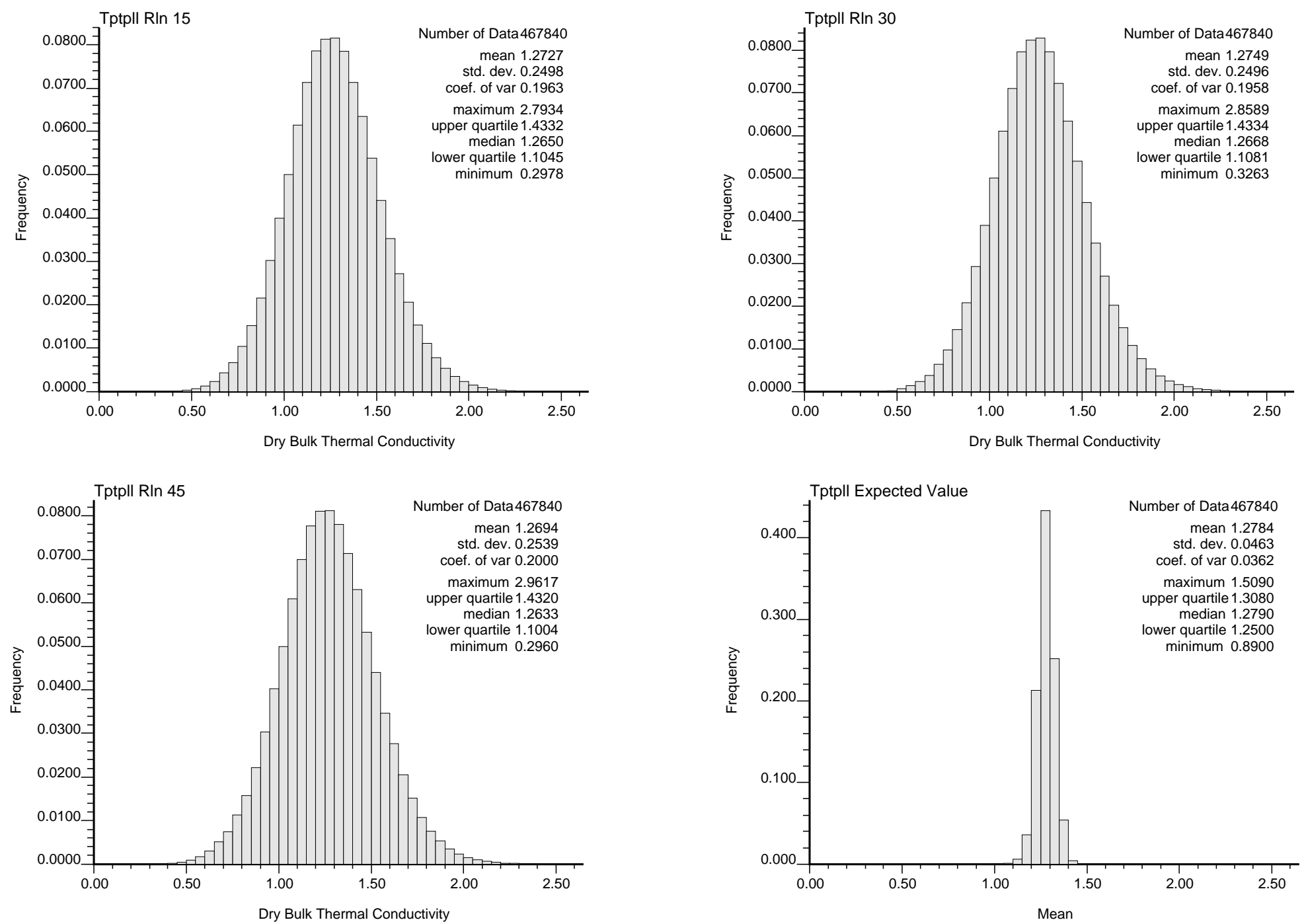

ì่

Dry Bulk Thermal Conductivity 
Tptpll RIn 15

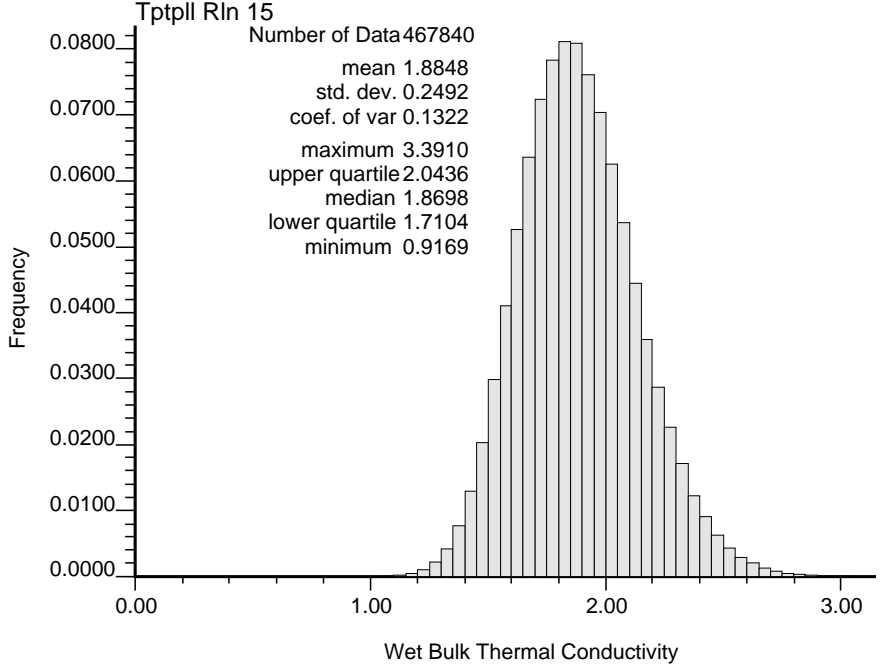

ì

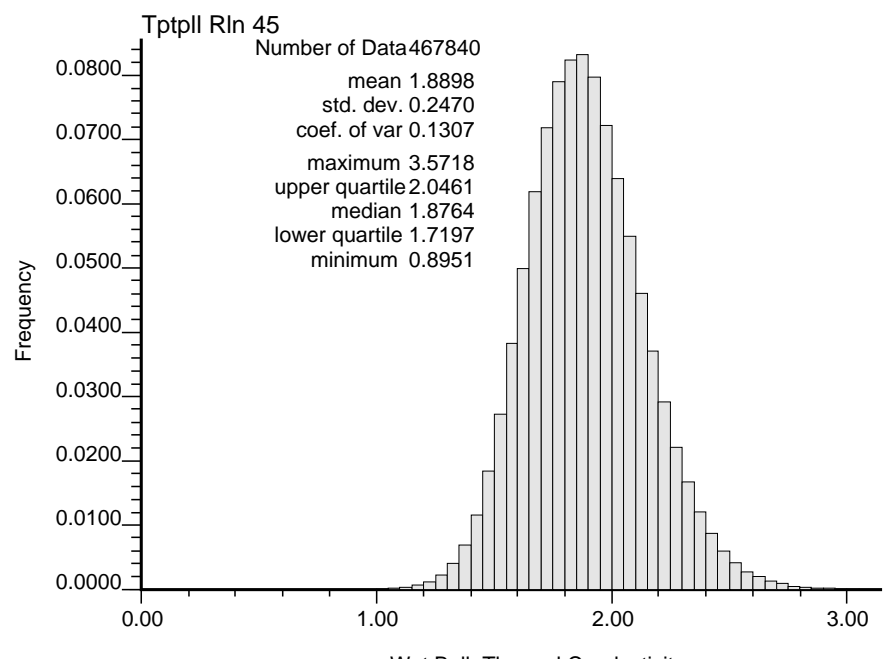

Wet Bulk Thermal Conductivity
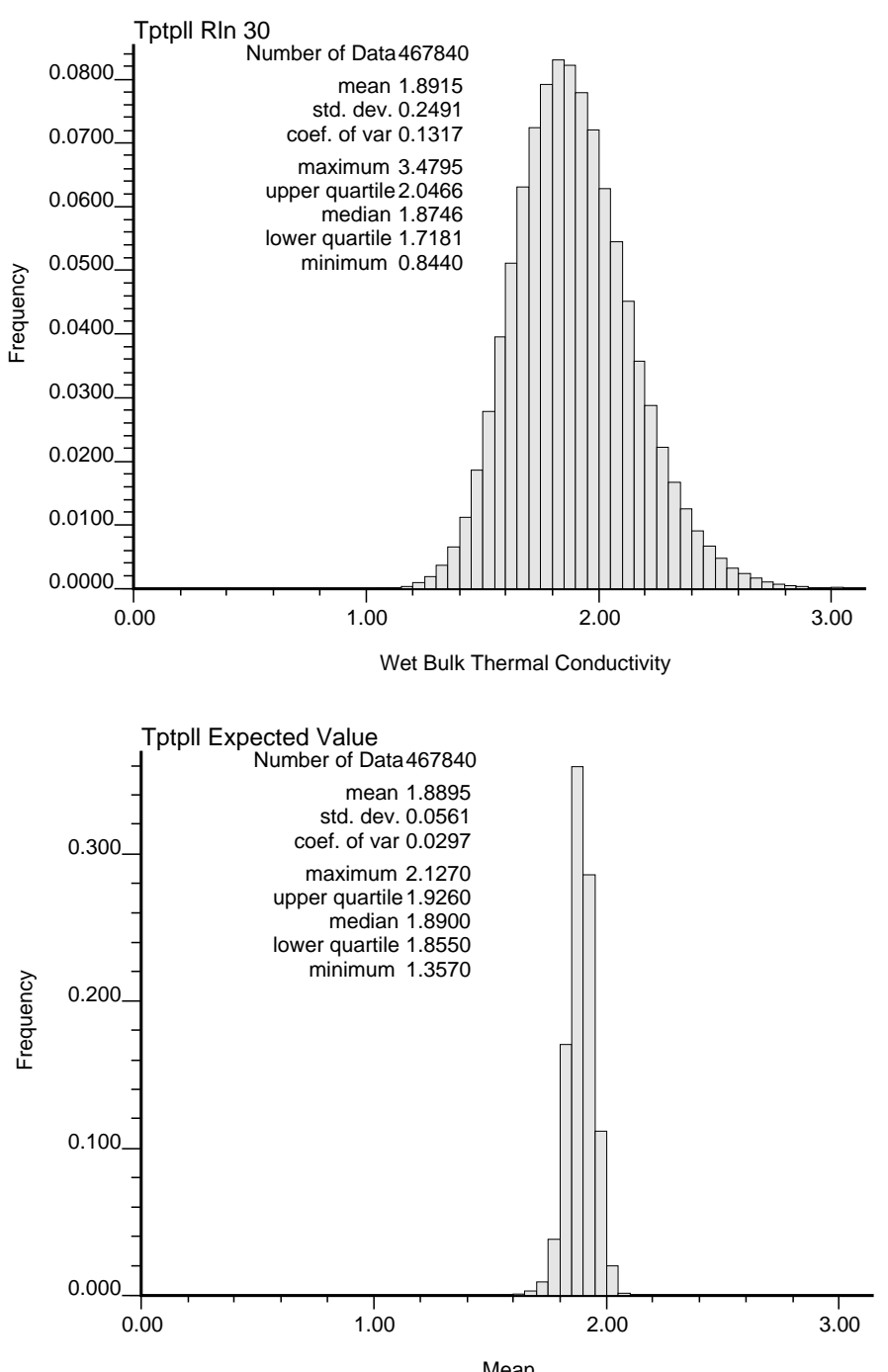

Mean 

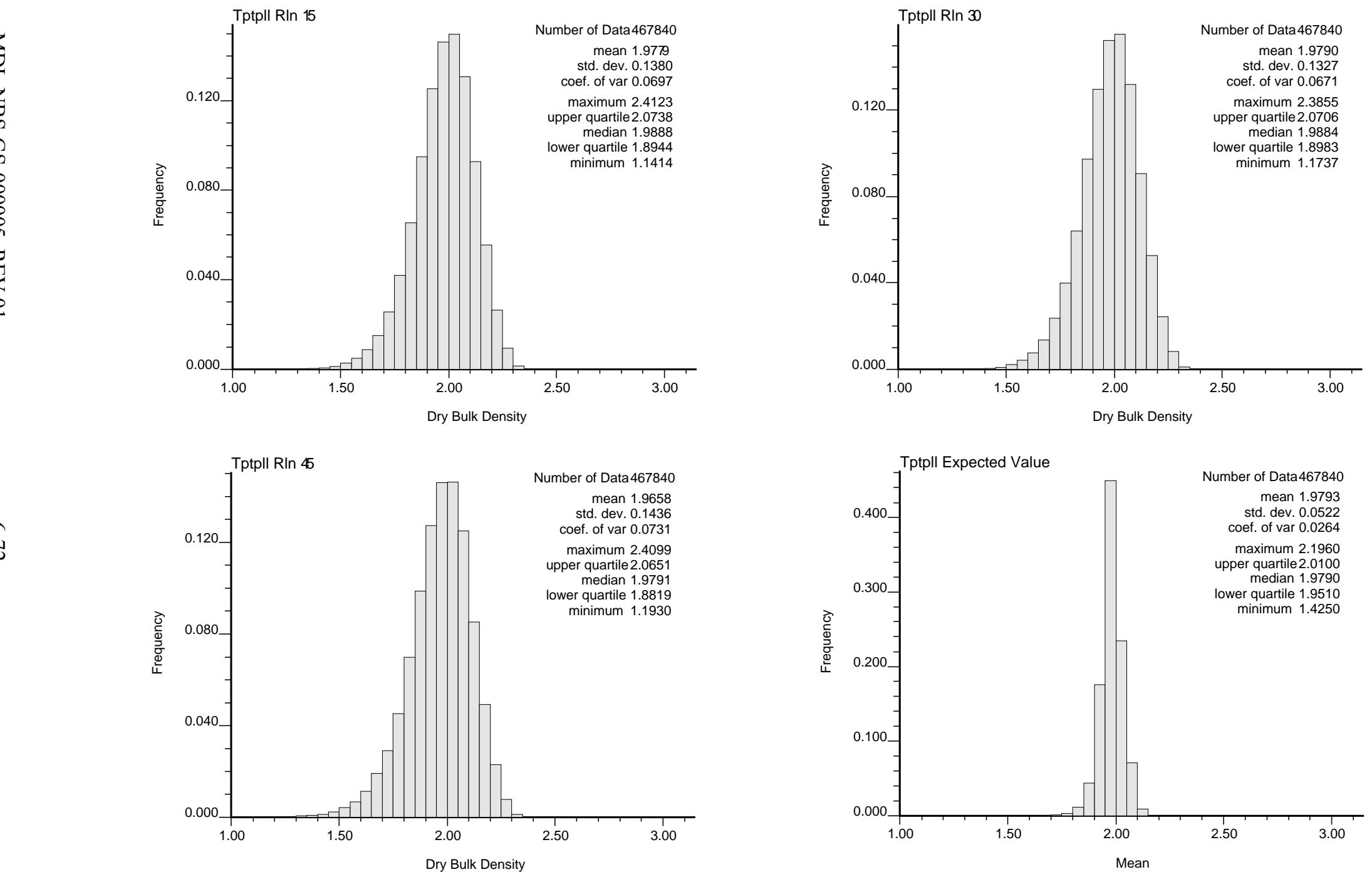

$\frac{i}{N}$

Figure 6-47. Dry Bulk Density ( $\mathrm{g} / \mathrm{cc}$ ) in the Tptpll 

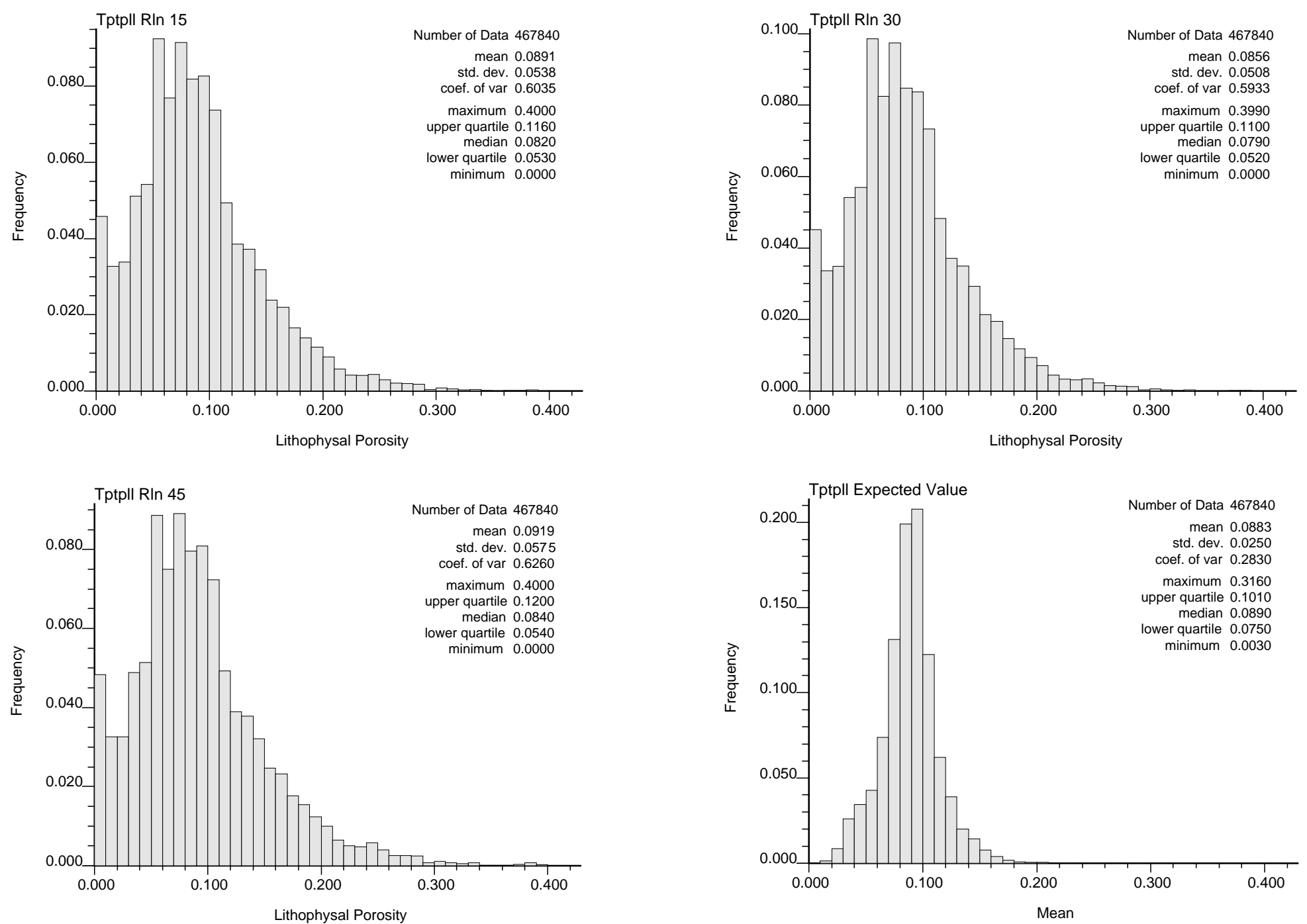

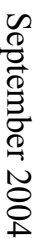

Figure 6-48. Lithophysal Porosity in the Tptpll 

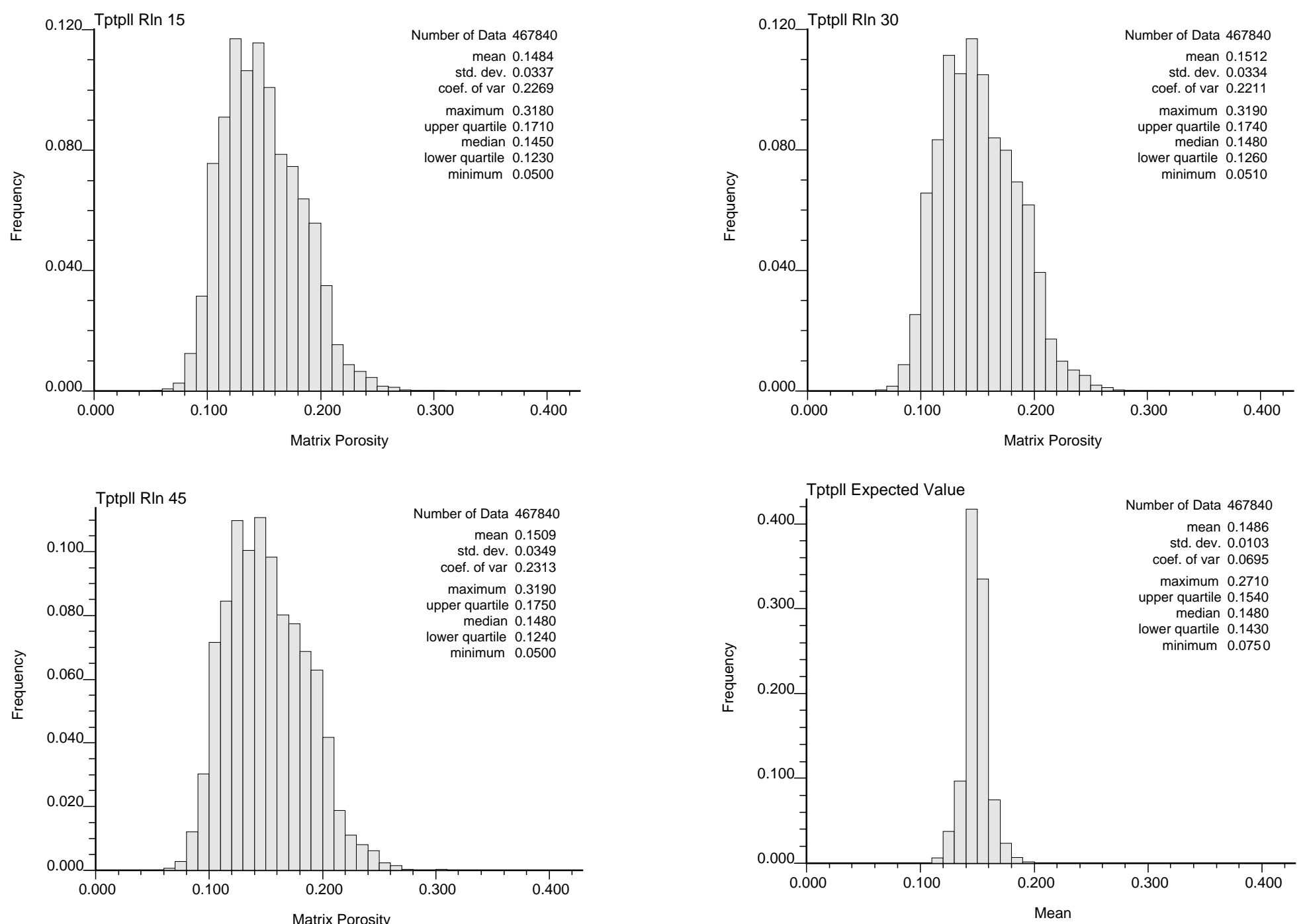

s
8
0
0
0
0
0
0
0
0

Figure 6-49. Matrix Porosity in the Tptpll 

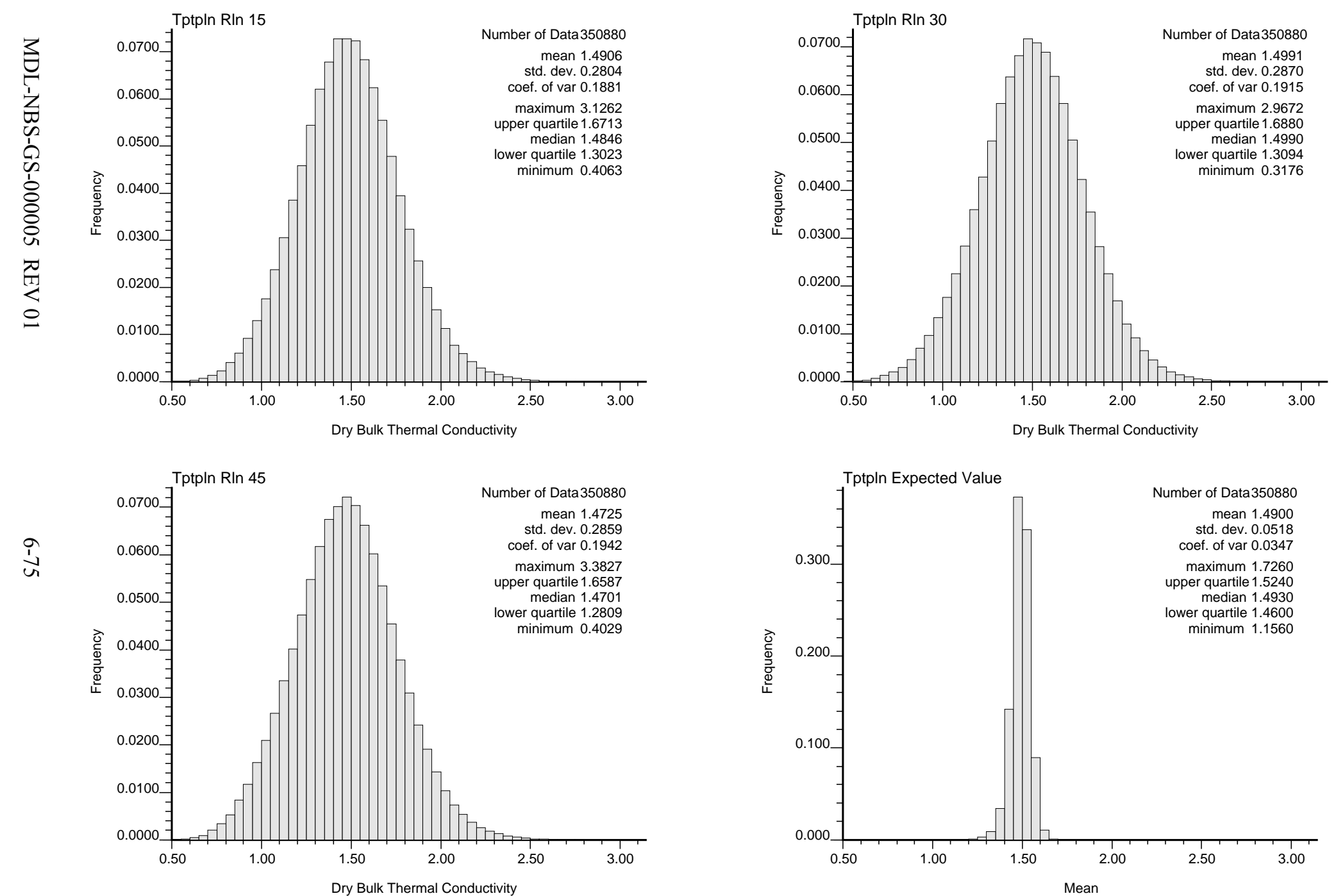

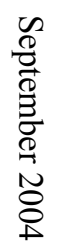

\section{Output DTN: SN0404T0503102.011 [DIRS 169129].}

Figure 6-50. Dry Bulk Thermal Conductivity (W/mK) in the Tptpln 

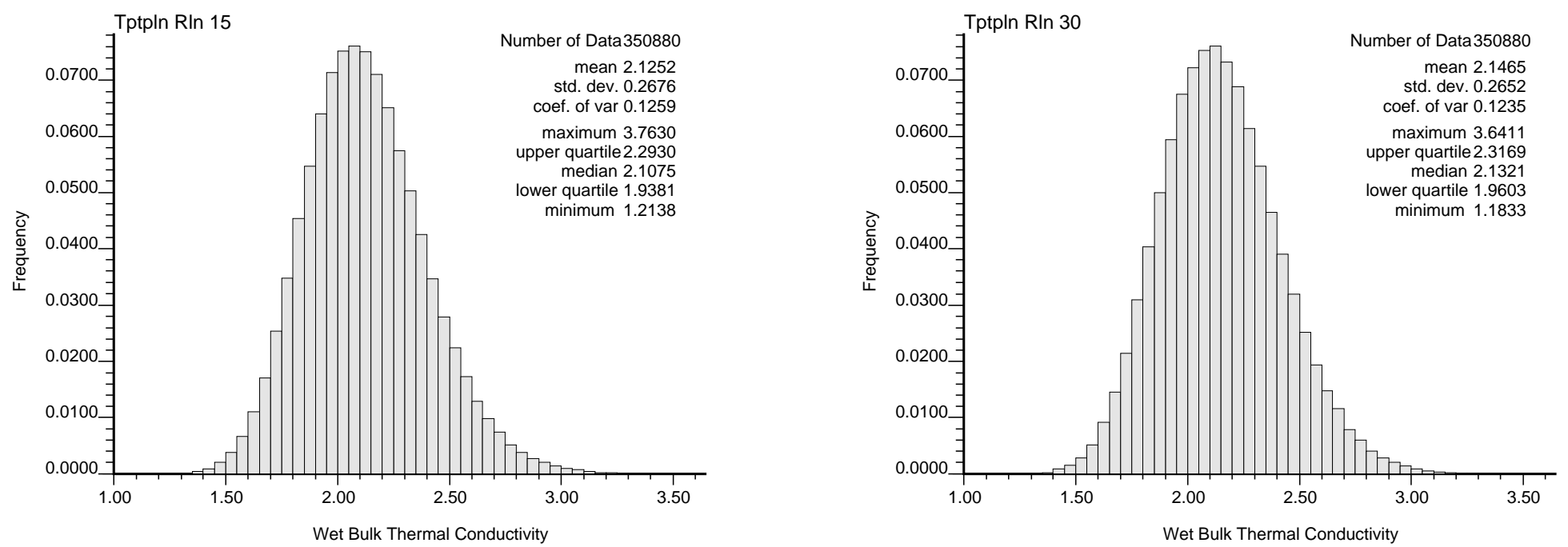

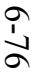
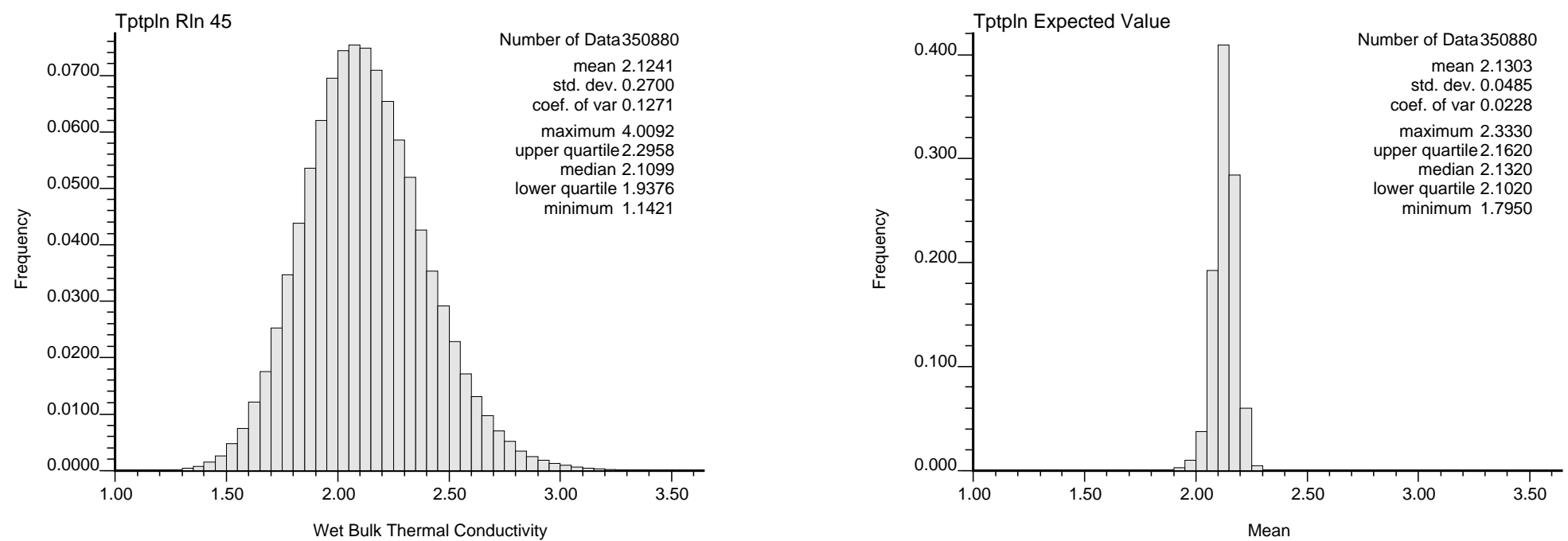

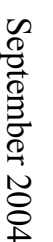

Output DTN: SN0404T0503102.011 [DIRS 169129].

Figure 6-51. Wet Bulk Thermal Conductivity $(\mathrm{W} / \mathrm{mK})$ in the Tptpln 

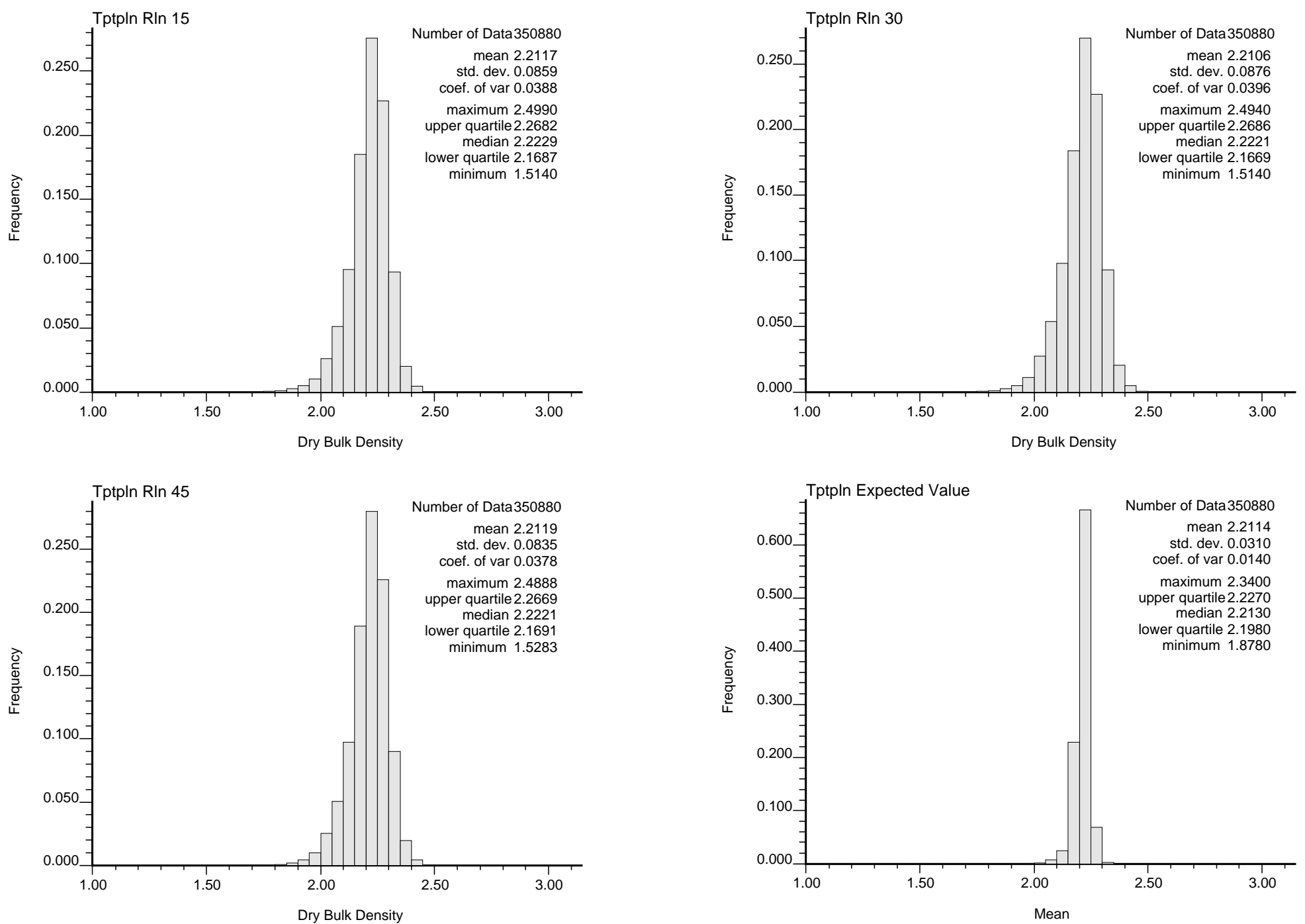

Figure 6-52. Dry Bulk Density (g/cc) in the Tptpln 

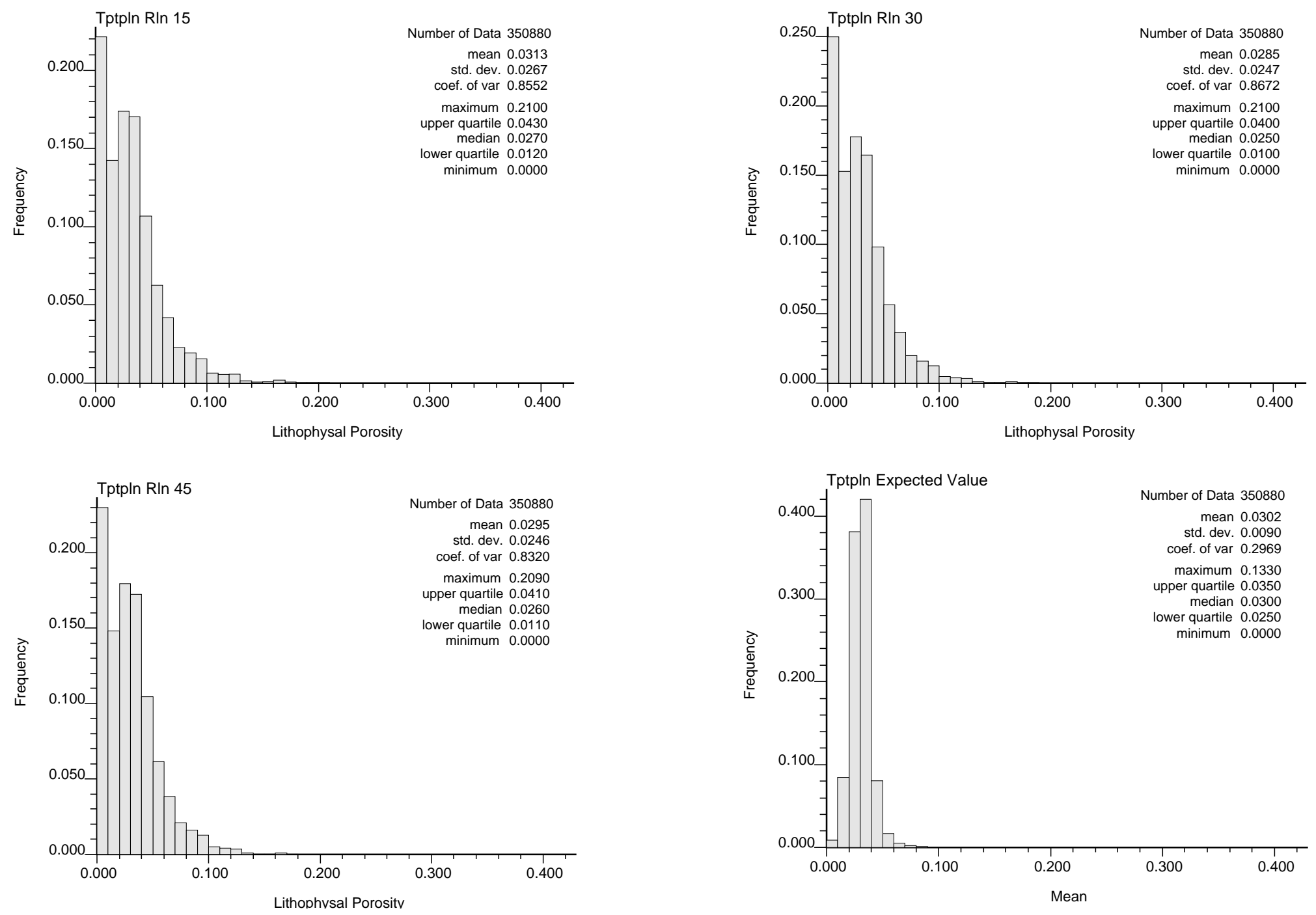

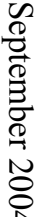

Figure 6-53. Lithophysal Porosity in the Tptpln 

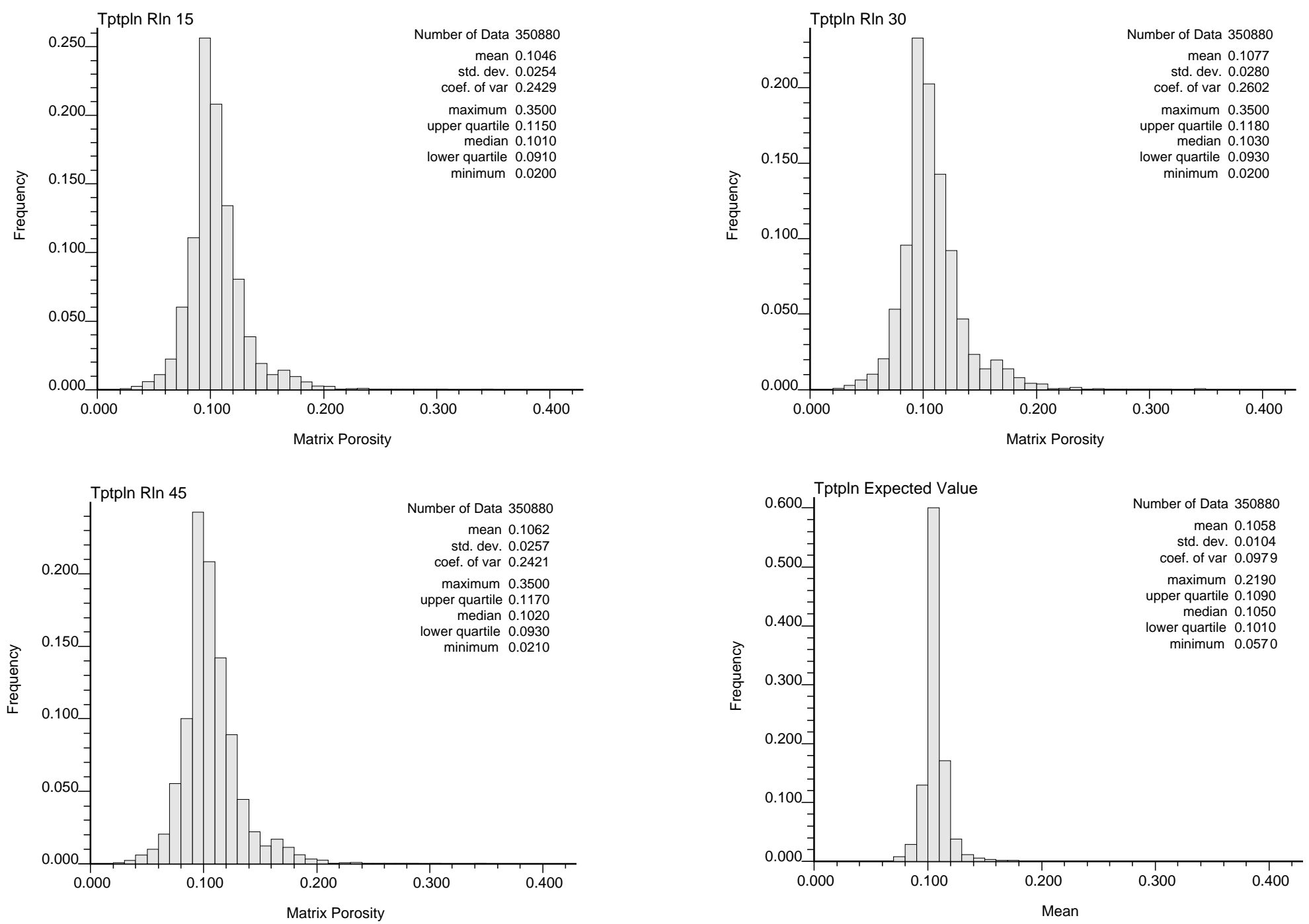

$n$
$\frac{0}{0}$
0
0
0
0
0
0
0
0

Figure 6-54. Matrix Porosity in the Tptpln 


\section{INTENTIONALLY LEFT BLANK}




\section{MODEL VALIDATION}

This section establishes that thermal conductivity and porosity models developed in Section 6 are validated, exhibit sufficient levels of accuracy, and are adequate for their intended uses consistent with the criteria provided in Section 2.2.1.1 of the TWP for this Model Report (BSC 2004 [DIRS 171708]). To support this proposition, models used to estimate matrix (Section 6.1.5) and lithophysal porosity (Section 6.1.4) are examined and calculated porosity values are compared with measured values to support the validity of these models. Next, the model of matrix thermal conductivity, presented in Section 6.1.7, is validated by comparing model results with thermal conductivity measurements obtained from laboratory core samples. Finally, the bulk thermal conductivity model, developed in Section 6.1.8, is validated by comparing model results with results of in situ thermal conductivity field tests. In addition, by validating the models for matrix and lithophysal porosity, models that estimate dry bulk density are inherently validated as well. This is true because dry bulk density is calculated directly from these parameters as discussed in Section 6.1.6.

The models developed in this report are based on a grid dimension of $50 \mathrm{~m} \times 50 \mathrm{~m}$. These were chosen to be appropriate for use in mountain-scale and drift-scale modeling (Section 6.1.2). With the exception of the ECRB lithophysal porosity validation in Section 7.3.1, the data used to corroborate these models are not at the model scale. For example, the scale of the field thermal conductivity tests described in Section 7.5 is roughly equivalent to the length of the heater that is $5 \mathrm{~m}$. This makes direct comparison between the mean model predictions and corroborative data difficult. For this reason the model validation criteria are usually prescribed such that the corroborative data must lie within the bounds of the models predictions. The exception to this is the matrix porosity validation described in Section 7.2.

As noted in the Technical Work Plan for: Near-Field Environment and Transport Thermal Properties Model and Analysis Reports Integration (BSC 2004 [DIRS 171708], Section 2.2.1.2), the Thermal Conductivity of the Potential Repository Horizon Model requires Level I Model Validation. The validation criteria used to establish the adequacy and accuracy of the scientific basis for the models are consistent with the intended use of the model.

\subsection{CONFIDENCE BUILDING DURING MODEL DEVELOPMENT}

As required by Section 5.3.2(b) of AP-SIII.10Q, appropriate confidence-building activities were conducted during model development and are summarized in the following paragraphs.

Inputs to this model report were obtained from appropriate laboratory and field sources and are suitable for intended use or qualified (see Tables 4-1 through 4-7 and associated discussion in Section 4.1). Detailed discussion regarding the input data analyses and decisions made regarding use of the data is found in Appendix B.

Calibration activities that were used to build confidence during model development are described in Section 6. Detailed discussion of model domain (boundaries) and discretization can be found in Section 6.1.2. The geostatistical simulation methods are discussed in Section 6.1.3. The simulation algorithms expand the available information in a stochastic manner that is consistent with the data ensemble and spatial context of those data. 
Any uncertainty in the bulk thermal conductivity values estimated with the two-parameter parallel model (Section 6.1.8) arises from the spatial heterogeneity and uncertainty of the two parameters used in this model, the matrix thermal conductivity and lithophysal porosity.

The matrix thermal conductivity (Section 6.1.7) depends on the matrix porosity (Section 6.1.5), thermal conductivity of the saturating fluid, thermal conductivity of the solid minerals, and geometry and connectivity of the solid. The thermal conductivity of the saturating fluid is constant, but the remaining three parameters are treated as spatially uncertain random functions. To supplement the available laboratory measurements of matrix porosity, an approach was developed to estimate the matrix porosity from petrophysical borehole log data (Method B, Section 6.1.4). The matrix porosity values derived from the petrophysical data are subject to uncertainties in the gathering and interpretation of these data. The laboratory testing of matrix thermal conductivity is reported to be accurate to \pm 5 percent (SNL 1998 [DIRS 118788]) and consequently this measurement uncertainty is propagated through to the matrix thermal conductivity model. Measurements from core samples and borehole petrophysical logs are used to derive models of spatial continuity for the matrix porosity and to condition the geostatistical simulations; therefore, the natural variability of the measured data is directly incorporated in the model.

The spatial heterogeneity and uncertainty of lithophysal porosity (Section 6.1.4) are addressed in a similar manner. A method of characterizing lithophysal porosity from borehole petrophysical data is developed and applied in this endeavor. The results are used to derive models of spatial continuity and to condition geostatistical simulations of lithophysal porosity that also include the underlying petrophysically based data variability. Since the lithophysal porosity estimated with the model was based entirely on the interpretation of the petrophysical data, it is potentially affected by any bias in the data upon which the model is constructed.

\subsection{MATRIX POROSITY MODEL VALIDATION}

Matrix porosity is used in the determination of matrix thermal conductivity and thus indirectly in the estimation of bulk thermal conductivity. The purpose of this section is to compare matrix porosity values determined from laboratory measurements on core samples with modeled values of porosity derived from petrophysical measurements in the same boreholes. Corroboration between the matrix porosity values obtained from laboratory core measurements and the model-based matrix porosity provides increased knowledge of the spatial variability of matrix porosity beyond that provided by core measurements alone.

Two types of matrix porosity measurements are available from laboratory core testing: RH porosity and OD porosity. The RH porosity allows some water to remain in the pores, while the OD porosity is determined by drying the sample in an oven until the interstitial water has been eliminated from the samples pores. Of the two, the OD measurement is theoretically more consistent with the petrophysical measurement since this measurement better represents the total water content of the sample, which is what the logging tool measures.

In order to validate the matrix porosity model, data from two boreholes were examined (USW SD-7 and USW SD-12). These boreholes were used in the validation process because they extend through the layers of interest and both core samples and petrophysical logs are 
available for each borehole. The validation was performed by comparing matrix porosity laboratory measurements of core with matrix porosity predicted by a calculation based on Method B and petrophysical measurement data (bulk density and neutron porosity) described in Section 6.1.4 and Appendix A. Matrix porosity determined from laboratory testing of the core samples is considered to be the best source of porosity data because laboratory measurements can be made under carefully controlled conditions. As noted in Section 6.1.4, Method B is used when core porosity data are not available, and the appropriate petrophysical measurements are available.

The matrix porosity model used the core matrix data as direct input (Method A) for these two borehole locations in a comparison with the petrophysical logs (Method B) at these same two locations. The USW SD-7 and USW SD-12 core measurements are thus being used to validate the approach of using Method B at other borehole locations in the model where there are no core measurements and only petrophysical logs are available. The matrix porosity model is considered valid if the difference between the calculated matrix porosity and the measured matrix porosity values from core samples is within \pm 5 percentage points (|core porosity-Method B porosity $\mid \leq 0.05$ ). The choice of \pm 5 percentage points is appropriate because matrix porosity evaluated using geophysical measurements is indirectly calculated using bulk density and neutron porosity logs and is sufficient for its intended use. The uncertainty in the matrix porosity model resulting from the use of Method B and the uncertainty related to the core measurement data are propagated into matrix thermal conductivity model. The accuracy of these logging measurements is affected by the drilling method, rock type, logging tool type and ultimately analyst interpretation and are subject to much greater uncertainty compared to measurements on core samples. Sample size or scale effects may also influence the direct comparison of core and petrophysical data. These arise because the core samples used to measure matrix porosity are made on small volumes of rock compared to the volume evaluated using petrophysical methods.

The validation of the matrix porosity model will primarily be made with data from the nonlithophysal zones as the presence of lithophysae and associated vapor-phase alteration can affect the estimation of matrix porosity; however, for completeness, the comparison in the lithophysal units is also shown. The calculation procedure is identical for all units.

\subsubsection{USW SD-7}

Figure 7-1(a) shows neutron porosity measurements for USW SD-7. As noted in Section 6.1.4, neutron porosity is assumed to reflect the volumetric water content of the rock. For comparison, the volumetric water content measured from core samples is also shown. It should be noted that there is good agreement between the neutron porosity measurements and the core volumetric water content data in all four layers.

Figure 7-1(b) shows the variation in bulk density from petrophysical logging of USW SD-7. As expected, the bulk density is the lowest in the lithophysal zones, Tptpul and Tptpll, due to the larger fraction of voids in these regions. The bulk density log generally increases with depth, with some local variations. 
Figure 7-1(c) shows matrix and lithophysal porosity calculated using Method B. In the Tptpul, the calculated matrix porosity decreases from top to bottom in the layer. The calculated matrix porosities are relatively constant in the lower three layers: Tptpmn, Tptpll, and Tptpln.

Figure 7-2 shows the comparison of the calculated matrix porosity with the RH and OD core porosity data. The agreement between the Method B calculation and the core measurement is very good in all four layers, with the calculation more closely matching the OD data. The agreement between core measurements and the Method B matrix porosity calculation is observed to be within the \pm 5 percent criterion. Below the Tptpln, the calculated matrix porosity differs from the measured core data due to a change in the particle density that is not accounted for in the calculation.

\subsubsection{USW SD-12}

Figure 7-3(a) shows the neutron porosity measurements for USW SD-12. For comparison, the volumetric water content measured from core samples is also shown. The agreement between the neutron porosity measurements and the core volumetric water content data in all four layers is not quite as good as that seen in USW SD-7. In general, the neutron porosity data over predicts the volumetric water content in USW SD-12.

Figure 7-3(b) shows the variation of bulk density from petrophysical logging for USW SD-12. The bulk density is the lowest in the upper lithophysal zone, Tptpul, and generally increases with depth. An uncharacteristic region of low density is also observed near the middle of the Tptpmn.

Figure 7-3(c) shows the calculated values of matrix and lithophysal porosity for USW SD-12. The calculated matrix porosities are generally higher in the lithophysal units than in the nonlithophysal units. Also, the calculated matrix porosities are relatively constant with depth in each of the four units.

Figure 7-4 shows the comparison of calculated matrix porosity with core measurements of the same property. Both $\mathrm{RH}$ and OD measurements are presented. The agreement between the calculated matrix porosity and the core measurements, while not as good as the agreement for USW SD-7, are still reasonably close in all four layers. The tendency of neutron porosity to be slightly high in this borehole leads to higher calculated matrix porosity. In the Tptpmn, where the neutron porosity and volumetric water content are in better agreement, the matrix porosity is also in agreement, matching the OD porosity measurements quite well. The agreement between core measurements and the Method B matrix porosity calculation is observed to be within the range of \pm 5 percent criterion for the non-lithophysal layers. The matrix porosity evaluated using Method B therefore has a potential uncertainty of \pm 5 percent, though as seen in Figures 7-2 and $7-4$, the uncertainty is typically less in the nonlithophysal layers. Matrix porosity uncertainty is propagated to the matrix thermal conductivity model that uses this parameter.

\subsubsection{Matrix Porosity Model Validation: Summary and Conclusions}

Matrix porosity data, based on core samples from the Tptpul, Tptpmn, Tptpll, and Tptpln, are unavailable for most of the exploration boreholes. Petrophysical measurements of neutron porosity and bulk density are more common and, as demonstrated in Sections 7.2.1 and 7.2.2, can be used to estimate the matrix porosity using the formulae given in Appendix A. Matrix 
porosity calculated with this approach is shown to meet the validation criteria in boreholes, USW SD-7 and USW SD-12 for which core data are available. This demonstrates that the matrix porosity model, developed on the basis of petrophysical data, is sufficient and valid for its intended use, and confirms the petrophysical method can be used when core data are not available. Further confidence is attained by recognizing that the equations developed in Appendix A simply account for the solid and liquid mass and pore volumes in the bulk rock mass.

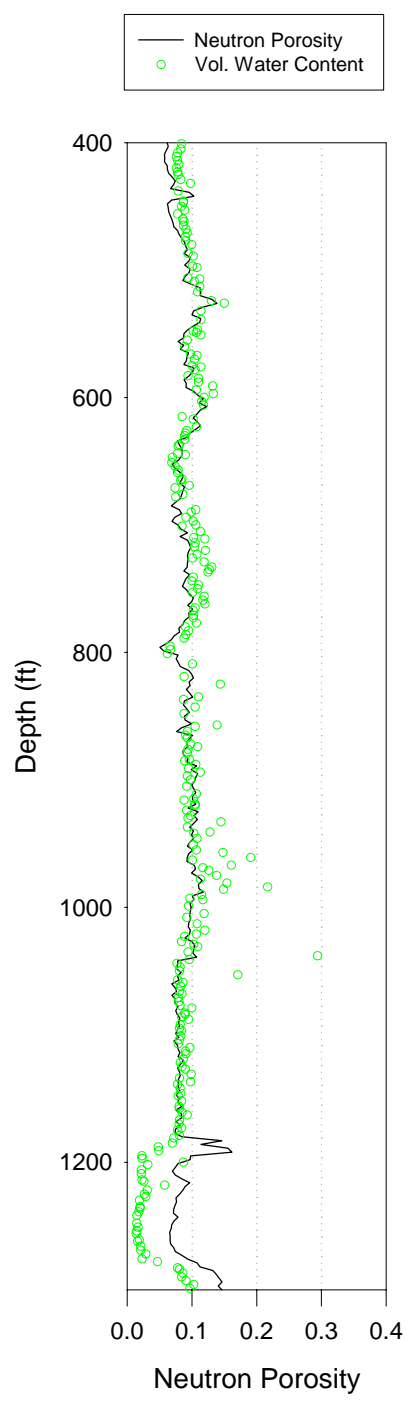

(a)

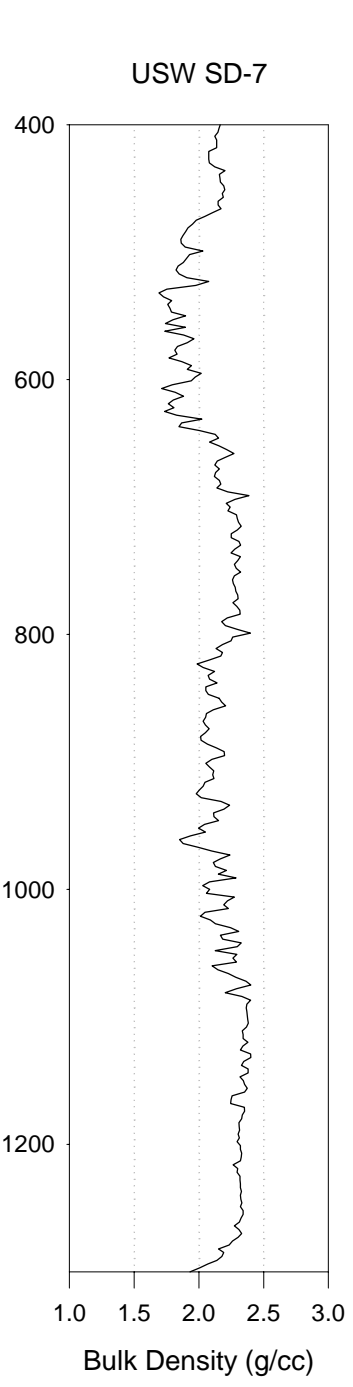

(b)

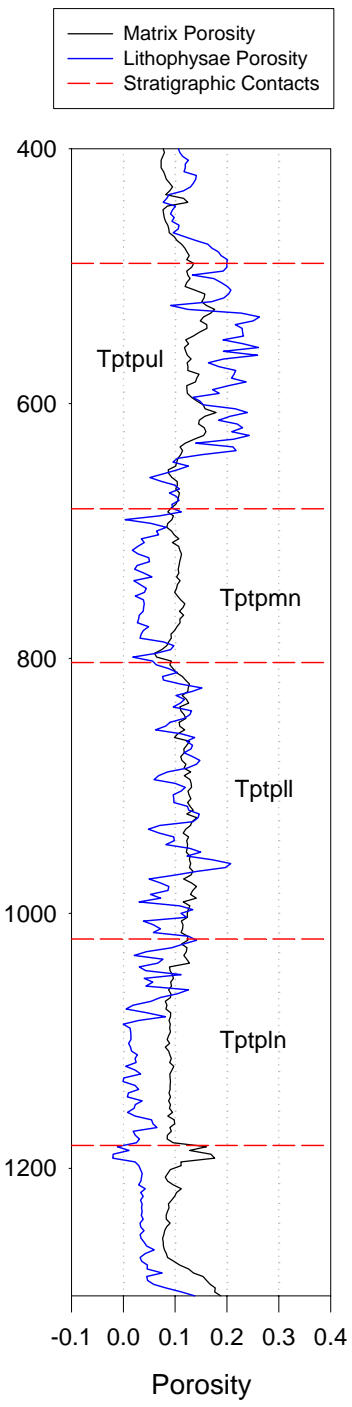

(c)

(a) (b) Input DTN: MO0010CPORGLOG.003 [DIRS 155959], (c) Output DTN: SN0404T0503102.011 [DIRS 169129].

Figure 7-1. USW SD-7 (a) (b) Core and Petrophysical Data; (c) Method B Porosity 


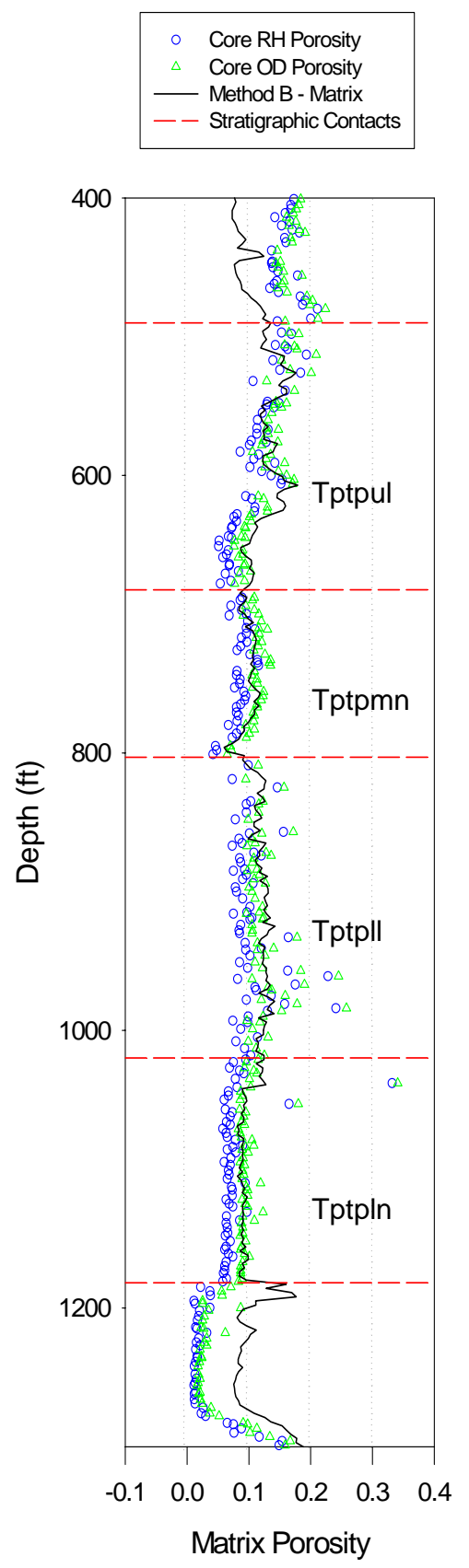

DTNs: $\quad$ Core RH and OD: Input DTN: MO0109HYMXPROP.001 [DIRS 155989]; Method B Matrix Output DTN: SN0404T0503102.011 [DIRS 169129].

NOTES: $\quad \mathrm{OD}=$ oven dried, $\mathrm{RH}=$ relative humidity.

Figure 7-2. USW SD-7 Comparison of Core and Method B Matrix Porosity 


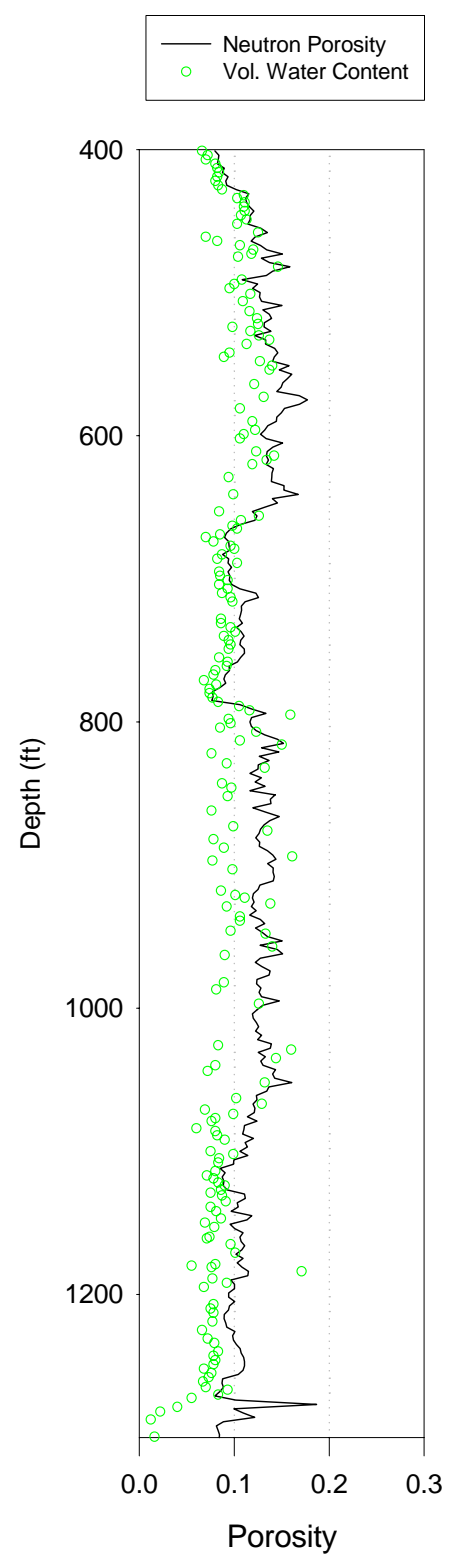

(a)

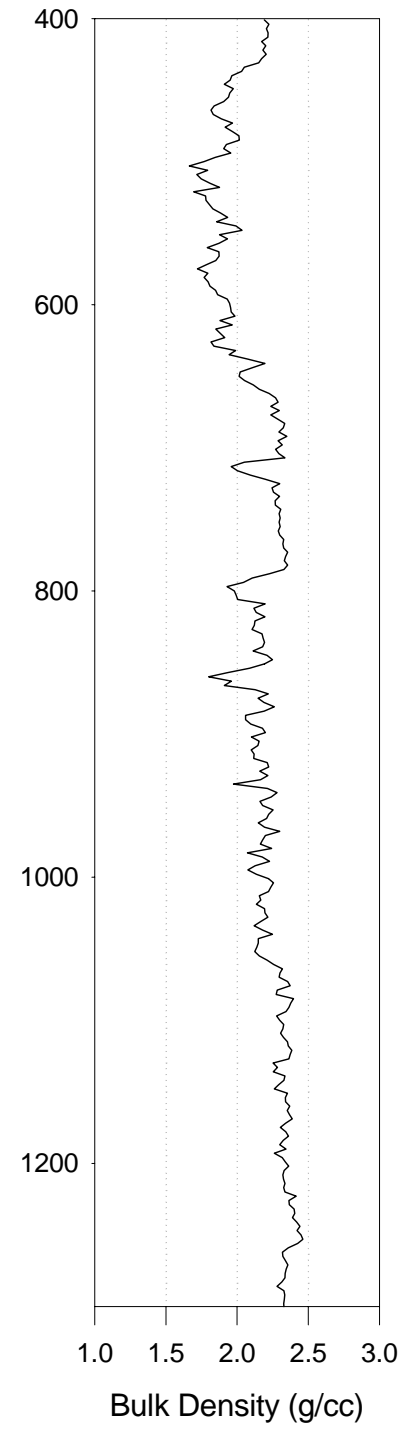

(b)

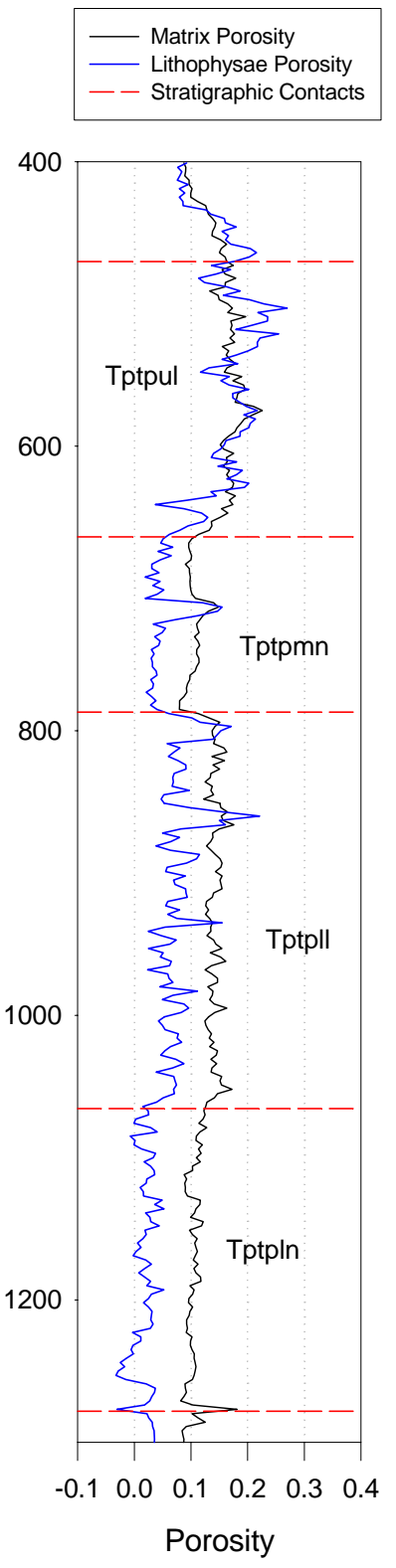

(c)

(a) (b) Input DTN: MO0010CPORGLOG.003 [DIRS 155959];

(c) Output DTN: SN0404T0503102.011 [DIRS 169129].

Figure 7-3. USW SD-12 (a) (b) Core and Petrophysical Data; (c) Method B Porosity 


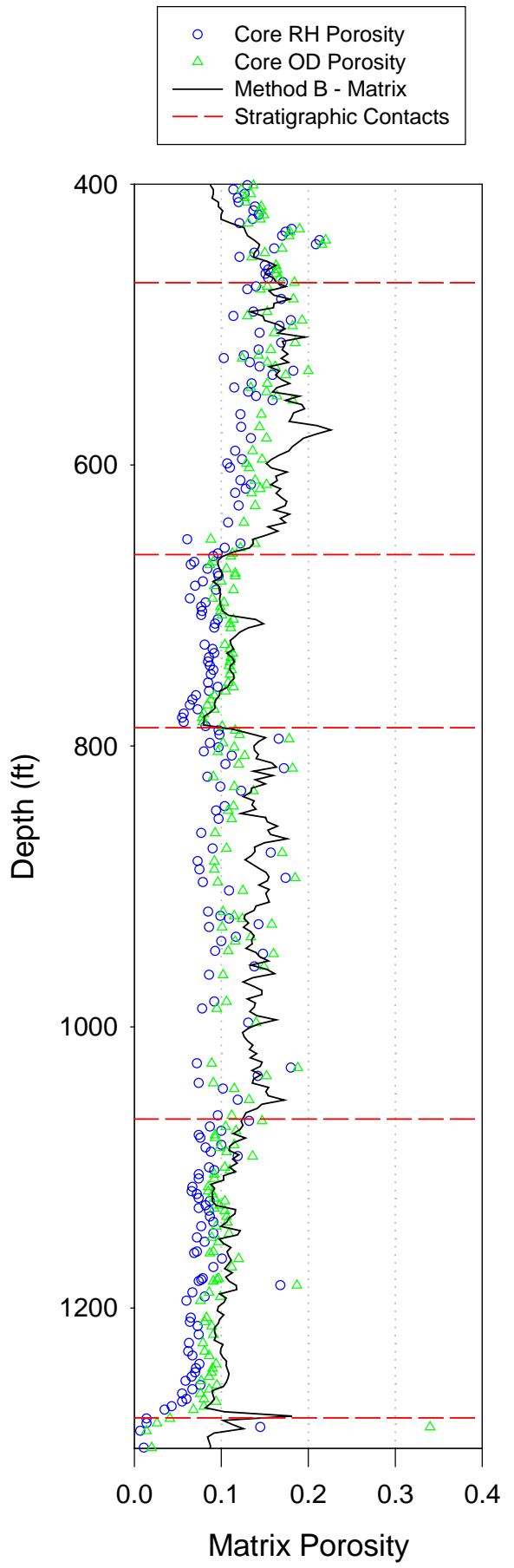

Core RH and OD: Input DTN: MO0109HYMXPROP.001 [DIRS 155989];

Method B Matrix Output DTN: SN0404T0503102.011 [DIRS 169129].

NOTES: $\mathrm{OD}=$ oven dried, $\mathrm{RH}=$ relative humidity.

Figure 7-4. USW SD-12 Comparison of Core and Method B Matrix Porosity 


\subsection{LITHOPHYSAL POROSITY MODEL VALIDATION}

The lithophysal porosity model is validated by comparing the geostatistically derived model realizations with lithophysae data obtained from mapping and borehole videos from the portion of the ECRB within the lower lithophysal zone (Tptpll). The lithophysal porosity model is based on results derived from petrophysical borehole measurements. The ECRB mapping and the borehole video data were not used to calibrate or condition the geostatistical model realizations during model development. These ECRB mapping and borehole video data, therefore, provide an independent set of data appropriate for validation of the lithophysal model. The lithophysal porosity model will be shown to be valid by demonstrating that the model predictions bound the observed data from the ECRB mapping and borehole video data from three field test locations.

The method used to develop the spatial distribution of lithophysal porosity depends on variograms (Figure 6.6) and conditioning data (Figure 6.5) developed specifically for each layer; however, the overall process is identical for each layer. Therefore, while the validation described in Sections 7.3.1 and 7.3.2 is based on comparison of model predictions with corroborative data obtained from the Tptpll, where the highest quality observations and the majority of the repository will be located, the model is also appropriate and adequate for the remaining layers considered in this report because an identical model development process is used in all layers.

In Section 7.3.1, lithophysal porosity predictions at specific locations along the ECRB in the lower lithophysal zone are compared with the data provided by DTN: MO0306MWDDDMIO.001 ([DIRS 165791] CalculationFiles.zip, file=Drift Deg AMR AF T-A-P Fit.xls, worksheet $=$ Percent Volume - Stats (Columns A, L, and P, Rows 23-206) and documented in the Drift Degradation Analysis (BSC 2004 [DIRS 166107], Appendix O) report. In Section 7.3.2, lithophysal porosity estimates (DTN: SN0205F3504502.010 [DIRS 159144], SEP Table S02126_001) obtained from video observation of lithophysae in boreholes drilled in support of the ECRB Thermal Conductivity Tests 1, 2, and 3 (Howard 2002 [DIRS 159152]), are compared with geostatistically derived lithophysal porosity for each test site.

The ECRB Cross-Drift is a 2.7-km long, 5-m diameter tunnel excavated entirely in the Topopah Spring Tuff (Mongano et al. 1999 [DIRS 149850], p. 3). As described in Mongano et al. (1999 [DIRS 149850], p.6]), the ECRB Cross-Drift begins in the upper-central portion of the upper lithophysal zone and descends geologically through all four lithostratigraphic units of interest before encountering a fault near the end of the drift. The Tptpul is exposed in the first kilometer (station $0+00$ to $10+15$ ) of the tunnel. The middle nonlithophysal zone, Tptpmn, is exposed over approximately $0.4 \mathrm{~km}$ (station $10+15$ to $14+44$ ) of the tunnel, while approximately $0.9 \mathrm{~km}$ of the tunnel (station $14+44$ to $23+26$ ) exposes the lower lithophysal zone, Tptpll. Between stations $23+26$ and 25+85, the lower nonlithophysal zone, Tptpln, is exposed. The uppermost portion of the Tptpul is exposed at the end of the excavation (station 25+90 to $26+57.5$ ) in the hanging wall of the eastern strand of the Solitario Canyon fault zone. Table 7-1 summarizes the four units and where they were encountered in the tunnel excavation. Because the majority of the repository will be excavated in the Tptpll, the focus of this validation will concentrate on this layer. 
Table 7-1. ECRB Cross-Drift Tunnel: Lithostratigraphic Units and Stations

\begin{tabular}{|l|l|}
\hline \multicolumn{1}{|c|}{ Unit } & \multicolumn{1}{c|}{ Stations } \\
\hline Tptpul & $0+00$ to $10+15$ and $25+90$ to $26+57.5$ \\
\hline Tptpmn & $10+15$ to $14+44$ \\
\hline Tptpll & $14+44$ to $23+26$ \\
\hline Tptpln & $23+26$ and $25+85$ \\
\hline
\end{tabular}

Source: Mongano et al. 1999 [DIRS 149850], Table 1.

\subsubsection{Comparison of Model Predictions with Feature Mapping in the Tptpll}

The first part of the validation of the lithophysal porosity model is accomplished by comparing the model prediction to the ECRB lithophysae mapping results documented in the Drift Degradation Analysis (BSC 2004 [DIRS 166107], Appendix O) report. The ECRB mapping data consists of a combination of data from angular and tape traverses, panel maps and large lithophysae survey (those lithophysae with one axis $>0.5 \mathrm{~m}$ ) in the Tptpll, in the Drift Degradation Analysis (BSC 2004 [DIRS 166107], Appendix O, Table O-1) report. Note that this analysis was performed prior to the supersession of DTN MO0306MWDDDMIO.001 [DIRS 165791] by MO0408MWDDDMIO.002 [DIRS 171483]. There are no significant changes in the large lithophysae mapping data presented in MO0408MWDDDMIO.002 [DIRS 171483], between stations $14+40$ to $17+55$, for which the model and mapping data are compared.

The tape traverses were made on 5-m intervals between stations $14+05$ and $23+35$, the angular traverses were made at 22 locations between stations 14+60 and 22+00, and the panel maps were made at 18 locations between stations 14+93 to 22+94 (BSC 2004 [DIRS 166107], Appendix O, Table O-1). The large lithophysae mapping was limited to the ECRB region between stations 14+40 and 17+55 (BSC 2004 [DIRS 166107], Appendix O, Table O-1). In contrast, the resolution of the model grid elements is $50 \mathrm{~m} \times 50 \mathrm{~m}$ x $4.57 \mathrm{~m}$ in the Tptpll (Table 6-2).

The model evaluation is accomplished by first converting the ECRB station coordinates corresponding to the locations of the panel maps (DTN: MO0208GSC02103.000 [DIRS 169978]) into stratigraphic coordinates as discussed in Section 6.1.2. Using these coordinates, the utility software POINT V. 1.0 (STN: 10826-1.0-00 [DIRS 158336], Table 3-1) locates the desired grid element and then reports the parameter values for all 50 realizations. Statistical measures of the resulting model data are used to characterize the local expected value and uncertainty of the lithophysal porosity model at each location and these results are compared to the mapping data in Figures 7-5a and 7-5b below. 


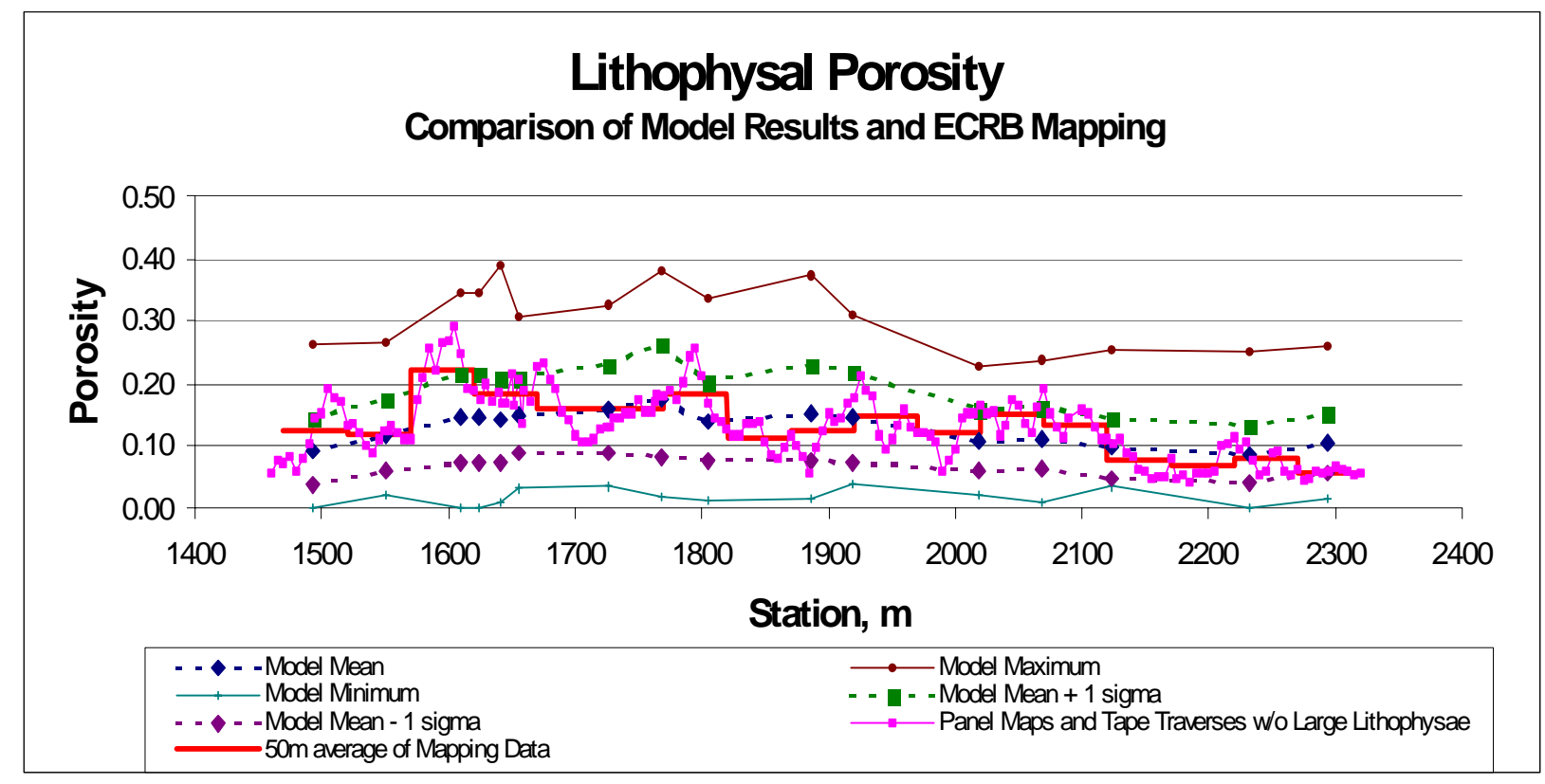

Input DTN: MO0306MWDDDMIO.001 [DIRS 165791]; Output DTN: SN0406T0503102.012 [DIRS 170045].

Figure 7-5a. Comparison of Model Results and ECRB Mapping (Without Large Lithophysae Data)

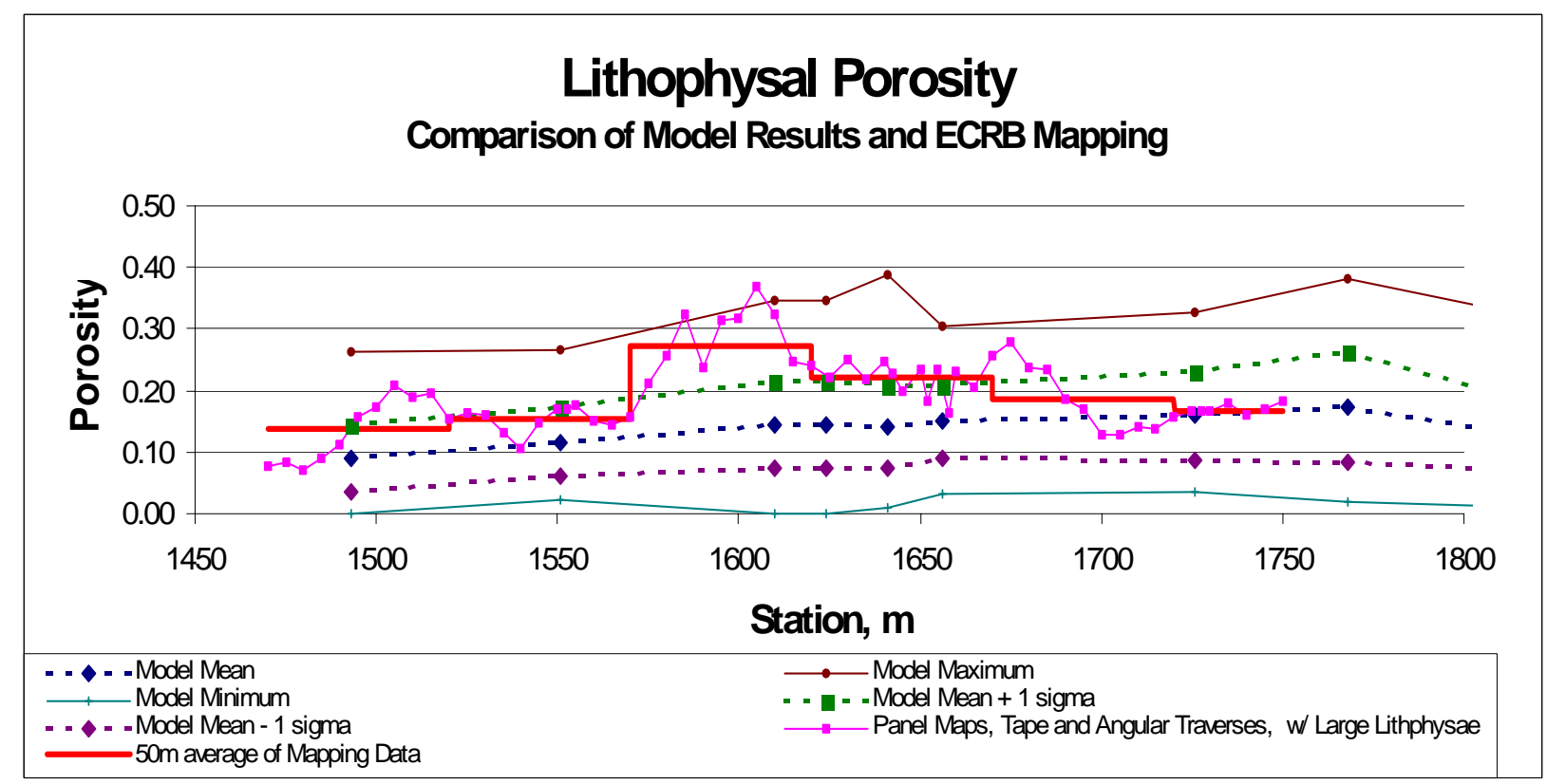

Input DTN: MO0306MWDDDMIO.001 [DIRS 165791]; Output DTN: SN0406T0503102.012 [DIRS 170045].

Figure 7-5b. Comparison of Model Results and ECRB Mapping (Including Large Lithophysae Data) 
The mapping data shown in Figure 7-5a, which do not include the large lithophysae mapping data, are bounded by the maximum and minimum values predicted by the model. Along most of the Tptpll, the mapping data are bounded by the mean \pm 1 standard deviation. The mean value for the Tptpll predicted by the model was 12.9 percent, which compares well with the mean of the combined panel maps, tape and angular traverses of 13.1 percent. The mapping data show greater variability compared to the model, which is due to the greater spatial frequency of data collection (few meters) compared to the model cell size $(50 \mathrm{~m})$. As stated in Section 6.1.2, the model grid size of $50 \mathrm{~m}$ was selected for consistency with the grid size of other models that use thermal conductivity as input. For illustrative comparison, the 5-m mapping data has also been averaged over $50-\mathrm{m}$ intervals and is seen to generally lie within the mean \pm 1 standard deviation predicted by the model.

Large lithophysae $(>0.5 \mathrm{~m})$ were originally mapped over a much shorter drift section of approximately $300 \mathrm{~m}$ in length. A second phase of the inventory was completed from $17+60$ to 25+35 (BSC 2004 [DIRS 166107], Appendix O4); however, the large lithophysae mapping data from this second phase were not available when these model validation activities were being performed.

The effect of incorporating the large lithophysae in the panel map, tape, and angular traverse data, and the comparison of these data with the model predictions is shown in Figure 7-5b. There are two locations in this mapping region (between station $16+00$ and $16+50$ ) where the maximum lithophysal porosity predicted by the model is exceeded by the mapping data, though only by a small amount. The model does however predict lithophysal porosity approaching 40 percent which agrees with the highest observed in the drift survey. A more appropriate evaluation is made when the 5-m data is averaged over the same scale used in the model development $(50 \mathrm{~m})$. In this case, the majority of the mapping data over the $300-\mathrm{m}$ drift length fall within the mean \pm 1 standard deviation predicted by the model. Since the lithophysal porosity estimated with the model was based entirely on the interpretation of the petrophysical data, it is potentially affected by any bias in the data upon which the model is constructed. It is possible that some borehole log data showing low bulk density values (i.e. in zones with potentially large lithophysal porosity) were interpreted as being adversely influenced by the drilling process, and not as an indication of higher lithophysal porosity. In such cases the low bulk density data in the suspect regions may have been edited out in the logs, thus leading to an underestimation of the lithophysal porosity in these parts of the borehole logs. This could lead to overestimation of bulk thermal conductivity. Note that the range of lithophysal porosity predicted by the model is quite large over the region for which the comparisons have been made. Modeling activities that incorporate lithophysal porosity should examine the sensitivity to the spatial variability and uncertainty of this parameter.

\subsubsection{Lithophysal Porosity in Thermal Conductivity Test Areas}

In this section, lithophysal porosity data (DTN: SN0205F3504502.010 [DIRS 159144], SEP Table S02126_001) are examined based on video recording of lithophysae features in the boreholes drilled in support of thermal conductivity field tests: ECRB Thermal Conductivity Tests 1, 2, and 3 (Howard 2002 [DIRS 159152]). Test 1 used two boreholes, one for the heater and the other for the thermocouples. Test 2 used six boreholes; three heater holes and three thermocouple holes. Test 3 used three holes; one heater and two thermocouple holes. Thus, a 
total of eleven boreholes were examined for this evaluation: ECRB-THERMK-001 and ECRB-THERMK-002 for the ECRB Thermal Conductivity Test 1; ECRB-THERMK-003, ECRB-THERMK-004, ECRB-THERMK-005, ECRB-THERMK-006, ECRB-THERMK-007, ECRB-THERMK-008 for ECRB Thermal Conductivity Test 2; and ECRB-THERMK-009, ECRB-THERMK-010, and ECRB-THERMK-011 for ECRB Thermal Conductivity Test 3. All three tests were performed in the Tptpll and are similar in construction (Howard 2002 [DIRS 159152]).

In ECRB Test 1 (Figure 7-6), the holes ECRB-THERMK-001 (for the heater element) and ECRB-THERMK-002 (for the thermocouple assembly) are oriented perpendicularly to each other and are separated in elevation by approximately $0.1 \mathrm{~m}$. Figure 7-6 illustrates the heater and thermocouple arrangement used in the two-hole heater test performed in the lower lithophysal unit. The heater, $5 \mathrm{~m}$ in length, was inset $3 \mathrm{~m}$ from the ECRB drift wall. A 5-m long array of 30 thermocouples was placed in a second borehole.

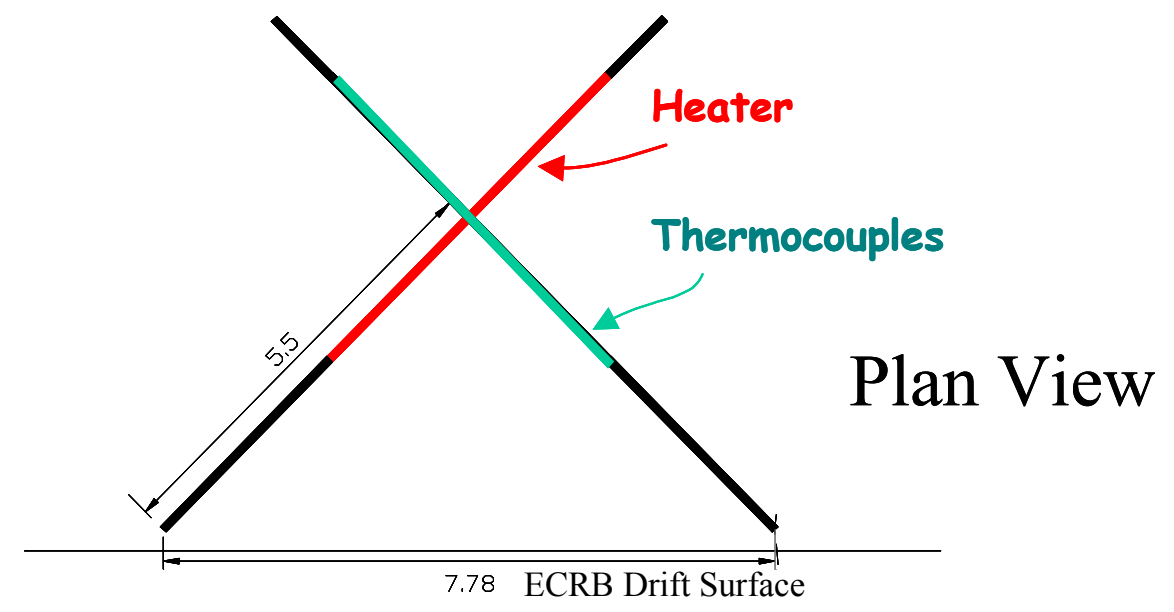

Source: Howard 2002 [DIRS 159152], pages 16 and 38.

Figure 7-6. ECRB Thermal Conductivity Test 1 and Test 3 Layout

In ECRB Test 2 (Figure 7-7), three heater holes and three thermocouple holes were used. The heater holes, ECRB-THERMK-003, ECRB-THERMK-004, and ECRB-THERMK-005, were spaced approximately $0.5 \mathrm{~m}$ apart in a horizontal plane. The three thermocouple holes, ECRB-THERMK-006, ECRB-THERMK-007, and ECRB-THERMK-008 were oriented perpendicularly to the heater holes in plan view. ECRB-THERMK-006 was angled downward from the drift wall and passed $0.6 \mathrm{~m}$ (center-to-center) below the middle heater hole, ECRB-THERMK-004. ECRB-THERMK-008 was angled upward from the drift wall and passed approximately $0.6 \mathrm{~m}$ (center-to-center) above the middle heater hole. ECRB-THERMK-007 was horizontally drilled and passed $0.2 \mathrm{~m}$ (center-to-center) above the middle heater hole. In plan view, these three thermocouple boreholes were spaced $1 \mathrm{~m}$ apart. 
In ECRB Test 3 (Figure 7-6), ECRB-THERMK-009 (the heater element) was located between and oriented perpendicularly to the two boreholes, ECRB-THERMK-010 and ECRB-THERMK-011, containing the thermocouple assemblies. Approximately $0.4 \mathrm{~m}$ of distance separates the central borehole, ECRB-THERMK-009, from the other two holes. In the plan view ECRB-THERMK-010 and ECRB-THERMK-011 overlay each other.

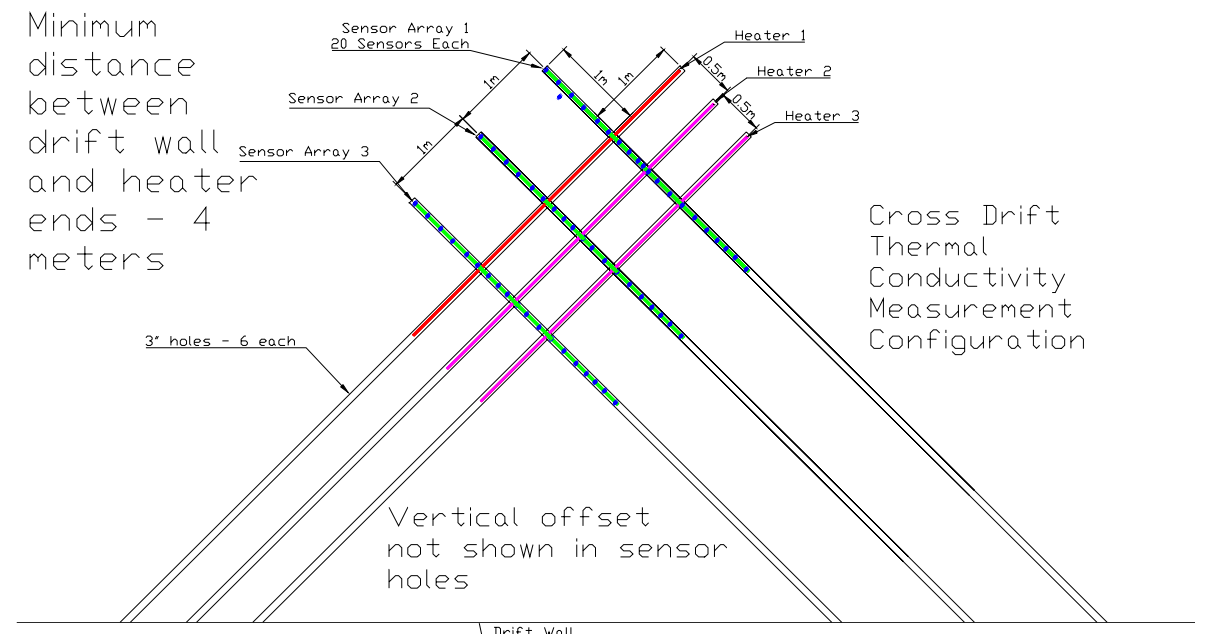

Source: After Howard 2002 [DIRS 159152], p. 41.

Figure 7-7. ECRB Thermal Conductivity Test 2 Layout

The locations and mean lithophysal porosities for each of the holes are presented in Table 7-2. The mean lithophysal porosity data from the borehole video are compared with predictions based on the geostatistically derived realizations. To perform this comparison it is necessary to determine the discretized grid element in which the borehole resides. The resolution of the grid elements is $50 \mathrm{~m} \times 50 \mathrm{~m} \times 4.57 \mathrm{~m}$ in the Tptpll (Table 6-2). This is accomplished by first converting the borehole coordinates into stratigraphic coordinates as discussed in Section 6.1.2. Using these coordinates, the utility software POINT V. 1.0 (STN: 10826-1.0-00 [DIRS 158336], Table 3-1) locates the desired grid element and then reports the parameter values for all 50 realizations. Statistical measures of the resulting data are used to characterize the local expected value and uncertainty of the lithophysal porosity model. Figures 7-8, 7-9, and 7-10 illustrate the histograms for lithophysal porosity at each test location, along with relevant statistics for each data set. 
Table 7-2. Borehole Locations and Mean Lithophysal Porosity for ECRB Thermal Conductivity Tests 1, 2, and 3

\begin{tabular}{|c|c|c|c|c|c|c|}
\hline Test & Borehole & Northing $\mathrm{m}$ & Easting $\mathrm{m}$ & Elevation $\mathrm{m}$ & $\begin{array}{c}\text { ECRB } \\
\text { Station } \mathrm{m}\end{array}$ & $\begin{array}{l}\text { Mean Lithophysal } \\
\text { Porosity } \%{ }^{3}\end{array}$ \\
\hline $\begin{array}{l}\text { Test } 1^{1} \\
\text { (2-Hole Test) }\end{array}$ & $\begin{array}{l}\text { ECRB-THERMK-001 } \\
\text { ECRB-THERMK-002 }\end{array}$ & $\begin{array}{l}233,311.0 \\
233,305.8\end{array}$ & $\begin{array}{l}170,706.1 \\
170,700.2\end{array}$ & $\begin{array}{l}1,107.8 \\
1,107.9\end{array}$ & $\begin{array}{l}15+62.2 \\
15+70.0\end{array}$ & $\begin{array}{c}8.1 \\
18.9\end{array}$ \\
\hline $\begin{array}{l}\text { Test } 2^{2} \\
\text { (6-Hole Test) }\end{array}$ & $\begin{array}{l}\text { ECRB-THERMK-003 } \\
\text { ECRB-THERMK-004 } \\
\text { ECRB-THERMK-005 } \\
\text { ECRB-THERMK-006 } \\
\text { ECRB-THERMK-007 } \\
\text { ECRB-THERMK-008 }\end{array}$ & $\begin{array}{l}233,333.5 \\
233,333.0 \\
233,332.5 \\
233,325.7 \\
233,324.8 \\
233,323.8\end{array}$ & $\begin{array}{l}170,731.9 \\
170,731.4 \\
170,730.8 \\
170,722.9 \\
170,721.9 \\
170,720.9\end{array}$ & $\begin{array}{l}1,106.9 \\
1,106.8 \\
1,106.9 \\
1,106.8 \\
1,107.1 \\
1,107.1\end{array}$ & & $\begin{array}{c}23.0 \\
19.1 \\
15.4 \\
22.4 \\
17.0 \\
7.8\end{array}$ \\
\hline $\begin{array}{l}\text { Test } 3^{1} \\
\text { (3-Hole Test) }\end{array}$ & $\begin{array}{l}\text { ECRB-THERMK-009 } \\
\text { ECRB-THERMK-010 } \\
\text { ECRB-THERMK-011 }\end{array}$ & $\begin{array}{l}233,195.7 \\
233,190.6 \\
233,190.7\end{array}$ & $\begin{array}{l}170,573.7 \\
170,567.9 \\
170,567.8\end{array}$ & $\begin{array}{l}1,109.3 \\
1,109.6 \\
1,109.1\end{array}$ & $\begin{array}{l}17+37.7 \\
17+45.4 \\
17+45.5\end{array}$ & $\begin{array}{l}24.8 \\
20.0 \\
31.5\end{array}$ \\
\hline
\end{tabular}

${ }^{1}$ Survey data (Northing, Easting, Elevation and ECRB Station) for Test 1 and Test 3 provided by Input DTN: MO0205GSC02070.000 [DIRS 159148].

${ }^{2}$ Survey data (Northing, Easting, Elevation ) for Test 2 boreholes provided by:

ECRB-THERMK-003 (BSC 2001 [DIRS 169604], ECRB-THERMK-004 (BSC 2001 [DIRS 169605], ECRB-THERMK-005 (BSC 2001 [DIRS 169606], ECRB-THERMK-006 (BSC 2001 [DIRS 169607], ECRB-THERMK-007 (BSC 2001 [DIRS 169607], and ECRB-THERMK-008 (BSC 2001 [DIRS 169607].

${ }^{3}$ Lithophysal porosity data provided by input DTN: SN0205F3504502.010 [DIRS 159144] (SEP Table S02126_001).

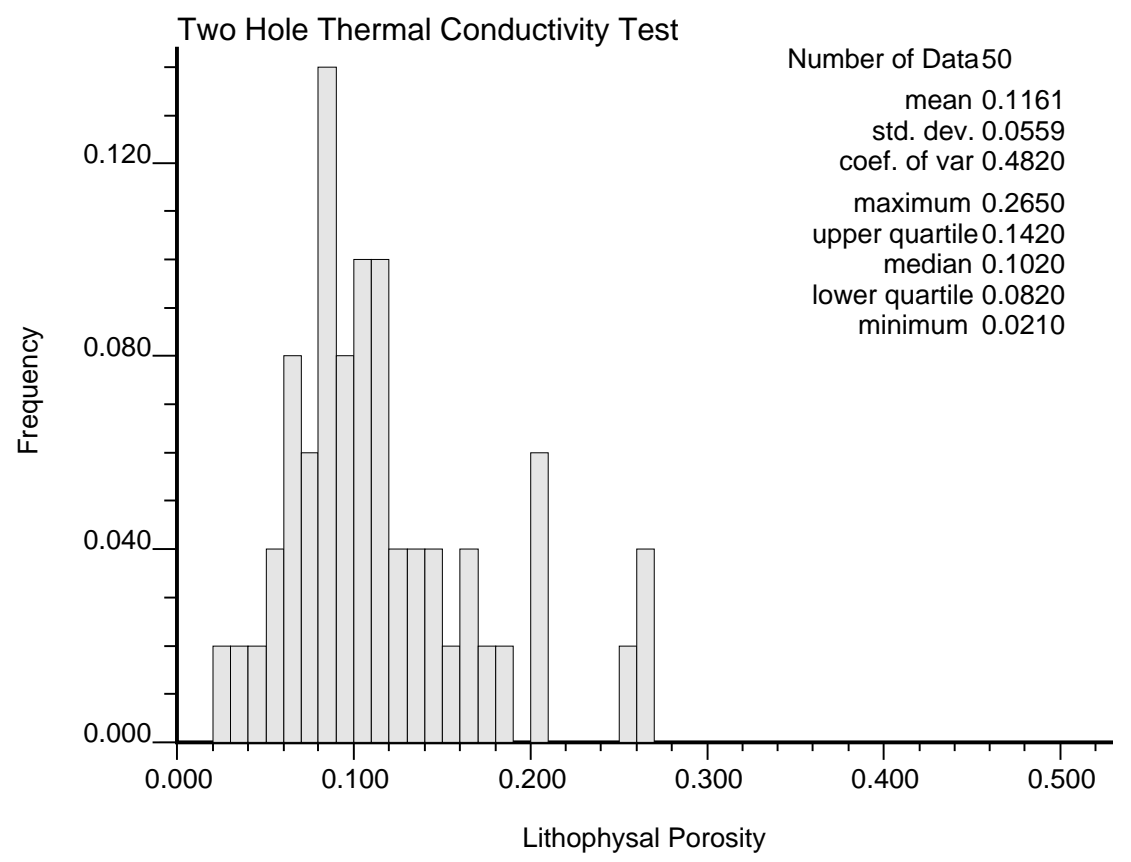

Output DTN: SN0404T0503102.011 [DIRS 169129].

Figure 7-8. Model Prediction of Lithophysal Porosity at Site of ECRB Thermal Conductivity Test 1 


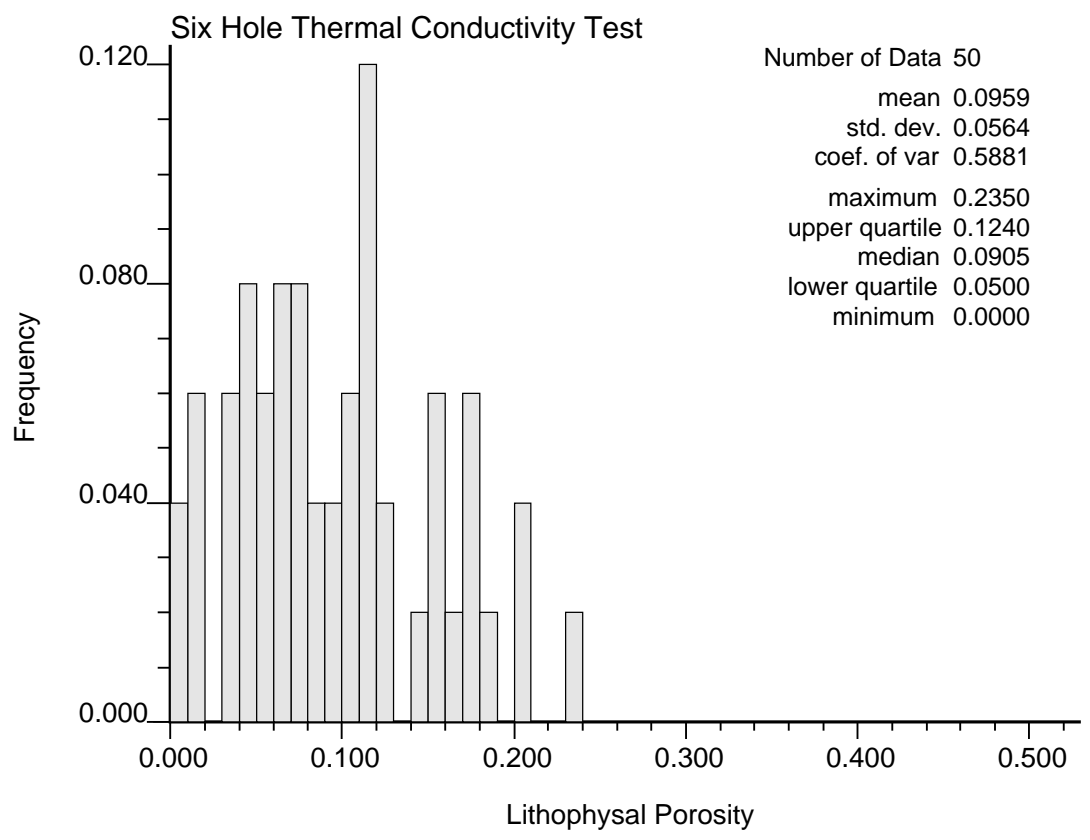

Output DTN: SN0406T0503102.012 [DIRS 170045].

Figure 7-9. Model Prediction of Lithophysal Porosity at Site of ECRB Thermal Conductivity Test 2

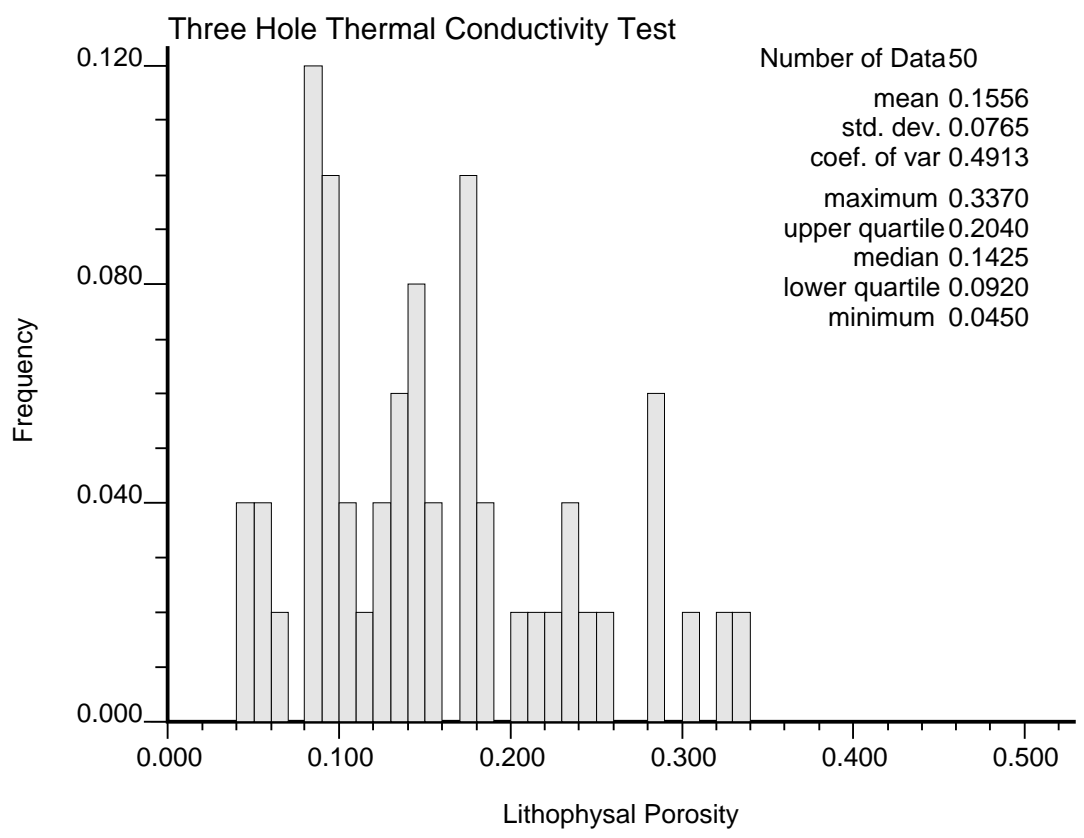

Output DTN: SN0404T0503102.011 [DIRS 169129].

Figure 7-10. Model Prediction of Lithophysal Porosity at Site of ECRB Thermal Conductivity Test 3 
For ECRB Test 1, the average measured lithophysal porosity over the length of borehole ECRB-THERMK-001 was 8.1 percent and over the length of ECRB-THERMK-002 was 18.9 percent (Table 7-2). The large difference in these values illustrates the variability of lithophysal porosity over relatively short distances. The geostatistically derived mean lithophysal porosity for the ECRB Test 1 site was 11.6 percent, with a standard deviation of 5.6 percent. For the 50 realizations the lithophysal porosity ranged from a minimum value of 2.1 percent to a maximum of 26.5 percent (Figure 7-8).

For ECRB Test 2, the average lithophysal porosity over the length of the boreholes varied between a minimum value of 7.8 percent for borehole ECRB-THERMK-008 to a maximum value of 23.0 percent for ECRB-THERMK-003 (Table 7-2). The geostatistically derived mean lithophysal porosity for this test site was 9.6 percent, with a standard deviation of 5.6 percent. For all 50 realizations, lithophysal porosity ranged from a minimum value of 0.0 percent to a maximum of 23.5 percent (Figure 7-9).

For ECRB Test 3, the average lithophysal porosity over the length of borehole ECRB-THERMK-009 was 24.8 percent, for ECRB-THERMK-010 the porosity was 20 percent, and for ECRB-THERMK-011 the porosity was 31.5 percent (Table 7-2). Similar to ECRB Tests 1 and 2, the mean lithophysal porosity shows significant variability. The geostatistically derived mean lithophysal porosity for this test site was 15.6 percent, with a standard deviation of 7.7 percent. For all 50 realizations, lithophysal porosity ranged from a minimum value of 4.5 percent to a maximum of 33.7 percent (Figure 7-10).

At all three test site locations, the histogram plots show a large range in model predictions of lithophysal porosity. The model predictions are somewhat lower at ECRB Test 1 than at ECRB Test 3, which is consistent with the video logs, which suggests that the model correctly predicts general spatial trends in lithophysal porosity. The eleven borehole lithophysal porosity estimates all lie within the range of the model predictions and thus satisfy the model validation criterion.

It should be noted that the scale of the model predictions is a function of the model cell size $(50 \mathrm{~m})$, and the spacing of the borehole data that the model is based on. The length of the boreholes used in all three tests is much smaller than the 50-m model cell size. The values from these holes possibly express a small-scale variability of the lithophysal porosity. This can also be seen by comparing, for example, the average lithophysal porosity from the three holes of Test 3 ( $\sim 25.4$ percent) with the lithophysal porosity value from the ECRB drift mapping shown on Figure 7-5b. This value between stations $17+37.7$ and $17+45.5$ (the location of the Test 3 boreholes per Table 7-2) is around 17 percent. Considering the effect of local variability, the lithophysal porosity estimates from the video observations are best compared with the range of values, rather than the mean, predicted by the model. Note that the range of lithophysal porosity predicted by the model is quite large at the locations for which the comparisons have been made. Modeling activities that incorporate lithophysal porosity should examine the sensitivity of repository performance measures to the spatial variability and uncertainty predicted by the geostatistical model. 


\subsubsection{Lithophysal Porosity Model Validation: Summary and Conclusions}

Lithophysal porosity model predictions, based on mass conservation equations developed in Appendix A and borehole petrophysical measurements are compared with estimates of lithophysal porosity from mapping data in the ECRB Cross-Drift. Mapping and petrophysical data show substantial variations in lithophysal porosity over small distances. Differences between model predictions and field data are likely due to petrophysical measurement interpretation of borehole logs (which may be responsible for the under-prediction by the model of the observed lithophysal porosity in parts of the ECRB Cross-Drift), differences in scale, and natural spatial variations.

Geostatistically derived values of lithophysal porosity are also compared to data obtained from video observations (DTN: SN0205F3504502.010 [DIRS 159144], SEP Table S02126_001) of eleven boreholes drilled for the ECRB Thermal Conductivity Tests 1, 2, and 3 (Howard 2002 [DIRS 159152]). The video data fall within the range of values predicted by the model. The high degree of spatial variability demonstrated by the video data supports the large range of possible values predicted by the model and the underlying model uncertainty at each location.

The lithophysal porosity model satisfactorily meets the validation criteria for both the ECRB and borehole comparisons and is sufficiently accurate and adequate for its intended use. The spatial variability and range of lithophysal porosity predicted by the geostatistical model and exhibited by the field mapping data should be evaluated by users of this data to assess the importance of this parameter with regard to repository performance measures.

\subsection{MATRIX THERMAL CONDUCTIVITY MODEL VALIDATION}

The matrix thermal conductivity model is validated by comparing the geostatistically derived model realizations of matrix thermal conductivity to matrix conductivity data from laboratory tests on core samples. The laboratory test data used in this comparison were not used to calibrate or condition the geostatistical model realizations during model development. These data are, therefore, provide an independent set of data appropriate for validation of the matrix thermal conductivity model.

The data consist of 10 samples acquired from Alcove 7 (DTN: SNL22100196001.002 [DIRS 153138]) and 20 samples acquired from the Drift Scale Test area in Alcove 5 (DTN: SN0203L2210196.007 [DIRS 158322]). The Alcove 7 samples were measured under $\mathrm{OD}$ conditions at $110^{\circ} \mathrm{C}$, and the Alcove 5 samples were measured after being saturated with water at $70^{\circ} \mathrm{C}$.

Model predictions under both wet and dry conditions are, therefore, examined in this validation exercise. As indicated in Section 2.2.1.1 of the technical work plan (BSC 2004 [DIRS 171708]), the matrix thermal conductivity model is considered valid because, as shown below, the measured values of matrix thermal conductivity are within the bounds predicted by the model for the locations of Alcove 7 and Alcove 5.

The parameters defining the matrix thermal conductivity model were not developed specifically for each individual layer. As noted in Section 6.1.7, of the three uncertain parameters which 
define the matrix thermal conductivity model, $\mathrm{k}_{\mathrm{s}}$ and $\gamma_{\mathrm{c}}$ were simulated unconditionally (same distribution for all layers, Figure 6-11) while matrix porosity was treated as a conditioned variable (Figure 6-8). Therefore, while the validation described in Section 7.4.1 is based on comparison of model predictions with corroborative data obtained from the Tptpmn, the model is also appropriate and adequate for the remaining layers considered in this report.

\subsubsection{Comparison of Matrix Thermal Conductivity Model to Laboratory Data}

To compare laboratory experimental results with model predictions, it is first necessary to determine the discretized grid element in which the core sample resides. This is accomplished by first converting the sample coordinates into stratigraphic coordinates as discussed in Section 6.1.2. Using these coordinates, the utility software POINT (Table 3-1) locates the desired grid element and then reports the parameter values for this element for all realizations. Statistical measures of the resulting output are used to characterize the models' local expected value and local uncertainty.

Both Alcove 5 and Alcove 7 are located within the middle nonlithophysal zone, Tptpmn. The conversion to stratigraphic coordinates thus requires estimates of the upper and lower lithostratigraphic contacts for the Tptpmn. The required inputs and the computed stratigraphic elevations are tabulated in Table 7-3

Table 7-3. Stratigraphic Coordinates of Alcove 5 and Alcove 7 Core Samples

\begin{tabular}{|l|c|c|c|c|c|c|}
\hline \multicolumn{1}{|c|}{ Location } & $\begin{array}{c}\text { Northing } \\
\text { (feet) }\end{array}$ & $\begin{array}{c}\text { Easting } \\
\text { (feet) }\end{array}$ & $\begin{array}{c}\text { Elevation } \\
\text { (feet) }^{-}\end{array}$ & $\begin{array}{c}\text { Top of } \\
\text { Tptpmn } \\
\text { (feet) }\end{array}$ & $\begin{array}{c}\text { Bottom of } \\
\text { Tptpmn }{ }^{2} \\
\text { (feet) }\end{array}$ & $\begin{array}{c}\text { Stratigraphic } \\
\text { Elevation (feet) }\end{array}$ \\
\hline $\begin{array}{l}\text { End centerline (face) at } \\
\text { invert of the Alcove 5 } \\
\text { Turnaround Niche }\end{array}$ & $767,869.9$ & $562,125.8$ & $3,489.5$ & $3,516.2$ & $3,397.9$ & 92.9 \\
\hline $\begin{array}{l}\text { Right Rib Alcove 7, } \\
\text { Station 0+88, on invert }\end{array}$ & $76,0592.0$ & $561,952.6$ & $3,610.6$ & $3,680.3$ & $3,543.8$ & 58.7 \\
\hline
\end{tabular}

${ }^{1}$ Survey data provided by input DTN: MO0205GSC02068.000 [DIRS 159147].

${ }^{2}$ Lithostratigraphic contacts derived from the Geologic Framework Model (GFM 2000) (Input DTN: MO0012MWDGFM02.002 [DIRS 153777]).

${ }^{3}$ Location data Alcove 7 samples provided by YMP 1997 [DIRS 159151].

Histogram plots of matrix thermal conductivity, specific to the coordinates provided in Table 7-3, are presented in Figure 7-11. These plots show model predictions of matrix thermal conductivity from all 50 realizations for the discretized locations that represent Alcove 5 and Alcove 7. In Figure 7-11(a), the water saturated (wet) matrix thermal conductivity for Alcove 5 is presented, and in Figure 7-11(b), the OD (dry) matrix thermal conductivity for Alcove 7 is presented. At both locations the spread in the data is rather broad, reflecting a high degree of uncertainty in the model predictions of matrix thermal conductivity at these particular locations. 


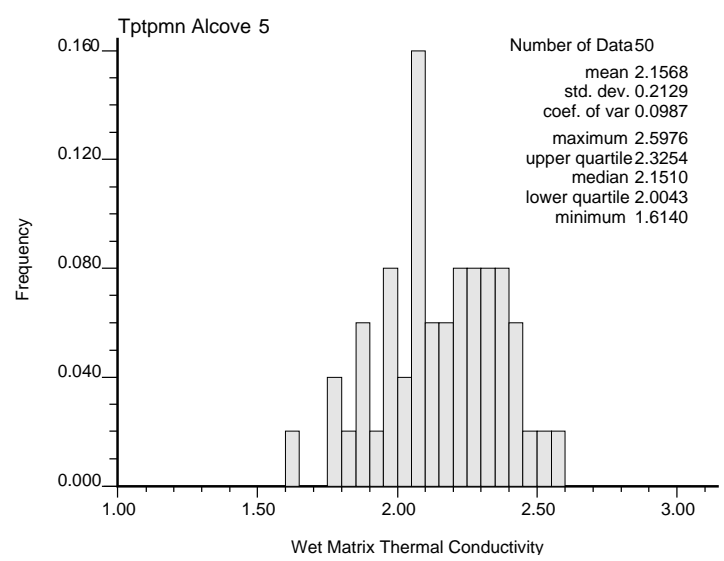

(a)

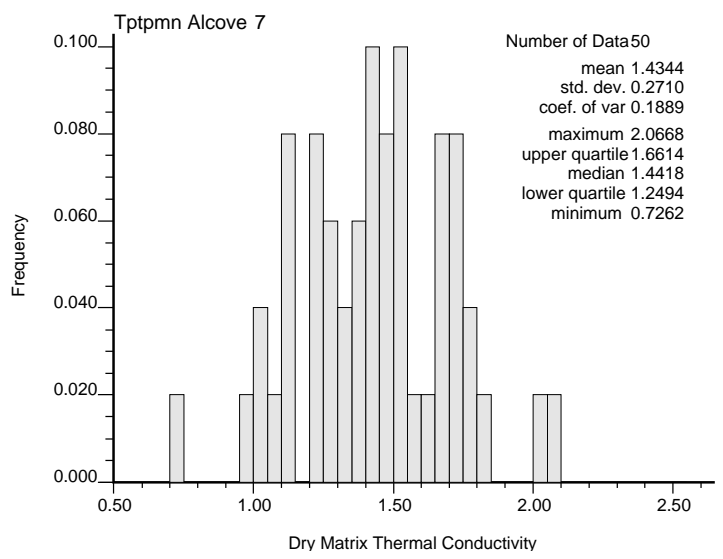

(b)

Output DTN: SN0404T0503102.011 [DIRS 169129].

Figure 7-11. Model Predictions of Matrix Thermal Conductivity (W/mK) at (a) Alcove 5 and (b) Alcove 7

The laboratory measurements from both Alcove 5 and Alcove 7 are fairly consistent across all specimens. Consequently, the specimen means may be interpreted as the "true" value of matrix thermal conductivity at their respective locations. These ranges of the experimental data and their mean values and associated standard deviations are given in Table 7-4.

Table 7-4. Statistical Measures of Alcove 5 and Alcove 7 Thermal Conductivity Measurements

\begin{tabular}{|l|c|c|c|c|}
\hline Location & $\begin{array}{c}\text { Number of } \\
\text { Samples }\end{array}$ & $\begin{array}{c}\text { Range of Sample } \\
\text { Thermal Conductivity } \\
\text { (W/mK) }\end{array}$ & $\begin{array}{c}\text { Mean Thermal } \\
\text { Conductivity } \\
\text { (W/mK) }\end{array}$ & $\begin{array}{c}\text { Standard Deviation } \\
\text { (W/mK) }\end{array}$ \\
\hline Alcove 5 & 20 & $1.9-2.3$ & 2.1 (wet) & 0.1 \\
\hline Alcove 7 & 10 & $1.63-1.67$ & 1.66 (dry) & 0.01 \\
\hline
\end{tabular}

Input DTN: SN0203L2210196.007 [DIRS 158322]; SNL22100196001.002 [DIRS 153138]).

NOTE: The Alcove 5 samples were tested at $70^{\circ} \mathrm{C}$ and the Alcove 7 samples were tested at $110^{\circ} \mathrm{C}$.

Comparisons of the experimentally derived mean values with the model predictions are quite good. In the case of Alcove 5, the experimental mean value of 2.1 is nearly equal to the mean prediction of 2.16 (Figure 7-11(a)). For Alcove 7, the experimental mean value of 1.66 is equal to the lower bound of the upper quartile and is also within one standard deviation, 0.27 , of the mean, 1.43 (Figure 7-11(b)). For Alcove 7, the model predictions range from 0.73 to 2.07 and for Alcove 5, the model predictions range from 1.61 to 2.60. In all cases, the experimental data fall within the range of the model predictions.

\subsubsection{Matrix Thermal Conductivity Model Validation: Summary and Conclusions}

Experimental thermal conductivity measurements of samples extracted from Alcoves 5 and 7 are compared with model predictions of wet and dry thermal conductivity. At both locations, the range in predictions is quite broad, indicating a relatively high level of model uncertainty. The uncertainty is a result of propagating uncertainties in each of the parameters, which define the model. The matrix thermal conductivity model satisfies the validation criterion and is sufficient 
and adequate for its intended use. Modeling activities incorporating matrix thermal conductivity should examine the sensitivity of repository performance measures to the spatial variability and uncertainty expressed by the geostatistical model.

\subsection{BULK THERMAL CONDUCTIVITY MODEL VALIDATION}

The bulk thermal conductivity model is validated by comparing the geostatistically derived model realizations of bulk thermal conductivity, at the approximate locations of the ECRB Thermal Conductivity Test 1, Test 2, and Test 3 (Howard 2002 [DIRS 159152]), with estimates of bulk thermal conductivity from these three field tests. These ECRB field test results were not used to calibrate or condition the geostatistical model realizations during model development and thus provide the independent set of data necessary for the validation of the bulk thermal conductivity model. The bulk thermal conductivity model is considered valid because, as shown below, the field test values of bulk thermal conductivity are within the maximum and minimum bounds predicted by the 50 realizations of the geostatistical model.

While the validation of the bulk thermal conductivity model described in Section 7.5.1 is based on comparison of model predictions and estimates of thermal conductivity from three tests performed in the Tptpll, the model is also appropriate and adequate for the remaining layers considered in this report because the model development is identical for all layers.

\subsubsection{ECRB Thermal Conductivity Tests 1, 2, and 3}

Figure 7-6 illustrates the heater and thermocouple arrangement used in ECRB Thermal Conductivity Test 1 (Howard 2002 [DIRS 159152]) performed in the lower lithophysal unit, Tptpll. The heater, $5 \mathrm{~m}$ in length, was inset $3 \mathrm{~m}$ from the ECRB drift wall. A 5-m long array of 30 thermocouples was placed in a second borehole. The thermocouple borehole was located $12 \mathrm{~cm}$ above the heater borehole. The thermocouple and heater boreholes were oriented to be perpendicular to each other. Insulation was placed in front of and after the heater and thermocouple assemblies to prevent heat loss from the boreholes. The data available from the test consist of temperatures as a function of time at the thermocouple locations.

Figure 7-7 illustrates the heater and thermocouple arrangement used in ECRB Thermal Conductivity Test 2 (Howard 2002 [DIRS 159152]). Three heater holes and three thermocouple holes were used. The heater holes, ECRB-THERMK-003, ECRB-THERMK-004, and ECRB-THERMK-005, were spaced approximately $0.5 \mathrm{~m}$ apart in a horizontal plane. The three thermocouple holes, ECRB-THERMK-006, ECRB-THERMK-007, and ECRB-THERMK-008, were oriented perpendicular to the heater holes in plan view. ECRB-THERMK-006 was angled downward from the drift wall and passed $0.6 \mathrm{~m}$ (center-to-center) below the middle heater hole, ECRB-THERMK-004. ECRB-THERMK-008 was angled upward from the drift wall and passed approximately $0.6 \mathrm{~m}$ (center-to-center) above the middle heater hole. ECRB-THERMK-007 was horizontally drilled and passed $0.2 \mathrm{~m}$ (center-to-center) above the middle heater hole. In plan view, these three thermocouple boreholes were spaced $1 \mathrm{~m}$ apart. Each thermocouple assembly consisted of 30 thermocouples.

ECRB Thermal Conductivity Test 3 (Howard 2002 [DIRS 159152]) is very similar to Test 1 . In this test, two boreholes were drilled for emplacement of thermocouple assemblies. The 
thermocouple boreholes were drilled approximately $0.4 \mathrm{~m}$ above (ECRB-THERMK-010) and below (ECRB-THERMK-011) the heater borehole (ECRB-THERMK-009). Each thermocouple assembly consisted of 30 thermocouples.

The heater assembly used in the ECRB Thermal Conductivity Tests can be mathematically represented as a finite line heat source. The temperatures around a finite length and diameter source heater may be computed by representing the heater as a series of small overlapping spheres, each with a diameter equal to the borehole diameter. Using the principle of superposition (Carslaw and Jaeger 1959 [DIRS 100968], p. 262), the temperature at a specified time and location is calculated by summing the contributions from each sphere. When heat conduction is the primary mode of heat transfer and the rock is both homogeneous and isotropic, the temperature at any distance from a heated sphere can be calculated using Equation 7-1 (Carslaw and Jaeger 1959 [DIRS 100968], p. 248, Equation 4).

$$
v=\frac{a^{2} F_{0}}{K r}\left\{\operatorname{erfc} \frac{r-a}{2(k t)^{1 / 2}}-\exp \left\lfloor\frac{r-a}{a}+\frac{k t}{a^{2}}\right\rfloor \operatorname{erfc}\left[\frac{r-a}{2(k t)^{1 / 2}}+\frac{(k t)^{1 / 2}}{a}\right]\right\}
$$

where:

$$
\begin{aligned}
& v=\text { Temperature }(\mathrm{K}) \\
& a=\text { Radius of sphere }(\mathrm{m}) \\
& F_{0}=\text { Heat flux at surface of sphere }\left(\mathrm{W} / \mathrm{m}^{2}\right) \\
& K=\text { Thermal conductivity }(\mathrm{W} / \mathrm{mK}) \\
& r=\text { Distance from center of sphere to measurement point }(\mathrm{m}) \\
& k=\text { Thermal diffusivity }\left(\mathrm{m}^{2} / \mathrm{s}\right) \\
& t=\text { Time }(\mathrm{s}) .
\end{aligned}
$$

Table 7-5. Summary of Results of ECRB Thermal Conductivity Tests 1, 2, and 3

\begin{tabular}{|c|c|c|}
\hline Test & Borehole & Bulk Thermal Conductivity (W/mK) \\
\hline 1 & ECRB-THERMK-002 & $1^{1.74^{1}}$ \\
\hline \multirow{2}{*}{2} & ECRB-THERMK-006 & 2.18 \\
& ECRB-THERMK-007 & 2.09 \\
& ECRB-THERMK-008 & 2.03 \\
& ECRB-THERMK-010 & 1.73 \\
3 & ECRB-THERMK-011 & 1.76 \\
& & ${\text { (average }=1.74)^{3}}^{2}$ \\
\hline
\end{tabular}

${ }^{1}$ Data provided by Input DTN: SN0206F3504502.012 [DIRS 159145].

${ }^{2}$ Data provided by Input DTN: SN0208F3504502.019 [DIRS 161883]. A single value of thermal conductivity was calculated using data from ECRB-THERMK-006, ECRB-THERMK-007, and ECRB-THERMK-008.

${ }^{3}$ Data provided by Input DTN: SN0206F3504502.013 [DIRS 159146]. A single value of thermal conductivity was calculated using data from both ECRB-THERMK-010 and ECRB-THERMK-011. 
A total of 1,312 spheres were used to represent each of the 5-m long heater elements. The average measured heat output was $433 \mathrm{~W}$ in Test 1 (DTN: SN0206F3504502.012 [DIRS 159145]), 449W in Test 2 (DTN: SN0207F3504502.015 [DIRS 170044]), and 505.5W in Test 3 (DTN: SN0206F3504502.013 [DIRS 159146]), and the radius of each borehole was $0.0381 \mathrm{~m}$ (1.5 in). Table 7-5 summarizes the values of bulk thermal conductivity determined for each thermocouple string. These thermal conductivity values are based on solutions of Equation 7-1, at each thermocouple location and for the time period of interest, that provide the best fit to the experimental measurements.

Following the procedures described in Section 6.1.8, values of wet and dry bulk thermal conductivity were obtained for all 50 realizations at each test location. Histogram plots of these data are presented in Figures 7-12(a) and (b), 7-13(a) and (b), and 7-14(a) and (b) for Tests 1, 2, and 3 , respectively.

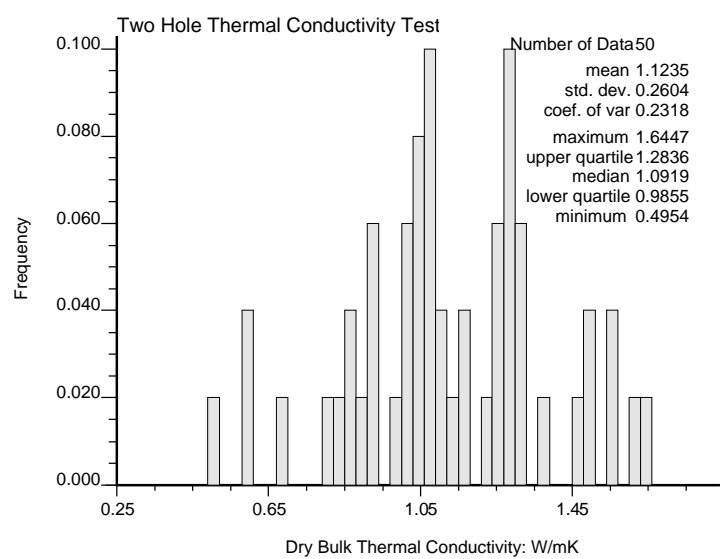

(a) dry

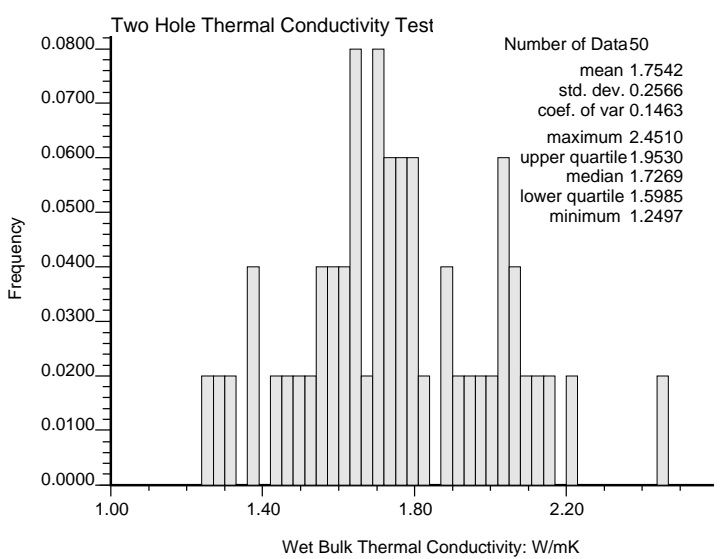

(b) wet

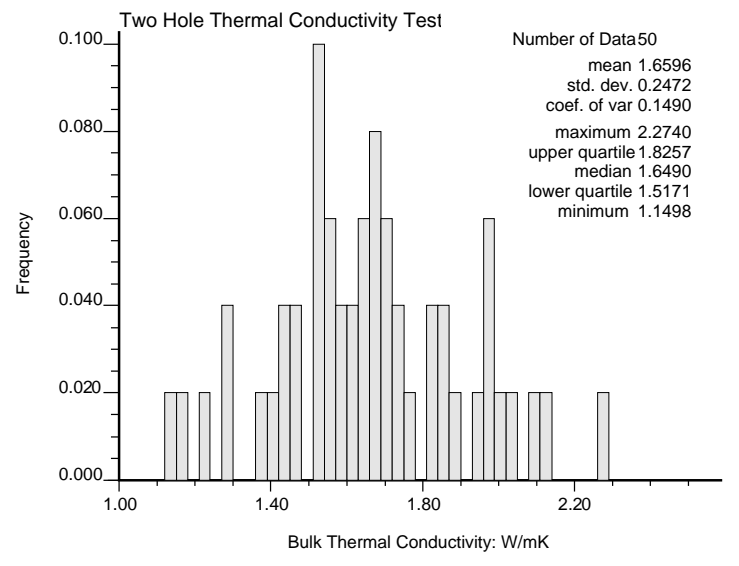

(c) $85 \%$ saturation

Output DTN: SN0404T0503102.011 [DIRS 169129].

Figure 7-12. Model Predictions of Bulk Thermal Conductivity (W/mK) ECRB Thermal Conductivity Test 1 


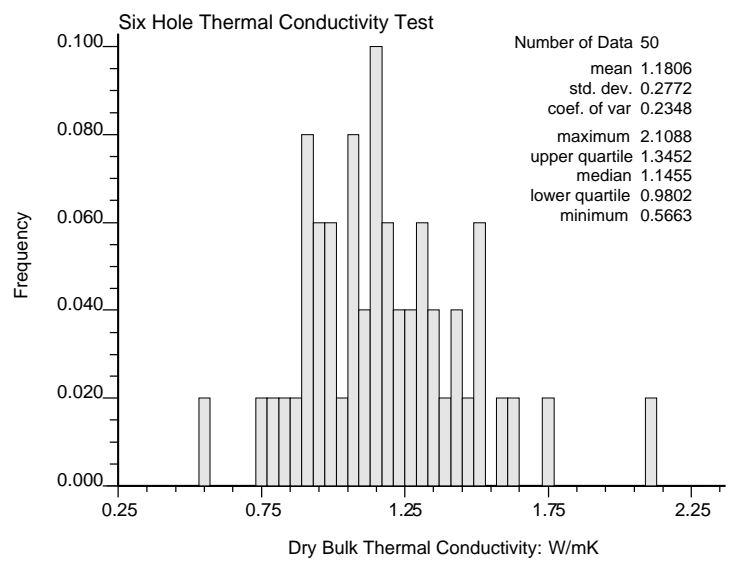

(a) dry

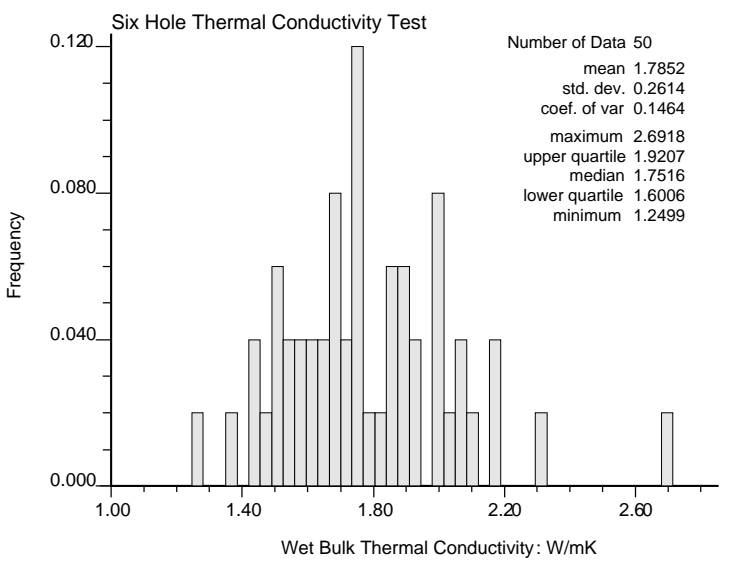

(b) wet

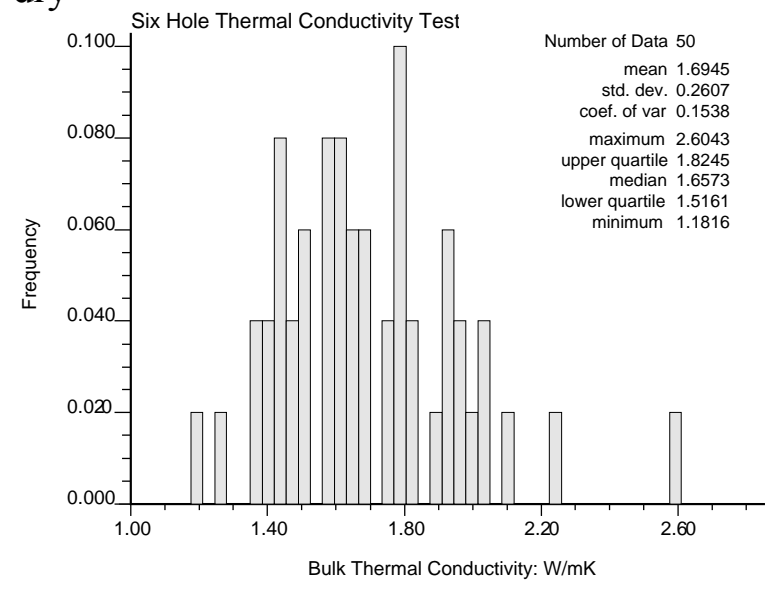

(c) $85 \%$ saturation

Output DTN: SN0406T0503102.012 [DIRS 170045].

Figure 7-13. Model Predictions of Bulk Thermal Conductivity (W/mK) ECRB Thermal Conductivity Test 2

To allow comparison of the experimental results given in Table 7-5 with the model predictions, an equation for bulk thermal conductivity can be derived that accounts for the influence of liquid saturation in the matrix. Expressions for wet and dry bulk thermal conductivity are obtained by substituting the appropriate wet or dry matrix thermal conductivity $\left(\mathrm{k}_{\mathrm{m}}^{\text {wet }}, \mathrm{k}_{\mathrm{m}}^{\mathrm{dry}}\right)$ into Equation 6-1.

$$
\begin{gathered}
\mathrm{k}_{\mathrm{b}}^{\mathrm{wet}}=\phi_{\mathrm{L}} \mathrm{k}_{\mathrm{a}}+\left(1-\phi_{\mathrm{L}}\right) \mathrm{k}_{\mathrm{m}}^{\mathrm{wet}} \\
\mathrm{k}_{\mathrm{b}}^{\mathrm{dry}}=\phi_{\mathrm{L}} \mathrm{k}_{\mathrm{a}}+\left(1-\phi_{\mathrm{L}}\right) \mathrm{k}_{\mathrm{m}}^{\text {dry }}
\end{gathered}
$$




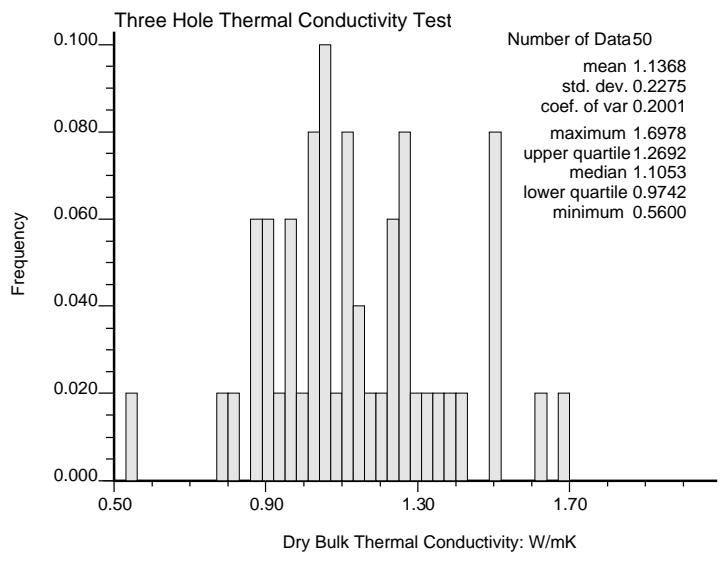

(a) dry

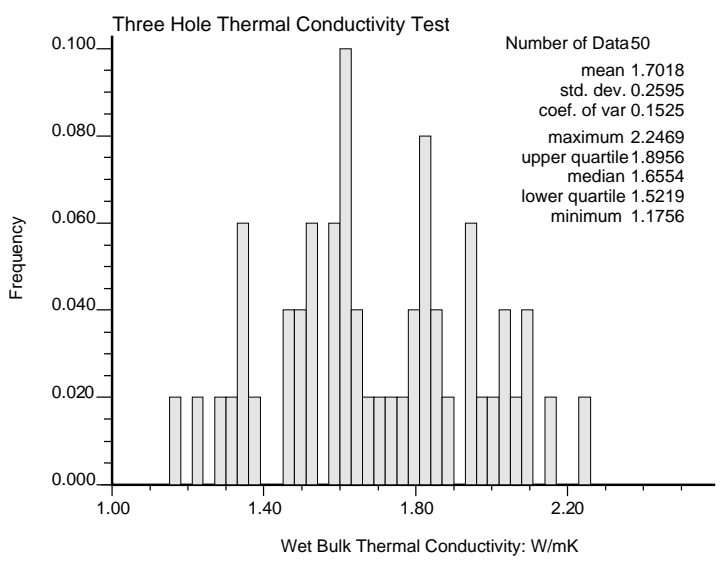

(b) wet

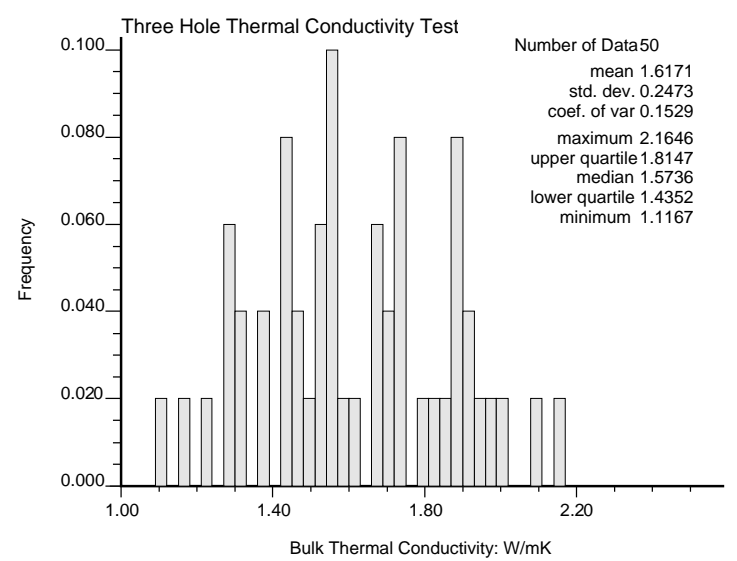

(c) $85 \%$ saturation

Output DTN: SN0404T0503102.011 [DIRS 169129].

Figure 7-14. Model Predictions of Bulk Thermal Conductivity (W/mK) ECRB Thermal Conductivity Test 3

The matrix thermal conductivity, $\mathrm{k}_{\mathrm{m}}$, was taken to be a linear function of the matrix water saturation, $\mathrm{S}_{\mathrm{w}}$, to perform this validation. This selection of linear interpolation in this analysis was based on SNL (1998 [DIRS 118788], Section 5.1) where the linear interpolation was shown to provide a slightly improved fit to laboratory measurements of thermal conductivity including the effects of saturation.

$$
\mathrm{k}_{\mathrm{m}}=\mathrm{k}_{\mathrm{m}}^{\mathrm{dry}}+\mathrm{S}_{\mathrm{w}}\left(\mathrm{k}_{\mathrm{m}}^{\mathrm{wet}}-\mathrm{k}_{\mathrm{m}}^{\mathrm{dry}}\right)
$$

Substituting Equation 7-4 into Equation 6-1 gives:

$$
\mathrm{k}_{\mathrm{b}}=\phi_{\mathrm{L}} \mathrm{k}_{\mathrm{a}}+\left(1-\phi_{\mathrm{L}}\right)\left\{\mathrm{k}_{\mathrm{m}}^{\mathrm{dry}}+\mathrm{S}_{\mathrm{w}}\left(\mathrm{k}_{\mathrm{m}}^{\mathrm{wet}}-\mathrm{k}_{\mathrm{m}}^{\mathrm{dry}}\right)\right\}
$$


Using Equation 7-3 allows Equation 7-5 to be written as:

$$
\mathrm{k}_{\mathrm{b}}=\mathrm{k}_{\mathrm{b}}^{\mathrm{dry}}+\mathrm{S}_{\mathrm{w}}\left(1-\phi_{\mathrm{L}}\right)\left(\mathrm{k}_{\mathrm{m}}^{\mathrm{wet}}-\mathrm{k}_{\mathrm{m}}^{\mathrm{dry}}\right)
$$

Solving Equations 7-2 and 7-3 for the term $\left(\mathrm{k}_{\mathrm{m}}^{\mathrm{wet}}-\mathrm{k}_{\mathrm{m}}^{\mathrm{dry}}\right)$ and substituting the result into Equation 7-6 gives the mathematical relationship for bulk thermal conductivity in terms of matrix water saturation and wet and dry bulk thermal conductivity.

$$
\mathrm{k}_{\mathrm{b}}=\mathrm{k}_{\mathrm{b}}^{\mathrm{dry}}+\mathrm{S}_{\mathrm{w}}\left(\mathrm{k}_{\mathrm{b}}^{\mathrm{wet}}-\mathrm{k}_{\mathrm{b}}^{\mathrm{dry}}\right)
$$

In order to use Equation 7-7, a value of matrix water saturation representative of the field experiments must be chosen. Since test-site-specific matrix water saturation information was not available, data from core samples taken from the Tptpll were examined (DTN: MO0109HYMXPROP.001 [DIRS 155989] and DTN: GS980808312242.014 [DIRS 106748]). A histogram plot of the matrix water saturation based on these core samples is presented in Figure 7-15. Note that the Tptpll is generally highly saturated. Consequently, for the purpose of evaluating Equation 7-7, a representative matrix water saturation of 0.85 is chosen for all tests. Results for other saturation states may be obtained using interpolation.

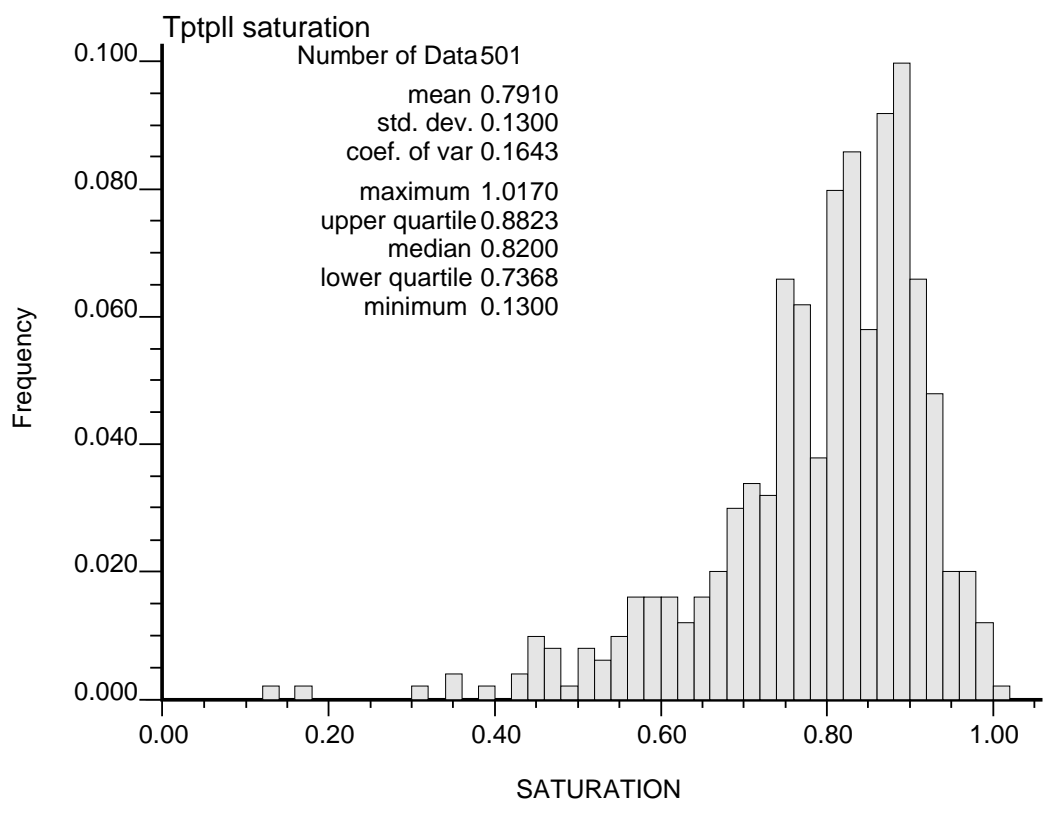

Output DTN: SN0404T0503102.011 [DIRS 169129].

Input DTN: MO0109HYMXPROP.001 [DIRS 155989] and GS980808312242.014 [DIRS 106748].

Figure 7-15. Histogram Plot of Matrix Water Saturation in the Tptpll 
Applying Equation 7-7 to the model-predicted pairs of wet and dry bulk thermal conductivity provides values of bulk thermal conductivity that can be compared directly with those calculated from the field experiments (Table 7-5). These predictions are presented in the form of histograms in Figures 7-12(c), 7-13(c), and 7-14(c).

For Test 1, the mean predicted bulk thermal conductivity at 85 percent saturation was $1.66 \mathrm{~W} / \mathrm{mK}$, with a standard deviation of $0.25 \mathrm{~W} / \mathrm{mK}$ (Figure 7-12(c)), which is reasonably close to the experimental value of $1.74 \mathrm{~W} / \mathrm{mK}$. For Test 2 , the mean predicted bulk thermal conductivity was $1.69 \mathrm{~W} / \mathrm{mK}$ with a standard deviation of $0.26 \mathrm{~W} / \mathrm{mK}$. For Test 3 , the mean predicted bulk thermal conductivity was $1.62 \mathrm{~W} / \mathrm{mK}$ with a standard deviation of $0.25 \mathrm{~W} / \mathrm{mK}$, which is also reasonably close to the reported experimental value of $1.74 \mathrm{~W} / \mathrm{mK}$. Thus, for Test 1 and Test 3, the experimental values fall within the range of predicted values and also within one standard deviation of the mean predictions (Figures 7-12 and 7-14). For Test 2, the experimental value of thermal conductivity was slightly greater than 1.5 standard deviations above the mean prediction but still within the range of values predicted by the model (Figure 7-13).

It should be noted that the bulk thermal conductivity values estimated from the three thermal tests are representative of much smaller volumes of rock than the size of the model cell. Therefore, these values may express the sub-grid-scale spatial variability of the conductivity. In addition, because the analytical model used to estimate bulk thermal conductivity from the field test measurements is based on conduction being the mode of heat transfer, the values listed in Table 7-5, and used in this validation, could actually represent an "effective" thermal conductivity. This would be the case if radiative heat transfer across the lithophysal cavities were also contributing to the heat transfer in the rock. This would lead to the true thermal conductivity being less than those values given in Table 7-5. The existence or magnitude of radiative effects; however, have not been evaluated for these tests.

\subsubsection{Bulk Thermal Conductivity Model Validation: Summary and Conclusions}

Experimentally derived estimates of bulk thermal conductivity from the ECRB Thermal Conductivity Tests 1, 2, and 3 were compared with geostatistical thermal conductivity estimates for the three sites. At each test location, the range in geostatistical predictions is quite broad, indicating a relatively high level of model uncertainty. The experimentally derived bulk thermal conductivity values fall within the range of model predicted by the geostatistical model. Based on the results presented, the bulk thermal conductivity model is validated and has been shown to be sufficiently accurate and adequate for its intended use in thermal simulations. The model includes the spatial variability and uncertainties of the underlying parameters. The spatial variability and uncertainty in bulk thermal conductivity predicted by the geostatistical model should be evaluated to assess the importance of this parameter with regard to repository performance measures. 


\section{INTENTIONALLY LEFT BLANK}




\section{CONCLUSIONS}

\subsection{SUMMARY}

The spatial variation and uncertainty of bulk thermal conductivity in the proposed repository horizon has been estimated through the application of selected theoretical models. Inputs to these models consist of the following stochastic, geostatistically simulated rock properties: matrix porosity, lithophysal porosity, matrix solid thermal conductivity, and matrix solid connectivity. Simulations of matrix and lithophysal porosity are conditioned to borehole measurements and thus anchor the subsequent calculations of matrix and bulk thermal conductivity for the repository host layers (Tptpul, Tptpmn, Tptpll, and Tptpln). Simulations of solid thermal conductivity and solid connectivity, however, are both unconditioned, and their uncertainty distributions are more broad. Consequently, even at locations where matrix and lithophysal porosity are known precisely (neglecting measurement error), there is some degree of matrix thermal conductivity uncertainty expressed in the model predictions of bulk thermal conductivity.

Highly variable measurements of lithophysal porosity in the lithophysal zones also contribute to uncertainty in bulk thermal conductivity. However, for the model adopted in this report, the univariate statistical properties of individual realizations and plots of the standard deviation in the Etype model suggest that the uncertainty in bulk thermal conductivity is dominated by uncertainty in matrix thermal conductivity.

The results of this modeling effort are found in Output DTNs: SN0404T0503102.011 [DIRS 169129] and SN0406T0503102.012 [DIRS 170045].

Results from in situ field thermal conductivity tests confirm the current model; however, the range of model predictions at the location of these test sites is rather large.

The results are internally consistent and reflect the pertinent measurements that have been acquired at Yucca Mountain. Significant effort has gone into collecting, analyzing, and filtering model inputs. The equations developed in Appendix A and used to compute matrix and lithophysal porosity from petrophysical measurements of bulk density and neutron porosity are innovative. These equations provide a means of incorporating the relatively vast quantity of borehole petrophysical measurements collected at Yucca Mountain into the model and greatly improve the model's predictive capabilities. The model results reflect the current understanding of the thermal conduction properties in the repository horizon and are suitable for their intended use.

In this work, the rock is conceptualized as a thermally isotropic composition of matrix and lithophysae. The rock properties developed in this report are applicable for use in numerical models where the concept of a continuum is employed. They are developed on a grid scale suitable for use in mountain and drift-scale modeling. The properties are not intended to be applicable to heat transfer at the scale of the matrix pore or the individual lithophysal cavity. It is noted that if the predicted mean values of thermal conductivity are used as input in other simulation models, then the results of these models will obviously not reflect the spatial heterogeneity or range of the thermal conductivity predicted by the model. To capture this effect 
it would be necessary to use the spatially variable thermal conductivity values given in the realizations produced by the model. When spatial heterogeneities are ignored, i.e. when a single value (mean) is used for an entire layer, it is desirable to conduct a sensitivity study to assess the impact of this approach on model performance measures.

\subsection{YUCCA MOUNTAIN REVIEW PLAN CRITERIA ASSESSMENT}

This section provides responses to the Yucca Mountain Review Plan acceptance criteria applicable to this model report. The acceptance criteria for the quantity and chemistry of water contacting engineered barriers and waste forms are referenced from Section 2.2.1.3.3.3 of NRC (2003 [DIRS 163274]) and 10 CFR 63.114(a)-(c) and (e)-(g) [DIRS 156605].

\subsubsection{Acceptance Criterion 1 - System Description and Model Integration Are Adequate}

(2) The abstraction of the quantity and chemistry of water contacting engineered barriers and waste forms uses assumptions, technical bases, data, and models, that are appropriate and consistent with other related U.S. Department of Energy abstractions. For example, the assumptions used for the quantity and chemistry of water contacting engineered barriers and waste forms are consistent with the abstractions of "Degradation of Engineered Barriers" (Section 2.2.1.3.1); "Mechanical Disruption of Engineered Barriers" (Section 2.2.1.3.2); "Radionuclide Release Rates and Solubility Limits" (Section 2.2.1.3.4); "Climate and Infiltration" (Section 2.2.1.3.5); and "Flow Paths in the Unsaturated Zone" (Section 2.2.1.3.6). The descriptions and technical bases provide transparent and traceable support for the abstraction of quantity and chemistry of water contacting engineered barriers and waste forms.

Basis: The data (Section 4.1), assumptions (Section 5), and technical bases (Section 6.1) used in the model development are appropriate and consistent with their intended use as inputs to mountain and drift scale coupled process models. The model descriptions and technical bases presented in Section 6.1 provide transparent and traceable support for their use in these coupled process models. The spatial variability and uncertainty expressed by the porosity and thermal conductivity model results presented in this report (Section 6.2) are appropriate for use by these coupled process models to assess the impact or sensitivity on the quantity and chemistry of water contacting engineered barriers and waste forms. Examples of coupled process models, which use these results in sensitivity analyses, are given in Section 6.2.

\subsubsection{Acceptance Criterion 2 - Data Are Sufficient for Model Justification}

(1) Geological, hydrological, and geochemical values used in the license application are adequately justified. Adequate description of how the data were used, interpreted, and appropriately synthesized into the parameters is provided.

Basis: Qualified, site-specific data obtained from core sample measurements and petrophysical well logging from the repository host horizon layers are used to develop the geostatistical models of porosity and thermal conductivity. The input data and their appropriateness in model selection and development are described in Sections 4.1 and 6. Adequate descriptions of how the data were used, interpreted, and synthesized into the developed parameters are included in Section 6 and Appendices A, B and C. 
(2) Sufficient data were collected on the characteristics of the natural system and engineered materials to establish initial and boundary conditions for conceptual models of thermal-hydrologic-mechanical-chemical coupled processes that affect seepage and flow and the engineered barrier chemical environment.

Basis: Sufficient qualified, site-specific data were collected from repository host horizon layers at Yucca Mountain, as described in Sections 4.1 and 6, to support development of the models of porosity and thermal conductivity. Using the sequential gaussian simulation method described in Section 6.1.3, these models characterize the spatial variability and uncertainty of porosity and thermal conductivity in the repository host horizon units. The results of these geostatistical models, summarized in Section 6.2 and DTN: SN0404T0503102.011 [DIRS 169129], are intended for use in thermal-hydrologic-mechanical-chemical coupled process models for examining the impact these parameters have on seepage and flow and the engineered barrier chemical environment. The models of porosity and thermal conductivity developed in this report are not used to establish initial or boundary conditions in conceptual models of thermalhydrologic-mechanical-chemical coupled processes.

\subsubsection{Acceptance Criterion 3 - Data Uncertainty Is Characterized and Propagated Through the Model Abstraction}

(1) Models use parameter values, assumed ranges, probability distributions, and bounding assumptions that are technically defensible, reasonably account for uncertainties and variabilities, and do not result in an under-representation of the risk estimate.

Basis: The input data described in Section 4.1 and used in the model development activities described in Section 6 are representative of the repository host horizon units. The data are technically defensible because they were obtained from Project qualified and controlled sources. Measurement errors, biases, and natural sample variabilities are propagated into the models that use these data. The sequential gaussian simulation method (Section 6.1.3) used to develop geostatistical realizations for each model (Sections 6.1.4-6.1.8) inherently reproduces the spatial variability and uncertainty exhibited by the underlying input data. For example, the uncertainty in the bulk thermal conductivity model (Section 6.1.8) results from the contributions of the uncertainties in the matrix thermal conductivity (Section 6.1.7) and lithophysal porosity models (Section 6.1.4). Therefore, the approach used to develop each of the models in this report reasonably accounts for uncertainties and variabilities and does not result in an under representation of the risk estimate.

(2) Parameter values, assumed ranges, probability distributions, and bounding assumptions used in the total system performance assessment calculations of quantity and chemistry of water contacting engineered barriers and waste forms are technically defensible and reasonable, based on data from the Yucca Mountain region (e.g., results from large block and drift-scale heater and niche tests), and a combination of techniques that may include laboratory experiments, field measurements, natural analog research, and process-level modeling studies. 
Basis: The thermal conductivity and porosity models, developed in this report, are used in coupled process modeling which support the TSPA-LA calculations of quantity and chemistry of water contacting engineered barriers and waste forms. The validation of the thermal conductivity and porosity models, as described in Section 7 , is based on corroboration with laboratory and field experiments, and field observations from the repository host horizon units characterized in this report. These validation and confidence building exercises provide justification that the models are technically defensible, reasonable and support the use of these models as input to coupled thermal-hydrologic-mechanical-chemical process-level models in TSPA-LA. These process-level models are directly utilized in evaluating the quantity and chemistry of water contacting engineered barriers and waste forms in TSPA-LA.

(3) Input values used in the total system performance assessment calculations of quantity and chemistry of water contacting engineered barriers (e.g., drip shield and waste package) are consistent with the initial and boundary conditions and the assumptions of the conceptual models and design concepts for the Yucca Mountain site. Correlations between input values are appropriately established in the U.S. Department of Energy total system performance assessment. Parameters used to define initial conditions, boundary conditions, and computational domain in sensitivity analyses involving coupled thermal-hydrologic-mechanical-chemical effects on seepage and flow, the waste package chemical environment, and the chemical environment for radionuclide release, are consistent with available data. Reasonable or conservative ranges of parameters or functional relations are established.

Basis: The geostatistical models developed in this report are intended to be used as inputs to calculations which directly support TSPA-LA with regard to quantity and chemistry of water contacting engineered barriers and waste forms. The models developed in this report are consistent with the available data because they are developed (Section 6) and validated (Section 7) using qualified, site-specific data. The geostatistical modeling approach described in Section 6.1.3 provides a reasonable range of parameters for use in TSPA-LA sensitivity calculations. Each realization honors the spatial continuity and statistics of the input data and provides a consistent set of parameters at each spatial location in the model. The thermal conductivity and porosity models, developed in this report, are not directly used to define initial conditions, boundary conditions, or computational domain in sensitivity analyses involving coupled thermal-hydrologic-mechanical-chemical effects on seepage and flow, the waste package chemical environment, and the chemical environment for radionuclide release.

(4) Adequate representation of uncertainties in the characteristics of the natural system and engineered materials is provided in parameter development for conceptual models, process-level models, and alternative conceptual models. The U.S. Department of Energy may constrain these uncertainties using sensitivity analyses or conservative limits. For example, the U.S. Department of Energy demonstrates how parameters used to describe flow through the engineered barrier system bound the effects of excavation-induced changes. 
Basis: The porosity and thermal conductivity models developed in this report provide estimates of the spatial variability and uncertainty in the repository host horizon units and are intended for use by the down-stream coupled thermal-hydrologic-mechanical-chemical process level models. Adequate representation of the uncertainty and spatial variability in the natural system is characterized in model development through the use of site-specific data (Section 4.1) and sequential gaussian simulation (Section 6.1.3). The model summary results described in Section 6.2 and the geostatistical realizations provided in output DTN: SN0404T0503102.011 [DIRS 169129] may be used to demonstrate the impact on seepage and engineered barrier environment resulting from natural system variability.

\subsubsection{Acceptance Criterion 4 - Model Uncertainty is Characterized and Propagated Through the Model Abstraction}

(2) Alternative modeling approaches are considered and the selected modeling approach is consistent with available data and current scientific understanding. A description that includes a discussion of alternative modeling approaches not considered in the final analysis and the limitations and uncertainties of the chosen model is provided.

Basis: Alternative conceptual models of matrix and bulk thermal conductivity are discussed in Sections 6.1.7 and 6.1.8 respectively. The rationale used in the model selection process is consistent with the data available for model development and the intended use of the models. The limitations of these models are discussed in Section 6.1. The appropriateness of the selected models is confirmed through the validation and confidence building exercises described in Section 7. 


\section{INTENTIONALLY LEFT BLANK}




\section{INPUTS AND REFERENCES}

The following is a list of the references cited in this document. Column 2 represents the unique six-digit numerical identifier (Document Input Reference System [DIRS] number), which is placed in the text following the reference callout (e.g. BSC 2002 [DIRS 158075]). The purpose of these numbers is to assist the reader in locating a specific reference. Within the reference list, multiple sources by the same author (e.g., BSC 2002) are sorted alphabetically by title.

\subsection{DOCUMENTS CITED}

Brodsky, N.S.; Riggins, M.; Connolly, J.; and Ricci, P. 1997. Thermal Expansion, 100653 Thermal Conductivity, and Heat Capacity Measurements for Boreholes UE25 NRG-4, UE25 NRG-5, USW NRG-6, and USW NRG-7/7A. SAND95-1955. Albuquerque, New Mexico: Sandia National Laboratories.

ACC: MOL.19980311.0316.

BSC (Bechtel SAIC Company) 2001. ESF ECRB Cross Drift - As-Built Thermal-K 169605 Borehole 004, April 30, 2001. YMP 130/38. Las Vegas, Nevada: Bechtel SAIC Company. ACC: MOL.20021010.0151.

BSC 2001. ESF ECRB Cross Drift - As-Built Thermal-K Borehole \#005, May 2, 169606 2001. YMP 130/40. Las Vegas, Nevada: Bechtel SAIC Company.

ACC: MOL.20021017.0243.

BSC 2001. ESF ECRB Cross Drift As-Built Thermal-K Boreholes 003, May 1, 169604 2001. YMP 130/39. Las Vegas, Nevada: Bechtel SAIC Company.

ACC: MOL.20021010.0152.

BSC 2001. ESF ECRB Cross Drift As-Built Thermal-K Boreholes \#006, 007 \& 008, 169607 May 23 and May 29, 2001. YMP 130/55, 56 \& 57, YMP 130/58, and YMP 130/64. Las Vegas, Nevada: Bechtel SAIC Company. ACC: MOL.20021015.0001.

BSC 2001. Thermal Conductivity Properties for the Tptpll and Tptpul. Input 155008 Transmittal 00472.Ta. Las Vegas, Nevada: Bechtel SAIC Company. ACC: MOL.20010716.0060.

BSC 2002. Technical Work Plan for: The Integrated Site Model. TWP-NBS-GS000003 REV 02. Las Vegas, Nevada: Bechtel SAIC Company.

ACC: MOL.20020417.0380.

BSC 2003. Subsurface Geotechnical Parameters Report. 800-K0C-WIS0-00400166660 000-00A. Las Vegas, Nevada: Bechtel SAIC Company.

ACC: ENG.20040108.0001.

BSC 2004. D\&E / PA/C IED Subsurface Facilities. 800-IED-WIS0-00103-000168370 00A. Las Vegas, Nevada: Bechtel SAIC Company. ACC: ENG.20040309.0028. 
BSC 2004. Drift Degradation Analysis. ANL-EBS-MD-000027, Rev. 03.

166107

Las Vegas, Nevada: Bechtel SAIC Company. ACC: DOC.20040915.0010.

BSC 2004. Heat Capacity Analysis Report. ANL-NBS-GS-000013 REV 01.

170003 Las Vegas, Nevada: Bechtel SAIC Company.

BSC 2004. Igneous Intrusion Impacts on Waste Packages and Waste Forms. MDL168960 EBS-GS-000002 REV 01. Las Vegas, Nevada: Bechtel SAIC Company. ACC: DOC.20040421.0002.

BSC 2004. Mineralogic Model (MM3.0) Report. MDL-NBS-GS-000003 REV 01. Las Vegas, Nevada: Bechtel SAIC Company. ACC: DOC.20040908.0006.

170031

BSC 2004. Multiscale Thermohydrologic Model. ANL-EBS-MD-000049, Rev. 02. Las Vegas, Nevada: Bechtel SAIC Company.

BSC 2004. Q-List. 000-30R-MGR0-00500-000-000 REV 00. Las Vegas, Nevada: Bechtel SAIC Company. ACC: ENG.20040721.0007.

BSC 2004. Rock Properties Model. MDL-NBS-GS-000004, Rev. 01. Las Vegas, Nevada: Bechtel SAIC Company. ACC: DOC.20040915.0011.

BSC 2004. Technical Work Plan for: Near-Field Environment and Transport 171708 Thermal Properties Model and Analysis Reports Integration. TWP-MGR-PA-000019 REV00 ICN 01. Las Vegas, Nevada: Bechtel SAIC Company.: ACC: DOC.20040920.0003.

BSC 2004. Ventilation Model and Analysis Report. ANL-EBS-MD-000030, 169862 Rev. 04. Las Vegas, Nevada: Bechtel SAIC Company.

Canori, G.F. and Leitner, M.M. 2003. Project Requirements Document. 166275 TER-MGR-MD-000001 REV 02. Las Vegas, Nevada: Bechtel SAIC Company. ACC: DOC.20031222.0006.

Carslaw, H.S. and Jaeger, J.C. 1959. Conduction of Heat in Solids. 2nd Edition. Oxford, Great Britain: Oxford University Press. TIC: 206085.

CRWMS M\&O 1996. Yucca Mountain Site Geotechnical Report. 169565 168361

170032 BAAA00000-01717-4600-00065 REV 00. Las Vegas, Nevada: CRWMS M\&O. ACC: MOL.19970425.0062.

Deutsch, C.V. and Journel, A.G. 1992. GSLIB Geostatistical Software Library and 100567 User's Guide. New York, New York: Oxford University Press. TIC: 224174.

Deutsch, C.V. and Journel, A.G. 1998. GSLIB Geostatistical Software Library and User's Guide. 2nd Edition. New York, New York: Oxford University Press.

100968 TIC: 240101. 
Flint, L.E. 1998. Characterization of Hydrogeologic Units Using Matrix Properties, Yucca Mountain, Nevada. Water-Resources Investigations Report 97-4243. Denver, Colorado: U.S. Geological Survey. ACC: MOL.19980429.0512.

Hadley, G.R. 1986. “Thermal Conductivity of Packed Metal Powders.”

153165 International Journal of Heat and Mass Transfer, 29, (6), 909-920. New York, New York: Pergamon Journals. TIC: 249320.

Hillel, D. 1980. Fundamentals of Soil Physics. New York, New York: Academic Press. TIC: 215655.

Holman, J.P. 1997. Heat Transfer. 8th Edition. New York, New York: McGrawHill. TIC: 239954.

Howard, C. 2002. Thermal K Field Program, Thermal Conductivity Field

100033 Measurements. Scientific Notebook SN-SNL-SCI-024-V1.

ACC: MOL.20020619.0494.

Hsu, C.T.; Cheng, P.; and Wong, K.W. 1995. “A Lumped-Parameter Model for Stagnant Thermal Conductivity of Spatially Periodic Porous Media.” Journal of Heat Transfer, 117, (2), 264-269. New York, New York: American Society of Mechanical Engineers. TIC: 252402.

Irvine, T.F., Jr. 1998. “Thermophysical Properties.” Chapter 2 of Handbook of Heat Transfer. 3rd Edition. Rohsenow, W.M.; Hartnett, J.P.; and Cho, Y.I., eds.

New York, New York: McGraw-Hill. TIC: 253612.

Isaaks, E.H. and Srivastava, R.M. 1989. Applied Geostatistics. New York,

101134 New York: Oxford University Press. TIC: 200301.

Kaviany, M. 1991. Principles of Heat Transfer in Porous Media. New York, New York: Springer-Verlag. TIC: 240655.

Kunii, D. and Smith, J.M. 1960. "Heat Transfer Characteristics of Porous Rocks." 153166 American Institute of Chemical Engineers Journal, 6, (1), 71-78. New York, New York: American Institute of Chemical Engineers. TIC: 249321.

Lienhard, J.H., IV and Lienhard, J.H., V 2003. A Heat Transfer Textbook. 3rd 169239 Edition. Cambridge, Massachusetts: Phlogiston Press. TIC: 255682.

Maxwell, J.C. 1954. A Treatise on Electricity and Magnetism. 3rd Edition 158165 (unabridged). Two volumes. New York, New York: Dover Publications. TIC: 252475. 
Mongano, G.S.; Singleton, W.L.; Moyer, T.C.; Beason, S.C.; Eatman, G.L.W.; 149850 Albin, A.L.; and Lung, R.C. 1999. Geology of the ECRB Cross Drift - Exploratory Studies Facility, Yucca Mountain Project, Yucca Mountain, Nevada. Deliverable SPG42GM3. Denver, Colorado: U.S. Geological Survey.

ACC: MOL.20000324.0614.

NRC (U.S. Nuclear Regulatory Commission) 2003. Yucca Mountain Review Plan, Final Report. NUREG-1804, Rev. 2. Washington, D.C.: U.S. Nuclear Regulatory Commission, Office of Nuclear Material Safety and Safeguards. TIC: 254568.

Paces, J.B.; Neymark, L.A.; Marshall, B.D.; Whelan, J.F.; and Peterman, Z.E. 2001. Ages and Origins of Calcite and Opal in the Exploratory Studies Facility Tunnel, Yucca Mountain, Nevada. Water-Resources Investigations Report 01-4049.

Denver, Colorado: U.S. Geological Survey. TIC: 251284.

Rohsenow, W.M. and Choi, H.Y. 1961. Heat, Mass, and Momentum Transfer. Englewood Cliffs, New Jersey: Prentice-Hall. TIC: 249864.

Sass, J.H.; Lachenbruch, A.H.; Dudley, W.W., Jr.; Priest, S.S.; and Munroe, R.J. 1988. Temperature, Thermal Conductivity, and Heat Flow Near Yucca Mountain, Nevada: Some Tectonic and Hydrologic Implications. Open-File Report 87-649. Denver, Colorado: U.S. Geological Survey. TIC: 203195.

SNL (Sandia National Laboratories) 1998. Laboratory Measurements of Thermal 118788 Conductivity as a Function of Saturation State for Welded and Nonwelded Tuff Specimens. Albuquerque, New Mexico: Sandia National Laboratories. ACC: MOL.19980901.0177.

Stephens, H.P. and Sinnock, S. 1979. Thermophysical Properties of Rocks--A 158151 Perspective on Data Needs, Sources and Accuracy. SAND79-1259C. Albuquerque, New Mexico: Sandia National Laboratories. TIC: 229997.

Torquato, S. 1987. “Thermal Conductivity of Disordered Heterogeneous Media from 165105 the Microstructure.” Reviews in Chemical Engineering, 4, (3-4), 151-204. London, England: Freund Publishing House. TIC: 249565.

YMP (Yucca Mountain Site Characterization Project) 1997. Sample Collection Report, Rock, Collected by A. Mitchell, May 7, 1997, (SPC00522296). Las Vegas, Nevada: Yucca Mountain Site Characterization Office.

ACC: DRC.19970714.0039. 


\subsection{CODES, STANDARDS, REGULATIONS, AND PROCEDURES}

10 CFR 63. Energy: Disposal of High Level Radioactive Wastes in a Geologic

Repository at Yucca Mountain, Nevada. Readily available.

NRC (U.S. Nuclear Regulatory Commission) 2003. Yucca Mountain Review Plan,

163274 Final Report. NUREG-1804, Rev. 2. Washington, D.C.: U.S. Nuclear Regulatory Commission, Office of Nuclear Material Safety and Safeguards. TIC: 254568.

AP-SIII.10Q, Rev. 2, ICN 7. Models. Washington, D.C.: U.S. Department of Energy, Office of Civilian Radioactive Waste Management. ACC: DOC.20040920.0002.

LP-SI.11Q-BSC, Rev. 0, ICN 0. Software Management. Washington, D.C.: U.S. Department of Energy, Office of Civilian Radioactive Waste Management.

ACC: DOC.20040225.0007.

AP-2.22Q, Rev. 1, ICN 1. Classification Analyses and Maintenance of the Q List. Washington, D.C.: U.S. Department of Energy, Office of Civilian Radioactive Waste Management. ACC: DOC.20040714.0002.

\subsection{SOURCE DATA, LISTED BY DATA TRACKING NUMBER}

GS980808312242.014. Physical Properties of Borehole Core Samples and Water USW SD-6. Submittal date: 08/11/1998.

MO0004QGFMPICK.000. Lithostratigraphic Contacts from MO9811MWDGFM03.000 to be Qualified Under the Data Qualification Plan, TDPNBS-GS-000001. Submittal date: 04/04/2000.

MO0010CPORGLOG.002. Calculated Porosity from Geophysical Logs Data from date: $12 / 18 / 2000$.

MO0109HYMXPROP.001. Matrix Hydrologic Properties Data. Submittal date: 09/17/2001.

MO0205GSC02068.000. Alcove \#5 Turn Out Samples Exploratory Studies Facilities (ESF). Submittal date: 05/30/2002. 
MO0205GSC02070.000. As-Built Enhanced Characterization of the Repository

159148

Block (ECRB) Thermal Conductivity Borehole TK1, TK2, TK9, TK10, and TK11

Collars. Submittal date: 05/30/2002.

MO0208GSC02103.000. As-Built Lithophysal Study Panel Targets, East West Cross

169978

Drift, Enhanced Characterization of the Repository Block (ECRB). Submittal date:

08/15/2002.

MO0306MWDDDMIO.001. Drift Degradation Model Inputs and Outputs. Submittal date: 06/19/2003.

MO0408MWDDDMIO.002. Drift Degradation Model Inputs and Outputs. Submittal

171483 date: 08/31/2004.

MO9510RIB00002.004. RIB Item: Stratigraphic Characteristics:

103801

Geologic/Lithologic Stratigraphy. Submittal date: 06/26/1996.

MO9906GPS98410.000. Yucca Mountain Project (YMP) Borehole Locations.

109059

Submittal date: 06/23/1999.

SN0203L2210196.007. Thermal Expansion and Thermal Conductivity of Test Specimens from the Drift Scale Test Area of the Exploratory Studies Facility at Yucca Mountain, Nevada. VA Supporting Data. Submittal date: 03/06/2002.

SN0205F3504502.010. Thermal Conductivity Field Program: Average Values of Abundance of Lithostratigraphic Features for Boreholes THERMK-001 through THERMK-011. Submittal date: 05/17/2002.

SN0206F3504502.012. Revised Thermal Conductivity, Volumetric Heat Capacity 159145 and Thermal Diffusivity Data for ECRB Thermal K Test 1 (Two-Hole Test). Submittal date: 06/07/2002.

SN0206F3504502.013. Revised Thermal Conductivity, Volumetric Heat Capacity 159146 and Thermal Diffusivity Data for ECRB Thermal K Test 3 (Three-Hole Test, with Results from 1/22/2002 through 4/9/2002). Submittal date: 06/07/2002.

SN0207F3504502.015. Thermal Conductivity Field Program: Data for Six-Hole Test 170044 Thermal Conductivity Measurements for Boreholes THERMK-003 through THERMK-008 (with results from 11/06/2001 through 4/9/2002). Submittal date: 07/02/2002.

SN0208F3504502.019. Thermal Conductivity, Volumetric Heat Capacity and 161883 Thermal Diffusivity Data for ECRB Thermal K Test 2 (Six-Hole Test). Submittal date: 08/30/2002.

SN9910T0501399.001. Three-Dimensional Rock Property Models for FY99 (RPM3.1). Submittal date: 10/18/1999. 
SNF40060298001.001. Unsaturated Zone Lithostratigraphic Contacts in Borehole

107372 USW SD-6. Submittal date: 10/15/1998.

SNL01A05059301.005. Laboratory Thermal Conductivity Data for Boreholes UE25 109002 NRG-4, NRG-5; USW NRG-6 and NRG-7/7A. Submittal date: 02/07/1996.

SNL01A05059301.007. Calculated Porosities for Thermal Conductivity Specimens 108980 from Boreholes UE25 NRG-4, UE25 NRG-5, USW NRG-6, and USW NRG-7/7a. Submittal date: 10/14/1998.

SNL22100196001.002. Laboratory Measurements of Thermal Expansion and 153138 Thermal Conductivity for Test Specimens from Alcove 5 and 7 and from SD Drill Holes of the Exploratory Studies Facility at Yucca Mountain, Nevada. Submittal date: 08/25/97.

SNL22100196001.006. Laboratory Measurements of Thermal Conductivity as a 158213 Function of Saturation State for Welded and Nonwelded Tuff Specimens. Submittal date: 06/08/1998.

\subsection{OUTPUT DATA, LISTED BY DATA TRACKING NUMBER}

SN0404T0503102.011. Thermal Conductivity of the Potential Repository Horizon 169129 Rev 3. Submittal date: 04/27/2004.

SN0406T0503102.012. Supporting Files for Thermal Conductivity of Potential Repository Horizon Model Report. Submittal date: 06/18/2004.

\subsection{SOFTWARE CODES}

Dynamic Graphics 2000. Software Code: EARTHVISION. V5.1. SGI/IRIX 6.5. 167994 10174-5.1-00.

SNL (Sandia National Laboratories) 2002. Software Code: Etype. V2.01. PC Windows 2000 Server. 10731-2.01.00.

SNL 2002. Software Code: GSLIB HISTPLT. V2.01. 10802-2.01-00.

SNL 2002. Software Code: GSLIB. V.1.4SGSIMV1.41. PC/Windows 2000 Server. 10110-1.4SGSIMV1.41-00.

SNL 2002. Software Code: GSLIB. V1.4MNSCOREV1.2.01. PC/Windows 2000

SNL 2002. Software Code: GSLIB. V1.0 MGAMV2V1.201. 10087-1.0GAMV2V1.201-02.

SNL 2002. Software Code: HSUINV. V.1.0. PC/Windows 2000 Server. 10804-1.0-00. 
SNL 2002. Software Code: LITHO. V1.0. 10800-1.0-00. 158256

SNL 2002. Software Code: MODGEOM. V.1.02. 10597-1.02-01. 158257

SNL 2002. Software Code: POINT. V1.0. 10826-1.0-00. 158336

SNL 2002. Software Code: SMOOTH. V.1.0. 10734-1.0-01. 158258

SNL 2002. Software Code: TCOND. V.1.0. 10801-1.0-00. 158260

Software Routine: GSLIB V1.4 MBACKTRV1.2. V1.2. 113642 
APPENDIX A

CALCULATIONS OF MATRIX AND LITHOPHYSAL POROSITY 


\section{CALCULATIONS OF MATRIX AND LITHOPHYSAL POROSITY}

\section{Method A:}

In this section an expression for lithophysal porosity based on matrix porosity, bulk density, particle (grain) density, and matrix water saturation is derived. A representative bulk volume of rock, $\mathrm{V}_{\mathrm{b}}$, can be partitioned into matrix volume, $\mathrm{V}_{\mathrm{m}}$, and lithophysae volume, $\mathrm{V}_{\mathrm{L}}$.

$$
\mathrm{V}_{\mathrm{b}}=\mathrm{V}_{\mathrm{m}}+\mathrm{V}_{\mathrm{L}}
$$

The matrix volume, $\mathrm{V}_{\mathrm{m}}$, can be partitioned into a volume of matrix solids, $\mathrm{V}_{\mathrm{ms}}$, and a volume of matrix pore-space, $\mathrm{V}_{\mathrm{mv}}$. It is assumed that the solids, $\mathrm{V}_{\mathrm{ms}}$, occur only in the matrix volume, $\mathrm{V}_{\mathrm{m}}$.

$$
\mathrm{V}_{\mathrm{m}}=\mathrm{V}_{\mathrm{ms}}+\mathrm{V}_{\mathrm{mv}}
$$

Matrix porosity, $\phi_{\mathrm{m}}$, is defined as the ratio of the volume of the matrix pore-space, $\mathrm{V}_{\mathrm{mv}}$, to the volume of the matrix, $\mathrm{V}_{\mathrm{m}}$.

$$
\phi_{\mathrm{m}}=\frac{\mathrm{V}_{\mathrm{mv}}}{\mathrm{V}_{\mathrm{m}}}
$$

Combining Equations A-2 and A-3, the volume of solids, $\mathrm{V}_{\mathrm{ms}}$, can be written as follows:

$$
\mathrm{V}_{\mathrm{ms}}=\mathrm{V}_{\mathrm{m}}\left(1-\phi_{\mathrm{m}}\right)
$$

Matrix water saturation, $\mathrm{S}_{\mathrm{w}}$, is defined as the ratio of the volume of water in the matrix pores, $\mathrm{V}_{\mathrm{w}}$, to the volume of the matrix pores, $\mathrm{V}_{\mathrm{mv}}$. The matrix pore space is assumed to contain water and air, while the lithophysae are assumed to be air filled. The lithophysae are air filled as a result of capillary forces that tend to hold water within the small-scale matrix voids.

$$
\mathrm{S}_{\mathrm{w}}=\frac{\mathrm{V}_{\mathrm{w}}}{\mathrm{V}_{\mathrm{mv}}}
$$

Using Equations A-3 and A-5 gives:

$$
\mathrm{V}_{\mathrm{w}}=\phi_{\mathrm{m}} \mathrm{S}_{\mathrm{w}} \mathrm{V}_{\mathrm{m}}
$$

Grain density, $\rho_{\mathrm{s}}$, is defined as the ratio of the mass of the solids, $\mathrm{m}_{\mathrm{s}}$, to the volume of solids, $\mathrm{V}_{\mathrm{s}}$, while water density, $\rho_{\mathrm{w}}$, is the ratio of the mass of water in the matrix pore-space, $\mathrm{m}_{\mathrm{w}}$, to the volume of the water, $\mathrm{V}_{\mathrm{w}}$. Bulk density, $\rho_{\mathrm{b}}$, is defined as the ratio of the mass of solids, $\mathrm{m}_{\mathrm{s}}$, plus mass of water, $\mathrm{m}_{\mathrm{w}}$, to the bulk volume, $\mathrm{V}_{\mathrm{b}}$. It is assumed that the mass of air occupying 
the pore-space is negligible compared to the mass of solids and water in the definition of bulk density.

$$
\begin{gathered}
\rho_{\mathrm{s}}=\frac{\mathrm{m}_{\mathrm{s}}}{\mathrm{V}_{\mathrm{ms}}} \\
\rho_{\mathrm{w}}=\frac{\mathrm{m}_{\mathrm{w}}}{\mathrm{V}_{\mathrm{w}}} \\
\rho_{\mathrm{b}}=\frac{\mathrm{m}_{\mathrm{w}}+\mathrm{m}_{\mathrm{s}}}{\mathrm{V}_{\mathrm{b}}} .
\end{gathered}
$$

Using Equations A-7 through A-9, the bulk density, $\rho_{b}$, can be written in terms of water, solid densities, and volumes as follows:

$$
\rho_{\mathrm{b}}=\frac{\mathrm{V}_{\mathrm{w}} \rho_{\mathrm{w}}+\mathrm{V}_{\mathrm{ms}} \rho_{\mathrm{s}}}{\mathrm{V}_{\mathrm{b}}} .
$$

Substituting Equations A-4 and A-6 into Equation A-10 gives:

$$
\rho_{\mathrm{b}}=\frac{\phi_{\mathrm{m}} \mathrm{S}_{\mathrm{w}} \rho_{\mathrm{w}} \mathrm{V}_{\mathrm{m}}+\left(1-\phi_{\mathrm{m}}\right) \rho_{\mathrm{s}} \mathrm{V}_{\mathrm{m}}}{\mathrm{V}_{\mathrm{b}}}
$$

Solving for the matrix volume, $\mathrm{V}_{\mathrm{m}}$ gives:

$$
\mathrm{V}_{\mathrm{m}}=\frac{\rho_{\mathrm{b}} \mathrm{V}_{\mathrm{b}}}{\phi_{\mathrm{m}} \mathrm{S}_{\mathrm{w}} \rho_{\mathrm{w}}+\left(1-\phi_{\mathrm{m}}\right) \rho_{\mathrm{s}}}
$$

Lithophysal porosity, $\phi_{\mathrm{L}}$, is defined as the volume of lithophysae pore-space, $\mathrm{V}_{\mathrm{L}}$, to the bulk volume, $\mathrm{V}_{\mathrm{b}}$ :

$$
\phi_{\mathrm{L}}=\frac{\mathrm{V}_{\mathrm{L}}}{\mathrm{V}_{\mathrm{b}}}=\frac{\mathrm{V}_{\mathrm{b}}-\mathrm{V}_{\mathrm{m}}}{\mathrm{V}_{\mathrm{b}}}=1-\frac{\mathrm{V}_{\mathrm{m}}}{\mathrm{V}_{\mathrm{b}}}
$$

Substituting the expression for matrix volume, $\mathrm{V}_{\mathrm{m}}$, from Equation A-12 into Equation A-13 gives:

$$
\phi_{\mathrm{L}}=1-\frac{\rho_{\mathrm{b}}}{\phi_{\mathrm{m}} \mathrm{S}_{\mathrm{w}} \rho_{\mathrm{w}}+\left(1-\phi_{\mathrm{m}}\right) \rho_{\mathrm{s}}}
$$


Equation A-14 gives an expression for calculating lithophysal porosity, provided estimates of bulk density, grain density, matrix water saturation, and matrix porosity are available. The bulk density, $\rho_{b}$, is obtained from petrophysical logging. The remaining parameters are obtained from laboratory tests on core samples.

\section{Method B:}

In this section expressions for matrix and lithophysal porosity based on bulk density, particle (grain) density, volumetric water content, and matrix water saturation are derived.

The volumetric water content, $\mathrm{V}_{\mathrm{wc}}$, is defined as the ratio of volume of water in the matrix pores, $\mathrm{V}_{\mathrm{w}}$, to the bulk volume, $\mathrm{V}_{\mathrm{b}}$ :

$$
\mathrm{V}_{\mathrm{wc}}=\frac{\mathrm{V}_{\mathrm{w}}}{\mathrm{V}_{\mathrm{b}}}
$$

Combining Equations A-5 and A-15 gives:

$$
\mathrm{V}_{\mathrm{w}}=\mathrm{S}_{\mathrm{w}} \mathrm{V}_{\mathrm{mv}}=\mathrm{V}_{\mathrm{wc}} \mathrm{V}_{\mathrm{b}} .
$$

Solving Equation A-16 for the volume of matrix voids $\left(S_{\mathrm{w}} \neq 0, \mathrm{~V}_{\mathrm{wc}} \neq 0\right)$ :

$$
\mathrm{V}_{\mathrm{mv}}=\frac{\mathrm{V}_{\mathrm{wc}} \mathrm{V}_{\mathrm{b}}}{\mathrm{S}_{\mathrm{w}}} .
$$

Using Equations A-3 and A-17 in Equation A-4 gives:

$$
\mathrm{V}_{\mathrm{ms}}=\mathrm{V}_{\mathrm{m}}\left(1-\frac{\mathrm{V}_{\mathrm{wc}} \mathrm{V}_{\mathrm{b}}}{\mathrm{V}_{\mathrm{m}} \mathrm{S}_{\mathrm{w}}}\right) .
$$

Using Equations A-15 and A-18 in Equation A-10 gives:

$$
\rho_{b}=\frac{V_{w c} V_{b} \rho_{w}+V_{m} \rho_{s}-\frac{V_{w c} V_{b} \rho_{s}}{S_{w}}}{V_{b}} .
$$

Solving Equation A-19 for $\mathrm{V}_{\mathrm{m}}$ gives:

$$
\mathrm{V}_{\mathrm{m}}=\frac{\left(\rho_{\mathrm{b}}-\mathrm{V}_{\mathrm{wc}} \rho_{\mathrm{w}}+\frac{\mathrm{V}_{\mathrm{wc}} \rho_{\mathrm{s}}}{\mathrm{S}_{\mathrm{w}}}\right) \mathrm{V}_{\mathrm{b}}}{\rho_{\mathrm{s}}} .
$$


From Equations A-3, A-17, and A-20 and expression for matrix porosity, $\phi_{\mathrm{m}}$, is obtained:

$$
\begin{gathered}
\phi_{\mathrm{m}}=\frac{\mathrm{V}_{\mathrm{mv}}}{\mathrm{V}_{\mathrm{m}}}=\frac{\mathrm{V}_{\mathrm{wc}} \mathrm{V}_{\mathrm{b}}}{\mathrm{S}_{\mathrm{w}} \mathrm{V}_{\mathrm{m}}} \\
\phi_{\mathrm{m}}=\frac{\rho_{\mathrm{s}}}{\mathrm{S}_{\mathrm{w}}\left(\frac{\rho_{\mathrm{b}}}{\mathrm{V}_{\mathrm{wc}}}-\rho_{\mathrm{w}}\right)+\rho_{\mathrm{s}}} .
\end{gathered}
$$

Equation A-22 gives an expression for evaluating matrix porosity, $\phi_{\mathrm{m}}$, from knowledge of the grain density, $\rho_{\mathrm{s}}$, bulk density, $\rho_{\mathrm{b}}$, matrix water saturation, $\mathrm{S}_{\mathrm{w}}$, and volumetric water content, $\mathrm{V}_{\mathrm{wc}}$.

Substituting the expression for matrix volume, $V_{m}$, from Equation A-20 into Equation A-13 gives an expression for lithophysal porosity, $\phi_{\mathrm{L}}$ :

$$
\phi_{\mathrm{L}}=1-\frac{\rho_{\mathrm{b}}}{\rho_{\mathrm{s}}}+\frac{\mathrm{V}_{\mathrm{wc}} \rho_{\mathrm{w}}}{\rho_{\mathrm{s}}}-\frac{\mathrm{V}_{\mathrm{wc}}}{\mathrm{S}_{\mathrm{w}}} .
$$

Equation A-23 gives an expression for calculating lithophysal porosity, provided estimates of bulk density, grain density, matrix water saturation, and volumetric water content are available. The bulk density, $\rho_{b}$, and volumetric water content, $V_{w c}$, are obtained from well-logging techniques; in particular, the volumetric water content, $\mathrm{V}_{\mathrm{wc}}$, is obtained from the neutron porosity $\log$. 
APPENDIX B

INPUT DATA ANALYSIS 


\section{INPUT DATA ANALYSIS}

This section documents the available core and petrophysical data and any decisions made regarding the use of these data. In addition, matrix and lithophysal porosity are calculated and plotted using the equations developed in Appendix A. Core measurements of volumetric water content are directly compared with petrophysical neutron porosity data when both are available for the borehole. The core measurements of volumetric water content are used to determine when the neutron porosity data appear to be high or low for a borehole. Borehole petrophysical data are also compared for nearby boreholes to determine consistency.

The figures presented in this appendix were developed in the Sigma Plot file well by well.jnb. The individual figures were exported from this Sigma Plot file as Windows Metafiles (extension WMF) and then imported into this word document. The file well by well.jnb and the individual figure files are located in directory Thermal_Cond/Attachment II of the output DTN SN0404T0503102.011 file Therm_CondData1.zip. 


\section{USW G-1}

The neutron porosity log data for USW G-1 appear to be high when compared with nearby boreholes USW H-1 and USW UZ-1/UZ-14. In those boreholes the neutron porosity is typically between 0.10 and 0.15 , while in USW G-1, readings typically exceed 0.2 . This borehole was drilled with water, which can lead to higher neutron porosity readings. There were also several regions for which null readings were obtained. Because of the high neutron porosity measurements and null data, the neutron porosity data were not used for this borehole.

The bulk density log for USW G-1 is similar to USW H-1 and USW UZ-1/UZ-14; therefore, lithophysal porosity was computed using Method C, assuming the matrix porosity $\left(\phi_{\mathrm{m}}=0.10\right)$ and water saturation $\mathrm{S}_{\mathrm{w}}=1$. The calculated lithophysal porosity in USW G-1 is similar to lithophysal porosity calculated for USW H-1 and USW UZ-1/UZ-14, except in the middle non-lithophysae zone, where up to 20 percent was calculated near the middle of the zone. The large values of lithophysal porosity around $780 \mathrm{ft}$ occur near the null values of neutron porosity and suggest washout. Therefore, Method $\mathrm{C}$ was used to calculate lithophysal porosity except for the middle non-lithophysae zone.

USW G-1

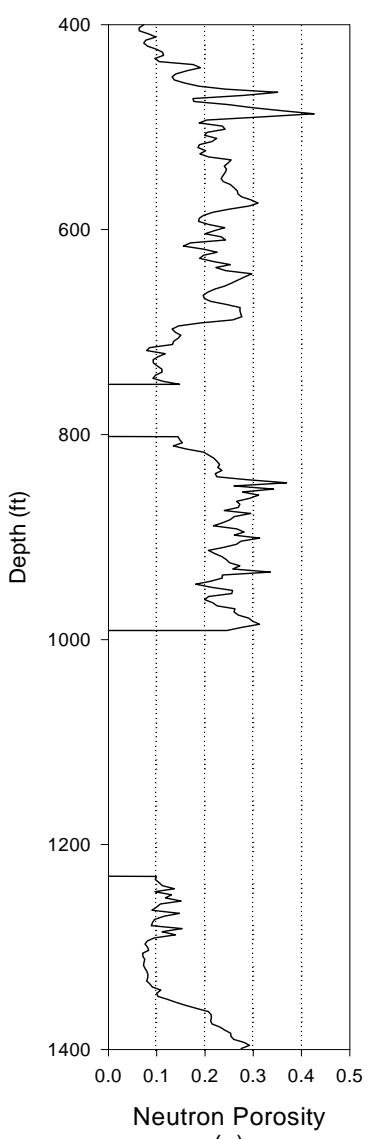

(a)

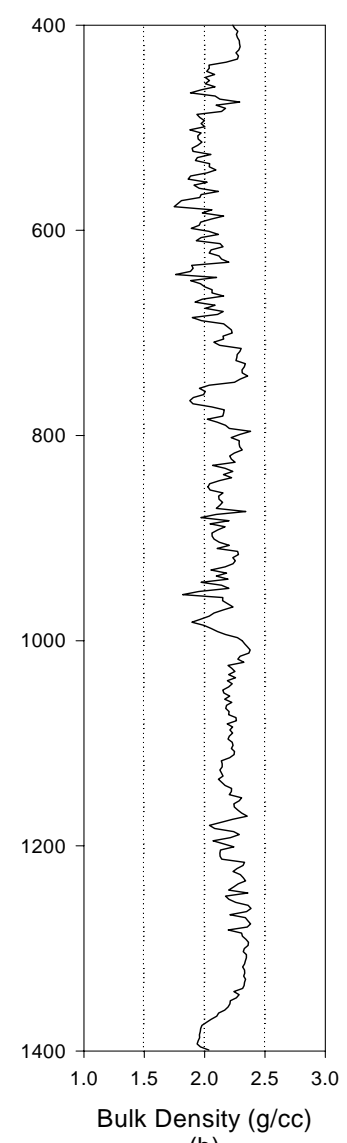

(b)

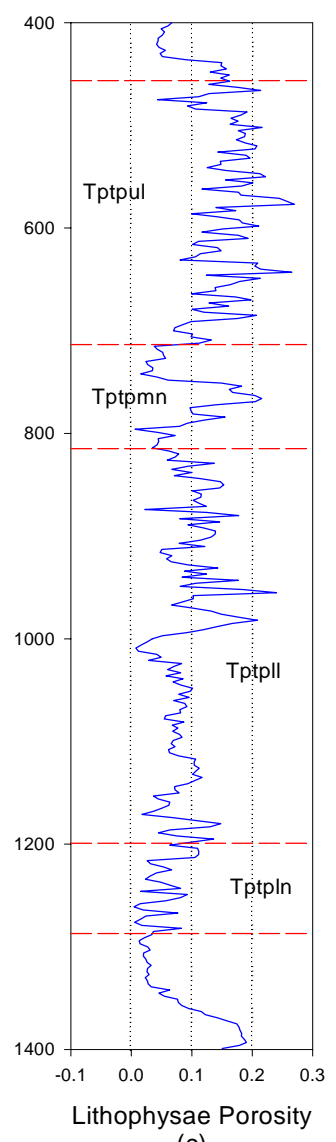

(c)

Input DTN: MO0010CPORGLOG.002 [DIRS 155229].

Figure B-1. USW G-1 


\section{USW G-2}

There are two sets of data available for USW G-2. After examining both sets, the choice was made to use the historic era data since the more modern data include many unusual spikes in bulk density, which is characteristic of borehole rugosity (roughness). Both the neutron porosity and the bulk density from the older data set compare well with data from nearby borehole USW WT-24. After applying Method B, the calculated matrix and lithophysal porosity are consistent with the neighboring borehole USW WT-24.

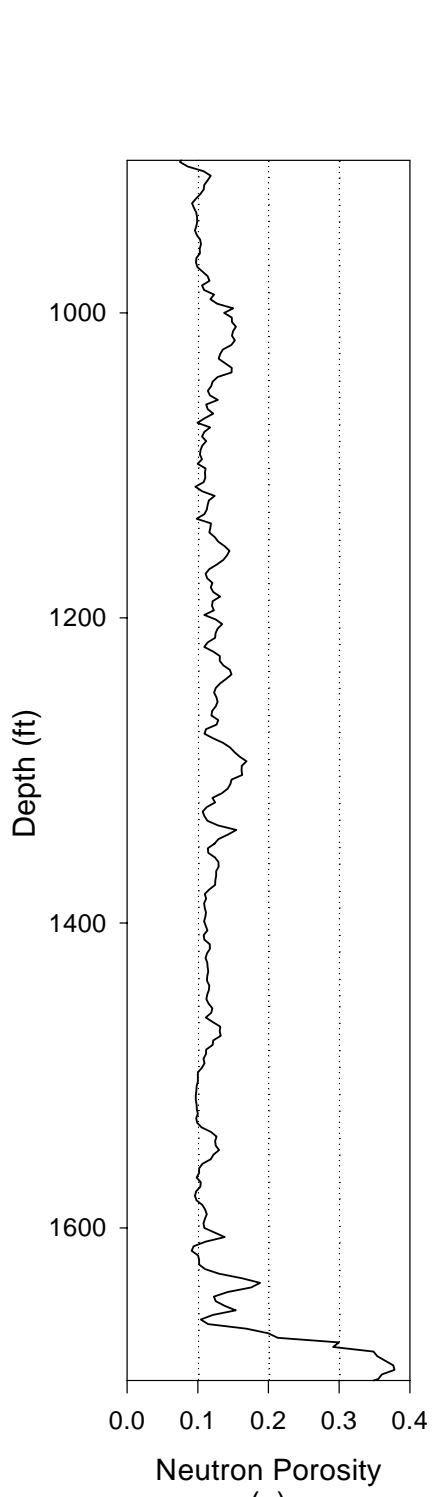

(a)

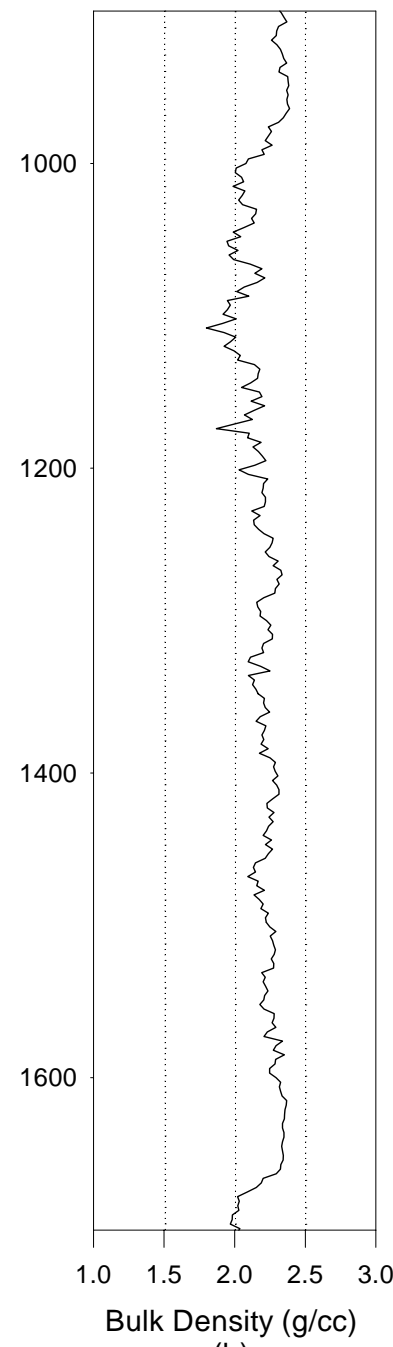

(b)

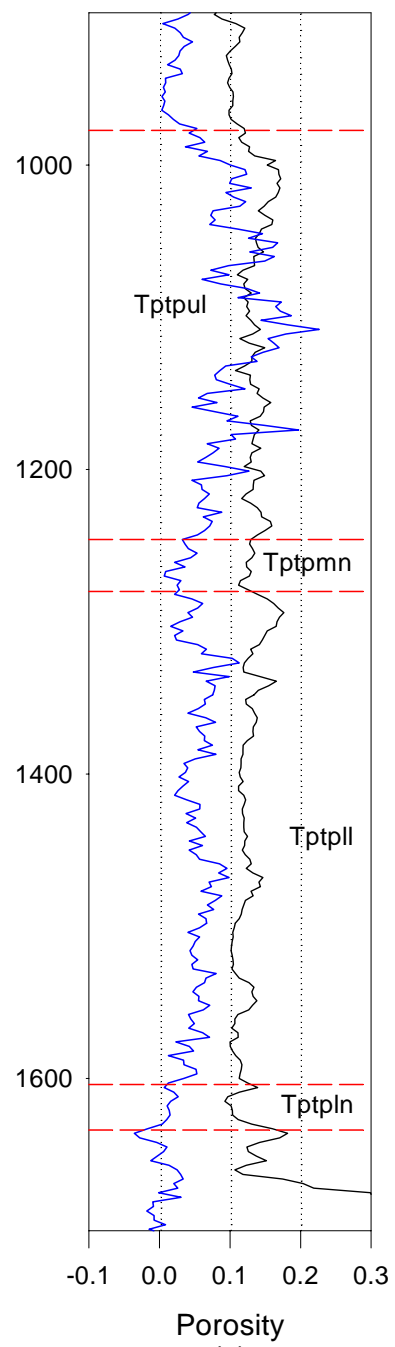

(c)

Input DTN: MO0010CPORGLOG.002 [DIRS 155229].

Figure B-2. USW G-2 


\section{USW G-3}

In USW G-3 the neutron porosity log, data look high but are consistent with the neutron porosity logs from neighboring boreholes USW H-3 and USW WT-7. This borehole was drilled with polymer mud as drilling fluid, which may explain the higher apparent neutron porosity. Bulk density data compare with nearby boreholes. Method B was applied to this borehole for the calculation of matrix and lithophysal porosity. The method yields very low lithophysal porosity in the lower lithophysae zone.

USW G-3

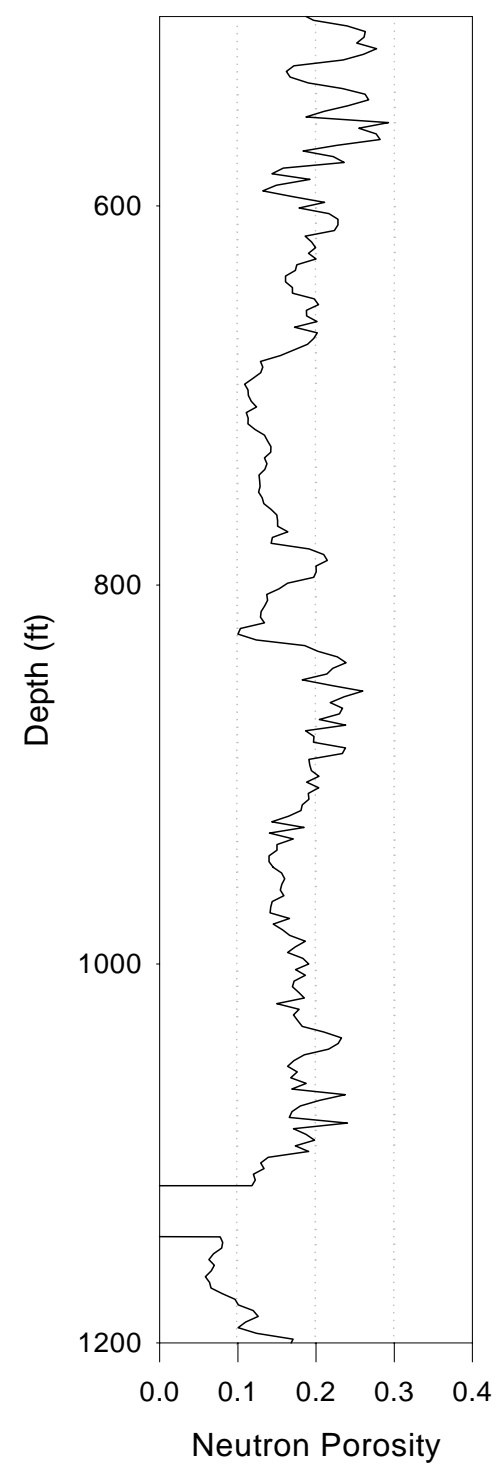

(a)

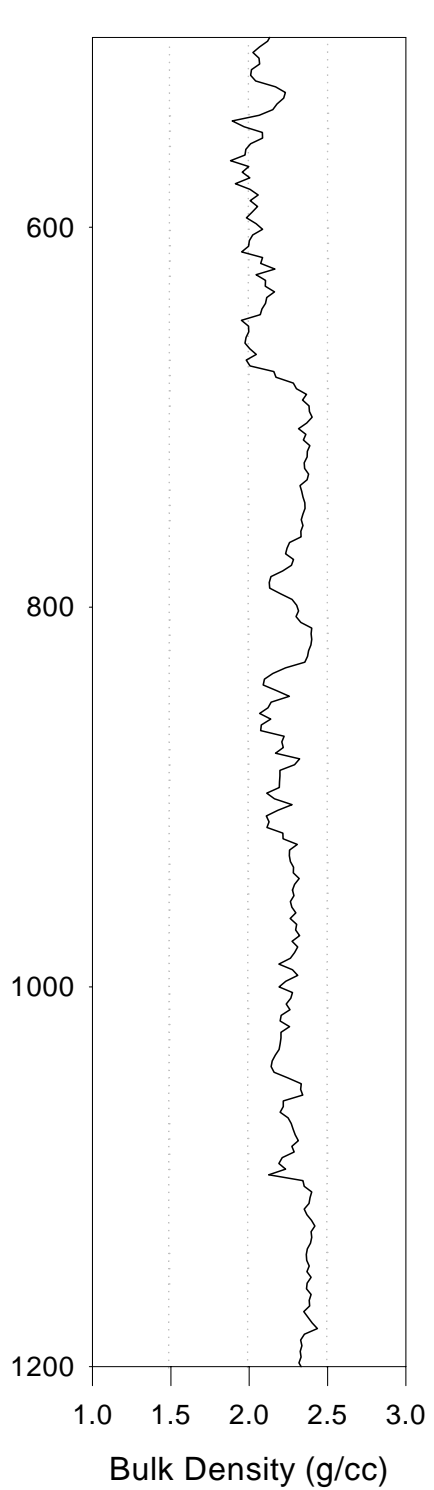

(b)

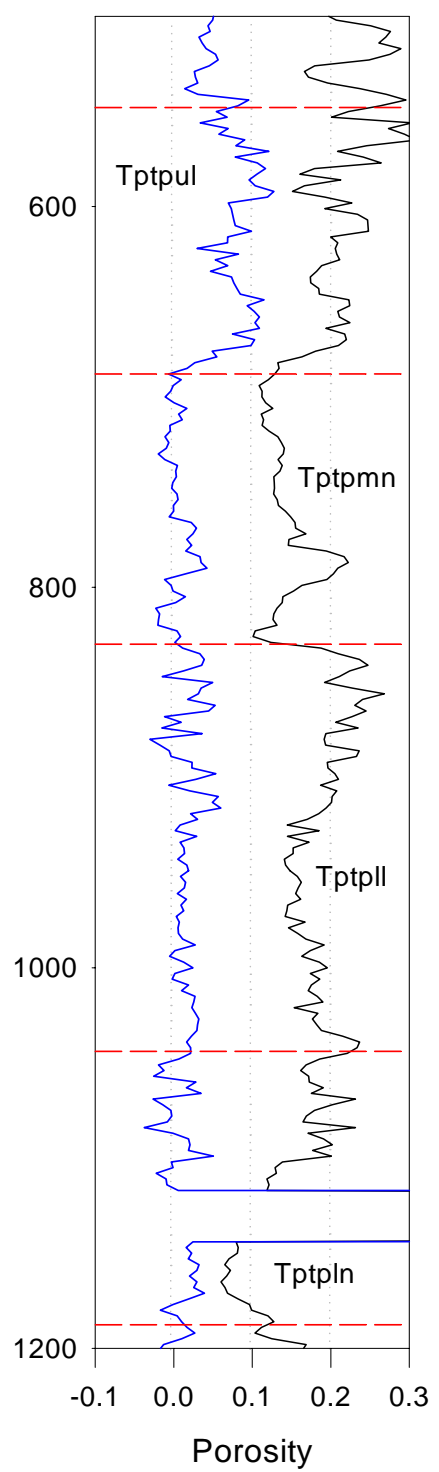

(c)

Input DTN: MO0010CPORGLOG.002 [DIRS 155229].

Figure B-3. USW G-3 


\section{USW G-4}

Essentially no neutron porosity data exist in the Tpt for USW G-4; however, the bulk density log is comparable to nearby borehole USW NRG-6. Method C was applied for computing lithophysal porosity.

USW G-4

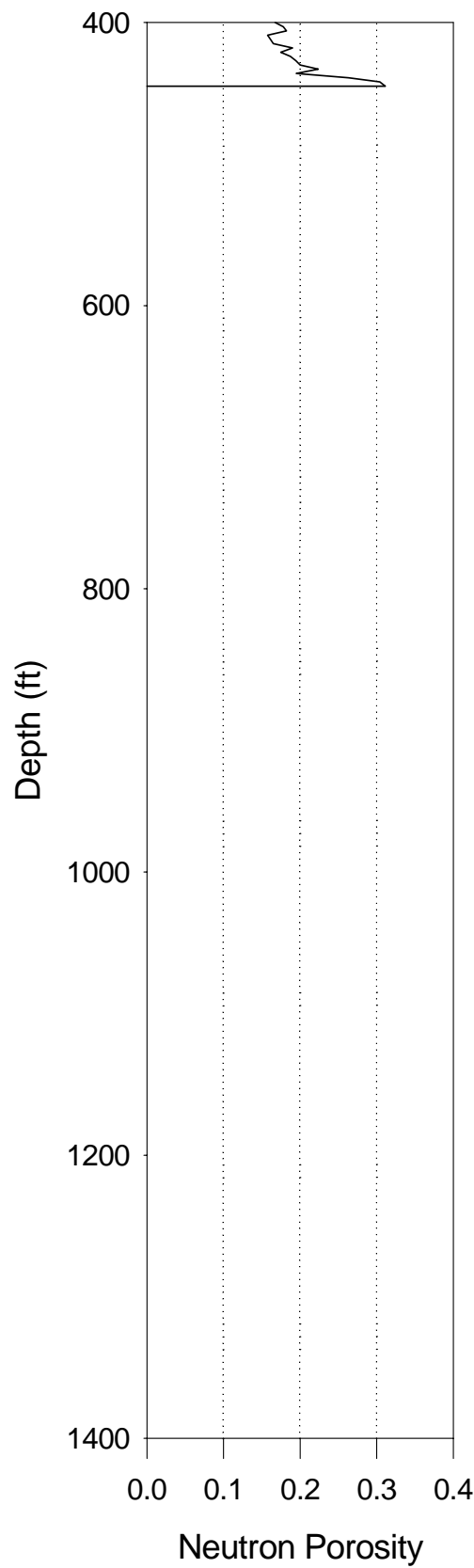

(a)

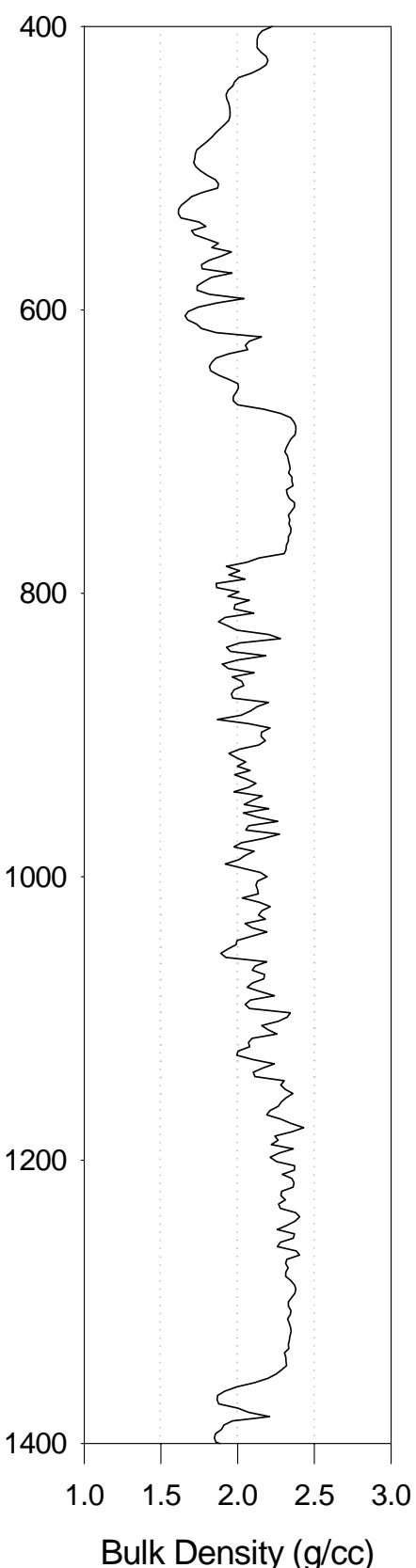

(b)

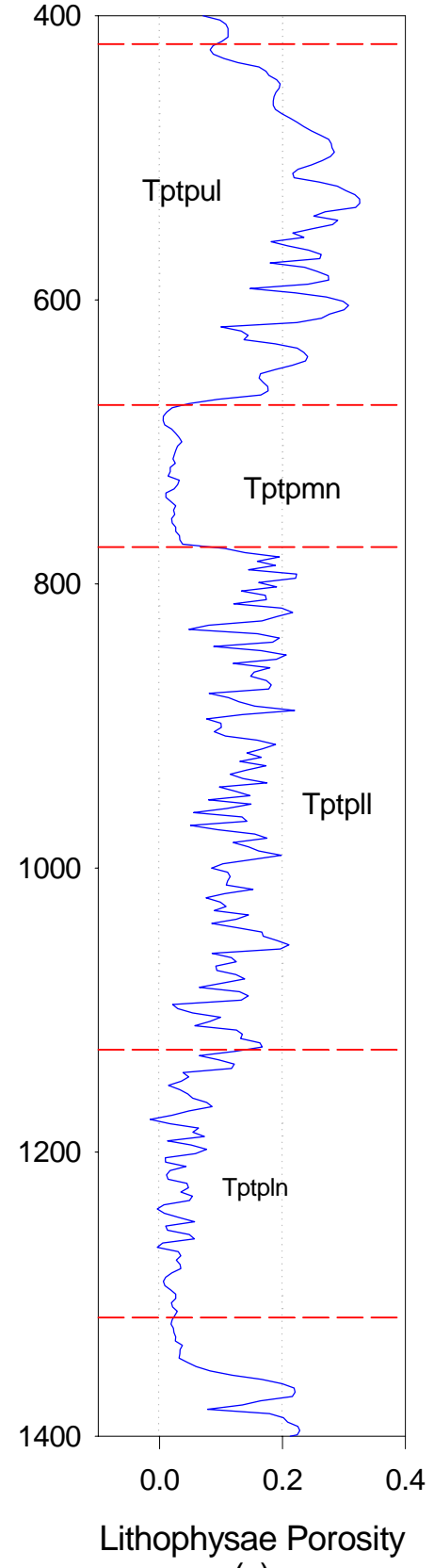

(c)

Input DTN: MO0010CPORGLOG.002 [DIRS 155229].

Figure B-4. USW G-4 


\section{USW H-1}

The neutron porosity and bulk density logs for USW H-1 are similar to those from nearby boreholes. Method B is used to calculate matrix and lithophysal porosity.

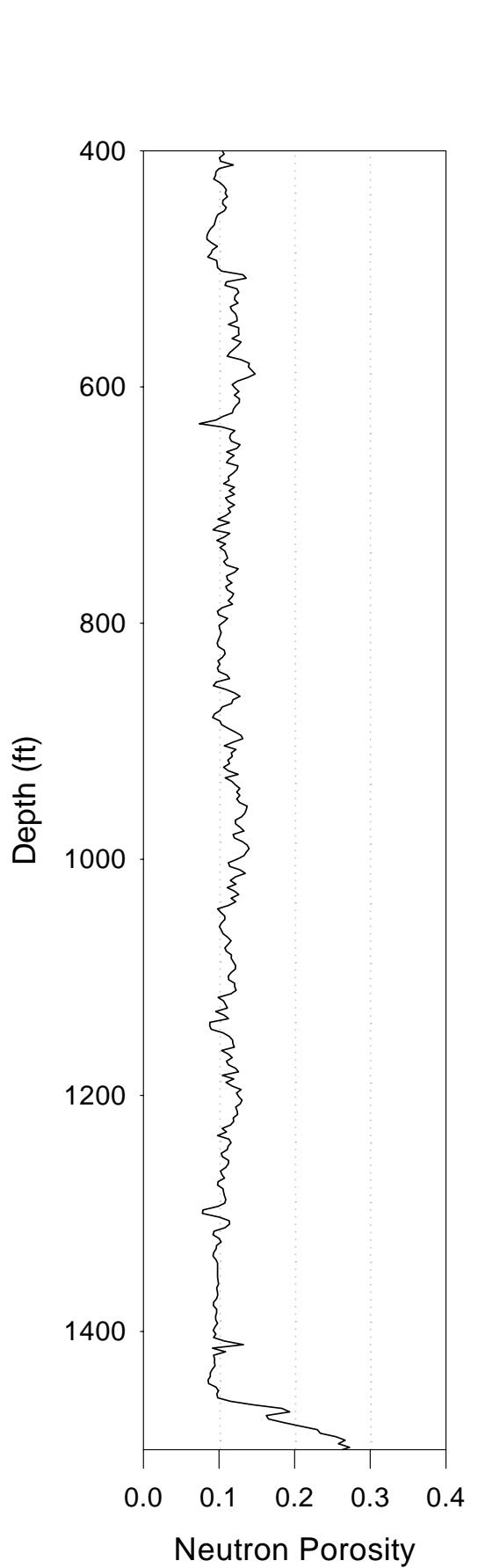

(a)

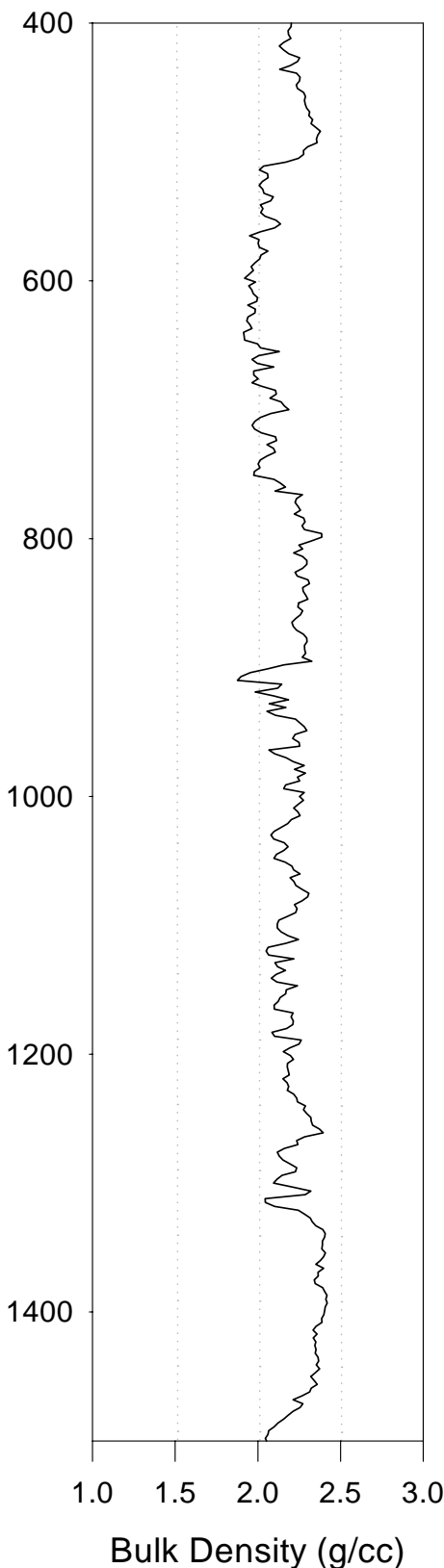

(b)

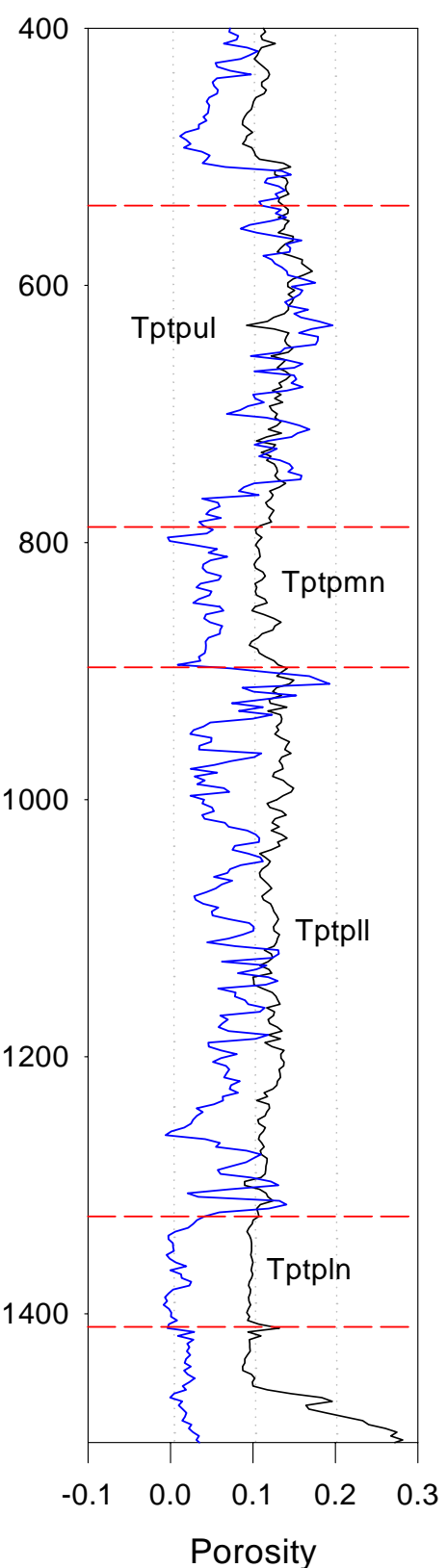

(c)

Input DTN: MO0010CPORGLOG.002 [DIRS 155229].

Figure B-5. USW H-1 


\section{USW H-3}

The neutron porosity from borehole USW H-3 looks a little high but is similar to USW H-4. The bulk density data for this well also compare favorably to data from USW H-4. Method B was applied to this borehole. The data below $958 \mathrm{ft}$, in the lower lithophysae unit, were neglected because of the absence of neutron porosity data.

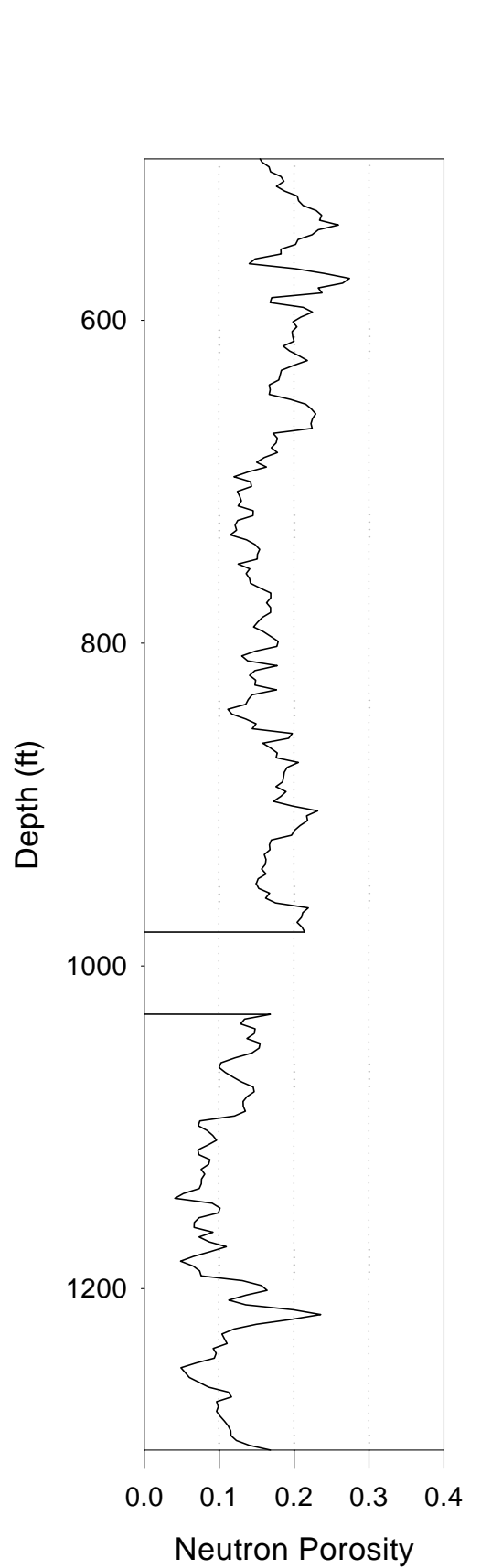

(a)

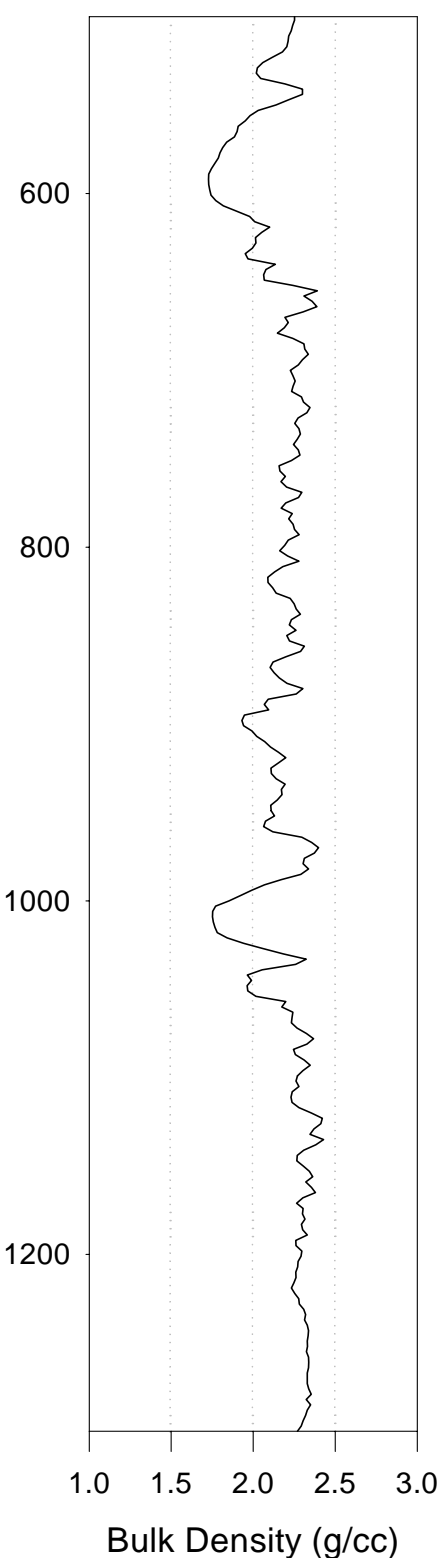

(b)

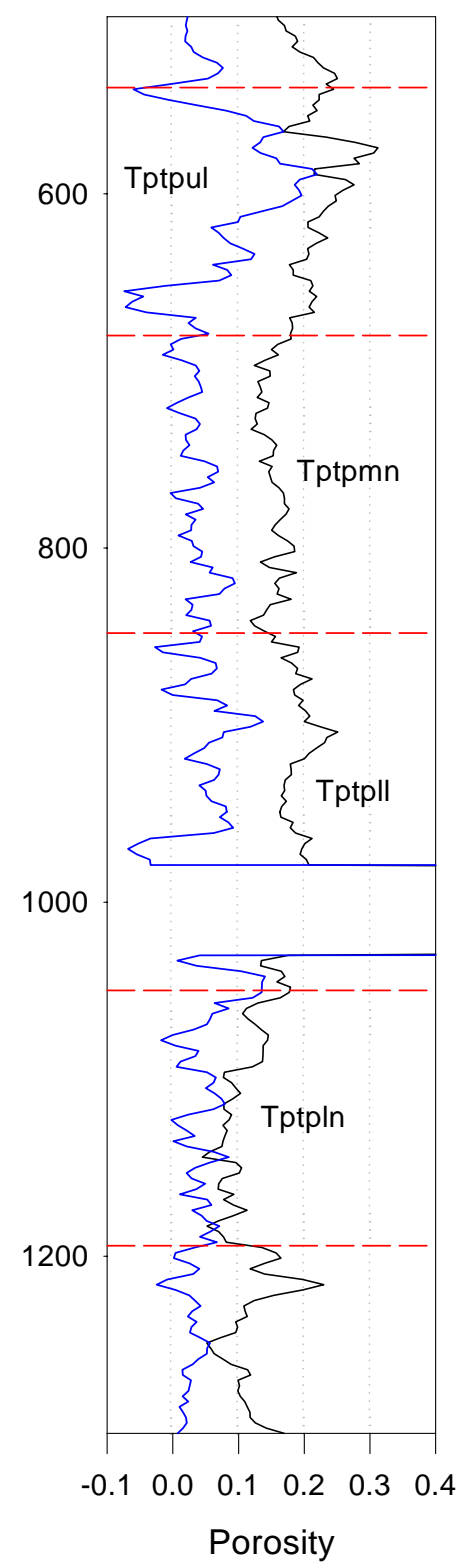

(c)

Input DTN: MO0010CPORGLOG.002 [DIRS 155229].

Figure B-6. USW H-3 


\section{USW H-4}

The neutron porosity data in borehole USW H-4 appear high in the lithophysae zones; however, this is the same type of behavior observed in neighboring boreholes USW H-3 and USW SD-12 and confirmed by core measurement. Method B was used for evaluation of matrix and lithophysal porosity for this borehole.

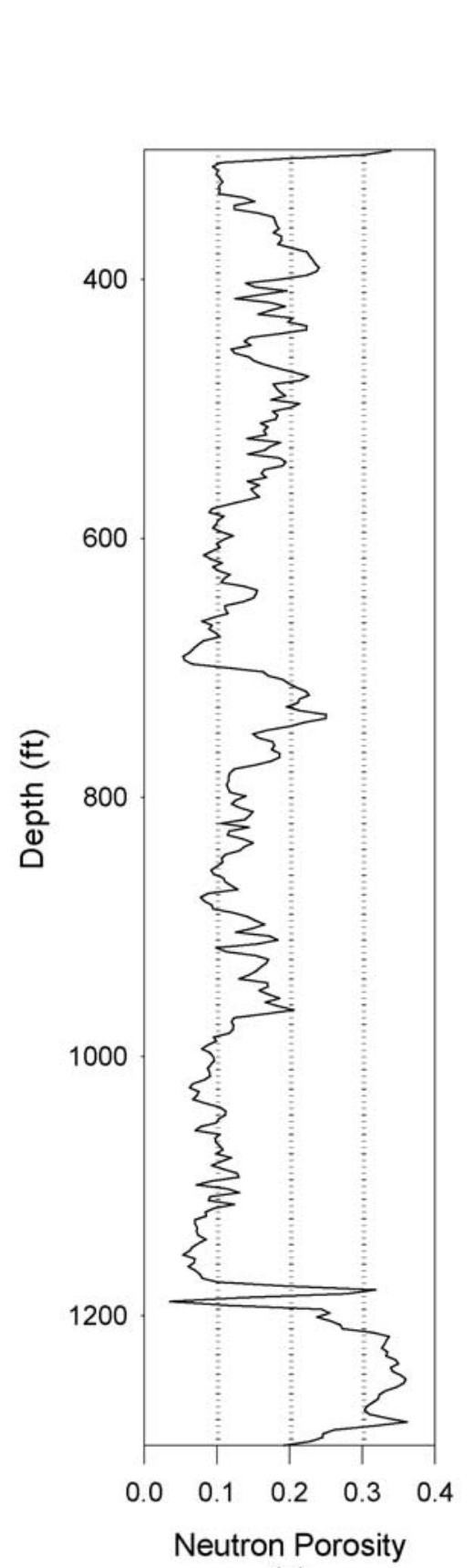

(a)

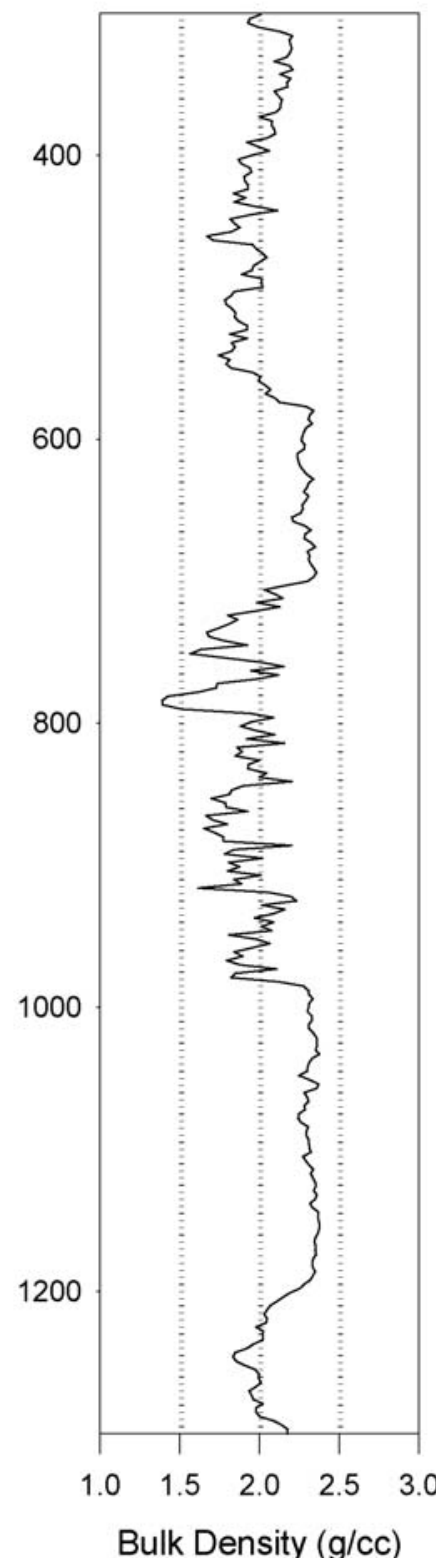

(b)

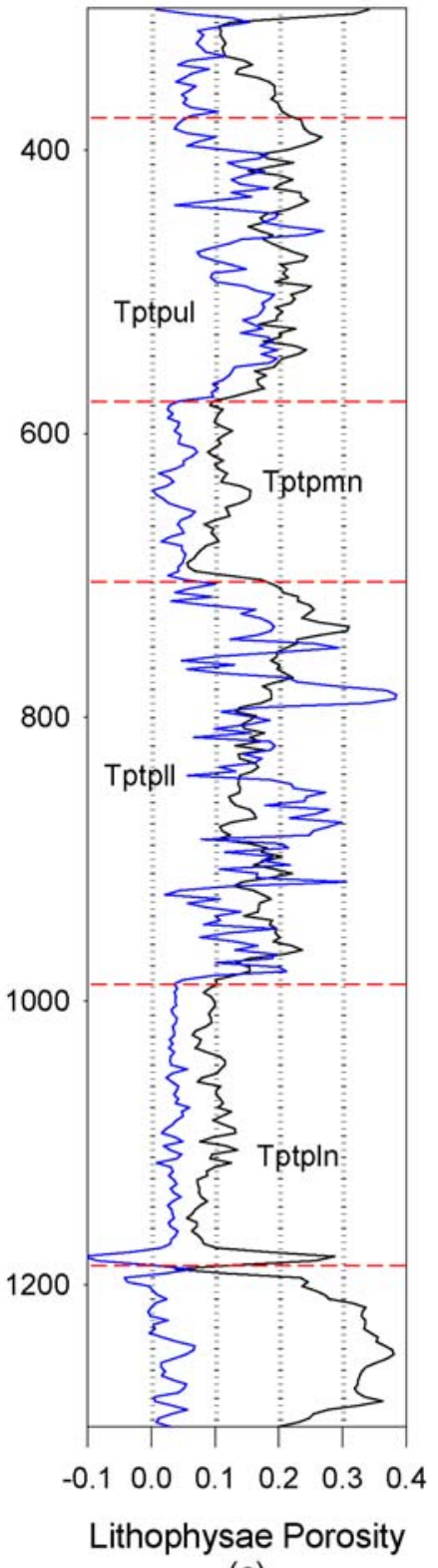

(c)

Input DTN: MO0010CPORGLOG.002 [DIRS 155229].

Figure B-7. USW H-4 


\section{USW H-5}

The neutron porosity and bulk density data for USW H-5 are very similar to the data for USW H-4. Method B was used to calculate matrix and lithophysal porosity for this borehole.

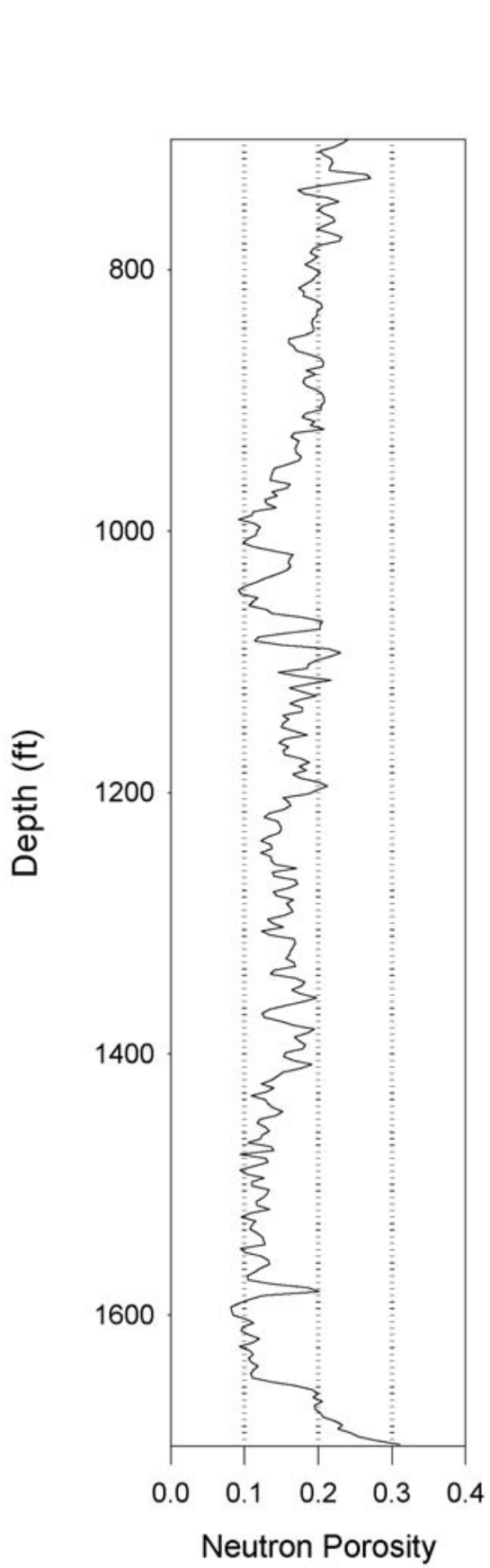

(a)
USW H-5

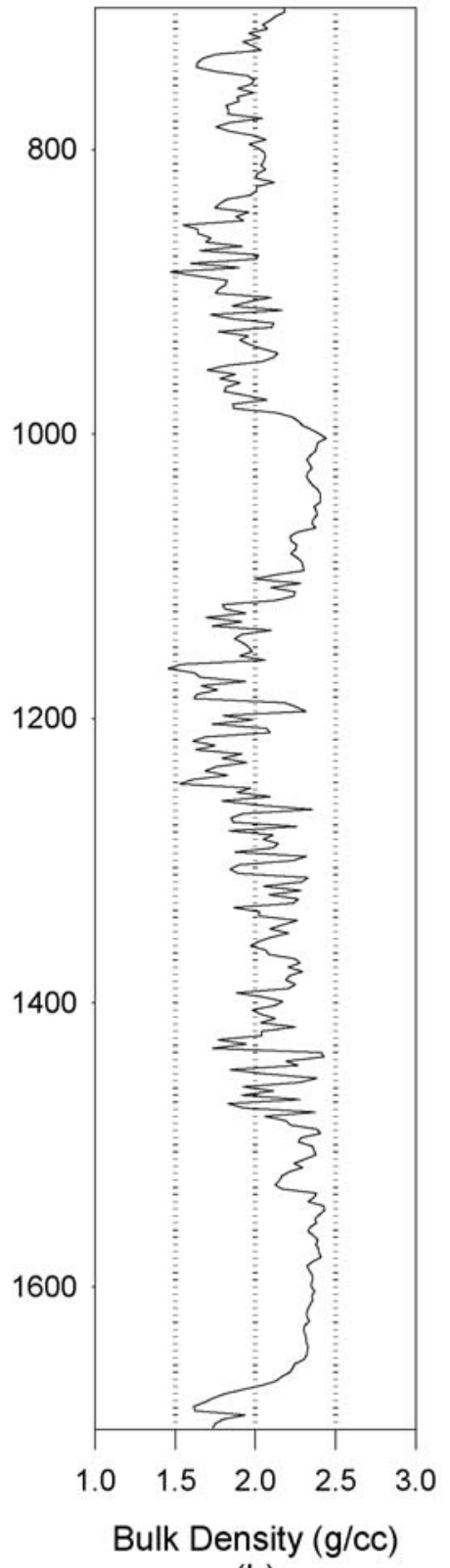

(b)
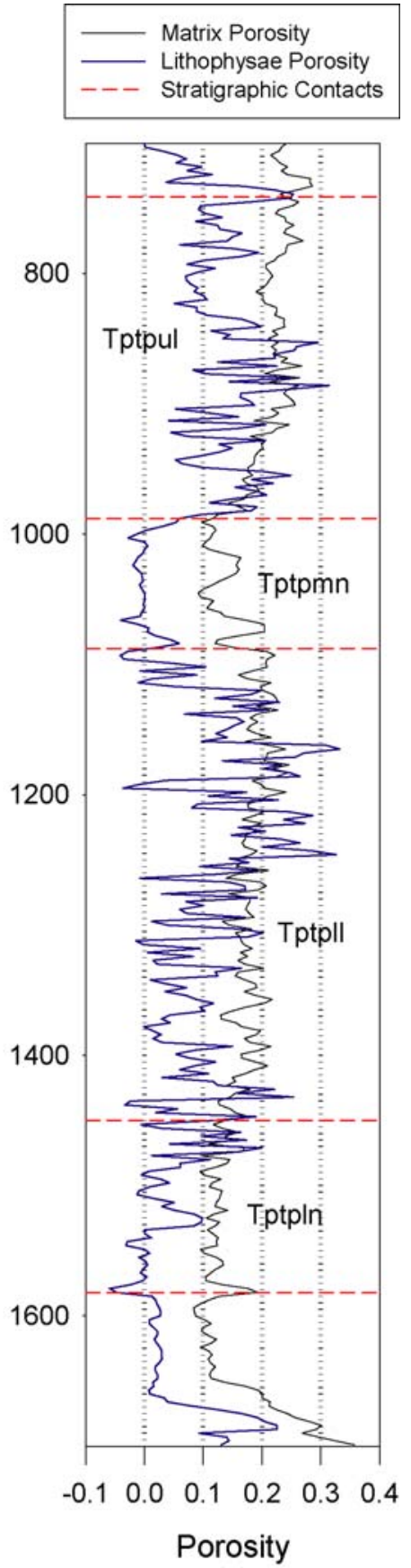

(c)

Input DTN: MO0010CPORGLOG.002 [DIRS 155229].

Figure B-8. USW H-5 


\section{USW H-6}

Both the neutron porosity and the bulk density data compare well with neighboring borehole USW H-5. Method B was used to calculate matrix and lithophysal porosity for this borehole.

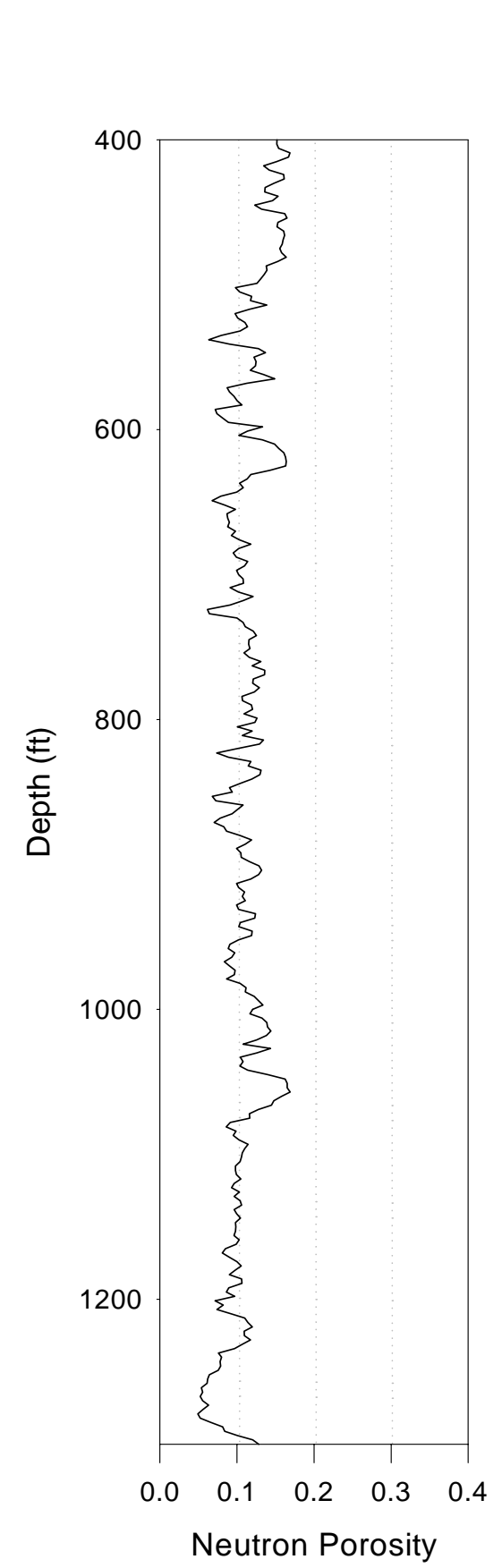

(a)

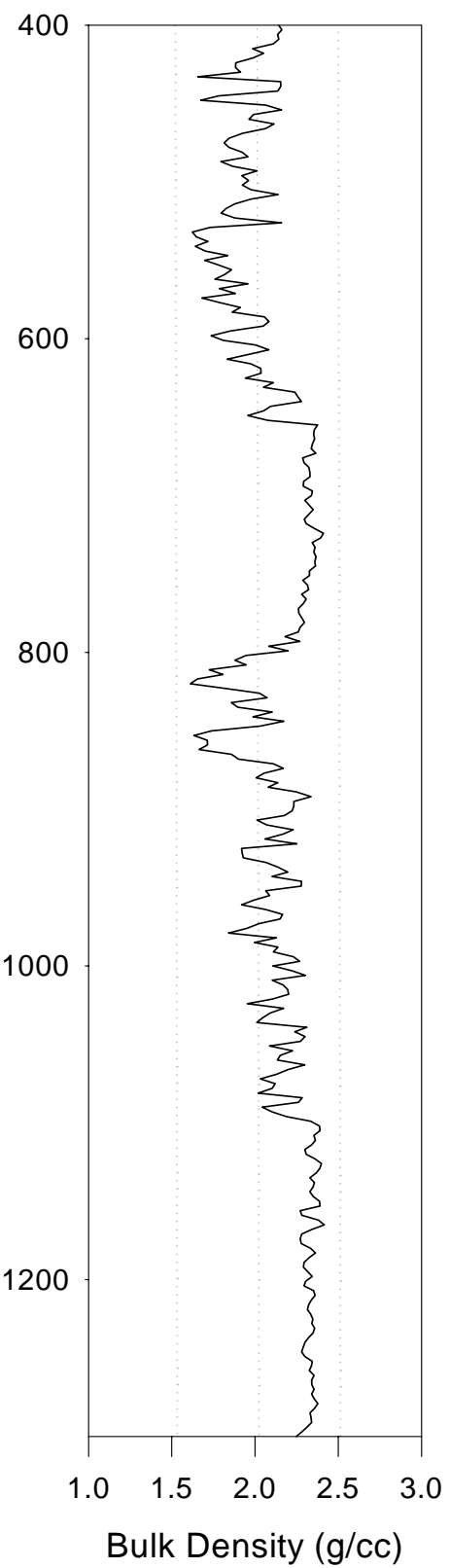

(b)

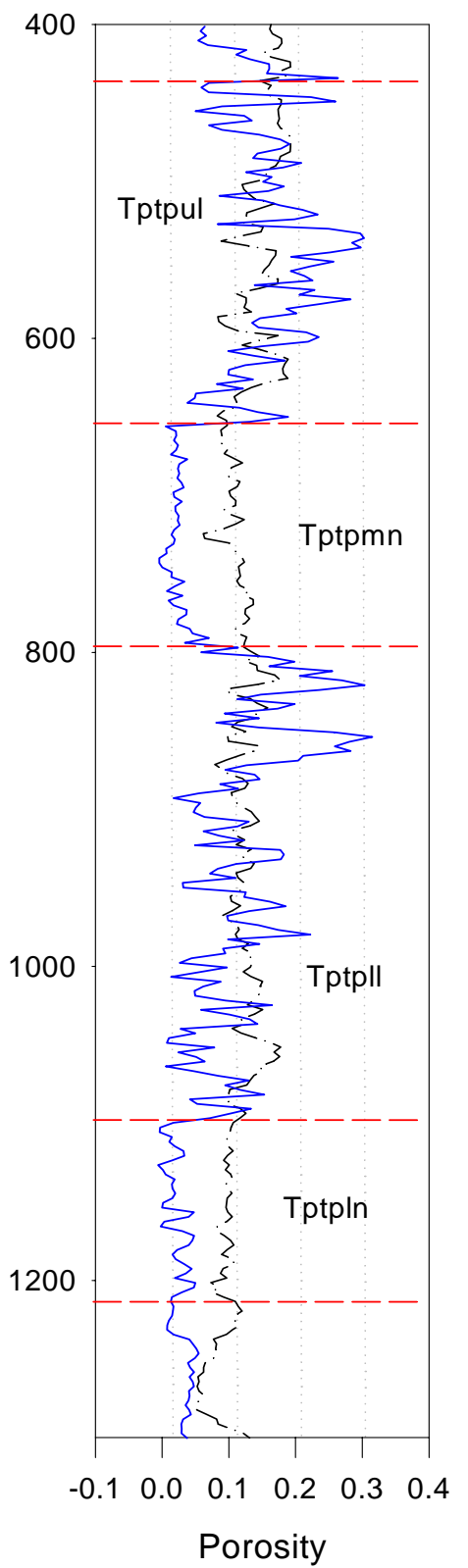

(c)

Input DTN: MO0010CPORGLOG.002 [DIRS 155229].

Figure B-9. USW H-6 


\section{UE-25 NRG \#4}

There are essentially no data for this borehole; therefore, it was removed from further consideration.

\section{USW NRG-6}

Both the neutron porosity and the bulk density data agree with typical readings from nearby boreholes. RH and OD core measurements compare well with calculated values of matrix porosity except for minor differences in the upper lithophysae zone. Given the abundant core data, OD core measurements will be used to represent matrix porosity, and Method A will be used to calculate lithophysal porosity.

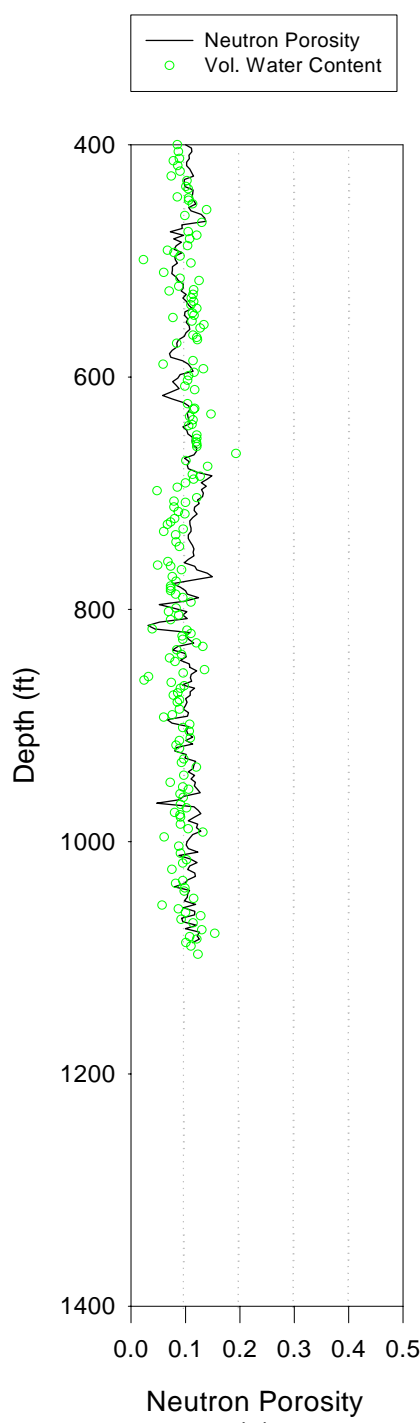

(a)

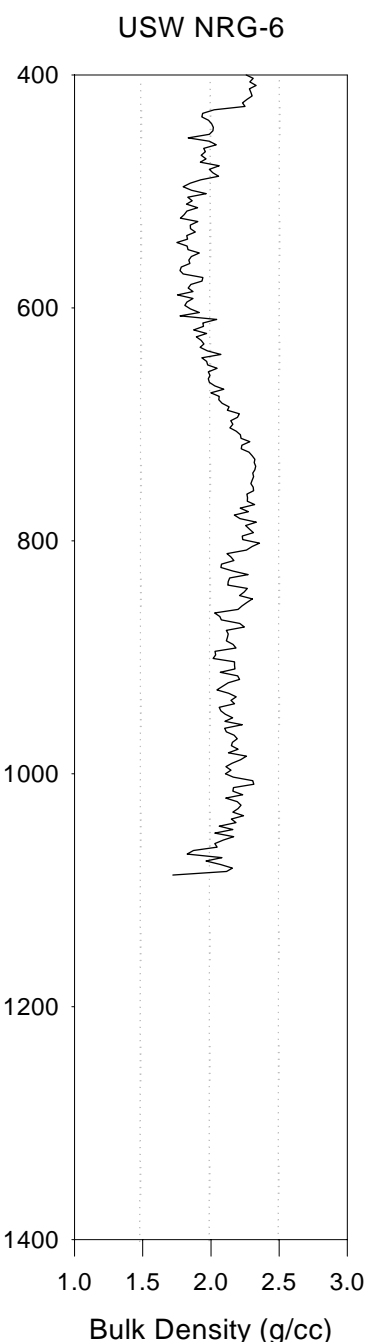

(b)

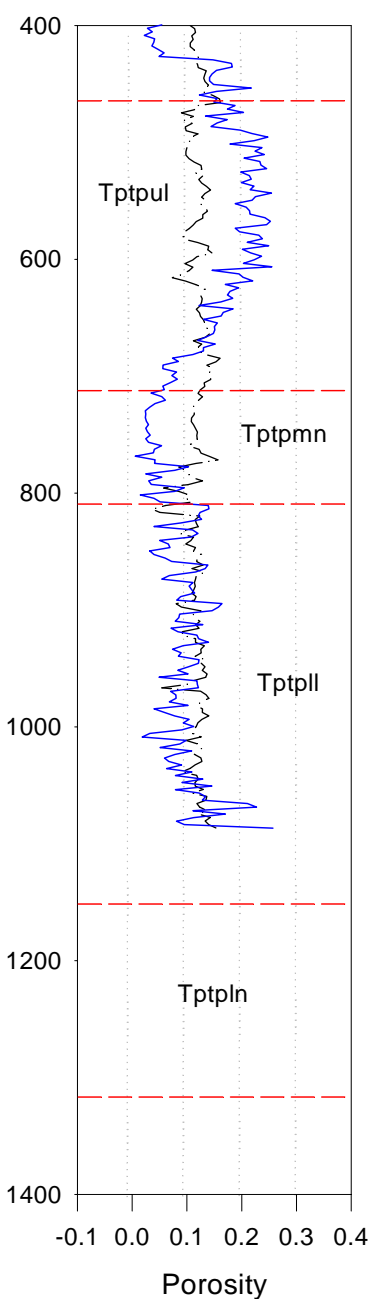

(c)

Input DTN: MO0010CPORGLOG.003 [DIRS 155959].

Figure B-10. USW NRG-6 Petrophysical 


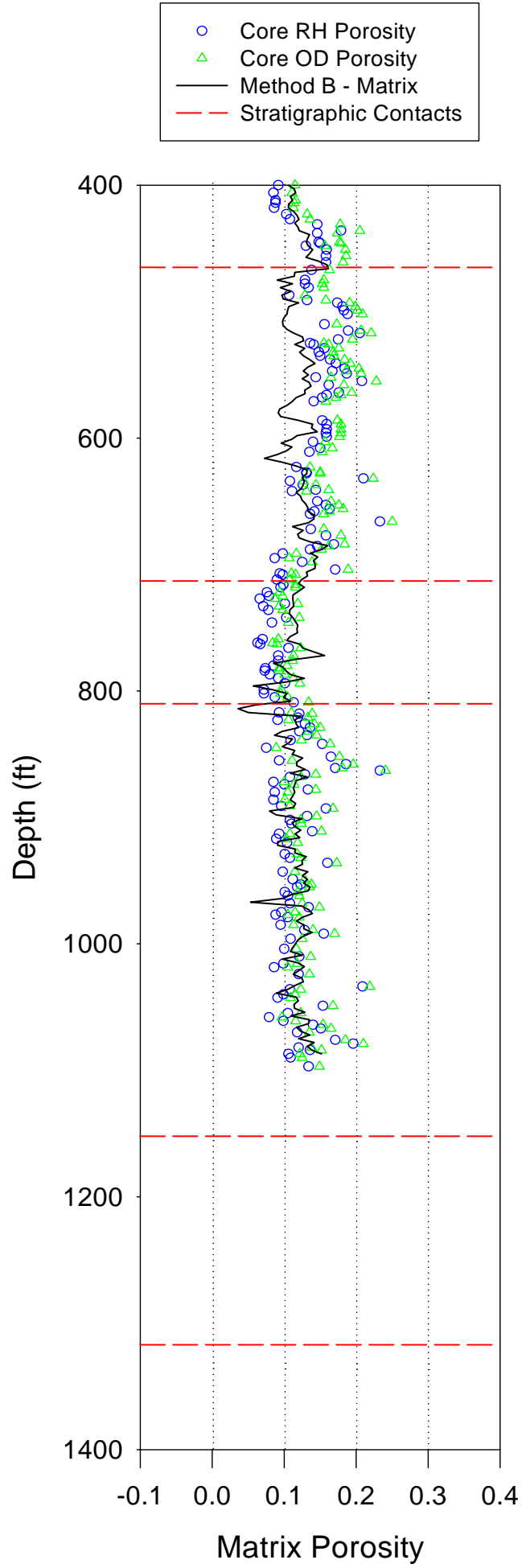

(a)
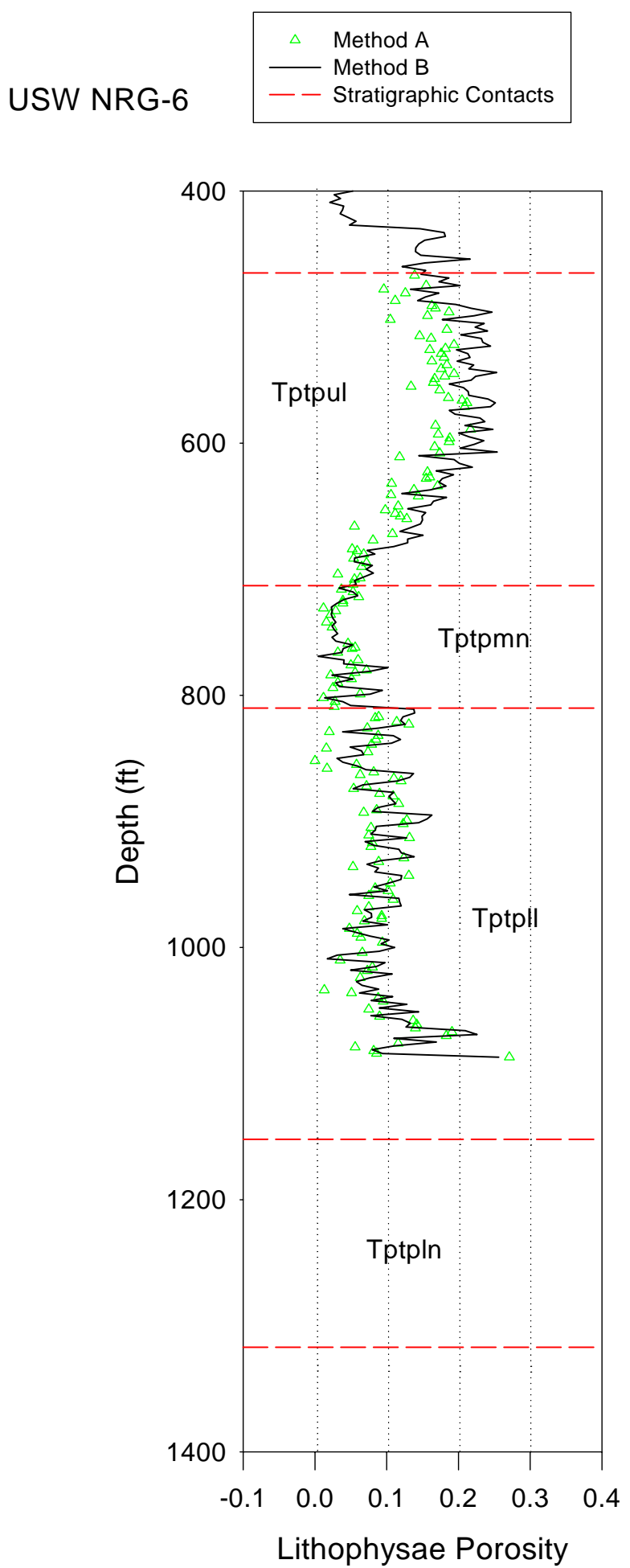

(b)

Input DTN: MO0109HYMXPROP.001 [DIRS 155989], Output DTN: SN0404T0503102.011 [DIRS 169129]. NOTES: $\mathrm{OD}=$ oven-dried; $\mathrm{RH}=$ relative humidity.

Figure B-11. USW NRG-6 Core 


\section{NRG-7/7a}

The neutron porosity for this borehole is unusually low, leading to low matrix porosities when calculated via Method B. This is confirmed by comparison with abundant core measurements. The low readings could be attributed to the use of the wrong matrix setting on the compensated neutron tool used to collect the data. The bulk density data compare favorably with the data from nearby borehole USW H-1. Therefore, lithophysal porosity is calculated from OD core measurements using Method A.

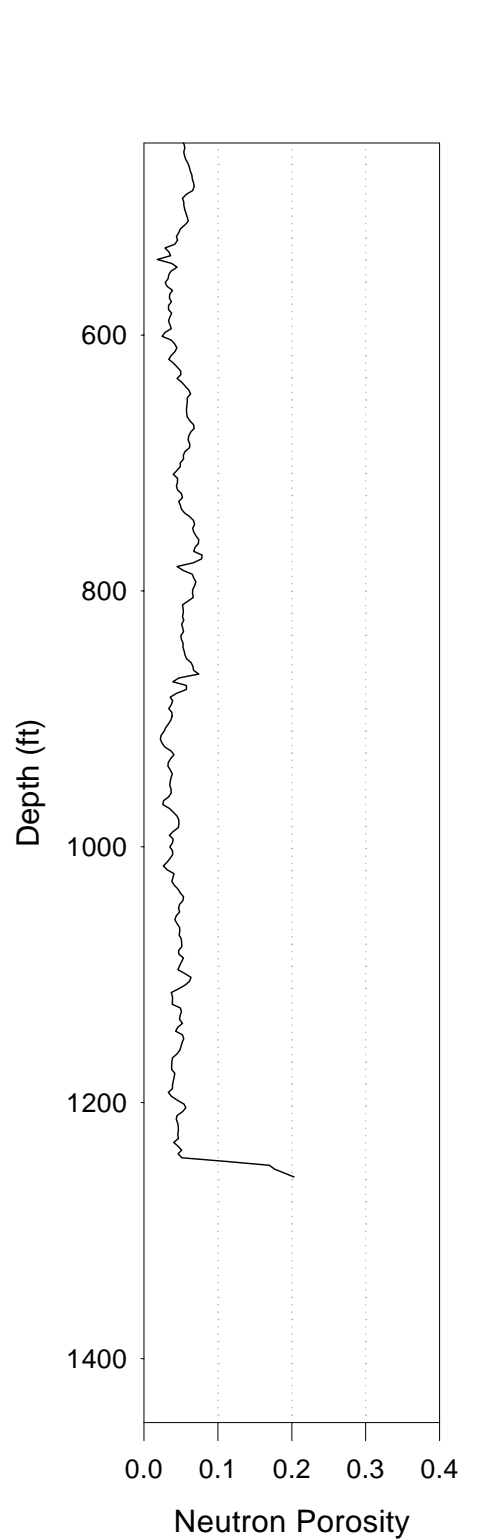

(a)

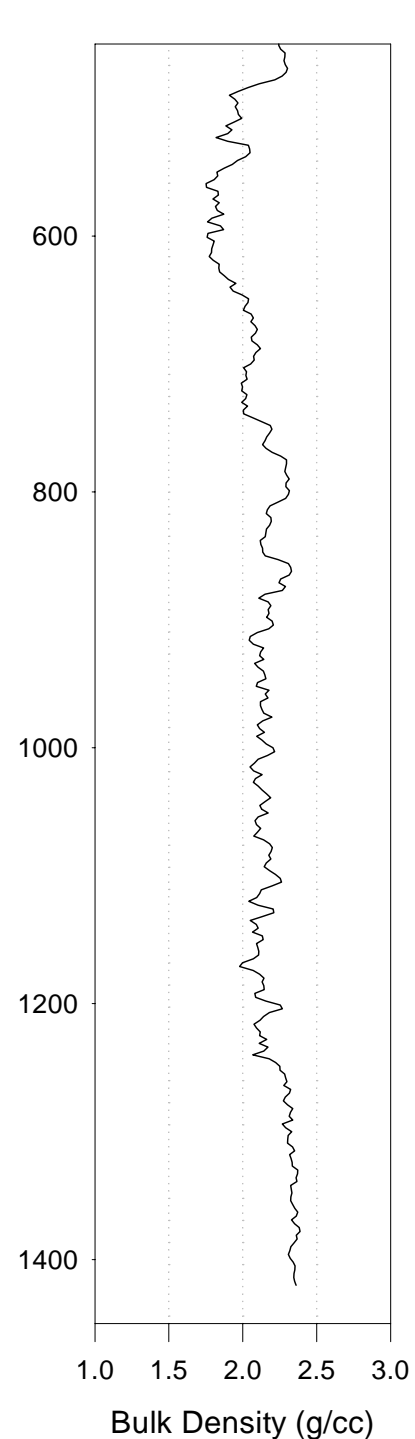

(b)

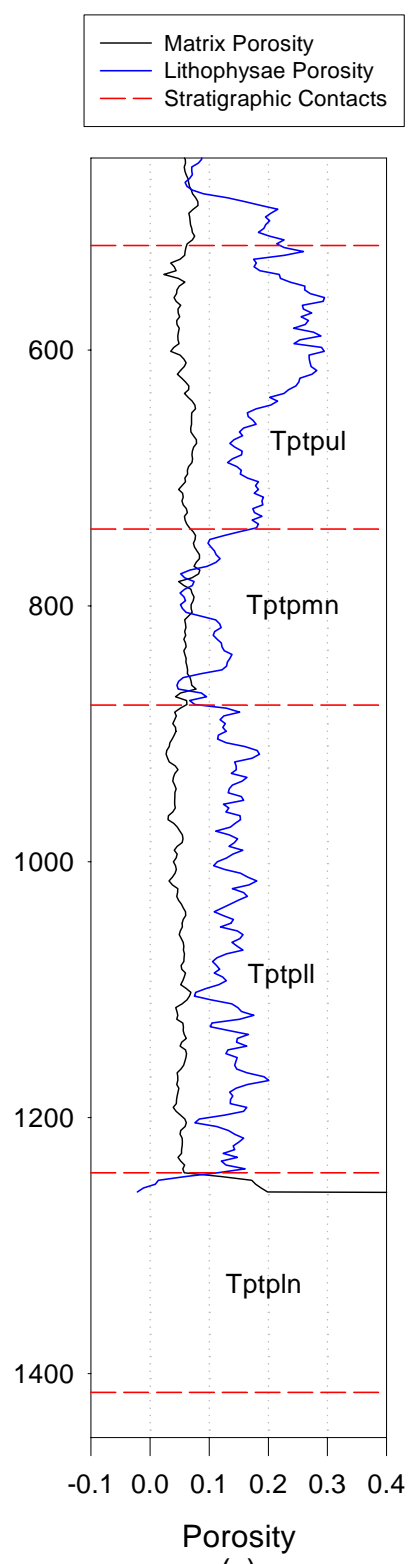

(c)

Input DTN: MO0010CPORGLOG.003 [DIRS 155959].

Figure B-12. USW NRG-7/7a Petrophysical 


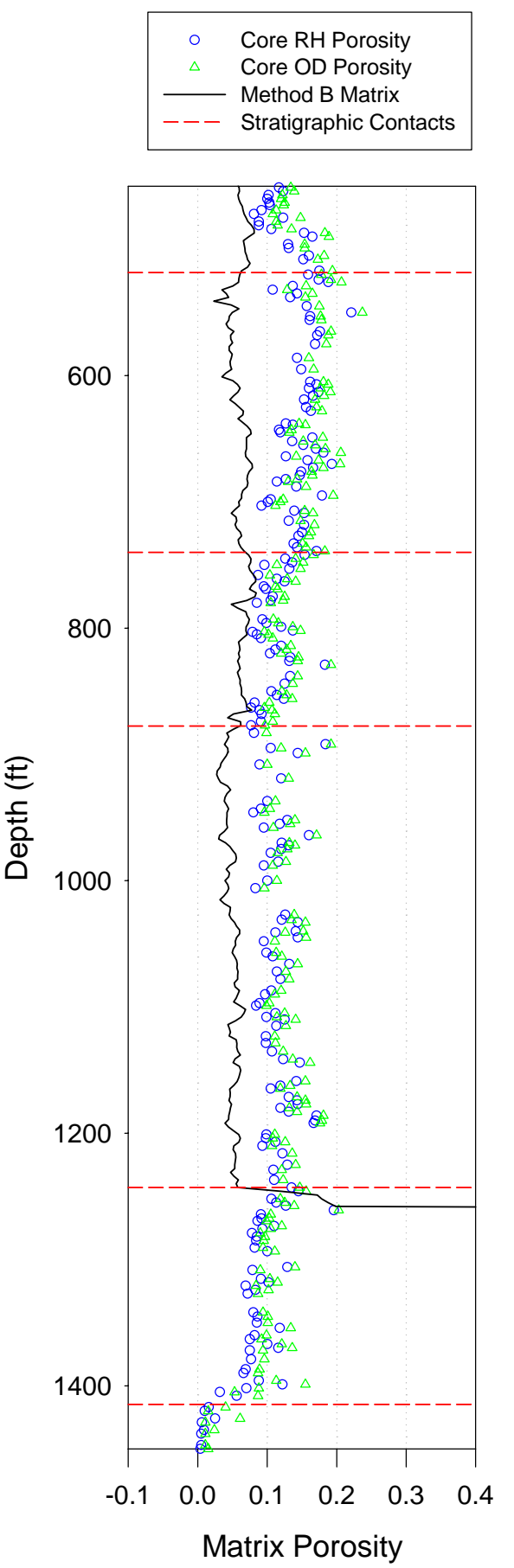

(a)
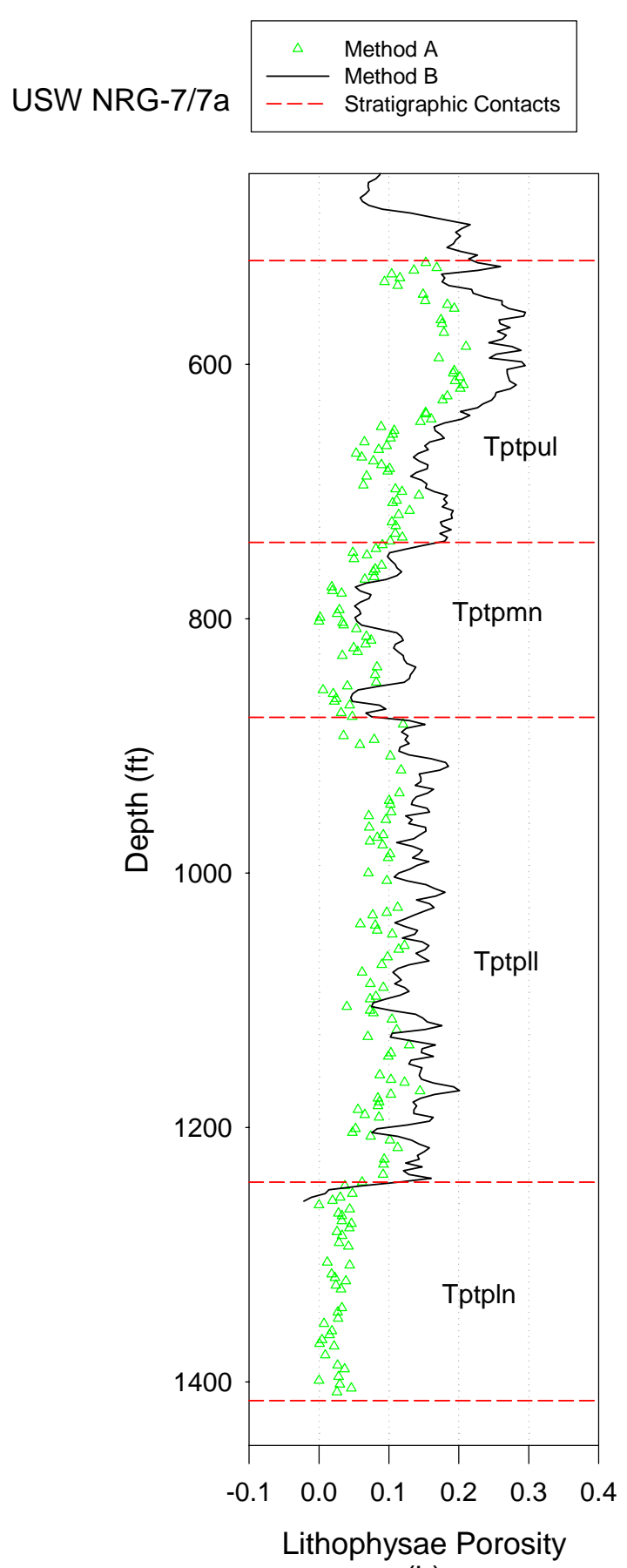

(b)

Input DTN: MO0109HYMXPROP.001 [DIRS 155989], Output DTN: SN0404T0503102.011 [DIRS 169129]. NOTES: $\mathrm{OD}$ = oven-dried; $\mathrm{RH}$ = relative humidity.

Figure B-13. USW NRG-7/7a Core 


\section{UE-25 ONC \#1}

The neutron porosity data appear low compared to data from nearby boreholes. This is particularly true in the upper lithophysae zone. The bulk density data agree with data from nearby boreholes; therefore, Method $\mathrm{C}$ was applied for the calculation of lithophysal porosity.

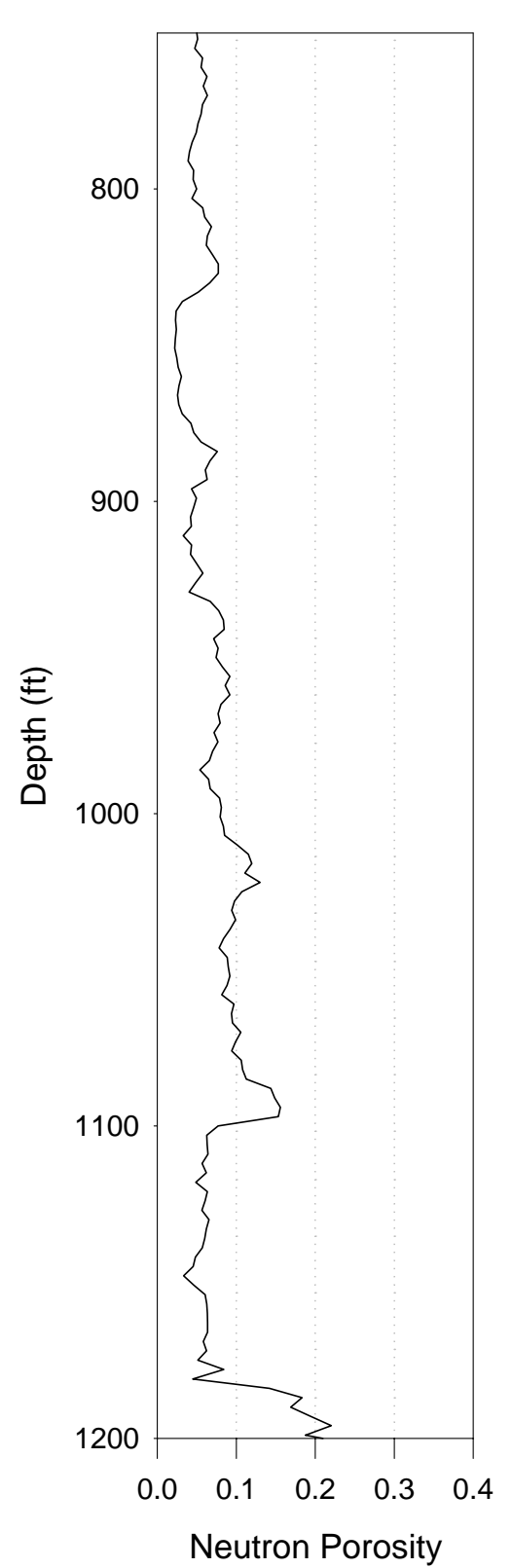

(a)

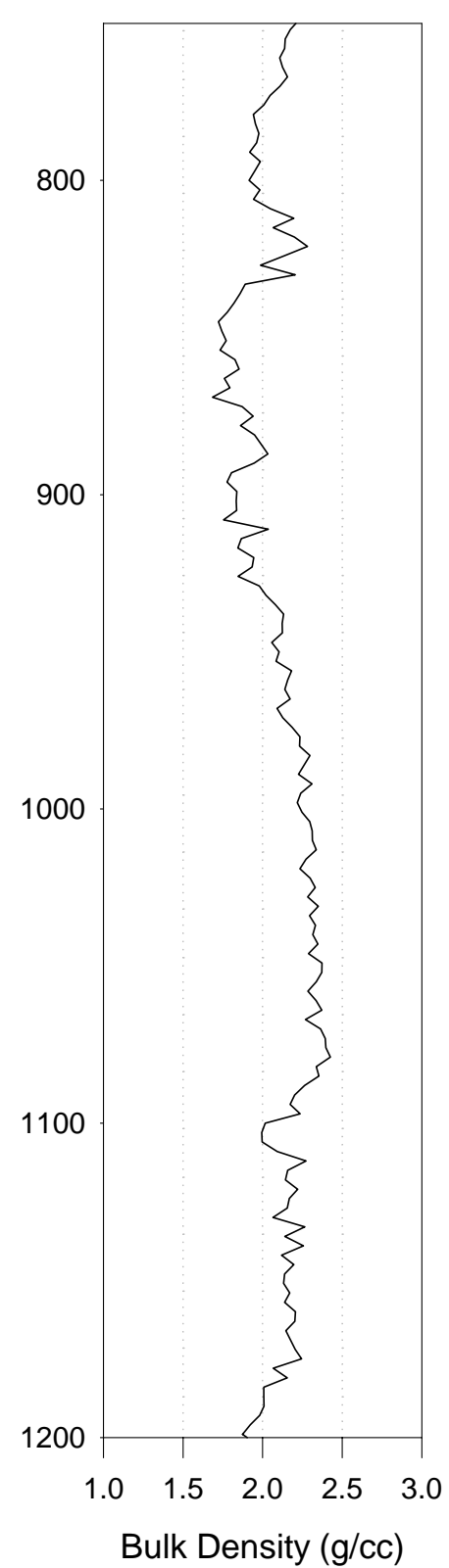

(b)

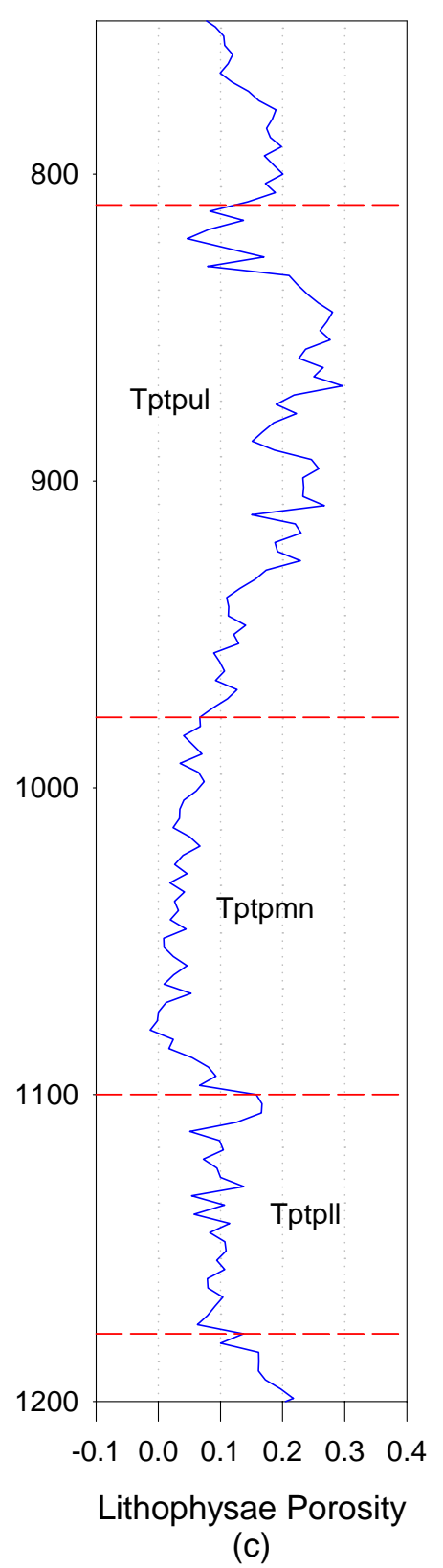

(c)

Input DTN: MO0010CPORGLOG.003 [DIRS 155959].

Figure B-14. UE-25 ONC \#1 


\section{UE-25 p \#1}

The neutron porosity and bulk density logs compare well with the logs from nearby boreholes. There are no core data available for this borehole; therefore, Method B was used to calculate matrix and lithophysal porosity.

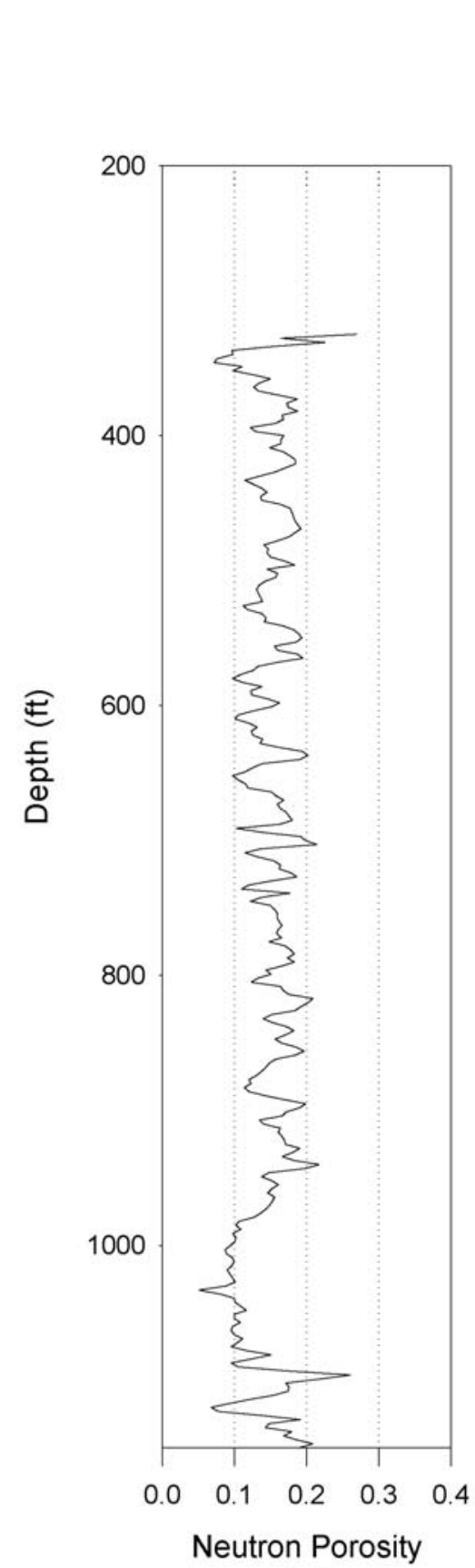

(a)
UE-25 $p \# 1$

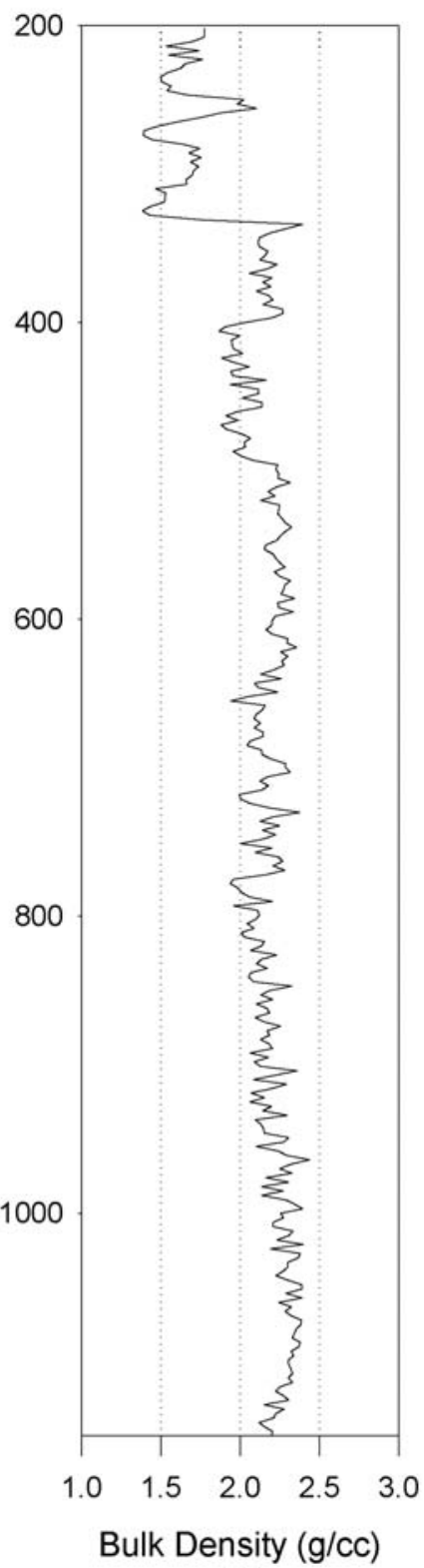

(b)
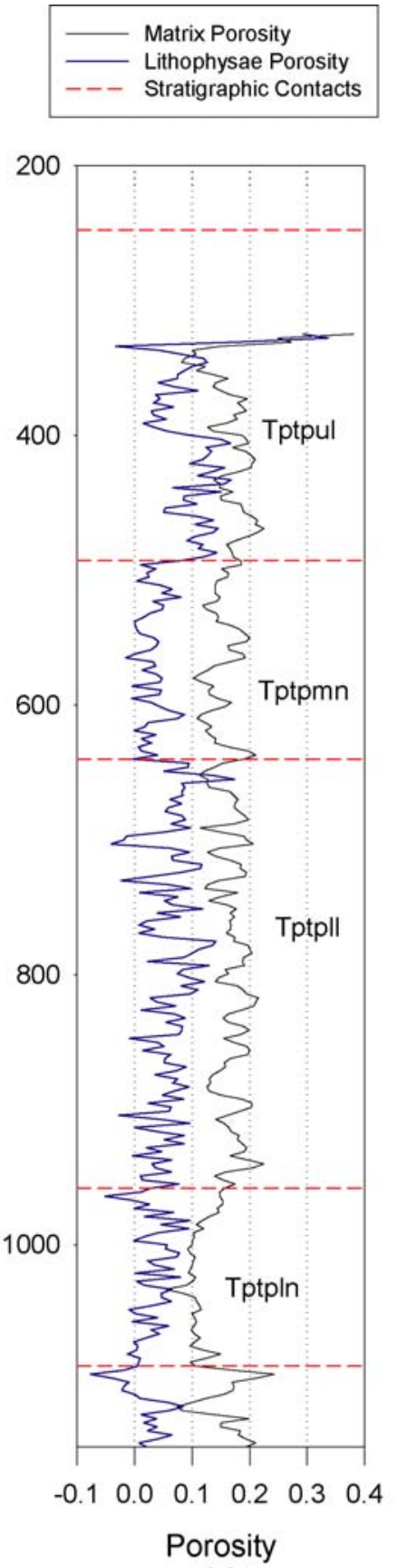

(c) 002460__UE_2501. ai

Input DTN: MO0010CPORGLOG.002 [DIRS 155229].

Figure B-15. UE-25 p \#1 


\section{USW SD-6}

The neutron porosity data for this borehole compare favorably with data in neighboring boreholes, particularly in lower units. The bulk density measurements show the effect of hole damage (rugosity) when compared to the other boreholes examined. There are a few core samples taken from this borehole in the lower nonlithophysal layer, which will be used to condition matrix porosity at this location. All other data from USW SD-6 were not used.

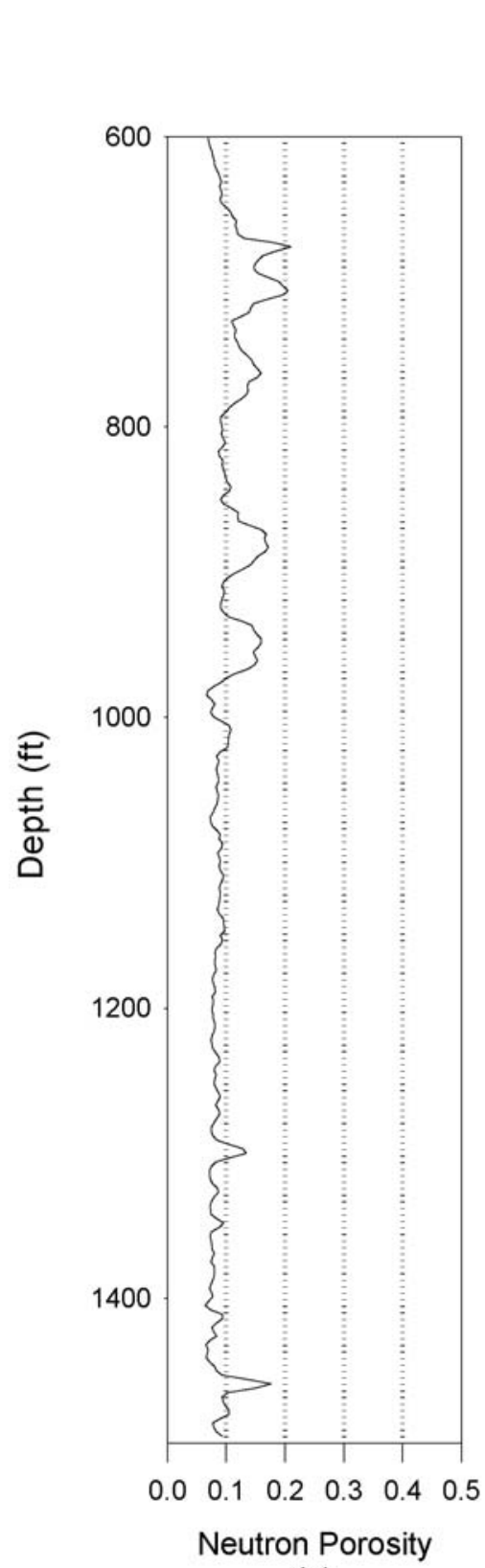

(a)

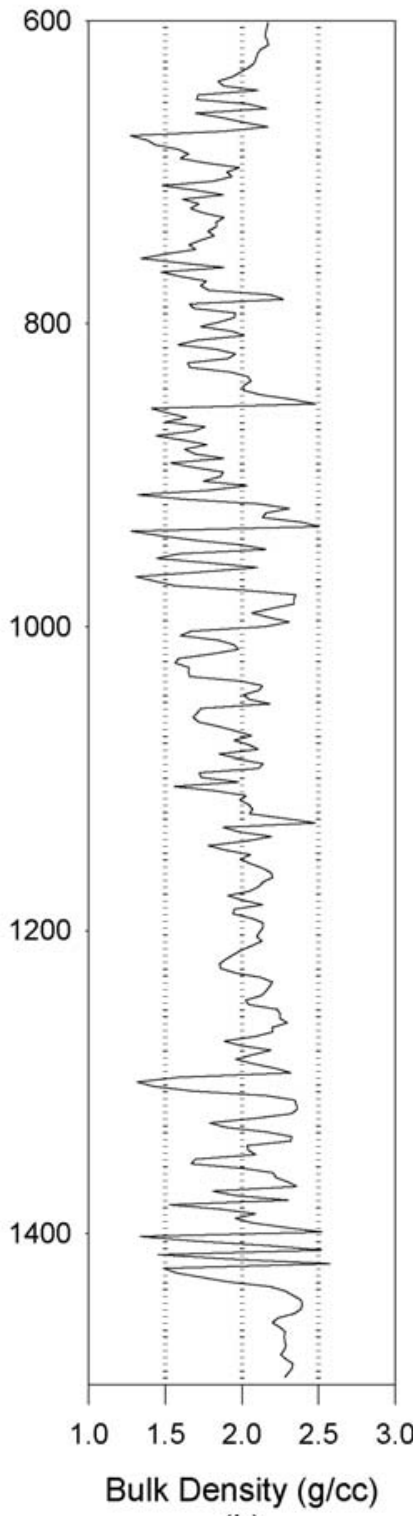

(b)

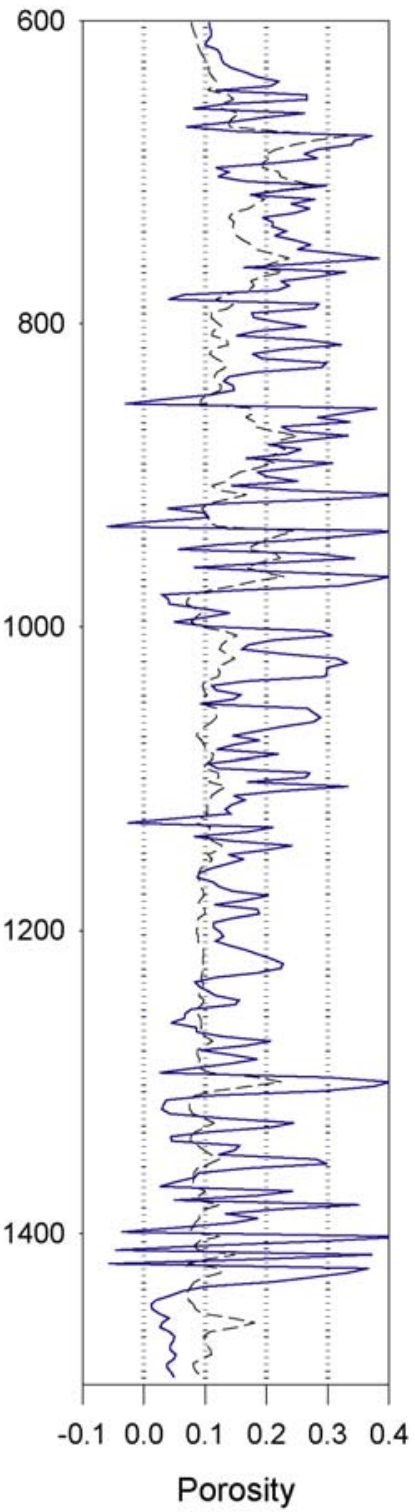

(c)

Input DTN: MO0010CPORGLOG.003 [DIRS 155959].

Figure B-16. USW SD-6 


\section{USW SD-7}

The neutron porosity and the bulk density data for this borehole compare well with data from neighboring boreholes. Abundant core data were available for this borehole, and good agreement between the neutron porosity and volumetric water content data was observed. Method A was used to compute lithophysal porosity.

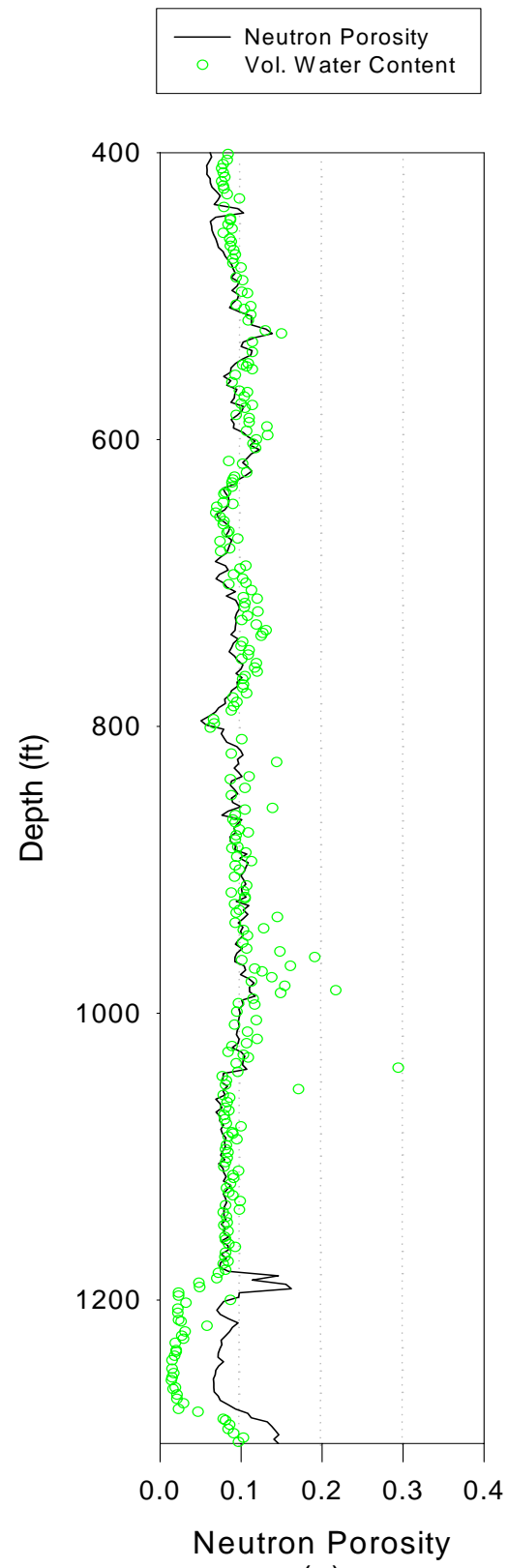

(a)

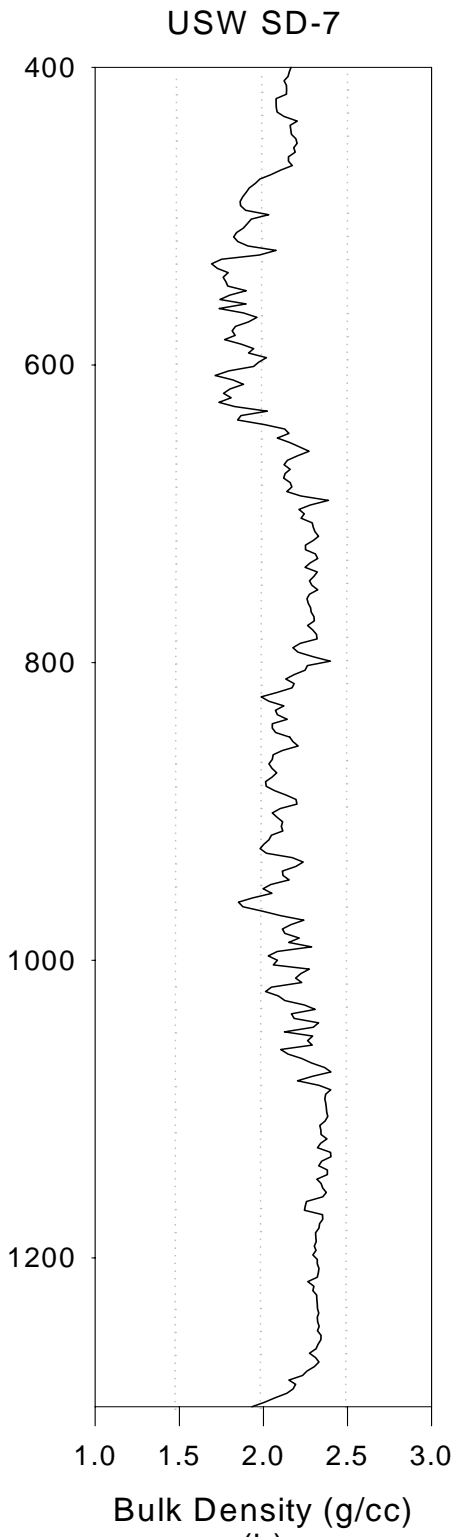

(b)
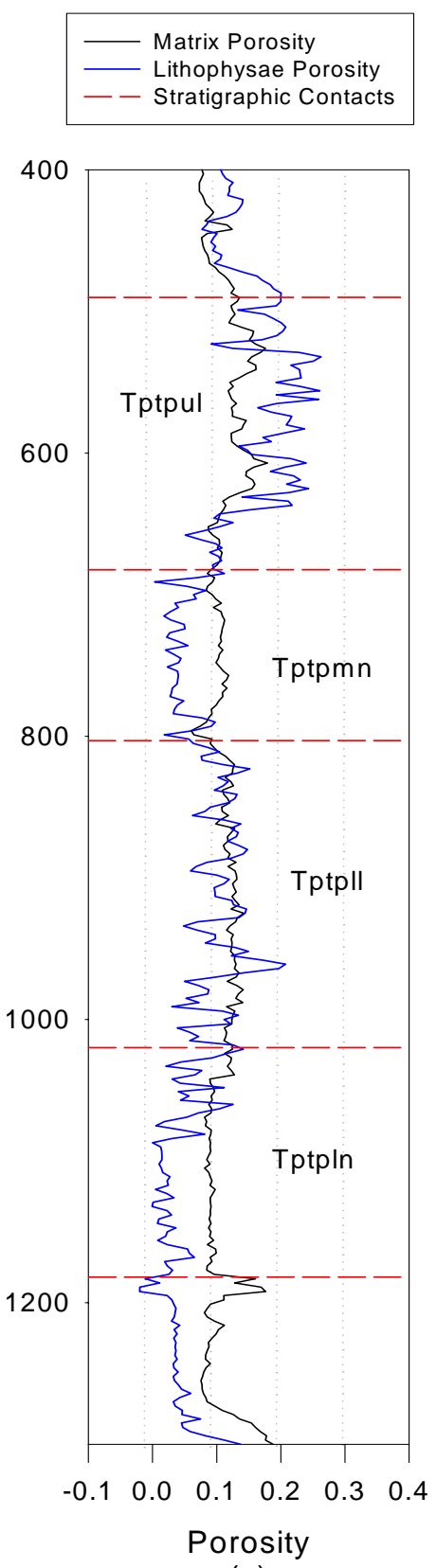

(c)

Input DTN: MO0010CPORGLOG.003 [DIRS 155959].

Figure B-17. USW SD-7 Petrophysical 


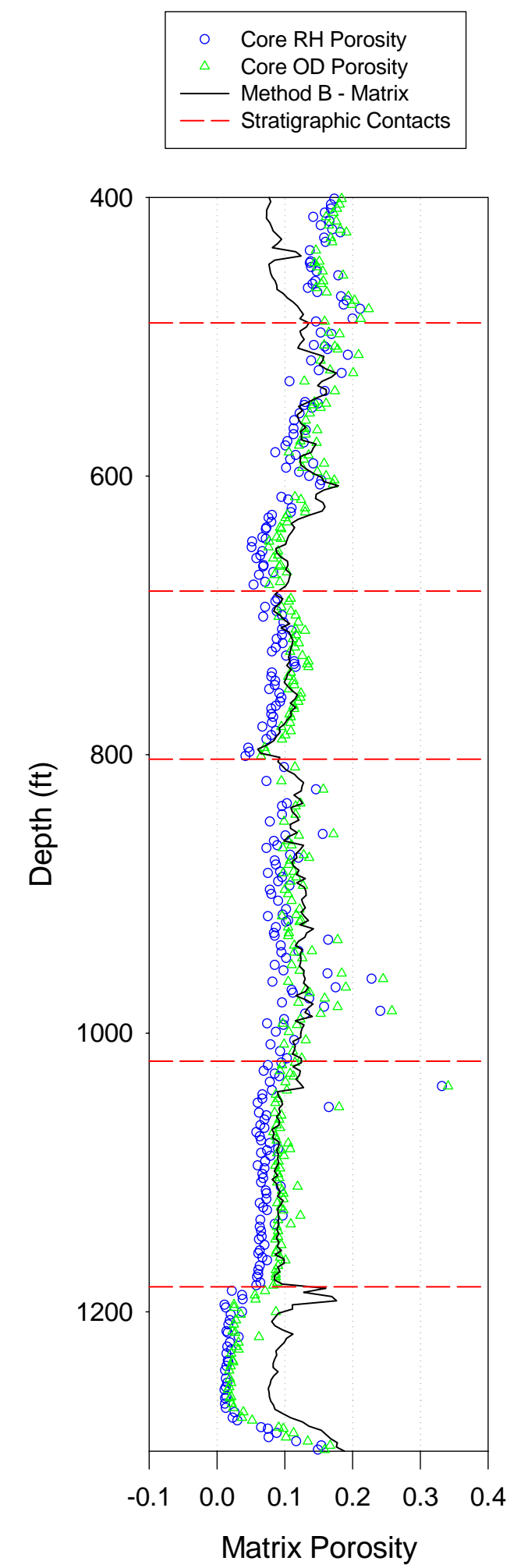

(a)
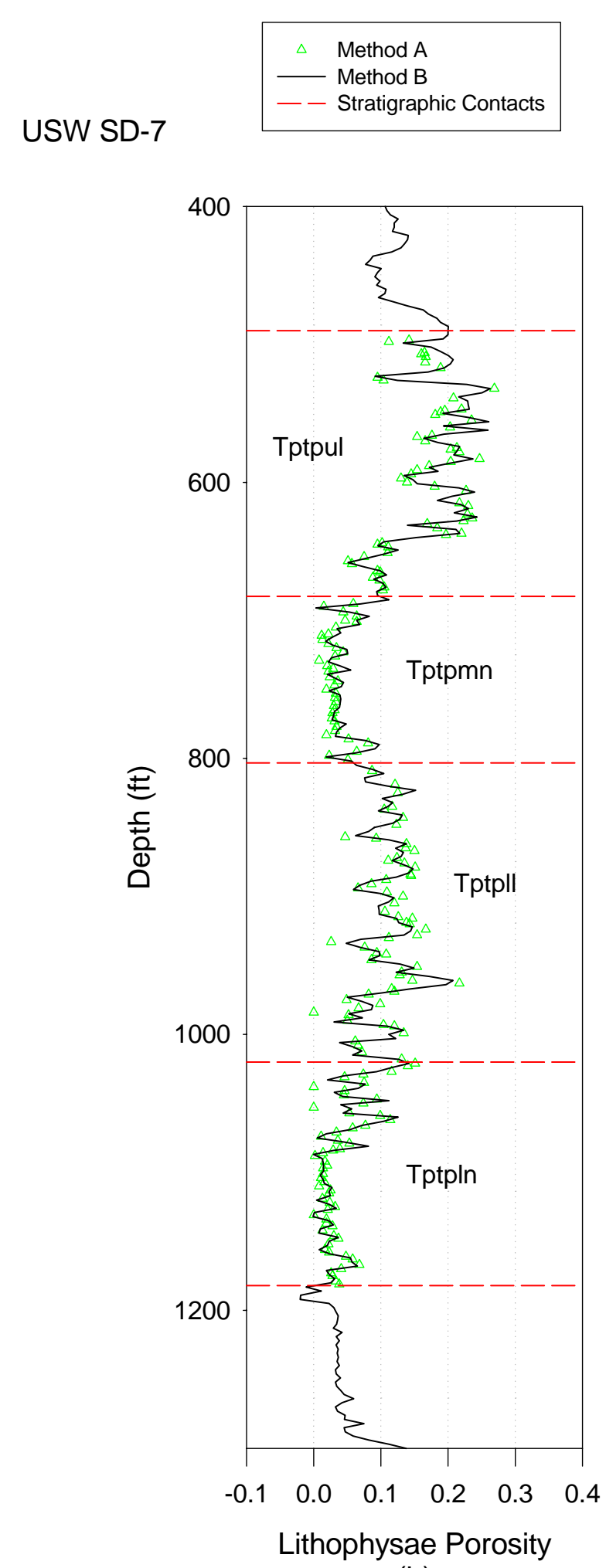

(b)

Input DTN: MO0109HYMXPROP.001 [DIRS 155989], Output DTN: SN0404T0503102.011 [DIRS 169129]. NOTES: $\mathrm{OD}=$ oven-dried; $\mathrm{RH}=$ relative humidity.

Figure B-18. USW SD-7 Core 


\section{USW SD-9}

Similar to the neutron porosity data from USW NRG-7/7A, the data for USW SD-9 look low compared to other boreholes. The neutron porosity data are low by the approximate difference between using a limestone porosity matrix and a sandstone porosity matrix. Comparison with the core volumetric water content data confirms this observation. Matrix porosity calculated by Method B is, therefore, also low and will not be used. The bulk density data are comparable to other borehole data and will be applied with the abundant core data to calculate lithophysal porosity using Method A.

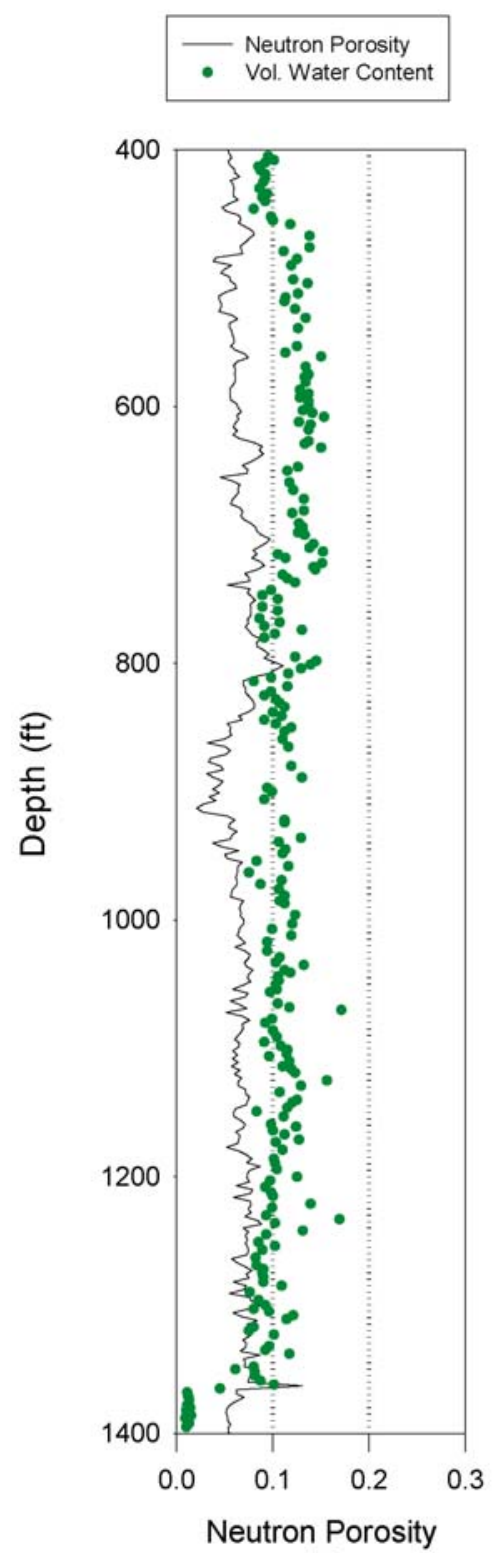

(a)

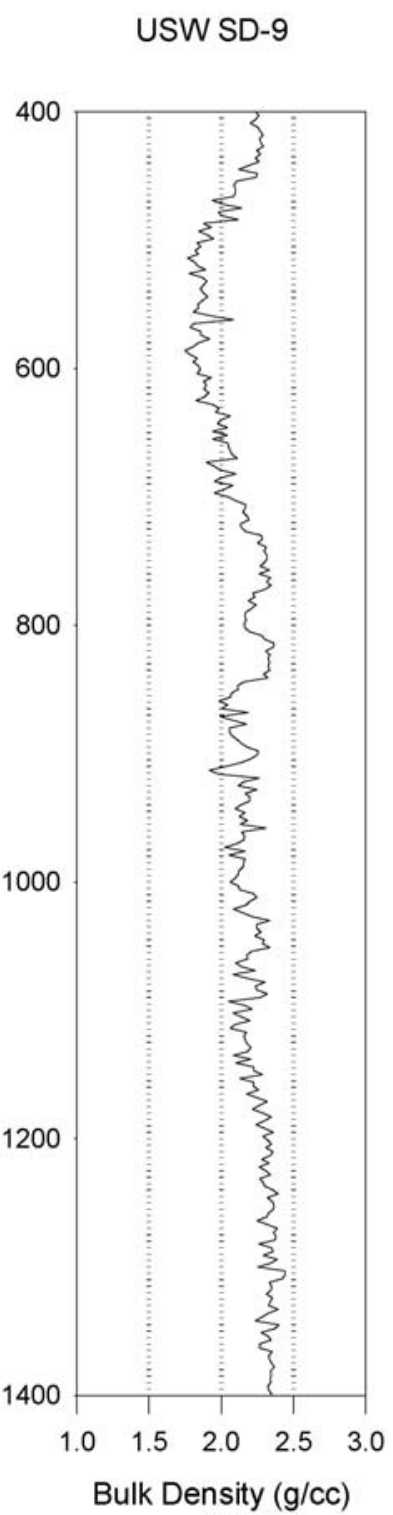

(b)

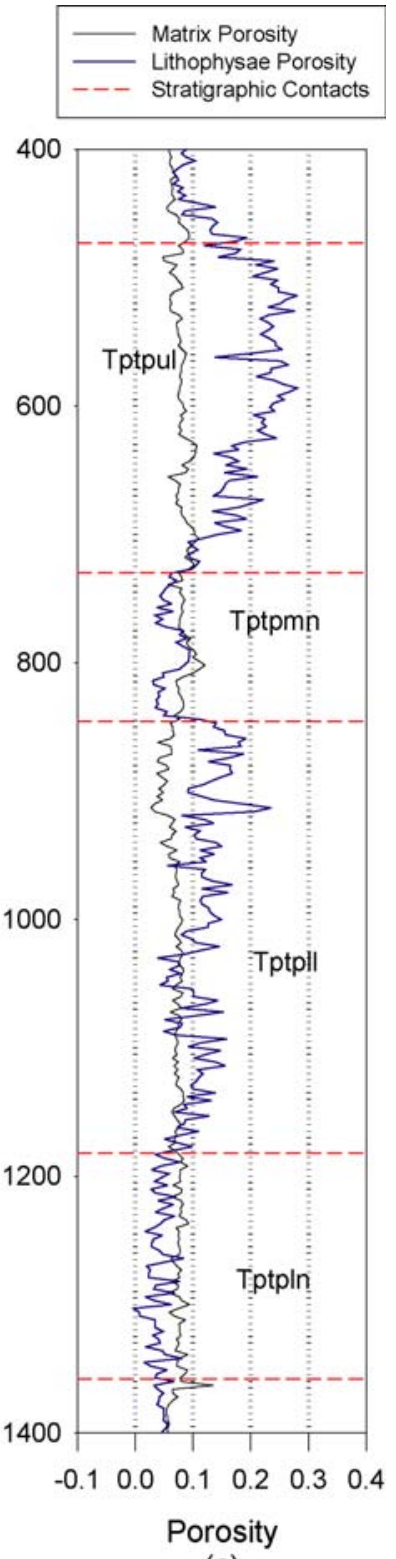

(c)

Input DTN: MO0010CPORGLOG.003 [DIRS 155959].

Figure B-19. USW SD-9 Petrophysical 


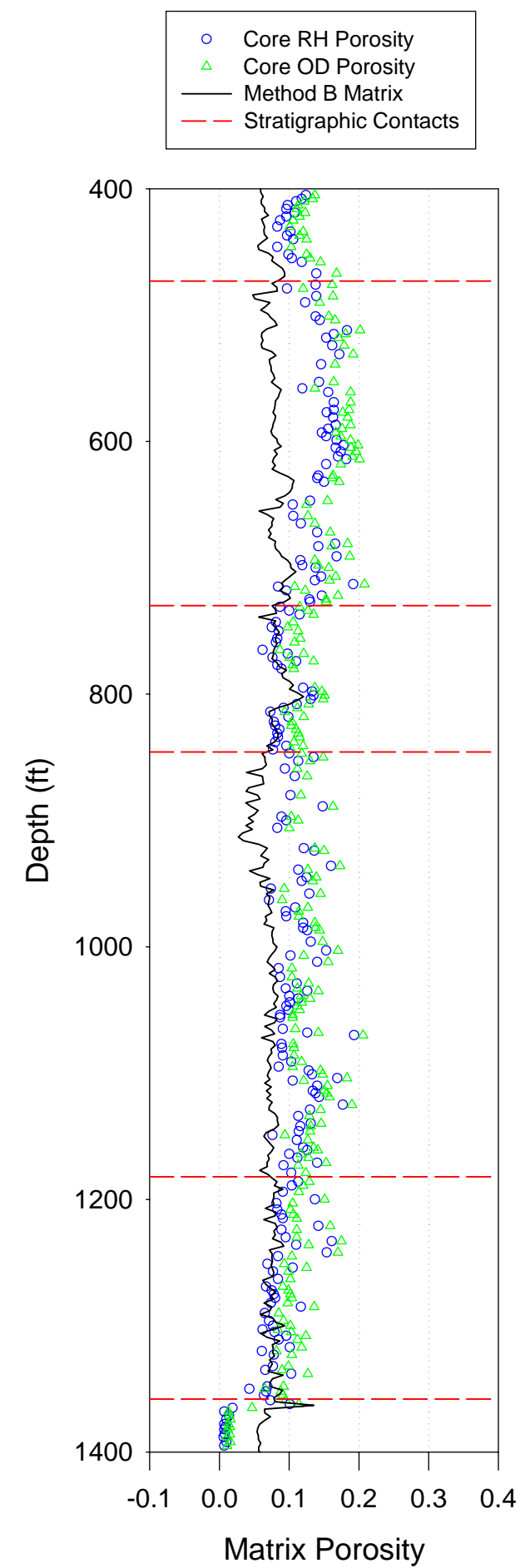

(a)
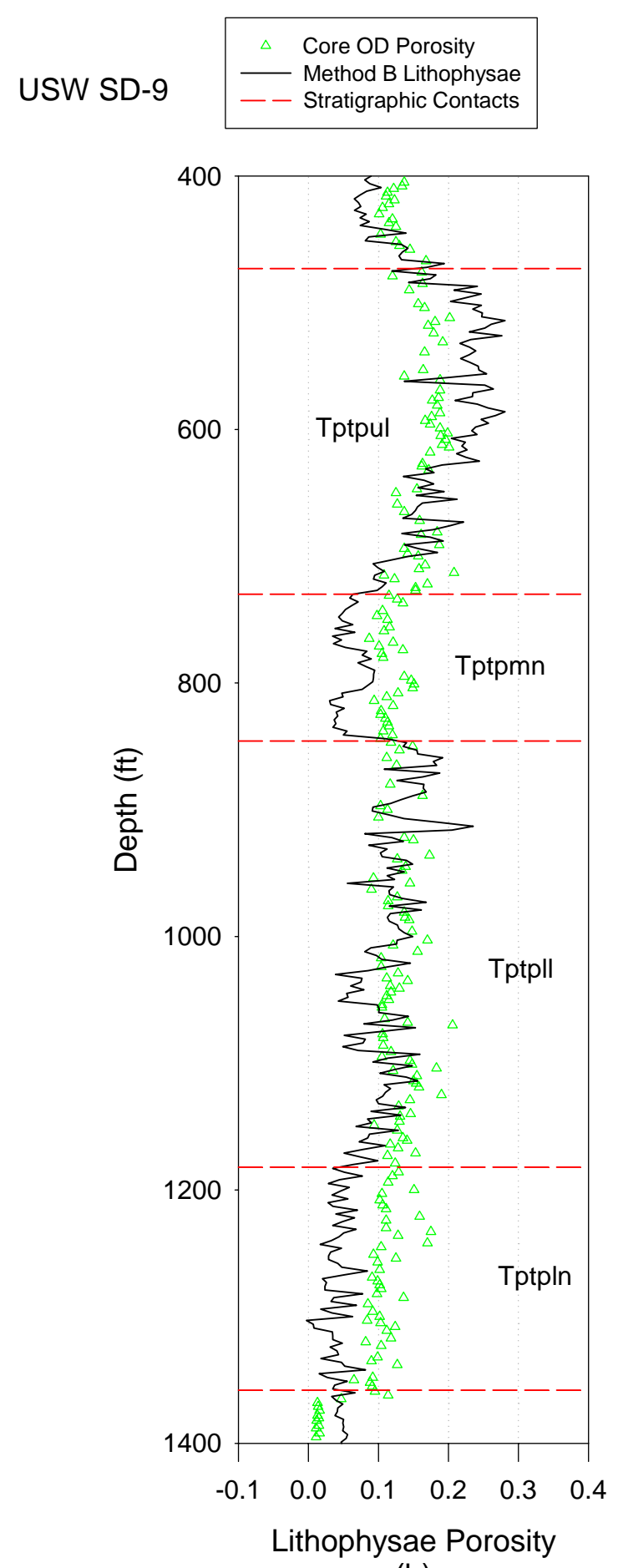

(b)

Input DTN: MO0109HYMXPROP.001 [DIRS 155989], Output DTN: SN0404T0503102.011 [DIRS 169129]. NOTES: $\mathrm{OD}=$ oven-dried; $\mathrm{RH}=$ relative humidity.

Figure B-20. USW SD-9 Core 


\section{USW SD-12}

The neutron porosity and the bulk density data for this borehole compare reasonably well with data from nearby boreholes. The volumetric water content determined from core samples agrees very well in the Tptpmn and somewhat less favorably in the other zones. Method A was used to evaluate lithophysal porosity using the bulk density data and core measurements of OD porosity.

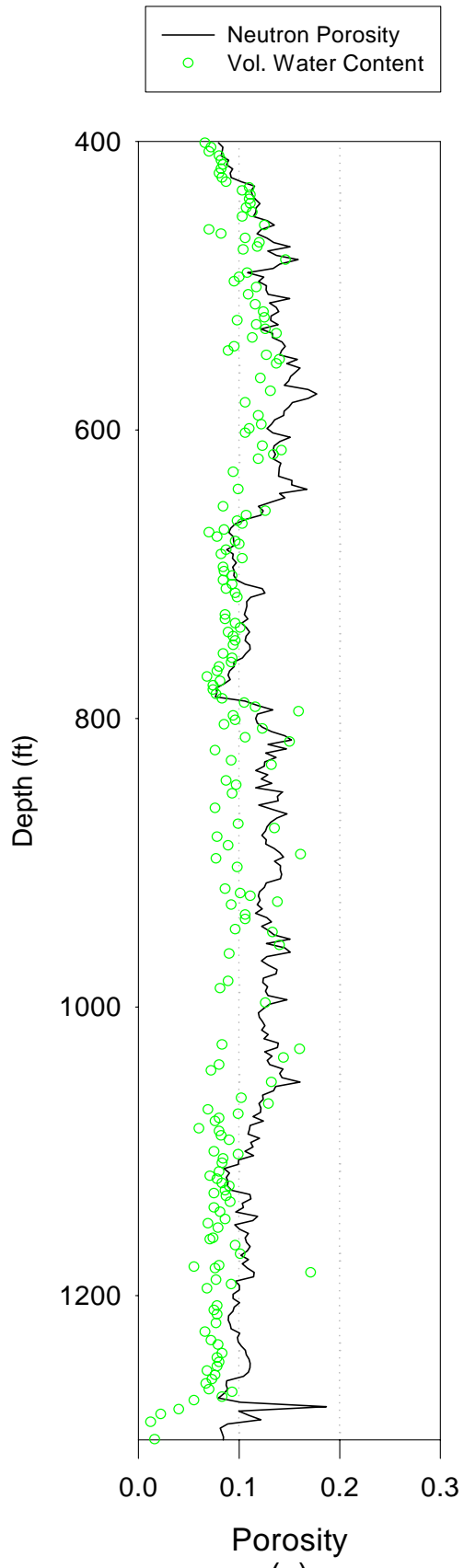

(a)

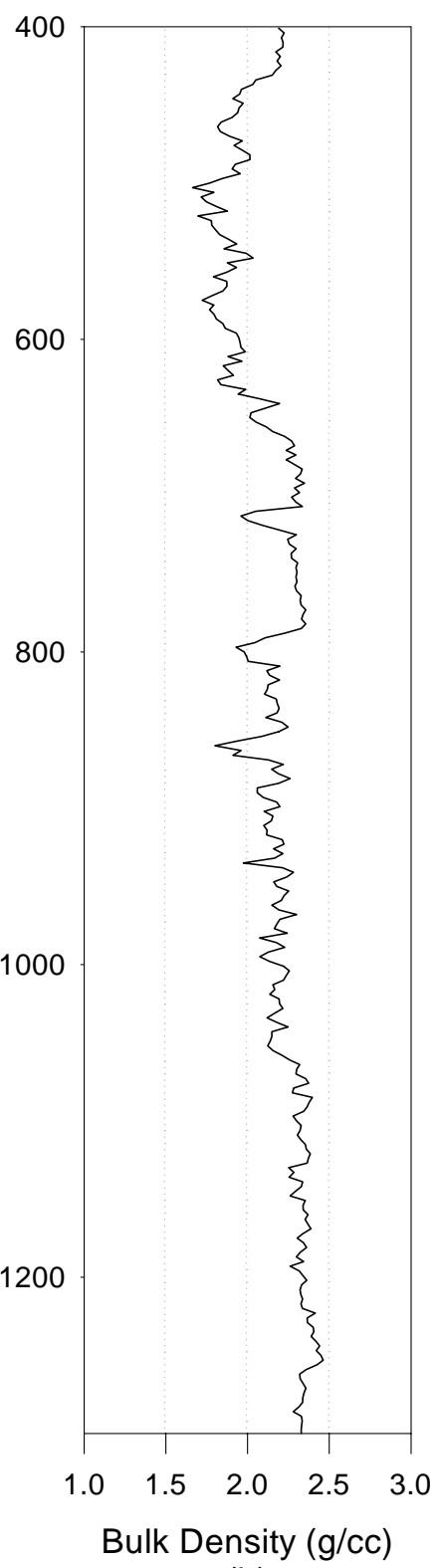

(b)

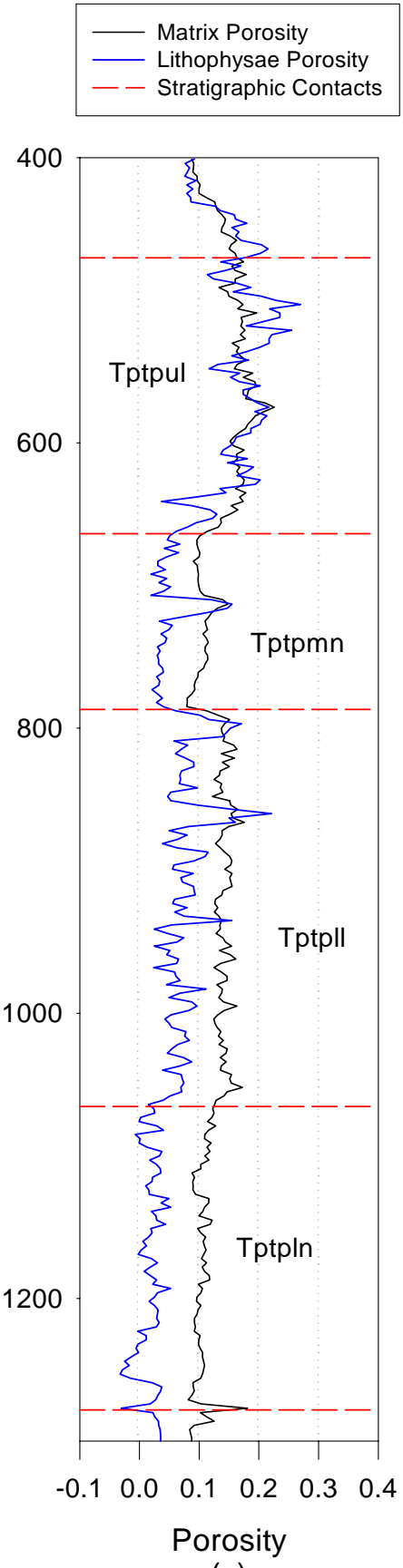

(c)

Input DTN: MO0010CPORGLOG.003 [DIRS 155959].

Figure B-21. USW SD-12 Petrophysical 


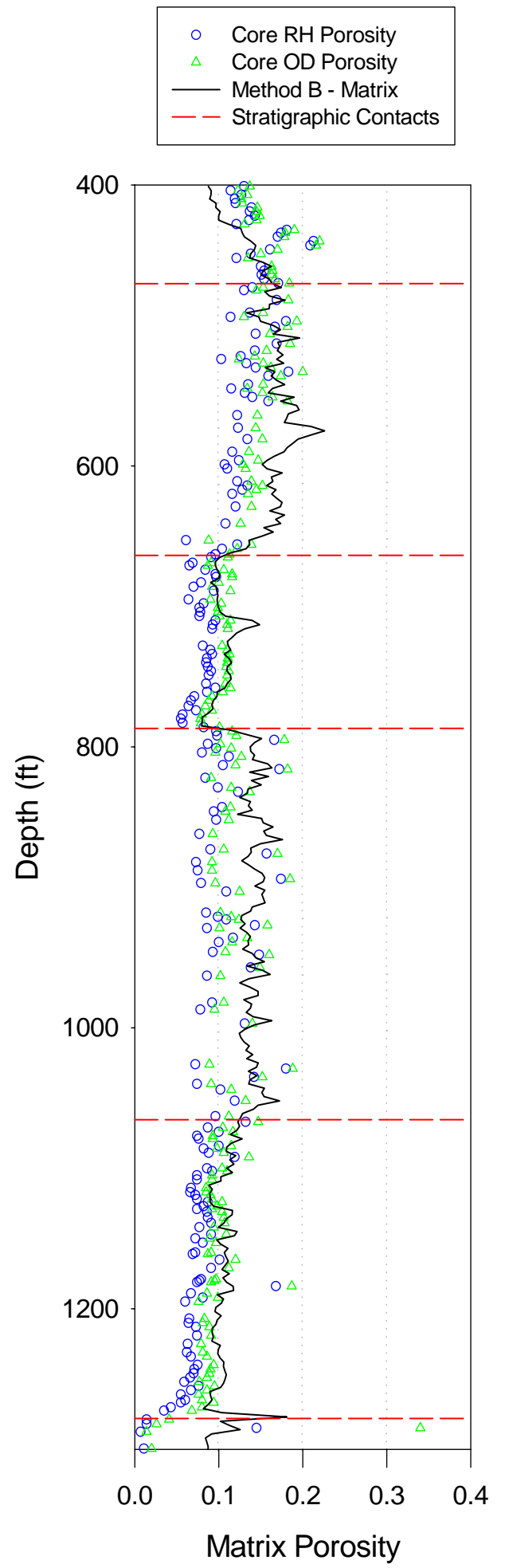

(a)
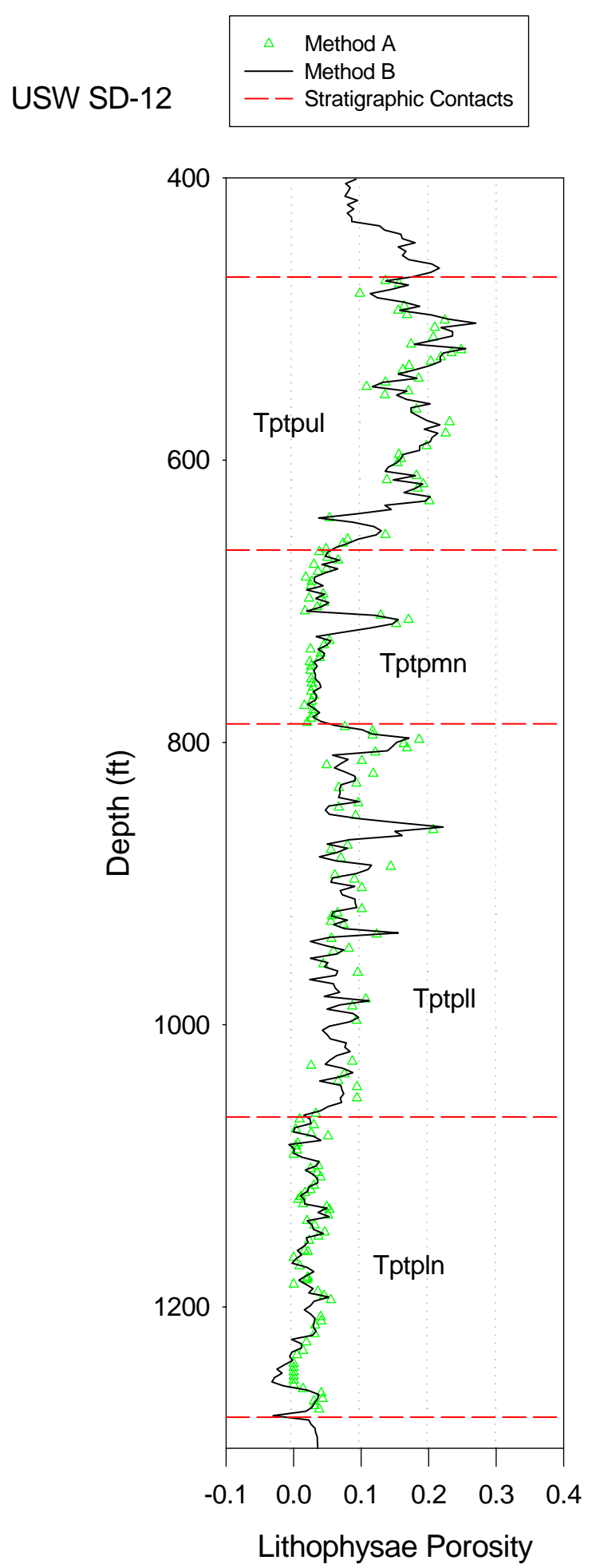

(b)

Input DTN: MO0109HYMXPROP.001 [DIRS 155989], Output DTN: SN0404T0503102.011 [DIRS 169129]. NOTES: OD = oven-dried; $\mathrm{RH}=$ relative humidity.

Figure B-22. USW SD-12 Core 


\section{USW UZ-1 / UZ-14}

Boreholes USW UZ-1 and USW UZ-14 are located very close to one another. The neutron porosity from USW UZ-1 is clearly too high compared to the neutron porosity from USW UZ-14 and to core measurements of volumetric water content from the same borehole. The bulk density log data look better in USW UZ-1 than in USW UZ-14. Consequently, the neutron porosity from USW UZ-14 is combined with bulk density from USW UZ-1 to calculate matrix and lithophysal porosity using Method B. Method A uses the OD core data from USW UZ-14, in conjunction with bulk density from USW UZ-1, to compute lithophysal porosity. The results compare quite well. Method A was ultimately used in the simulations.

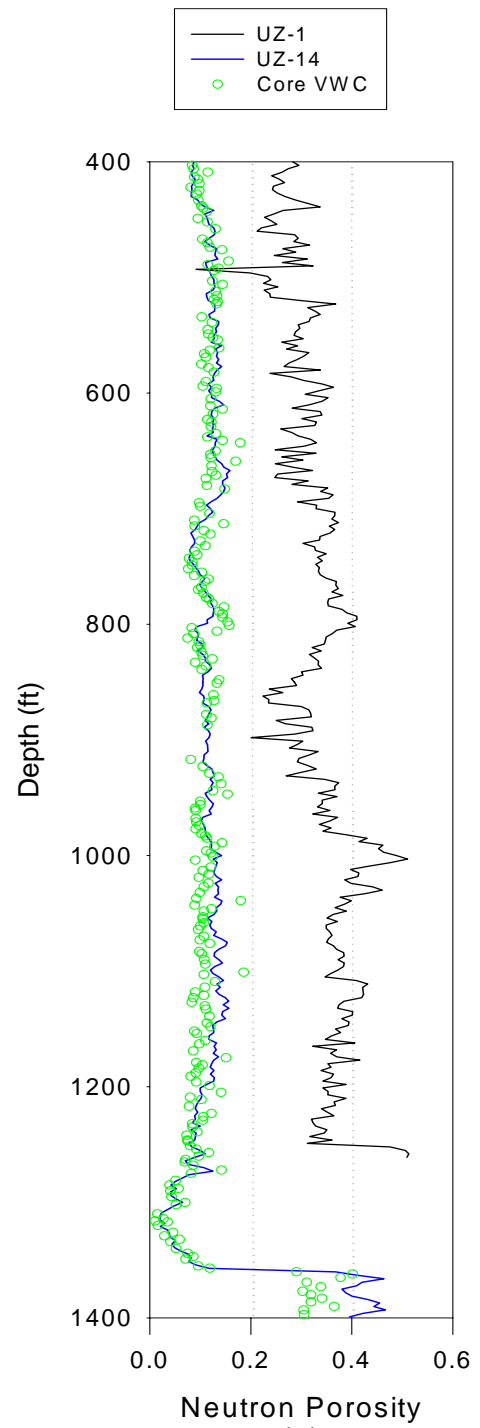

(a)

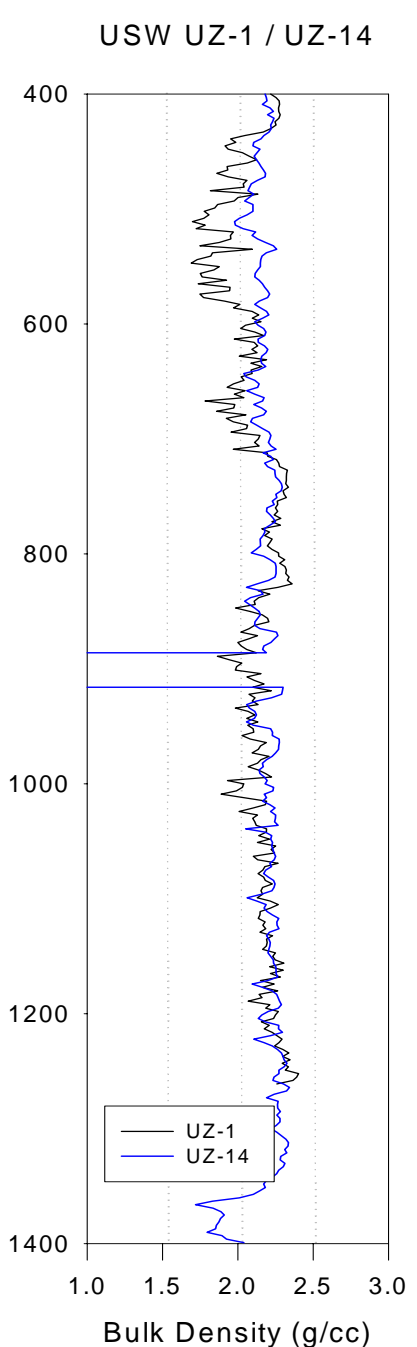

(b)

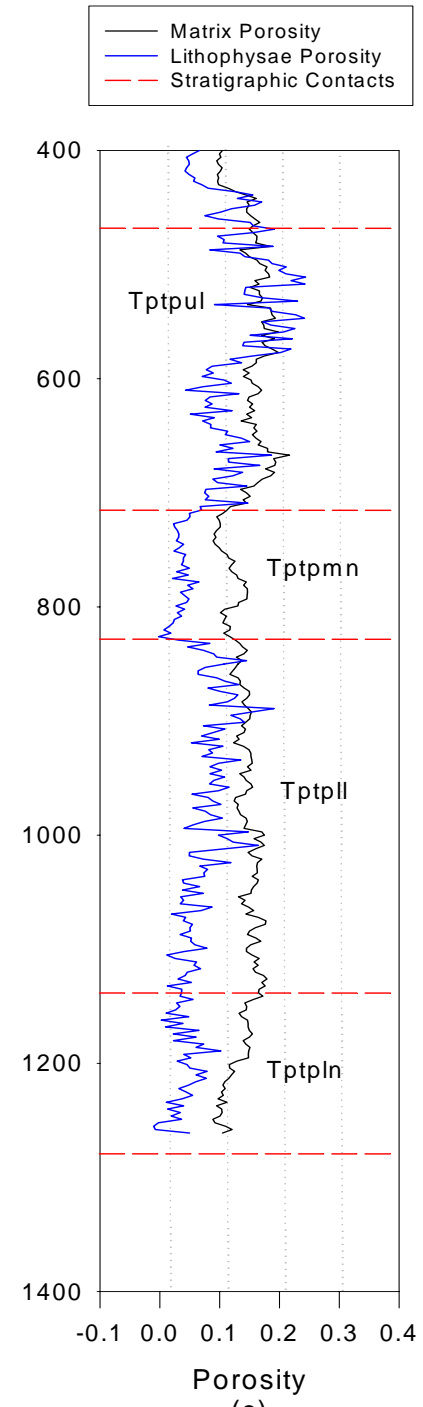

(c)

Input DTN: MO0010CPORGLOG.003 [DIRS 155959].

NOTE: $V W C=$ volumetric water content.

Figure B-23. USW UZ-1/UZ-14 Petrophysical 


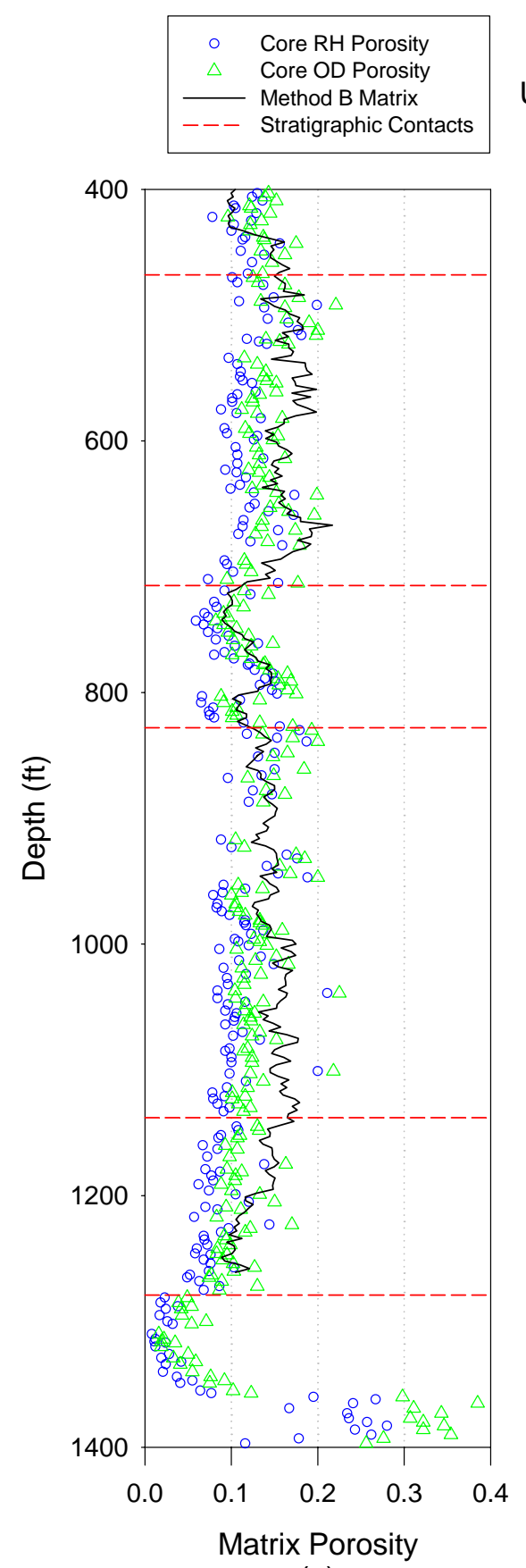

(a)
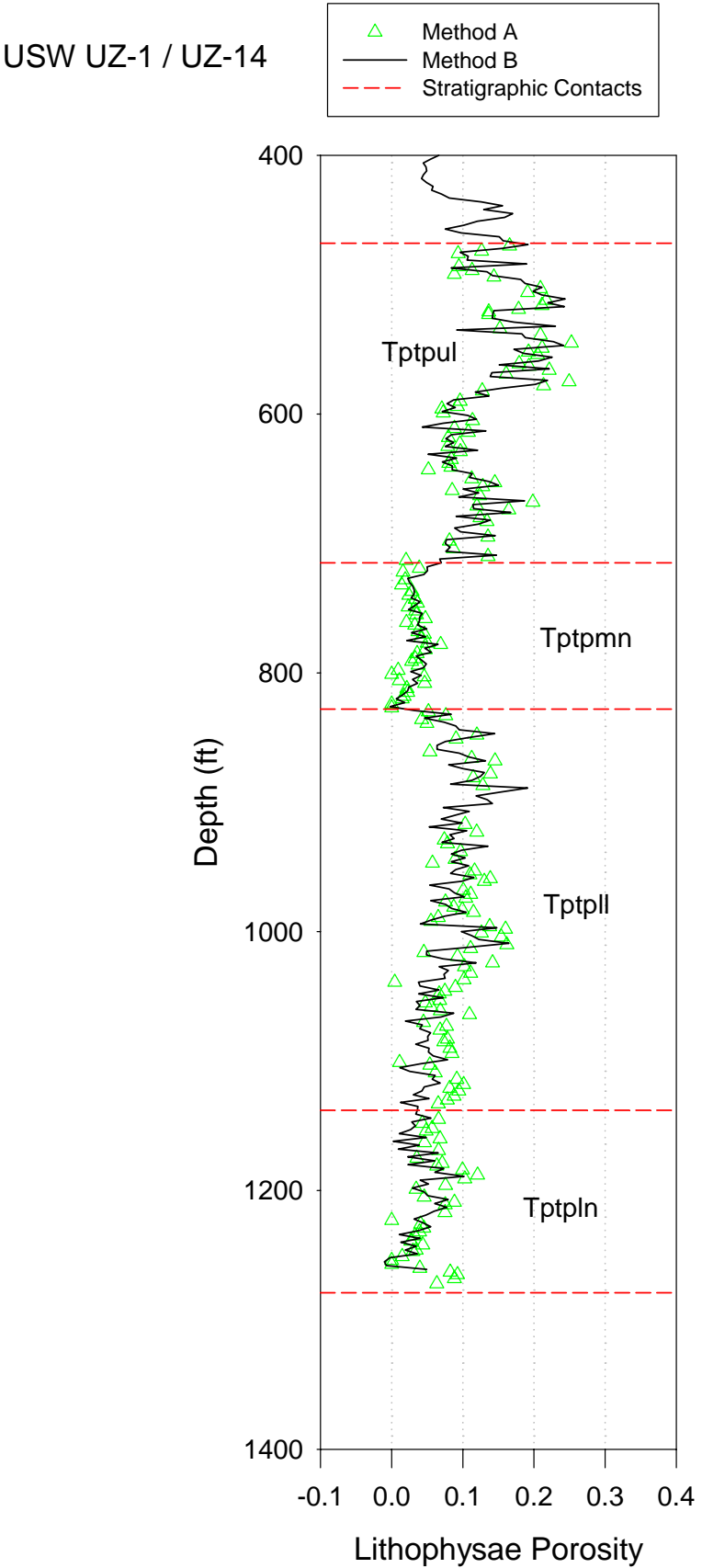

(b)

Input DTN: MO0109HYMXPROP.001 [DIRS 155989], Output DTN: SN0404T0503102.011 [DIRS 169129]. NOTES: $\mathrm{OD}=$ oven-dried; $\mathrm{RH}=$ relative humidity.

Figure B-24. USW UZ-1/UZ-14 Core 


\section{USW UZ-6}

The neutron porosity and the bulk density data for this borehole are consistent with data from nearby boreholes. Method B was applied for calculating matrix and lithophysal porosity for this borehole.

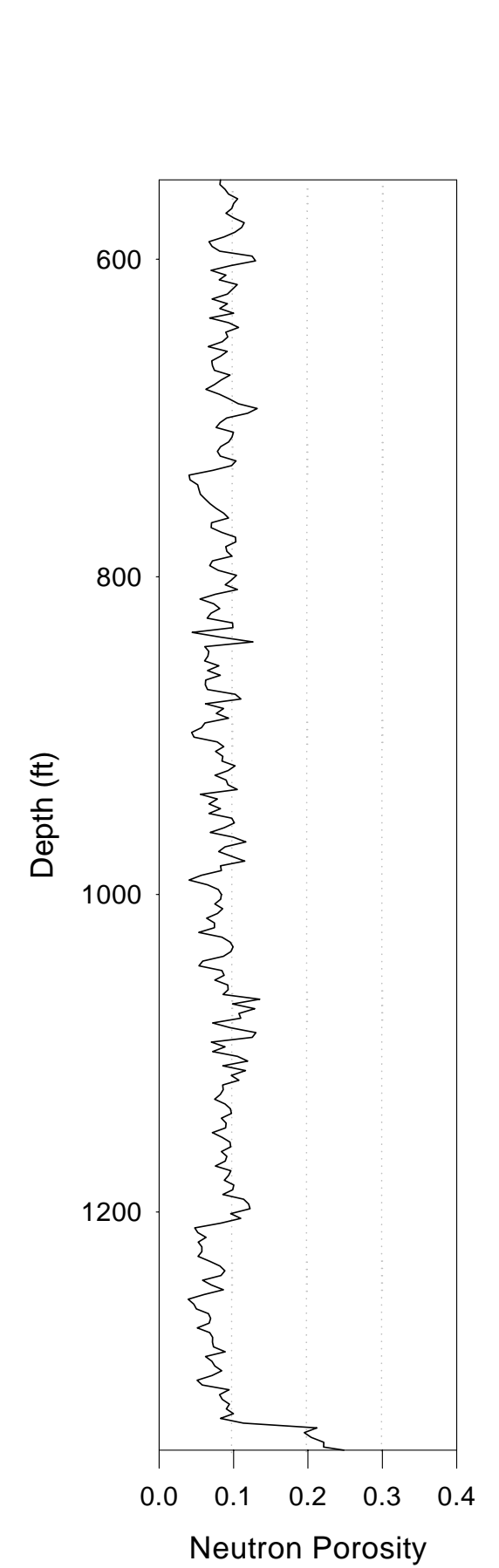

(a)

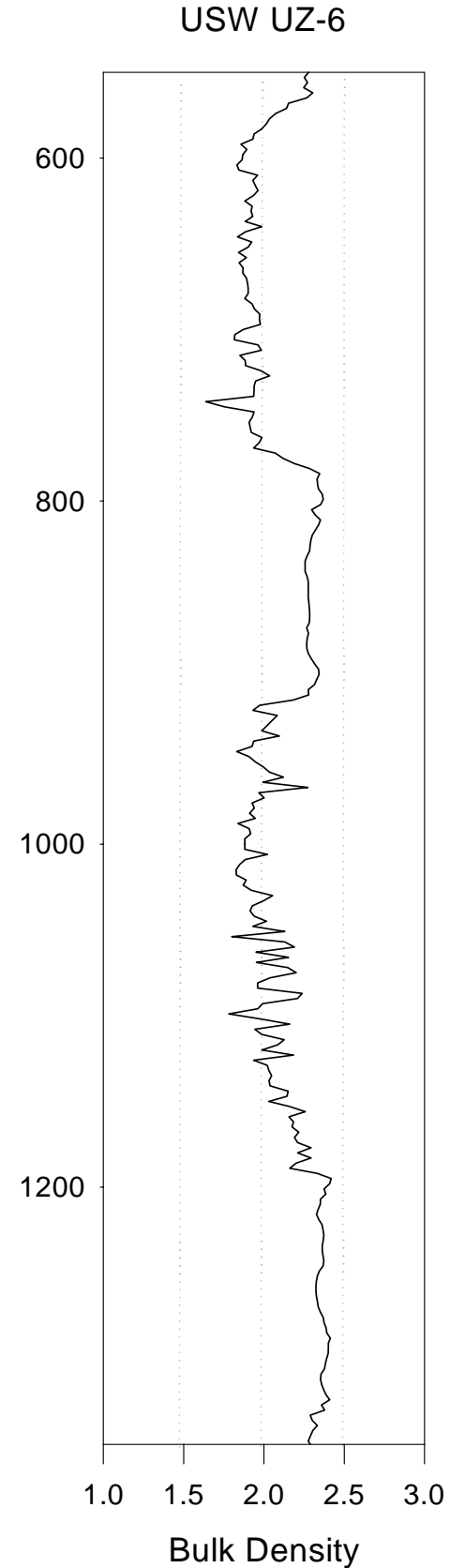

(b)

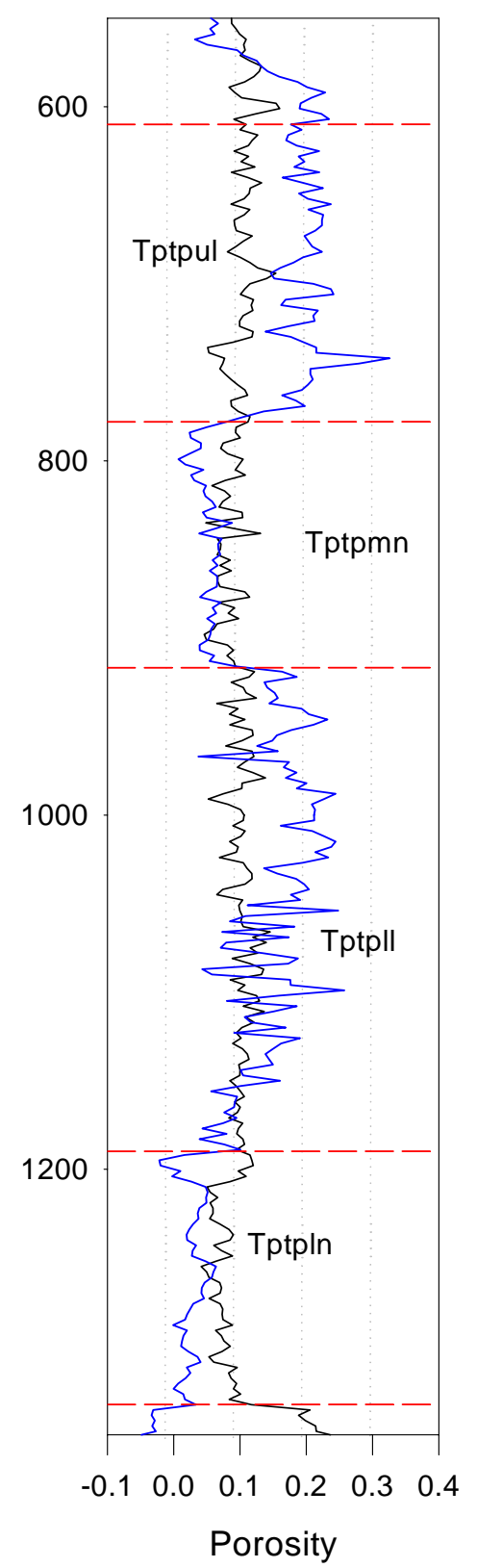

(c)

Input DTN: MO0010CPORGLOG.002 [DIRS 155229].

Figure B-25. USW UZ-6 


\section{USW UZ-16}

As observed in the neutron porosity data for boreholes USW NRG-7/7a and USW SD-9, the neutron porosity data are high compared with the volumetric water content measured from core samples. As in these other boreholes, the lower neutron porosity could be the result of using a less accurate porosity matrix. The higher neutron porosity data lead to calculated matrix porosities that are also a little high. The bulk density data compare with the respective data from nearby boreholes. Method A was applied to calculate lithophysal porosity for this borehole. It may be noted that the volumetric water content remains relatively constant in the 8 to 11 percent range regardless of the presence of lithophysae. The core volumetric water content may be the best measure of matrix porosity since it will be largely unaffected by small lithophysae. This seems to be the case for this borehole where core porosity measurements are slightly greater in the lithophysae zones than in the non-lithophysae zones.

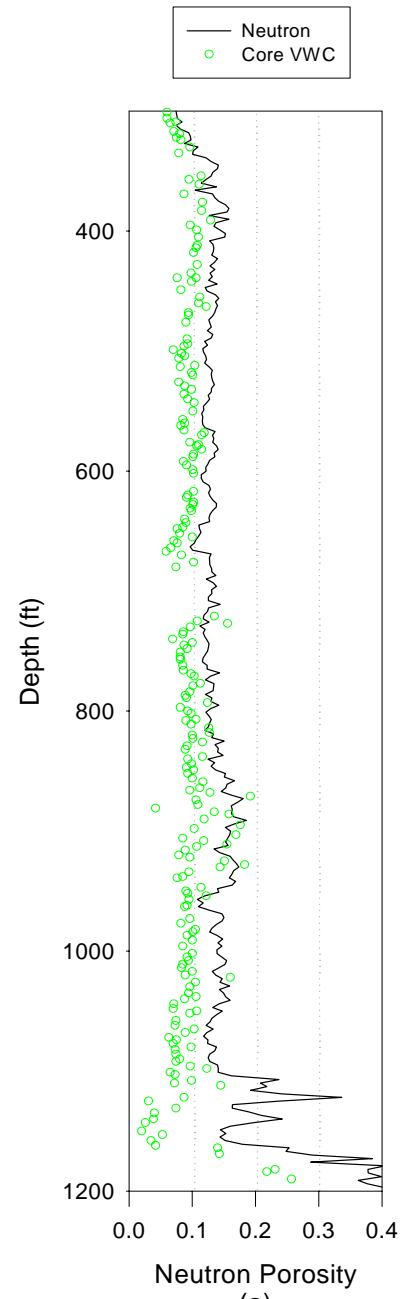

(a)

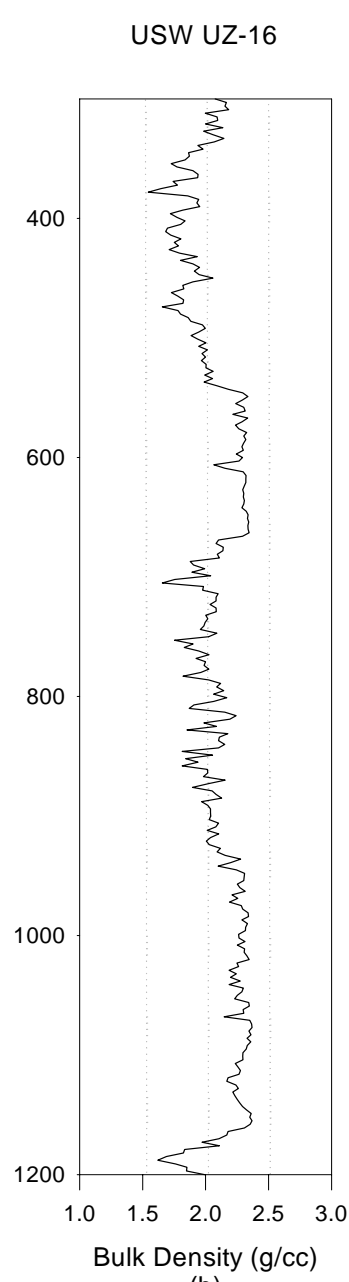

(b)

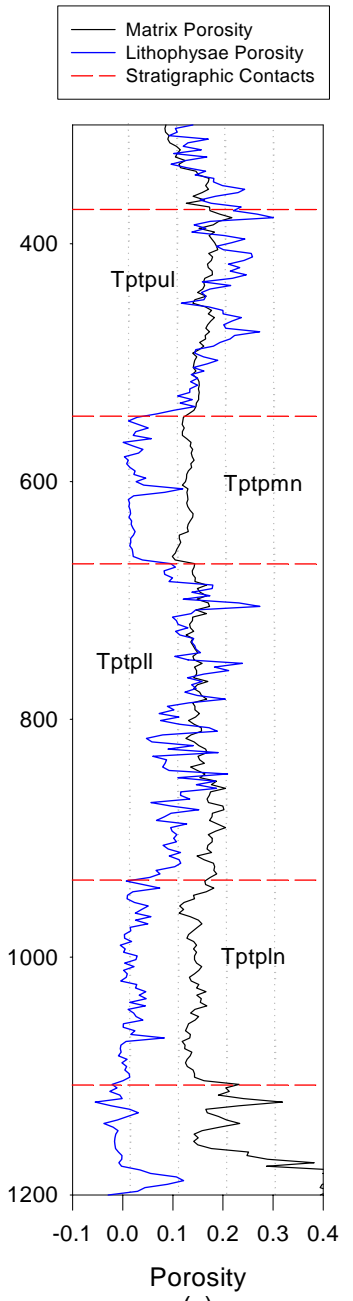

(c)

Input DTN: MO0010CPORGLOG.003 [DIRS 155959].

NOTE: $V W C=$ volumetric water content.

Figure B-26. USW UZ-16 Petrophysical 


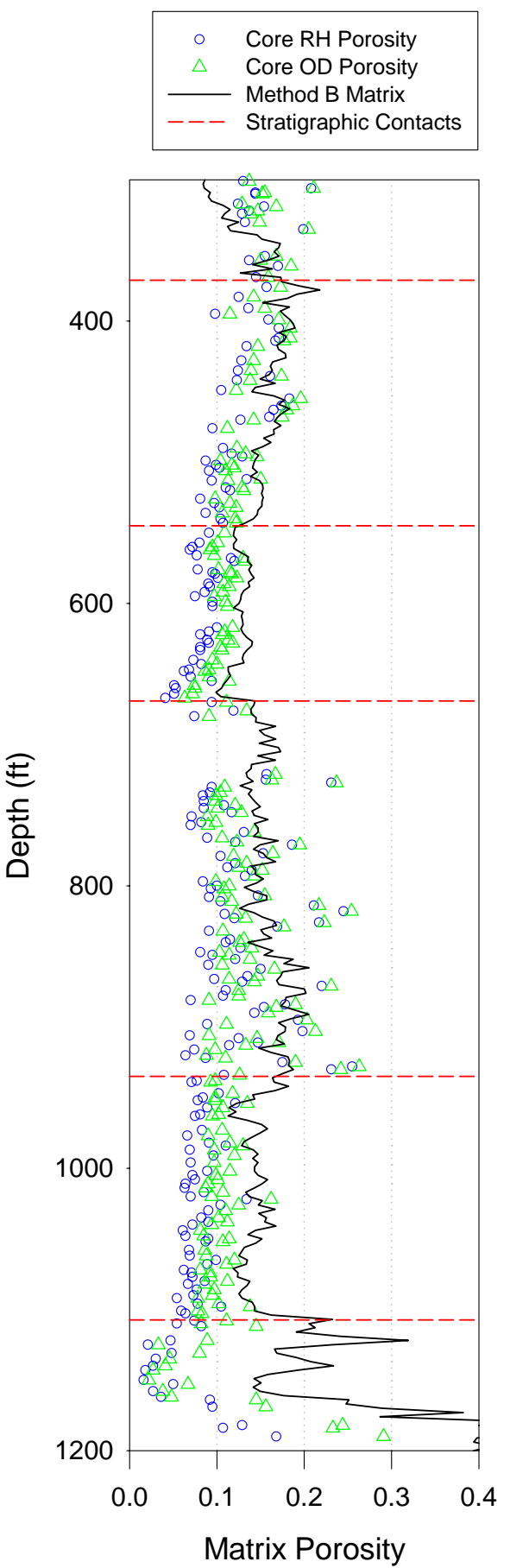

(a)
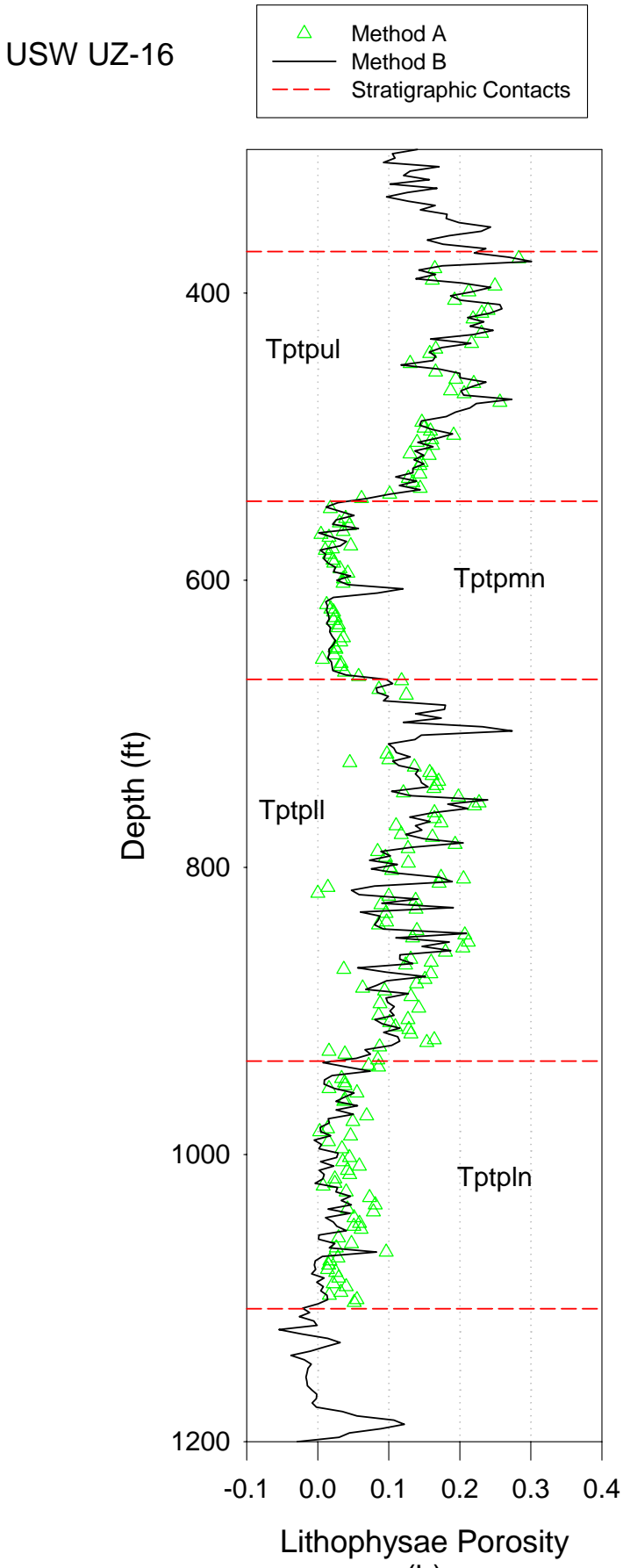

(b)

Input DTN: MO0109HYMXPROP.001 [DIRS 155989], Output DTN: SN0404T0503102.011 [DIRS 169129]. NOTES: $\mathrm{OD}=$ oven-dried; $\mathrm{RH}=$ relative humidity.

Figure B-27. USW UZ-16 Core 


\section{USW UZ-7a}

The neutron porosity log for borehole USW UZ-7a is generally high compared with core volumetric water content data. Method A was applied to calculate lithophysal porosity.

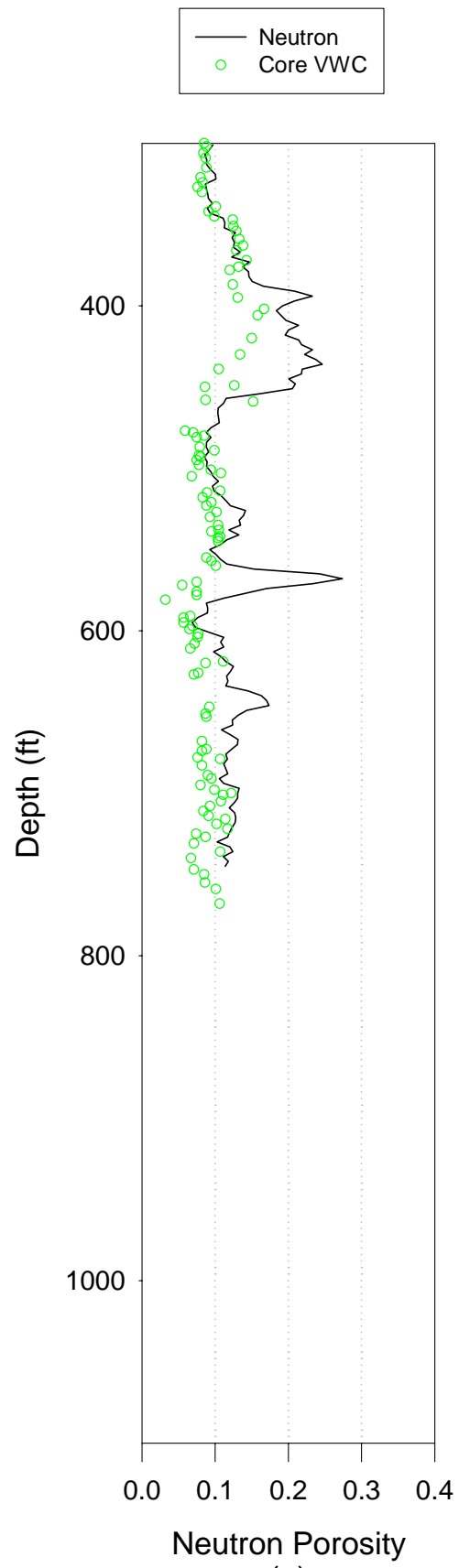

(a)

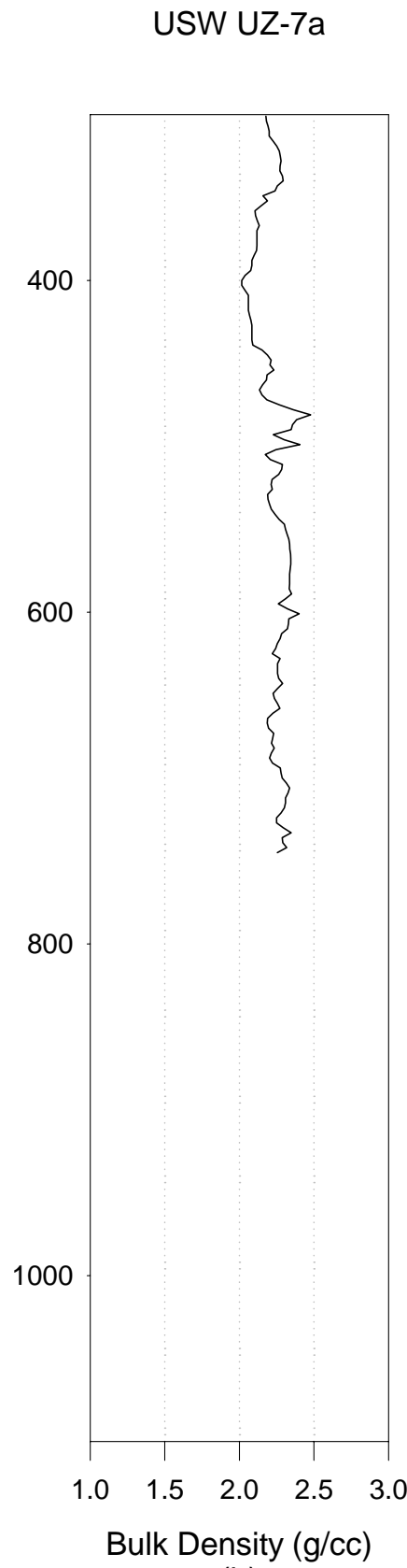

(b)

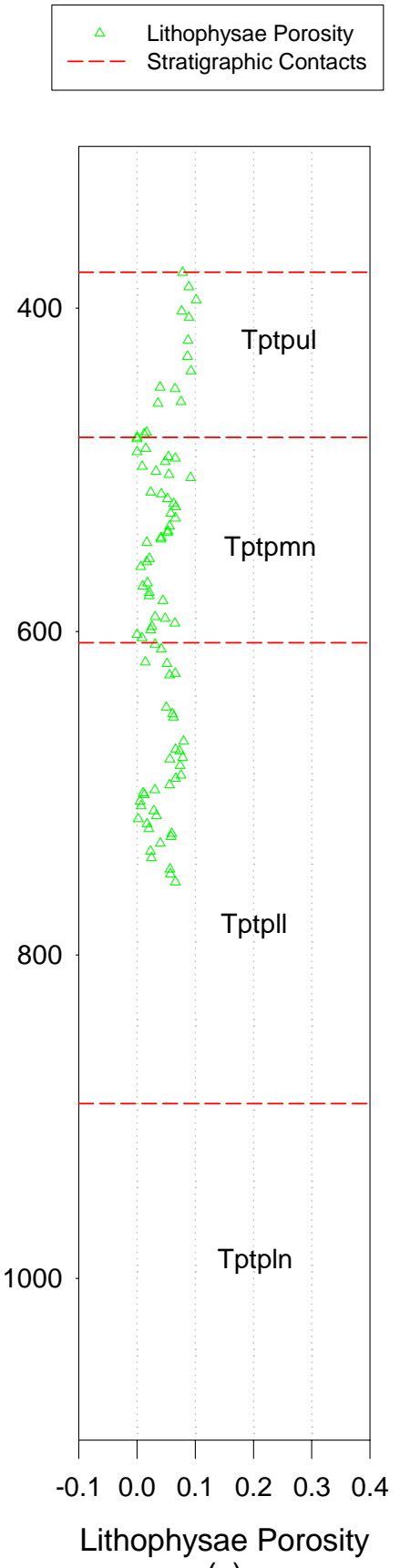

(c)

Input DTN: MO0010CPORGLOG.003 [DIRS 155959].

NOTE: $V W C=$ volumetric water content.

Figure B-28. USW UZ-7a 


\section{USW WT-1}

The neutron porosity and bulk density data for USW WT-1 compare reasonably with neighboring boreholes. Method B was used to calculate the matrix and lithophysal porosity for this borehole.

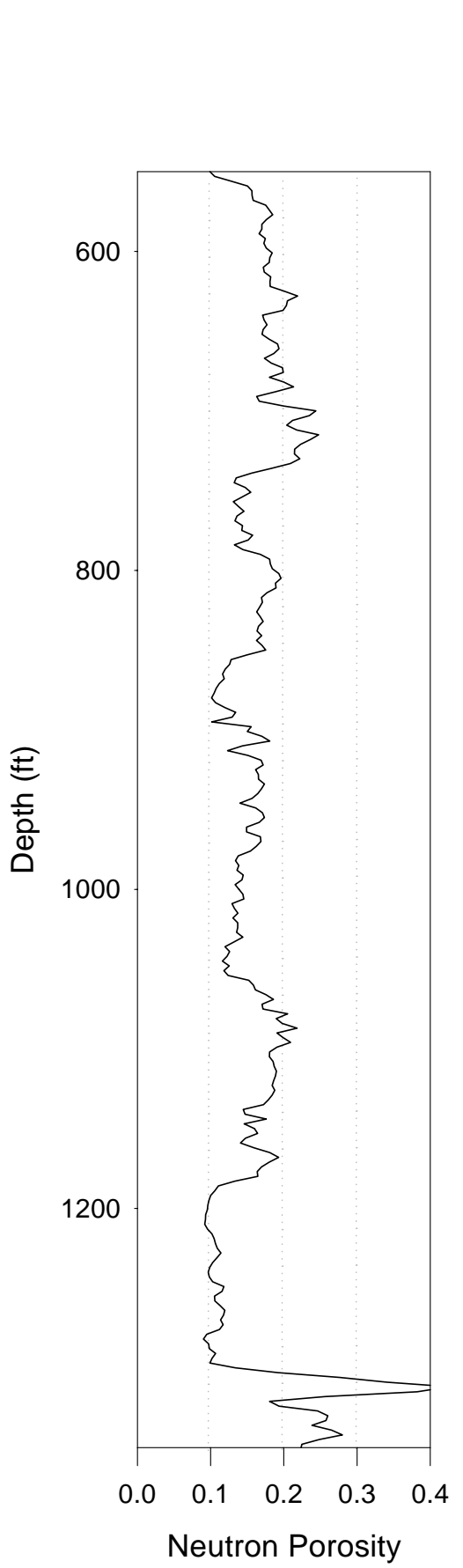

(a)

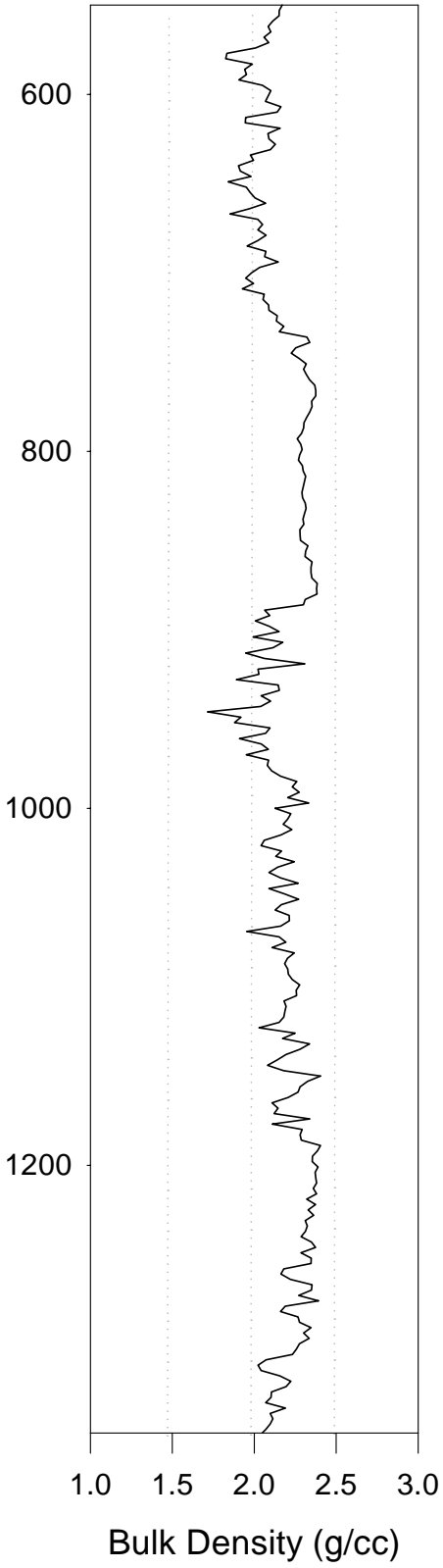

(b)

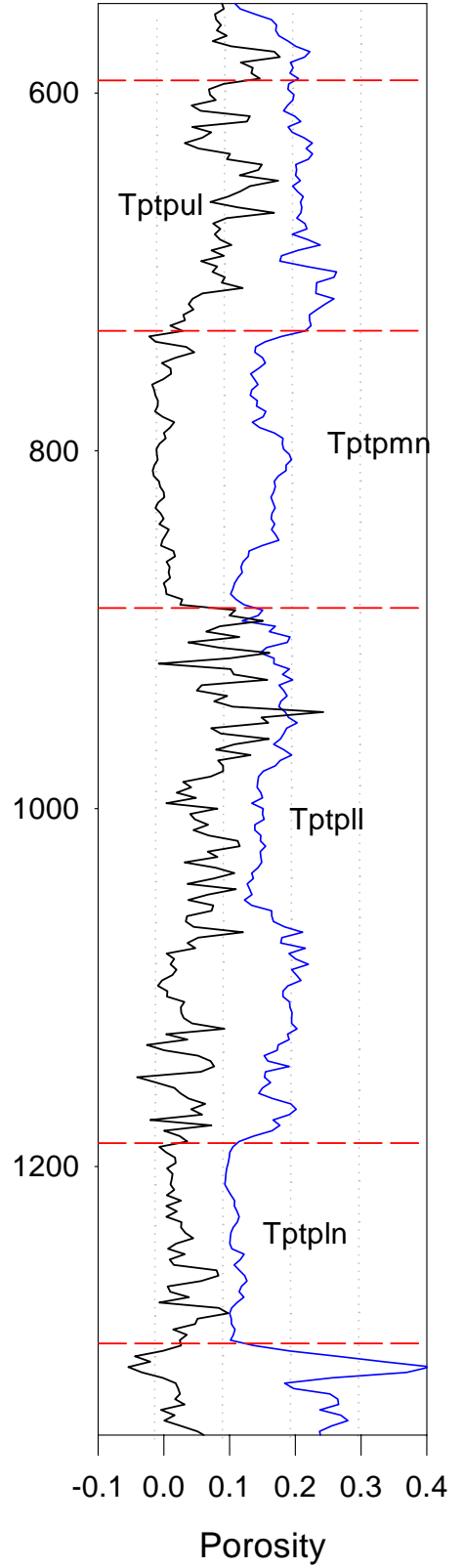

(c)

Input DTN: MO0010CPORGLOG.002 [DIRS 155229].

Figure B-29. USW WT-1 


\section{USW WT-10}

The neutron porosity data for USW WT-10 are high over the bottom half of the upper lithophysae zone when compared to other boreholes in the area. Method C was used to calculate lithophysal porosity in this borehole.

USW WT-10

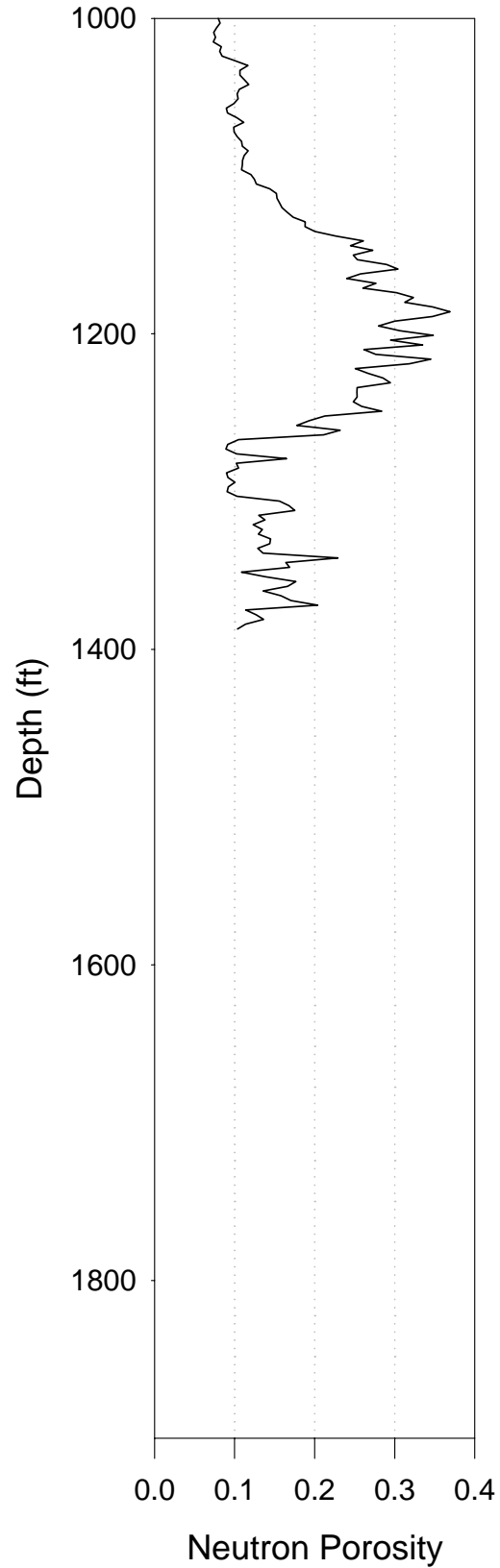

(a)

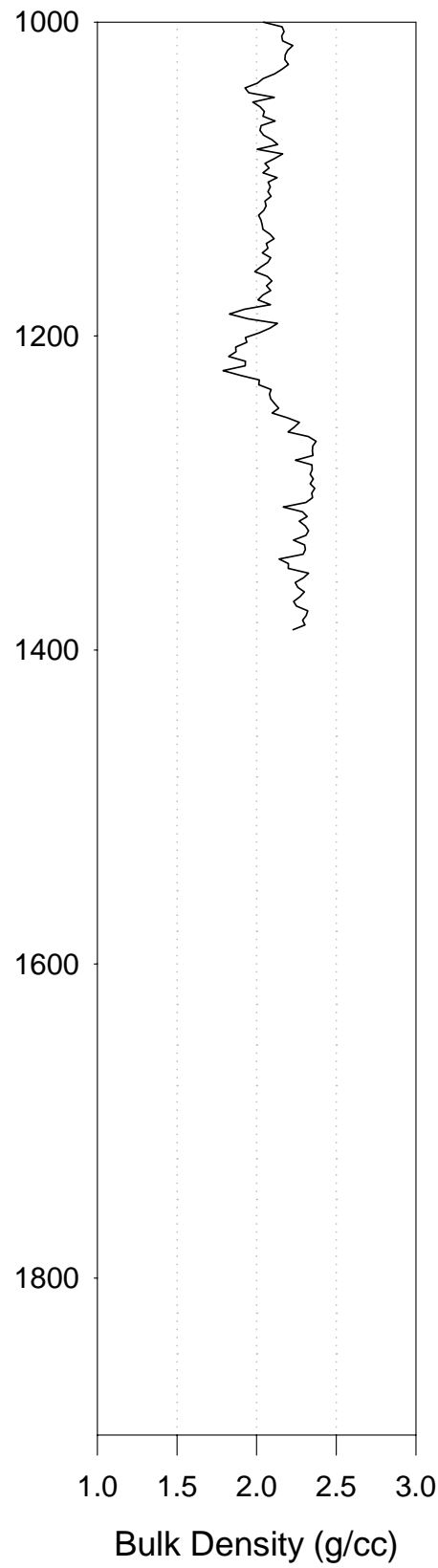

(b)

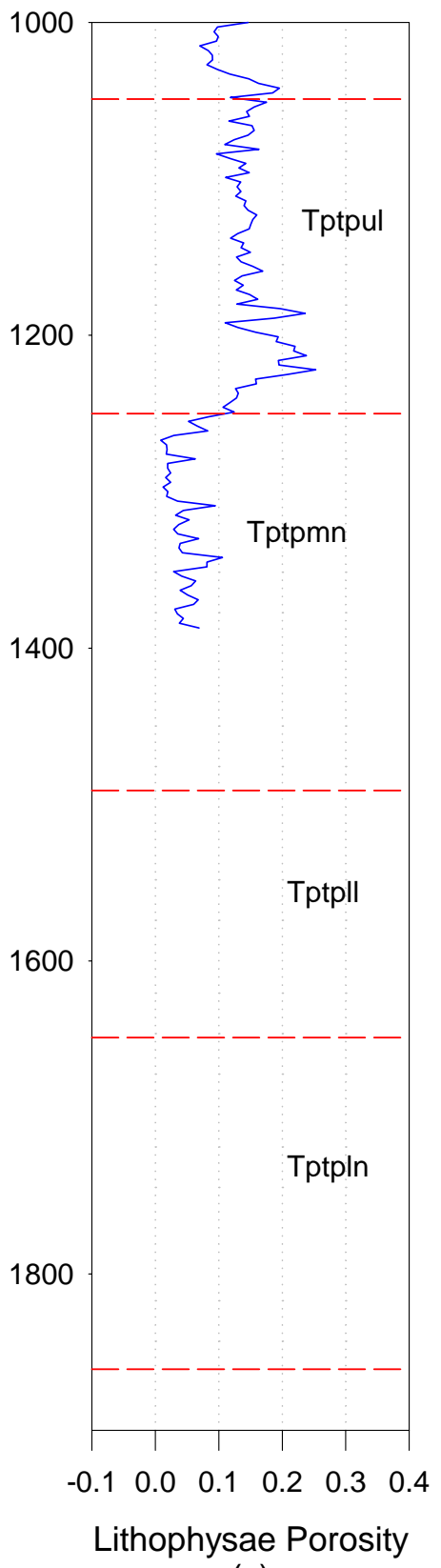

(c)

Input DTN: MO0010CPORGLOG.002 [DIRS 155229].

Figure B-30. USW WT-10 


\section{USW WT-11}

The neutron porosity and the bulk density data for borehole USW WT-11 compare favorably with data from other boreholes. Method B was used to calculate matrix and lithophysal porosity for this borehole.

USW WT-11

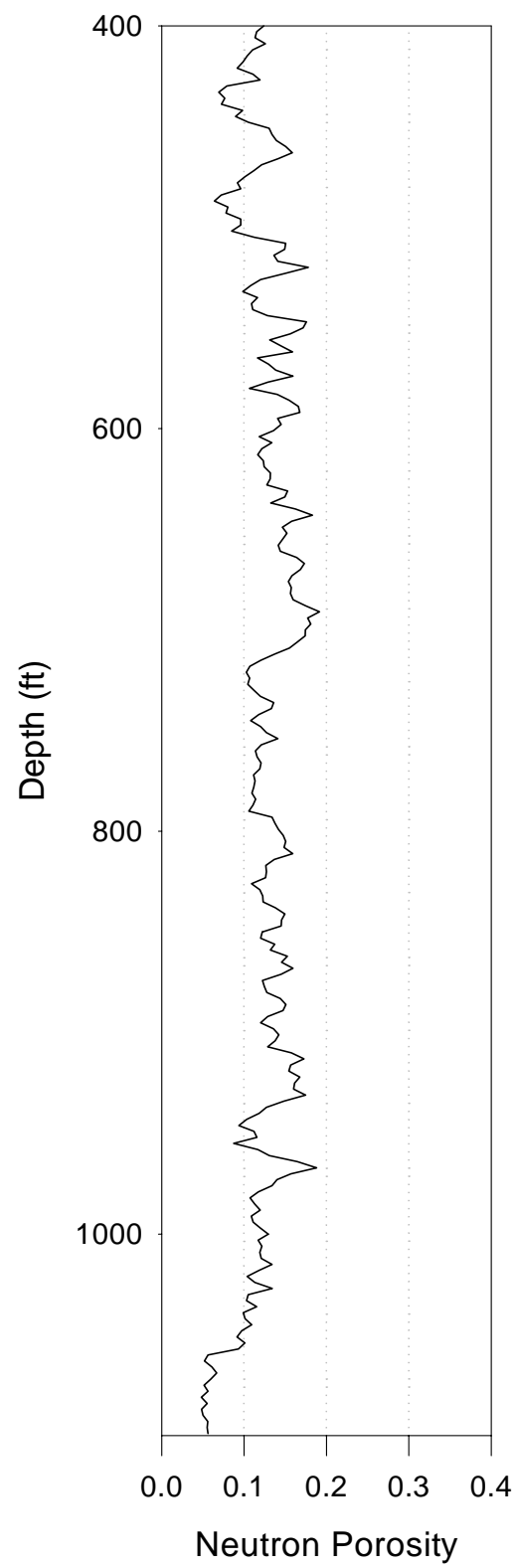

(a)

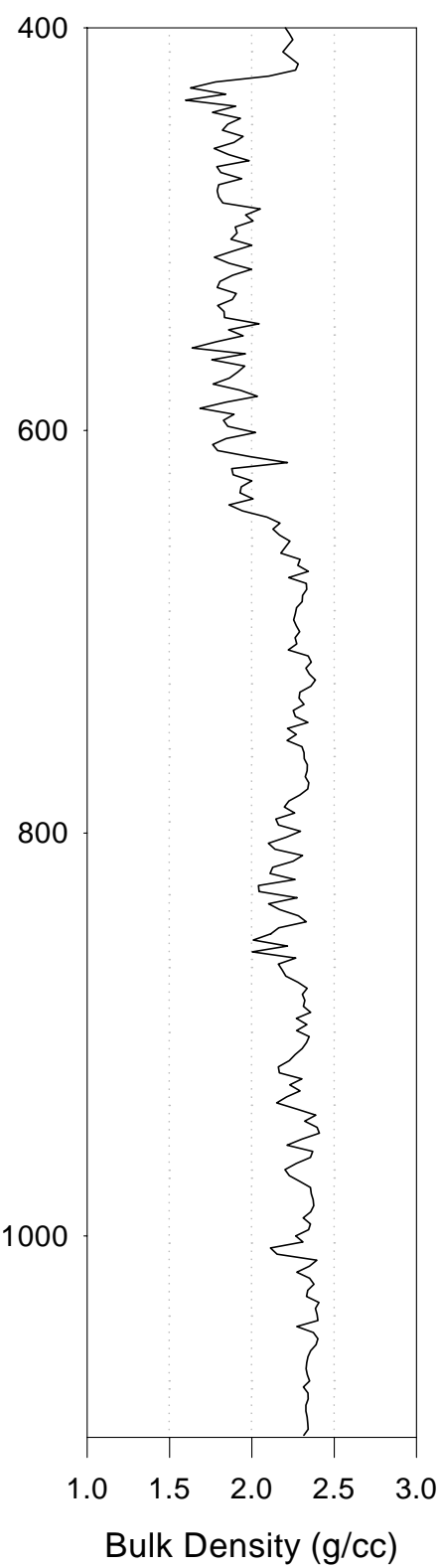

(b)

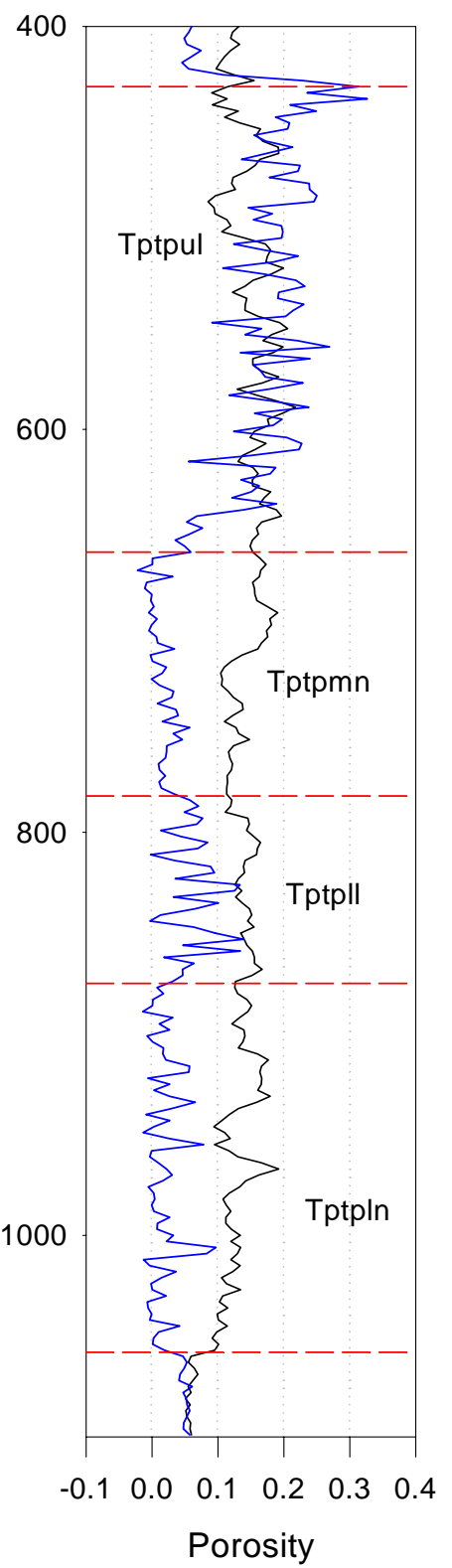

(c)

Input DTN: MO0010CPORGLOG.002 [DIRS 155229].

Figure B-31. USW WT-11 


\section{UE-25 WT \#12}

The neutron porosity and the bulk density data for UE-25 WT \#12 compare favorably with data from other boreholes. Method B was used to calculate matrix and lithophysal porosity for this borehole.

UE-25 WT-12

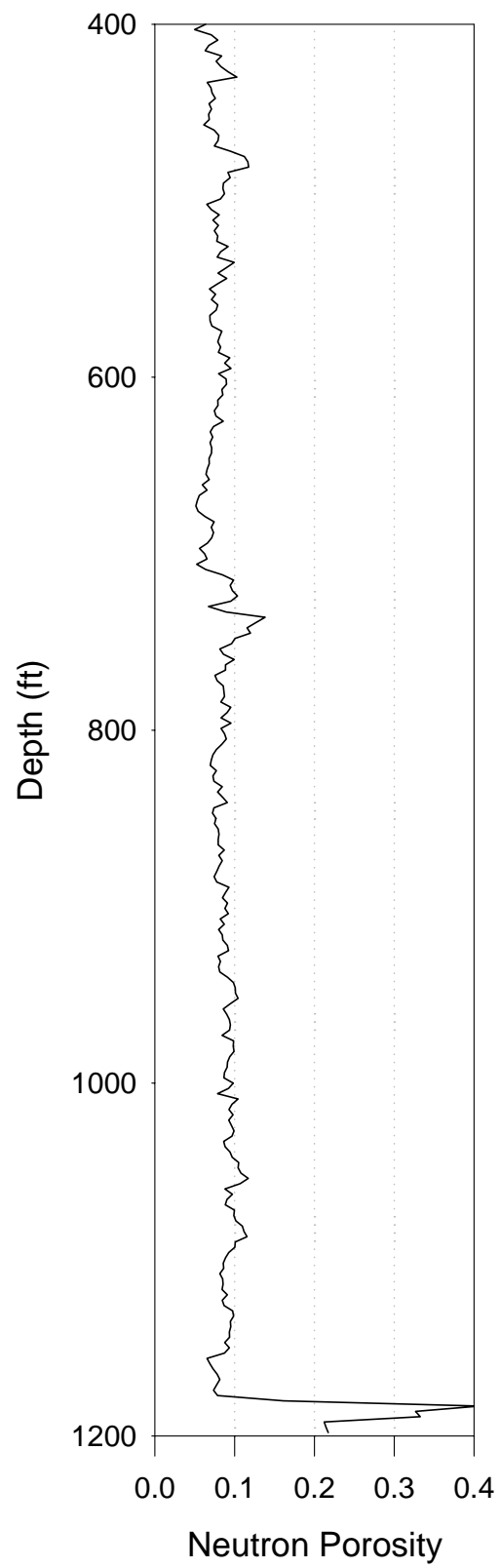

(a)

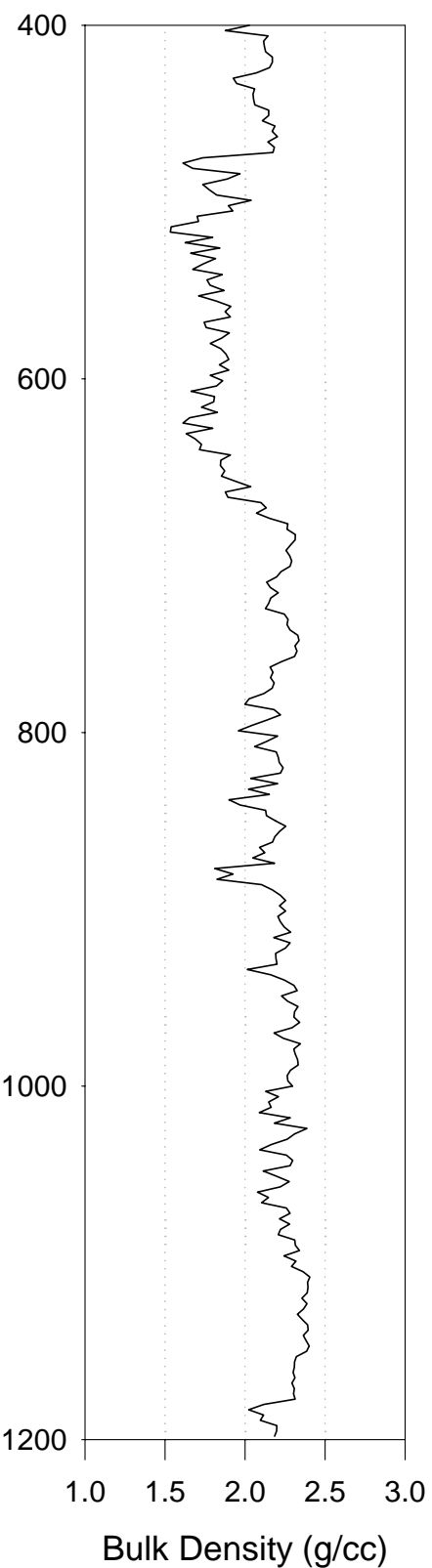

(b)

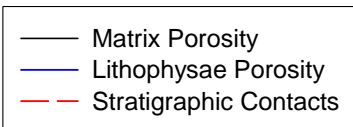

400

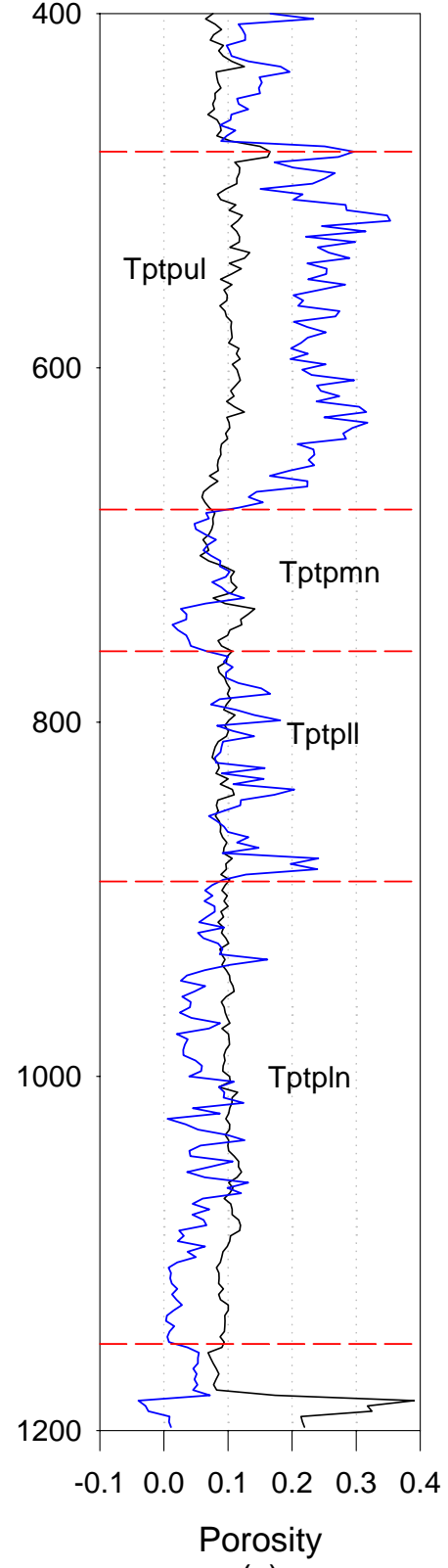

(c)

Input DTN: MO0010CPORGLOG.002 [DIRS 155229].

Figure B-32. UE-25 WT \#12 


\section{UE-25 WT \#13}

The neutron porosity data for UE-25 WT \#13 are consistently higher than data from other boreholes, while the bulk density data are consistent with other borehole density recordings. Method C was used to calculate lithophysal porosity for this borehole.

UE-25 WT-13

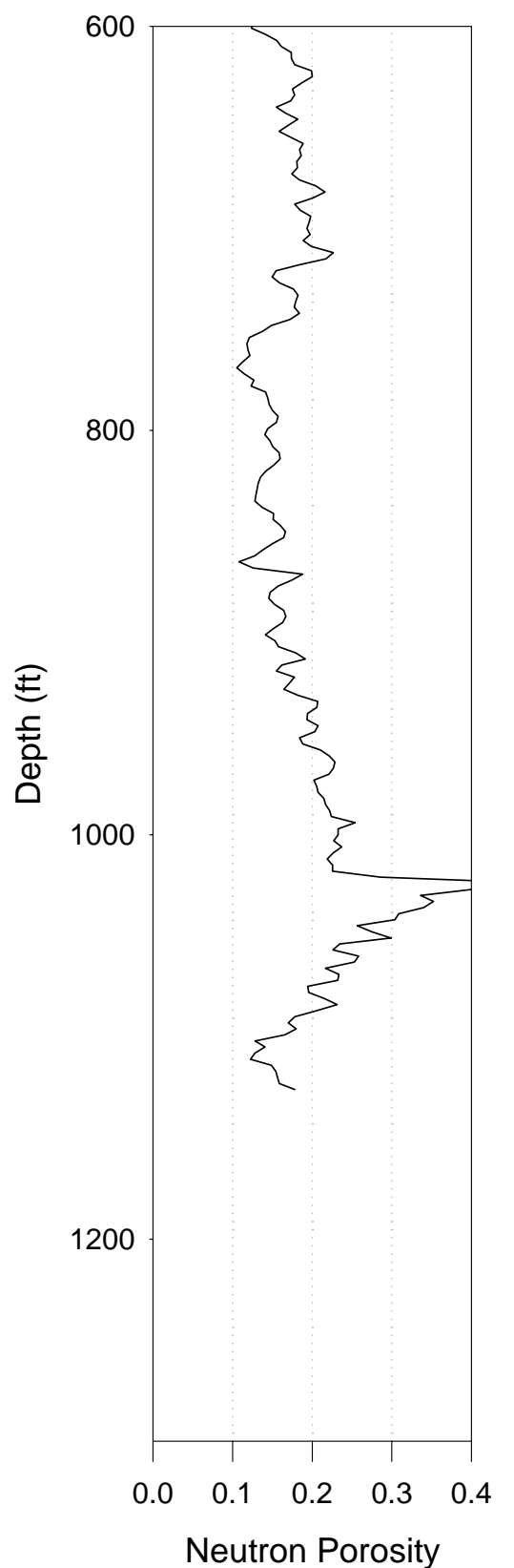

(a)

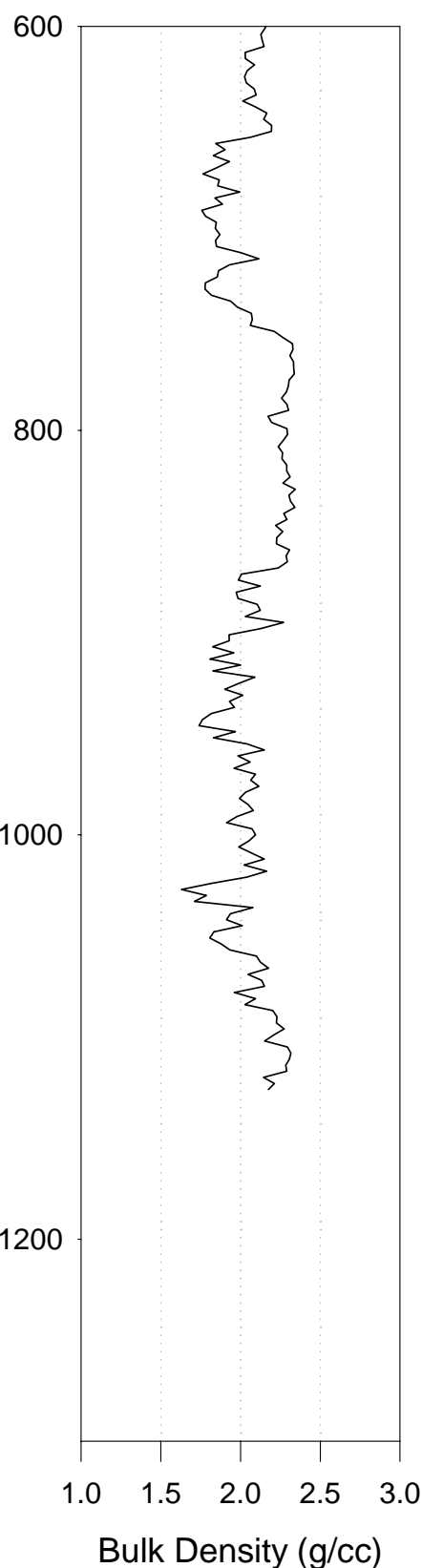

(b)

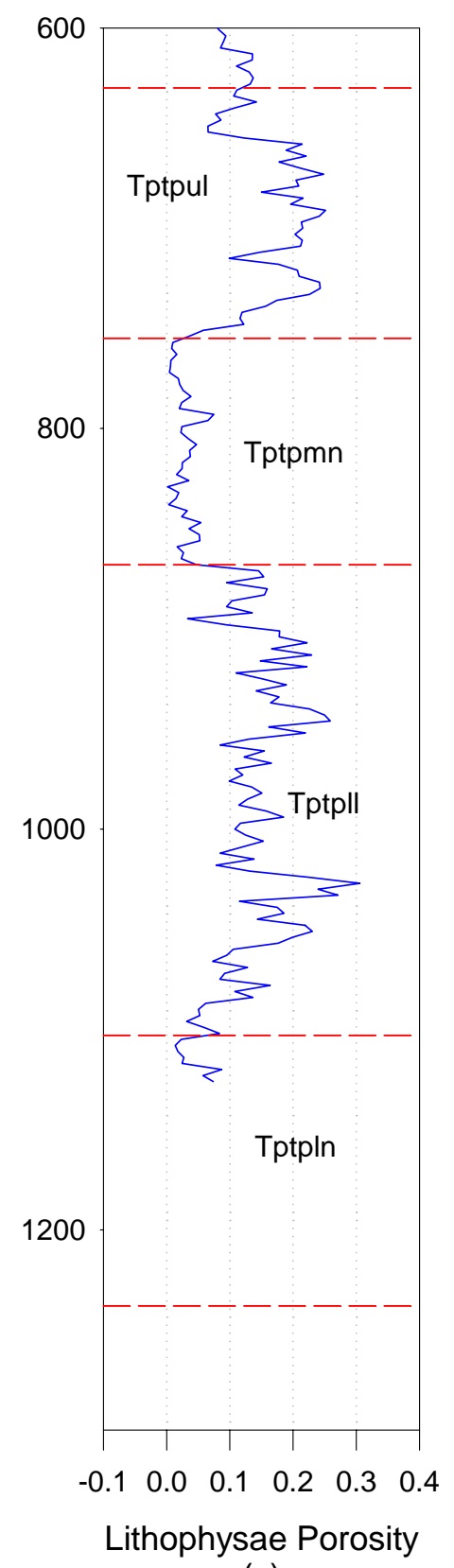

(c)

Input DTN: MO0010CPORGLOG.002 [DIRS 155229].

Figure B-33. UE-25 WT \#13 


\section{UE-25 WT \#14}

The neutron porosity and the bulk density data for borehole UE-25 WT \#14 compare favorably with data from other boreholes. Method B was used to calculate matrix and lithophysal porosity for this borehole.

UE-25 WT \#14

Matrix Porosity

— Lithophysae Porosity

Stratigraphic Contacts

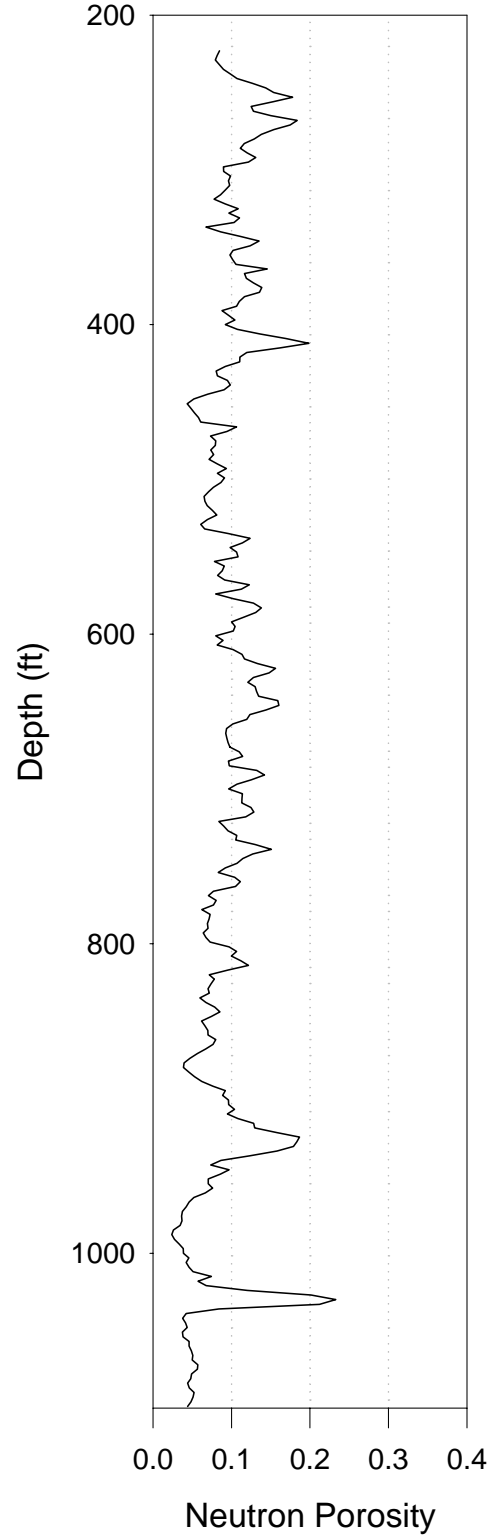

(a)

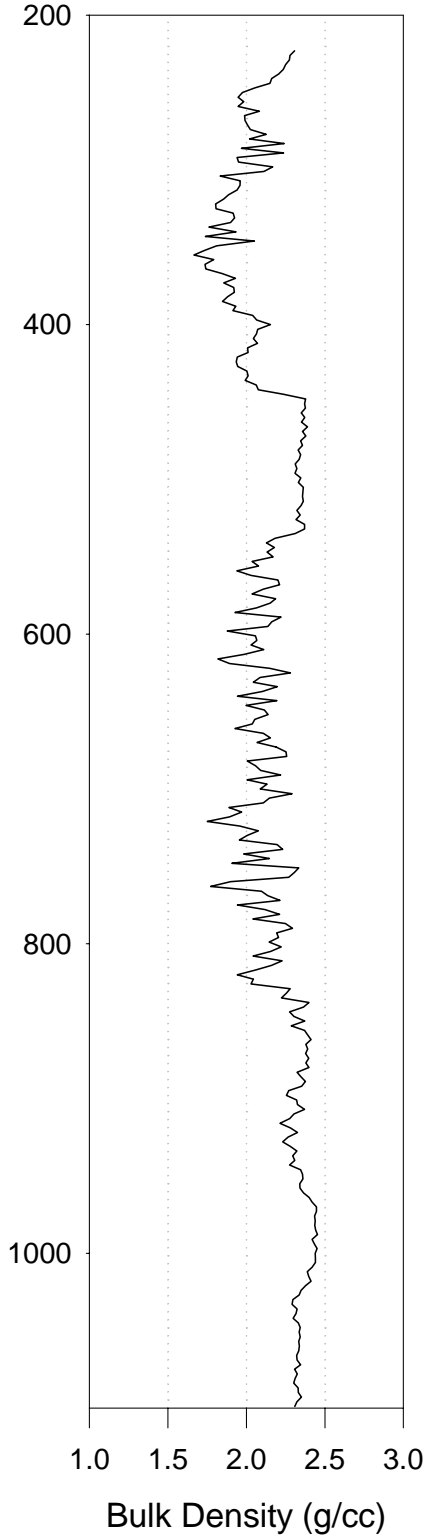

(b)

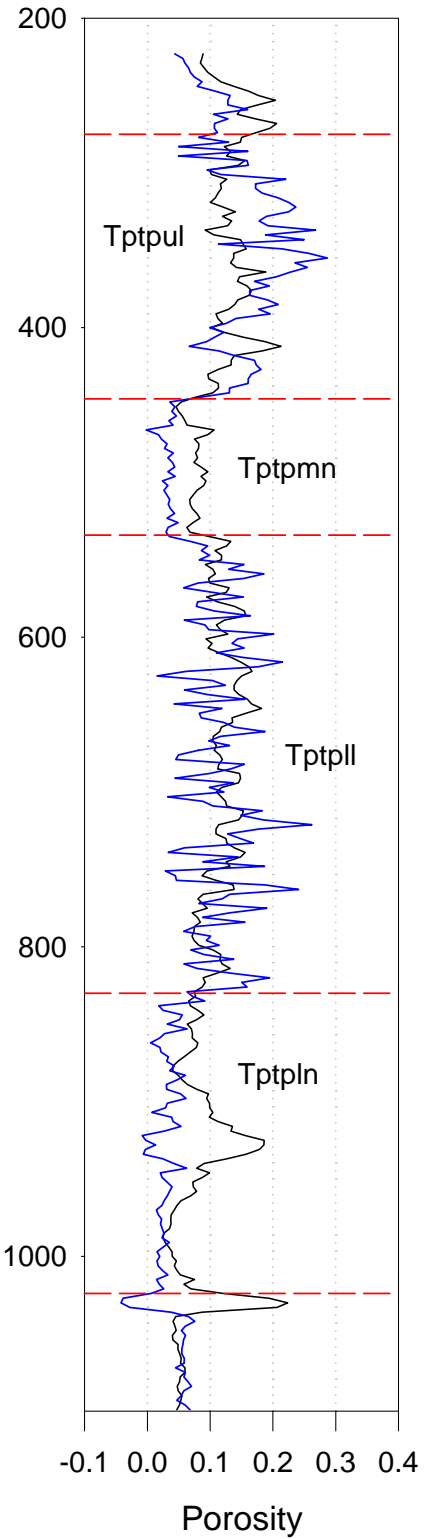

(c)

Input DTN: MO0010CPORGLOG.002 [DIRS 155229].

Figure B-34. UE-25 WT \#14 


\section{UE-25 WT \#15}

The neutron porosity data for UE-25 WT \#15 may be a little high compared to other boreholes. Method B was used to calculate matrix and lithophysal porosity for this borehole.

UE-25 WT \#15

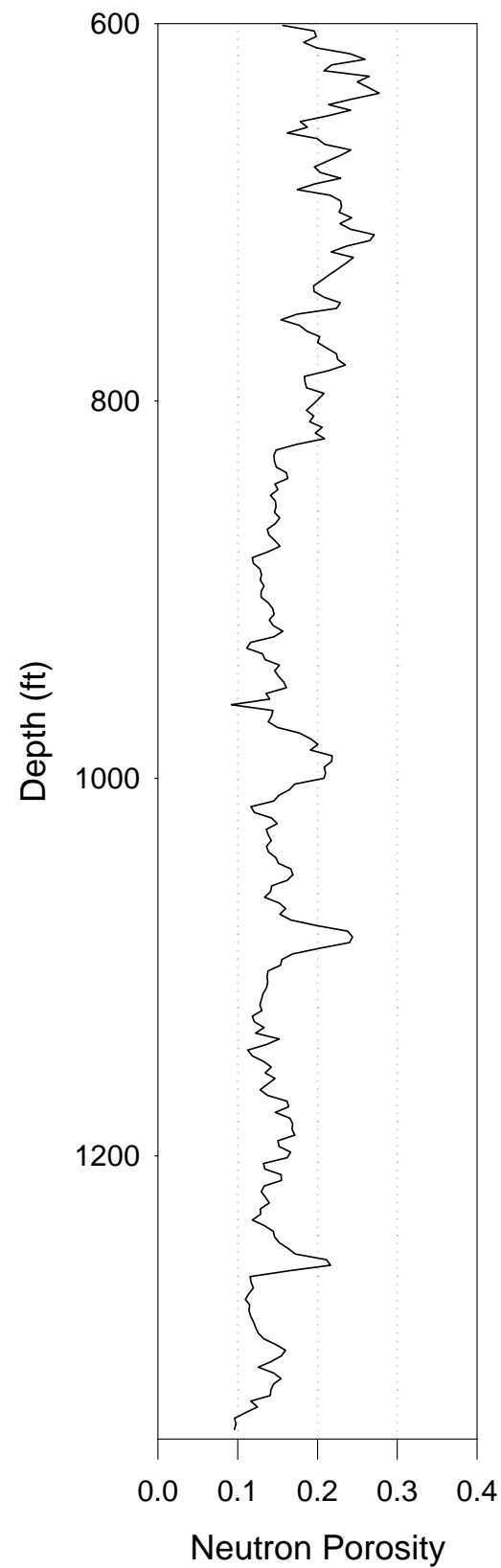

(a)

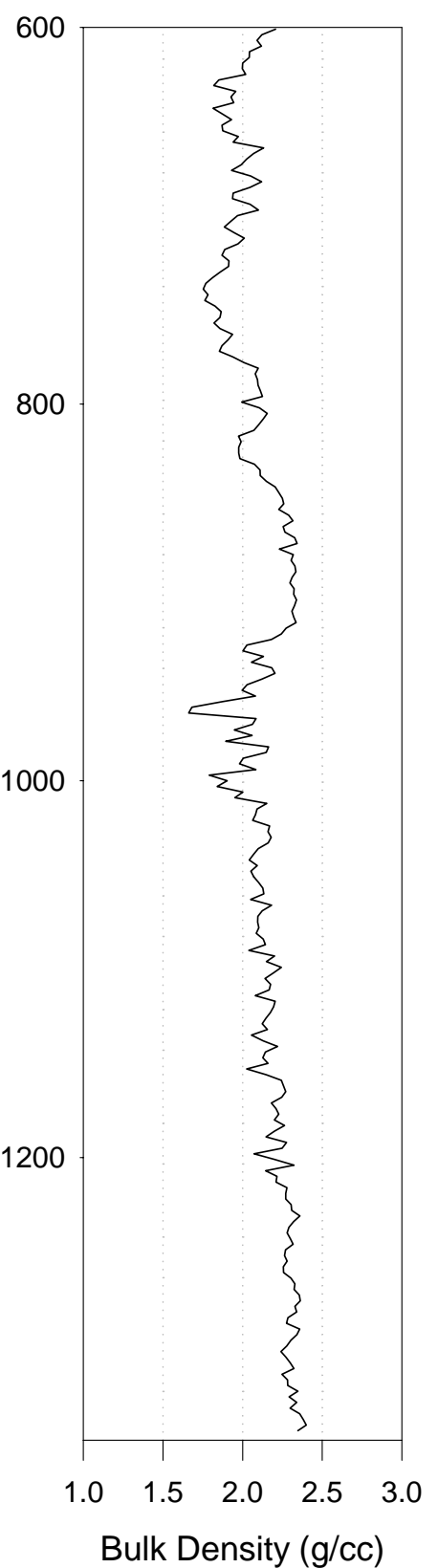

(b)

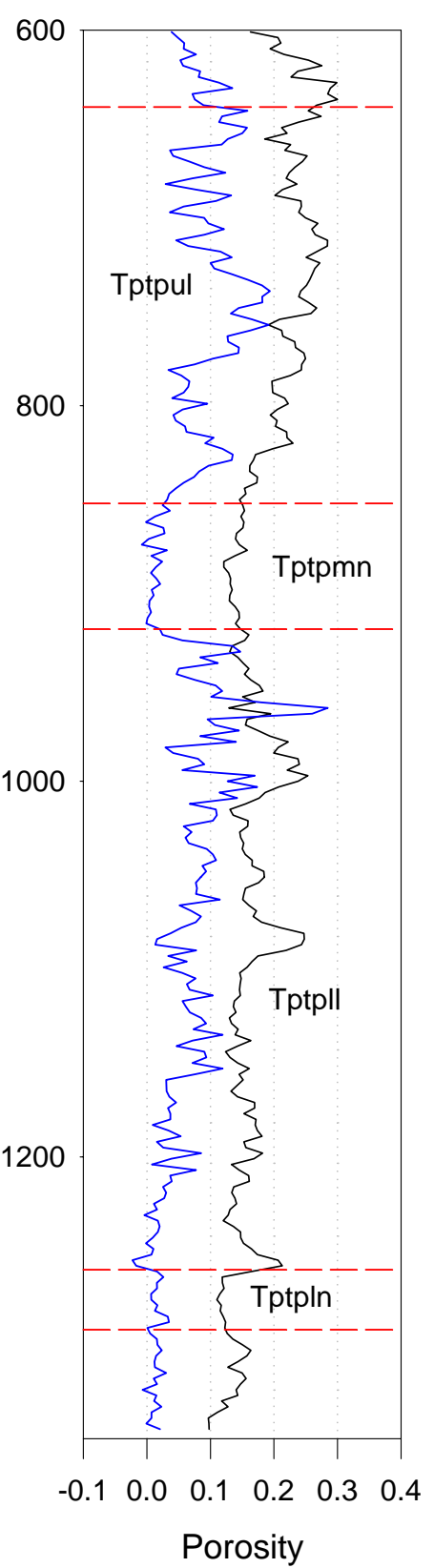

(c)

Input DTN: MO0010CPORGLOG.002 [DIRS 155229].

Figure B-35. UE-25 WT \#15 


\section{UE-25 WT \#16}

The neutron porosity data for UE-25 WT \#16 look a little high compared to other boreholes. Method B was used to calculate the matrix and lithophysal porosity for this borehole.

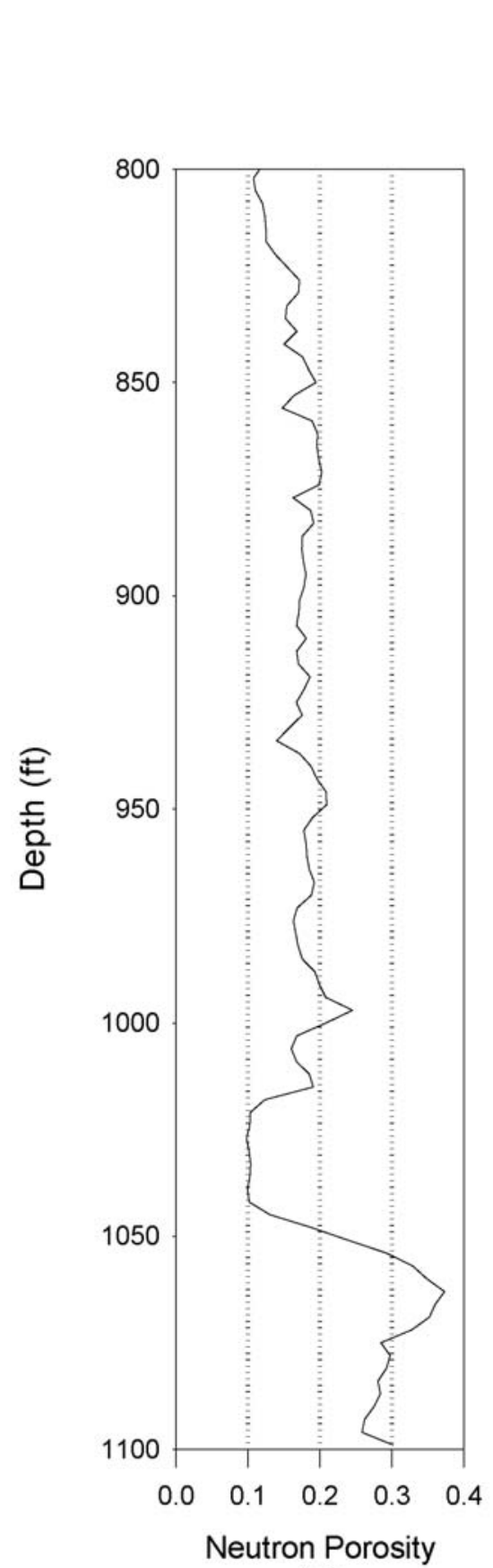

(a)

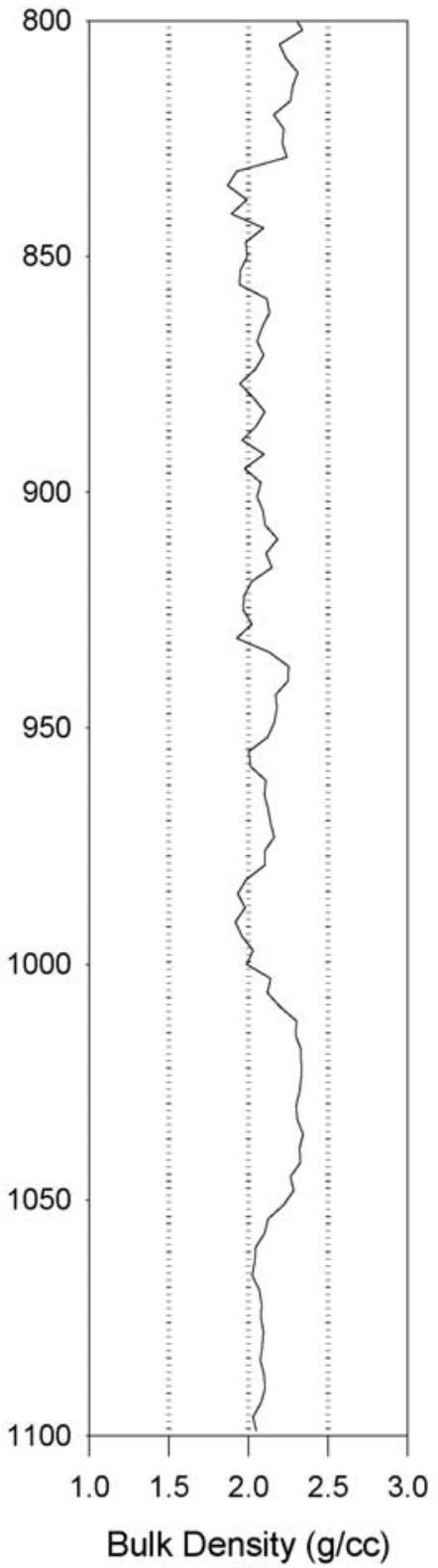

(b)
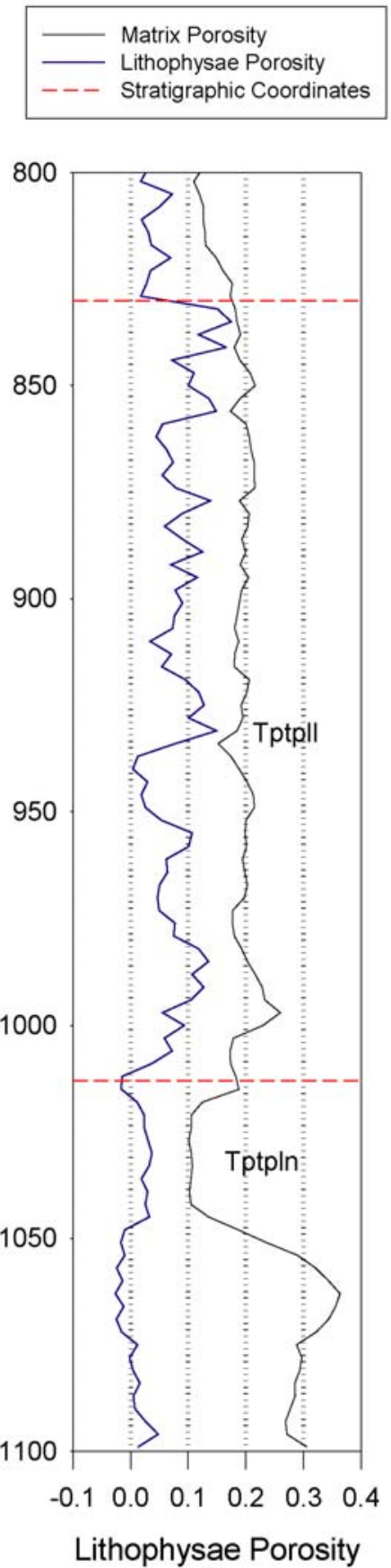

(c)

Input DTN: MO0010CPORGLOG.002 [DIRS 155229].

Figure B-36. UE-25 WT \#16 


\section{UE-25 WT \#17}

The effect of borehole rugosity is reflected in the neutron porosity data for UE-25 WT-\#17. The bulk density data are similar to other boreholes, despite reported severe borehole enlargement throughout much of the recording interval. After comparing the calculated porosities from Methods B and C, Method C was chosen. The lower nonlithophysae unit data were not used because negative values were calculated.

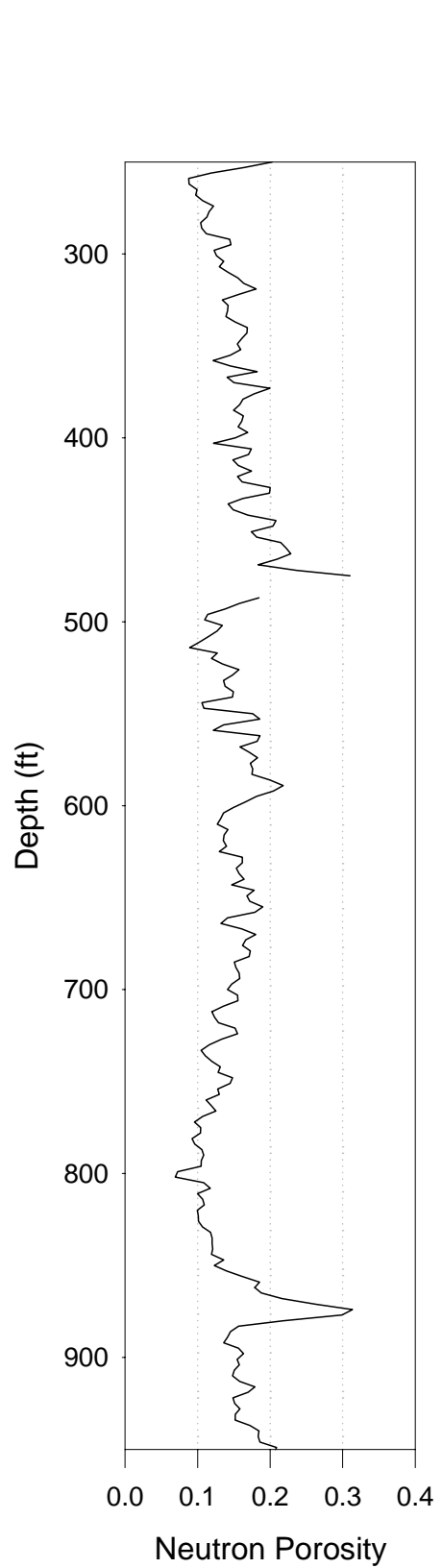

(a)

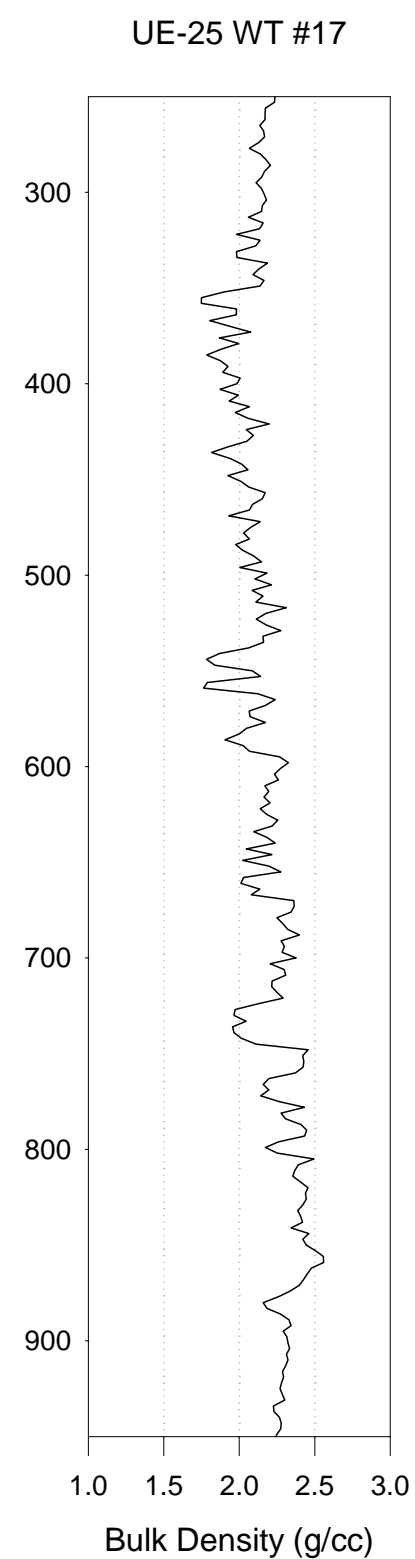

(b)
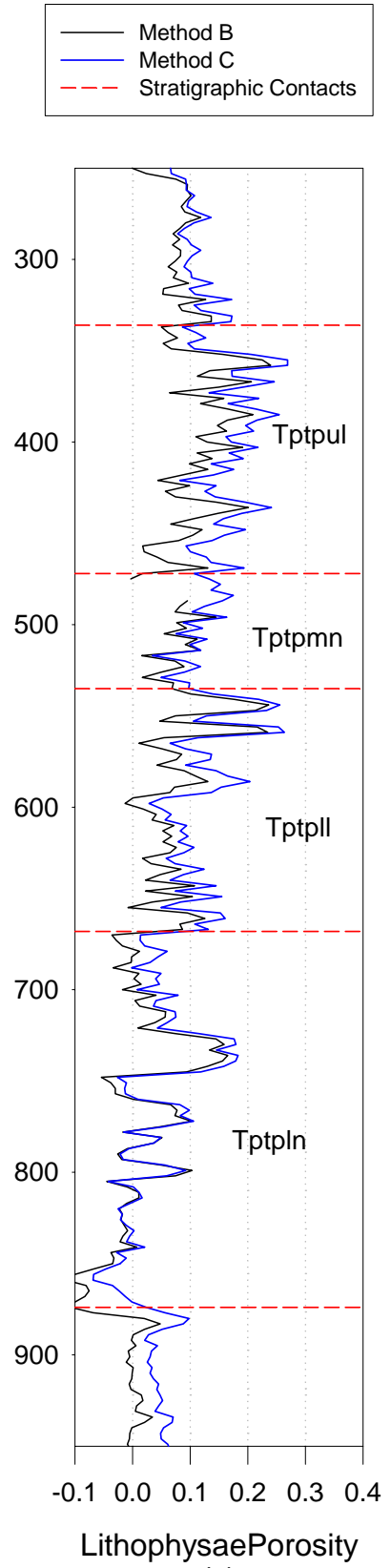

(c)

Input DTN: MO0010CPORGLOG.002 [DIRS 155229], Output DTN: SN0404T0503102.011 [DIRS 169129].

Figure B-37. UE-25 WT \#17 Method C 


\section{UE-25 WT \#18}

The neutron porosity data for borehole UE-25 WT \#18 may be a little high in the upper lithophysae zone but otherwise match the corresponding data from other boreholes. The bulk density data are also representative of other borehole data. Method B was used to calculate matrix and lithophysal porosity for this borehole.

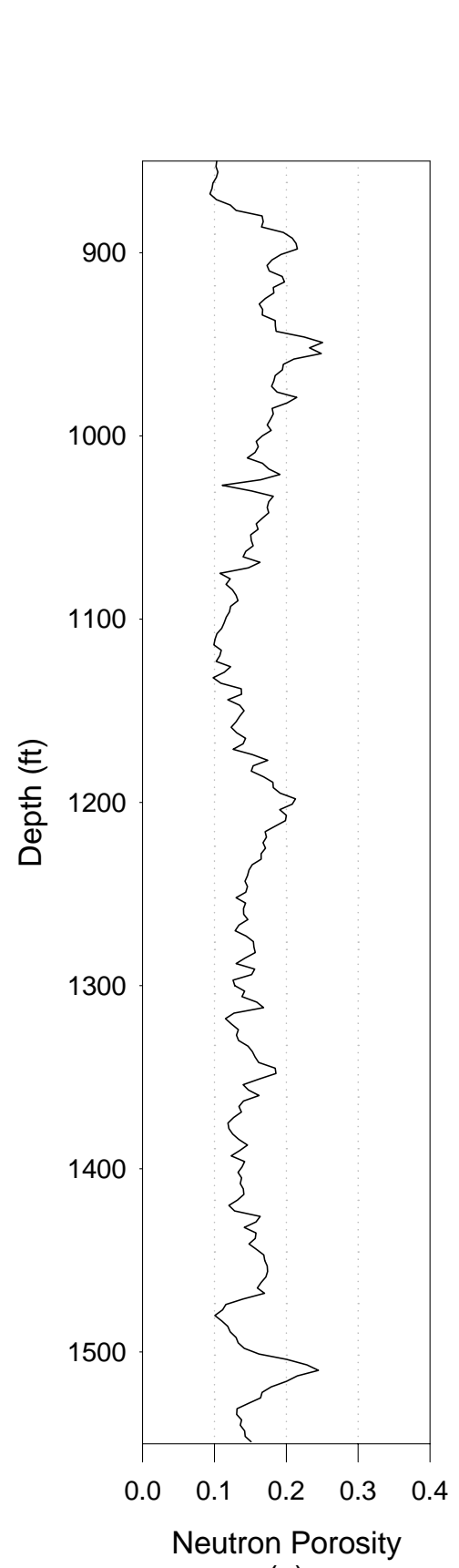

(a)

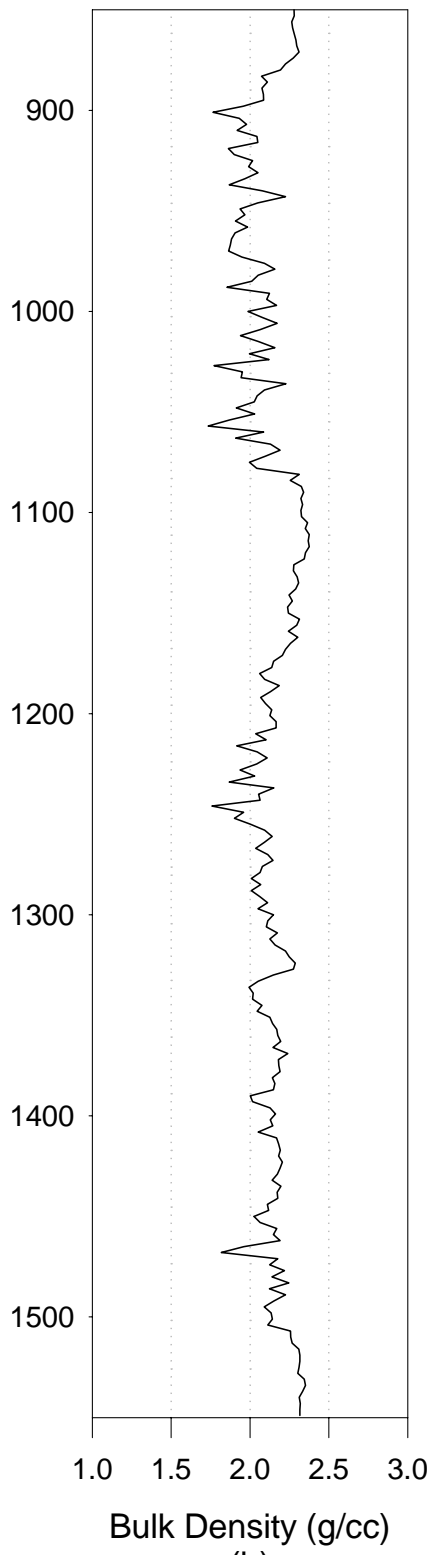

(b)

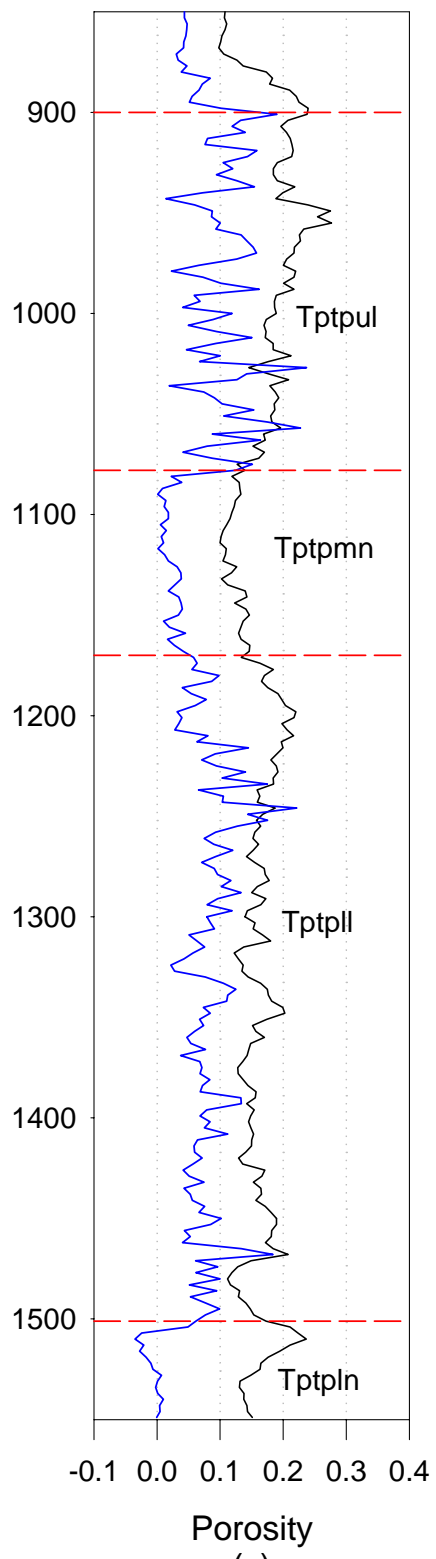

(c)

Input DTN: MO0010CPORGLOG.002 [DIRS 155229].

Figure B-38. UE-25 WT \#18 


\section{USW WT-2}

The neutron porosity and the bulk density data for borehole USW WT-2 are similar to the respective data from other boreholes. Method B was used to calculate matrix and lithophysal porosity for this borehole.

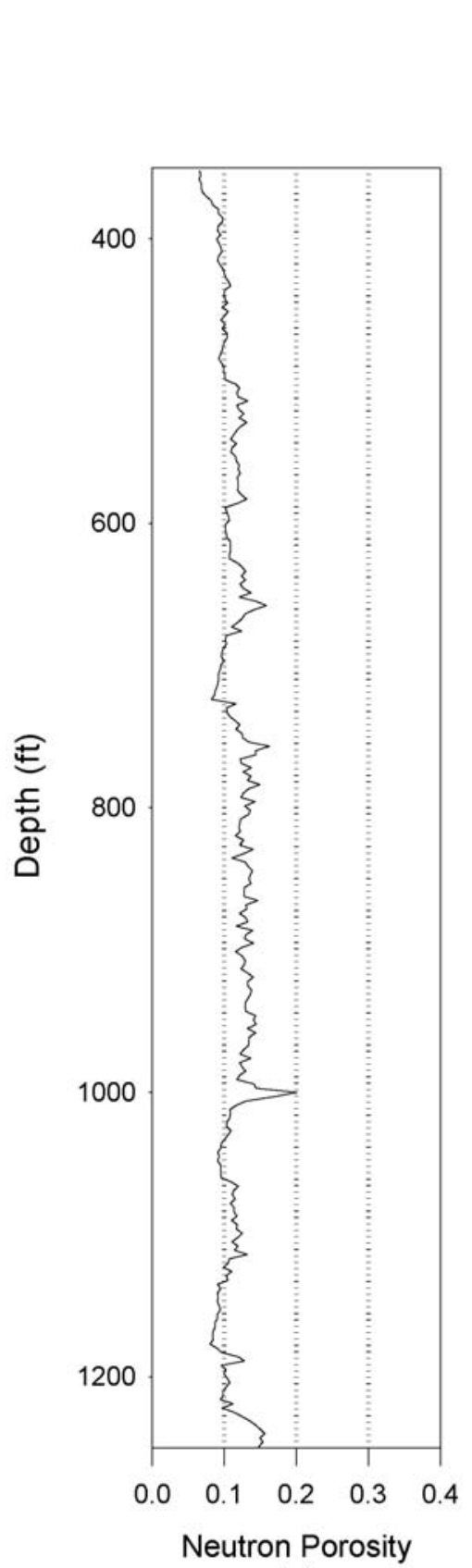

(a)

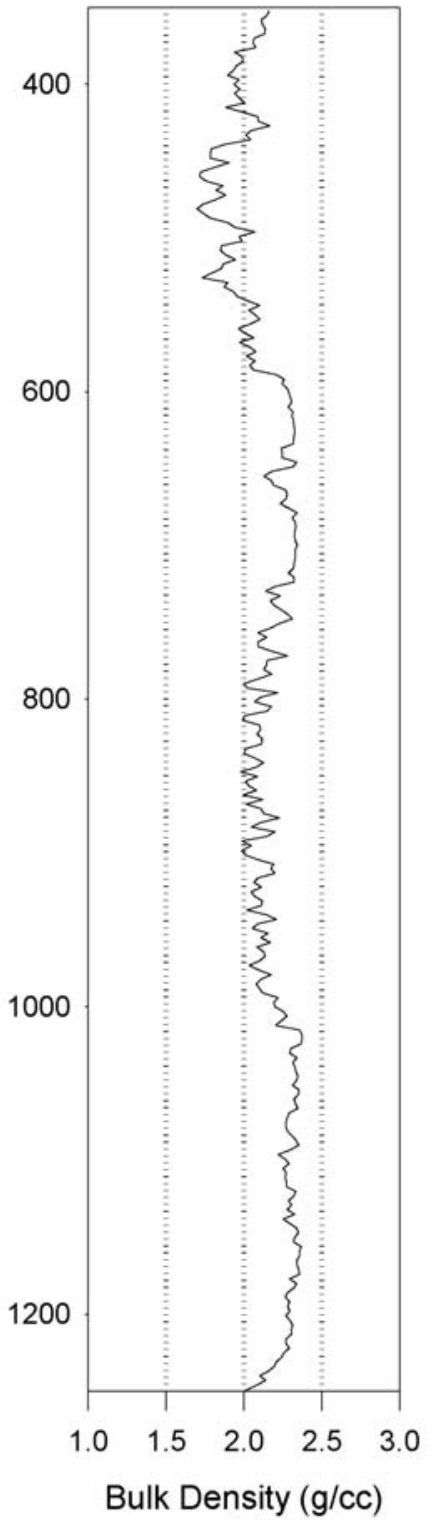

(b)

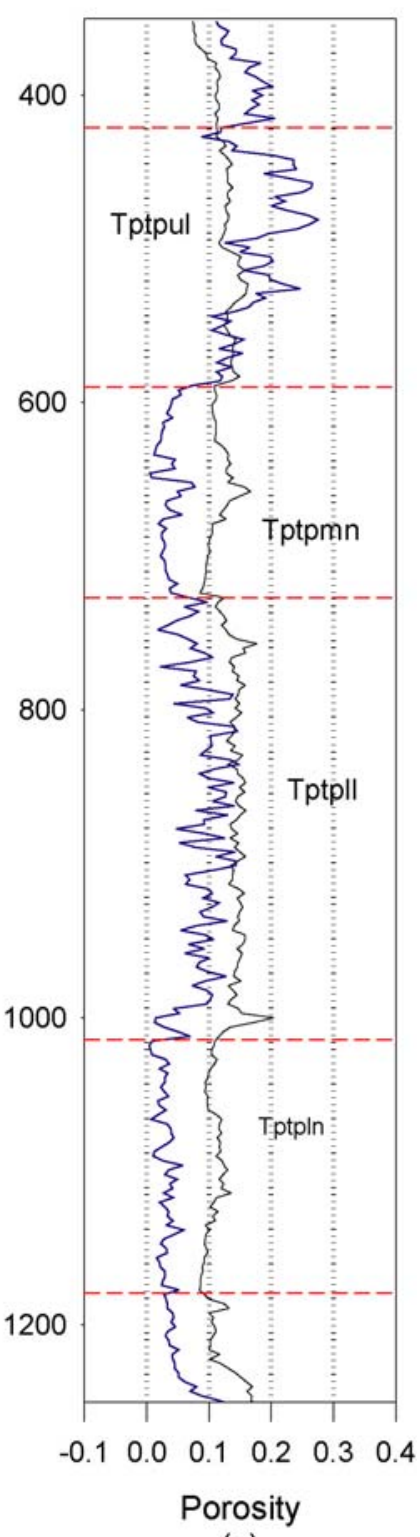

(c)

Input DTN: MO0010CPORGLOG.002 [DIRS 155229].

Figure B-39. USW WT-2 


\section{USW WT-24}

The neutron porosity and the bulk density data for borehole USW WT-24 are typical of data from other boreholes. Method B was used to calculate matrix and lithophysal porosity for this borehole.

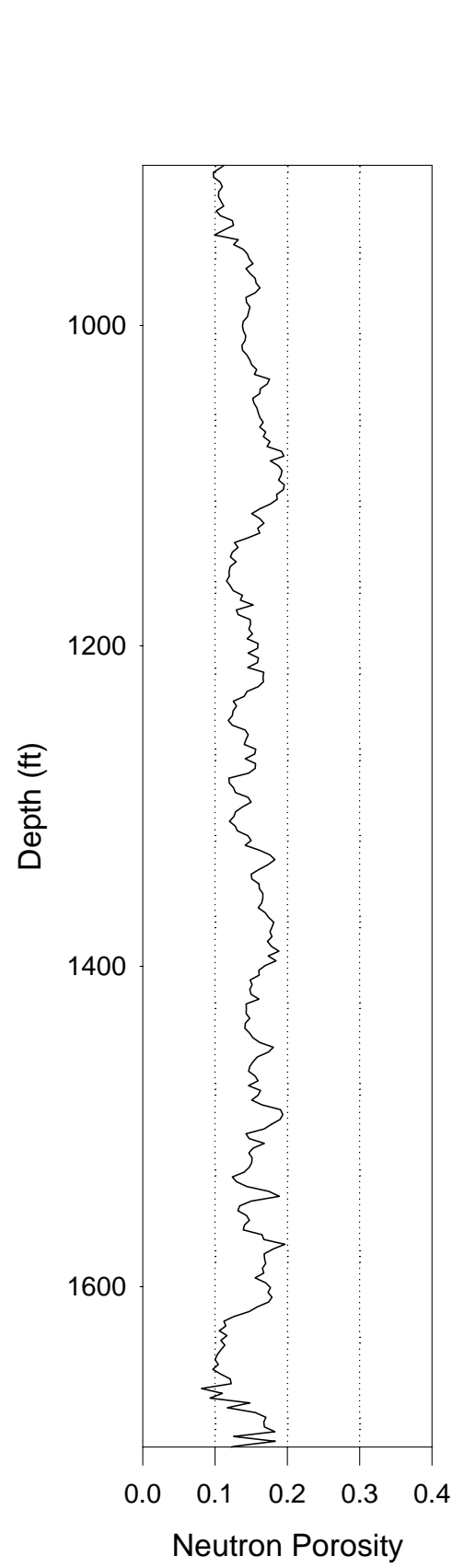

(a)

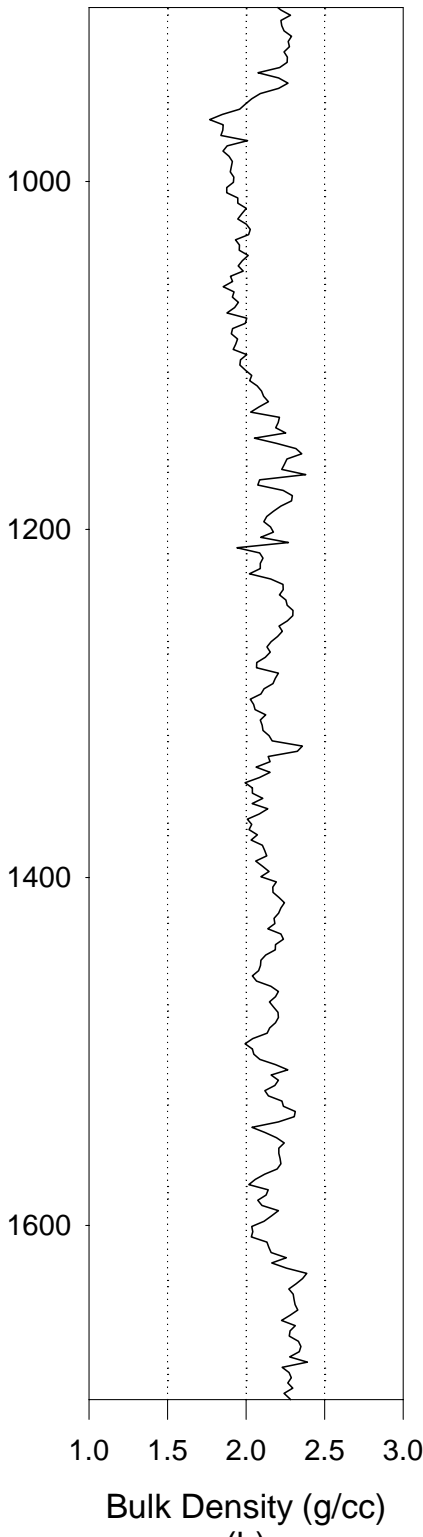

(b)

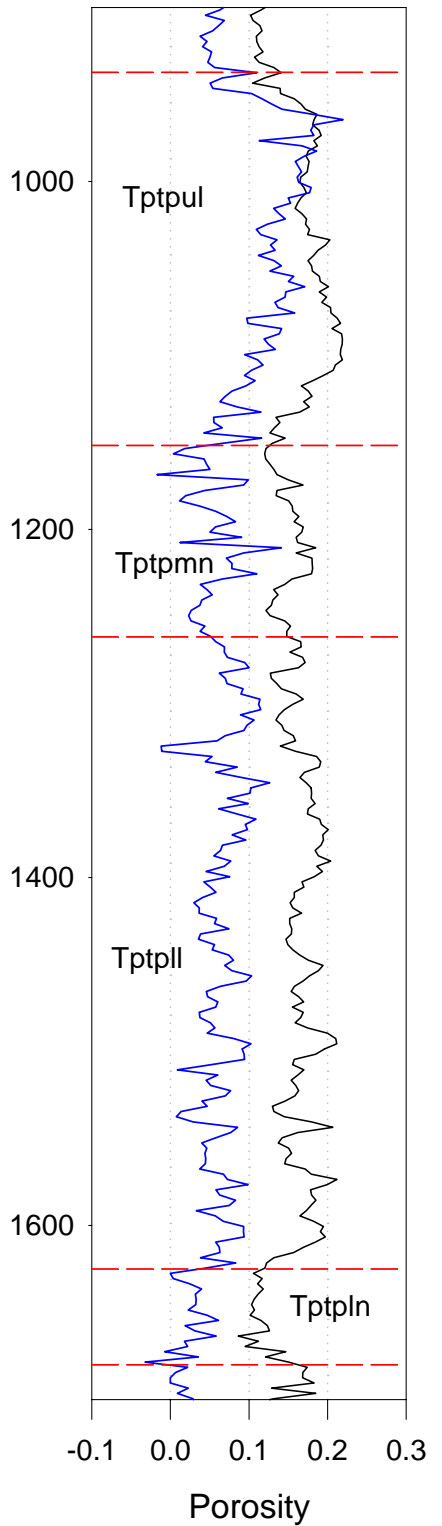

(c)

Input DTN: MO0010CPORGLOG.003 [DIRS 155959].

Figure B-40. USW WT-24 


\section{UE-25 WT \#3}

Method B was used to calculate the matrix and lithophysal porosity in borehole UE-25 WT \#3. According to the stratigraphic picks, the Tptpln should occur between 35 and $189 \mathrm{ft}$. The value of $189 \mathrm{ft}$ seems reasonable based on the calculated lithophysal porosity. However, a better estimate of the top of the Tptpln appears to be about $130 \mathrm{ft}$. Therefore, in this work, the range 130 to $189 \mathrm{ft}$ was used to represent the Tptpln. The data above $130 \mathrm{ft}$ were not used.

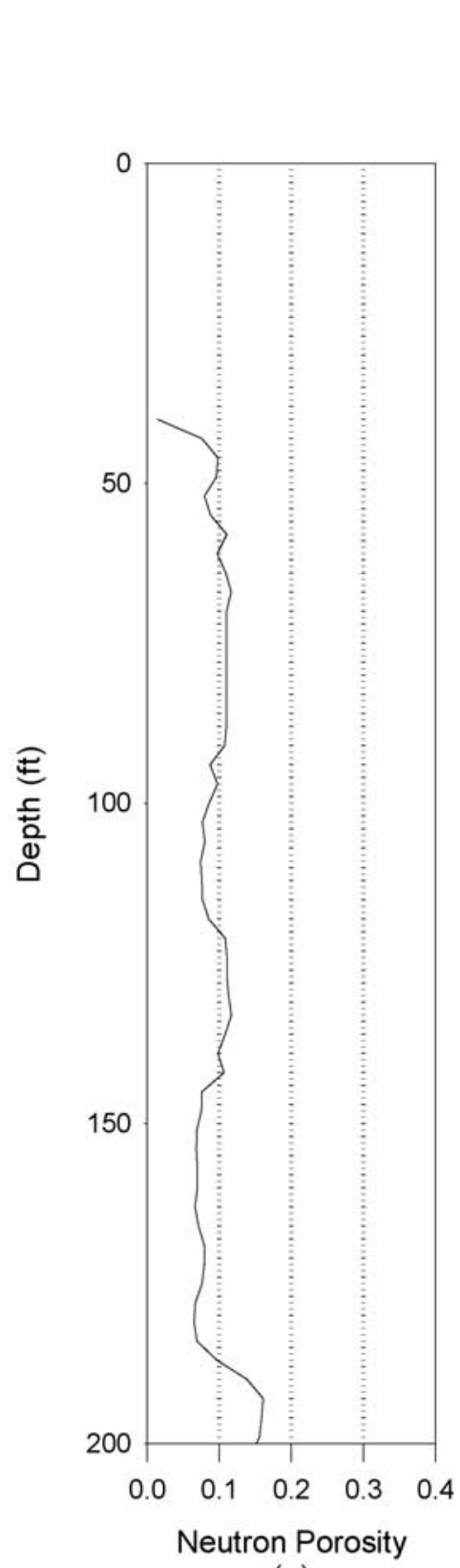

(a)

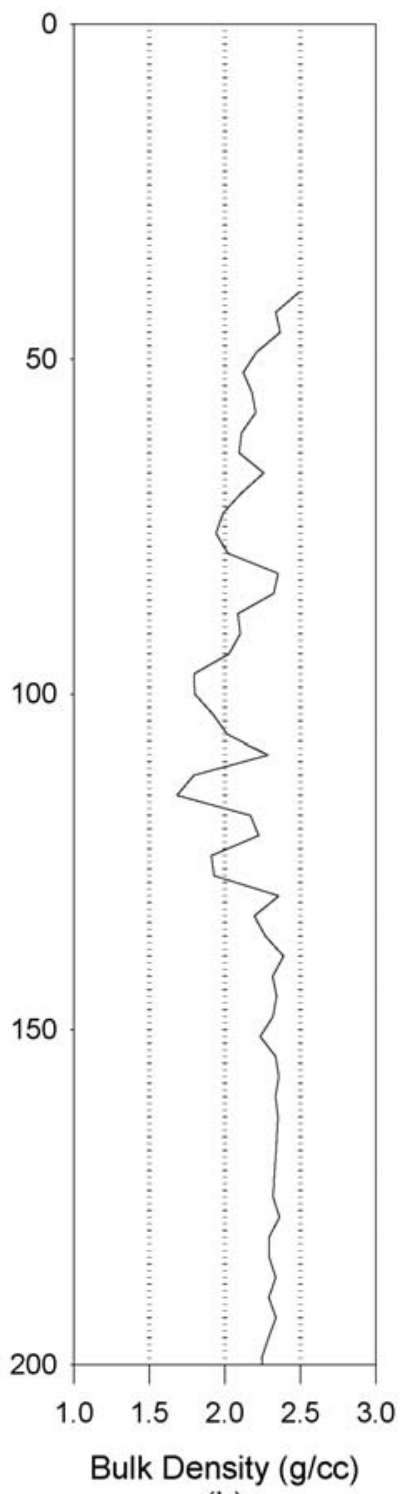

(b)
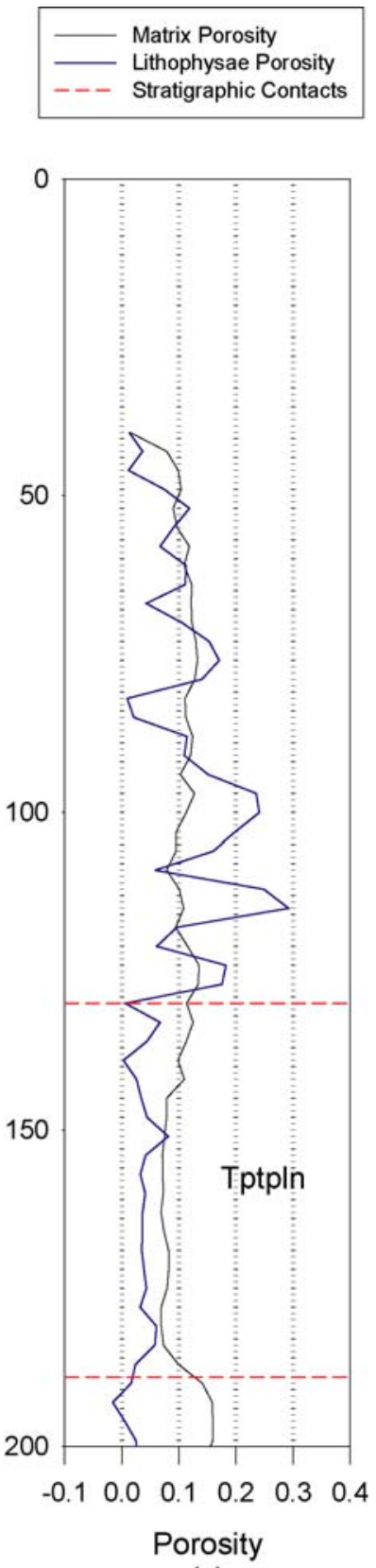

(c)

Input DTN: MO0010CPORGLOG.002 [DIRS 155229].

Figure B-41. UE-25 WT \#3 


\section{UE-25 WT \#4}

The neutron porosity and the bulk density data for borehole UE-25 WT \#4 are consistent with other boreholes. Method B was used to calculated the matrix and lithophysal porosity for this borehole.

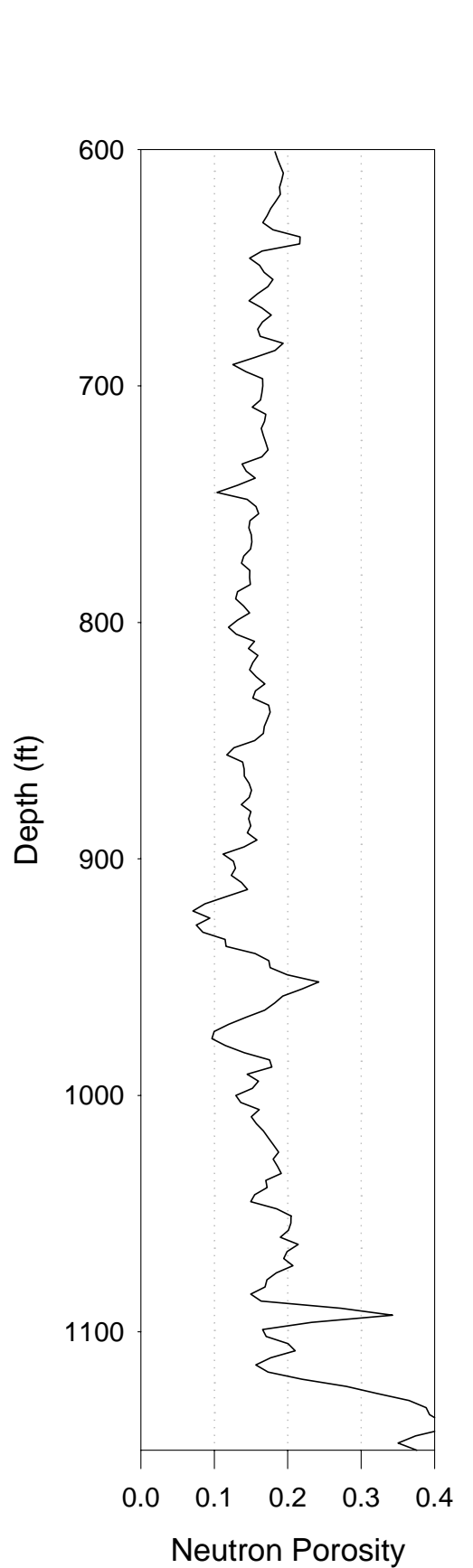

(a)

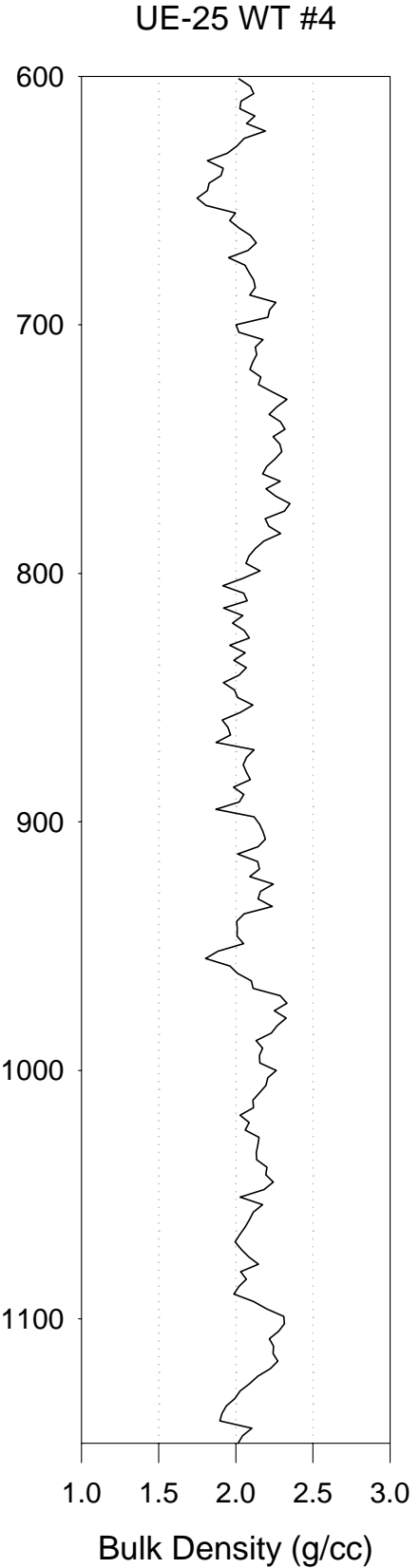

(b)
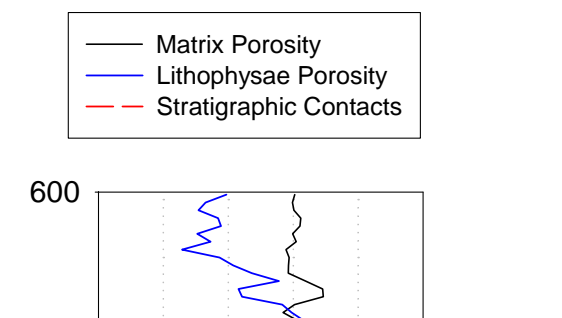

\section{Lithophysae Porosity}

(c)

Input DTN: MO0010CPORGLOG.002 [DIRS 155229].

Figure B-42. UE-25 WT \#4 


\section{USW WT-7}

The neutron porosity data for borehole USW WT-7 look a little high in the upper lithophysae while the bulk density data are consistent with other boreholes. Using Method B to calculate matrix and lithophysal porosity gave results that were consistent with neighboring boreholes USW H-3 and USW G-3. Method B was chosen over Method C because there was no clear reason to believe the neutron porosity data were outside the range of other borehole data.

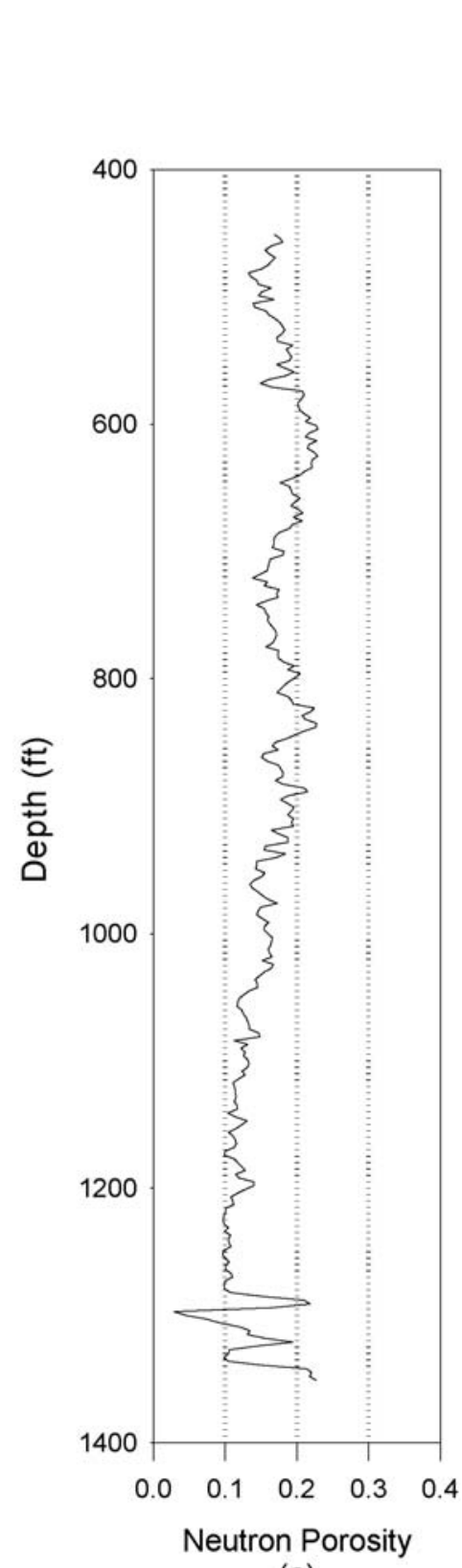

(a)

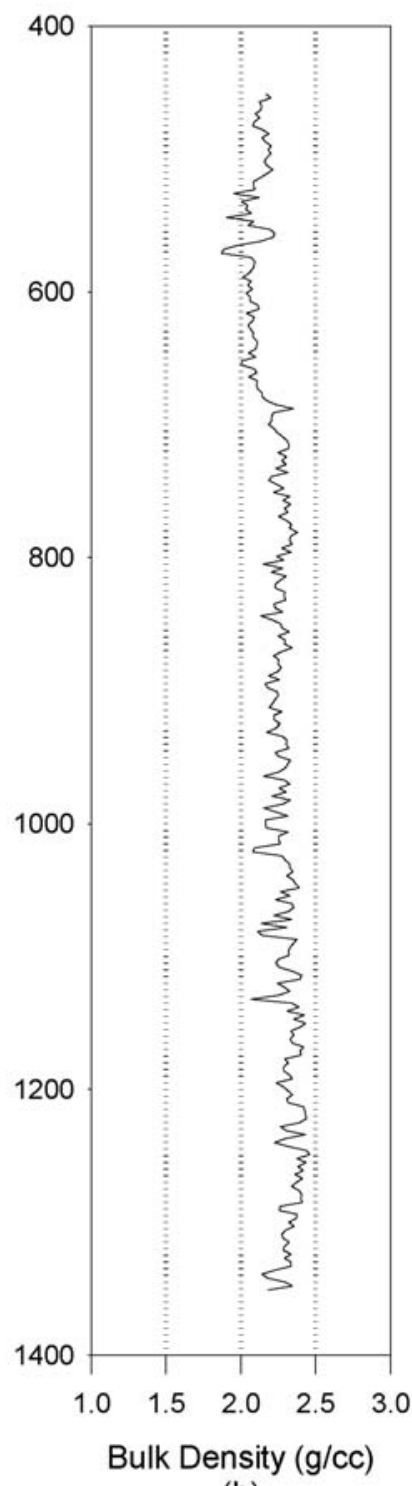

(b)

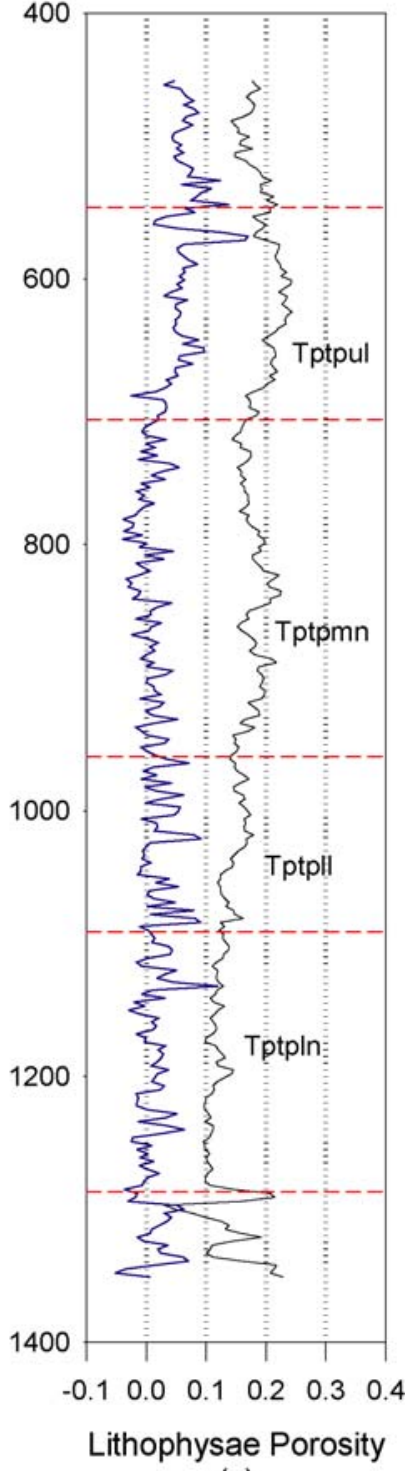

(c)

Input DTN: MO0010CPORGLOG.002 [DIRS 155229].

Figure B-43. USW WT-7 
APPENDIX C

MATRIX THERMAL CONDUCTIVITY DATA 


\section{MATRIX THERMAL CONDUCTIVITY DATA}

This appendix presents the results of laboratory thermal conductivity measurements considered in the development of model parameter distributions for matrix thermal conductivity. Several data were excluded from model calibration because they were not collected under an approved quality assurance program or experimental results were questionable. This appendix documents the data considered and describes why certain data are excluded.

All of the data selected for calibration of the matrix thermal conductivity model satisfy the following three screening criteria:

1. They are fully qualified and verified according to the appropriate procedures.

2. They are appropriate for the model calibration procedure described in Section 6.1.7, which requires the measurement of thermal conductivity under both water-saturated (wet) and air-saturated (dry) conditions. In addition, an estimate of the porosity of the sample is also required.

3. Experimental results must appear to be reasonable and reproducible.

Only two DTNs satisfy all three criteria. The first DTN (SNL01A05059301.005 [DIRS 109002]) was developed from Thermal Expansion and Thermal Conductivity Measurements for Boreholes UE25 NRG-4, UE25 NRG-5, USW NRG-6, and USW NRG-7/7A (Brodsky et al. 1997 [DIRS 100653]). This report documents the thermal conductivity measurements on core samples extracted from various boreholes. Thermal conductivity measurements from this report are reproduced in Table C-1. For the dry measurements, the values reported at the nominal temperature of $110^{\circ} \mathrm{C}$ (actual range was 108.3 to $111.3^{\circ} \mathrm{C}$ ) were used. For the wet measurements, the values reported at the nominal temperature of $70^{\circ} \mathrm{C}$ (actual range was 68.9 to $70.8^{\circ} \mathrm{C}$ ) were used. For samples where more than one measurement of thermal conductivity was reported at the specified temperature, the average of the reported values is given in Table C-1. Data that are highlighted in Table $\mathrm{C}-1$ are excluded from this analysis for the reason noted in the table footnotes. Finally, the porosity values for these samples are provided by DTN: SNL01A05059301.007 [DIRS 108980]. Several samples were obtained from the Topopah Spring Tuff Crystal Rich Non-lithophysal (Tptrn) and Lithophysal (Tptrl) zones (Figure 6-1). These samples are appropriate as potential input to this model because in terms of their matrix composition and, hence, their thermal conductivity, they are equivalent to the Topopah Spring Crystal Poor Lithophysal (Tptp) member.

The "dry" thermal conductivity specimens were placed in an oven and heated at $\leq 2^{\circ} \mathrm{C}$ per minute until the oven reached approximately $110^{\circ} \mathrm{C}$. They were dried until subsequent weighings 120 to 128 hours apart showed that the masses were stable to within 0.05 percent (Brodsky et al. 1997 [DIRS 100653], pp. 9 to 10). The thermal conductivity measurements conducted on the "wet" $70^{\circ} \mathrm{C}$ samples were vacuum saturated (96-100 percent), then encapsulated in a moisture containment cells to preserve saturation during testing (Brodsky et al. 1997 [DIRS 100653], p. 14). 
The second DTN (SNL22100196001.006 [DIRS 158213]) was developed from Laboratory Measurements of Thermal Conductivity as a Function of Saturation State for Welded and Nonwelded Tuff Specimens (SNL 1998 [DIRS 118788]). This data set includes both wet and dry thermal conductivity measurements for six samples extracted from Alcove 5 in the Tptpmn. These data are reproduced in Table $\mathrm{C}-2$.

Table C-1. Borehole Thermal Conductivity Measurements

\begin{tabular}{|c|c|c|c|c|c|c|}
\hline Location & $\mathrm{T} / \mathrm{H}$ unit & & Specimen ID (dry/wet) & Porosity & $\begin{array}{c}\text { Dry Thermal } \\
\text { Conductivity at } \\
\text { Nominal } \\
\text { Temperature of } \\
110^{\circ} \mathrm{C} \\
\mathrm{W} /(\mathrm{mK}) \\
\end{array}$ & $\begin{array}{l}\text { Wet Thermal } \\
\text { Conductivity at } \\
\text { Nominal } \\
\text { Temperature of } \\
70^{\circ} \mathrm{C} \\
\mathrm{W} /(\mathrm{mK})\end{array}$ \\
\hline NRG4 & TSw1 & Tptrn & $529.0 \mathrm{~B} / 529.0 \mathrm{~A}$ & 0.165 & 1.16 & 1.67 \\
\hline NRG4 & TSw1 & Tptrn & $545.0 \mathrm{G}$ & 0.238 & 0.90 & \\
\hline NRG4 & TSw1 & Tptrn & $586.2 \mathrm{~B} / 586.2 \mathrm{~A}$ & 0.194 & 0.95 & 1.64 \\
\hline NRG4 & TSw1 & Tptrn & $590.5 \mathrm{~B}$ & 0.187 & 1.00 & \\
\hline NRG4 & TSw1 & Tptrn & $610.5 \mathrm{~B}$ & 0.144 & 1.10 & \\
\hline NRG4 & TSw1 & Tptrn & $619.9 B$ & 0.132 & 1.14 & \\
\hline NRG4 & TSw1 & Tptrn & $654.0 \mathrm{~B} / 654.0 \mathrm{~A}$ & 0.137 & 1.16 & 1.80 \\
\hline NRG5 & TSw1 & Tptpmn & 781.8A / 781.8A & 0.157 & 1.00 & 1.92 \\
\hline NRG5 & TSw1 & Tptpmn & 791.6A / 791.3A & 0.246 & 0.82 & 1.78 \\
\hline NRG5 & TSw2 & Tptpmn & $834.8 \mathrm{~B} / 834.8 \mathrm{~A}$ & 0.089 & 1.66 & 1.92 \\
\hline NRG5 & TSw2 & Tptpmn & 843.5A / 843.5A & 0.088 & 1.65 & 2.20 \\
\hline NRG5 & TSw2 & Tptpmn & 848.0B / 848.0B & 0.121 & 1.50 & 2.61 \\
\hline NRG5 & TSw2 & Tptpmn & 853.8A / 852.5B & 0.087 & 1.71 & 2.26 \\
\hline NRG5 & TSw2 & Tptpmn & 874.9B / 874.3B & 0.086 & 1.68 & 2.32 \\
\hline NRG5 & TSw2 & Tptpmn & 879.6A / 879.6A & 0.087 & 1.63 & 3.09 \\
\hline NRG5 & TSw2 & Tptpmn & 886.5B / 886.5B & 0.124 & 1.37 & 2.53 \\
\hline NRG5 & TSw2 & Tptpmn & 893.3B / 893.3B & 0.112 & 1.46 & 2.75 \\
\hline NRG5 & TSw2 & Tptpmn & 899.8B / 899.8B & 0.110 & 1.48 & 2.77 \\
\hline NRG6 & TSw1 & Tptrn & 277.5E / 277.5D & 0.100 & 1.26 & 1.68 \\
\hline NRG6 & TSw1 & Tptrn & 321.1E / 321.1D & 0.150 & 1.17 & 1.71 \\
\hline NRG6 & TSw1 & Tptrn & $354.9 \mathrm{C} / 354.9 \mathrm{~B}$ & 0.150 & 1.14 & 1.49 \\
\hline NRG6 & TSw1 & Tptrn & 392.1D / 392.1C & 0.040 & 1.19 & 1.55 \\
\hline NRG6 & TSw1 & Tptrn & $416.0 \mathrm{~K} / 416.0 \mathrm{~J}$ & 0.090 & 1.29 & 1.55 \\
\hline NRG6 & TSw1 & Tptrn & $421.8 \mathrm{D} / 421.8 \mathrm{C}$ & 0.127 & 1.19 & 1.70 \\
\hline NRG6 & TSw1 & Tptrn & $425.3 \mathrm{~B} / 425.3 \mathrm{~A}$ & 0.138 & 1.26 & 1.82 \\
\hline NRG6 & TSw1 & Tptrl & $451.2 \mathrm{~B} / 451.2 \mathrm{~A}$ & 0.185 & 1.29 & 1.70 \\
\hline NRG6 & TSw1 & Tptpul & $556.1 \mathrm{~B} / 556.1 \mathrm{~A}$ & 0.277 & 0.91 & 2.04 \\
\hline NRG6 & TSw1 & Tptpul & $693.1 \mathrm{C} / 693.1 \mathrm{C}$ & 0.139 & 1.39 & 1.93 \\
\hline NRG6 & TSw2 & Tptpmn & 757.0B / 757.0A & 0.096 & 1.61 & 2.02 \\
\hline NRG6 & TSw2 & Tptpmn & 778.1B / 778.1A & 0.084 & 1.71 & 1.85 \\
\hline
\end{tabular}


Table C-1. Borehole Thermal Conductivity Measurements (Continued)

\begin{tabular}{|c|c|c|c|c|c|c|}
\hline Location & $T / H$ unit & & Specimen ID (dry/wet) & Porosity & $\begin{array}{c}\text { Dry Thermal } \\
\text { Conductivity at } \\
\text { Nominal } \\
\text { Temperature of } \\
110^{\circ} \mathrm{C} \\
\mathrm{W} /(\mathrm{mK}) \\
\end{array}$ & $\begin{array}{l}\text { Wet Thermal } \\
\text { Conductivity at } \\
\text { Nominal } \\
\text { Temperature of } \\
70^{\circ} \mathrm{C} \\
\mathrm{W} /(\mathrm{mK}) \\
\end{array}$ \\
\hline NRG6 & TSw2 & Tptpmn & 787.5B / 787.5A & 0.112 & 1.60 & 1.72 \\
\hline NRG6 & TSw2 & Tptpmn & 802.7D / 802.7C & 0.094 & 1.67 & 1.78 \\
\hline NRG6 & TSw2 & Tptpmn & 809.4B / 809.4A & 0.092 & 1.64 & 1.66 \\
\hline NRG6 & TSw2 & Tptpll & $900.4 \mathrm{D} / 900.4 \mathrm{C}$ & 0.144 & 1.50 & 2.23 \\
\hline NRG6 & TSw2 & Tptpll & 926.3E / 926.3-D & 0.129 & 1.54 & 2.15 \\
\hline NRG6 & TSw2 & Tptpll & 987.0B / 987.0A & 0.118 & 1.55 & 2.04 \\
\hline NRG7 & TSw1 & Tptrn & $312.8 \mathrm{D} / 312.8 \mathrm{C}$ & 0.106 & 1.33 & 1.63 \\
\hline
\end{tabular}

\begin{tabular}{|l|l|l|}
\hline & Wet thermal conductivity was not measured. & \\
\hline & $\begin{array}{l}\text { Measured wet thermal conductivity is outside the } \\
\text { calibration range. }\end{array}$ & \\
\hline & $\begin{array}{l}\text { Data from specimen ID 556.1B/556.1A were not } \\
\text { used due to ambiguity in one document that cited } \\
\text { the data. The data in DTN: SNL01A05059301.005 } \\
\text { [DIRS 109002] are correct. The impact of not } \\
\text { including these data is expected to be minimal } \\
\text { because specimen ID 556.1B/556.1A data are within } \\
\text { the range of the remaining specimen data. }\end{array}$ & \\
\hline $\begin{array}{l}\text { A measured wet and dry pair is not theoretically } \\
\text { possible for the calculated porosity. This statement } \\
\text { assumes that a parallel flow model is the limiting } \\
\text { case regarding how close two measurements may } \\
\text { be to one another. }\end{array}$ & $\begin{array}{l}\text { Porosity is obtained from SNL01A05059301.007 } \\
\text { [DIRS 108980] } \\
\text { When grain density is available, the equation } \\
\text { porosity=1-(dry bulk density/grain density) was used. }\end{array}$ & $\begin{array}{l}\text { When grain density is not available, the equation } \\
\text { porosity = (saturated bulk density - dry bulk } \\
\text { density)/density of water was used. The same } \\
\text { samples were not used to evaluate the dry, bulk or } \\
\text { grain density though they were from the same core. }\end{array}$ \\
\hline & \multicolumn{2}{|c|}{ SNLO1A05059301.005 IDIRS 1090021, SNL01A05059301.007 /DIRS 108980). } \\
\hline
\end{tabular}

Input DTNS: $\quad$ SNL01A05059301.005 [DIRS 109002], SNL01A05059301.007 [DIRS 108980]. 
Table C-2. Alcove 5 Thermal Conductivity Data

\begin{tabular}{|l|c|c|c|c|c|}
\hline \multicolumn{1}{|c|}{ Alcove 5 Specimen } & $\begin{array}{c}\text { Pretest } \\
\text { Mass (g) }\end{array}$ & $\begin{array}{c}\text { Dry Mass } \\
(\mathbf{g})\end{array}$ & Porosity $^{\mathbf{1}}$ & $\begin{array}{c}\text { Dry Thermal } \\
\text { Conductivity } \\
(\mathbf{W} /(\mathbf{m K}) \text { ) }\end{array}$ & $\begin{array}{c}\text { Saturated Thermal } \\
\text { Conductivity } \\
\text { (W/(mK)) }\end{array}$ \\
\hline SPC00515193-G-H & 60.896 & 58.407 & 0.097 & 1.81 & 2.3 \\
\hline SPC00515196-G-H & 60.856 & 58.319 & 0.099 & 1.72 & 2.25 \\
\hline SPC00515199-G-H & 60.954 & 58.497 & 0.096 & 1.87 & 2.33 \\
\hline SPC00515193-C-V & 61.196 & 58.822 & 0.092 & 1.82 & 2.28 \\
\hline SPC00515196-C-V & 60.946 & 58.389 & 0.099 & 1.81 & 2.27 \\
\hline SPC00515199- C-V & 60.916 & 58.305 & 0.101 & 1.8 & 2.27 \\
\hline
\end{tabular}

Input DTN: SNL22100196001.006 [DIRS 158213].

${ }^{1}$ Porosity is calculated using Equation C-1.

In Table C-2, the values of porosity, $\phi$, are computed from the change in mass of the sample that takes place between the pretest and dry states. The equation used to calculate porosity is:

$$
\phi=\frac{\left(M_{p r e}-M_{d r y}\right) / \rho_{w}}{\pi r^{2} l}
$$

where $\mathrm{M}_{\text {pre }}$ and $\mathrm{M}_{\text {dry }}$ are the mass of the pretest (given as 96-99 percent water-saturated) and OD sample, respectively, $\rho_{w}$ is the density of water $(1.0 \mathrm{~g} / \mathrm{cc}), r$ is the sample radius (nominally $2.54 \mathrm{~cm}$ ), and $l$ is the sample length (nominally $1.27 \mathrm{~cm}$ ). There is an inconsistency in using Equation C-1 to calculate the porosity because that equation implicitly assumes the sample is initially saturated. For example, specimen SPC00515193-G-H has a saturated mass of $60.994 \mathrm{~g}$ (SNL22100196001.006 [DIRS 158213]). Using this value in Equation C-1 results in a porosity value of 0.101 compared to 0.097 . The relative error is less than 5 percent and would have minimal impact on subsequent model development.

There are two other qualified DTNs that contain thermal conductivity data for the Tptpmn. Unfortunately, neither satisfies the model calibration procedure screening criteria. The first is DTN: SN0203L2210196.007 [DIRS 158322], which only has water-saturated thermal conductivity measurements, and the second is DTN: SNL22100196001.002 [DIRS 153138], which only has OD measurements. These data are, therefore, not used in the matrix thermal conductivity model calibration. The data were, however, used to validate the resulting matrix thermal conductivity model as discussed in Section 7.4. 
APPENDIX D

STRATIGRAPHIC CONTACTS 


\section{STRATIGRAPHIC CONTACTS}

Table D-1. Stratigraphic Contacts

(Units $=$ feet)

\begin{tabular}{|c|c|c|c|c|c|c|}
\hline Borehole & Tptpul & Tptpmn & Tptpll & Tptpln & Tptpv3 & Comment \\
\hline G-1 & 456.5 & 713.4 & 814.8 & $1,199.2$ & 1287 & $\mathrm{P}$ \\
\hline G-2 & 977.2 & 1246 & 1280 & 1604 & $1,633.8$ & $\mathrm{P}$ \\
\hline G-3 & 548 & 688 & 830 & 1044 & $1,186.7$ & $\mathrm{P}$ \\
\hline G-4 & 420 & 674 & 774 & $1,127.9$ & $1,316.5$ & $\mathrm{P}$ \\
\hline $\mathrm{H}-1$ & 538 & 788 & 897 & 1,324 & 1,410 & $\mathrm{P}$ \\
\hline $\mathrm{H}-3$ & 540 & 680.1 & 848.1 & $1,049.9$ & 1,194 & $\mathrm{P}$ \\
\hline $\mathrm{H}-4$ & 376 & 576 & 703 & 987 & 1,185 & $\mathrm{P}$ \\
\hline $\mathrm{H}-5$ & 741 & 988 & 1088 & 1,450 & 1,582 & $\mathrm{P}$ \\
\hline $\mathrm{H}-6$ & 435 & 653 & 795 & 1,097 & 1,213 & $\mathrm{P}$ \\
\hline NRG-4 & 700 & $875^{*}$ & $965^{*}$ & $1,302^{*}$ & $1,351^{*}$ & $\mathrm{P}$ \\
\hline NRG-6 & 465.5 & 713 & 810 & $1,152 *$ & $1,317^{*}$ & $\mathrm{~B}$ \\
\hline NRG-7 & 518.4 & 740 & 877.6 & 1,243 & $1,414.8$ & $\mathrm{~B}$ \\
\hline ONC-1 & 810 & 977 & 1,100 & 1,178 & 1,178 & $\mathrm{P}$ \\
\hline P-1 & 248 & 493 & 640 & 958 & 1,090 & $\mathrm{P}$ \\
\hline SD-6 & 645.7 & 853 & 995 & 1,305 & 1,456 & $\mathrm{C}$ \\
\hline SD-7 & 490 & 682.5 & 803.3 & 1,020 & 1,182 & B \\
\hline SD-9 & 473 & 730 & 845.8 & 1,182 & 1,358 & B \\
\hline SD-12 & 470.2 & 663.7 & 786.9 & $1,065.5$ & 1,278.1 & $\mathrm{B}$ \\
\hline UZ-1 & 470 & 717 & 830 & $1,144^{*}$ & $1,281^{*}$ & $\mathrm{P}$ \\
\hline UZ-6 & 610 & 778 & 917 & 1,190 & 1,333 & $\mathrm{P}$ \\
\hline UZ-14 & 468 & 715 & 828 & 1,138 & $1,279.1$ & C \\
\hline UZ-16 & 371 & 545 & 669 & 935 & $1,107.5$ & B \\
\hline UZ-7a & 377.8 & 480 & 607 & $892 *$ & $1,060 *$ & $\mathrm{~B}$ \\
\hline WT-1 & 593 & 733 & 888 & 1,187 & 1,299 & $\mathrm{P}$ \\
\hline WT-10 & 1,049 & 1,250 & $1,491^{*}$ & $1,649 *$ & $1,861^{*}$ & $\mathrm{P}$ \\
\hline WT-11 & 430 & 661 & 782 & 875 & 1,058 & $\mathrm{P}$ \\
\hline WT-12 & 478 & 680 & 760 & 890 & 1,151 & $\mathrm{P}$ \\
\hline WT-13 & 630 & 755 & 868 & 1,103 & $1,238^{*}$ & $\mathrm{P}$ \\
\hline WT-14 & 275 & 446 & 534 & 830 & 1,024 & $\mathrm{P}$ \\
\hline WT-15 & 641 & 852 & 919 & 1,260 & $1,292^{*}$ & $\mathrm{P}$ \\
\hline WT-16 & 830 & 830 & 830 & 1,013 & 1,013 & $\mathrm{P}$ \\
\hline WT-17 & 336 & 472 & 535 & 668 & 874 & $\mathrm{P}$ \\
\hline WT-18 & 900 & 1,078 & 1,170 & 1,501 & 1,501 & $\mathrm{P}$ \\
\hline WT-2 & 421 & 590 & 727 & 1,014 & 1,179 & $\mathrm{P}$ \\
\hline
\end{tabular}


Table D-1. Stratigraphic Contacts (Continued)

\begin{tabular}{|c|c|c|c|c|c|c|}
\hline \multicolumn{1}{|c|}{ (Units = feet) } \\
\hline Borehole & Tptpul & Tptpmn & Tptpll & Tptpln & Tptpv3 & Comment \\
\hline WT-24 & 937.4 & $1,151.7$ & $1,261.7$ & 1,625 & 1,680 & $\mathrm{P}$ \\
\hline WT-3 & 11 & 11 & 11 & 35 & 189 & $\mathrm{P}$ \\
\hline WT-4 & 660 & 727 & 785 & 1,091 & 1,091 & $\mathrm{P}$ \\
\hline WT-7 & 546 & 706 & 959 & 1,091 & 1,287 & $\mathrm{P}$ \\
\hline
\end{tabular}

NOTES: $\mathrm{B}=$ Both types of data; $\mathrm{C}=$ Cored data only; $\mathrm{P}=$ Petrophysical data only.

*Indicates depth value (in feet) was modeled or interpolated based on Geologic Framework Model (GFM2000) (Input DTN: MO0012MWDGFM02.002 [DIRS 153777]).

The all remaining depth values (in feet) were obtained from Input DTN: MO0004QGFMPICK.000 [DIRS 152554], except for borehole SD-6 where DTN: SNF40060298001.001 [DIRS 107372] was used. All depths are measured from ground surface to the top of the unit. 